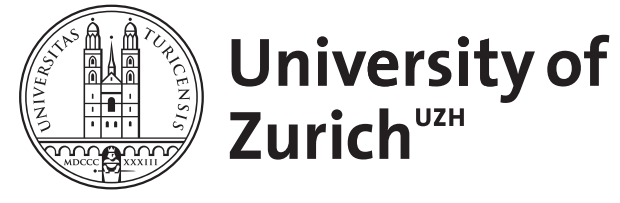

\title{
Spiele und Spielzeug im antiken Palästina
}

Hübner, Ulrich

\begin{abstract}
Erstmals wird hier das Thema "Spielen und Spielzeug" für den Raum des antiken Palästina vom Neolithikum bis in die byzantinische Zeit monographisch abgehandelt. Dabei werden alle relevanten Quellen berücksichtigt, sowohl die literarischen und epigraphischen Texte als auch die archäologischen, ikonographischen und ethnologischen Funde und Belege. Damit wird ein Aspekt palästinischen Alltagslebens als eine zentrale menschliche Lebensäusserung neu entdeckt.
\end{abstract}

Posted at the Zurich Open Repository and Archive, University of Zurich

ZORA URL: https://doi.org/10.5167/uzh-150406

Monograph

Published Version

Originally published at:

Hübner, Ulrich (1992). Spiele und Spielzeug im antiken Palästina. Freiburg, Switzerland / Göttingen, Germany: Universitätsverlag / Vandenhoeck Ruprecht. 


\section{ORBIS BIBLICUS ET ORIENTALIS}

Im Auftrag des Biblischen Instituts

der Universität Freiburg Schweiz, des Seminars für Biblische Zeitgeschichte der Universität Münster i. W. und der Schweizerischen Gesellschaft für orientalische Altertumswissenschaft herausgegeben von Othmar Keel unter Mitarbeit von Erich Zenger und Albert de Pury

\section{Zum Autor:}

Ulrich Hübner (1952) studierte nach dem Wehrdienst in Mainz, Basel, Bethel/ Bielefeld und Tübingen Evangelische Theologie, Vorderasiatische Archäologie und altorientalische Sprachen. Er nahm an den Ausgrabungen auf Tell esSebac, Hirbet el-M̌̌săs (Negev) und Tell el- ${ }^{c}$ Orēme (Galiläa) teil. Nach seiner Assistenzzeit an der Universität Mainz war er von 1984-1986 Vikar in Bad Kreuznach. Seitdem arbeitet er als Wissenschaftlicher Assistent für Altes Testament und Biblische Archäologie an der Universität Heidelberg, wo er mit der Dissertation «Die Ammoniter. Untersuchungen zur Geschichte, Kultur und Religion eines transjordanischen Volkes im 1. Jahrtausend v.Chr.» (1991) promoviert wurde, für die er 1992 von der Akademie der Wissenschaften zu Göttingen mit dem Hanns-Lilje-Preis zur Förderung der theologischen Wissenschaft ausgezeichnet wurde. Er veröffentlichte zahlreiche Artikel zu exegetischen, archäologischen und epigraphischen Problemen in verschiedenen Zeitschriften und Lexika. 


\section{Orbis Biblicus et Orientalis 121}

Ulrich Hübner

\section{Spiele und Spielzeug im antiken Palästina}

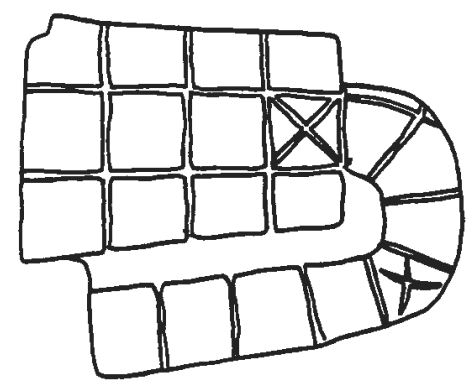

Universitätsverlag Freiburg Schweiz Vandenhoeck \& Ruprecht Göttingen 
Die Deutsche Bibliothek - CIP-Einheitsaufnahme

\section{Hübner, Ulrich:}

Spiele und Spielzeug im antiken Palästina / Ulrich Hübner. - Freiburg, Schweiz:

Univ.-Verl.; Göttingen: Vandenhoeck und Ruprecht, 1992

(Orbis biblicus et orientalis; 121)

ISBN 3-525-53755-7 (Vandenhoeck und Ruprecht)

ISBN 3-7278-0847-0 (Univ.-Verl.)

NE: GT

Die Druckvorlagen wurden vom Verfasser

als reprofertige Dokumente zur Verfügung gestellt

(C) 1992 by Universitätsverlag Freiburg Schweiz

Vandenhoeck \& Ruprecht Göttingen

Paulusdruckerei Freiburg Schweiz

ISBN 3-7278-0847-0 (Universitätsverlag) ISBN 3-525-53755-7 (Vandenhoeck \& Ruprecht)

Digitalisat erstellt durch Florian Lippke, Departement für Biblische Studien, Universität Freiburg Schweiz 
Für Renate 
"Tous les gens d'esprit aiment le jeu à la fureur" G.E. LESSING, Minna von Barnhelm IV,2 


\section{INHALTSVERZEICHNIS}

Abkürzungsverzeichnis

1.Vorspiel 1

2.Versteck- und 'Sandkasten'-Spiele 21

3.Götter-Spiele 24

$\begin{array}{ll}\text { 4.Spiel-Tiere } & 28\end{array}$

$\begin{array}{ll}\text { 5.Ball-Spiele } & 38\end{array}$

6.Astragale $\quad 43$

$\begin{array}{ll}\text { 7.Würfel } & 61\end{array}$

$\begin{array}{ll}\text { 8.Brett-Spiele } & 67\end{array}$

$\begin{array}{ll}\text { 9.Kreisel } & 86\end{array}$

10.Iunx 90

11.Puppen $\quad 92$

12.Zwischenspiel: Verschiedenes 98

13.Possenreißer, Gaukler und Rollen-Spiele 103

14.Hellenistisch-römisch-byzantinische Massenbelustigungen 111

$\begin{array}{ll}\text { 15.Gewicht-Heben } & 127\end{array}$

16.Agonistische Metaphorik im Neuen Testament 129

$\begin{array}{ll}\text { 17.Nachspiel: Spielen und Leben } & 134\end{array}$

$\begin{array}{lr}\text { Bibliographie } & 149\end{array}$

$\begin{array}{ll}\text { Register } & 201\end{array}$

1. Stellenregister $\quad 201$

$\begin{array}{ll}\text { 2. Ortsregister } & 210\end{array}$

$\begin{array}{ll}\text { Abbildungsverzeichnis } & 215\end{array}$

$\begin{array}{ll}\text { Abbildungen Nr. 1-60 } & 218\end{array}$ 


\section{VORWORT}

Bei meiner Arbeit an einer Monographie über die kulturgeschichtlichen Aspekte von Kindheit und Jugend im eisenzeitlichen Israel und Juda war ich auf das Problem von Kinderspielen und Kinderspielzeug gestoßen. Im Dezember 1990 hatte ich dann auf dem Kolloquium des Deutschen Vereins zur Erforschung Palästinas 'Kulturgeschichte Israels als Aufgabe der Biblischen Archäologie' in Rauischholzhausen bei Gießen einen Vortrag über "Spiele und Spielzeug im antiken Palästina" gehalten. Dort wurde mir von verschiedener Seite die Anregung gegeben, ihn zu einer kleinen Monographie auszuweiten. Dieser Anregung bin ich gerne gefolgt.

Dabei habe ich soweit wie möglich alle wesentlichen Arten von Quellen benutzt - literarische und epigraphische, archäologischee und ikonographische Belege sowie ethnologisches Vergleichsmaterial - , aber keine Vollständigkeit der Belege, sondern nur eine repräsentative Auswahl angestrebt. Die Spielregeln der antiken Spiele werden, soweit sie überhaupt bekannt sind, nur in ihrem Grundprinzip, nicht aber mit allen ihren möglichen Varianten beschrieben. Soweit sie historisch belegbar sind, habe ich auch versucht, auf die kultischen, magischen und symbolischen Bedeutungen der Spiele einzugehen. Im Mittelpunkt steht der spielerische Aspekt der Spiele im engeren Sinn.

Die Übersetzungen, die nicht von mir stammen, sind nicht eigens gekennzeichnet, ihre Übersetzer aber in der Regel über das Literaturverzeichnis leicht zu identifizieren.

Die Bibliographie ist wesentlich umfangreicher ausgefallen als ich es ursprünglich geahnt hatte; so kann sie sich vielleicht als Ausgangspunkt für weitere Arbeiten zur Spielforschung im antiken Vorderasien als nützlich erweisen. Sie zeigt zugleich, daß wir in einem Zeitalter leben, in dem wir noch nie soviel wissen konnten wie jemals zuvor - wenn wir nur die zahlreichen Belege aller Art (und die auf sie Bezug nehmende Sekundärliteratur) zur Kenntnis nehmen.

$\mathrm{Zu}$ danken habe ich für verschiedene Hinweise, Ratschläge und Hilfe bei der Beschaffung von Literatur vor allem A. BERLEJUNG (Heidelberg), $\mathbf{H}$. HAUPTMANN (Heidelberg), E. HINDERLING-ROTHENBACH (Basel), I. HÖLDER (Bonn), R. INEICHEN (Fribourg), J. KAMLAH (Tübingen), M. LÄMMER (Köln) und S. PAUL (Mitterhausen / Arnstorf). E.A. KNAUF (Heidelberg) und $H$. WEIPPERT (Heidelberg) haben das Manuskript einer kritischen Durchsicht unterzogen und mir einige wertvolle Hinweise gegeben; alle verbliebenen Fehler und Versehen gehen selbstverständlich zu meinen Lasten. 
D. TROBISCH (Heidelberg) danke ich für seine freundliche Hilfe bei der technischen Gestaltung des Manuskripts und dem Herausgeber O. KEEL (Fribourg) für die Aufnahme in die Reihe "Orbis Biblicus et Orientalis".

Heidelberg / Mainz, im März 1992

\section{ABKÜRZUNGSVERZEICHNIS}

Die Abkürzungen für Zeitschriften und Reihen folgen S. SCHWERTNER, Internationales Abkürzungsverzeichnis für Theologie und Grenzgebiete, Berlin - New York 1976. Soweit nicht bei S. SCHWERTNER erfaßt, folgen die Abkürzungen für den Bereich von Keilschrifttexten und Verwandtes AHw bzw. RlA, für die rabbinische Literatur H.L. STRACK - G. STEMBERGER, Einleitung in Talmud und Midrasch, München 71982 , für den Bereich der Archäologie den Zeitschriftenverzeichnissen der Archäologischen Bibliographie 1983 bzw. dem Abkürzungsverzeichnis des Deutschen Archäologischen Instituts (DAI).

Zusätzlich oder abweichend von S. SCHWERTNER werden verwendet:

ÄAT Ägypten und Altes Testament

ALASP Abhandlungen zur Literatur Alt-Syriens - Palästinas

BAIAS Bulletin of the Anglo-Israel Archaeological Society

BAOM Bulletin of the Ancient Orient Museum

BAR Biblical Archaeology Review

BAR.IS British Archaeological Reports, International Series

BASOR.S BASOR Supplement

BCH.S Bulletin de correspondence héllenique. Supplement

BEATAJ Beiträge zur Erforschung des Alten Testaments und des antiken Judentums

BN Biblische Notizen

CJHSPhE Canadian Journal of History of Sport and Physical Education

DarS Ch. DAREMBERG - E. SAGLIO (ed.), Dictionnaire des Antiquités Grecques et Romains I-V, Paris 1877-1919 = 1962-1963

EAEHL Encyclopedia of Archaeological Excavations in the Holy Land

ESI Excavations and Surveys in Israel

GM Göttinger Miszellen

GOF Göttinger Orientforschungen

HAL $^{3}$ Hebräisches und Aramäisches Lexikon zum Alten Testament, ed. W. BAUMGARTNER et al.

Hatra F. VATTIONI (ed.), Iscrizioni di Ḥatra, Neapel 1981 
HdArch Handbuch der Archäologie

JSH Journal of Sport History

JSHRZ Jüdische Schriften aus hellenistisch-römischer Zeit

JSOT(.S) Journal for the Study of the Old Testament. (Supplement)

KAW Kulturgeschichte der antiken Welt

LA Liber Annuus. Studium Biblicum Franciscanum

LE Die Leibeserziehung

KBSW Kölner Beiträge zur Sportwissenschaft

MVS Münchener Vorderasiatische Studien

NBL Neues Bibel-Lexikon

NESE Neue Ephemeris für semitische Epigraphik

OBO Orbis Biblicus et Orientalis

OGI DITTENBERGER W. (ed.), Orientis Graeci Inscriptiones Selectae I-II, Leipzig 1903-1905

PAM Jerusalem, Palestine Archaeological Museum

P.Mas. H.M. COTTON - J. GEIGER (ed.), Masada II, Jerusalem 1989

P.Ness. L. CASSON - E.L. HETTICH (ed.), Excavations at Nessana II: The Literary Papyri, Princeton/NJ 1950

PPUAES Publications of the Princeton University Archaeological Expedition to Syria in 1904-1905 and 1909

P.Ryl. Catalogue of the Greek and Latin Papyri in the John Rylands Library, Manchester

RES Répertoire d'épigraphie sémitique

SAK(.B) Studien zur altägyptischen Kultur. (Beiträge)

SCI Scripta Classica Israelitica

StJLA Studies in Judaism in Late Antiquity

STT Sultantepe Tablets I-II, ed. P.R. GURNEY - J.J. FINKEISTEIN - P. HuLIN, London 1957. 1964

TA Tel Aviv

TAM Tituli Asiae Minoris

TUAT Texte aus der Umwelt des Alten Testaments

UBL Ugaritisch-biblische Literatur

VSE F. VATTIONI, I sigilli ebraici I-III, Bib. 50 (1969), 357-388; Aug. 11 (1971), 447-454; AION 28 (1978), 227-254

ZAH Zeitschrift für Althebraistik

Die Schreibweise biblischer PN und ON richtet sich, wenn nicht anders nötig, nach dem "Ökumenischen Verzeichnis der biblischen Eigennamen nach den Loccumer Richtlinien" (Stuttgart 21981).

Zur Zitierweise: Nach der ersten Erwähnung einer Monographie o.ä. mit den vollständigen bibliographischen Angaben wird sie im folgenden nur noch mit Verf., abgekürztem Titel und Erscheinungsjahr angegeben; bei Aufsätzen u.ä. wird der Titel des Aufsatzes nach der ersten Erwähnung stets weggelassen. 


\section{VORSPIEL}

"Iß, trink, spiel! Alles andere taugt nicht soviel wie dies". Dieses Epigramm hat, will man Athenaios 12,530 glauben, der seinerseits Aristobul zitiert, auf dem angeblichen Grabmal des sagenhaften Königs Sardanapal gestanden; jedenfalls soll Alexander d.Gr. es auf seinem Feldzug gegen die Perser nahe dem kilikischen Anchiale gesehen haben ${ }^{1}$.

Ein derartiges Grab-Epigramm ist im antiken Palästina in israelitischen, jüdischen, christlichen oder moslemischen Kreisen nahezu undenkbar ${ }^{2}$ - nicht aber in 'heidnischen'3. Und doch gehören Ess- und Trinkgefäße sowie Spielzeug in Palästina häufig zum Grabinventar - nicht nur zu dem der Bronzeund Eisenzeit: Der Tod wurde - auch später noch - weniger als Nicht-Sein, sondern mehr als eine um ein gewisses $\mathrm{Ma} B$ an Lebensqualität verminderte Form diesseitiger Existenz verstanden. Der Verstorbene sollte im Leben nach

1 Sardanapallos Anaknydaraxē̄ pais Agchialē kai Tarson edeimen hēmerē miēe. Esthie, pine, paize. Hōs talla toutou ouk axia. Daß das angebliche Grabepigramm auch anders überliefert wird, sei hier nur der Vollständigkeit halber noch erwähnt, z.B. Polybios, hist. 8,12,3; Cicero, Tusc. 5,35; Dion Chrys., orat. 4,135; Augustin, de civ. dei 2,20; Klemens Alex., Strom. 2,118,6, vgl. 1,159,1; Anth. Graeca 7,325; 16,27. Vgl. auch F.H. WEISSBACH, Sardanapal, RE II 1,2 (1920), 2436-2475; W. RölLIG, Sardanapal, KP 4 (1975), 1550f; O. HoLL, Sardanapal, LCI $2(1972=1990)$, 44f. Auf dem Grabmal soll eine steinerne Figur ( = Sardanapal) gestanden haben, die die Finger der rechten Hand zusammenbringt, als wolle sie schnipp en (psēphos daktylōn); mit dem Schnippen der Finger habe sie den Sinn des Epigramms unterstreichen wollen (tou apokrotēmatos eoika legein) - zu diesem Gestus (assyr. ubāna tarāṣu) vgl. U. MAGEN, Assyrische Königsdarstellungen - Aspekte der Herrschaft (BagF 9; Mainz 1986), 94-104.

2 In Israel konnten immerhin theologische Außenseiter wie Qoh. 8,15 (auch 2,24; 3,13; 5,17f; 9,7) formulieren: "So preise ich denn die Freude, da es nämlich nichts Gutes für den Menschen unter der Sonne gibt außer zu essen und zu trinken und sich zu freuen"; auch bTaan. 11a "Ich will nach Hause gehen, essen und trinken, und Friede über dich, meine Seele!" (dort allerdings als Negativ-Beispiel zitiert) und die Sprüche Igaudias in deo pie z(eses); vivas in deo p(ie) z(eses)] auf Glas-Schalen mit Darstellungen von Adam und Eva bzw. des Lazarus aus dem 4.Jh.s n.Chr., vgl. M. SCHULzE, in: Gallien in der Spätantike (Mainz 1980), Nr. 138. 141. Vgl. auch R. SMEND, Essen und Trinken - ein Stück Weltlichkeit des Alten Testaments, (1977), in: ders., Die Mitte des Alten Testaments. Ges. Studien 1 (München 1986), 200-211.

3 Vgl. z.B. auch Herodot 2,78; CIL VIII 2, Nr. 17938 = ILS 8626f ("venari, lavari, ludere, ridere, occ est vivere") (Thamugadi - Timgād / Numidien); CIL VI, Nr. 16169 (Rom) ("...ioceris, ludas, hortor hfc (sic) summa est severitas") oder CIL II, Nr. 2262 (Cordoba) ("... tu, qui stas et leges titulum meum, lude, iocare, veni"). 
dem Tode 4 annähernd so essen, trinken und spielen können wie im Leben vor dem Tode; nur hielt man dies nicht auch noch in der Grabinschrift fest. Die Grabinventare in Israel und Juda zeigen jedenfalls, daß nach den weitverbreiteten Vorstellungen der Volksfrömmigkeit die Toten in der Unterwelt mit vielen verschiedenen Aktivitäten beschäftigt waren, so z.B. auch spielten, während in der Unterwelt, so wie sie sich alttestamentlichen Theologen vorstellten, davon kaum die Rede ist ${ }^{5}$. In bronze- wie eisenzeitlichen u.a. Gräbern ist eine ganze Reihe von verschiedenartigem Spielzeug belegt, vor allem Astragale und Würfel, Brettspiele und Terrakotten.

Wenn die literarische Hinterlassenschaft einer Kultur hauptsächlich in einer 'Heiligen Schrift' überliefert worden ist und deren Verfasser und Redaktoren weitgehend aus Kreisen mehr oder weniger professioneller Propheten, Priester und Theologen stammen, die sich so gerne mit den sogenannten großen Dingen ihres Lebens befassen, dann ist die Wahrscheinlichkeit gering, daß sich ihre Aufmerksamkeit gerade den alltäglichen Dingen zugewandt hat. Insofern überrascht es kaum, wenn man den Heiligen Schriften Alten und Neuen Testaments nur relativ wenig über so kleine, alltägliche Dinge wie Spielen und Spielzeug entnehmen kann. Daß 'man' sich in Palästina seit Jahrtausenden innerhalb aller Bevölkerungs- und Altersschichten aber gerne und häufig dem Spielen hingab, wird nicht nur durch einen Vergleich mit den Nachbarkulturen nahegelegt, sondern auch durch das einheimische archäologische Fundmaterial. Die konkrete Wirklichkeit einer Religion ist eben nicht immer an den Maßstäben ihrer orthodoxen Vertreter zu messen; Orthodoxie ist immer nur ein Ausschnitt dieser Wirklichkeit, und nicht selten ist sie ein mehr oder weniger deutlich von den anderen Teilwirklichkeiten isoliertes Phänomen.

Das kümmerliche Bild von der Wirklichkeit, das entstünde, wenn man sich allein auf die Angaben der literarischen Quellen verlassen müßte, ergäbe ein groteskes Zerrbild. Es muß nicht eigens betont werden, daß das Desinteresse der Autoren und Redaktoren an den kleinen Alltäglichkeiten selbstverständlich aufs engste mit ihren anderweitigen Interessen, mit den Formen der von ihnen gewählten Literaturgattungen u.ä. zusammenhängt. Typisch ist es nun gerade, wenn alltägliche Dinge, die Jahrhunderte oder gar Jahrtausende lang niemanden gestört haben und denen auch deshalb keine literarische Auf-

4 Vgl. weiter z.B. Pausanias 10,31,1; Euripides, Iph. in Aulis 195ff; Pindar, frg. 107; Herodot 2,122,1.

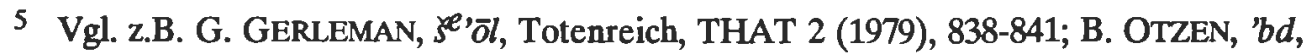
ThWAT 1 (1970-1973), 24; H. RINGGREN - K.-J. ILLMAN - H.-J. FABRY, mût, ThWAT 4 (1982-1984), 763-787; CH. BARTH, Die Errettung vom Tode in den individuellen Klage- und Dankliedern des Alten Testaments (Zürich ${ }^{2} 1987$ ), 52-122. 
merksamkeit zuteil wurde, innerhalb kurzer Zeit eines bis dahin ungeahnten Maßes an Interesse und Zuwendung teilhaftig werden: dann nämlich, wenn diese kleinen, jedermann selbstverständlichen Dinge nicht mehr durch Nichtbeachtung unterbewertet, sondern durch überaus moralische Betrachtung negativ - überbewertet werden. Aus den bis dahin alltäglichen Selbstverständlichkeiten werden dann Dinge, die mit Vorurteilen, Verboten und Strafandrohungen überzogen werden - aber deshalb noch lange nichts von ihrer munter weiter gepflegten Alltäglichkeit verlieren. So können auch aus vergleichsweise harmlosen Spielen leicht ludi diaboli werden ${ }^{6}$. Eine gewisse Grämlichkeit ist schon bei Sir. 30,9 zu hören: "Verhätschelst du dein Kind, so mußt du dich vor ihm fürchten; spielst du mit ihm (sympaixon autō), so wird es dich betrüben".

Im folgenden will ich einen Überblick über die entsprechenden Denkmäler und Quellen geben ${ }^{7}$. Der chronologische Rahmen umfaßt die Zeit von den

$6 \mathrm{Zu}$ den pompa diaboli vgl. J.H. WASZINK, Pompa diaboli, VigChr 1 (1947), 13-41; H. JÜRGENS, Pompa diaboli. Die lateinischen Kirchenväter und die Schauspiele (TBAW 46; Stuttgart u.a. 1972), passim.

7 M. BARAN, Kinderspiele, in: The Proceedings of the Xth International Congress of Classical Archaeology, Ankara - Izmir 1973, Vol. I (Ankara 1978), 433-435; H. BARDTKE, Spiel, spielen, Spielleute, Calwer Bibellexikon 51985 , 1269; G. BERTRAM, paizō; empaizo, ThWNT 5 (1954), 625-635; S.A. CARTLEDGE, Games, NT, IDB 2 (1962), 353f; C.C. CoHN, Gambling, EJ 7 (1971), 299-303; M. CoHN, Spiel und Wette, JL 4,2 (1930), 548f; C. DIEM, Weltgeschichte des Sports und der Leibeserziehung (Stuttgart 1960), 318-322; W. DommERSHAUSEN, Spiel, BL ${ }^{2} 1968$, 1623f; K. GALLING, Spielgerät, BRL (1927), 494f; J.H. GREENSTONE, Gambling, JE 5, 563; W.H. GRoss, Spiele, KP 5 (1975), 310-313; M. GRUNWALD, Games and Sports, JE 5 (1904), 564f; E. HALlE, Die Leibeserziehung bei den Juden, LE 1962, 273-280; E.W. HEATON, Biblischer Alltag. Zeit des Alten Testaments (München 1960), 70f; E. KALT, Spiel, Biblisches Reallexikon 2 (21939), 732f; S. KRAUSS, Talmudische Archäologie III (Leipzig 1912), 102-121; M. KRANZ, Probleme der Leiblichkeit im biblichen (sic) Judentum (Diss. phil. masch.; Köln 1965), 53ff; Y.-T. LEWINSKI, Games, EJ 7 (1971), 303-308; L. Löw, Beiträge zur jüdischen Alterthumskunde II: Die Lebensalter in der jüdischen Literatur von physiologischem, rechts-, sitten- und religionsgeschichtlichem Standpunkte betrachtet (Szegedin 1875), 279ff; S. MUNTNER, Leibesübungen bei den Juden, Menorah 4,6-7 (1926), 378-393; ders. - F.A. THEILHABER, Sport und Körperkultur bei den Juden, JL 4,2 (1930), 560-567; S. RAPPAPORT, Spiele, JL 4,2 (1930), 550-554; B. REICKE - E. ESKING, Spiel, BHH 3 (1966), 1832-1835; R.F. SCHNELL, Games, OT, IDB 2 (1962), 352f; H.L. STRACK - P. BillerBECK, Kommentar zum Neuen Testament aus Talmud und Midrasch Bd. III (München 21954), 599f; P. THOMSEN, Spiel und Spielzeug, RLV 12 (1928), 345f; H. WEIPPERT, Spielgerät, BRL ${ }^{2}$ (1977), 310f; dies., Palästina in vorhellenistischer Zeit (HdArch Vorderasien II 1; München 1988), 331f. 479 
frühesten Belegen bis ins Mittelalter, wobei der Schwerpunkt auf die Spanne von der Bronzezeit bis in die römisch-byzantinische Zeit gelegt wird. Der geographische Rahmen umfaßt Palästina diesseits und jenseits des Jordan. Methodisch gesehen sollen in einer repräsentativen Auswahl das archäologische Fundmaterial aus Palästina sowie die entsprechenden literarischen, epigraphischen, ikonographischen und ethnologischen Belege herangezogen, soweit wie möglich - aufeinander bezogen und durch Kulturvergleiche vor allem mit Phönizien, Syrien, Mesopotamien, Arabien, Ägypten, Griechenland und Rom $^{8}$ sowie ethnologischem Material abgesichert werden'. Auf 'Musik

(Anm. 9); zu H. UEBERHORST, Leibesübungen in den Hochkulturen Mesopotamiens. Wertung des Leibes und der Leibesübungen in Altisrael. Leibesübungen im alten Ägypten, in: ders. (ed.), Geschichte der Leibesübungen Bd. 1 (Berlin - München Frankfurt a.M. 1972), 161-177. 178-189. 190-226 vgl. die Rezension von W. DECKER M. LÄMMER, Kritische Bemerkungen zu einer Geschichte der Leibesübungen, Sportwiss. 2 (1972), 312-322. Nützlich sind auch die Bibliographien von W. DECKER et al., weil sie auch die Nachbarkulturen Ägyptens und nicht nur 'Sport' im engeren Sinn erfassen, vgl. W. DECKER (et al.), Annotierte Bibliographie zum Sport im alten Ägypten (1978), passim; ders., Stadion 5 (1979), 161-192; 7 (1981), 153-172; 8-9 (1982-1983), 183214; ders., Nikephoros 1 (1988) 245-268; ders. et al., Nikephoros 2 (1989), 185-216. 217240; auch ders., Sport im Alten Ägypten, SAK.B 4 (1991), 35-35.

8 Zur relativen Einheitlichkeit der Mittelweerwelt vgl. F. BRAUDEL - G. DUBY - M. AYMARD, Die Welt des Mittelmeeres. Zur Geschichte und Geographie kultureller Lebensformen (Frankfurt a.M. 1990), passim.

9 Vgl. z.B. auch R. PINON, Probleme einer europäischen Kinderspielforschung, HBVK 58 (1967), 9-45, der neben forschungsgeschichtlichen Aspekten vor allem die Notwendigkeit interdisziplinären bzw. kulturvergleichenden Arbeitens betont; vgl. auch $\mathbf{H}$. EICHBERG, Die Kulturrelativität des Spiels, Jb. Deutsch als Fremdsprache 8 (1982), 159-177; G. SCHLÄGER, Einige Grundfragen der Kinderspielforschung, ZVKK 27 (1917), 106-121. 199-215; 28 (1918), 15-25; 33-34 (1924), 137-152; B. SUTTON-SMITH, Forschung und Theoriebildung im Bereich von Spiel und Sport, ZP 21 (1975), 325-334; K.H. RuBIN, Early Play Theories Revisited: Contributions to Contemporary Research and Theory, in: D.J. PEPLER - K.H. RUBIN (ed.), The Play of Children: Current Theory and Research (Contributions to Human Development 6; Basel u.a. 1982), 414; CH. LOMBARD, An Introduction to the Ethnological Study of Children's Games, in: J. RAABE et al. (ed.), Child and Play. Theoretical Approaches and Teaching Applications (Paris 1980), 48-63. Zu den Problemen der Klassifikation von Spielzeug vgl. z.B. P.N. BorATAV, Classification générale des jeux, in: $\mathrm{VI}^{\mathrm{e}}$ Congrès Internationale des Sciences Anthropologiques et Ethnologiques II,2 (Paris 1964), 141-148. Zur Forschungsgeschichte vgl. z.B. auch H. SCHEUERL, Zum Stand der Spielforschung, in: W. EINSIEDLER (ed.), Aspekte des Kinderspiels (Weinheim und Basel 1985), 9-31; I. WEBERKELleRmanN, Nachwort, in: dies. - R. FAlKENBERG (ed.), Was wir gespielt haben (Frankfurt a.M. 1992), 330ff. 
(-Instrumente) spielen', 'Tanzen' und 'Reigenlieder und -spiele'10 wird hier kaum eingegangen, auch wenn Kleinkinder z.B. gerne mit Rasseln (Abb. 1) und Klappern ${ }^{11}$ gespielt haben. Rasseln und Klappern konnten - insbesondere bei ausgesetzten Kindern - auch als Amulette dienen ${ }^{12}$. Auf die symbolischen bzw. metaphorischen Bedeutungen des Spielzeugs wird nur dann eingegangen, wenn sie auf der Basis der Quellen des prähellenistischen Palästinas auch einigermaßen erkennbar sind. Belege werden vor allem auf der Realebene des Spielens im engeren Sinn interpretiert.

Bewußt wird hier auf Definitionen von "Spiel" und "Spielzeug"13 verzichtet: Im theatrum mundi kann - empirisch bzw. phänomenologisch betrachtet schlechterdings alles zum Spielzeug werden; mit allem und jedem läßt sich

10 Vgl. z.B. S. MitTMANN, "Reigentänze" in Ex 32,18, BN 13 (1980), $41-45$ oder das Reigenlied in den Acta Joh. 94-96, H. DANIEL-RoPS (ed.), Die apokryphen Evangelien des Neuen Testaments (Zürich 21958), 155-157; S. STÖCKLIN-MEIER, Der Schneider hat 'ne Maus erwischt. Lebendiges Kreisspiel (Zürich 1973), 52ff.

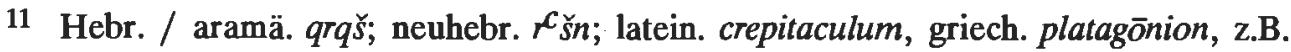
Martial, epigr. 14,54; Pollux 9,127; Tertullian, adv. Iud. 9. Vgl. A. MAU, Crepitaculum, RE 4 (1901), 1705f; A. HUG, Spiel, RE III A 2 (1929), 1765; ders., Spielzeug, a.a.O., 1774f; E. HICKMANN, Rassel, LÄ 5 (1984), 150f; H.-G. BuCHHOLZ, Rasseln und Schellen, Reifen, Wippen und Schaukeln, in: S. LASER (ed.), Sport und Spiel (ArchHom T; Göttingen 1987), 100-109, Abb. 39, Taf. IV; F.A.G. BECK, Album of Greek Education. The Greeks at School and at Play (Sydney 1975), 48, Nos. 286ff; K. SCHNEIDER, Platagōnion, RE 40 (1950), 2254f; L. BECQ DE FOUQUIERES, Les jeux des anciens (Paris 21873), 1ff; A.E. KLEIN, Some Greek Playthings, TPAPA 62 (19319; XXVIIf; J. VÄTERLEIN, Roma ludens. Kinder und Erwachsene beim Spiel im antiken Rom (Heuremata 5; Amsterdam 1976), 18f; E. SCHMIDT, Spielzeug und Spiele der Kinder im klassischen Altertum (Südthüringer Forschungen 7/71; Meiningen 1971), 25-28; R. SCHMIDT, Die Darstellung von Kinderspielzeug und Kinderspiel in der griechischen Kunst (Raabser Märchen-Reihe 3; Wien 1977), 15-19.

12 Vgl. z.B. A. HÄHNLE, Gnōrismata (Diss. phil.; Tübingen 1929), 66ff. 100f. $143 f$.

13 Zu Definitionsversuche vgl. z.B. H. RETTER, Spielzeug (1979), 205ff; R. VoGELSANG, Die mathematische Theorie der Spiele (1963), 13-18; G. KLAUS, Spieltheorie in philosophischer Sicht (1968), 27ff; L. SCHENK-DANZINGER, Studien zur Entwicklungspsychologie und zur Praxis der Schul- und Beratungspsychologie (München - Basel 1963), 86ff. 93ff; R. VAN DER KOOIJ, Empirische Spielforschung. Überblick und neuere Ergebnisse, in: K.J. KREUZER (ed.), Handbuch der Spielpädagogik 1 (Düsseldorf 1983), 89-158; H. SCHEUERL, Das Spiel. Untersuchungen über sein Wesen, seine pägadogischen Möglichkeiten und Grenzen (Weinheim - Basel 91979), 68ff. 123ff; vgl. auch ders., Zur Phänomenologie des Spiels, in: Das Spiel, ed. Ausschuß Deutscher Leibeserzieher (Frankfurt a.M. 1959), 29-42. Zu den verschiedenen Spiel-Theorien vgl. Kap. 17. 
spielen $^{14}$. Als Bei-Spiel mag das Liebes-Spiel dienen: Die Geliebte kann schon im Vor-Spiel - zur Gespielin, der Geliebte zum Gespiel werden (H1. 1,1ff); Liebes-Spiele ${ }^{15}$ haben häufig Kinder und zuweilen Nach- und TrauerSpiele zur Folge (z.B. 2.Sam. 11-12). Erotische Spiele unter Kindern ${ }^{16}$ gab es sicherlich auch im antiken Palästina, auch wenn es nicht direkt belegbar ist. Ein Kind kann zum Spielzeug seiner Eltern (Anth. Graeca 7,643: athyrma), der Mensch zum Spielball der Götter (Kap. 3), ein Tier zum Spielzeug eines Menschen werden (Kap. 4). Tiere spielen; das Spiel der Wellen und das Spiels des Lichts faszinieren Menschen ebenso wie Macht- und Ränkespiele (z.B. 2.Sam. 10-12; 1.Kön. 21). Mit Waffen läßt sich - von Kindesbeinen an bis ins hohe Alter hinein - gut Krieg spielen (Kap. 12) ${ }^{17}$. Und im Prinzip konnte

14 Auf Definitionen wird in der Spielforschung aus guten Gründen häufig verzichtet: Realdefinitionen sind nicht möglich. Zur erkenntnistheoretischen Begründung vgl. z.B. B. VANDEnBerg, Play: A Concept in Need of a Definition?, in: D.J. PEPLER - K.H. RUBIN (ed.), The Play of Children: Current Theory and Research (Contributions to Human Development 6; Basel u.a. 1982), 15-20; L. WITTGENSTEIN, Philosophische Untersuchungen, in: ders., Schriften 1 (Frankfurt a.M. 1960), 324-326: "Sag nicht: 'Es $m u \beta$ ihnen etwas gemeinsam sein, sonst hießen sie nicht Spiele' - sondern schau, ob ihnen allen etwas gemeinsam ist. - Denn, wenn du sie anschaust, wirst du zwar nicht etwas sehen, was allen gemeinsam ist, aber du wirst Ähnlichkeiten, Verwandtschaften, sehen... Wie ist denn der Begriff des Spiels abgeschlosen? Was ist noch ein Spiel und was ist keines mehr? Kannst du die Grenzen angeben? Nein. Du kannst welche ziehen: denn es sind noch keine gezogen... Wie würden wir denn jemandem erklären, was ein Spiel ist? Ich glaube, wir werden ihm Spiele beschreiben, und wir könnten der Beschreibung hinzufügen: 'Das, und Ähnliches, nennt man Spiele'. Und wissen wir selbst denn mehr? Können wir etwa nur dem Andern nicht genau sagen, was ein Spiel ist? - Aber das ist nicht Unwissenheit. Wir kennen die Grenzen nicht, weil keine gezogen sind. Wie gesagt, wir können - für einen besonderen Zweck - eine Grenze ziehen. Machen wir dadurch den Begriff erst brauchbar? Durchaus nicht! Es sei denn, für diesen besonderen Zweck".

15 E. BERNE, Spiele der Erwachsenen. Psychologie der menschlichen Beziehungen (Reinbek bei Hamburg 1970), 162ff. "Ein [bzw. das gefährlichste] Spielzeug ist das Weib", so F. NiETZSCHE, Also sprach Zarathustra, Von alten und jungen Weiblein (Werke. Kritische Gesamtausgabe 6,1; Berlin 1968), 81.

16 Vgl. z.B. A. ADLER, Erotische Kinderspiele, Anthropophyteia 8 (1911), 256-258; N. KLUGE, Sexuelle Grunderfahrungen im Spiel, in: K.J. KREUZER (ed.), Handbuch der Spielpädagogik 2 (Düsseldorf 1983), 145-156; E. BORNEMANN, Die Umwelt des Kindes im Spiegel seiner "verbotenen" Lieder, Reime und Rätsel. Studien zur Befreiung des Kindes II (Olten - Freiburg i.Br. 1974), 51ff.

17 Tacitus, Germ. 32; Polybios, hist. 1,84; Philostrat, imag. 2,6; Alexander d.Gr. soll am Euphrat zu seinen Soldaten gesagt haben: hë gar symbolē tou polemou paignion hēmin estin, Leben und Taten Alexanders von Makedonien 2,9,4 (ed. H. VAN THIEL); J.W. VON GOETHE, Aus meinem Leben. Dichtung und Wahrheit I 2 (Werke in sechs Bän- 
jedes Spiel kultisch als Ordal, Orakel, Votivgabe o.ä. benutzt werden, in Ritualen die Grenze zwischen Spiel und Kult leicht verschwimmen ${ }^{18}$. Die verschiedenen Kulturen des antiken Palästina gehörten nicht zu modernen Wegwerfgesellschaften; insofern kam den einzelnen Gegenständen ein höherer Wert, eine vermehrte Wiederverwendung und vor allem ein Mehrfachgebrauch bzw. eine Multifunktionalität und Polyvalenz zu. Dies erschwert dem heutigen Betrachter häufig eine klare Unterscheidung von spielerischer Benutzung auf der einen und kultischer, magischer (und juridischer) Verwendung der Gegenstände auf der anderen Seite wie z.B. bei Rasseln, Bällen (Kap. 5), Astragalen (Kap. 6), Würfeln (Kap. 7) ${ }^{19}$, Brettspielen (Kap. 8) ${ }^{20}$ und Puppen (Kap. 11).

$\mathrm{Da} B$ die historische Wirklichkeit nur bruchstückhaft erfaßt werden kann, muß nicht weiter betont werden. Wenn man sich vor Augen hält, daß ein erheblicher Teil des antiken Spielzeugs aus vergänglichen Materialien wie Leder, Holz, Textilstoffen, ungebranntem Lehm u.ä. hergestellt war ${ }^{21}$, aus lebenden Vögeln, Schildkröten ${ }^{22}$, Heuschrecken ${ }^{23}$, Käfern ${ }^{24}$, Affen ${ }^{25}$, Bären ${ }^{26}$,

den, Bd. 5; Wiesbaden 31952), 44 ("Knabenmärchen"); L. WürHRICH, Windrädchenlanze und Steckenpferd. Kinderturnier und Kampfspielzeug um 1500, ZSA 38 (1981), 279-289; Usāma Ibn Munqid, Ein Leben im Kampf gegen Kreuzritterheere (Kitäb al-

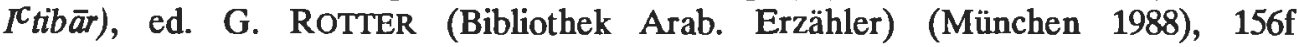
(Lanzenspiele der Kreuzfahrer bei Tiberias). Zur neueren Diskussion vgl. z.B. CH. BÜTTNER, Kriegsspielzeug oder die Organisierung der Feindseligkeit, Kindheit 1 (1979), 153-168; ders., Kriegsspiele - Anlaß, Dynamik und Interventionsmöglichkeiten, Kindheit 4 (1982), 163-181; E.W. PAXSON, War Gaming, in: E.M. AVEDON - B. SuTTON-SMITH (ed.), The Study of Games (New York u.a. 1971), 278-301.

18 Vgl. unten Kap. 5 und z.B. A.E. JENSEN, Spiel und Ergriffenheit, Paid. 2 (1942), 124-139.

19 W.S. ANDREws, Magic Squares and Cubes (London 1917 = New York 1960), passim.

20 N. PENNICK, Games of the Gods: The Origin of Board Games in Magic and Divination (London u.a. 1988), passim.

21 Vgl. z.B. Aristophanes, nub. 877f; Plutarch, Dion 9; Lukian, somn. 2; Joh. Chrysostomos, in Matth. hom. 33,9 (Kinder bauen aus Scherben und Lehm Häuschen).

22 Vgl. z.B. Hom. Hymn., Herm. 24ff. 152. 242. Zur Symbolik der Schildkröten vgl. z.B. H. GOSSEN - A. STEIER, Schildkröte, RE 2,3 (1921), 427-433; W. RICHTER, Schildkröte, KP 5 (1975), 9f; U. SEIDL, Die babylonischen Kudurru-Reliefs (OBO 87; Fribourg Göttingen 1989), 152-154. Zum sog. 'Schildkröten-Spiel' (griech. chelōne) vgl. z.B. Pollux 9,125; L. BECQ DE FOUQUIERES, Les jeux des anciens ( ${ }^{1873), 38-43 ; ~ F . ~ S C H E I D E-~}$ WElLER, Erinnas Klage um Baukis, Ph. 100 (1956), 40-51.

23 S. KRAUSS, Talmudische Archäologie III (1912), 111.

24 Aristophanes, nub. 763. Vgl. allgemein H. GosSEN, Käfer, RE 10 (1919), 1478-1489. 
Delphinen ${ }^{27}$, Elephanten ${ }^{28}$ oder anderen Haus- und Wildtieren bestand oder aber spontane Erfindungen der Kinder waren ${ }^{29}$, dann ist klar, wie gering der Annäherungswert der folgenden Überlegungen an die historische Wirklichkeit ist; fehlende Belege für ein Spiel müssen keineswegs auf die Nichtexistenz dieses Spiels hindeuten. Für Palästina fehlen literarische Quellen (vgl. Ovid, tristia 2,471ff) wie die Schriften des Sueton ${ }^{30}$ bzw. des aus Naukratis stammenden Pollux ${ }^{31}$, die Traktate des römischen Kaisers Claudius über das

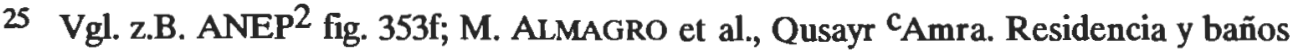
omeyas en el desierto de Jordania (Madrid 1975), Taf. 39. 42; E. BRUNNER-TraUT, Die altägyptischen Scherbenbilder (Bildostraka) der deutschen Museen und Sammlungen (Wiesbaden 1956), 98f, Nr. 100, Taf. 3:100; J. MEUSZYNSKI, Die Rekonstruktion der Reliefdarstellungen und ihrer Anordnung im Nordwestpalast von Kalhu (Nimrūd) (BagF 2; Mainz 1981), 33, Taf. 5, D 7; C. NIEBUHR, Reisebeschreibungen nach Arabien und anderen umliegenden Ländern, Bd. 1 (Kopenhagen 1774 = Hamburg $1837=$ Graz 1968), 189.

26 Deckenmalerei im tonnengewölbten Apodyterium des omayyadischen $Q u s \bar{e}_{r} c_{A m r a}$, M. AlMAGRO et al., Qusayr cAmra (1975), Taf. 39. 42; H. SCHWEIGER, Bären mit Humor, in: F.K. DöRNER (ed.), Vom Bosporus zum Ararat (KAW 7; Mainz ${ }^{3} 1991$ ), 96.

27 Vgl. literarisch z.B. Plinius d.J., ep. 9,33,2 (delphinum gestatorem collusoremque puerorum); Pausanias 3,25,7; Plutarch, septem sap. conv. 20 oder ikonographisch die zahlreichen Münzen griechischer und römischer Zeit mit den auf einem Delphin reitenden Eros, Taras, Phalanthos u.a. Auch C.K. TAYLOR - G.S. SAAYMAN, Play and Imitation in Dolphins, in: J.S. BRUNER et al. (ed.), Play - Its Role in Development and Evolution (New York 1976), 239-243.

28 Plutarch, de fort. 98 (Elephant als paignion). Zu Elephanten - meist als Kriegsspielzeug - in Palästina vgl. z.B. neben 1.Makk. 6,32; 8,6; 2.Makk. 11,21; 13,2; 3.Makk. 5,6 auch R. and A. OVADIAH, Hellenistic, Roman and Early Byzantine Mosaic Pavements in Israel (Rom 1987), Nr. 17. 31. 62. 77. 176. 240; P. MAIBERGER, Elefant, NBL 1 (1991), 511; H.H. SCULLARD, The Elephant in the Greek and Roman World (London 1974), 178ff; H.R. BALDUS, Eine antike Elefanten-Dressur. Zu einem Münzbild König Jubas II., Chiron 20 (1990), 217-220.

29 H. Zulliger, Das selbsterfundene Spiel als Ausdrucksmittel des Kindes, Pädagog. Rundschau 19 (1965), 250-252; M.A. PULASKI, Toys and Imaginative Play, in: J.L. SINGER (ed.), The Child's World of Make-Believe. Experimental Studies of Imaginative Play (New York u.a. 1973), 74-103; E. BIBLOW, Imaginative Play and the Control of Aggressive Behavior, in: J.L. SINGER (ed.), The Child's World of Make-Believe (1973), 104-128; M. ULICH, "Eene, meene muh / raus bis du". Rituale und Freiräume im traditionellen Kinderspiel, ZP 31 (1985), 735-746.

30 Sueton, Claudius 33. J. TaIllardat (ed.), Suétone. Peri blasphēmiōn. Peri paidiōn (Extraits byzantines) (Nouvelle Collection de Textes et Documents; Paris 1967), 64ff u.ö.; vgl. z.B. auch Suidas (ed. A. ADLER) 4,581.

31 Pollux, Onomastica, ed. E. BETHE (Lexicographi Graeci 9,1-3; Stuttgart 1900-1937 = 1966), passim, zitiert vor allem aus der verlorenen Schrift Suetons. Das "Buch der 
Würfelspiel (Sueton, Claud. 33,2) oder des Arztes Galenos über das BallSpielen $^{32}$, Spiele-Listen wie die von J. Fischart (1590) ${ }^{33}$ und Darstellungen wie das Gemälde "Kinderspiele" (1560) von Pieter Bruegel d.Ä. ${ }^{34}$. Ebensowenig existiert ein ludus globi, wie es Nikolaus von Kues (1401-1464) erfunden und dazu gleich eine detaillierte Spielbeschreibung verfaßt hatte ${ }^{35}$; letzteres kann man heute wieder (wie die meisten antiken Spiele auch $^{36}$ ) - gewissermaßen im Nachdruck - käuflich erwerben, die Spielfreude vergeht einem allerdings beim Globus-Spiel recht bald angesichts der theologischen Über-

Spiele" von Alphons X. (dem Weisen) von Kastilien (1282) ist dagegen erhalten (Madrid, Bibl. des Escorial): ALFONSO EL SABIO, Libros de Acedrex, Dado et Tablas. Das Schachzabelbuch König Alfons des Weisen, ed. A. STEIGER (Zürich - Erlenbach 1941), passim; vgl. auch A.G. SolAlinde (ed.), Antología de Alfonso X el Sabio (Buenos Aires - México 1941), 171ff.

32 De parvae pilae exercitu, ed. F. und L. FETZ, Gymnastik bei Philostrat und Galen (Studientexte zur Leibeserziehung 4; Frankfurt a.M. 1969), 101-106.

33 Geschichtklitterung (Gargantua). Text der Ausgabe letzter Hand von 1590, ed. U. NYSSEN (Düsseldorf 1963), 238-251; H. RAUSCHEN, Die Spiele der Jugend aus Fischarts Gargantua cap. XXV, Jb. für Geschichte, Sprache und Literatur ElsaßLothringens 24 (1908), 53-145; A. ISLER, Von den Spielen des Gargantua (Zürich 1965), passim. Auch P.G. BREWSTER, The Earliest Known List of Games: Some Comments, AcAor 23 (1959), 33-42; K. RANKE, Meister Altswerts Spielregister, SAVK 48 (1952), 137-197 oder die Liste bei C. Collodi (LORENZINI), Le avventure di Pinocchio (Florenz 1880 = Turin 1968), Kap. 31 (nel Paese dei balocchi).

34 Wien, Kunsthistorisches Museum. Vgl. z.B. J. HILLs, Das Kinderspielbild von Pieter Bruegel d.Ä., (1560) (Veröffentlichung des Österreichischen Museums für Volkskunde 10; Wien 1957), passim; K. HAIDING, Das Spielbild Pieter Bruegels, in: Bausteine zur Geschichte, Völkerkunde und Mythenkunde 1.Hb.bd. (Wien 1937), 58-74; P. PORTMANN, Pieter Bruegel d.̈̈., Kinderspiele (Orbis pictus 36; Bern - Stuttgart 1961), passim; D. ElSCHENBROICH, Kinder werden nicht geboren. Studien zur Entstehung der Kindheit (Frankfurt a.M. 1977), 79-90. Auch D. VON GERSDORF, Kinderbildnisse aus vier Jahrtauseñden (Berlin 21989), 120-133.

35 L. Gabriel - D. DuPre - W. DuPre (ed.), Nikolaus von Kues. Philosophischtheologische Schriften (Studien- und Jubiläumsausgabe Bd. 3, lateinisch - deutsch; Wien 1967), 221-355; vgl. auch G. HEINZ-MOHR, Das Globusspiel des Nikolaus von Kues. Erwägungen zu einer Theologie des Spiels (Kleine Schriften der Cusanus-Gesellschaft H. 8; Trier 1965), passim. Angeblich von W.A. MOZART stammt das 'Musikalisches Würfelspiel. Eine Anleitung, Walzer und Schleifer mit zwei Würfeln zu componieren, ohne Musikalisch zu seyn, noch von der Composition etwas zu verstehen', ed. K.H. TAUBERT (Mainz 1956), passim.

36 Vgl. z.B. TH. KEndall, Passing through the Netherworld. The Meaning and Play of Senet, an Ancient Egyptian Funerary Game (Belmont/MA 1978), passim, ist als Beilage zu einem nachgebauten Senet-Spiel erarbeitet; auch Strategie und Zufall. Die Wie- 
frachtung, die dem Spiel den Spielwitz weitgehend nimmt. Im übrigen hat Augustin, auf dessen Spieltisch (mensa lusoria) in Mailand neben anderer Literatur auch die Briefe des Apostels Paulus lagen (conf. 8,6,14), sein Bekehrungserlebnis womöglich einem Kinderspiel zu verdanken (conf. 8,12) ${ }^{37}$.

Quod non est in actis, non est in mundo: Dieser Grundsatz, historisch konsequent auf das antike Palästina und seine spielende Bevölkerung angewendet, würde zu absurden Ergebnissen führen ${ }^{38}$. Das sei an einem Beispiel erläutert: Kinder aller Zeiten haben gerne geschaukelt, sei es auf Strick- oder Brettschaukeln (Wippen); aus verschiedenen vor- und nachhellenistischen Mittelmeerkulturen und aus Vorderasien ist das gut belegbar (Abb. 2) ${ }^{39}$. Sollten palästinische Kinder des 1.Jahrtausends v.Chr. nicht geschaukelt haben? Natürlich haben sie geschaukelt; es ist nur nicht direkt belegbar, aber aus vergleichbaren Kulturen im Analogieverfahren - m.E. nahezu zwingend - voraus-

dergeburt des 5000 Jahre alten Brettspiels aus den Grabkammern der Pharaonen. Pharao-Brettspiele (H.A. RENZ), München o.J.

37 Zum Problem vgl. S. MENDNER, Gesellschaftsspiele, RAC 10 (1978), 889f. Zum Motiv vgl. J. BolTE, Die Legende von Augustin und dem Knäblein am Meere, ZVVK 16 (1906), 90-95 ('Des Knaben Wunderhorn': Augustin und der Engel - Mit der Muschel schöpft das Büblein / aus dem Meer in ein Sandgrüblein).

38 An Ignoranz nur schwer zu überbieten z.B. A. JANATA, Vorderasien, in: E. BECKER-DONNER et al. (ed.), Spiel und Spielzeug aus aller Welt. Sonderausstellung 1971/72, Museum für Völkerkunde Wien (Wien 1971), 32-34, hier mit einigen ausgewählten Blüten zitiert: "Die Kinder Vorderasiens haben äußerst wenig Spielzeug"; dies führt "zu dem Schluß, daß die Kinder dieses Raumes kaum Spielzeug kennen". "Es wäre nun falsch, aus dem wenigen Spielzeug den Schluß zu ziehen, die Kinder Vorderasiens spielen nicht". "Die Literatur bringt so gut wie nichts zum Thema".

39 Vgl. z.B. die max. $16 \mathrm{~cm}$ hohe, bemalte minoische Schaukel-Terrakotta aus Hagia Triada (Arch. Mus. Heraklion): A. Evans, The Palace of Minos at Knossos, Vol. 4,1 (New York 1964), 24-27, fig. 13a-b; K. GRÖBER - J. METZGER, Kinderspielzeug aus alter Zeit (Hamburg 21965), 112. 212, Nr. 28; H.-G. BUCHHOLZ, in: S. LASER (ed.), Sport und Spiel (1987), 111-116, Abb. 42; auch L. BECQ DE FOUQUIERES, Les jeux des anciens (21873), 54-57; F.A.G. BECK, Album of Greek Education (1975), 48, Nos. 290-295; K. SCHAUENBURG, Erotenspiele, AW 7,3 (1976), 42f; J. Väterlein, Roma ludens (1976), 47-49, Abb. 15; R. SCHMIDT, Die Darstellung von Kinderspielzeug und Kinderspiel (1977), 56-64; L. GRASBERGER, Erziehung und Unterricht im klassischen Alterthum I 1 (Würzburg 1864), 116-128; F. KLEPZIG, Kinderspiele der Bantu (Meisenheim a.G. 1972), 337. 448 u.ö.; G. JACOB, Altarabisches Beduinenleben, nach den Quellen geschildert (Berlin $21897=$ Hildesheim 1967), 113; C. NIEBUHR, Reisebeschreibungen nach Arabien, Bd. 1 (1774 = Graz 1968), 170f, Taf. 25:D-G; J.L. BURCKHARDT, Reisen in Arabien (Weimar 1830 = Stuttgart 1963), 145. 
zusetzen ${ }^{40}$. Immerhin dürfte Jes. 66,12 ( $\xi^{c c}$ II pulp. $)^{41}$ belegen, daß Eltern ihre Säuglinge gerne auf ihren Knien geschaukelt haben ${ }^{42}$.

Andere Beispiele für Spiele, die im antiken Palästina (bisher) kaum oder überhaupt nicht belegbar sind, aber mit großer Wahrscheinlichkeit vorausgesetzt werden können, sind z.B. Huckepack ${ }^{43}$, Tauziehen sowie Zieh- und Zerrkämpfe ${ }^{44}$, das Werfen von (flachen) Steinen oder Scherben auf Wasser-

40 Griech. aiōra, petauron; latein. oscilla; arab. murğêeha; neuhebr. nadnedāh. Vgl. z.B. E. BÖHR, Der Schaukelmaler (Forschungen zur antiken Keramik 2.Reihe, Kerameus 4; Mainz 1982), 52; H.-G. BuCHHOLZ, in: S. LASER, Sport und Spiel (1987), 111-116; A. DIERICHS, Erotik in der Kunst Griechenland (AW Sd.-Heft; Mainz 1988), Abb. 65a; B.C. DIETRICH, A Rite of Swinging during the Anthesteria, Hermes 89 (1961), 36-50; L. DEUBNER, Spiele und Spielzeug der Griechen, Antike 6 (1930), 168f, Abb. 11, Taf. 16a. b; W. EHLERS, Oscilla, RE 18,1 (1942), 1567-1578; W. FAUTH, Anthesteria, KP 1 (1975), 372-374; W. Kroll - E. MEHL, Petauron, RE 19,1 (1937), 1124f; W.L. LACEY, Die Familie im alten Griechenland (KAW 14; Mainz 1983), Abb. 34; W. BURKERT, Homo Necans (RVV 32; Berlin - New York 1972), 236ff; M.P. NILSson, Griechische Feste von religiöser Bedeutung mit Ausschluß der attischen (1906 = Darmstadt 1957), 233. 236f; H. RÜHFEL, Kinderleben im klassischen Athen (KAW 19; Mainz 1984), 21f, Abb. 9a; J. VÄTERLEIN, Roma ludens (1976), 47; G. WENTZEL, Aiōra (Alētis), RE 1 (1893), 1043f; auch E. Patlagean, Byzanz im 10. und 11.Jahrhundert, in: PH. ARIES G. DUBY (ed.), Geschichte des privaten Lebens I (Frankfurt a.M. 1989), 567; H. SBRZESNY, Die Spiele der !Ko-Buschleute unter besonderer Berücksichtigung ihrer sozialisierenden und gruppenbindenen Funktionen (Monographien zur Humanethologie 2; München - Zürich 1976), 94; J. HILlS, Das Kinderspielbild von Pieter Bruegel d.Ä. (1957), 9f, Nr. 5 (Mädchen schaukelt in Zimmer).

41 HAL 4 ( $\left.{ }^{3} 1990\right)$, $1489 f$.

$42 \mathrm{Zu}$ den bekanntesten europäischen Schaukel- und Kniereiter-Liedern gehört "Hoppe hoppe Reiter / wenn er fällt, dann schreit er / Fällt er in den Teich, findt ihn keiner gleich / Fällt er in die Hecken, fressen ihn die Schnecken / fressen ihn die Müllermücken, die ihn vorn und hinten zwicken / Fällt er in den tiefen Schnee, dann gefällts ihm nimmermeh / Fällt er in den Graben / fressen ihn die Raben / Fällt er in den Sumpf / dann macht er einen Plumpf", vgl. F.M. BöHME, Deutsches Kinderlied und Kinderspiel (Leipzig 1897 = Nendeln 1967), 73ff, Nr. 313ff; H.M. ENZENSBERGER (ed.), Allerleihrau. Viele schöne Kinderreime (1961), 59-69; B. und SH. SUTTON-SMITH, Hoppe, hoppe, Reiter. Die Bedeutung von Kinder-Eltern-Spielen (Zürich - München 1986), 37-45.

43 O. KeEL (ed.), Altorientalische Miniaturkunst (Mainz 1990), 110ff; L. GRASBERGER, Erziehung und Unterricht im klassischen Alterthum I 1 (1864), 109-114; C. ROBERT, Griechische Kinderspiele auf Vasen, AZ 37 (1879), 78-82; F. BROMMER, Huckepack, GettyMusJ 6-7 (1978-1979), 139-146; vielleicht auch A. FroVA, Scavi di Caesarea Maritima (Rom 1966), 203-205, No. 8.

44 Vlg. z.B. Pollux 9,112.116; Platon, Theait. 181A; J. TAlllardat (ed.), Suétone. Peri paidiōn (1967), Nr. 7; ANEP ${ }^{2}$ Nr. 217. Allgemein L. BECQ DE FOUQUIERES, Les jeux 
flächen ${ }^{45}$ oder in Bäume ${ }^{46}$, Plantschen und gelegentliches Schwimmen (bQidd. 29a; jŠeq 50a) ${ }^{47}$, das Spielen mit dem Reifen und Treib-Stecken ${ }^{48}$

des anciens (21873), 94-98; A. MAU, Dielkystinda, RE 9 (1903), 475; A. HUG, Skaperda, RE III A 1 (1927), 439; L. GRASBERGER, Erziehung und Unterricht im klassischen Alterthum I 1 (1864), 98-105. 160; F.M. BöHME, Deutsches Kinderlied und Kinderspiel $(1897=1967), 626$, Nr. $509 f$.

45 Vgl. z.B. Pollux 9,119; J. Taillardat (ed.), Suétone. Peri paidiōn (1967), Nr. 9; Minucius Felix, Octavian 3,5f: "... sahen wir ein paar Jungen, die im Spiel um die Wette Steine ins Meer [bei Ostia] schleuderten. Dieses Spiel besteht darin, einen runden, von den Wogen glatt polierten Stein ... flach in die Finger zu nehmen und ihn, gebückt und nahe am Boden, so weit wie möglich über die Wogen hinsausen zu lassen. ... Als Sieger gilt bei den Jungen der, dessen Stein am weitesten geflogen und am häufigsten in die Höhe gesprungen ist"; allgemein L. BECQ DE FOUQUIERES, Les jeux des anciens (21873), 113; A. MAU, Epostrakismos, RE 6,1 (1907), 251; L. GRASBERGER, Erziehung und Unterricht im klassischen Alterthum I 1 (1864), 60f; F.M. BÖHME, Deutsches Kinderlied und Kinderspiel $(1897=1967)$, 604, Nr. 469; J. SCHEFTELOWTTZ, Alt-palästinensischer Bauernglaube in religionsvergleichender Beleuchtung (Hannover 1925 = Osnabrück 1975), § 61. 133f.

46 Vor allem in Nußbäume, die sich darüber literarisch heftig beklagten, vgl. Nux $125 f$. $151 f$ oder Anth. Graeca 9,3: "Nun werfen Jungen so im Vorbei spielend mit Steinen nach mir. Immerfort treffen sie mich; schon haben sie alle meine Äste und mein sprossend Gezweig mit ihren Steinen geknickt. Hat es noch Zweck, ein Fruchtbaum zu sein? Ich Armer, ich brachte meine Früchte doch nur, um mich mißhandelt zu sehn".

47 Die üblicherweise angeführten Belege Jes. 25,11; Ez. 47,5 und Ps. 6,7 (HAL 4, 1225 $s h h$, sh hw) werden neuerdings von W. VON SODEN, Ist im Alten Testament schon vom Schwimmen die Rede?, ZAH 4 (1991), 165-170 bezweifelt. Vgl. z.B. auch 1.Makk. 9,48; Apg. 27,42f; Epiphanios, Panar. 30,7 (GCS 25,342) (der minderjährige Sohn des jüdischen Patriarchen trieb sich gerne im Bad von Gadara herum und stellte dort den Mädchen nach); Joseph., Ant. 15,3,3 ( $\$ 53-56$ ); ders., BJ 1,22,2 ( $\$ 437$ ) sowie die ausgegrabenen (Swimming-)Pools (griech. kolymbēthra) z.B. im römerzeitlichen Jericho (Tulül

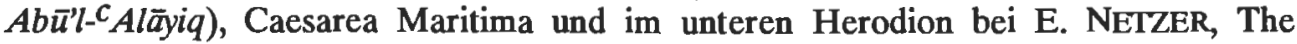
Winter Palaces of the Judean Kings at Jericho at the End of the Second Temple Period, BASOR 228 (1977), 3f, fig. 1 und 4; L.I. LEVINE - E. NETZER, Excavations at Caesarea Maritima 1975, 1976, 1979 - Final Report (Qedem 21; Jerusalem 1986), 176; E. NETZER, Greater Herodium (Qedem 13; Jerusalem 1981), 28 sowie auch die aus Ägypten importierten spätbronzezeitlichen Salblöffel in Gestalt einer Schwimmerin aus Dēr elBalah Grab 118, Megiddo Stratum VII A, Tell es-Sacidìye Grab 101 und Bet-Schean Grab 90 bei T. DoTHAN, Excavations at the Cemetery of Deir el-Balah (Qedem 10; Jerusalem 1979), 61-63, fig. 142-144; G. LouD, The Megiddo Ivories (OIP 52; Chicago 1938), 18, Pl. 40-42; J.B. PRITCHARD, The Cemetery at Tell es-SaCidiyeh, Jordan (Philadelphia/PN 1980), 13, fig. 3:9; 50:1; E.D. OREN, The Northern Cemetery of Beth Shan (Leiden 1973), 121. 229, fig. 49:26; I. GAMER-WALLERT, Der verzierte Löffel (ÄA 16; Wiesbaden 1967), 18ff, Taf. 11ff. Vgl. auch die reizvollen Beobachtungen zum Schwimmen der Knaben von Hippo an der nordafrikanischen Küste bei Plinius d.J., ep. 9,33,2 oder z.B. Pausanias 3,25,7; Plinius d.Ä., nat. hist. 9,24-33; Aelian, nat. anim. 2,6-8; 
sowie mit dem Springseil ${ }^{49}$ (vor allem bei Mädchen), sich Spiegeln im Wasser- oder Metall-Spiegel (Ausonius, Mosella 225-239), das Stehlen von

W. THESIGER, Die Brunnen der Wüste. Mit den Beduinen durch das unbekannte Arabien (München - Zürich 21991), 273. 284; M. KRANZ, Probleme der Leiblichkeit (Diss. phil. masch.; Köln 1965), 87; W. KRAMPE, Die Gymnastik in der Bibel, Deutsche TurnZeitung 31 (1881), 313ff; M. BUBER, Die Erzählungen der Chassidim (Zürich 1949), 680; M. Griaule, Jeux et divertissements abyssins (BEHE.R 49; Paris 1935), 66ff und allgemein L. GRASBERGER, Erziehung und Unterricht im klassischen Alterthum III (1881), 215-224; W. DECKER, Schwimmen, LÄ 5 (1984), 765f; S. OPPERMANN, Schwimmen, KP 5 (1975), 47; A. HERMANN, Ertrinken, RAC 6 (1966), 374f. 381-383; G. PUTZKE, Geschichte des Schwimmsports, in: G.A.E. BOGENG (ed.), Geschichte des Sports aller Völker und aller Zeiten, Bd. II (Leipzig 1926), 420-443; E. MEHL, Antike Schwimmkunst (München 1927), passim; ders., Schwimmen, RE Suppl. 5 (1931), 847864; F. ROSENTHAL, Gambling in Islam (Leiden 1975), 56f; Pseudo-Ovid, De Vetula, ed. P. KLOPSCH (Leiden - Köln 1967), 1,246-261.

48 Reifen neuhebr. galgal; akkad. pukku, mekkû, vgl. aber AHw 642. 878; B. LANDSBERGER, Einige unerkannt gebliebene oder verkannte Nomina des Akkadischen, WZKM 56 (1960), 124-126; (neu)hebr. galgal; griech. trochos; latein. trochus, vgl. z.B. Martial, epigr. 14,168f; Horaz, carm. 3,24,57; Artemidor 1,55; Ovid, tristia 2,486; ders., ars amandi 3,383; auch A. HUG, Rota, RE II 1 (1914), 1148-1152; auch H.-G. BUCHHOLZ, in: S. LASER (ed.), Sport und Spiel (1987), 109-111, Abb. 41; J. FINK, Die römischen Katakomben (AW Sondernr.; Mainz 1978), 26, Abb. 18; L. BECQ DE FOUQUIERES, Les jeux des anciens ( ${ }^{2} 1873$ ), 159-170; F.A.G. BECK, Album of Greek Education (1975), 47f, Nos. 286-289; R. SCHMIDT, Die Darstellung von Kinderspielzeug und Kinderspiel (1977), 31-39; L. GRASBERGER, Erziehung und Unterricht im klassischen Alterthum I 1 (1864), 81-84; F.K. MATHYS, Im Freien gespielt (1975), 17f; K. TRAPP, Bantu-Spiele. Ein Beitrag zur ethnologischen Spielforschung (Diss. phil. masch.; Bonn 1960), 92-95; F. KLEPZIG, Kinderspiele der Bantu (1972), 60. 336 u.ö.; A. LuKACSY, Spiele der Welt (Budapest 1972), 100; F.V. GruNFELD, Spiele der Welt (1979), 181183; J.J. HESS, Von den Beduinen des Innern Arabiens (Zürich - Leipzig 1938), 139.

49 Neuhebr. hbl-qpyṣh; akkad. keppû, vgl. AHw ${ }^{2}$ 467; B. LANDSBERGER, WZKM 56 (1960), 120-124; S. PAUL, Notizen zu einigen afrikanischen Geschicklichkeitsspielen (Lic. phil. masch.; Uppsala 1962), 173ff; H. SBRZESNY, Die Spiele der !Ko-Buschleute (1976), 92-94; F. KLEPZIG, Kinderspiele der Bantu (1972), 138-140 u.ö.; F.V. GRUNFELD, Spiele der Welt (1979), 177-179. Angeblich auch ikonographisch vor allem auf Siegeln belegt, vgl. z.B. W.H. WARD, The Seal Cylinders of Western Asia (Washington/DC 1910), 296, Nos. 912-923; M.-TH. BARRELET, Les déesses armées et ailées, Syria 32 (1955), 242f, fig. 11. 13; auch F. BLOCHER, Untersuchungen zum Motiv der nackten Frau in der altbabylonischen Zeit (MVS 4; München 1987), 200f; R. MAYER-OPIFICIUS, Götterpaare in Kleinasien und Mesopotamien, in: Studien zur Religion und Kultur Kleinasiens. FS für F.K. DÖRNER zum 65.Geb., Vol. II (Leiden 1978), $598 f$ ('geflügeltes Seil'). Bei dem weitaus größten Teil des ikonographischen Materials haben z.B. D. Collon, First Impressions. Cylinder Seals in the Ancient Near East (London 1987), 170, No. 777 oder O. KEEL allerdings zweifelsfrei recht, wenn sie daran festhalten, daß die Göttin ihren Schleier hebe bzw. ihren Rock einladend auf die Seite 
Obst aus des Nachbars Garten (Augustin, conf. 2,4,9) oder das mutwillige Zerbrechen irdener Gefäße (bJoma 78b), was nicht nur der kleine Jesus, sondern auch der kleine Goethe ${ }^{50}$ hin und wieder gerne gemacht haben sollen $^{51}$. Daß der neunjährige Jesus und seine gleichaltrigen Spielkameraden gerne auf Bäume kletterten, ist im Armenischen Kindheitsevangelium 23,3 klar bezeugt ${ }^{52}$. Das römische Spiel "capita aut navia" ("Kopf oder Schiff"), ein Glücksspiel mit Münzen, das dem heutigen Spiel "Kopf oder Zahl" bzw. "Schrift oder Adler"53 entspricht, konnte in Palästina mit den dort im Umlauf befindlichen einheimischen und fremden Münzen ebenso gut gespielt werden (Abb. 15. 43) ${ }^{54}$ wie "chalkismos", bei dem man eine Münze wie einen FingerKreisel zum Rotieren brachte 55 . Das erste Spielzeug, das Kindern in die Finger kam, dürften in der Regel die Amulette (gewesen) sein, die den Neugeborenen von Eltern und anderen Verwandten geschenkt wurden ${ }^{56}$.

geschoben habe: Deine Blicke sind wie Tauben (SBS 114-115; Stuttgart 1984), Abb. $47 f$. 99; ders., Das Hohelied (ZB AT 18; Zürich 1986), 73f, Abb. 24f; ders., (ed.), Altorientalische Miniaturkunst (1990), 40, Abb. 38.

50 Aus meinem Leben. Dichtung und Wahrheit $\left({ }^{3} 1952\right)$, 8. Zu Goethe vgl. darüberhinaus W. KAYSER, Goethe und das Spiel, in: ders., Kunst und Spiel (Göttingen 1961), 30-46

51. H. DANIEL-ROPS (ed.), Die apokryphen Evangelien (2 1958), 74. (87).

52 H. DANIEL-ROPS (ed.), Die apokryphen Evangelien (21958), 74; vgl. z.B. auch M. GRIAULE, Jeux et divertissements abyssins (1935), 68f.

53 Vgl. z.B. Macrobius, saturn. 1,7,22; Paulinus von Nola, Poem. ult. 76 (PL 61,998); A. MAU, Capita aut navia, RE 3 (1899), 1513; K.L. TALlQUIST (ed.), Arabische Sprichwörter und Spiele (Helsingfors 1897), 136.

54 Römische 'Capita aut navia'-Münzen aus Palästina vgl. z.B. Y. MESHORER, CityCoins of Eretz-Israel and the Decapolis in the Roman Period (Jerusalem 1984), fig. 20. 23 (Dor), 33 (Caesarea Maritima), 41 (Aschkelon), 83. 85 (Tiberias), 166 (Jerusalem), 224 (Gadara); vgl. auch Y. MESHORER - Sh. QEDAR, The Coinage of Samaria in the Fourth Century BCE (Jerusalem 1991), 23. 37f. 47. 71, No. 16, Pl. 2:16 u.ö. Natürlich konnte das Spiel auch mit jeder anderen Münze gespielt werden.

55 Vgl. z.B. Pollux 7,206; 9,118; Eustathios, Il. 986,43; J. TAILlardat (ed.), Suétone. Peri paidiōn (1967), Nr. 16; L. BECQ DE FouQuIERES, Les jeux des anciens ( ${ }^{2} 1873$ ), 298f; A. MAU, Chalkismos, RE III 2 (1899), 2092; L. GRASBERGER, Erziehung und Unterricht im klassischen Alterthum I 1 (1864), 70 f. 159.

56 Vgl. z.B. bQidd. 73b; L. BLAU, Das altjüdische Zauberwesen (Budapest $1898=$ Graz 1974), 86-96; K. GALLING, Amulett, BRL 2 1977, 10f; B. MERSHEN, Amulette als Komponenten des Volksschmuckes im Jordanland, in: Pracht und Geheimnis. Kleidung und Schmuck aus Palästina und Jordanien, ed. G. VöLGER et al. (Köln 1987), 106-109; dies., Amulets and Jewelry from Jordan - A Study on the Function and Meaning of Recent Bead Necklaces, Tribus 38 (1989), 43-58; E. SCHMIDT, Spielzeug und Spiele der Kinder im klassischen Altertum (1971), 5-24. 
Dem Alten Testament läßt sich zum Thema "Spielen und Spielzeug" nicht viel, aber weit mehr als gewöhnlich angenommen wird, entnehmen. Die im Arabischen und anderen semitischen Sprachen übliche Wurzel $l^{c} b$ ist im Alten Testament nur 2.Chr. 36,16 im hitp. belegt $\left(l^{c} b b\right.$ - "sein Spiel mit jdm. treiben") ${ }^{57}$. Das Verb shq, das im qal "lachen" u.ä. meint ${ }^{58}$, ist auch im pi. belegt ${ }^{59}$; dort kann es die Bedeutung "Scherze machen, scherzen" [Gen. 19,14 (geloiazein; quasi ludere); Ri. 16,25 (paizein, empaizein; ludere ante eos)] oder sei es positiv [Gen. 26,8 (paizein; iocare)], sei es negativ [Gen. 39,14.17 (empaizein ${ }^{60}$; inludere)] - im erotischen Sinn "miteinander scherzen" bzw. "seinen Mutwillen / sein Liebesspiel treiben" heißen. In Gen. 21,9, wo von dem Sohn Hagars im part. pi. $m^{e}$ saḥeq (paizōn; ludens) die Rede ist, ist - auch aus dem Blickwinkel der eifersüchtigen Sara - die Konnotation "spielend" keineswegs auszuschließen: das selig vor sich hinspielende Kind erweckt in ihr Neid und Mißgunst; in der späteren Überlieferung von Gen. 21,9 dramatisieren die Targume Neofiti, Jeruschalmi I und II das harmlose $m^{e_{s a}} \bar{e} \bar{e} q$ als Götzendienst, das Targum-Fragment aus der Kairoer Geniza gar als Mordversuch an Isaak. Gegen Ende des sog. 'Tanzes um das Goldene Kalb' (Ex.

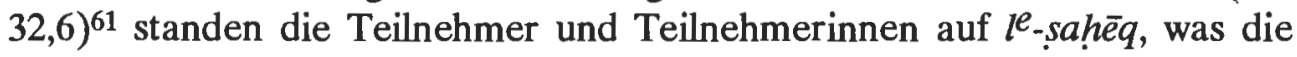
Septuaginta und Paulus in 1.Kor. 10,7 mit paizein ${ }^{62}$ und die Vulg. mit ludere übersetzen. Der masoretische Text hat hier, wie so oft, bewußt auf Eindeutig-

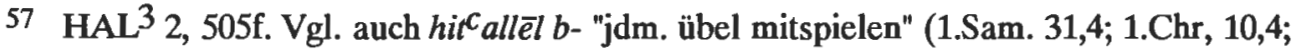
Jer. 38,19, vgl. Ex. 10,2; Num. 22,29; Ri. 19,25; 1.Sam. 6,6; auch Mark. 15,16-20), vgl. $\mathrm{HAL}^{3}$ 3, 789; arab. u.a. $l{ }^{c} c_{i b a}$ "spielen", $l a c^{c}(i) b$ "Spiel", $l u^{c} b a$ "Spielzeug, Puppe", mal $c_{a b a}$ "Spielzeug", F. Rosenthal, Gambling in Islam (1975), 9ff. Vgl. G. DalmaN, Aramäisch-Neuhebräisches Handwörterbuch zu Targum, Talmud und Midrasch (Göttingen 31938 = Hildesheim u.a. 1987), 218 hif., ithp. ("seinen Mutwillen treiben, spotten") sowie $\boldsymbol{C} \boldsymbol{b}^{\prime}$ ' "Gespött"; M. JASTROW, Dictionary of the Targumim, Talmud Babli, Yerushalmi and Midrashic Literatures (New York 1903 = 1989), 713 ("to mock, talk lascivious", "sport, mockery").

58 Gen. 17,17; 18,12f.15; 21,6 (gelan, syncharein; ridere, conridere); vgl. das Nomen in Gen. 21,6; Ez. 23,32 (gelōs; risum, derisum) und den PN Yṣhqq bzw. Yšhq, ein Hypokoristikon von *Ys/(s)hq'l.

59 KBL 801; $\mathrm{HAL}^{3}$ 3, 955. Vgl. G. DALMAN, Aramäisch-Neuhebräisches Handwörterbuch $\left({ }^{3} 1938=1987\right), 361$ "scherzen, heiter sein"; auch M. JASTROw, Dictionary of the Targumim (1903 = 1989), 1274 "(to be bright), to laugh; to jest, sport".

60 G. BERTRAM, ThWNT 5 (1954), 629-635.

61 Zur literarkritischen bzw. redaktionsgeschichtlichen Einordnung vgl. z.B. P. WEIMAR, Das Goldene Kalb. Redaktionskritische Erwägungen zu Ex 32, BN 38-39 (1987), 122-124.

62 G. BERTRAM, ThWNT 5 (1954), 625-629. 
keit verzichtet und seinen Lesern und Leserinnen einen gewissen Spielraum zur freischwebenden Phantasie geboten, die manch bürgerlichen Exegeten männlichen Geschlechts zu Visionen von "sexuellen Orgien" geführt hat ${ }^{63}$. In jedem Fall hat schon der alttestamentliche Verfasser bzw. Glossator unter lesahẹ $q$ etwas ganz Schlimmes verstanden, sei es daß man nach dem sog. 'Tanz ums Goldene Kalb' zum Würfeln ging, sich - schon etwas ernsthafter - sog. 'Darbietungen zur Belustigung einer Gottheit' 64 hingegeben hatte oder aber eben ganz anderen Spielen Erwachsener nachgegangen war. An ersteres haben möglicherweise schon die Septuaginta und damit auch Paulus gedacht, indem sie die Stelle mit paizein und ludere und nicht mit empaizein bzw. inludere wiedergegeben haben.

Die Wurzel-Variante ${ }^{65}$ shqq, die im qal mit "lachen, scherzend unterhalten" zu übersetzen ist ${ }^{66}$, hat im pi. mehrere Bedeutungen ${ }^{67}$. In den meisten Fällen ist "scherzen, froh sein" [Ri. 16,25; Jer. 15,17; 30,19; 31,4; Prov. 26,19 (griech. paizein, latein. ludere)] oder "tanzen, musizieren = (Musik) spielen" gemeint

63 So z.B. M. NoTH, Das 2.Buch Mose. Exodus (ATD 5; Göttingen 51973), 204 (übersetzt 198 "um sich zu belustigen"); vgl. auch H. GRESSMANN, Die Anfänge Israels (Von 2.Mose bis Richter und Ruth) (SAT I 2; Göttingen 21922), 65 übersetzt "erhoben sich zum Tanz" und erläutert 66 " Den Schluß bilden unzüchtige Tänze", vgl. auch P. GERLACH - J. PAUL, Goldenes Kalb, LCI $2(1970$ = 1990), 478-482.

64 O. KEEL, Die Weisheit spielt vor Gott. Ein ikonographischer Beitrag zur Deutung

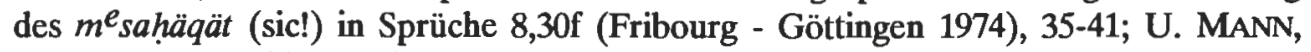
Der Ernst des heiligen Spiels, ErJb 51 (1982), 41-50.

65 R.M. VoIGT, Die Laterale im Semitischen, WO 10 (1979), 110 u.ö.

66 Vgl. z.B. Ri. 16,27; Prov. 1,26; 29,9; 31,25; Qoh. 3,4; Hi. 5,22; 29,24; 30,1; 39,7.18.22; 41,21; Ps. 2,4; 37,13; 52,8; 59,9; Threni 1,7; Sir. 13,6.11; 47,3. KBL 918; HAL ${ }^{3}$ 4, 1226; zu mişhāq (Hab. 1,10) $\mathrm{HAL}^{3}$ 2, 605; zu śhwq $\mathrm{HAL}^{3}$ 4, 1225f "Lachen, Vergnügen, Gespött". Vgl. G. DALMAN, Aramäisch-Neuhebräisches Handwörterbuch (31938 = 1987), 410 "lachen", pi. "spielen", hif. "ausgelassen machen"; auch M. JASTROW, Dictionary of the Targumim (1903 = 1989), 1550 sh $h$, shq: "(to be bright), to laugh; to jest, sport". Vgl. äth. šahaqa und šeheqa; akkad. šehēqu AHw 1209a "niesen?" [vgl. AHw 644

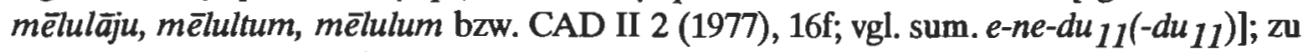
Hatra Nrn. 23, 125 und 232 vgl. auch R. DEGEN, New Inscriptions from Hatra (Nos. 231-80), JEOL 20-23 (1968-1974), 404f, No. 232 (šhqth), zu KAI Nr. 244 (= Hatra Nr. 23) vgl. H. INGHOLT, in: F. ROSENTHAL (ed.), An Aramaic Handbook I 2 (PLO NS 10; Wiesbaden 1967), 45, No. 6 (lṣ̌hqh).

67 E. JENN, Das hebräische Piel. Syntaktisch-semasiologische Untersuchung einer Verbalform im Alten Testament (Zürich 1968), 154-156 ("fröhliche Tätigkeit, die aus verschiedenen, abwechslungsreichen, aufeinanderfolgenden Einzelaktionen besteht, die nur im Resultativ und nicht im Aktualis zusammengefaßt werden"). Vgl. śhq hitp. 2.Chr. 30,10 "verspotten, sich lustig machen". 
[1.Sam. 18,7; 2.Sam. 6,5.2168; 1.Chr. 13,8; 15,29; Prov. 8,30f ${ }^{69}$ (griech. paizein, euphrainesthai, latein. ludere) $]^{70}$; in einigen Fällen ist das pi. aber am besten mit "spielen" wiederzugeben (Sir. 47,3 griech. paizein, latein. ludere, hebr. șhq).

2.Sam. 2,14 (șhq pi.; griech. paizein enōpion; latein. ludere coram) dürfte belegen, daß es auch Kampfspiele unter jungen Männern gegeben hat; der Kampf 'Zwölf gegen Zwölf' zwischen den Anführern Abner und Joab bzw. ihren benjaminitischen und judäischen Gefährten bei Gibeon war allerdings wohl von Anfang an blutiger Ernst ${ }^{71}$. Spiele dieser Art scheinen im vorhellenistischen Palästina keine nennenswerte Bedeutung gehabt zu haben ${ }^{72}$, in ih-

68 Vgl. dazu O. KeEL, Die Weisheit spielt vor Gott (1974), 35-41 (Radschlagen unter ägyptischem Einfluß); dazu auch W. DEONNA, Le symbolisme de l'acrobatie antique (Collection Latomus 9; Brüssel 1953), 6-23 u.ö.

69 Vgl. O. KEEL, Die Weisheit spielt vor Gott (1974), 21-30. 68-74.

70 Auch andere Verben bzw. Wurzeln meinen meist oder stets "Musik(-Instrumente) spielen" u.ä., z.B. $h w l$, zmr I (pi.), ngn, $n s ̧ h$ I (pi.), śkl I (hi.), šm ${ }^{c}$ hi. Auf die Bedeutungen "Musik(-Instrumente) spielen" und "Tanzen" wird im Folgenden nicht eingegangen; vgl. dazu H. SEIDEL, Musik in Altisrael (BEATAJ 12; Frankfurt a.M. 1989), passim; zu Spiel-Liedern G. DALMAN, Palästinischer Diwan (Leipzig 1901), 182-184; kulturgeschichtlich J. HuIZINGA, Homo Ludens. Vom Ursprung der Kultur im Spiel (Hamburg 1956 = 1987), 173ff.

71 Vgl. dazu L.W. BATTEN, Helkath Hazzurim, 2 Samuel 2,12-16, ZAW 26 (1906), 9094; O. EISSFELDT, Ein gescheiterter Versuch der Wiedervereinigung Israels (2.Sam 2,12-3,1), (1951), in: ders., Kleine Schriften III (Tübingen 1966), 137-144 ("Vertretungskampf", "stellvertretender Ernstkampf"); ders., Noch einmal: Ein gescheiterter Versuch der Wiedervereinigung Israels, (1952), in: ders., Kleine Schriften III (1966), 147-150; F.C. FENSHAM, The Battle between the Men of Joab and Abner as a Possible Ordeal by Battle?, VT 20 (1970), 356f; H.-P. STÄHLI, Knabe - Jüngling -

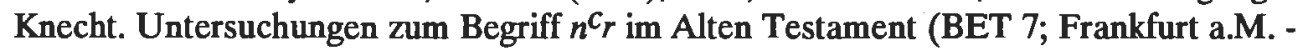
Bern - Las Vegas 1978), 137-149 (rein militärische Auseinandersetzung); O. KEEL, Die Weisheit spielt vor Gott (1974), 33f; U. MANN, ErJb 51 (1982), 37f; auch A. LESKY, Ein ritueller Scheinkampf bei den Hethitern, (1926), in: ders., Gesammelte Schriften (Bern - München 1966), 310-317.

72 Zu Zweikämpfen vgl. z.B. R. DE VAUX, Les combats singuliers dans l'Ancien Testament, RB 40 (1959), 495-508 = ders., Bible et Orient (Paris 1967), 217-230. Zum Zweikampf des Sinuhe vgl. z.B. TGI ${ }^{3}$ (1979), 5f; W. DECKER, Ringen, LÄ 5 (1984), 265f; ders. (ed.), Quellentexte zu Sport und Körperkultur im alten Ägypten (1975), 2631; ders., Annotierte Bibliographie zum Sport im Alten Ägypten (St.Augustin 1978), Nrn. 2654-269; P. BEHRENS, Sinuhe B 134ff oder die Psychologie des Zweikampfes, GM 44 (1981), 7-11; E.A. KNAUF, Zum "Einzelkämpfer" Sinuhe B 110, GM 33 (1979), 33; E. BlumENTHAL, Zu Sinuhes Zweikampf mit dem Starken von Retjenu, in: Fontes atque Pontes. FS für H. BRUNNER, ed. M. GöRG (ÄAT 5; Wiesbaden 1983), 42-46; J. WELLHAUSEN, Muhammed in Medina (Berlin 1882), 53. 
rer hellenistisch-römischen Spielart aber umso größere. Versuche, im Alten Testament Hinweise auf Ringkämpfe aufzeigen zu wollen (2.Sam. 18,11; Jes. 11,5; Hi. 38,3; 40,7), überzeugen zumeist nicht ${ }^{73}$, auch wenn es durchaus möglich ist, daß sie gelegentlich tatsächlich durchgeführt wurden, wie es für den Alten Orient (Gilgamesch-Epos; Lugalbanda) ${ }^{74}$ und benachbarte Kulturen ${ }^{75}$ leicht nachweisbar ist. In hellenistisch-römischer Zeit sind Ring- und

73 Vgl. den Ringkampf Jakobs am Jabboq Gen. 32,23-33. Vgl. allgemein z.B. C.H. GoRDON, Belt-Wrestling in the Bible World, HUCA 23 (1950-1951), 131-136; A. BUTTERWECK, Jakobs Ringkampf am Jabbok. Gen. 32,4ff in der jüdischen Tradition bis zum Frühmittelalter (Judentum und Umwelt 3; Frankfurt a.M. - Bern 1981), passim; M.B. PoliakoF, Jacob, Job, and other Wrestlers: Reception of Greek Athletics by Jews and Christians in Antiquity, JSH 11,2 (1984), 48-65; auch Philo Alex., spec. 2,229f. Zu Palästina, Judentum und Islam vgl. z.B. auch M. KRANZ, Probleme der Leiblichkeit (Diss. phil. masch.; Köln 1965), 129f; R. ROSENTHAL - R. SIVAN, Ancient Lamps in the Schloessinger Collection (1978), No. 66; C. NIEBUHR, Reisebeschreibungen nach Arabien, Bd. 1 (1774 = 1968), 169f; M.E. Rogers, Domestic Life in Palestine (London 1862 = 1989), 180f; H. RIEDEL, Leibesübungen und körperliche Erziehung in der osmanischen und kamâlistischen Türkei (Körperliche Erziehung und Sport 14; Würzburg 1942), 36-38; F. ROSENTHAL, Gambling in Islam (1975), 56.

74 ANET $^{3} 78$ (Gilgamesch); TUAT 2, 34 (Lugalbanda I,346). Vgl. auch C.H. GoRDON, HUCA 23 (1950-1951), 131-136; M. DIETRICH - O. LORETZ, Ringen und Laufen als Sport in Ugarit, (KTU 1.6 VI 16b-22a), UF 19 (1987), 19-22; O. LoRETZ, Ugarit und die Bibel (Darmstadt 1990), 221-225; ANEP $^{2}$ fig. 218f; J. BOESE, Altmesopotamische Weihplatten. Eine sumerische Denkmalsgattung des 3.Jahrtausends v.Chr. (UAVA 6; Berlin - New York 1971), 176f. 211f, Taf. 9-11. 40; ders., Ringkampfdarstellungen in Frühdynastischer Zeit, AfO 22 (1968-1969), 30-38; H. FRANKFORT, More Sculptures from the Diyala Region (OIP 60; Chicago 1943), 32, No. 305, P1. 54 A-D; L. DELAPORTE, Catalogue des Cylindres Orientaux et des cachets de la Bibliothèque Nationale (Paris 1920), 75, Pl. 12, No. 132; D. Collon, First Impressions (1987), 155-157, Nos. 702-706. 709; G. OFFNER, Jeux corporels en Sumer. Documents relatifs à la compétition athlétique, RA 56 (1962), 31-38; L. JAKOB-ROST, Sport im Alten Orient?, Altertum 11 (1965), 7, Abb. 5f; E. STROMMENGER, in: Sumer, Assur, Babylon. 7000 Jahre Kunst und Kultur an Euphrat und Tigris (Mainz 1978), Nr. 80f; J.M. SAsSON, Reflections on an Unusual Practice reported in ARM X:4, Or. 43 (1974), 404-410 (zu TUAT 2,84f); W. KNAUTH, Die sportlichen Qualifikationen der altiranischen Fürsten, Stadion 2 (1976), 63-65; G. WIDENGREN, Der Ringkampf im alten Iran, in: ders., Der Feudalismus im alten Iran (WAAFLNW 40; Köln - Opladen 1969), 155 f.

75 Zum alten Ägypten vgl. W. DECKER, Sport und Spiel im Alten Ägypten (München 1987), 80-90; ders. (ed.), Quellentexte zu Sport und Körperkultur im alten Ägypten (1975), 81-84; ders., Neue Dokumente zum Ringkampf im alten Ägypten, KBSW 5 (1976), 7-24; ders., Annotierte Bibliographie zum Sport im Alten Ägypten (1978), Nrn. 237-249; A.D. TounY - S. WENIG, Sport in Ancient Egypt (Leipzig 1969), 15-21; H. WILSDORF, Ringkampf im alten Ägypten (Körperliche Erziehung und Sport 5; Würzburg - Aumühle 1939), passim; J. VANDIER, Manuel d'archéologie égyptienne IV (Paris 
Boxkämpfe (Kap. 16) auch für Palästina belegt ${ }^{76}$; Hiob ${ }^{77}$ und Jakob ${ }^{78}$ wurden später als (Glaubens-) Ringer bzw. -Boxer verehrt. Esau und Jakob trugen ihre späteren Konflikte laut Gen. 25,22 (rșs hitpoel) schon pränatal mit Fäusten und Füßen aus. Das neunjährige Jesus-Kind ließ sich gerne auf Ringkämpfe mit seinen Spielkameraden ein (Armen. Kindheitsev. 21,6f). Im römerzeitlichen Alexandrien erhielten Kinder jüdischer Eltern Sport-Unterricht (Philo Alex., spec. 2,229f: gymnastike kai aleiptikē).

1964), 527-533; A. WIEDEMANN, Das Spiel im alten Ägypten (Elberfeld 1912 = Sonderabdruck aus ZVRV 3), 173f; arab. șirä ${ }^{\mathcal{C}}$.

Griech. palaismosynē, palē; vgl. z.B. auch Plinius d.Ä., nat.hist. 7,205; allgemein S. LASER, Sport und Spiel (1987), 49-52, Abb. 14-18; E. REISCH, Akrocheirismos, RE 1 (1894), 1197f; E.N. GARDINER, Wrestling, JHS 25 (1905), 14-31. 263-293; F.A.G. BECK, Album of Greek Education (1975), 34f, Nos. 193-197; M.B. POLIAKOFF, Kampfsport in der Antike. Das Spiel auf Leben und Tod (Zürich - München 1989), 39-79; L. GRASBERGER, Erziehung und Unterricht im klassischen Alterthum II (1866), 331-383; III (1881), 177-214; M. WUNNERLICH, Griechische Wettkampf- und Palästradarstellungen. Eine Untersuchung zu den Darstellungsprinzipien schwerathletisch-agonaler Darstellungen in der Zeit vom Ende des 8. bis zum Ende des 6.Jh.s v.Chr. (Diss. phil. masch.; Freiburg i.B. 1986), 154-249 u.ö.; O.W. REINMUTH, Ringkampf, KP 4 (1975), 1436f; S. MARINATOS - M. HIRMER, Kreta, Thera und das mykenische Hellas (München ${ }^{3} 1976$ ), 144f, Abb. 106; auch J. HuIZINGA, Homo Ludens (1956 = 1987), 50f. 58. $103 \mathrm{ff}$ u.ö.

76 Vgl. z.B. Test.Hiob 4,10; 27,3f: "Und der, der oben zu liegen kam, brachte den unter ihm Liegenden zum Schweigen, seinen Mund mit Sand verstopfend, und brach ihm jedes Glied"; Lukian, Anacharsis 1: "Die einen winden sich umeinander herum und suchen einer dem anderen ein Bein zu unterschlagen; andere packen sich bei der Gurgel, wenden alle Kräfte an, einander unter sich zu kriegen, und wälzen sich miteinander im Kot herum wie die Schweine". Laut der Expositio totius mundi et gentium E 32 waren im spätantiken Palästina die Ringer (athletae luctatores) aus Aschkelon und die Allkämpfer (pammacharii) aus Gaza berühmt.

77 Vgl. z.B. auch Test.Hiob 4,10; 27,3f; Origines, de orat. 30,2; Hieronymus, contra Ioannem Hierosol. 30; Joh. Chrysostomos, ep. 6; ders., de stat. 1,11; ders., In Matthaeum hom. 23-24,6 (PG 57, 395); ders., Frag. in Beat. Job (PG 64, 536 u.ö.); ders., Ad pop. Antioch. hom. 5,1 (PG 49,68f); Didymos der Blinde, Kommentar zu Hiob I (Tura-Papyrus), ed. A. HENRICHS (PTA 1; Bonn 1968), 48f. 100f. 128f. 144f. 210. 254f; II (PTA 2; 1968), $72 \mathrm{f}$ u.ö.; Gregor d.Gr., Moralia in Job 1,3,4 (PL 75, 530). Vgl. auch M.B. PoLIAKOFF, JSH 11,2 (1984), 48-65. Gemeint sind wohl die entsprechenden Übungen im Pankration (und Pentathlon?), vgl. O.W. ReINMUTH, Pankration; Pentathlon, KP 4 (1975), 460.617.

78 Vgl. z.B. Philo Alex., leg. all. 3,190; Didymos der Blinde, Kommentar zu Hiob II (1968), $72 \mathrm{f}$. 
"Eile aber rasch in dein Haus, erheitere dich dort, spiele ${ }^{79}$ dort und tue, was dir in den Sinn kommt...!"

[Sir. 32,15f (Vulg.)]

79 Sir. 32,11f LXX: paize, hebr. rșwn. 


\section{VERSTECK- UND 'SANDKASTEN'-SPIELE}

Auch Spiele wie z.B. (Nach-)Lauf-1 und Fangspiele ${ }^{2}$ wie Plumpsack ${ }^{3}$ oder 'Blinde-Kuh' bzw. 'Blinde Fliege' (griech. chalkē myia) $\left.{ }^{4}\right]$ oder VersteckSpiele $^{5}$ sind gelegentlich in literarischen Quellen festgehalten: Das Jesus-

1 J. TAIllardat (ed.), Suétone. Peri paidiōn (1967), Nr. 17; C.A. ForBes, Ostrakinda, RE 36 (1942), 1673; P. ZAZOFF, Ephedrismos. Ein altgriechisches Spiel, AuA 11 (1962), 35-42; K. TRAPP, Bantu-Spiele (Diss. phil.; 1960), 81-83; H. GÜNTHER, Um Ball und Tor. Streifzug durch die Geschichte der Ball-, Wurf- und Laufspiele (1955), passim; F. PINCZOWER, Der jüdische Läufer (Berlin 1937), passim; N. WECKLEIN, Der Fackelwettlauf, Hermes 7 (1873), 437-452; M. DIETRICH - O. LORETZ, UF 19 (1987), 19-22; auch H. EHELOFF, Wettlauf und scenisches Spiel im hethitischen Ritual (SPAW.PH 21; Berlin 1925), passim; D. WIEDEMANN, Der Sinn des Laufes im alten Ägypten (Diss. phil. masch; Wien 1975), (mir nicht zugänglich); ders., Lauf, LÄ 3 (1980), 939f; ders., "... an diesem schönen Tage des Laufens" (Pyr. 1555b), GM 83 (1984), 91-93 (beschränkt sich allerdings fast nur auf die kultischen Funktionen des Laufs).

2 M. COHEN, Jeux Abyssins, JA 18 (1911), 465-467; K. WEHRHAN, Kinderlied und Kinderspiel (Leipzig 1909), 43.

3 Pollux 9,115; L. GRASBERGER, Erziehung und Unterricht im klassischen Alterthum I 1 (1864), 52f; L. BECQ DE FouQuiERES, Les jeux des anciens ( $\left.{ }^{2} 1873\right)$, 91; A. HUG, Schoinophylinda, RE II A 1 (1921), 618; F.M. BÖHME, Deutsches Kinderlied und Kinderspiel $(1897=1967)$, 556-559, Nr. 366; S. STÖCKLIN-MEIER, Der Schneider hat 'ne Maus erwischt (1973), 67ff.

4 Neuhebr. mśhq h-snwrym. Pollux 9,123; J. TaILlardat (ed.), Suétone. Peri paidiōn (1967), Nr. 17; A. MAU, Chalkē myia, RE III 2 (1899), 2067; E. SCHUPPE, Taenia, RE 2,4 (1932), 2004; L. GRASBERGER, Erziehung und Unterricht im klassischen Alterthum I 1 (1864), 40-42; L. BECQ DE FouquierES, Les jeux des anciens (21873), 88; K. FrEEMAN, Copper Fly, GaR 6 (1936), 28f; F.K. MATHYS, Im Freien gespielt (1975), 27f; W. HOENERBACH, Das nordafrikanische Schattentheater (1959), 72 (arab. wäb $\bar{i} s$, hallet); K.L. TALLQUIST, Arabische Sprichwörter und Spiele (1897), 138f; F. KLEPZIG, Kinderspiele der Bantu (1972), 110f. 476f u.ö.; F.M. BöHME, Deutsches Kinderlied und Kinderspiel $(1897=1967), 627-632$, Nr. 511-519; S. STÖCKLIN-MEIER, Der Schneider hat 'ne Maus erwischt (1973), 61ff; J. HILLS, Das Kinderspielbild von Pieter Bruegel d. ̈. (1957), 22-24. (30), Nr. 27.

5 Vgl. z.B. Pollux 9,117; L. BECQ DE FOUQUIEREs, Les jeux des anciens ( $\left.{ }^{2} 1873\right)$, 83; A. MAU, Apodidraskinda, RE 2 (1896), 2819; L. GRASBERGER, Erziehung und Unterricht im klassischen Alterthum I 1 (1864), 42-49; M. BUBER, Die Erzählungen der Chassidim (Zürich 1949), 191; F.M. BöHME, Deutsches Kinderlied und Kinderspiel (1897 = 1967), 561f u.o..; K. TRAPP, Bantu-Spiele (Diss. phil.; 1960), 76-81; F. KLEPZIG, Kinderspiele der Bantu (1972), 107ff. 264ff. 361ff u.ö.; H. SBRZESNY, Die Spiele der !Ko-Buschleute (1976), 102f. 133; I. WEBER-KELLERMANN - R. FALKENBERG (ed.), 
Kind wollte mit seinen Nachbarskindern (Versteck) spielen, sie aber nicht mit ihm. Deshalb versteckten sie sich in einem Ofen. Zur Strafe verwandelte es sie in junge Geißlein, auf das Wehgeschrei der Mütter hin aber wieder zurück in Menschenkinder ${ }^{6}$, die nun gerne mit ihm spielten. In Hi. 21,11 ist vom Hüpfen (rqd pi.) der Kinder die Rede?

Laut dem Kindheitsevangelium des Thomas spielte das Jesus-Kind offenbar auch gerne am Bach und staute dort das Wasser ${ }^{8}$. Aus anderen Kulturen ist gut belegt, daß Kinder gerne im Sand spielten ${ }^{9}$. Auch im Alten Testament wird dies m.E. - an einer einzigen Stelle - belegt: Im Hintergrund der Zeichenhandlung des Propheten Ezechiel (Ez. 4f) ${ }^{10}$ in Jerusalem steht wohl nichts anderes als ein 'Sandkasten'-Spiel von Kindern, nämlich das spieleri-

Was wir gespielt haben (1992), 88ff; M. GRLAULE, Jeux et divertissements abyssins (1935), 117ff; E. MrTwWOCH, Abessinische Kinderspiele. Amharische Texte übersetzt und erklärt, MSOS 13 (1910), 110f; J.J. HESS, Von den Beduinen des Innern Arabiens (1938), 139.

6 Überliefert im Arab. Kindheitsev. (40,1), vgl. W. SCHNEEMELCHER (ed.), Neutestamentliche Apokryphen I (Tübingen; 51987), 366; H. DANIEL-RoPS (ed.), Die apokryphen Evangelien ( $\left.{ }^{2} 1958\right), 85 f$.

7 Vgl. HAL ${ }^{3}$ 4, 1201f; E. JENNI, Das hebräische Piel (1968), 153f. Vgl. auch A. CHRISTIAN, Volkskundliche Aufzeichnungen aus Haleb / Syrien, Anthr. 12-13 (1917-1918), 1025; F.M. BöHME, Deutsches Kinderlied und Kinderspiel $(1897=1967)$, 590f. 599ff, Nr. 436. 451ff; J. DE VRIES, Untersuchung über das Hüpfspiel. Kinderspiel - Kulttanz (FF Communications 70,173; Helsinki 1957), 3-49. Das bekannteste Hüpfspiel wird im Deutschen "Himmel und Hölle" oder auch "Paradies-Hüpfen" genannt, vgl. dazu F.K. MATHYS, Im Freien gespielt. Kleine Historie des Kinderspiels (Basel 1975), 14-16. Zu Hüpf-Spielen, Bockspringen (aramä. $m$ šwrt') u.ä. vgl. z.B. G. DALMAN, Palästinischer Diwan (1901), 182-184; W. DECKER, Annotierte Bibliographie zum Sport im Alten Ägypten (1978), Nrn. 176-178; E.S. EATON, An Egyptian High Jump, BMFA 35 (1937), 54f; Z. SAAD, Khazza lawizza, ASAE 37 (1937), 212-218; A.D. TOUNY - S. WENIG, Sport in Ancient Egypt (1969), 31f; P.G. BREWSTER, The Egyptian Game Khazza lawizza and its Burmese Counterparts, ZE 85 (1960), 211-213; auch W. DERBOLAV, Der Kopf- und Handstand als Gauklerstück und Kinderspiel, Leibesübungen und körperliche Erziehung 13 (1937), 534-538.

8 Kindheitsev. des Thomas 2,1-3,3, vgl. W. SCHNEEMELCHER (ed.), Neutestamentliche Apokryphen I $\left(5_{1987}\right), 353 \mathrm{f}$.

9 Vgl. z.B. Horaz, sat. 2,3,247ff; Seneca, de const. sap. 12,2; auch J. VÄTERIEIN, Roma ludens (1976), 49f; H. HELTZER, Kind und Schaffen. Experimente über konstruktive Betätigungen im Kleinkindalter (Quellen und Studien zur Jugendkunde 7; Jena 1931), $62 \mathrm{ff}$.

10 Alles Notwendige dazu bei CH. UEHLINGER, "Zeichne eine Stadt ... und belagere sie!" Bild und Wort in einer Zeichenhandlung Ezechiels gegen Jerusalem (Ez. 4f), in: 
sche Erbauen einer 'Burg' aus Sand und anderen Materialien sowie deren Belagerung und Zerstörung. Das Kinderspiel wird hier von einem Erwachsenen übernommen und gezielt verfremdet; diese Übernahme eines Kinderspiels durch einen Erwachsenen wurde als kindisch und darum als provozierend empfunden.

"Da siehst du mal, so ist das Leben! Es ist kein Kinderspiel! Also müssen wir's ertragen, kapierst du?"

[Nağı̌ Mahfüz, Die Midaq-Gasse (1947 / 1985), 309]

Jerusalem: Texte - Bilder - Steine. FS für H. und O. KEEL, ed. M. KÜCHLER - CH. UEHLINGER (NTOA 6; Göttingen - Fribourg 1987), 111-200. 


\section{GÖTTER-SPIELE}

Auch Götter spielten hin und wieder gerne ${ }^{1}$, so auch Jahwe - frei nach Nietzsche läßt es sich so formulieren: 'Im ächten Gotte ist ein Kind versteckt: das will spielen'2. Jahwe spielte gelegentlich nicht nur mit Bällen, wie sich Jes. 22,18 entnehmen läßt ${ }^{3}$, sondern vor allem mit exklusivem, lebendem Spielzeug, mit dem zu spielen sonst keinem geraten war (Hi. 40,29), mit dem Lewiathan ${ }^{4}$ (Ps. 104,26b śhq pi.; empaizein, inludere) ${ }^{5}$. Das krokodilähnliche Untier wird zum Spieltier degradiert bzw. domestiziert; so kann Jahwe das Chaos-Tier befrieden und die Ordnung der Welt wiederherstellen. Auch die Wetten, die Jahwe mit dem Satan schloß (Hi. 1,6ff; 2,1ff), spielen auf die spiel-theologischen Elemente eines mit den Menschen - und dem Satan spielenden Gottes an 6 .

1 Vgl. H. RaHNER, Der spielende Mensch (Einsiedeln 41957), 15ff; E. LEFEVRE, Theatrum Mundi: Götter, Gott und Spielleiter im antiken Drama, in: Theatrum Mundi. Götter, Gott und Spielleiter im Drama von der Antike bis zur Gegenwart. FS für H. KUNISCH zum 80.Geb., ed. F. LINK - G. NIGGL (LWJ Sonderbd.; Berlin 1981), 49-91; F. LINK, Götter, Gott und Spielleiter, in: Theatrum Mundi (1981), 1-47; W. BURKERT, Götterspiele und Götterburleske in altorientalischen und griechischen Mythen, ErJb 51 (1982), 335-367.

2 Also sprach Zarathustra (Werke. Kritische Gesamtausgabe 6,1; 1968, 81): "Im ächten Manne ist ein Kind versteckt; das will spielen. Auf, ihr Frauen, so entdeckt mir doch das Kind im Manne".

3 Vgl. die Ball spielenden Götter Eros und Dionysos in Apoll. Rhod., Argon. 3,117130.

4 E. LIPINSKI, liwjātāan, ThWAT 4 (1982-1984), 521-527; O. KEEL, Jahwes Entgegnung an Ijob (Göttingen 1978), 141-156; vgl. auch ANEP ${ }^{2}$ Nos. 670 (Kalksteinrelief aus Malatya, 8.Jh.v.Chr.). 671 (gravierte Muscheleinlage unbekannter Herkunft). 691 (akkadisches Zylindersiegel aus Tell Asmar), auch M. NOVELECK, in: Archäologie zur Bibel. Kunstschätze aus den biblischen Ländern (Mainz 1981), 78f, Abb. 28. Vgl. auch die Erzählung über das Jesus-Kind im Pseudo-Matthäus-Ev., W. SCHNEEMELCHER (ed.), Neutestamentliche Apokryphen I ( $\left.{ }^{5} 1987\right), 367$; H. DANIEL-Rops (ed.), Die apokryphen Evangelien (21958), 59.

5 (l-šhq) b-w ist wohl besser als "mit ihm (= Lewiathan)" als "in ihm (= Meer)" zu verstehen, vgl. LXX und Vulg. (drakōn houtos, hon enplasas empaizein autō; draco iste quem formasti ad inludendum ei), auch bAZ 3b. Zu Ps. 104,25f vgl. zuletzt CH. UEHLINGER, Leviathan und die Schiffe in Ps 104,25-26, Bib. 71 (1990), 499-526.

6 Vgl. z.B. G.M. MARTIN, "Wir wollen hier auf Erden schon..." Das Recht auf Glück (Stuttgart u.a. 1970), 79ff; H. SCHORLEMMER, Hiob auf der Bühne. Die dramatischen 
Als deus ludens befand sich Jahwe in guter Gesellschaft: Wenn Poseidon im Wagen über das Meer eilte, hüpften die Seeungeheuer spielerisch aus den Klüften hervor (Ilias 13,27-29); Poseidon war eine Art Schutzgott der Wagen(-rennen) und Reiter ${ }^{7}$ wie Nabū der Gott des Schnellaufs ${ }^{8}$ oder Apollon der Schutzgott der Bogenschützen ${ }^{9}$ und Faustkämpfer; der Name des edomitischen Nationalgottes, Qōs, leitet sich vom "Bogen" (arab. qaus) ab ${ }^{10}$. Herakles spielte in einem ihm geweihten Tempel Würfel mit einem Vertreter seines Kultpersonal (Plutarch, quaest. Rom. 35). Aus dem Enūma elǐ̌ ist bekannt, wie der Großvater Anu seinem göttlichen Enkel Marduk den 'Vierwind' zum Spielen (?) schenkt ${ }^{11}$, mit dem der jugendliche Gott einige der erwachsenen Götter ärgerte. Als der ägyptische König Rhampsinitos nach seinem Tod in den Hades hinabgestiegen war, soll er dort mit Demeter Würfel gespielt haben (sygkybeyein), wobei er bald gewonnen, bald verloren habe (Herodot 2,122,1) ${ }^{12}$. Laut Plutarch, de Iside et Osiride 12, spielte Hermes (Thot) mit der Mondgöttin (Selene) an einem Spielbrett; 'Theuth' galt als Erfinder des Brett- bzw. Würfelspiels (Platon, Phaidros 274d), Hermes und Pan als Schutzgötter der Brettspiele (Eustathios, Od. 1397,28), weswegen ihnen auch gelegentlich entsprechendes Spielzeug geweiht wurde (z.B. Anth. Graeca 6,309).

Das menschliche Leben konnte mit einem Würfelspiel verglichen werden (Plutarch, de tranq. animi 5 unter Bezug auf Platon, Politeia 604c); gespielt wurde dieses Spiel von den Göttern: "Die Würfel des Zeus fallen immer gut"

und theatralen Elemente des alttestamentlichen Buches Hiob (Diss. phil. masch.; München 1983), 135ff u.ö.; G. TheOBald, Hiobs Prozeß und Gottes Gericht. Die poetische Theodizee des Welttheaters (Diss. theol. masch.; Heidelberg 1990), 30ff.

7 Vgl. z.B. Homer, Il. 23,584; Pindar, Ol. 1,70ff.

8 AHw 555 Nabû ša li-is-me; E. WEIDNER, "Nabû, der (Gott) des Schnellaufs", AfO 16 (1952-1953), 66.

9 Auch Jahwe betätigte sich als Bogenschütze, vgl. z.B. Hiob 16,12; Threni 3,12.

10 Vgl. vor allem E.A. KNAUF, Qaus, UF 16 (1984), 93-95.

11 W.G. LAMBERT - S.B. PARKER (ed.), Enūma Eliš. The Babylonian Epic of Creation. The Cuneiform Text (Birmingham - Oxford 1966 = 1974), 5, I 106; vgl. AOB 2 112; ANET $^{3} 62.502$ sowie AHw 644 (mēluläju, mēlultu(m), mēlulu(m).

12 Auch Origines, contra Celsum 2,55. Vgl. G. ROEDER, Rampsinitos, RE I A 1 (1914), 140-147 und - allerdings problematisch - S. BIREH, Le roi Rhampsinite et le jeu de Dames, RAr. NS 12 (1865), 56-65; ders., Rhampsinites and the Game of Draughts, Transactions of the Royal Society of Literature of the United Kingdom 9 (1870), 256270 und A.B. LLOYD, Herodotus Book II (EPRO 43,3; Leiden 1988), $52\left({ }^{*} R^{C_{-}}\right.$sssw $s^{3}$ $N t)$. 
(Sophokles, frg. 809) ${ }^{13}$. Athene sah den brettspielenden Helden gerne beim Spielen zu${ }^{14}$. Laut Platon, nomoi 644d-645b. 803c-804b spielten die Götter als Drahtzieher - gerne mit Menschen als Marionetten ${ }^{15}$; wir sind "ein Kinder-Spiel Gottes" (paignion theou: Maximos Confessor, Peri diaphorōn aporiōn, PG 91,1416; vgl. Platon, nomoi 803f). "Enim vero di nos quasi pilas homines habent" (Plautus, capt. 1,22) ${ }^{16}$. Die verschiedenartigen Spiele von Diony$\operatorname{sos}^{17}$ und Eros ${ }^{18}$ sind allgemein bekannt; auf letztere hat auch Meleagros von Gadara in seinen Epigrammen verschiedentlich hingewiesen (Anth. Graeca 5,$214 ; 12,47$ ). Der kleine Hermes spielte gerne mit Schildkröten (Hom. Hymn., Herm. 24ff u.ö.).

13 Vgl. auch Aelian, var. hist. 12,15.

14 K. SCHEFOLD, Anhang I: Die Brettspieler, JdI 52 (1937), 69f; H.-G. BUCHHOLZ, in: S. LASER (ed.), Sport und Spiel (1987), 159-184, Nrn. 98-186.

15 Ähnlich z.B. auch Aristoteles, de mundo 398b; Marc Aurel 7,3; Apuleius, de mundo 27; Gellius, Noct. Att. 14,1,23; Philo Alex., de fug. 46. Vgl. z.B. G. ARDLEY, The Role of Play in the Philosophy of Platon, Ph. 42 (1967), 226-244; H. GUNDERT, Wahrheit und Spiel bei den Griechen. Homer - Tragödie - Platon, in: W. MARX (ed.), Das Spiel. Wirklichkeit und Methode (Freiburger Dies Universitatis 13; Freiburg i.Br. 1967), 1334; ders., Zum Spiel bei Platon, in: Beispiele. FS für E. FINK zum 60.Geb., ed. L. LANDGREBE (Den Haag 1965), 188-221; E. FiNK, Spiel als Weltsymbol (Stuttgart 1960), 77ff; I. OOMS, Spiel und Ernst bei Platon (Diss. phil. masch.; Bonn 1957), passim; W. RIDGEWAY, The Game of Polis and Plato's Rep. 422E, JHS 16 (1896), 288-290; H.D. RANKIN, Toys and Education in Plato's Laws, Hermathena 92 (1958), 62-65; W. BURKERT, ErJb 51 (1982), 335-367; W. BLUM, Kleists Marionettentheater und das Drahtpuppengleichnis bei Platon, ZRGG 23 (1971), 40-49; U. MANN, ErJb 51 (1982), 22-27. Vgl. auch das Gedicht von A. vON CHAMISSO, Das Riesen-Spielzeug, in: ders., Werke I (Berlin ${ }^{6}$ 1874), 248f.

16 "enim vero di nos quasi pilas homines habent".

17 Vor allem mit seinem Spielzeug Ball, Klapper, Kreisel, Würfel, Spiegel u.a., vgl. z.B. Nonnos, Dion. 6,165ff; 9,128; Orph. Frag. 31.34 (O. KERN). Bücher wie das von A. und R. KLEIN, Das Spielzeug des Dionysos (Sokratische Hefte 23; Mannheim 1982), passim, gehören eher zu jener Gattung esoterischer Literatur, die wenig Information und umso mehr Spekulation bietet, was bei Büchern über Spiele nicht selten der Fall ist.

18 Vgl. z.B. Anakreon, Frag. 111(34):1; Apoll. Rhod., Argon. 3,117ff; Lukian, Dial. deor. 4,3; P. ZAZOFF (ed.), Antike Gemmen in deutschen Sammlungen Bd. IV (Wiesbaden 1975), 170, Nr. 839, Taf. 109:839; A.D. TrENDALl - G. SCHNEIDERHERRMANN, Eros with a Whipping-Top on an Apulian Pelike, BABesch 50 (1975), 267 270; K. SChauENBuRG, AW 7,3 (1976), 39-52; 7,4 (1976), 28-35; A. HAMBURGER, Gems from Caesarea Maritima ('CAtiqot ES 8; Jerusalem 1968), Nos. 95-101; M. HENIG - M. WhitiNG, Engraved Gems from Gadara in Jordan (Oxford 1987), Nos. 166-184. 
Auch das Jesus-Kind spielte verschiedenste Spiele ${ }^{19}$; dabei konnte es vorkommen, daß einer seiner Spielkameraden vom Dach stürzte und sich das Genick brach, was dem Jesus-Kind Gelegenheit gab, seine frühen Fähigkeiten als Totenerwecker unter Beweis zu stellen ${ }^{20}$.

Hin und wieder spielten auch Götter Mensch: So spielte z.B. Ptah Mensch, um diesem beim Tempelbau zu helfen ${ }^{21}$. Daß Menschen immer wieder versuchten, Gott zu spielen, ist sattsam bekannt (z.B. Sueton, Aug. 70,2).

"ludit in humanis divina potentia rebus"

(Ovid, ex Ponto 4,3,49)

19 Vgl. auch W. BRÜCKNER, Spiel, LCI $4(1972=1990)$, $190 f$.

20 O. CullmanN, Kindheitsevangelium des Thomas $(9,1)$, in: W. SCHNEEMELCHER (ed.), Neutestamentliche Apokryphen I ( $\left.{ }^{5} 1987\right), 356$.

21 E. HoRNUNG, Pharao ludens, ErJb 51 (1982), 514. 


\section{SPIEL-TIERE}

Nicht nur die Götter, sondern auch die Menschen - vor allem Kinder - der verschiedensten antiken Kulturen spielten gerne mit lebendem Spielzeug. So spielten z.B. nicht nur Ägypter ${ }^{1}$, Nabatäer ${ }^{2}$, Griechen ${ }^{3}$ und Römer ${ }^{4}$, sondern auch Judäer und Israeliten beiderlei Geschlechts gerne mit lebenden Vögeln, die mit einer Schnur am Fuß am Davonfliegen gehindert wurden (Hi. 40,29: șhq pi.; paizein) ${ }^{5}$ oder auch in Käfigen gehalten wurde (Abb. 3)6. Lebende

1 Vgl. z.B. E. BRUNNER-TraUT, Lieblingstier, LÄ 3 (1980) 1054-1056; L. KEIMER, Quelques remarques sur la huppe (uppa epops) dans l'Égypte Ancienne, BIFAO 30 (1931) 305-331; L. STÖRK, Gans, LÄ 2 (1977), 373-375; ders., Wiedehopf, LÄ 6 (1986) 1245f; A. WIEDEMANN, Das Spiel im alten Ägypten (1912), 171.

2 I. PARlasCA, Terrakottenfunde aus Petra, in: M. LinDNER - J.P. ZeITLER (ed.), Petra - Königin der Weihrauchstraße (Fürth 1991), 120, Abb. 30f. Vgl. auch M. GRIAULE, Jeux et divertissements abyssins (1935), $29 \mathrm{ff}$.

3 Vgl. z.B. H. BIESANTZ, Die thessalischen Grabreliefs. Studien zur nordgriechischen Kunst (Mainz 1965), 25f, Taf. 9:K 48; L. DEUBNER, Antike 6 (1930) 164. 172, Abb. 18, Taf. 18a-c. 19b; G. KocH-HARNACK, Knabenliebe und Tiergeschenke. Ihre Bedeutung im päderastischen Erziehungssystem Athens (Berlin 1983), passim; H. RÜHFEL, Kinderleben im klassischen Athen (1984), 141-146; ders., Das Kind in der griechischen Kunst von der minoisch-mykenischen Zeit bis zum Hellenismus (KAW 18; Mainz 1984), z.B. Abb. 33. 38-41. 44. 53. 72-74. 87. 96f. 100. 103. 106. 109f ("Ganswürger": 254-258, Abb. 108); S. MENDNER, RAC 10 (1978), 858f. 868. 890f; auch A. HERMARY, Catalogue des Antiquités de Chypre: Sculptures. Musée du Louvre. Département des Antiquités Orientales (Paris 1989), 69-111. 275-277; Y. PAPAOIKONOMOU, L'enfant aux astragales. A propos d'une stèle funéraire crétoise, BCH 105 (1981), 255-263. Vgl. auch J. HILLS, Das Kinderspielbild von Pieter Bruegel d.Ä. (1957), passim.

4 Vgl. z.B. Ovid, met. 10,260f; Plautus, capt. 1002; ders., mel. 162; Plinius d.J., ep. 4,2,3f; Plinius d.Ä., nat. hist. 10,120 u.ö.; Sueton, Tib. 72; Catull, carm. 2 und 3; Augustin, conf. 1,19; auch L. BECQ DE FOUQUIERES, Les jeux des anciens ( $\left.{ }^{2} 1873\right)$, 133-158; A. HUG, RE III A 2 (1929), 1765. 1777f; E. SCHMIDT, Spielzeug und Spiele der Kinder im klassischen Altertum (1971), 28-33; J. VÄTERLEIN, Roma ludens (1976), 50-53; R. HeRZoG, Das Kind mit der Fuchsgans, JÖAI 6 (1903), 215-236, Taf. 8; G. JENNISON, Animals for Show and Pleasure in Ancient Rome (Manchester 1937), 99ff; F. SAGLIO, Bestiae mansuelae, circures, DarS 1,1 (1877), 689-705.

$5 \mathrm{LXX}$ paixē de en autō hōsper omeō $\bar{e}$ dēseis auton hōsper strouthion paidiō?; Vulg. (Hi. 40,24) numquid inludes ei quasi avi aut ligabis illum ancillis tuis? Vgl. auch die späthethitische Stele des 8.Jh.s v.Chr. (vermutlich) aus Maraş (Paris, Louvre, AO 19222), z.B. W. ORTHMANN, Untersuchungen zur späthethitischen Kunst (SBA 8; Bonn 1971), 87. 370. 528, Taf. 48d: Maraş D/4; K. BrTtEL, Die Hethiter (Universum der Kunst; München 1976), Abb. 316 sowie die palästinischen Sprichwörter "Du willst das 
Vögel wurden auch gerne - an Kinder $\left(l_{-n} c_{r w t y k}\right)$ - verschenkt, wie sich Hi. 40,29 entnehmen läßt ${ }^{7}$ : "Kannst du mit ihm (= Lewiathan) spielen wie mit einem Vogel oder ihn für deine Mädchen anbinden?". Ein Teil der elf steinernen ex-voto-Statuen von 2-3jährigen Kindern, die 1963 in einer favissa des Eschmun-Tempels in Bustān eš-Sēh am Ufer des Bostrenos (Nahr el-Auwalī) südlich von Sidon gefunden wurden und aus dem Anfang des 4.Jh.s v.Chr. stammen $^{8}$, zeigen Knaben, die mit Vögeln und Schildkröten ${ }^{9}$ spielen (Abb. 4);

Vöglein und seine Schnur" und "Lieber ein Sperling in der Hand als zehn auf dem Baum", L. HAEFELI, Spruchweisheit und Volksleben in Palästina (Luzern 1939), Nr. 573. 576; R.W. BREDNICH, Vogel am Faden. Geschichte und Ikonographie eines vergessenen Kinderspiels, in: Studien zu Kultur, Sprache und Landesgeschichte. FS für M. ZENDER zum 65.Geb., ed. E. ENNEN - G. WIEGELMANN, Bd. I (Bonn 1972), 573-597. Auch Käfer konnten mit einer Schnur am Davonfliegen gehindert werden, vgl. Aristophanes, nub. 763.

6 Sir. 11,30; Test.Hiob 27,1, vgl. Jer. 5,27; z.B. auch Martial, epigr. 14,77. Vgl. auch die - metaphorisch gemeinten - Darstellungen auf Mosaikfußböden byzantinischer Synagogen und Kirchen in Palästina: M. AVI-YONAH, Nacaran, EAEHL 3 (1977), 891-894; ders., Mosaic Pavements in Palestine, QDAP 3 (1934), 62; D.C. BARAMKI - ders., An Early Christian Church at Khirbet ${ }^{C^{2}}$ Asida, QDAP 3 (1934), 18; F.J. BuIss, Excavations at Jerusalem 1894-1897 (London 1898), 253-259; S. LEVY - M. AVI-YONAH, The Ancient Synagogue of $\mathrm{Ma}^{\mathrm{c}}$ on (Nirim), Rabinowitz-Bulletin 3 (1960), 29, fig. 13, Pl. 7:1; C. DAUPHIN - G. EDELSTEIN, L'église byzantine de Nahariya (Israël). Étude Archéologique (Byz. Mnēmeia 5; Thessaloniki 1984), 52ff, Pl. 10a. 19a. 26a. 27. 43b; R. HACHLILI, On the Mosaicists of the "School of Gaza", ErIs 19 (1987), 46-58, fig. 1ff (hebr.; English Summary 74*); U. LUX, Eine altchristliche Kirche in Mādeba, ZDPV 83 (1967), 170, Taf. 31:B; A. OVADIAH, Gaza, EAEHL 1 (1976), 413; M. PICCIRILlo, Chiese e mosaici di Madaba (SBF.CMa 34; Jerusalem 1989), 130f; A.D. TRENDALL, The Shellal Mosaic (Canberra 1957), 22, fig. 5, Pl. 2; S. SAller - B. BAGATTI, The Town of Nebo (Khirbet el-Mekhayyat) and other Ancient Christian Monuments in Transjordan (SBF.CMa 7; Jerusalem $1949=1982)$, 237f, Pl. 40:3 (Mādeba); M. PICCIRILlo, Chiese e mosaici della Giordania Settentrionale (SBF.CMi 30; Jerusalem 1981), Tav. 32 (Gerasa). Hinzuzuziehen sind auch die zahlreichen Darstellungen von Vögeln, die ein Halsband tragen, vgl. z.B. nur U. LuX, ZDPV 83 (1967), 172. 177, Anm. 47, Taf. 35:C; dies., Die Apostel-Kirche in Mādeba, ZDPV 84 (1968), 112, Taf. 20-22. 30-32. Auch GH. KANAFAN, Das Land der traurigen Orangen. Palästinensische Erzählungen I (Basel 1983), 127-136.

7 Vgl. auch G. Koch-HARANCK, Knabenliebe und Tiergeschenke (1983), 96ff u.ö.

8 M. DUNAND, Sondages archéologiques effectués à Bostan-ech-Cheikh près Saïda, Syria 7 (1926), 4, Pl. 3; 4:2; ders., La statuaire de la favissa du temple d'Echmoun à Sidon, in: Archäologie und Altes Testament. FS für K. GALLING, ed. A. KuschKE - E. KUTSCH (Tübingen 1970), 61-67, Taf. 1a. 3a.b; СH. VIROLLEAUD, Les travaux archéologiques en Syrie 1922-23, Syria 5 (1924), 49, Pl. 17; E. MiCHON, La Collection archéologique de l'Université Saint Joseph acquise par le Musée de Beyrouth, Syria 3 (1922), 172, A, No. 22; L. GANZMANN - H. AN DER MEIJDEN - R.A. STUCKY, Das Eschmun- 
ein Teil der erhaltenen phönizischen Beischriften weist sie als Königssöhne aus ${ }^{10}$. Auch Heuschrecken wurden von Kindern gerne als lebendes Spielzeug gehalten (mŠabb. 9,7). Die in der Antike so beliebten Tiergärten ${ }^{11}$ waren beliebte Spielplätze für Kinder [Basilios von Seleukia, de vita Theclae 2,8 (PG $85,577 \mathrm{f})]$.

heiligtum von Sidon. Die Funde der türkischen Ausgrabungen von 1901 bis $1903 \mathrm{im} \mathrm{Ar}$ chäologischen Museum in Istanbul, IM 37 (1987), 103-112, Nr. 66. 68. 70. 71. 73, Taf. 33-35, auch A. PARrot et al., Die Phönizier (Universum der Kunst; München 1977), 120-123. 305, Abb. 132. Vergleichbare Statuen wurden u.a. auch in Dor und al-Mina (südwestl. von Antiochia) gefunden, vgl. E. STERN, Phoenician Discoveries at Tel Dor, Qad. 22 (1989), 108-110 (hebr.); C.L. WoOLLEY, Excavations at al-Mina, Sueidia, JHS 58 (1938), 19-21, fig. 7 (Level III). Zum Statuen-Typ auch L. GANZMANN-MEYER, "Temple-Boys" - Weihestatuen klassischer Zeit in Griechenland, auf Zypern und im Vorderen Orient (Liz. phil. masch.; Universität Basel 1979), 29f. 51-65. 80f, Kat.-Nrn. VO 1-14; TH. HADZISTELIOU-PrICE, The Type of the Crouching Child and the 'Temple Boys', ABSA 64 (1969), 85-111; CH. VORSTER, Griechische Kinderstatuen (Diss. phil. Bonn 1982; Köln 1983), 372-375, Kat.-Nrn. 125-134: Auch M.H. CHEHAB, Les terres cuites de Kharayeb, BMB 10 (1951-1952), 40f; 11 (1953-1954), Pl. 47ff u.ö.; J.W. Crowfoot, in: ders. et al., The Objects from Samaria. Samaria-Sebaste III (London 1957), 84.

9 Vgl. auch F. PETRIE, Gerar (London 1923), 18, Pl. 39:8 (AH 196); A. REIFENBERG, Ein neues hebräisches Gewicht, JPOS 16 (1936), 39-43, Pl. III A; S. MOSCATI, L'epigrafia ebraica antica 1935-1950 (Rom 1951), 101, Tav. 24:1f.

$10 \mathrm{Vgl}$. vor allem $\mathrm{M}$. DUNAND, Nouvelles inscriptions phéniciennes du temple d'Eshmoun à Bostan-ech-Cheikh, près Sidon, BMB 18 (1965), 105-109, Pl. 1f; J. TEIXIDOR, Bulletin d'épigraphie sémitique (1964-1980) (BAH 127; Paris 1986), 11. 89. 172. 210f. 371f. 467; P. MAGNANINI, Le iscrizioni fenicie dell'Oriente (Rom 1973), 12; $\mathrm{CH}$. BUTTERWECK, TUAT 2 (1991), 594, Nr. 4; J.C.L. GiBSON, Textbook of Syrian Semitic Inscriptions III (Oxford 1982), 114-116, No. 29; W. RölLIG, Beiträge zur nordsemitischen Epigraphik 3: Eine neue phönizische Dynastie in Sidon, WO 5 (1969-1970), 121124. Die Inschrift auf dem Sockel der liegenden Knabenfigur Abb. 4 lautet: $h s m l z$ ' $\checkmark$ ytn

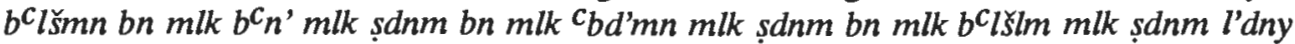
l'lšmn $b^{c_{n}}$ ydl ybrk - "Dies ist die Statue, die darbrachte $B^{c} l \zeta l m$, der Sohn des Königs

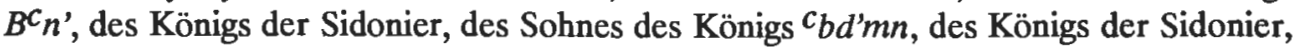
des Sohnes des Königs $B^{c} l s ̌ l m$, des Königs der Sidonier, für seinen Herrn, (den) Eschmun, an der Quelle Ydl. Er spende Segen!".

11 P. GRIMAL, Les jardins romains à la fin de la république aux deux premiers siècles de l'empire (BEFAR 155; Paris 1943), 306ff; H. PITSCH, Zoologischer Garten, LÄ 6 (1986), 1420-1423; auch F. ORTH, Glirarium, RE 13 (190), 1425f; ders., Leporarium, RE 24 (1925), 2068f; weitere Lit. bei U. HÜBNER, Die Ammoniter (ADPV; Wiesbaden 1992), Kap. 2.2, Nr. 1., Anm.60. 
Das in Jes. 11,8 benutzte Bild vom Frieden zeigt $^{12}$, in welche Gefahren Kleinkinder aufgrund ihrer Tierliebe und Neugier geraten konnte: Giftschlangen eignen sich wenig zum Spielen, jedenfalls nicht für Kinder ${ }^{13}$, eher schon für Erwachsene, z.B. für Schlangenbeschwörer bzw. - bändiger (Jer. 8,17; Ps. 58,5f; Qoh. 10,11; Sir. 12,13; bAZ 18b) ${ }^{14}$. Aber auch andere Spiele konnten für Kinder lebensgefährlich werden: Es war ein Spiel mit dem Feuer, wenn der Erwachsene, dem die halbwüchsigen Lausbuben $\left(n^{c}\right.$ rym qtnym bzw. yldym) einen Streich spielen wollten und ihn wegen seiner Glatze verspotteten, ein Gottesmann war (2.Kön. 2,23f $)^{15}$, oder wenn Kinder auf den Flachdächern ihrer Elternhäuser quasi unmittelbar am Abgrund spielten (Kindheitsev. des Thomas 9,1) ${ }^{16}$. Ein angehender König wie David spielte natürlich "mit jungen Löwen wie mit Böckchen und mit Bären wie mit jungen Stieren", also mit Tieren, die seinem Prestige als zukünftigem Herrscher entsprachen (Sir. 47,3: śhq, paizein, ludere).

Wie sehr das Spielen der Kinder mit Tieren - jedenfalls nach heutigen Begriffen - Tierquälerei ähneln konnte, zeigen neuere und antike Belege: "Oft sah ich kinder, welche an einem faden angebundene halbtote kleine Vögel als spielzeuge benutzten, wie uns ähnliches auch aus dem hebräischen Alterthum bezeugt wird (Hi 40,24). Thierquälerei allerlei art findet man bei schritt und

$12 \mathrm{Zu}$ den textkritischen und grammatischen Problemen des Verses vgl. z.B. O. KAISER, Das Buch des Propheten Jesaja Kapitel 1-12 (ATD 17; Göttingen 51981), 239-246; H. WILDBERGER, Jesaja 1-12 (BK 10,1; Neukirchen-Vluyn 21980), 436-458.

13 H. DANIEl-Rops (ed.), Die apokryphen Evangelien ( ${ }^{2} 1958$ ), 86f (Arab. Kindheitsev.); vgl. auch Lucan, de bello civ. 8,908.

14 L. HAEFELI, Spruchweisheit und Volksleben in Palästina (1939), Nr. 591; H. BLÜMNER, Fahrendes Volk im Altertum (SBAW.PPH 6; München 1918), 22; E.W. LANE, Sitten und Gebräuche der heutigen Egypter II (1856), 219-221; Hist. Aug., Heliog. 23; Plinius d.̈., nat. hist. 25,11; 28,19.30; vgl. auch H. GEIST (ed.), Pompeianische Wandinschriften (München 1936), 100f; Dig. 47,11,11; CIL IV 1595 (Pompeji).

15 W. ToM, "Kaalkop, ga op!, Kom op! Of: Vaar op!"?, GTHT 59 (1959), 149-151; B.J. DIEBNER, "Glatzkopf, komm herauf...!" (2Kön. 2,23f.), DBAT 20 (1984), 169-179. Vgl. Horaz, sat. 1,3,140ff, wo von einem würdigen Philosophen die Rede ist: "Die frechen Buben zupfen dir den Bart; mußt wacker deinen Stock gebrauchen, und sie dir vom Leibe halten, sonst umdrängt dich die Schar, du aber belferst laut und platzest elend vor Wut", oder Horaz, de arte poet. 455f: "Höchstens hänseln ihn (sc. einen wahnsinnigen Dichter) die Buben und sind so unvorsichtig, ihm nachzulaufen"; vgl. auch Varro, sat. Agatho 10ff. Zu Neckreimen vgl. auch E. BORNEMANN, Unsere Kinder im Spiegel ihrer Lieder, Reime, Verse und Rätsel. Studien zur Befreiung des Kindes I (1973), $92 \mathrm{ff}$.

16 Vgl. auch G. AGDE et al., Sicherheit auf Kinderspielplätzen (Wiesbaden 1981), passim; G. MEINECKE, Selbstgefährdungstendenzen im Spiel eines Säuglings, PsB 2 (1956), 299-307. 
tritt im orient"17. Der kleine Hermes spielte gerne mit lebenden Schildkröten, was ihn aber nicht daran hinderte, ihre Panzer zu Resonanzkörpern seiner Lyra zu verarbeiten: "Er drehte sie nach oben, nahm einen Meißel, grau und eisern, bohrte der Schildkröt, die in den Bergen daheim ist, das Lebensmark aus dem Rückgrat" (Hom. Hymn., Herm. 40-42) ${ }^{18}$. Und wenig später heißt es an gleicher Stelle: "Wand um die Schultern die Windel, als wäre er ein lallendes Kindlein; dreht mit den Fäustchen im Spiel das Laken sich um die Kniee, lag und klammerte fest in der Linken die liebliche Schildkröt" (a.a.O. 151154); auch wenn hier ebenfalls die schon verarbeitete Schildkröte gemeint ist, zeigen Formulierungen und Wortwahl deutlich, da $B$ auch lebende Tiere von Kindern der Antike als Spiel- und 'Kuschel'-Tiere benutzt worden sind'19. Aber auch Erwachsene (miß-)brauchten zuweilen Tiere als 'Kuschelobjekte' (2.Sam. 12,3). Kinder dürften auch mit handgemachten Kuscheltieren, die sich aus Textilstoffen, Haaren, Stroh u.ä. leicht herstellen ließen ${ }^{20}$, gespielt haben.

In späthellenistisch-frührömischer Zeit fühlten sich orthodox-observante Kreise dazu berufen, das Spielen mit Vögeln zu verurteilen, indem sie es als Luxus der Oberschichten denunzierten (Bar. 3,16f) ${ }^{21}$ und dabei vielleicht an 'Brief'-Tauben o.ä. dachten (vgl. Abb. 7); auch in bSan. 24b. 25a.b; bŠabb. 30b u.a. wird der Tauben-Flug (mpry hy ywnym) verboten ${ }^{22}$. Falknerei als Spielart der Jagd bzw. Sport der Oberschichten war im alten Orient wahrscheinlich

17 K.L. TAllouisT (ed.), Arabische Sprichwörter und Spiele (1897), 69.

18 Vgl. Pausanias 2,19,7. Aus dem griechischen und römischen Bereich gibt es zahllose Darstellungen von Lyren (griech. auch chelys, chelönē!), deren Resonanzkörper aus einem Schildkrötenpanzer besteht, vgl. z.B. A.J. NEUBECKER, Altgriechische Musik. Eine Einführung (Darmstadt 1977), 69-72, Taf. II. IV:2.

19 Vgl. z.B. auch J. Pollard, Birds in Greek Life and Myth (Plymouth 1977), 135-140 ("Birds as Pets"); G. VAN HooRN, Choes and Anthesteria (Leiden 1951), 46-49 ("Pet Animals"); F.A.G. BECK, Album of Greek Education (1975), 49f, Nos. 296-310 ("Pets").

20 D. MORTON, Kuscheltiere - kunterbunt und selbstgemacht (Stuttgart 1977), passim.

21 hoi archontes tōn ethnōn ... hoi en tois omeois tou ouranou empaizontes; Vulg. principes gentium ... qui in avibus caeli inludunt.

22 Vgl. z.B. S. KRAUSS, Talmudische Archäologie III (1912), 111; E.D. OREN, The 'Herodian Doves' in the Light of Recent Archaeological Discoveries, PEQ 101 (1968), 56-61; auch O. KEEL, Vögel als Boten (OBO 14; Fribourg - Göttingen 1977), 34ff u.ö. $\mathrm{Zu}$ Abbildungen von Tauben mit einem Halsband vgl. z.B. U. LUX, ZDPV 83 (1967), 172. 177, Anm. 47, Taf. 35:C; dies., ZDPV 84 (1968), 112, Taf. 20-22. 30-32. Ethnologisches Material z.B. bei F. ROSENTHAL, Gambling in Islam (1975), 52-55; V. HARMS, Der Terminus "Spiel" in der Ethnologie (Hamburg 1969), 190-202. 
nicht bekannt und kam wohl erst in byzantinischer ${ }^{23}$ bzw. islamischer ${ }^{24}$ Zeit in Palästina auf (bSan. 95a $\mathrm{a}^{25}$; bŠabb. 94a). Dressierte Tiere dienten gelegentlich spielerischem Vergnügen (vgl. Abb. 6): Auf einer Bulle des 4.Jh.s v.Chr. aus dem Wadĩ ed-Dāliye ist eine mythologische Import-Szene zu sehen, auf der ein junger Satyr einen Reiher an einem Halsstrick mit sich führt (Abb. 5) ${ }^{26}$. Ein Mosaik aus einem byzantinischen Kloster bei Bet-Schean zeigt einen sitzenden Mann, der auf einer Längsflöte einem Hund oder Bär (?) mit rotem Halsband aufspielt; dieser macht dazu 'Männchen' (Abb. 8) ${ }^{27}$. Ein palästinisches Sprichwort lautet: "Wer mit der Katze spielen will, muß auch ihre Krallen ertragen können"28.

23 Vgl. z.B. den Mosaikfußboden in Mādeba, Hippolytos-Saal [M. PICCIRILLo, Chiese e mosaici di Madaba (1989), 55] und das omayyadische Kohlebecken aus Hirbet elFedēn bei Mafraq, in: Der KöNIGSWEG (1987), 319. 347f, Nr. 352.

24 K. REITER, Falknerei im Alten Orient? Ein Beitrag zur Geschichte der Falknerei, MDOG 120 (1988), 189-206; dies., Falknerei im Alten Orient? II. Die Quellen, MDOG 121 (1989), 169-196; dies., Falknerei in Ugarit, UF 22 (1990), 271-278; D. Collon, First Impressions (1987), 155, No. 701; vgl. AHw 454 (kassūusu). 1062 (surdūu); M. MAINZER, Über Jagd, Fischfang und Bienenzucht bei den Juden in der tannäischen Zeit (Frankfurt a.M. 1910), 34-37; L. MERCIER, La Chasse et les Sports chez les Arabes (Paris 1927), 81-106; W. DIEM, Falknerei, Lex. der Islam. Welt 1 (1974), 170; F. VIRE, Bayzara, EI 1 (1960), 1152-155; W.E. JENNINGS-BRAMLEY, Sport among the Bedawîn, PEQ 1900, 369-376; al-Gitrif Ibn Qudāma al-Ġassānī, Die Beizvögel (Kîtāb ḍawāĩ ațtayr). Ein arabisches Falknereibuch des 8.Jahrhunderts, ed. D. MÖLLER - F. VIRE (Hildesheim 1987), passim.

25 Hier wird die Falkenjagd in die Zeit von David zurückverlegt.

26 M.J.W. LEITH, Greek and Persian Images in Pre-Alexandrine Samaria: The Wâdi ed-Dâliyeh Seal Impressions (Ph.D. Diss. unpubl.; Harvard University 1990), 219-233. 490, Pl. 21:1 (WD 2 / RM 958), vgl. allgemein W. RICHTER, Reiher, KP 4 (1975), 1370. Vgl. auch die Darstellungen von an einer Leine geführten Straussen auf byzantinischen Mosaiken in Palästina, z.B. in Qașr el-Halläbät [H. BUSCHHAUSEN (ed.), Byzantinische Mosaiken aus Jordanien (Wien 1986), Ảbb. 132] und auf Nebo / Ğebel en-Nebā (a.a.O., Abb. 133, Taf. II) und Tauben mit Halsbändern (Abb. 7), F. SüHLING, Die Taube als religiöses Symbol im christlichen Altertum (RQ.S 24; Freiburg i.Br. 1930), 261-296.

27 G.M. FIrzGerald, A Sixth Century Monastery at Beth-Shan (Scythopolis) (Publ. of the Palestine Section of the University Museum Pennsylvania 4; Philadelphia/PN 1939), 9, Pl. 16. 17:2; vgl. auch R. RosentHAL - R. SivaN, Ancient Lamps in the Schloessinger Collection (Qedem 8; Jerusalem 1978), Nos. 614. 673; J.H. ILIFFE, Imperial Art in Trans-Jordan. Figurines and Lamps from a Potter's Store at Jerash, QDAP 11 (1945), 17, Pl. 6:91 und allgemein E. BRUNNER-TRAUT, Lieblingstier, LÄ 3 (1980), 1054-1056; DECKER, Dressur, LÄ 1 (1975), 1145; H.G. FISCHER, Hunde, LÄ 3 (1980), 77-82.

28 L. HAEFELI, Spruchweisheit und Volksleben in Palästina (1939), Nr. 603; K.L. TAllouist (ed.), Arabische Sprichwörter und Spiele (1897), 23. 
Ebenso war die Jagd keineswegs nur ein auf Nahrungserwerb gerichtetes Unternehmen, sondern hatte neben ihren kultischen und magischen ${ }^{29}$, pädagogischen ${ }^{30}$ und propagandistischen Aspekten häufig auch Züge spielerischen Freizeitvergnügens vor allem der jeweiligen Oberschichten ${ }^{31}$.

Mit hoher Wahrscheinlichkeit wurden im antiken Palästina auch Hahnen(und Wachtel-)Kämpfe als Freizeitbeschäftigung und Volksbelustigung durchgeführt; darauf deuten die Darstellungen von Kampfhähnen auf judäischen Siegeln (VSE Nrn. 69 und 252) (Abb. 9) ${ }^{32}$ sowie die zahlreichen Abbildungen von (Kampf-)Hähnen auf Mosaiken ${ }^{33}$, Öllampen ${ }^{34}$, Gemmen $^{35}$ und in

29 Vgl. z.B. W.W. MÜLlER, The Meaning of Sabaic KRWM, in: Arabian Studies in Honour of M. GHUL, ed. M.M. IBRAHIM (Wiesbaden 1989), 89-96 (mit weiterführender Literatur).

30 Vor allem zur Wehr- bzw. Kriegserziehung, vgl. z.B. Plutarch, de lib. educ. 11.

31 Vgl. z.B. K. GALling, Jagd, BRL ${ }^{2}$ (1977), 150-152; W.E. JENNINGS-BRAMLEY, PEQ 1900, 369-376; W. HEIMPEL - L. TRÜMPELMANN, Jagd, RIA 5 (1976-1980), 234 238; W. HELCK, Jagd und Wild im alten Vorderasien (Hamburg 19678), passim; M. KRANZ, Probleme der Leiblichkeit (Diss. phil. masch.; Köln 1965), 121-125; M. MAINZER, Über Jagd, Fischfang und Bienenzucht bei den Juden (1910), 4-40; O. LORETZ, Ugarit und die Bibel (1990), 226f; V. OlivovA, Games and Sport Elements in Ancient Mesopotamia, History of Physical Education and Sport 2 (1974), 52-56; H. ALTENMÜLLER, Jagd; Jagddarstellungen, LÄ 3 (1980), 221-224. 224-230; G. DALMAN, Petra und seine Felsheiligtümer (Leipzig 1908), 97 u.ö.; W. DECKER, Sport und Spiel im Alten Ägypten (1987), 155-175; ders. (ed.), Quellentexte zu Sport und Körperkultur im alten Ägypten (1975), 47. 66ff u.ö.; ders., Annotierte Bibliographie zum Sport im Alten Ägypten (1978), Nrn. 473-559; A.D. TOUNY - S. WENIG, Sport in Ancient Egypt (1969), 61-75; W. KNAUTH, Stadion 2 (1976), 69-85; ders. - S. NADJMABADI, Das altiranische Fürstenideal von Xenophon bis Ferdousi (Wiesbaden 1975), 112ff; L. MERCIER, La Chasse et les Sports chez les Arabes (1927), 8ff. 107ff; H. RIEDEL, Leibesübungen und körperliche Erziehung (1942), 26-31; ANEP $^{2}$ fig. 182-190; Joseph., BJ 1,21,13 (§ 429); Pseudo-Ovid, De Vetula, ed. P. KLOPSCH (1967), 1,262-357.

32 R. HESTRIN - M. DAYAGI-MENDELS (ed.), Inscribed Seals (Jerusalem 1979), 20f, Nos. 5 (Tell en-Naṣbe, ANEP ${ }^{2}$ fig. 277). 6; auch ANEP ${ }^{2}$ fig. 793 (el-Ğib)); Y. AHARONI, Beer-Sheba I (Tel Aviv 1973), 17, Pl. $28: 2$ (Tell es-Sebac, Stratum II).

33 Vgl. z.B. E.T. RICHMOND, Basilica of the Nativity. Discovery of the Remains of an Earlier Church, QDAP 5 (1936), 75-81, Pl. 38 (Bethlehem); F.M. DRAKE, A Sixth Century Greek Mosaic at Um Jerar, PEQ 1918, 122-124 und die transjordanischen Mosaikfußböden in Hirbet el-Muhaiyit (Kirche des Amos und Kasiseos), Madeba ('Kathedrale') oder Rās es-Siyāğa, vgl. U. LUX, ZDPV 83 (1967), 172. 177, Anm. 47, Taf. 35D; M. PiCcIRILlo, Chiese e mosaici di Madaba (1989), 26. 53. 130f. 151. 195f. 329; R. STILlWELl (ed.), Antioch on-the-Orontes II. The Excavations 1933-1936 (Princeton/NJ - London - Den Haag 1938), 189f, Pl. 48:64. 
Form zoomorpher Gefäße ${ }^{36}$. "Der Kampfhahn ist besser als die anderen (Hähne). Sein Merkmal ist der rote Kamm, der dicke Hals, das schmale und besonders schwarze Auge, die scharfen Krallen, und daß er die Stimme er-

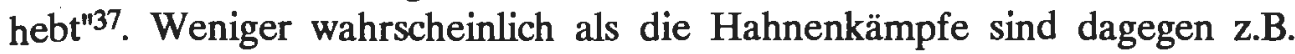
Stierkämpfe bzw. -spiele ${ }^{38}$ u.ä. Nicht belegt, aber als wahrscheinlich anzunehmen ist für das antike Palästina auch das Nachahmen von Tierstimmen durch Kinder, wie es H. Heine 1827 in seinem Buch der Lieder (Die Heimkehr 38) beschrieb: "Mein Kind, wir waren Kinder / Zwei Kinder, klein und froh / Wir krochen ins Hühnerhäuschen / Versteckten uns unter das Stroh // Wir krähten wie die Hähne / und kamen Leute vorbei - / Kikereküh! sie glaubten / es wäre Hahnengeschrei".

34 R. ROSENTHAL - R. Sivan, Ancient Lamps in the Schloessinger Collection (1978), Nos. 163. 363f. 388.

35 Vgl. z.B. M. HENIG - M. WHITING, Engraved Gems from Gadara in Jordan (Oxford 1987), Nos. 380f.

36 Vgl. z.B. DeR KöNIGSWEg (Mainz 1987), Nr. 278 (Gerasa); R. RoSENTHAL - R. SrVAN, Ancient Lamps in the Schloessinger Collection (1978), No. 617; auch L. BECQ DE FouQuiERES, Les jeux des anciens ( $\left.{ }^{1873}\right), 148-158$; PH. BRUNEAU, Le motif des coqs affrontés dans l'imagerie antique, BCH 890 (1965), 90-121; K. SCHAUENBURG, Ganymed und Hahnenkämpfe auf römischen Sarkophagen, AA 1972, 501-516; O.W. REINMUTH, Hahnenkämpfe, KP 2 (1975), 917f; K. SCHNEIDER, Hahnenkämpfe, RE 7 (1912), 2210-2215; Tierbilder aus vier Jahrtausenden. Antiken der Sammlung L. Mildenberg (Mainz 1983), Nr. 16. 197; C. GEERTZ, Deep Play: Notes on the Balinese Cockfight, Daed. 101 (1972), 1-37. Literarische Belege z.B. Anth. Graeca 6,155; 7,424 (Epigramm des Antipatros von Sidon!); Artemidor 3,5; Theokrit 22,75f; Babrios, myth. 5; Columella 8,2,4f. Zu Wachtel-Kämpfen vgl. z.B. Marc Aurel 1,6.

37 Al-Qazwiñ $\bar{l}$, Die Wunder des Himmels und der Erde (Bibliothek Arab. Erzähler; Stuttgart 1986), 219. Allgemein F. ROSENTHAL, Gambling in Islam (1975), $57 \mathrm{f}$.

38 Vgl. z.B. H. SEYRIG, Quelques cylindres orientaux, Syria 32 (1955), 34-37, Pl. 4:2; ders., Cylindre représentant une tauromachie, Syria 33 (1956), 169-174; D. Collon, First Impressions (1987), Nos. 707-710; O. KEEL (ed.), Altorientalische Miniaturkunst (1990), 41, Abb. 39. Auf einer minoischen Mandmalerei in Auaris / Nil-Delta ist ein Stier-Akrobat belegt, H. DATTENBERG, Stierspringer am Nil, Bild der Wissenschaft 12 (1991), 139; auch S. MARINATOS - M. HIRMER, Kreta, Thera und das mykenische Hellas (München ${ }^{3}$ 1976), 112. 123. 144f u.ö., Abb. 14. 96f. 106f. 121, Taf. 17; A. REICHEL, Die Stierspiele der kretisch-minoischen Kultur, AM 34 (1909), 85-99, Taf. II; J. AYMARD, Quelques remarques sur les jeux avec les taureau à l'époque romaine, $\mathrm{EtCl} 23$ (1955), 259-266; S. LASER, Sport und Spiel (1987), 75-78, Abb. 29f; W. DECKER, Annotierte Bibliographie zum Sport im Alten Ägypten (1978), Nrn. 140f; P. BEHRENS, Stierkampf, LÄ 6 (1986), 16f (gab es im Alten Ägypten nicht); W. DEONNA, Le symbolisme de l'acrobatie antique (1953), $23 \mathrm{ff}$. $96 \mathrm{ff}$. 
Wie die wilden Tiere untereinander (Hi. 40,20) ${ }^{39}$, so spielten die Menschen auch gerne mit den ungefährlichen Spezies unter ihnen. Die zahlreichen Terrakotta-Tiere der Bronze-, Eisen- und Nacheisenzeit, die in den Siedlungen und Gräbern Judas und Israels gefunden wurden ${ }^{40}$, dürften z.T. als Kinderspielzeug - auch als Ersatz für lebendes Spielzeug - benutzt worden sein (Abb. 10) ${ }^{41}$. Eine Reihe von Terrakotta-Tieren waren mit zwei Achsen versehen und konnten mit Hilfe einer Schnur gezogen werden (Abb. 11) ${ }^{42}$. Laut dem Kindheitsevangelium des Thomas spielte der fünfjährige Jesus am Bach und formte dabei aus Lehm Spatzen ${ }^{43}$, um sie dann zum Leben zu erwecken und fliegen $\mathrm{zu}$ lassen ${ }^{44}$ und laut dem Arabischen Kindheitsevangelium 26,1f formte der siebenjährige Jesus mit seinen gleichaltrigen Spielkameraden aus

39 "Denn bwl (Tribut / Holz ?) bringen (die) Berge zu ihm (= Behemot) und alle wilden Tiere, die dort spielen". LXX epelthōn de ep'oros akrotomon epoiēsen charmonēn tetraposin en tō tartarō; Vulg. (Hi. 40,15) huic montes herbas fenunt omnes bestiae agri ludent ibi.

40 Vgl. z.B. N. AvigaD, Discovering Jerusalem (Nashville - Camden - New York 1983), 35; T.A. HollaND, A Study of Palestinian Iron Age Baked Clay Figurines, with special Reference to Jerusalem: Cave 1, Levant 9 (1977), 121-155; U. HÜBNER, Figurinen aus Terrakotta, in: V. FRTTZ (ed.), Kinneret. Ergebnisse der Ausgrabungen auf dem Tell el-C Orème am See Gennesaret 1982-1985 (ADPV 15; Wiesbaden 1990), 119 121, Taf. 42 C-D. 102; zum Fundmaterial in Transjordanien vgl. A.J. CAMR, A Study of the Clay Figurines and Zoomorphic Vessels of Tans-Jordan during the Iron Age, with special Reference to their Symbolism and Function (Ph.D. Thesis, unpubl.; University of London 1980), Nos. 115ff.

41 Vgl. z.B. E. BRUNNER-TRAUT, Spielzeug, LÄ 5 (1984), 1154; E. FEUCHT, Vom Nil zum Neckar (Berlin u.a. 1986), Nr. 548; G.L. SPALINGER, in: A. EGGEBRECHT (ed.), Ägyptens Aufstieg zur Weltmacht (Mainz 1987), Nr. 93; A. WIEDEMANN, Das Spiel im alten Ägypten (1912), 170f; S. LASER, Sport und Spiel (1987), 93-96, Abb. 36; J. VÄTERLEIN, Roma ludens (1976), 51f; aber auch N. CHOLIDIS, Tiere und tierförmige Gefäße auf Rädern. Gedanken zum Spielzeug im Alten Orient, MDOG 121 (1989), 197 220; O. REUTHER, Die Innenstadt von Babylon (Merkes) (WVDOG 47; Leipzig 1926 = Osnabrück 1968), 32, Abb. 39 ("fahrbare Topfkuh"). Im griechischen und römischen Bereich sind theriomorphe Terrakotten häufig in Kinder-Gräbern belegt, vgl. z.B. H. CÜPPERS et al. (ed.), Die Römer an Mosel und Saar (Mainz 21983), 187-189. 252-255. 314f, Nr. 123f. 212. 271.

42 Vgl. z.B. R. ZIAS, A Roman Tomb at c $_{A r} c_{a r a} c_{A}$ Atiqot ES 14 (1981), 64, fig. 5, Pl. 10:4 (Grab des 1.-2.Jh.s n.Chr.); L.Y. RAHMANI, Finds from a Sixth to Seventh Centuries Site near Gaza, I: The Toys, IEJ 31 (1981), 72-76, Pl. 13f; auch S. LASER, Sport und Spiel (1987), 93f, Anm. 460, Abb. 36; Tierbilder aus vier Jahrtausenden (1983), Nr. 73.

43 Zu Spatzen als Spiel-Tieren vgl. z.B. Augustin, conf. 1,19,30.

44 O. CullmanN, in: W. SchneEMElcher (ed.), Neutestamentliche Apokryphen I $\left(5_{1987}\right), 353$; H. DANIEL-ROPS (ed.), Die apokryphen Evangelien (21958), 62f. 84; Qoran, Sure 3,49 . 
Lehm Esel-, Rinder-, Vögel- und andere Tier-Figurinen, die er ebenfalls belebte. In seinen Kindertagen fertigte Lukian aus Wachs Rinder, Pferde und Menschen (Lukian, somn. 2); sofern dies während des Unterrichts geschah, hatte sein Spiel ein derbes Nachspiel: Er kassierte vom Lehrer Prügel - ein Ungemach, das Kindern in vergleichbaren Situationen durch Erwachsene, die sich als Spielverderber aufspielten, häufig widerfuhr ${ }^{45}$. "Das Leben ist (k)ein Kinderspiel"46. Aristophanes, nub. 877ff zufolge bastelten sich Knaben aus Apfelschalen Frösche und aus Leder Pferde und Wagen ${ }^{47}$ zum Spielen, laut Platon, nomoi 643b-c Häuschen u.ä. 48; andere Kinder spielten mit Steckenpferden ${ }^{49}$. In Ägypten sind Krokodil-und Katzen-Figürchen mit beweglichen Unterkiefern und ähnliches mehr belegt ${ }^{50}$.

"Laß die Gedanken in die Lüfte fliegen, wie Maikäfer, an dem Fuß den Faden!"

(Aristophanes, nub. 763)

45 Vgl. z.B. Augustinus, conf. 1,9,14f; 1,10,16; H. DANIEL-Rops (ed.), Die apokryphen Evangelien (21958), 88.

46 Vgl. z.B. Sap.Sal. 15,12; H. HERTER, Das Leben ein Kinderspiel, (1961), in: ders., Kleine Schriften, ed. E. VoGT (München 1975), 584-597.

47 Laut dem Leben und Taten Alex.s von Makedonien (ed. H. VAN THIEL) 1,1,5f (vgl. 1,5,1) sich Pharao Nektanebos Schiffchen und Menschen aus Wachs - allerdings zwecks einer Hydromantie.

48 Vgl. z.B. E. HANFMANN, Über das Bauen der Kinder, Zt. für Kinderforschung 36 (1930), 255-334.

49 Horaz, sat. 2,3,248 (equitare in harundine longa); Aelian, var.hist. 12,15; Plutarch, Agesil. 25; ders., Apophtegm. Lacon. 70 (kalamon peribainein); L. GRASBERGER, Erziehung und Unterricht im klassischen Alterthum I 1 (1864), 28-30; L. BECQ DE FOUQUIERES, Les jeux des anciens (21873), 73f; R. SCHMIDT, Die Darstellung von Kinderspielzeug und Kinderspiel (1977), 103; M. GRIAULE, Jeux et divertissements abyssins (1935), Pl. II:5; F.K. MATHYS, Im Freien gespielt (1975), 22-24; H. SBRZESNY, Die Spiele der !Ko-Buschleute (1976), 105-107; L. WÜTHRICH, ZSA 38 (1981), 279-289; F.M. BöHME, Deutsches Kinderlied und Kinderspiel (1897 = 1967), 80, Nr. 356: "Hopp, hopp, hopp! Pferdchen, lauf Galopp / Über Stock und über Steine, aber brich dir nicht die Beine! / Hopp, hopp, hopp! Pferdchen, lauf Galopp / Hopp, hopp, ho! Das Pferdchen frißt kein Stroh / muß dem Pferdchen Hafer kaufen, daß es kann im Trabe laufen".

50 T. BALDACCI, Musik, Tanz und Spiel, in: A.M. DonADoni-RoverI (ed.), Das Alte Ägypten. Das Alltagsleben. Ägyptisches Museum Turin (Mailand 1987), 265; K. GRÖBER - J. METZGER, Kinderspielzeug aus alter Zeit $\left({ }^{2} 1965\right)$, 111. 212, Nr. $23 f$. 


\section{BALL-SPIELE}

"Totus gaudeo, mea pila est" (Plautus, Trucul. 705): In allen antiken Kulturen $^{1}$ spielten Götter ${ }^{2}$ und Menschen, Kinder und Erwachsene ${ }^{3}$ beiderlei

1 Allgemein z.B. G. CHANAN - H. FranCIS, Toys and Games of Children of the World (Paris - Barcelona 1984), passim; K. GOEPEL, Beiträge zur Geschichte des Ballspiels (Eberswalde 1909), passim; F.M. BÖHME, Deutsches Kinderlied und Kinderspiel (1897. = 1967), 606-615, Nr. 473-482; S. PAUL, Afrikanische Ballspiele, BaA 18 (1970), 155ff; H. GÜNTHER, Um Ball und Tor. Streifzug durch die Geschichte der Ball-, Wurf- und Laufspiele (Leipzig 1955), 130-148; S. MENDNER, Das Ballspiel im Leben der Völker (Münster i.W. 1956), 42-49.

Zu Griechen und Römer (griech. sphaira, latein. pila, follis) vgl. z.B. Homer, Od. 6,100ff; Horaz, sat. 1,5,49; Laus Pisonis 185-189; Martial, epigr. 7,32,7ff; Petronius, satyr. 27; Pollux 9,104; Ovid, ars amat. 3,353-380; ders., tristia 2,485; ders., met. 10,262; Plinius d.A., nat. hist. 7,205; Isidor von Sevilla, etym. 18,69; Sidonius Apoll., ep. 17 (PL 58, 548); Apoll. Rhod., Argon. 3,117-130; Augustin, conf. 1,19; J. TAILlardat (ed.), Suétone. Peri paidiōn (1967), Nr. 2 oder auch L. BECQ DE FOUQUIERES, Les jeux des anciens (2 1873), 47-51. 176-211; F.A.G. BECK, Album of Greek Education (1975), 51f, Nos. 311-322; E. BÖHR, Der Schaukelmaler (1982), 49; L. GRASBERGER, Erziehung und Unterricht im klassischen Alterthum I 1 (1864), 84-96. 159f; R.C. JENSEN, The Kourion Ballplayer, RDAC 1984, 281-284, Pl. 63; L. DEUBNER, Antike 6 (1930), 169172, Abb. 3. 12-15, Taf. 17; H.R. IMMERWAHR, An Inscribed Terracotta Ball in Boston, GRBS 8,4 (1967), 255-266; W. GRÜNDEL, Griechische Ballspiele, AA 1925, 80-95; E. MEHL, Stammen die modernen Ballspiele von einem altägyptischen Fruchtbarkeitsbrauch ab?, LE 6 (1953), 8-12; H. GEIST (ed.), Pompeianische Wandinschriften (1936), 74-77; F.K. MATHYS, 4500 Jahre Fußball, Basler Magazin 22 (1990), 1-5; A. MAU, Ballspiel, RE 2 (1896), 2832-2834; ders., Episkyros, RE 11 (1907), 1999f; S. MENDNER, RAC 10 (1978), 852f. 864f. 871. 885f; H. HOMMEL, Tanzen und Spielen, (1949), in: ders., Symbola I (Hildesheim u.a. 1976), 18-22; H. BECK et al. (ed.), Polyklet. Der Bildhauer der griechischen Kunst (Mainz 1990), 508, Nr. 3; S. LASER, Sport und Spiel (1987), 90 93; G. RADKE, Trigon, RE II 13 (1939), 139; O.W. REINMUTH, Ballspiel, KP 1 (1975), 943; ders., Ephedrismos, KP 2 (1975), 292; A. SCHMTT, Spielen, wie die Römer spielten, in: Jahresbericht des Beethoven-Gymnasiums Bonn 1977/78, 19-21; K. SCHNEIDER, Pilarius, RE 20,2 (1950), 1320-1322; G. SCHNEIDER-HERRMANN, Der Ball bei den Westgriechen, BABesch 46 (1971), 123-133; J. TAILlardat (ed.), Suétone. Peri paidiōn (1967), 68f; M.N. TODD, Teams of Ballplayers at Sparta, ABSA 10 (1903-1904), 63-67; K. SCHAUENBURG, AW 7,3 (1976), 45-47; 7,4 (1976), 28-31; J. VÄTERLEIN, Roma ludens (1976), 39-45, Abb. 11; E. WEGNER, Das Ballspiel der Römer (Diss. phil. Rostock; Würzburg 1938), passim; P. ZAZOFF (ed.), Antike Gemmen in deutschen Sammlungen Bd. IV (1975), 170, Nr. 839, Taf. 109:839.

Zum Harpastum-Phaininda vgl. z.B. Klemens Alex., Paid. 3,46-51; E. HessEL, Das Spiel Phaininda-Harpastum, Gym. 67 (1960), 226; S. MENDNER, Das Spiel Phaininda- 
Geschlechts und aller sozialen Schichten ${ }^{4}$ mit Bällen - so auch im eisenzeitlichen Israel (dūr Jes. 22,18) $)^{5}$. Aus dem Drohwort gegen einen hohen Jerusalemer Beamten Jes. $22,15^{*}-18$ kann man schließen, daß sie zumeist aus Wolloder Stoffresten [Knäuel (?) $s^{\ell}$ nepāh Jes. 22,18] $]^{6}$, Haaren ${ }^{7}$, Federn (z.B. Mar-

Harpastum, Gym. 66 (1959), 517-524; L.B. MrTCHELl, Ancient Ball Games, CJ 34 (1938-1939), 103; O.W. REINMUTH, Harpaston, KP 2 (1975), 943; E. WAGNER, Hockeyspiel im Altertum, Ph. 103 (1959), 137-140; ders., Kritische Bemerkungen zum Harpastum-Spiel, Gym. 70 (1963), 356-366.

Ethnologische Belege (für Vorderasien) z.B. E.J. BANKs, Bismya or The Lost City of Adab (New York - London 1912), 411; L. MERCIER, La Chasse et les Sports chez les Arabes (1927), 173ff; E. MrTTWOCH, MSOS 13 (1910), 127ff; H. SCHMIDT - P. KAHLE (ed.), Volkserzählungen aus Palästina I (FRLANT 17. 47; Göttingen 1918. 1930), 186189, Bd. II: 100. $142 f$ ('Kugelspiel', eine Art Hockey); K.L. TALLQUIST (ed.), Arabische Sprichwörter und Spiele (1897), 126-128 u.ö.; auch M. CoHEN, JA 18 (1911), 479-482; M. GRIAULE, Jeux et divertissements abyssins (1935), 75ff; I. WEILER - CH. ULF, Sport bei den Völkern der alten Welt (Darmstadt $\left.{ }^{2} 1988\right)$, 29ff. 209ff. $265 f f$.

2 U.a. mit Menschen als Spielbällen.

3 MT $k(-) d w r$. LXX nur kai ripsei se; Vulg. quasi pilam mittet te, vgl. $\mathrm{HAL}^{3}$ 1, 209; HAL $^{3}$ 2, 439; neuhebr. kdwr-mśhq, vgl. das griech. Lehnwort [sphaira (Ball)] in hebr. bzw. aramä. spyr'/ $h$, vgl. S. KRAUSS, Griechische und lateinische Lehnwörter im Talmud, Midrasch und Targum II (Berlin $1899=$ Hildesheim 1964), 408; arab. kura, țabe, tubbe; neuhebr. kadûr. In Jes. 29,3 ist $k$-dwr wohl "ringsum", "wie im Kreis" (Aquila und Theodotion sphaira, Vulg. quasi spheram in circuitu) und nicht mit LXX (hōs David = ${ }^{*} k$-Dwd), BHS z.St. oder $\mathrm{HAL}^{3}$ 3, 439 zu übersetzen, vgl. O. KAISER, Jesaja 13-39 (ATD 18; Göttingen 31983), 209-213; H. WILDBERGER, Jesaja 28-39 (BK AT 10,3; Neukirchen-Vlyun 1982), 1097-1111; H. DONNER, Israel unter den Völkern (VT.S 11; Leiden 1964), 154ff.

4 Nach dem Leben und Taten Alex.s von Makedonien (ed. H. VAN THIEL) 1,36,1ff; 1,38,7; 2,7,1 hatte der achämenidische König Darius III. Alexander d.Gr. einen Ball, eine Geißel und ein goldenes Kästchen als Kinderspielzeug zugeschickt, die der Empfänger aber als Symbole des Erdballs, der Herrschaft und des Tributs interpretierte. Laut Plutarch, de coh. ira 9 demütigte Magas von Kyrene den Dichter Philemon, indem er ihm Astragale und einen Ball überreichte.

5 Vgl. auch bSan. 77b; jSanh. 10,1; 28a; tŠabb 10 (11), 12f; auch S. KrAusS, Talmudische Archäologie III (1912), 109f; L. BAUER, Volksleben im Lande der Bibel (Leipzig 21903), 74; J.H. ILIFFE, Pre-Hellenistic Greek Pottery in Palestine, QDAP 2 (1933), 20, No. 14, Pl. 7a (Tell Ğemme). Zu den text- und literarkritischen, redaktionsgeschichtlichen und lexikographischen Problemen vgl. z.B. O. KAISER, Jesaja 13-39 (31983) 120126; H. WILDBERGER, Jesaja 13-27 (BK AT 10,2; Neukirchen-Vluyn 1978), 831-841.

6 Vgl. HAL ${ }^{3}$ 3, 973 șnp I und II sowie șnph; vgl. auch KBL 809 "Wickel"; M. JASTROW, Dictionary of the Targumim $(1903=1989)$, 1096; H.L. GINSBERG, Some Emendations in Isaiah, JBL 69 (1950), 55f; R. MARTIN-ACHARD, L'oracle contre Shebnâ et le pouvoir des clefs, Es. 22,15-25, ThZ 24 (1968), 241-254. 
tial, epigr. 14,45$)^{8}$ und / oder Leder (z.B. Platon, Phaidon 110b) bestanden haben, also Vollbälle waren, wie dies durch zahlreiche Originalfunde in Ägypten belegt ist ${ }^{9}$ und die nach unserer heutigen Vorstellung eher Stoff-Ballen als Bällen ähnelten, da sie nicht immer die Idealform einer Kugel erreichten (pilae proprietas est cum aequalitate quadam rotunditas, Seneca, nat. Rom. IV B 11,3$)^{10}$. Auch die schon genannten Kinder-Statuen des frühen 4.Jh.s v.Chr. aus Sidon zeigen Kinder mit Bällen; auf einem attischen, schweinsköpfigen Rhyton aus Šêh Zenad / Syrien sind Knaben bei einem Ball-Spiel zu sehen (Abb. 12) ${ }^{11}$. Der Jüngling Apollonius von Tyros spielte mit dem älteren Archistrates von Kyrene im dortigen Gymnasium Ball (Hist. Apoll. regis Tyri 13). Da luftgefüllte, elastische Hohlbälle (latein. follis, folliculus, culleus) erst verhältnismäßig spät aufkamen (z.B. Martial, epigr. 14,45.47), dürften die meisten Ballspiele nur aus Fangen und Werfen bestanden haben; Kinder dürften stattdessen zuweilen auch mit aufgeblasenen Tierschläuchen (hebr. 'wb, hmt, n'd, rqb; griech. askos, askopytinese, latein. ascopa, uter) Ball oder besser eine Art 'Ballon' gespielt haben ${ }^{12}$. Schäden, die durch unvorsichtiges

7 Latein. pila = der mit Haar gestopfte Ball; Anth. Graeca 14,62: "Mächtig bin ich behaart, doch halten Blätter die vielen Haare verborgen, sofern nirgends ein Löchlein erscheint".

8 Latein. pila paganica $=$ der mit Federn gefüllte Ball.

9 Latein. pila. Vlg. z.B. W. DECKER, Sport und Spiel im Alten Ägypten (1987), 119124; ders., Ball; Ballspiel, LÄ 1 (1975), 608. 609f; ders., Annotierte Bibliographie zum Sport im Alten Ägypten (1978), Nrn. 275-281; C.-B. ARNTS, in: A. EGGEBRECHT (ed.), Ägyptens Aufstieg zur Weltmacht (1987), Nr. 92; F.W.M. PETRIE, Objects of Daily Use (London 1927), 58f, PI. 51:361-367 (aus Papyrus und Leder); A.D. TOUNY - S. WENIG, Sport in Ancient Egypt (1969), 45-48; J. VANDIER, Manuel d'archéologie égyptienne IV (1964), 514f; A.R. DAVID, Toys and Games from Kahun in the Manchester Museum Collection, in: Glimpses of Ancient Egypt. Studies in Honour of H.W. FAIRMAN, ed. J. RUFFle - G.A. GABALLA - K.A. KTTCHEN (Warminster 1979), 12, PI. 3 [12.Dyn., aus Leder bzw. Holz]; zum Ballspiel in Ägypten z.B. J.F. BoRGHOUTS, The Evil of Apopis, JEA 59 (1973), 114-150, spez. 122-140 (Ball-Ritus); vgl. O. KEEL, Die Weisheit spielt vor Gott (1974), 31-33; F.K. MATHYS - M. TRIET (ed.), Spiel und Sport im alten Ägypten (Basel 1978), 53; E. OTTO, Ball, Schlagen des, LÄ 1 (1975), 608f; C.E. DEVRIES, A Ritual Ball Game?, in: Studies in Honor of J.A. WILSON (SAOC 35) (Chicago/IL 1969), 25-35; A. WIEDEMANN, Das Spiel im alten Ägypten (1912), 173.

10 S. HERBERGER pflegte schlichter zu sagen: "Der Ball ist rund".

11 E. Potrier et al., La nécropole de Cheikh Zenad, Syria 7 (1926), 193-208, Pl. 40; ders., Note complémentaire sur le rhyton de Cheikh Zenad, Syria 8 (1927), 174.

12 Vgl. M. DoLCH, Vom Ursprung des luftgefüllten Lederballs, Stadion 7 (1981), 5392. Zum Spiel askōliasmos z.B. J. TallLaRDaT (ed.), Suétone. Peri paidiōn (1967), Nr. 12; Pollux 9,121; vgl. L. BECo DE FouguiERES, Les jeux des anciens ( $\left.{ }^{2} 1873\right)$, 241-245; L. GRASBERGER, Erziehung und Unterricht im klassischen Alterthum I 1 (1864), 36-40; 
Ball-Spiel angerichtet wurden, werden im Corpus Iuris Civilis (z.B. Dig. 9,2,11; vgl. bSan. 77b) ${ }^{13}$ juristisch behandelt: "Einige spielten Ball (pila) und jemand hat etwas zu heftig den Ball geworfen. Dieser fiel auf die Hand eines Barbiers, dessen Rasiermesser die Kehle des Sklaven, den er gerade barbierte, durchschnitt. Wen hier ein Verschulden trifft, der fällt unter das Aquilische Gesetz... Und sicherlich, wenn er dort seine Tätigkeit verrichtete, wo man gewöhnlich spielte oder ein lebhafter Durchgangsverkehr war, so muß man ihm dies anrechnen. Andererseits ist aber auch folgendes nicht zu beanstanden: Wenn sich jemand einem Barbier, der seinen Sitz an einem gefährlichen Ort aufstellt, anvertraut, so muß er sich bei sich selbst beklagen".

Bei den Griechen und Römern galt das Ballspiel als medizinisch vorteilhafte Übung14. Es konnte nicht nur im Alltag, sondern auch in der Unterwelt, und darüberhinaus auch als Glücks- und Orakelspiel gespielt werden. Auch bei verschiedenen kultischen Anlässen wurde mit Bällen gespielt ${ }^{15}$. Insofern verwundert es kaum, daß man sich in christlichen Gottesdiensten bzw. Gotteshäusern späterer Zeit ebenfalls - wenn auch nur gelegentlich - in liturgischem Ballspiel ${ }^{16}$ übte. Auch das in der christlichen Ikonographie weitverbrei-

E. REISCH, Askōliasmos, RE 2 (1896), 1698-1700; W. DEONNA, Un divertissement de table "A cloche-pied" (Collection Latomus 40; Brüssel 1959), 27-29; und K. LATTE, Askōliasmos, (1957), in: ders., Kleine Schriften zu Religion, Recht, Literatur und Sprache der Griechen und Römer (München 1968), 700-707, der zu Recht bestreitet, daß es sich dabei um ein Hüpfen auf einem Schlauch handele.

13 A. WACKE, Unfälle bei Sport und Spiel nach römischem und geltendem Recht, Stadion 3 (1977), 12-20.

14 Vgl. z.B. Plinius d.J., ep. 3,1,8; Celsus, de med. 1,2.6; F. und L. FETZ (ed.), Gymnastik bei Philostrat und Galen (1969), 101-106.

15 Vgl. z.B. G. SCHNEIDER-HERRMANN, BABesch 46 (1971), 123-133.

16 Vgl. z.B. R.W. HeNDERSON, Ball, Bat and Bishop. The Origin of Ball Games (New York 1947), passim. Ball-Spiele von Klerikern in Bischofskirchen an Festtagen als Teil der Liturgie, z.B. die Oster-Pilota in der Kathedrale von Auxerre im 16.Jh. [CH. du CANGE, Glossarium mediae et infimae Latinitatis, Vol. VI (1896 = Graz 1954), $253 \mathrm{f}$ (pelota); H. RAHNER, Der spielende Mensch $\left({ }^{4} 1957\right)$, 44ff. 58ff], auch R. GUARDINI, Die Liturgie als Spiel, in: ders., Vom Geist der Liturgie (Ecclesia Orans 1; Freiburg 1922), 56-70. Zum Ballspiel höherer Geistlicher als Gesundheitsübung vgl. M. DOLCH, Paolo Corteses Bemerkungen über das Ballspiel der geistlichen Würdenträger (1510), Stadion 8-9 (1982-1983), 85-97; auch H. GüNTHER, Um Ball und Tor (1955), 181-184. Daneben sei noch darauf hingewiesen, daß es - von den Kultspielen des alten Ägypten abgesehen [z.B. E. HoRNUNG, ErJb 51 (1982), 479ff; J.F. BORGHOUTS, JEA 59 (1973), 122ff] - in den christlichen Kirchen eine Vielzahl verschiedenster geistlicher Spiele gab und gibt, vgl. z.B. LUDUS DE ANTICHRISTO. Lateinisch und deutsch, ed. R. ENGEISING (reclam 8561; Stuttgart 1985), passim; R. SCHMID, Raum, Zeit und Publikum des geistlichen Spiels (München 1975), passim; R. WARNING, Ritus, Mythos und geistliches 
tete Bild des Jesus-Kindes mit dem Erd-Ball in der Hand erinnert ebenso wie Alexander d.Gr. mit dem ihm von seinem später besiegten Gegner Darius III. geschenkten Ball an die Spielelemente theologischen Nachdenkens ${ }^{17}$. Bei Platon, Phaidon 110b heißt es: "Man sagt also zuerst, o Freund, diese Erde sei so anzusehen, wenn sie jemand von oben herab betrachtete, wie die zwölfteiligen ledernen Bälle, in so bunte Farben geteilt".

"Die Bälle gleichen der Hetäre, weil sie von Hand zu Hand wandern und zu vielen kommen" (Artemidor 1,55)

Spiel, in: M. FunrmanN (ed.), Terror und Spiel. Probleme der Mythenrezeption (München 1971), 211-239; W. FLEMMING, Weihnachtsspiele, RGG 6 (31962), 15691571; auch O. SEYDEL, Spiel und Ritual. Überlegungen zur Reform des Gottesdienstes, WPKG 60 (1971), 507-515. Zu den antiken Leichenspielen vgl. L.E. ROLLER, Funeral Games in Greek Literature, Art and Life (Ph.D. Diss. University of Pennsylvania 1977; Ann Arbor/MI 1981), passim. Zum Problem 'Kult und Spiel' allgemein vgl. z.B. die unterschiedlichen Positionen bei J. HuIZINGA, Homo Ludens (1956 = 1987), passim und A.E. JENSEN, Mythos und Kult bei Naturvölkern ( ${ }^{2} 1960$ = München 1991), 71-104.

17 Leben und Taten Alex.s von Makedonien (ed. H. vAN THIEL) 1,36,1ff; 1,38,7; 2,7,1. Vgl. allgemein auch P.E. SCHRAMM, Sphaira - Globus - Reichsapfel. Wanderung und Wandlung eines Herrschaftszeichen von Caesar bis Elisabeth II. (Stuttgart 1958), $2 \mathrm{ff.}$ 


\section{ASTRAGALE}

Besonders viel wurde und wird in Palästina mit Astragalen ${ }^{1}$ gespielt, also mit den Sprunggelenkknochen verschiedener Tiere (Abb. 13), wie die osteologischen und ikonographischen Befunde zeigen. Die Astragale stammten dabei in der Regel von Schafen und Ziegen, aber auch häufig von Schweinen ${ }^{2}$ und Rindern ${ }^{3}$ oder von Wildtieren wie mesopotamischen Damhirschen ${ }^{4}$ oder Gazellen ${ }^{5}$. Die Knochen konnten unbearbeitet bleiben, wurden aber auch

1 Griech. Astragalos, astris, astrichos und entsprechend astragalismos (neugriech. kotsia); latein. talus, taxillus und entsprechend ludus talarius. Als griech. Lehnwort im Hebräischen bzw. Aramäischen: 'istraqlîta'; sum. zi-in-gi; akkad. kisallu, auch kursinnu, $\mathrm{AHw}^{2}$ 488. 511f; B. LANDSBERGER, WZKM 56 (1960), 127-129; vgl. (neu-)hebr. qars/șol ( $\left.\mathrm{HAL}^{3} 3,1069\right)$, aram. qars/sul(l)a, syr. qurșelä; vgl. auch hebr. bzw. aramä. grm: HAL $^{3}$ 1, 195; DISO 53; G. DALMAN, Aramäisch-Neuhebräisches Handwörterbuch (31938 = 1987), 87; M. JASTROW, Dictionary of the Targumim $(1903=1989)$, 269f; arab. ğim; AHw 326 (harmil): H. SCHMIDT - P. KAHLE (ed.), Volkserzählungen aus Palästina II (1930), Abb. 35 (Kinder in $B \vec{\imath} r$-Zêt, die mit Schafsastragalen spielen); Grabepigramm des Meleagros von Gadara auf Antipatris von Sidon in Anth. Graeca 7,428; auch J.J. HESS, Von den Beduinen des Innern Arabiens (Zürich - Leipzig 1938), 139f; P.G. BREWSTER, A Sampling of Games from Turkey, EW 11 (1960), 16; M. GRIAULE, Jeux et divertissements abyssins (1935), 110ff; E. LOVETT, The Ancient and Modern Game of Astragals, Folkl. 12 (1901), 280-289; B. ATTKEN, The Game of Knucklebone "Jugar a las tabas", Folkl. 62 (1951), 329.

2 Vgl. z.B. S. SALLER, Iron Age Tombs at Nebo, Jordan, LA 16 (1965-1966), 264; F. ZAYADINE, RB 75 (1968), 564; P.W. LAPP, The 1963 Excavations at Tacannek, BASOR 173 (1964), 35; ders., Taanach by the Waters of Megiddo, BA 30 (1967), 23; ders., The 1968 Excavations at Tell Tacannek, BASOR 195 (1969), 45-47; A.T. ClASON, Animals, in: G. VAN DER KOOU - M.M. IBRAHIM (ed.), Picking up the Threads... A Continuing Review of Excavations at Deir Alla, Jordan (Leiden 1989), 39, fig. 36; U. HÜBNER, Schweine, Schweineknochen und ein Speiseverbot im alten Israel, VT 39 (1989), 225236.

3 Vgl. z.B. R. ZIEGLER - J. BoESSNECK, Tierreste der Eisenzeit II, in: V. FRTTZ (ed.), Kinneret (1990), 134. 143. 151. 153f, Tab. 2 u.ö.; C.A. SCHAEFFER, Fouilles et découvertes des XVIIIe et XIXe Campagnes, 1954-1955, in: Ugaritica IV (MRS 15; BAH 74; Paris 1962), 103-105, fig. 64.

4 Vgl. z.B. R. ZIEGLER - J. BoESSNECK, in: V. FrITZ (ed.), Kinneret (1990), 134. 143. 151. 153f, Tab. 2 u.ö.; Taf. 44:1.

5 Vgl. z.B. Theophrast, char. 5,9 (dorkadeious astragalous) oder z.B. S. HELLWING, Human Exploitation of Ancient Animal Resources in the Early Iron Age Strata at Tel Beer-Sheba, in: Z. HERZOG (ed.), Beer-Sheba II (Tel Aviv 1984), 105-115, Table 15; F. VON LUSCHAN - W. ANDRAE, Die Kleinfunde von Sendschirli (Sendschirli V; Berlin 
häufig bearbeitet. Die zumeist bezeugte Art der Bearbeitung ist das Abschleifen der vorstehenden Kanten und das Abflachen und / oder Polieren der Langseiten ${ }^{7}$; damit wurde erreicht, daß bei der spielerischen Verwendung als Würfel und bei der kultischen Verwendung als Los die vier Langseiten etwa gleichmäßig häufig zum Stillstand kamen. Der auf diese Art bearbeitete Astragal war stets ein vierseitiger Würfel bzw. Los. Daneben konnten Astragale auch ein- oder mehrfach durchbohrt werden ${ }^{8}$; die Durchbohrungen wur-

1943), 122f, Abb. 173f, Taf. 59 p-q [geschliffene Spielsteine (aus Beuteln oder Kästchen) in Haufen zu 20 oder mehr Stück]. Vgl. auch allgemein F. PoPLIN, Contribution ostéoarchéologique à la connaissance des astragales de l'Antre Corycien, in: L'Antre Corycien II (BCH.S 9; Athen - Paris 1984), 381-393; R. ZIEGLER - J. BOESSNECK, in: V. FRITZ (ed.), Kinneret (1990), 154, Taf. 45:7.

6 Vgl. z.B. R. ZIEGLER - J. BOESSNECK, in: V. FrITZ (ed.), Kinneret (1990), 134. 143. 151. 153f, Tab. 2 u.ö., Taf. 44:1; F. ZAYADINE, RB 75 (1968), 564; P.E. MCGOWERN G.V. FOSTER, The Late Bronze and Early Iron Ages of Central Transjordan: The Baq$c_{\text {ah Valley Project, 1977-1981 (University Museum Monograph 65; Philadelphia/PN }}$ 1986), 271. 317-319, fig. 92, Pl. 34; R. POPPA, Kāmid el-Lōz 2: Der eisenzeitliche Friedhof. Befunde und Funde (SBA 18: Bonn 1978), 33. 61 (Gräber 2. 24 und 29).

7 Vgl. z.B. D.T. ARIEL, Excavations at the City of David 1978-1985, Vol. II (Qedem 30; Jerusalem 1990), 144, fig. 25; V.I. KERKHOF, Catalogue of the Shechem Collection in the Rijksmuseum van Oudheden in Leiden, OMRO 50 (1969), 85; H. LERNAU, Animal Remains, in: Y. AHARONI (ed.), Lachish V (Tel Aviv 1975), 87f. 91, Pl. 30:3.3a; W.J. BenNetT - J.A. Blakeley (ed.), Tell el-Hesi. The Persian Period (Stratum V). The Joint Archaeological Expedition to Tell el-Hesi Vol. 3 (ASOR Excavation Reports; Winona Lake/IN 1989), 286-288, fig. 213 ("gaming piece?"); R. ZIEGLER - J. BOESSNECK, in: V. FRTTZ (ed.), Kinneret (1990), 134. 143. 151. 153f, Tab. 2 u.ö., Taf. 45:7; P.L.O. GUY, Megiddo Tombs (OIP 33; Chicago 1938), 177, Pl. 115:11 (Tomb 251: 70 Stück, davon 2 bearbeitet); R.A.S. MACALISTER, Gezer III (1912), 11, Pl. 29:72; F.W.M. PETRIE, Ancient Gaza III. Tell el Ajjūl (London 1933), 11, Pl. 29:72; M. PEZARD, Qadesh. Mission archéologique à Tell Nebi Mend (BAH 15; Paris 1931), 59, Pl. 32, fig. 1:1; P.J. RIIS - M.-L. BUHL, Hama II 2. Fouilles et Recherches de la Fondation Carlsberg 19311938: Les objects de la Période dite Syro-Hittite (âge du fer) (Kopenhagen 1990), 216f, fig. 99:815f; F. VON LUSCHAN - W. ANDRAE, Die Kleinfunde von Sendschirli (1943), 122f, Abb. 173f, Taf. 59 p-q; H. GoldMan, Excavations at Gözlü Kule, Tarsus, Vol. II: From the Neolithic through the Bronze Age (Princeton/NJ 1956), 311. 318, Pl. 440: 116. 118 ("worn smooth from use as a polisher").

8 Häufig sind die Metallstifte verloren, aber wohl stets vorauszusetzen. Beispiele für durchbohrte Astragale ohne erhaltenen Metallstifte sind öfters bezeugt: z.B. R. ZIEGLER - J. BOESSNECK, in: V. FRITZ (ed.), Kinneret (1990), 134. 143. 151. 153f, Tab. 2 u.ö., Taf. 45:8; R.S. LAMON - G.F. SHIPTON, Megiddo I (OIP 42; Chicago/IL 1939), Pl. 77:10 (Stratum V); P.L.O. GuY, Megiddo Tombs (1938), 177, Pl. 115:24 (Tomb 258); R.M. BOEHMER, Die Kleinfunde aus Boğazköy aus den Grabungskampagnen 1931-1939 und 1952-1969 (Boğazköy-Hattuša 7; WVDOG 87; Berlin 1972), 181f, Taf. 65:1865-1881 (Spielwürfel und / oder Gewichte oder Anhänger); K. BITTEL - H.-G. GÜTERBOCK, 
den mit Metallstiften aus Eisen ${ }^{9}, K_{\text {Kupfer }}{ }^{10}$, Bronze oder Blei ${ }^{11}$ gefüllt und machten die überaus leichten Astragale schwerer, so daß sie besser und weiter geworfen bzw. gewürfelt werden konnten und gegebenenfalls auch - als gezinkte Astragale - häufiger auf die richtige Seite zum Liegen kamen. Daneben konnten Astragale auch geölt ${ }^{12}$, geometrisch (Abb. 14) ${ }^{13}$ oder figürlich ${ }^{14}$ verziert werden, z.T. waren sie auch bemalt ${ }^{15}$ oder markiert ${ }^{16}$ bzw. beschriftet ${ }^{17}$. Diese Verzierungen dürften nicht nur ästhetischen Gesichtspunkten entsprochen, sondern vor allem spiel- und kultpraktische Bedeutung besessen haben. Sie markierten die verschiedenen Seiten des Astragals und gaben so den einzelnen Würfen klar zuzuordnende Werte ähnlich den Zahlzeichen

Vorläufiger Bericht über die dritte Grabung in Boğazköy, MDOG 72 (1933), 27f, Abb. 12; H. Goldman, Excavations at Gözlü Kule, Tarsus, Vol. II (1956), 311. 318, Pl. 440:117; W.B. EMERY, The Royal Tombs of Ballana and Qustul (Mission Archéologique de Nubie 1929-1934; Kairo 1938), 347, Pl. 87:G, Cat.-No. 746 (Grab 50:2 in Ballāna / Nubien).

9 H.H. VON DER OSTEN, The Alishar Hüyük Seasons of 1930-1932, Part II (OIP 29; Researches in Anatolia 8; Chicago/IL 1937), 243. 427 (aus heth. und posthethitischer Zeit); ders., Part III (OIP 30; Researches in Anatolia 9; Chicago/IL 1937), 101, fig. 101 (2.Hälfte 1.Jt.v.Chr.); D.S. REESE, The Kition Astragali, in: V. KARAGEORGHIS (ed.), Excavations at Kition 5,2. The Pre-Phoenician Levels (Nikosia 1985), 287f.

10 F.W.M. PETRIE, Ancient Gaza III (1933), 11, Pl. 29:71; R.A.S. MACALISTER, Gezer III (1912), 11, P1. 29:71.

11 F. VON LUSCHAN - W. ANDRAE, Die Kleinfunde von Sendschirli (1943), 122f, Abb. 173f, Taf. 59 p-q; C.A. SCHAEFFER, in: Ugaritica IV (1962), 103-105, fig. 64; H.H. vON DER OSTEN, The Alishar Hüyük Seasons of 1930-1932, Part II (1937), 243. 427 (aus hethitischer und posthethitischer Zeit); ders., Part III (1937), 101, fig. 101 (2.Hälfte 1.Jt.v.Chr.); R.M. BOEHMER, Die Kleinfunde aus der Unterstadt von Boğazköy. Grabungskampagnen 1970-1978 (Boğazköy-Hattuša 10; Berlin 1979), 44, Taf. 27; K. BRAUN - Th.E. HAEVERNICK, Bemalte Keramik und Glas aus dem Kabirenheiligtum bei Theben (Das Kabirenheiligtum bei Theben IV) (Berlin 1981), 113f, Taf. 34:27ff.

12 T. ÖzGÜÇ, Kültepe Kazisi Raporu 1948. Ausgrabungen in Kültepe (TTKY 5,10; Ankara 1950), 207, Pl. 65:411f.

13 V.I. KERKHOF, OMRO 50 (1969), 84, fig. 25:28 (Flechtband-Verzierung).

14 F.W.M. PETRIE, Objects of Daily Use (1927), 57, Pl. 49:227.

15 A. STILlwell, The Potters' Quarter: The Terracottas (Corinth 15,2) (1952), 237, Nos. 7f, P1. 54 (aus Terrakotta, durchbohrt und bemalt).

16 Vgl. z.B. R.H. DornEmanN, The Archaeology of the Transjordan in the Bronze and Iron Ages (Milwaukee/WI 1983), fig. 68:403 (5d) ( ${ }^{c}$ Ammān); F.W.M. PETRIE, Objects of Daily Use (1927), 57, Pl. 49:230.232.

17 Vgl. z.B. IG XIV, Nr. 2419,8f; P. AMANDRY, Os et coquilles, in: L'Antre Corycien II (BCH.S 9; 1984), 370-375; D.M. RoBINSON, Excavations at Olynthus Part X. Metal and Minor Miscellaneous Finds (Baltimore/MD - London 1941), 503, Pl. 154. 
sechsseitiger Würfel: Im römischen Bereich wurde der höchste Wurfe Venus genannt, der niedrigste canis; der Verlierer konnte so leicht 'auf den Hund kommen'18. Außerdem konnten und können die an sich nahezu wertlosen Astragale durch Imitate aus Fayence ${ }^{19}$, Elfenbein ${ }^{20}$, Gold ${ }^{21}$, Bronze $^{22}$, Glas $^{23}$, Stein $^{24}$, Bernstein ${ }^{25}, \mathrm{Harz}^{26}$, Holz $^{27}$ oder Ton ${ }^{28}$ und seit unserem Jahrhundert

18 Vgl. z.B. Pollux 9,100; J. JÜTHNER, Die Namen der Astragalwürfe, JÖAI.Bh. 23 (1926), 105-116. Zum Würfeln mit Astragalen, Hexaedern etc. in seiner Bedeutung für die Vorgeschichte der Stochastik vgl. z.B. R. INEICHEN, "Die Wahrscheinlichkeit ist nämlich ein Grad der Gewißheit...", Bull. Soc. Fribourg Sc. Nat. 75 (1986), 59-93; ders., Schwierigkeiten mit dem Wahrscheinlichkeitsbegriff - ein Blick in die Geschichte, Zentralblatt für Didaktik der Mathematik 19 (1987), 103-107; ders., Didaktik und Elementarmathematik. Das Problem der drei Würfel in der Vorgeschichte der Stochastik, Elemente der Mathematik 42 (1987), 69-75; ders., Dante-Kommentare und die Vorgeschichte der Stochastik, Historia Mathematica 15 (1988), 264-269; ders., Modellbildung von Zufallsphänomenen im Laufe der Geschichte. Einige Illustrationen zur Didaktik der Stochastik, Der Mathematikunterricht 6 (1990), 41-49; K.-G. HAGSTROEM, Les préludes antiques de la théorie des probabilités (Stockholm 1932), 28ff; N.L. RABINOVITCH, Probability and Statistical Inference in Ancient and Medieval Jewish Literature (Toronto 1973), 21ff. 151 u.ö.

19. Vgl. z.B. P.L.O. GUY, Megiddo Tombs (1938), 177, Pl. 115:24 ("a model astragalus", mittelbronzezeitl. Grab 258).

20 Vgl. z.B. J.-W. MEYER, Spielbretter aus Kāmid el-Lōz, in: R. HACHMANN (ed.), Frühe Phöniker im Libanon. 20 Jahre deutsche Ausgrabungen in Kāmid el-Lōz (Mainz 1983), 130, Nr. 29 (KL 78:1045-47. 1049-51.1053); W.J. TArT, Game-Boxes and Accesso-

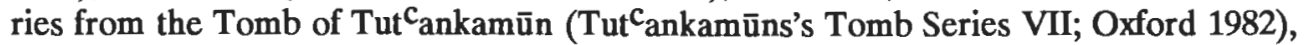
38-41, Pl. 10. 16; E.B. Pusch, Das Senetspiel im Alten Ägypten (MÄS 38; Berlin 1979), 200. 248, Taf. 46. 61f; S. LASER, Sport und Spiel (1987), 117, Anm. 580; Properz 2,24,13; Martial, epigr. 14,14.

21 Vgl. z.B. Sueton, Tib. 14; Apoll. Rhod., Argon. 3,117f; IG.EMi II-III² (1927), Nr. 1533:32: astragalion epichry/ (vergoldet?!).

22 Vgl. z.B. G.R. DAvidSON, The Minor Objects. Corinth 12 (Princeton/NJ 1952), 217-222, Pl. 100; K. BraUn - TH.E. HAEVERNICK, Bemalte Keramik und Glas aus dem Kabirenheiligtum bei Theben (1981), 113f, Taf. 34:27ff; M. COMSTOCK - C. VERMEULE, Greek and Roman Bronzes in the Museum of Fine Arts, Boston (Boston/MA 1971), 463f, Nr. 639 (römisch).

23 Vgl. z.B. G.R. Davidson, The Minor Objects. Corinth 12 (1952), 217-222, Pl. 100; K. BRAUN - TH.E. HAEVERNICK, Bemalte Keramik und Glas aus dem Kabirenheiligtum bei Theben (1981), 113f, Taf. 34:27ff; S. LASER, Sport und Spiel (1987), 117, Anm. 580 .

24 Vgl. z.B. K. BRAUn - TH.E. HAEVERNICK, Bemalte Keramik und Glas aus dem Kabirenheiligtum bei Theben (1981), 113f, Taf. 34:27ff; F.W.M. PETRIE, Objects of Daily Use (1927), 57, Pl. 49:226-229; S. LASER, Sport und Spiel (1987), 117, Anm. 580. 
durch Plastik ${ }^{29}$ ersetzt werden; ebenso konnten sie auch als motivische Vorlagen für Glücksbringer ${ }^{30}$ verwendet oder auch auf Schnüren zu Ketten und Peitschen bzw. Geißeln aufgezogen werden ${ }^{31}$. Astragale wurden aus der Hand, einem Würfel-Becher (griech. phimos, pyxis; latein. cornea, fritillus) ${ }^{32}$ oder einem Würfel-Turm (griech. pyrgos; latein. turriculum) ${ }^{33}$ geworfen; auf einem byzantinischen Mosaik in Daphne bei Antiochia / Orontes ist ein Würfelturm abgebildet (Abb. 19) 34 .

25 Vgl. z.B. K. BRAUN - Th.E. HAEVERNICK, Bemalte Keramik und Glas aus dem Kabirenheiligtum bei Theben (1981), 113f, Nr. 161.

26 W.J. TAIT, Game-Boxes and Accessories from the Tomb of Tut ${ }^{c}$ ankamūn (1982), 39f, Pl. 16:585v.

27 Anakreon, Frag. 82(54):2.

28 Vgl. z.B. H. CARNARVon - H. CARTER, Five Years' Explorations at Thebes. A Record of Work 1907-1911 (London u.a. 1912), 76, No. 17 (aus Grab 37); A.N. STILLWELL, The Potters' Quarter. The Terracottas (Corinth 15,2) (1952), 237, Nos. 7f, Pl. 54 (aus Terrakotta, bemalt und durchbohrt; aus dem "Circular South Shrine").

29 Vgl. z.B. R.M. BOEHMER, Die Kleinfunde aus der Unterstadt von Boğazköy (1979), 44.

30 K. PARLASCA, Einige singuläre Funde aus Petra, in: M. LINDNER - J.P. ZetrLer (ed.), Petra - Königin der Weihrauchstraße (1991), 131, Abb. 6.

31 B. NEUTSCH, Archäologische Grabungen und Funde im Bereich der unteritalischen Soprintendenzen von Tarent, Reggio di Calabria und Salerno (1949-1955), AA 1956, 215f, Abb. 14 (Grab in Tarent); D.C. KURTZ - J. BOARDMAN, Thanatos. Tod und Jenseits bei den Griechen (KAW 23; Mainz 1985), 247.

32 Der keilschriftliche Text auf dem Würfel des Jahälu setzt wahrscheinlich einen Würfelbecher o.ä. voraus (s.u. Kap. 7)! Vgl. allgemein A. MAU, Fritillus, RE 13 (1910), 108-110; W. BECHER, Oxybaphon, RE 36 (1942), 2021f und neben den zahlreichen ikonographischen Belegen [J. VÄTERLEIN, Roma ludens (1976), 12, Abb. 1] z.B. Aischines 1,59; Horaz, sat. 2,7,15; Martial, epigr. 4,14,8f; 11,6,2; 13,1,7; Anth. Lat. 193; Sidonius Apoll., ep. 17 (PL 58,548); Juvenal, sat. 14,5; Seneca, apocoloc. 14,4-15,1; Isidor von Sevilla, etym. 18,61. Auch K. VolKmanN, Das Becherspiel. Darstellungen des Zauberers in der bildenden Kunst (Düsseldorf 1954), $1 \mathrm{ff}$.

33 Vgl. z.B. Anth. Graeca 9,482,23f; Martial, epigr. 14,16; Sidonius Apoll., ep. 5,17,6; 8,12,5; Isidor, etym. 18,60f. Zu Originalfunden vgl. H.G. HoRN, Si per me misit, nil nisi vota feret. Ein römischer Spielturm aus Froitzheim, BJB 189 (1989), 139-160 (mit den beiden Inschriften "utere, felix, vivas!" und "pictos victos hostis deleta, ludite securi!", vgl. auch ILS 8626a) und W.B. EMERY, The Royal Tombs of Ballana and Qustul (1938), 344-346, fig. 111, Pl. 9:C; 87:B (Grab No. 3-98 in el-Qusțul / Nubien).

34 D. LEVI, Antioch Mosaic Pavements, Vol. I-II (Princeton/NJ - London - The Hague 1947), 326-337, fig. 136, Pl. 79b-c (Yakto Complec, Room B, Mosaic of Megalopsychia, Topographical Border). Ein weiterer ikonographischer Beleg bei H. STERN, Le 
Da man häufig mehr als ein oder zwei Astragale verwendete ${ }^{35}$, wurden sie gerne in geflochtenen, gewobenen oder ledernen Beuteln, Säckchen oder Körbchen (griech. phormiskos) aufbewahrt ${ }^{36}$. Darauf deuten die verschiedenen Haufen von z.B. $20^{37}, 50^{38}, 70^{39}, 120^{40}, 150^{41}$ oder mehr Astragalen in Gräbern und Wohnbereichen, die am besten erklärt werden können, wenn man annimmt, sie hätten in Säckchen oder Tüchern gesteckt, wie das auch durch zahlreiche Abbildungen aus dem griechischen und römischen Bereich belegt ist ${ }^{42}$. Der hošaen, die Brust- bzw. Orakeltasche des Hohenpriesters war

calendrier de 354. Étude sur son texte et ses illustrations (BAH 55; Paris 1953), 283ff, Pl. 13 (und 19).

35 M. Dothan, Ashdod II-III ('cAtiqot ES 9-10; Jerusalem 1971), 67, fig. 30:1; J. ELGAVISH, Archaeological Excavations at Shiqmona: Field Report I. The Levels of the Persian Period, Seasons 1963-1965 (Haifa 1968), Pl. 64:179 (hebr.); I.W. CoRNWALL, Collections of Animal Bones from Tombs of E.B.-M.B. Outsize Type, in: K.M. KENYON, Excavations at Jericho II (London 1965), 702f; P.J. RIIS - M.-L. BUHL, Hama II 2 (1990), 216f, fig. 99:815f; S. BEN-ARIEH - G. EDELSTEIN, Akko. Tombs near the Persian Garden ('Atiqot ES 12; Jerusalem 1977), 27, Pl. 8:5 (zwei Astragale = "game pieces" aus dem spätbronzezeitlichen Grab B3).

36 G.F. PINNEY, Money-bags?, AJA 90 (1986), 218.

37 P.W. LAPP, BASOR 195 (1969), 45-47; W.F. ALBRIGHT - J.L. KeLSO, The Excavation of Bethel (AASOR 39; Cambridge/MA 1968), 88 (22 Astragale); F. VON LUSCHAN - W. ANDRAE, Die Kleinfunde von Sendschirli (1943), 122f, Abb. 173f, Taf. 59 p-q. 9 Astragale z.B. bei Anth. Graeca 7,427.

38 R.A.S. MACALISTER, Gezer II (1912), 302: "In two or three places also, piles of the astragalus-bone of the sheep were used, polished smooth on the two plane sides; single specimens were likewise common. They were most frequent in the upper strata; close to the Maccabean Castle was found a pile of fifty such bones. These were no doubt used as playthings".

39 P.L.O. GUY, Megiddo Tombs (1938), 177, Pl. 115:11 (Tomb 251); P.W. LAPP, BASOR 173 (1964), 35 (76 Astragale); S. LLOYD, Beycesultan Vol. III,1: Late Bronze Age Architecture (London 1972), 12f, Pl. 6a (77 Astragale). Ein Schüler wird für besonders gute Schulleistungen mit 80 Astragalen belohnt, Anth. Graeca 6,308.

40 J.-B. HumberT - F. ZAYADINE - M. NAJJAR, Citadelle d'Amman, Jebel Qalach 1988-1989, LA 39 (1989), 252.

41 Vgl. z.B. F. ZAYADINE, RB 75 (1968), 564; P.W. LAPP, BASOR 173 (1964), 35, note 50 (643 Astragale); C. DAVARAS, Das Grab eines kretischen Wettkampfsiegers? Vorläufiger Grabungsbericht, Stadion 5 (1979), 199f, Abb. 8 (174 Astragale im Grab 12 der Nekropole von Lato pros Kamara in Ostkreta); C. RICCA, Locri epizephyrii, NSc 1913, Suppl. 11 (Rom 1914), 9-11, fig. 10 (587 Astragale in einem Grab in Locri).

42 Griech. kybēyia, kybesis, kibisis. Vgl. z.B. auch Platon, Lysis 206e; B. SCHMALTZ, Terrakotten aus dem Kabirenheiligtum bei Theben. Menschenähnliche Figuren, menschliche Figuren und Gerät (Das Kabirenheiligtum bei Theben V) (Berlin 1974), 141; 
wohl mit Astragalen, Würfel, Wurfstäbchen o.ä. gefüllt ${ }^{43}$. Astragale konnten natürlich auch in tönernen Gefäßen ${ }^{44}$ aufbewahrt werden, wie dies z.B. auf Hirbet el-Muhaiyit ${ }^{45}$, in Taanach ${ }^{46}$ oder in Megiddo $^{47}$ der Fall ist. Da eine Reihe von Astragal-Spielen mit mehreren Exemplaren gespielt wurden und die Astragale dabei gleichzeitig dazugewonnen oder eben auch verloren werden konnten, mußte jeder Spieler einen mehr oder weniger großen Vorrat davon stets bei sich haben. $\mathrm{Da}$ es dabei auch zu einer regelrechten Astragalomanie kommen konnte, zeigen verschiedene Grabfunde ${ }^{48}$.

Astragale wurden nicht nur unterschiedlich bearbeitet, sondern auch an ganz unterschiedlichen Orten gefunden, z.B. in Tempeln, Heiligtümern ${ }^{49}$ und

O. TOUCHEFEU-MEYNIER, Un nouveau "phormiskos" à figures noires, RAr 1972, 93102; R. HAMPE, Die Stele aus Pharsalos im Louvre (BWPr 107; Berlin 1951), passim [vgl. ders., Antikes und modernes Griechenland, ed. E. SIMON (KAW 22; Mainz 1984), 191-197]; vgl. auch F. VON LUSCHAN - W. ANDRAE, Die Kleinfunde von Sendschirli (1943), 122f, Abb. 173f, Taf. 59 p-q; M. RIEMSCHNEIDER, Spielbrett und Spielbeutel in Antike und Mittelalter, AEth 8 (1959), 309-326.

43 HAL $^{3}$ 1, 348; W. DOMMERSHAUSEN, hošaen, ThWAT 3 (1977-1982), 277-279; E. LIPINSKI, 'Urìm and Tummim, VT 20 (1970), 495f; STT I, No. 73; LKA Nr. 137; E. REINER, Fortune-Telling in Mesopotamia, JNES 19 (1960), 23-35 [akkad. aban (la) erē̌si].

44 R. De MecouenEm et al., Memoires de la Mission Archéologique en Iran 29. Mission des Susiane (Paris 1943), 48, fig. 40:9-12.

45 S. SALLER, LA 16 (1965-1966), 264 (Tomb 84).

46 P.W. LAPP, BASOR 173 (1964), 35 (20 Astragale "in a jug of cooking ware").

47 G. Loud, Megiddo II (1948), 44f, fig. 100-102, Pl. 285:5 (643 Astragale in einem Krater, Stratum V A ?), vgl. P.W. LAPP, BASOR 173 (1964), 35, note 50.

48 Vgl. z.B. auch R. HAMPE, Die Stele aus Pharsalos (1951), 16; D.M. RoBINSON, Excavations at Olynthus Part X (1941), 502-502; auch K.E. LøGSTRUP, Spielleidenschaft, RGG 5 (31962), 245-248; Horaz, epist. 1,18,21f.

49 O. TUFNELL - CH.H. INGE - L. HARDING, Lachish II. The Fosse Temple (London u.a. 1940), 39.94 ["used for divination" (?) aus Fosse Temple, Structure I); H. LERNAU, Animal Remains, in: Y. AHARONI (ed.), Lachish V (1975), 87f. 91, Pl. 30:3.3a; 32:1f; ders., Mammalian Remains, in: B. ROTHENBERG (ed.), The Egyptian Mining Temple at Timna. Researches in the Arabah 1959-1984, Vol. I (London 1988), 250; vgl. Cave I in Jerusalem H.J. FRANKEN - M.L. STEINER, Excavations in Jerusalem 1961-1967, Vol. II: The Iron Age Extramural Quarter on the South-East Hill (British Academy Monographs in Archaeology No. 2; Oxford u.a. 1990), 44; M. DUNAND, in: Archäologie und Altes Testament. FS für K. GALling (1970), 61-67; D.S. REESE, The Kition Astragali, in: V. KARAGEORGHIS (ed.), Excavations at Kition V,2 (1985), 282-291; Y. PAPAOIKONOMOU, BCH 105 (1981), 259, fig. 2 (römische Kinderstatue aus dem Asklepios-Tempel in Lissos/Kreta). Vgl. auch P.W. LAPP, BASOR 195 (1969), 45-47; J. BOESSNECK, Die Tierknochenfunde aus dem Kabirenheiligtum bei Theben (Böotien) (München 1973), 9, fig. 22-29; Anth. Graeca 6,309. 
Kirchen $^{50}$, privaten Wohnbereichen ${ }^{51}$ und Palästen ${ }^{52}$, Gräbern ${ }^{53}$ oder auf Schiffen ${ }^{54}$. Ethnologische Vergleiche sowie Abbildungen und literarische

50 M.-J. Chavane, Salamine de Chypre VI: Les petits objects (Paris 1975), (185-)189, Pl. 50:553; (51:547-552; 52:553-556).

51 Der allergrößte Teil des Fundmaterials von Kinneret stammt aus Wohnbereichen, R. ZIEGLER - J. BOESSNECK, in: V. FrITZ (ed.), Kinneret (1990), 134. 143. 151. 153f, Tab. 2 u.ö., auch wenn - wie in den meisten Grabungsberichten bei dem osteologischen Fundmaterial üblich - dort leider keine Locus-Angaben gemacht werden; R.W. HAMILTON, Excavations at Tell Abu Hawām, QDAP 4 (1934), 61, Pl. $32: 382$ (Stratum V = Spätbronzezeit II); E. GRANT, Rumeileh being Ain Shems Excavations III (Biblical and Kindred Studies 5; Haverford 1934), P1. $53: 45$ (storage room 316); ders. - G.E. WRIGHT, Ain Shems Excavations V (Biblical and Kindred Studies 8; Haverford 1939), 155 [storage room 316 (1933) IIa locus "used in gaming"]; vgl. auch R.H. DORNEMANN, The Archaeology of the Transjordan (1983), fig. 68:403 (5d) ( ${ }^{C} A m m \bar{a} n$ ); M. DOTHAN, Ashdod II-III (1971), 67, fig. 30:1; P.J. RIIS - M.-L. BUHL, Hama II 2 (1990), 216f, fig. 99:815f (zwei bearbeitete Stücke aus Bâtiment II).

52 C.A. SCHAEFFER, in: Ugaritica IV (1962), 103-105, fig. 64; J.-W. MEYER, in: R. HACHMANN (ed.), Frühe Phöniker im Libanon (1983), 101-104. 130, Kat.-Nr. 29; ders., Die Spielbretter KL 78:534 und KL 536 bis, in: R. HACHMANN (ed.), Bericht über die Ergebnisse der Ausgrabungen in Kāmid el-Lōz in den Jahren 1977 bis 1981 (SBA 36; Bonn 1986), 135f, Taf. 24:2; S. BÖKÖNYI, Tierknochen aus dem Bereich der Werkstatt von Kāmid el-Lōz, in: B. FRISCH et al., Kāmid el-Lōz 6. Die Werkstätten der spätbronzezeitlichen Paläste (SBA 33; Bonn 1985), 202, Tab. 27 [7 Stück aus Grube $028=$ Opferreste]; H. FrANKFORT et al., The Gimilsin Temple and the Palace of the Rulers at Tell Asmar (OIP 43; Chicago 1940), 213.

53 S. SALLER, LA 16 (1965-1966), 264; F. ZAYADINE, RB 75 (1968), 564; P.W. LAPP, BASOR 195 (1969), 45-47; I.W. CORNWALL, in: K.M. KENYON, Excavations at Jericho II (1965), 702f; P.L.O. GUY, Megiddo Tombs (1938), 177, Pl. 115:11.24 (Tombs 251. 258); F.W.M. PETRIE, Beth-Pelet I (Tell Fara) (London 1930), 8. 10-12, Pl. 36 (Tomb 201); R.A.S. MACALISTER, Gezer III (1912), 11, Pl. 36:19 u.ö.; S. BEN-ARIEH G.EDELSTEIN, Akko (1977), 27, Pl. 8:5 (Tomb B3); M.T. ForTUNA, Campagne di scavo ad Akko 1961-1962 (Memorie dell'Istituto Lombardo - Accademia di Scienze e Lettere, Classe di Lettere, Scienze morali e storiche 29,4; Milano 1966), 532, fig. 51 (hell. Grab 62,32); L.G. HARDING, Two Iron Age Tombs from ${ }^{c}$ Amman, QDAP 11 (1945), 68; P.E. MCGOWERN - G.V. FosTER, The Late Bronze and Early Iron Ages of Central Transjordan (1986), 271. 317-319, fig. 92, Pl. 34; TH. MACRIDY, Sépulture enfantine de Harah, RB 13 (1904), 361, PI. 5:12.14; P.J. RIIS, Hama II 3. Fouilles et Recherches de la Fondation Carlsberg 1931-1938: Les Cimetières à Crémation (Kopenhagen 1948), 35. 174-177, fig. 22; R. POPPA, Kāmid el-Lōz 2: Der eisenzeitliche Friedhof (1978), 33. 61 (Gräber 2. 24. 29); O. ReUTHER, Die Innenstadt von Babylon $(1926=1968), 156.163$ (Knaben-Grab); O.W. MuSCARELlA, The Iron Age at Dinkha Tepe, Iran, MMJ 9 (1974), 80f, note 21; H. CARTER, Tut-ench-Amun. Ein ägyptisches Königsgrab 3 (Leipzig 1934), 146. 157, Taf. 40; vgl. W.J. TAIT, Game-Boxes and Accessories from the Tomb of Tut ${ }^{c}$ ankamūn (1982), 38-41; V. KARAGEORGHIS, Excavations in the Necropo- 
Quellen aus Nachbarkulturen zeigen, daB sie zu sehr unterschiedlichen Zwecken verwendet werden konnten.

Überall, wo Tiere geschlachtet bzw. gegessen wurden, fielen Astragale an. Der Gastgeber, den Astragalspiele störten, mußte also dafür sorgen, daB er seinen Gästen kein Essen vorsetzte, bei dem Astragale abgenagt und dann als Spielzeug verwendet werden konnten (Plautus, mil. glor. 163f). Ein Teil des Fundmaterials stellt somit nichts anderes als Speise- 55 oder Opferreste dar ${ }^{56}$, aus denen jederzeit Spiel- bzw. Losastragale bezogen werden konnten. Ein anderer Teil des Materials, in jedem Fall aber die bearbeiteten Astragale, können aufgrund ethnologischer Parallelen und aufgrund der literarischen und ikonographischen ${ }^{57}$ Quellen der Nachbarkulturen als Spielwürfel ${ }^{58}$ und /

lis of Salamis II (London 1970), 56, Pl. 109:10-13 (Tomb 27A); ders., A Late Cypriote Tomb at Tamassos, RDAC 1965, 19, No. 80; P. DuCos, Le jeu d'osselets de la tombe 6 de Politico, RDAC 1965, $28 f$.

54 G.F. BASS, Cape Gelidonya. A Bronze Age Shipwreck (TAPhS NS 57,8; Philadelphia/PA 1967), 132f, fig. 139. 143. Mit welchen Gegenständen die Matrosen auf dem Schiff von Jafo nach Tarschisch das Los über Jona bestimmt haben, geht aus dem alttestamentlichen Text nicht hervor (Jona 1,7).

55 Vgl. z.B. S. HellwiNG, Faunal Remains from the Early Bronze and Late Bronze Ages at Tel Kinrot, TA 15-16 (1988-1989), 212-220; ders. - N. FEIG, Animal Bones, in: Z. Herzog et al. (ed.), Excavations at Tel Michal, Israel (Minneapolis/MN - Tel Aviv 1989), 240, Tables 22.9ff; E. TCHERNOW - I. DRORI, Economic Patterns and Environmental Conditions at $\underline{\text { Hirbet }} e$ l-M $\ \bar{a} \$ during the Early Iron Age, in: V. FRTTZ - A. KEMPINSKI (ed.), Ergebnisse der Ausgrabungen auf der Hirbet el-M $\ \bar{a} \breve{s}$ (ADPV; Wiesbaden 1983), 221f, Table 3, Pl. 118:1-3: 119:14; S. HELlWING - Y. ADJEMAN, Animal Bones, in: I. FINKELSTEIN (ed.), c'Izbet Șartah. An Early Iron Age Site near Rosh $\mathrm{Ha}^{c_{a y i n} \text { Is- }}$ rael (BAR.IS 229; Oxford 1986), 146, Table 8.6; A. VON DEN DRIESCH - J. BOESSNECK, Reste von Haus- und Jagdtieren aus der Unterstadt von Boğazköy-Hattuša 1958-1977 (Bogazköy-Hattuša 11; Berlin 1981), 66, Taf. 11:36.

56 S. BöKÖNYI, in: B. FRISCH et al., Kāmid el-Lōz 6 (1985), 202, Tab. 27 (7 Stück aus Grube $028=$ Opferreste); E.A. SPEISER, Excavations at Tepe Gawra, Vol. I: Levels IVIII (Philadelphia/PN 1935), 33.

57 Vgl. z.B. Polyklet, astragalizontes (Plinius d.Ä., nat. hist. 34,55) (verloren) [vgl. z.B. CH. PiCARD, Les Antécédents des "Astragalizontes" Polyclétéens et la consultation par les dés, Rev.Et.Gr. 42 (1929), 121-136; A. BrUECKNER, Polyklets Knöchelwerfer (BWPr 77; Berlin 1920), passim] oder das Marmorbild des athenischen Malers Alexandros aus Herculaneum (Neapel, Nat. Mus. Inv.-Nr. 9562) aus dem 1.Jh.v.Chr. (aufgrund älterer Vorlagen), vgl. z.B. TH. Kraus - L. von MATT, Lebendiges Pompeji (Köln 1973), 201, Nr. 284; C. RoBERT, Die Knöchelspielerinnen des Alexandros (HWPr 21; Halle 1897), passim; H. MIELSCH, Zur Deutung und Datierung der Knöchelspielerinnen des Alexandros, MDAI.R 86 (1979), 233-248, Taf. 49-57. 
oder als Loswürfel interpretiert werden. Eine eindeutige Grenze zwischen beiden ist aufgrund dieser Doppelfunktion nicht zu ziehen ${ }^{59}$ : Von dem Heiligtum des Geryon beim illyrischen Patavium berichtet Sueton (Tib. 14), daß der römische Kaiser Tiberius dort mit goldenen Astragalen (tali) ein Orakel eingeholt habe; daß die Astragale die höchste Zahl zeigten, war ihm ein Zeichen seiner großen Zukunft. Auf dem Revers von Münzen des 3.Jh.s n.Chr. aus Ephesos, Samos, Hierapolis, Hypaipa, Aphrodisias u.a. sind Kinder abgebildet, die vor einer Statue der Artemis und Aphrodite bzw. des Apollo mit Astragalen spielen, also innerhalb des Kultes zur Ausrichtung der Astragalomantik eingesetzt wurden (Abb. 15) ${ }^{60}$. Von dem achäischen Höhlen-Heiligtum bei Buraïkos schreibt Pausanias $(7,25,10)$, daß man dort mit Hilfe von Astragalen und einer Deute-Tafel Orakel erhalten konnte: "Wer den Gott (=Herakles) befragen will, betet vor der Statue, und nach dem Gebet nimmmt er vier Astragale, die reichlich beim Herakles liegen, und läßt sie auf den Tisch fallen. Der zu jeder Astragal-Figur auf einer Tafel verzeichnete passende Wortlaut liefert die Erklärung der Figur". In einigen arabischen Losbüchern, die von präislamischen bzw. antiken Traditionen mitgeprägt sind, werden die Städte Gaza, Hebron, Jerusalem, Nāblus und Șafed regelmä-

58 E. SEllin - C. WATZiNGer, Jericho (1913 = 1973), 155, Nr. 21, Abb. 189: "wohl zum Spielen dienend".

59 Vgl. z.B. K. BITTEL - H.-G. GÜTERBOCK, MDOG 72 (1933), 27f, Abb. 12 (Astragale für Würfelspiel, durchbohrte Astragale für Schmuck); H.-G. BUCHHOLZ, in: S. LASER (ed.), Sport und Spiel (1987), 181ff. Zu den Astragalen im griechischen und römischen Bereich vgl. z.B. L. BECQ DE FOUQUIERES, Les jeux des anciens (Paris 1873), 325-356; L. DEUBNER, Antike 6 (1930), 173f, Abb. 24; ders., Zum Astragalspiel, AA 44 (1929), 272-281; A. HUG, RE III A 2 (1929), 1764-1778; J. JÜTHNER, JÖ̈AI.Bh. 23 (1926), 105-116; H. LAMER, RE 13,2 (1927), 1933-1935. 2020f u.ö.; O.W. REINMUTH, Astragalos, KP 1 (1975), 659f; H. LECLERQ, Jeux et Jouets, DACL 7,2 (1927), 25222524, fig. 6253ff; F.W.M. PETRIE, Objects of Daily Use (1927), 57, P1. 49:229; A. MAU, Astragalos, RE II 2 (1896), 1793-1795; M. ALINE DE SION, La Forteresse Antonia à Jérusalem et la Question du Prétoire (Paris 1956), 120ff; S. KRAUSS, Talmudische Archäologie III (1912), 108. 111; S. LASER, Sport und Spiel (1987), 117-122; S. MENDNER, RAC 10 (1978), 849. 854. 872; B. NEUTSCH, Spiel mit dem Astragal, in: Ganymed. Heidelberger Beiträge zur antiken Kunstgeschichte, ed. R. HERBIG (Heidelberg 1949), 1828; F.V. GRUNFELD, Spiele der Welt (1979), 162f; G. ROHLFS, Antikes Knöchelspiel im einstigen Großgriechenland. Eine vergleichende historisch-linguistische Studie (Tübingen 1963), 1ff; J. TAILlaRDaT (ed.), Suétone. Peri paidiōn (1967), Nr. 1; Isidor von Sevilla, etym. 18,60ff; auch S. MARINATOS - M. HIRMER, Kreta, Thera und das mykenische Hellas (31976), 1436f, Abb. 113 (spätmino. I); M. LEHMANN-FILHES, Vielseitige Verwendung der Schafknochen in Island, ZVVK 19 (1909), 434: "Astragalus, ... der in Island als Wahrsageknochen... den Namen 'vala' führt".

60 F. IMHOOF-BLUMER, Beiträge zur Erklärung griechischer Münztypen IV: Knöchelspiel vor Kultbildern, Nomisma 6 (1911), 4-7, Taf. 1:8-16. 
Big genannt ${ }^{61}$. Auch die Interpretationen von Astragalen und Würfeln in der Traumdeutung weisen auf ihre Doppelfunktion hin ${ }^{62}$. Neben den üblichen Würfeln gab es auch eigene Los- oder Orakel-Würfel mit entsprechenden Sprüchen, Gebetstexten (vgl. den Würfel des Jahāalu) oder Symbolen ${ }^{63}$.

$\mathrm{Zu}$ den wenigen ikonographischen Belegen für Astragalspieler und -spielerinnen aus Palästina gehören zwei Bullen des 4.Jh.s v.Chr. aus dem Wädi edDāliye: Die eine zeigt zwei knieende Gestalten - wahrscheinlich ein bärtiger Sartyr und eine nackte Nymphe - , die mit fünf Astragalen pentelith $a^{64}$ spielen

61 G. WEIL, J.G. Wetzsteins freie Nachdichtung eines arabischen Losbuches, MSOS 31 (1928), 1-69. Allgemein auch J. BOLTE, Zur Geschichte der Losbücher, in: G. WICKRAM, Werke 4, ed. J. BOLTE (Tübingen 1903 = Hildesheim u.a. 1974), 276-348.

62 Artemidor 3,1; Das Arabische Traumbuch des Ibn Sirin, ed. H. KLOPFER (München 1989), 124.

63 Vgl. z.B. F. HeINEVETTER, Würfel- und Buchstabenorakel in Griechenland und Kleinasien (Breslau 1912), 1ff; G. KAIBEL, Ein Würfelorakel, Hermes 10 (1876) 193-202 (griech. beschrifteter Würfel aus dem pamphylischen Attalia) oder P. PERDRIZET, Le jeu alexandrin de l'icosaèdre, BIFAO 30 (1931), 1-16, Pl. If (u.a. ein griech. beschrifteter, zwanzigseitiger Bronzewürfel aus dem hell. Ägypten, der vielleicht aus jüdischen Kreisen Alexandrias stammt); auch R. HEBERDEY, $\mathrm{Zu}$ den kleinasiatischen Astragalenorakeln, WSt 50 (1932), 82-95; ders., Tituli Asiae Minoris III 1: Tituli Pisidiae (Wien 1949), 23-36; J. NoLlE, Südkleinasiatische Losorakel in der römischen Kaiserzeit, AW 18,3 (1987), 41-49.

64 Das 'Fünfstein-Spiel' (pente/alitha / pentebola / pentelithizein), das ikonographisch auch für Palästina belegt ist [M.J.W. LEITH, Greek and Persian Images in Pre-Alexandrine Samaria (1990), 58. 268-284. 492, Pl. 27:1 (WD 44 / Rm 941)], ist ein Geschicklichkeitsspiel, das von zwei Spielern gespielt; der Geschicktere ist der Gewinner: Dabei werden fünf Astragale (oder Nüsse o.ä.) hochgeworfen und müssen mit dem Handrücken aufgefangen werden; die nicht aufgefangenen Astragale müssen mit den Fingern der Hand aufgesammelt werden, auf der ein Teil der Astragale liegt. Vgl. vor allem Pollux 9,126; auch L. BECQ DE FOUQUIERES, Les jeux des anciens ( $\left.{ }^{2} 1873\right), 51-54$; L. GRASBERGER, Erziehung und Unterricht im klassischen Alterthum I 1 (1864), 71-74. 159; R. SCHMIDT, Die Darstellung von Kinderspielzeug und Kinderspiel (1977), 49-53. 55f; R. HAMPE, Die Stele aus Pharsalos (1951), passim; H. LAMER, Das Fünfsteinspiel, Philologische Wochenschrift 48 (1928), 571-576; TH. KRAUS - L. VON MATT, Lebendiges Pompeji (Köln 1973), 201, Nr. 284; E. LEMKE, Das Fangsteinchenspiel, ZVVK 16 (1906), 46-66; J. MÜllER, Das Fangsteinchenspiel in den Rheinlanden, ZVVK 28 (1918), 26-41; P.G. BREWSTER, A Collection of Games from India, with some Notes on Similar Games in other Parts of the World, ZE 80 (1955), 98f; ders., EW 11 (1960), 15; S. PAUL, Afrikanische Fangsteinchenspiele, ZE 96 (1971), 32-70; G. RoHLFS, Antikes Knöchelspiel im einstigen Großgriechenland (1963), 10; C. NIEBUHR, Reisebeschreibung nach Arabien, Bd. $1(1774$ = 1968), 171; R.M. BOEHMER - N. WREDE, Astragalspiele in und um Warka, BaghM 16 (1985), 399-404. 
(Abb. 16); die andere Bulle zeigt einen knieenden geflügelten Eros, der wahrscheinlich ebenfalls mit Astragalen spielt (Abb. 17) ${ }^{65}$. Zu den bekanntesten ikonographischen Belegen ${ }^{66}$ des Alten Orients gehört das späthethitische Orthostatenrelief aus Karkemisch ${ }^{67}$ (Abb. 18): Zwei Prinzen [Söhne des Königs (?) Iariri $\left.{ }^{68}\right]$ spielen im Hocken miteinander mit Astragalen.

Ethnologische Belege ${ }^{69}$ und Kulturvergleiche zeigen, daß man mit Astragalen verschiedene Arten von Glücks-, Geschicklichkeits- und Ratespielen spielte. So konnte mit Astragalen (oder Nüssen, Eicheln u.a.) z.B. ōmilla ge-

Zum 'Meistwurf-Spiel' pleistobolinda vgl. Pollux 7,206; 9,95f. 117; R. HAMPE, Die Stele aus Pharsalos im Louvre (1951), passim; S. LASER, Sport und Spiel (1987), 119-121; R. SCHMIDT, Die Darstellung von Kinderspielzeug und Kinderspiel (1977), 45-49. 55; R.M. BOEHMER - N. WREDE, BaghM 16 (1985), 399-404.

65 M.J.W. LErTH, Greek and Persian Images in Pre-Alexandrine Samaria (1990), 209218. 492, PI. 21:1 (WD 40 / RM 937).

66 Vgl. auch die Darstellungen auf jüdischen Öllampen römischer Zeit: V. SUSSMAN, Ornamented Jewish Oil-Lamps from the Destruction of the Second Temple through the Bar-Kokhba Revolt (Warminster - Jerusalem 1972), 97f, Nos. 171-173; dies., Astragal Menorah on Clay Lamps, Qad. 13 (1980), 119-121 (hebr.); auch F.A.G. BECK, Album of Greek Education (1975), 53, Nos. 342-345.

67 Ankara, Arkeologji Müzesi, Inv.-Nr. 92: D.G. HoGARTH, Carchemish I (London $1914=1969)$, Pl. B 7b; W. ORTHMANN, Untersuchungen zur späthethitischen Kunst (1971), 18. 33. 35. 135. 510. 556, Taf. 31:f; 71:f [Karkemis (IV) G/6]; ders., Der Alte Orient (PKG 14; Berlin 1975), 431, Taf. 359; K. BrTTEL, Die Hethiter (1976), Abb. 295; E. AKURGAL, Die Kunst der Hethiter (München ${ }^{2} 1976$ ), 97. 117, Taf. 122; S. LASER, Sport und Spiel (1987), 134, Abb. 49b. Zu den hieroglyphischen Beischriften, die keine Auskünfte zu den Spielen geben, vgl. vor allem P. MERIGGI, Manuale di Eto Geroglifico, Parte I: Testi - $1^{\text {a }}$ Serie. I testi neo-etei più o meno completo (Incunabula Graeca 14; Rom 1967), 19-23, No. 9; J.D. HawkINS, Some Historical Problems of the Hieroglyphic Luwian Inscriptions, AnSt 29 (1979), 157-162; R. WERNER, Kleine Einführung ins Hieroglyphen-Luwische (OBO 106; Fribourg - Göttingen 1991), 63, fig. 33.34 h.i., Nr. 33 h.i.

68 Zum unklaren Status des Iariri vgl. zusammenfassend J.D. HAWKINS, AnSt 29 (1979), 157-162; ders., Karkamis, RIA 5 (1976-1980), 442-445.

69 Arab. $k a^{c} b$; ${ }^{c} c_{\text {chet }}$ ěs-šakk. Vgl. z.B. L. BAUER, Volksleben im Lande der Bibel (Leipzig 21903), 74f; R.M. BoEHMER, Die Kleinfunde aus der Unterstadt von Boğazköy (1979), 44; ders. - N. WREDE, BaghM 16 (1985), 399-404; C. NIEBUHR, Reisebeschreibung nach Arabien, Bd. 1 (1774 = 1968), 172; G. RoHLFS, Antikes Knöchelspiel im einstigen Großgriechenland (1963), 7ff; C.A. SCHAEFFER, in: Ugaritica IV (1962), 103-105; J. HILls, Das Kinderspielbild von Pieter Bruegel d.Ä. (1957), 4-7, Nr. 1 (drei Mädchen). 
spielt werden ${ }^{70}$, das darin bestand, nach anderen Astragalen zu werfen, die sich in einem Kreis befanden, oder auch tropa (orca) ${ }^{71}$, eine Art Klicker- oder Murmeln-Spiel ${ }^{72}$, das darin bestand, die Astragale o.ä. in eine Vertiefung oder aber in ein Gefäß zu werfen. Eine andere Form war eine Ratespiel, das bei Griechen bzw. Römern artiazein bzw. ludere par impar (vgl. posinda ${ }^{73}$ ) ge-

70 Vor allem Pollux 9,102; Suidas 3,610 (ed. A. ADLER). Vgl. z.B. E. BERNERT - W. KROLL, Omilla, RE 35,1 (1939), 379; L. GRASBERGER, Erziehung und Unterricht im klassischen Alterthum I 1 (1864), 65-67. 158; R. SCHMIDT, Die Darstellung von Kinderspielzeug und Kinderspiel (1977), 53f. 56; G. ROHLFS, Antikes Knöchelspiel im einstigen Großgriechenland (1963), 10.

71 Vor allem Pollux 9,103; Martial, epigr. 4,14,9; 5,84; 14,1; 14,19; Anth. Graeca 12,212; 14,116.138; Seneca, de const. sap. 12,2; Catull, carm. 61,132ff; Augustin, conf. 1,19; Photios, Lex. p. 606,8; Persius, sat. 3,50; Schol. Platon Lys. 206e (p. 320) und Nux 85f. Vgl. z.B. A. SCHMTT, Spielen, wie die Römer spielten, in: Jahresbericht des BeethovenGymnasiums Bonn 1977/78, 17; L. BECQ DE FOUQUIERES, Les jeux des anciens (21873), 114-118; R. SCHMIDT, Die Darstellung von Kinderspielzeug und Kinderspiel (1977), 54-56; L. GRASBERGER, Erziehung und Unterricht im klassischen Alterthum I 1 (1864), 68f. 158f; K. SCHNEIDER, Tropa, RE 13,2 (1939), 660f; M. ALINE DE SION, La Forteresse Antonia à Jérusalem (1956), 121. 127; L. BAUER, Volksleben im Lande der Bibel (21903), 74; auch S. MENDNER, RAC 10 (1978), 867f. 889; E.J. BANKS, Bismya or The Lost City of Adab (1912), 411 "The boys sailed tiny boats on the canal, hurled limps of clay in slings, made windwheels, played marbles, and threw dice. I have seen a ball game in the desert, a game of tag, and leap-frog. A common game is to throw nuts at a mark, and the lucky boy hits it, has all the nuts the other have thrown".

72 Auch Marmeln, Klicker, Schusser oder Ömmer genannt (latein. wohl pilula), d.h. Spielkugeln aus Glas, Ton, Stein u.a. (an deren Stelle auch mit Nüssen, Bohnen, Kastanien, Knöcheln o.ä. gespielt werden konnte): z.B. Augustin, conf. 1,19,30; F. RoSENTHAL, Gambling in Islam (1975), 60f; F. KLEPZIG, Kinderspiele der Bantu (1972), $89 f$ u.ö.; K. GRÖBER - J. METZGER, Kinderspielzeug aus alter Zeit ( $\left.{ }^{2} 1965\right)$, 106. 212, Nr. 2; F.V. GRUNFELD, Spiele der Welt (1979), 158-160; J. HILLS, Das Kinderspielbild von Pieter Bruegel d.Ä. (1957), 47f, Nr. 62; W. MOHR, Murmelspiel. Ein Experiment, in: FS für J. TrueR zum 70.Geb., ed. W. FOERSTE - K.-H. BORCK (Köln - Graz 1964), 47-68; F.M. BöHME, Deutsches Kinderlied und Kinderspiel $(1897=1967), 615 f, \mathrm{Nr}$. 484; I. WEBER-KELLERMANN - R. FALKENBERG (ed.), Was wir gespielt haben (1992), 33ff; F.K. MATHYS, Im Freien gespielt (1975), 5-7; R. HOLLER, Murmeln, Schusser, Klicker (München 31990), passim; J. PIAGET, Das moralische Urteil beim Kinde (Zürich 1954), 10ff; auch J. KolleSCH, Aristoteles, De motu anim. 701b 2-9, Ph. 104 (1960), $143 f$ (griech. Kylindroi-Spiel).

Zum Spiel mit Ball-großen Kugeln vgl. F. HÜBNER - U. KOCH, Boule, Pétanque, Boccia (homo ludens; München 1988), passim.

73 Vgl. z.B. Aristophanes, Plutos 1055ff; Aristoteles, rhet. 3,5; Pollux 7,206; L. GRASBERGER, Erziehung und Unterricht im klassischen Alterthum I 1 (1864), 154; K. SCHNEIDER, Posinda, RE 43 (1953), 830f. 
nannt wurde: Ein Spieler, sei er Sklave ${ }^{74}$ oder Kaiser ${ }^{75}$, verbirgt einer Anzahl kleiner Gegenstände, z.B. Astragale ${ }^{76}$ oder auch Nüsse ${ }^{77}$, in den Händen; der Gegenspieler muß erraten, ob ihre Zahl gerade oder ungerade ist. Hatte er recht, gewann er die Gegenstände; hatte er falsch getippt, mußte er seinem Mitspieler ebenso viele geben ${ }^{78}$. Die einfachste Art war, einen Astragal als einfachen, vierseitigen Würfel zu benutzen, und zwar allein beim reinen Würfelspiel ${ }^{79}$ oder aber als Würfel für eines der Brettspiele ${ }^{80}$ oder andere Spiele.

Mit Astragalen und Würfeln spielten Lebende und Tote ${ }^{81}$, Götter ${ }^{82}$, Könige $^{83}$ und Helden ${ }^{84}$ ebenso wie gewöhnliche Sterbliche, Männer und Frauen $^{85}$, Knaben und Mädchen ${ }^{86}$, jung und alt ${ }^{87}$. Darius III. soll Alexander

\author{
74 Aristophanes, Plutos 816. \\ 75 Sueton, Aug. 71. \\ 76 Vgl. z.B. Platon, Lysis 206e; vgl. Schol. Plat. Lysis $206 \mathrm{e}$. \\ 77 Vgl. z.B. Horaz, sat. 2,3,248.
}

78 Vor allem Pollux 7,105; 9,101; Nux 79f; Platon, Lysis 206e; Aristophanes, Plutos 816; Horaz, sat. 2,3,248; Sueton, Aug. 71; Aristoteles, rhet. 3,5,4. Vgl. auch L. BECQ DE FouquiERES, Les jeux des anciens (21873), 284-289; L. GRASBERGER, Erziehung und Unterricht im klassischen Alterthum I 1 (1864), 143-145; A. MAU, Artiazein, RE 2 (1896), 1149; S. MENDNER, RAC 10 (1978), 856. 867; G. ROHLFS, Antikes Knöchelspiel im einstigen Großgriechenland (1963), 10; J. VÄTERLEIN, Roma ludens (1976), 35f; F.M. BÖHME, Deutsches Kinderlied und Kinderspiel $(1897=1967)$, 635, Nr. 530; M. GRIAULE, Jeux et divertissements abyssins (1935), 186ff; A. LuKACSY, Spiel der Welt (1972), 85f.

79 Vgl. z.B. Pollux 9,99; Eustathios, Il. 1289,50; ders., Od. 1397,35.

80 F.W.M. PETRIE, Beth-Pelet I (1930), 8. 10-12, Pl. 36 (Tomb 201: in gleichem Grab wie ein Felderspiel); J.-W. MEYER, in: R. HACHMANN (ed.), Frühe Phöniker im Libanon (1983), 130, Nr. 29 (KL 78:1045-1047. 1049-1051. 1053); ders., in: R. HACHMANN (ed.), Bericht über die Ergebnisse der Ausgrabungen in Kāmid el-Lōz in den Jahren 1977 bis 1981 (1986), 135f, Taf. 24:2.

81 Vgl. die Astragal-Funde in Gräbern; z.B. auch Anth. Graeca 7,427.

82 Sophokles, frg. 809; Lukian, dial. deorum 4,3f; 5,2; Apoll. Rhod., Argon. 3,117ff; Anakreon 111(34):1; Meleagros von Gadara, in: Anth. Graeca 12,47.

83 Vgl. z.B. Plutarch, Anton. 29. Der römische Kaiser Claudius, ein leidenschaftlicher Würfelspieler (Sueton, Claudius 33), wurde in der Unterwelt dafür bestraft, daß er ähnlich wie Sisyphos - unentwegt Würfel spielen mußte mit einem Würfelbecher ohne Boden, so jedenfalls Seneca, Apocol. (12,3). 14,3f.

84 Vgl. z.B. Philostrat, Heroik. 19,2 (KAYSER).

85 Mädchen und Frauen: vgl. Grabinventare; Pausanias 6,24,7; 10,30,2; Ovid, ars amat. 3,353-380; J. DöRIG, Tarentinische Knöchelspielerinnen, MusHelv 16 (1959), 29-58. Knaben und Männer: vgl. Grabinventare; Aristophanes, vesp. 293ff; Polybios, hist. 39,2; Pausanias 6,24,7. 
d.Gr. einen Brief nach Phönizien gesandt und ihm darin angekündigt haben, er werde ihn mit Astragalen und einer Klapper zu seiner Mutter nach Makedonien zurückschicken88; König Magas von Kyrene demütigte den Dichter Philemon, indem er ihm offentlich Astragale und einen Ball als Zeichen der Infantilität überreichte (Plutarch, de coh. ira 9) ${ }^{89}$.

Zuweilen konnte es geschehen, daß Spieler - nicht nur bei Betrügereien ${ }^{90}$ so in Streit gerieten ${ }^{91}$, daB Freundschaften zerbrachen ${ }^{92}$ und es zu Mord und Totschlag ${ }^{93}$ und entsprechenden Verurteilungen kam $^{94}$; oder sie erlagen ihrer

86 Vgl. z.B. Aristophanes, vesp. 293ff; Anth. Graeca 6,308f; 12,44.46; Artemidor 3,1; Lukian, dial. deorum 4,3; 5,2; Pausanias 10,30,2; Platon, Lysis 206e; Plutarch, Alkibiades 2,15; ders., de coh. ira 9; ders., Lys. 8,5; auch Kinder-Gräber und das Relief aus Karkemisch; H. RÜHFEL, Das Kind in der griechischen Kunst (1984), 248-252, Abb. 105; J. VÄTERLEIN, Roma ludens (1976), 37f, Abb. 13; K. GRÖBER - J. METZGER, Kinderspielzeug aus alter Zeit (21965), 106. 212, Nr. 1 ("Griechische Mädchen beim Knöchelspiel", Ethnograph. Museum Neuchâtel); H. HEYDEMANN, Die Knöchelspielerin im Palazzo Colonna zu Rom (HWPr 2; Halle 1897), passim; P.R. FRANKE - M. HIRMER, Die griechische Münze (München 21972), 141, Taf. 194:674 (Stater des 4.Jh.s v.Chr. aus Tarsus). Einzelne Astragale als Stadt- bzw. Glückssymbole u.ä. sind auf Münzen z.B. aus Athen, Eleusis, Rhodos, Kyzikos, Selge/Pisidien, Tarsus oder Idalion, Kition und Paphos auf Zypern häufig belegt.

87 Vgl. z.B. Horaz, sat. 2,7,15.

88 Leben und Taten Alex.s von Makedonien (ed. H. VAN THIEL), 1,39,3.

$89 \mathrm{Zu}$ Astragalen als Symbolen für Kinder vgl. auch Pausanias 6,24,7.

90 Vgl. z.B. Prov. 26,19 (mśhq, paizōn, ludens); Apollonios Rhodios, Argon. 3,117-130; Plutarch, Lys. 8,5; Augustin, conf. 1,19,30; 'Cyprian', CSEL 54,3 (1871), 92-104 mit A. HARNACK, Der pseudocyprianische Tractat de aleatoribus (TU 5,1; Leipzig 1888), 11ff; W.G. BRAUDE, The Midrash on Psalms I (New Haven/CT 199), 364; Th. KRAUS - L. VON MATT, Lebendiges Pompeji (1973), Abb. 222. 224; auch das Bild 'Il baro' von M. Caravaggio (Rom 1594). In einem pompeianischen Graffito wird eigens betont, daß der Gewinn beim Würfelspiel mit gutem Gewissen (fide bona) zustande gekommen sei, H. GEIST (ed.), Pompeianische Wandinschriften (1936), 76f.

91 'Cyprian', CSEL 54,3 (1871), 92ff mit A. HARNACK, Der pseudocyprianische Tractat de aleatoribus (1888), 11ff; Artemidor 3,1; Das Arabische Traumbuch des Ibn Sirin, ed. H. KLOPFER (1989), 124: "würfeln bedeutet Streit". Vgl. auch J. KNOBLOCH, Griech. kindynos m. 'Gefahr' und das Würfelspiel, Glotta 53 (1975), 78-81.

92 Plutarch, de coh. ira 14. Vgl. die deutschen Sprichworte: "Würfel, Weiber, Wein, bringen Lust und Pein" und "Im Spiel gibt's keine Freundschaft". Daß Freundschaften durch Würfelspielen auch entstehen konnten, ist selbstverständlich, vgl. Ammianus Marc., hist. 28,4,21.

93 Vgl. z.B. Homer, Il. 23,88; zu den Morden und bürgerkriegsähnlichen Ausschreitungen im Anschluß an Wagenrennen während der byzantinischen Zeit in Caesarea Maritima und Neapolis vgl. unten Kap. 16 und z.B. Malalas, Chronogr. 15, § 382; 18, § 446. 
Spielsucht ${ }^{95}$ und verschuldeten sich immens ${ }^{96}$ : "Versatur enim eorum vita ut tessera, volvitur census in tabula, fit ludus de periculo et de ludo periculum ... clamor plaudentium, fletus despoliatorum, gemitus deplorantium" (Ambrosius, de Tobia 11).

$\mathrm{Zu}$ den Loswürfeln und ex-votos ${ }^{97}$ wird man in der Regel das Fundmaterial aus Tempeln und Heiligtümern zählen dürfen wie z.B. die Astragale aus dem Fosse Temple (Structure I) in Lachisch ${ }^{98}$. Es diente divinatorischen (astragalomanteia) ${ }^{99}$ und eventuell auch juridischen Zwecken ${ }^{100}$. Eine Interpretation als bloße Amulette oder Schmuckstücke überzeugt nicht ${ }^{101}$, auch

94 Vgl. z.B. Cicero, Phil. 2,56 (lege, quae est de alea, condemnatus; de alea condemnatus); F. ROSENTHAL, Gambling in Islam (1975), 67ff.

95 Vgl. z.B. Cicero, Phil. 2,56 (studium); Klem. Alex., Paid. 3,11,75 ('Gewinnsucht': hēe dia tōn astragalōn meletē pleonexias); Augustin, conf. 1,19,30 (amor ludendi); Sueton,

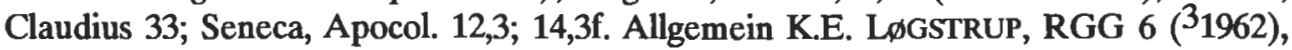
245-248; A. MERGEN, Spielsucht, in: FS für W. SARSTEDT zum 70.Geb., ed. R. HAMM (Berlin - New York 1981), 189-196; U. FRÖHLING (ed.), Droge Glücksspiel (München 1984), passim; J. BRAKHOFF (ed.), Glück - Spiel - Sucht. Beratung und Behandlung von Glücksspielern (Freiburg i.B. 1989), passim; auch F.M. DOSTOJEVSKY, Der Spieler. Aus den Erinnerungen eines jungen Mannes (russ. 1867) (Leipzig 1921), passim.

96 Vgl. z.B. Cicero, Phil. 2,56; Tacitus, Germ. 24.

97 IG.EMi 4,1 (1929), 72, Nr. 121:68ff.

98 O. TUFNELL - CH.H. INGE - L.G. HARDING, Lachish II (1940), 39.94.

99 Vgl. z.B. Sueton, Tib. 14,3; Pausanias 7,25,10; Schol. Pind. Pyth. 4,337; CIL I p. 267ff. Vgl auch E. WEIDNER, Ein Losbuch in Keilschrift aus der Seleukidenzeit, Syria 33 (1956), 175-182 (BM 33333B); J. BOTTERO, Deux curiosités assyriologiques. Note additionelle, Syria 33 (1956), 17-35; F. HEINEVETTER, Würfel- und Buchstabenorakel in Griechenland und Kleinasien (1912), 1ff; TH. HOPFNER, Astragalomanteia, RE Suppl. 4 (1924), 51-56; V. EHRENBERG, Losung, RE 13 (1927), 1451-1504; M. LICHTENSTEIN L.I. RABINOWITZ, Lots, EJ 11 (1971), 510-513; vgl. auch Kap. 7 u.ö.

100 Vgl. zusammenfassend H.H. SCHMID, gōräl, Los, THAT I $\left({ }^{3} 1978\right), 412-415$; W. DOMMERSHAUSEN, ThWAT 1 (1970-1973), 991-998. Los arab. qur $\boldsymbol{c}$, griech. klēros, klēroō, vgl. im AT 'wr(ym) II $=\mathrm{HAL}^{3} 1$, 24; tummim $=\mathrm{HAL}^{3} 4,1612$; hosaen = HAL $^{3}$ 1, 348; T. FAHD, La divination arabe (1966), $177 f f$.

101 R. ZIEGLER - J. BoESSNECK, in: V. FrITZ (ed.), Kinneret (1990), 134. 143. 151. 153f ("Umhängsel"); R.S. LAMON - G.F. SHIPTON, Megiddo I (1939), 148, Pl. 77:10 ("astragalus amulet", Stratum V); P.W. LAPP, BA 30 (1967), 23 (Amulette als "charms against the underworld and its evils" oder Lose; beide Funktionen schließen sich nicht aus).

Gewichte in Form von Astragalen bzw. mit Astragalen als Symbolen sind in Phönizien, Syrien u.a. gut belegt, vgl. z.B. P. BorDREUIL - E. GuBEL, Bulletin d'antiquités archéologiques du Levant inédites ou méconnues VI (BAALIM), Syria 67 (1990), 508, fig. 26; W. KuBITSCHEK, Ein Bronzegewicht aus Gela, JÖAI 10 (1907), 127f, Taf. 6, vgl. IG 
wenn Astragale durchbohrt und an einer Schnur zu einer Kette aufgereiht werden konnten. Allerdings müssen Astragale in Heiligtümern nicht generell als Orakel-Lose interpretiert werden; in 'rites de passage' konnten Knaben bzw. junge Männer ihr Spielzeug, seien es Astragale ${ }^{102}$, Bälle, Kreisel (z.B. Anth. Graeca 6,309) oder Kampfhähne (z.B. Anth. Graeca 6,155), als Weihgaben einer Gottheit darbringen wie Mädchen bzw. junge Frauen ihre Bälle (z.B. Anth. Graeca 6,280) und Puppen (Kap. 5 und 11). Und daß man auch in Heiligtümerm mit Astragalen und anderem Spielzeug einfach nur gespielt hat, ist keineswegs unwahrscheinlich ${ }^{103}$.

Neben die Astragale, die wohl spätestens seit dem Neolithikum als Spielwürfel und Losorakel verwendet worden waren ${ }^{104}$, traten in Palästina seit der Mittelbronzezeit Würfel in der Form von Pyramidenstümpfen und Kuben

XIV, Nr. 593; 2419,7; CIG IV, Nr. 852 (Gela / Sizilien); M. LANG - M. CrosBY, Weights, Measures and Tokens. The Athenian Agora X (Princeton/NJ 1964), 25-27, Pl. 1-3: H. LAMER, RE 13,2 (1927), 2020; auch R.M. BOEHMER, Die Kleinfunde aus Bogazköy aus den Grabungskampagnen 1931-1939 und 1952-1969 (1972), 181f, Taf. 65:1865-1881; C.A. SCHAEFFER, in: Ugaritica IV (1962), 103-105, fig. 64 (ca. 280 gr. schwer); S. LASER, Sport und Spiel (1987), 119f, Anm. 592, Taf. Ia. Zu dem bekannten Bronzegewicht $(93,07 \mathrm{~kg}$ schwer) in Form eines Astragals mit griechischer Weihinschrift an Apollon (2.Hälfte 6.Jh.v.Chr.), gefunden 1901 in Susa als persische Kriegsbeute aus dem Apollo-Tempel von Didyma (Paris, Louvre), vgl. z.B. A. REHM (ed.), Didyma II: Die Inschriften (Berlin 1958), 6f, Nr. 7, Abb. 10; H. LuSCHEY, Iran und der Westen von Kyros bis Khosrow, AMI NF 1 (1968), 20, Taf. 12:1.

Außerdem sind auch zahlreiche Gefäße in Form eines Astragals belegt, vgl. V. KARAGEORGHIS, Chronique des fouilles et découvertes archéologiques à Chypre en 1964, BCH 89 (1965), 242, fig. 15; S. LASER, Sport und Spiel (1987), 119f, ebenso Gemmen, vgl. z.B. F. HEINEVETTER, Würfel- und Buchstabenorakel in Griechenland und Kleinasien (1912), 46.

Zur steinernen Statuenbasis in Form eines Astragals (65 $\mathrm{cm}$ hoch) aus Olympia vgl. G. TREU, Die Bildwerke von Olympia in Stein und Thon (Olympia III; Berlin 1897), 212214, Abb. 239, Taf. 55:4f.

$\mathrm{Zu}$ Metallbarren in Astragalform vgl. Diodor, hist. 5,2 und H.TH. BOSSERT, Ein hethitisches Königssiegel. Neue Beiträge zur Geschichte und Entzifferung der hethitischen Hieroglyphenschrift (IF 17; Berlin 1944), 180ff, Abb. 63.

102 Vgl. z.B. IG IV ${ }^{2}$, Nr. 121, Z. $68 f f$ (Epidauros).

103 Vgl. unten und z.B. TH. WIEGAND - H. KNACKFuss, Didyma I (Berlin 1941), 138: "Offenbar ist also hier bei der Opferstätte im späteren Altertum allerlei privater Orakelzauber mit den Orakel- und Spielknöcheln der Opfertiere getrieben worden".

104 Vgl. z.B. J.D. EVANS, Excavations in the Neolithic Settlement at Knossos, 1957-60, Part I, ABSA 59 (1964), 236, fig. 61:14; Pl. 59f; A. Mosso, Ceramica neolitica di Phaestos e vasi dell'epoca minoica primitiva, MAnt 19 (1908), 148f, fig. 5. 
auf ${ }^{105}$. Sie verdrängten die Astragale aber keineswegs; vielmehr wurden und werden seitdem Astragale und Würfel nebeneinander - als Spiel- und Loswürfel - verwendet. Statt Astragalen und Würfeln konnten auch Wurfstäbe als Zufalls- (bzw. Wahrscheinlichkeits)-Generatoren bei bestimmten Brettspielen (Kap. 8) benutzt werden. (Lose bzw. Orakel konnten natürlich nicht nur mit Hilfe von Astragalen und Würfeln ermittelt werden $\left.{ }^{106}\right)$.

"Ein Kind mit Würfeln, Knöcheln oder Steinen spielen zu sehen, ist nicht schlimm; denn Kinder spielen doch immer"

(Artemidor 3,1)

$105 \mathrm{Zu}$ anderen Würfelformen vgl. z.B. F.W.M. PETRIE, Objects of Daily Use (1927), 57, Pl. 49:234ff ("pentagonal dodecahedron", "eikosihedron"); H. LAMER, RE 13,2 (1927), 2023-2026; F. HEINEVETTER, Würfel- und Buchstabenorakel in Griechenland und Kleinasien (1912), 48ff; R. DE MECQUENEM et al., Memoires de la Mission Archéologique en Iran 29 (1943), 45. 48, fig. 40:2.7f; W. DEONNA, Les dodécaèdres GalloRomaines en Bronze, ajourés et bouletés. A propos du dodécaèdres d'Avenches, Bulletin d'Association pro Aventico 16 (1954), 19-89.

106 Neben der in Kap. 7 genannten Literatur vgl. auch die acht Arad-Ostraka Nrn. 5057 und ihre Interpretation durch Y. AHARONI, Arad Inscriptions (Jerusalem 1981), 87 und die elf mit Personennamen beschrifteten Masada-Ostraka Nrn. 429-440 (locus 113), die Y. YADIN, Masada (Hamburg ${ }^{3} 1967$ ), 201; ders. - J. NAVEH, Masada I (Jerusalem 1989), 3. 28-31 mit Hilfe von Joseph., BJ 7,9,1 (§ 397) als Lose interpretiert, was nicht unumstritten ist, vgl. z.B. S.J.D. CoHEN, Masada: Literay Tradition, Archaeological Remains and the Credibility of Josephus, JJS 33 (1982), 385-405 oder L.H. FELDMAN, Masada: A Critique of Recent Scholarship, in: J. NEUSNER (ed.), Christianity, Judaism, and other Greco-Roman Cults, Part 3 (StJLA 12,3; Leiden 1975), 235-248. Zum Ostrakismos im griechisch-römischen Bereich vgl. O.W. REINMUTH, Ostrakismos, RE 18 (1942), 1674-1685; ders., KP 4 (1975), 376f; H. VolkmanN, Psephisma, KP 5 (1975), 1643. 


\section{WÜRFEL}

Neben den Astragalen als vierseitigen Würfeln wurden in Palästina natürlich auch sechsseitige (meist kubische) und rhomboïde (prismatische) Würfel aus Ton ${ }^{1}$, Knochen $^{2}$, Stein ${ }^{3}$, Elfenbein ${ }^{4}$, Fayence ${ }^{5}$, Kristall ${ }^{6}$ u.ä. verwendet, die in Wohnvierteln (z.B. Tell Bët Mirsim, Tell Abū Slēme), Gräbern (z.B. Jerusalem, Bet-Schean, Sichem $)^{7}$ und anderen Fundorten gefunden wurden. Die Würfelflächen konnten bemalt sein ${ }^{8}$, die Zahlwerte bzw. -zeichen (griech. sēmeion, stigmē, tōpos, trēma) als "Augen" (latein. ocellati) ${ }^{9}$ eingebohrt, eingelegt oder eingeritzt oder (zusätzlich) mit Farbe aufgemalt sein. Die Würfel konnten bei reinen Würfel- und Brettspielen u.ä. ${ }^{10}$, aber auch als Orakel- bzw. Loswürfel (klēroi) eingesetzt werden (kybomanteia) ${ }^{11}$. Zu letzteren gehört der

1 Vgl. z.B. A.D. TUSHINGHAM, Excavations in Jerusalem 1961-1967, Vol. I (1985), 58. 285. 344, fig. 69:10.

2 Vgl. z.B. M. Dothan - Y. Porath, Ashdod IV ('Atiqot 15; Jerusalem 1982), 48, Pl. 27:8; A.D. TUSHINGHAM, Excavations in Jerusalem, Vol. I (1985), 58. 151. 258. 261. 275. 285. 344, fig. 69:8f. 11f; L.Y. RAHMANI, The Tomb of Jason (c'Atiqot HS 4; Jerusalem 1964), 25, Pl. 14:3 (hebr.); ders., Jason's Tomb, IEJ 17 (1967), 90, Pl. 24:D; CH. ClAMER, A Late Bronze Age Burial Cave near Shechem, Qad. 14 (1981), $33 \mathrm{f}$ (hebr.).

3 Vgl. z.B. Geser, Megiddo, Tell el- ${ }^{c}$ A $\breve{g} \breve{g} \breve{u l}$.

4 Vgl. z.B. Bet-Schean, Geser, Tell Bēt Mirsim, Tell el-CA A ğğül.

5 A. BIRAN, The Dancer from Dan, the Empty Tomb and the Altar Room, IEJ 36 (1986), 179-181, fig. 10, Pl. 21:c.

6 Petronius, satyr. 33,2 (tesserae).

7 In den römischen Katakomben konnten Würfel als eine Art Grabbeigabe in den frischen Kalkmörtel der Grabverschlüsse gedrückt werden, vgl. z.B. J. FINK, Die römischen Katakomben (1978), 18, Abb. 9.

8 R.A.S. MACALISTER, Gezer II (1912), 303f.

9 Vgl. z.B. Sueton, Aug. 83; 'Cyprian', CSEL 54,3 (1871), 92ff; A. HARNACK, Der pseudocyprianische Tractat de aleatoribus (1888), 23 (ossuonum multiformi numero); CIL VIII Nr. 7998 (puncta); allgemein K. SCHNEIDER, Ocellati, RE 34 (1937), 1765.

10 F.V. GRUNFELD, Spiele der Welt (1979), 134-137.

11 Dazu sind wohl vor allem Würfel zu zählen, die in kultischem Kontext gefunden wurden; ein Beispiel könnte das eisenzeitliche Exemplar aus Dan sein: A. BIRAN, IEJ 36 (1986), 179-181, fig. 10, Pl. 21:c. Vgl. z.B. auch S. KRAUSS, Talmudische Archäologie III (1912), 110-113; S. LASER, Sport und Spiel (1987), 122f; F. HARTMANN, Alea, RE 1 (1894), 1358f; W.W. HALlo, The First Purim, BA 46 (1983), 19-29. 
berühmte kubische Würfel (pūuru $)^{12}$ des Jahălu, eines hohen neuassyrischen Beamten (abarakku rabu) ${ }^{13}$ zur Zeit Salmanassars III. Der Würfel stammt wahrscheinlich aus Assur und ist an vier Seiten in Keilschrift beschrieben 14; der akkadische Text enthält die Bitte des Jaȟălı an die Götter Assur und Adad um eine gute Ernte in den von ihm regierten Gebieten ${ }^{15}$. Ob die Götter die Würfel-Bitte erfüllt haben, ist unbekannt; Tatsache aber ist, daß Jahāalu mehrfach in den Eponymatslisten genannt wird (833, 824 und 821 v.Chr.) ${ }^{16}$. Noch heute werden vor allem in orthodoxen und römisch-katholischen Kreisen des Christentums Gebetswürfel verwendet, die in jedem Devotionaliengeschäft erhältlich sind (Abb. 20); auf den sechs Seiten der Würfel befinden sich verschiedene Gebete, von denen jeweils eines durch Würfeln 'abgerufen' werden kann.

Bei den sechsseitigen, zumeist kubischen Würfeln (Hexaeder) mit den Zahlwerten 1-6 sind die Zahlwerte häufig so angeordnet, daß die gegenüberliegenden Seiten die Zahl 7 ergeben ${ }^{17}$; letztere sind mit den modernen kubischen Würfeln mehr oder weniger identisch"18: "Sechs, eins, fünf, zwei, drei und vier läßt rollen der Würfel" (Anth. Graeca 14,8). Aus römischer Zeit sind

12 AHw 881f (vgl. auch isqu AHw ${ }^{2}$ 388f), vgl. arama. und hebr. pūr; sum. gił̌-Jub-ba. Vgl. latein. tessera, griech. kybos, dazu z.B. H. CHANTRAINE, Tessera, KP 5 (1975), 615f; K. REGLING, Tessera, RE II 9 (1934), 851-854; Pollux 7,203-206; 9,99-101.

$13 \mathrm{AHw}^{2} 3 \mathrm{f}$.

14 Yale Babylonian Collection No. 7058. F.J. STEPHENS, Votive and Historical Texts from Babylonia and Assyria (YOS, Babylonian Texts 9; New Haven 1937), 17f, No. 73, Pl. 27. 45; E. MICHEL, Die Assur-Texte Salamanassars III. (858-824). 3.Fortsetzung, WO 1 (1949), 261-264 (20.Text); W.W. HALlo, BA 46 (1983), 19-29; W. VON SoDEN, "Als die Götter (auch noch) Mensch waren." Einige Grundgedanken des altbabylonischen Atramhasis-Mythus, (1969), in: ders., Aus Sprache, Geschichte und Religion Babyloniens. Ges. Aufsätze (Neapel 1989), 153f.

15 K. KESSLER, Untersuchungen zur historischen Topographie Nordmesopotamiens nach keilschriftlichen Quellen des 1.Jahrtausends v.Chr. (BTAVO.B 26; Wiesbaden 1980), $170 f$.

16 A. UNGNAD, Eponymen, RIA 2 (1938), 448; F. WEIDNER, Die assyrischen Eponymen, AfO 13 (1941), 308f. 314.

17 Vgl. z.B. L.Y. RAHMANI, The Tomb of Jason (1964), 25, Pl. 14:3 (hebr.); ders., IEJ 17 (1967), 90, Pl. 24:D; A. BIRAN, IEJ 36 (1986), 179-181, fig. 10, Pl. 21:c; CH. ClAMER, Qad. 14 (1981), 33f (hebr.); R. DE MECQUENEM et al., Memoires de la Mission Archéologique en Iran 29. Mission des Susiane (1943), 47, fig. 40:16.

18 Vgl. auch J.D. BUCHENMATTH, Die 7.Seite des Würfels (homo ludens; München 1990), passim; A. GöRGENS, Alte und neue Würfelspiele (Düsseldorf 1987), passim; H. KREUZER, Würfelspiele (Wiesbaden 1987), passim; F. PRUSS, Würfelspiele für jung und alt (Niedernhausen/Ts. 1990), passim. 
gelegentlich Würfel von Falschspielern belegt: Diese Würfel waren innen an einer Seite mit Blei u.ä. beschwert; geschah das innen an der Seite mit dem Zahlwert 1, kam der Würfel beim Spiel häufig mit den Zahlwert 6 nach oben zum Stillstand. "Corriger la fortune" nannten das die Falschspieler aller Zeiten wohl ${ }^{19}$. Um zu gewinnen, bedurfte es einer gewissen Geschicklichkeit: "Invida puncta / iubent felice / ludere doctum" [CIL VIII, Nr. 7998 (Numidien)] ${ }^{20}$. Mit ungeschickten und dummen Gegnern spielte man meist nicht gerne: "Levate da locu, ludere nescis, idiota recede!"21.

Würfel ${ }^{22}$ stammen z.B. vom bronzezeitlichen Tell Bêt Mirsim ${ }^{23}$, Tell el$c_{A} \breve{g} \breve{g} \bar{u} l^{24}$, Sichem ${ }^{25}$ und aus Bet-Schean ${ }^{26}$, die meist noch Pyramidenstümpfe

19 G.E. LESSING, Minna von Barnhelm IV 2.

20 Frei übersetzt lautet die Inschrift auf einem Spielbrett: "Neidische Augen (des Würfels) verlangen fürs glückliche Spielen Geschick (des Spielers)".

21 M. IHM, in: Bonner Studien. Aufsätze aus der Altertumswissenschaft. R. KEKULE gewidmet (Bonn 1890), 234, Nr. 23 (Marino).

22 Vgl. auch E. KLENGEL-BRANDT, Spielbretter und Würfel aus Assur, AoF 7 (1980), 119-126; L. WoOlley, Ur Excavations Vol. IV: The Early Period (Philadelphia 1956), 44. 79, fig. 7 (U.6551; U.18850); E.A. SPEISER, Excavations at Tepe Gawra, Vol. I (1935), 82. 164, Pl. 37a; G.F. DALES, Of Dice and Men, JAOS 88 (1968), 14-23; E.C.L. DURING CASPERS, Of linga Stones and Gaming Boards, AION 47 (1987), 67-74. Frühe griechische Belege z.B. R. HAMPE, Neuerwerbungen 1957-1970. Katalog der Sammlung Antiker Kleinkunst des Archäologischen Instituts der Universität Heidelberg, 2.Bd. (Mainz 1971), 31f, Taf. 34:53; S. KARUSU, Der Erfinder des Würfels. Das älteste griechische mythische Portrait, AM 88 (1973), 55-65, Taf. 53-55; H. LAMER, RE 13,2 (1927), 1935ff. 2021ff. Zum Würfelspiel auch H. LÜDERS, Das Würfelspiel im alten Indien, (1907), in: ders., Philologica Indica. Ausgewählte Kleine Schriften (Göttingen 1940), 106-175.

23 W.F. Albright, The Excavation of Tell Beit Mirsim II: The Bronze Age (AASOR 17; New Haven/CT 1938), 48, § 55, Pl. 21:b (Stratum D, Mittelbronzezeit II); ders., A Set of Egyptian Playing Pieces and Dice from Palestine, Mizraim 1 (1933), 130-134, Pl. 16.

24 W.M.F. PETrIE, Ancient Gaza I (London 1931), 8, Pl. 23:11; ders., Ancient Gaza III (1933), 11, Pl. 28:12-14; ders., Ancient Gaza IV (London 1934), 10f, Pl. 24. 36:21-27; ders. et al., City of Shepherd Kings. Ancient Gaza V (London 1952), 18, Pl. 21:80.

25 CH. Clamer, Qad. 14 (1981), 33 f (hebr.).

26 E.D. OREN, The Northern Cemetery of Beth Shan (Leiden 1973), 93, fig. 34:4 (zwei Exemplare, davon eines fragmentarisch, aus Elfenbein, wahrscheinlich Spätbronzezeit I, aus Tomb 42). 
darstellen und bei denen von den sechs Seiten des Würfels nur vier Zahlwerte aufweisen ${ }^{27}$.

Kubische und rhomboïde, d.h. sechsseitige und prismatische Exemplare sind z.B. im bronzezeitlichen Geser ${ }^{28}$, Tell el-C $\boldsymbol{A}_{\mathrm{g} g ̆ \mathrm{~g}} \bar{l}^{29}$ und Sichem (Abb. 22) ${ }^{30}$, im eisenzeitlichen Sichem (Abb. 21) ${ }^{31}$, Lachisch (Abb. 23) ${ }^{32}$ und Dan (Abb. 24) ${ }^{33}$, im hellenistischen Geser ${ }^{34}$, im römischen Bēt Ğibrîn ${ }^{35}$, Masada ${ }^{36}$, Jerusalem ${ }^{37}$ und Samaria ${ }^{38}$, dem byzantinischen Geser $^{39}$ und im mittelalterlichen ${ }^{c} A \underline{t} \underline{t l}^{40}{ }^{40}$ und Jerusalem ${ }^{41}$ bezeugt ${ }^{42}$. Auf Tell Abū Slēme glaubte F.W.M.

27 Vgl. z.B. auch T. KENDALl, in: A. EgGEbrecht (ed.), Ägyptens Aufstieg zur Weltmacht (Mainz 1987), Nr. 90; D.E. MCCOWN - R.C. HAINES, Nippur I. Temple of Enlil, Scribal Quarter and Soundings (OIP 78; Chicago/IL 1967), Pl. 153:11; R. DE MECQUENEM et al., Memoires de la Mission Archéologique en Iran 29 (1943), 45-48, fig. 40. Ob das Exemplar bei R.W. HAMILTON, QDAP 4 (1934), 61, Pl. 32:378 ein Würfel ist, ist m.E. nicht ganz klar.

28 R.A.S. MACALISTER, Gezer III (1912), 11, Pl. 28:10ff.

29 F.W.M. PETRIE, Ancient Gaza III (1933), 11, Pl. $28: 12$.

30 CH. Clamer, Qad. 14 (1981), $33 f$ (hebr.).

31 Achtseitiger Würfel des 9.-8.Jh.s v.Chr. aus Elfenbein aus dem 'Government Granary' (Building 5900): G.E. WRIGHT, Shechem. The Biography of a Biblical City (New York - Toronto 1965), 163, fig. 83; K. JAROక, Sichem. Eine archäologische und religionsgeschichtliche Studie mit besonderer Berücksichtigung von Jos 24 (OBO 11; Göttingen - Fribourg 1976), 53. 188, Abb. 140.

32 Y. AHARONI, Lachish V (1975), 16, Pl. 15:7 (Stratum III).

33 A. BIRAN, IEJ 36 (1986), 179-181, fig. 10, P1. 21:c.

34 R.A.S. MACAlister, Gezer II (1912), 304, fig. 443:8.

35 F.J. BLISS - R.A.S. MACALISTER, Excavations in Palestine during the Years 18981900 (1902), Pl. 90:0.

36 Y. YADIN, Masada (31967), 145.

37 B. BAGaTTI - J.T. MILIK, Gli scavi del "Dominus Flevit" (Monte Oliveto - Gerusalemme), Parte I: La Necropoli del Periodo Romano (SBF.CMa 13; Jerusalem $1958=$ 1981), 183 ("dalli nelle tombe 23, 162"), Tav. 42:128:13; 42:129:7f; N. AVIGAD, Discovering Jerusalem (1983), 193, fig. 224; L.Y. RAHMANI, The Tomb of Jason (1964), 25 , Pl. 14:3 (hebr.); ders., IEJ 17 (1967), 90, Pl. 24:D; A.D. TUSHINGHAM, Excavations in Jerusalem, Vol. I (1985), 58. 285. 344, fig. 69:10.

38 G.A. REISNER - C.S. FISHER - D.G. LYON, Harvard Excavations at Samaria 19081910, Vol. I (Cambridge 1924), 28; dies., Vol. II (1924), 371. 374, fig. 241:16a. Vgl. auch TH. MACRIDY, Sépulture enfantine de Harah, RB 13 (1904), 361, Pl. 5:9f.

39 R.A.S. MACAlisTER, Gezer I (1912), 317; ders., Vol II-III (1912), 304, Pl. 78:26.

40 C.N. Johns, Excavations at Pilgrims' Castle, 'Atlit, (1932): The Ancient Tell and the Outer Defences of the Castle, QDAP 3 (1934), 149, PI. 60:2. 
PETRIE - vor allem aufgrund von sechs Würfeln -, "a gambler's house" aus dem 4.Jh.v.Chr. ausgegraben zu haben ${ }^{43}$ - ebenso gut kann es sich aber auch um die Werkstatt eines Würfelproduzenten handeln. Die Würfel (2.3.Jh.n.Chr.) aus dem Gebäude 1048 in Jerusalem südlich der Südwestecke dürften darauf hinweisen, daß sich hier entweder um eine Spielhölle ${ }^{44}$ oder um eine Orakelbude der Legionäre der Legio X Fretensis handelt ${ }^{45}$.

Die hebräische bzw. aramäische Bezeichnung für "Los", "Los-Würfel", "Würfel", pür (Est. 3,7; 9,24), wurde in römisch-byzantinischer Zeit durch das griech. kybos (bzw. kybeia) verdrängt ${ }^{46}$, indem letzteres als Lehnwort ins Hebräische übernommen wurde ( $q w b y$ '). Ebenso ersetzte griech. astragalos bzw. astragalion ein hebräisches Wort für Knöchel - wahrscheinlich qrs $/ s(w) l^{47}$ durch das Lehnwort 'strqlyl'48; in der Septuaginta wird das Hapaxlegomenon 'psym $^{49}$ (Ez. 47,3) von Aquila, Symmachos und Theodotion mit heōs astragalōn (Vulg. ad talos; Targ. my qrṣlyn; Syr. l-qwrṣl') übersetzt; auch at.-hebr.

41 A.D. Tushingham, Excavations in Jerusalem, Vol. I (1985), 58. 151. 258. 261. 275. 285. 344, fig. 69:8f. 11f.

42 Weitere undatiere bzw. undatierbare Exemplare aus Palästina: R.S. LAMON - G.M. SHIPTON, Megiddo I (1939), Pl. 77:17 (Oberflächenfund); N. ZORI, Nahalat Issachar (Jerusalem 1977), 21, P1. 7:4 (hebr.); F.G. ANDERSEN, Shiloh II (Kopenhagen 1985), 101, Nr. 329. Für den islamischen Bereich vgl. F. ROSENTHAL, Gambling in Islam (1975), 35.

43 F.W.M. PETRIE, Anthedon, Sinai (London 1937), 8. 11, Pl. 31:3-5.8.

44 Vgl. z.B. L. DEuBNER, Antike 6 (1930), 174f (Epidauros).

45 B. MAZAR, Der Berg des Herrn. Neue Ausgrabungen in Jerusalem (Bergisch Gladbach 1979), 218 ("täglicher Bedarf der Legionäre"); M. BEN-Dov, In the Shadow of the Temple. The Discovery of Ancient Jerusalem (Cambridge 1985), 198 (Raum für Priester der Legio X Fretensis), auch R.W. DAVIES, The Daily Life of the Roman Soldier under the Principate, ANRW II 1 (1974), 332f.

46 Vgl. griech. kybeutēs "Würfelspieler", der zu mittelhebr. qübyūsțōs wird.

47 Vgl. HAL 3 3, 1069 (im AT nur Ps. 18,37 par. 2.Sam. 22,37; Vulg. tali mei); M. JASTROW, Dictionary of the Targumim $(1903=1989), 1423$. 1425; G. DALMAN, Aramäisch-Neuhebräisches Handwörterbuch $(1938=1987)$, 391f; akkad. kursinnu(m) AHw 511f. Auch hebr. grm [HAL ${ }^{3}$ 1, 195; G. DALMAN, Aramäisch-Neuhebräisches Handwörterbuch $(1938=1987), 87]$ könnte Knöchel bzw. Astragale semantisch umfaßt haben.

48 Vgl. S. KraUSS, Griechische und lateinische Lehnwörter $(1899=1964), 85 f$.

49 HAL $^{3}$ 1, 77; M. JASTROW, Dictionary of the Targumim (1903 = 1989), 106; G. DALMAN, Aramäisch-Neuhebräisches Handwörterbuch (1938 = 1987), 34. 
$p \mathrm{sh}^{50}$ (Sach. 11,16) und at.-aramä. $p s^{51}$ (Dan. 5,24 Theodotion) werden in der Septuaginta mit astragalos und in der Vulg. mit ungula übersetzt.

"Alea iacta est" (Sueton, Caes. 32)

$50 \mathrm{HAL}^{3}$ 3, 912; M. JASTROW, Dictionary of the Targumim (1903 = 1989), $1233 f$.

51 G. DALMAN, Aramäisch-Neuhebräisches Handwörterbuch (1938 = 1987), 339; M. JASTROW, Dictionary of the Targumim $(1903=1989), 1168.1191$. 


\section{BRETT-SPIELE}

Brettspiele [griech. psēphos $>$ hebr. / aramä. psyps ${ }^{1}$ ] konnten nicht nur auf einem tragbaren, mobilen Brett ${ }^{2}$ im eigentlichen Sinne gespielt werden; die Spielfelder konnten ebenso gut - ortsfest - in den Sand gezeichnet ${ }^{3}$, auf einen flachen Felsblock eingemeißelt oder eine Steinplatte eingraviert werden. In Palästina sind wie in den umliegenden Nachbarkulturen verschiedene Arten von Brettspielen belegt:

Das 30-Felderspiel bzw. sein Spielbrett besteht aus drei parallelen Reihen von (meist) jeweils 10, in der Regel quadratischen Feldern, die aber auch vor allem wenn die 'Spielbretter' als Graffiti auf größeren Steinen oder Felsblöcken angebracht waren - zu runden Vertiefungen umgestaltet werden konnten. Es ist in Ägypten seit der Frühzeit bis in die ptolemäische Zeit bezeugt, wurde Senet (snt) genannt, in allen sozialen Schichten, bei den verschiedensten Gelegenheiten und von Toten und Lebenden gespielt und war das beliebteste Gesellschaftsspiel Ägyptens ${ }^{4}$. Auch wenn die Spielregeln nicht

1 S. KRAUSS, Griechische und lateinische Lehnwörter im Talmud, Midrasch und Targum II (1899 = 1964), 470-472.

2 Neuhebr. luah; griech. abax, abakion, têlia, sēlia, pessos (s.u.), tabla, taula; latein. tabula, alveus u.a.; vgl. z.B. W.H. GROSs, Abacus; alveus, KP 1 (1975), 1f. 284; ders., tabula lusoria, KP 5 (1975), 481; Fr. HULTSCH, Abacus, RE 1 (1893), 5; H. LECLERQ, Jeu, tables de, DACL 7,2 (1927), 2469-2481; A. MAU, Alveus, RE 2,2 (1894), 1705; F. PALITZSCH, Brettspiele in vorgeschichtlichen Zeiten, Deutsche Schachzeitung 86 (1931), 98-100; H.-G. BUCHHOLZ, in: S. LASER (ed.), Sport und Spiel (1987), 126-184, Abb. 4659, Taf. V-VIII.

3 J.J. Hess, Von den Beduinen des Innern Arabiens (1938), 140; N. SCHMIDT, Sinai und Rotes Meer (Köln 1988), 47; J. RAABE et al., The Child and Play (1982), fig. 13. 43; W. THESIGER, Die Brunnen der Wüste (21991), 260.

4 Vgl. z.B. A. GARDINER, Egyptian Grammar (Oxford ${ }^{3} 1982$ ), 547, Y 5; W. DECKER, Spiel, LÄ 5 (1984), 1150; F.V. GrUNFELD, Spiele der Welt (1979), 53-55; TH. Kendall, Passing through the Netherworld. The Meaning and Play of Senet, an Ancient Egyptian Funerary Game (1978), passim; ders., in: A. EGGEBRECHT (ed.), Ägyptens Aufstieg zur Weltmacht (1987), Nr. 90; H.D. SCHNEIDER, in: A. EGGEBRECHT (ed.), Ägyptens Aufstieg zur Weltmacht (1987), Nr. 91; E. MEISSENBURG, Altägyptische, -griechische und -römische Brettspiele. Eine Bibliographie, Börsenblatt für den Deutschen Buchhandel. Frankfurter Ausgabe 23.Jg., H. 72 (Sept. 1967), 2055-2060; ders., Živa antika 22 (1972), 171-182; R. ANTHEs, Mit Rahineh 1956 (University Museum Monograph; Philadelphia/PN 1965), 118. 127, Nos. 170. 241, Pl. 40d; TH. DEVERIA, Les jeux des dames en Égypte, in: ders., Memoirs et Fragments II (Bibliothèque 
näher bekannt sind, so ist doch klar, daß es von zwei Personen mit jeweils mehreren Spielsteinen gespielt wurde; die Spieler saßen sich an den Schmalseiten des Spielbrettes gegenüber und bewegten ihre Spielsteine mit Hilfe von Würfeln, Astragalen oder Wurfstäben ${ }^{5}$ weiter. In Palästina ist das Spiel spätestens seit dem Neolithikum bekannt ${ }^{6}$. Besonders häufig ist es im frühbronze-

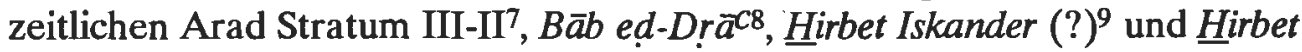

Égyptologique 5; Paris 1897), 83-96; E. HorNuNG (ed.), Das Totenbuch der Ägypter (Zürich - München 1979), 59. 423, Abb. 8a; H.J.R. MURRAY, A History of Board-Games other then Chess (Oxford 1952), 13ff; W. NEEDLER, A Thirty-Square DraughtBoard in the Royal Ontario Museum, JEA 39 (1955), 60-75; B.E.J. PETERSON, Brettspiel, LÄ 1 (1975), 853f; M. PIEPER, Das Brettspiel der alten Ägypter und seine Bedeutung für den ägyptischen Totenkult (Wissenschaftliche Beilage zum Jahresbericht des Königstädtischen Realgymnasiums zu Berlin, Programm 114; Berlin 1909), passim; E.B. PUSCH, Senet, LÄ 5 (1984), 851-855; ders., Das Senetspiel im Alten Ägypten, Teil 1,1-2 (1979), passim; W.M. REFAT, Le jeu de trente cases dans l'Égypte Ancienne, Vol. I: Texte; Vol. II: Figures et Planches (Diss. phil. Université libre; Brüssel 1972), passim; W.J. TAIT, Game-Boxes and Accessories from the Tomb of Tut ${ }^{c}$ ankamūn (1982), Pl. 312. 22; auch M. SAlEH - H. SOURouZIAN (ed.), Die Hauptwerke im Ägyptischen Museum Kairo (Mainz 1986), Nr. 189. 216; J. VANDIER, Manuel d'archéologie égyptienne IV (1964), 493-508; A. WIEDEMANN, Das Spiel im alten Ägypten (1912), 184ff.

5 Die Wurfstäbe hatten leicht gerundete Ober- und flache Unterseiten; nach ihrer Lage auf der Ober- oder Unterseite entschied sich das Vorrücken der Spielsteine; mit den Wurfstäben konnten ebenso wie mit Würfeln und Astragalen auch Los-('Stab-') Orakel durchgeführt werden (s.u.). Belege z.B. H. FranKFoRT et al., The Gimilsin Temple and the Palace of the Rulers at Tell Asmar (1940), 213; E.B. PUSCH, Das Senetspiel im Alten Ägypten, Teil 1,1-2 (1979), 200f. 248, Taf. 61; H.D. SCHNEIDER, in: A. EGGEBRECHT (ed.), Ägyptens Aufstieg zur Weltmacht (1987), Nr. 91. Daneben konnte man natürlich mit Stäben auch reine Stabspiele spielen, also die Stäbe als Hauptspielmittel und nicht nur als Antriebsmittel für eine andere Spielart, benutzen, vgl. das arab. la $c^{c}$ bat at-t tab , eine vor allem in Ägypten bekannte Form des Glücksspiels mit Stäbchen aus Palmengerten.

6 M. Sebbane, Early Bronze and Middle Bronze I Board Games in Canaan and the Origin of the Egyptian Senet Game, ErIs 21 (1990), 233-248 (hebr.; English Summary 109*); leider nur erwähnt ohne exakte Beschreibung und Abbildung ist ein Brettspiel bei O. BAR-YOSEF, Pre-Pottery Neolithic Sites in Southern Sinai, BA 45 (1982), 10. Kaum datierbare Belege: F.W.M. PETRIE, Gerar (London 1928), 19, Pl. $42: 8$ (Tell Ğemme); B. MACDONALD, The Wadi el Ḥasā Archaeological Survey 1979-1983, WestCentral Jordan (Waterloo/Ontario 1988), 284, Photo 30. Zum neolithischen Fundmaterial aus Nevali Çori / Südostanatolien gehören Steine mit Vertiefungen, die vielleicht als Spiele interpretiert werden können (freundlicher Hinweis von H. HAUPTMANN, Heidelberg).

7 R. AMIRAN, Early Arad (Jerusalem 1978), Pl. 80:22f.26 (?); 139:3.

8 J.R. LEE, Early Bronze Game Stones from Bab edh-Dhra, Jordan, Levant 14 (1982), 171-174, Pl. 14f. 
$e z$-Zeraqū $n^{10}$, im spätbronzezeitlichen Geser ${ }^{11}$ sowie im eisenzeitlichen Hazor Stratum VIII (Abb. 25) ${ }^{12}$, Geser ${ }^{13}$, Lachisch Gräber $120^{14}$ und 521 ${ }^{15}$, Megiddo Stratum VA ${ }^{16}$ und Tell el-Fār $c a$ Süd Grab 201 (Abb. 26) ${ }^{17}$ bezeugt ${ }^{18}$. Daneben gibt es eine Reihe von Funden in Phönizien (Kämid el-Lōz $z^{19}$, Byblos ${ }^{20}$ ), Syrien $^{21}$, Mesopotamien ${ }^{22}$, Iran ${ }^{23}$ und auf Zypern ${ }^{24}$. Die eisenzeitlichen Belege

9 S. RICHARD - R.S. BORAAS, Preliminary Report of the 1981-82 Seasons of the Expedition to Khirbet Iskander and its Vicinity, BASOR 254 (1984), 83, fig. 19 (Oberflächenfund).

10 Bislang unpubliziert; es handelt sich dabei um eine ganze Reihe fragmentarisch und vollständig erhaltener, steinerner Spielbretter mit runden Einbohrungen als Spielfeldern. Den Hinweis darauf verdanke ich J. KAMLAH (Tübingen).

11 R.A.S. MACALISTER, Gezer II-III (1912), 299f, Pl. 201:1.8; Pl. 201:7 ist angeblich hellenistisch.

12 Y. YADIN, Hazor II (Jerusalem 1960), 34, Pl. 78:6 = 164:13: zweiseitiges Spielbrett mit $5+5+12$ (?)-Felderspiel auf der Gegenseite.

13 R.A.S. MACALISTER, Gezer II-III (1912), 299f, Pl. 201:6.

14 O. TUFNELL, Lachish III (1953), 196. 381f, Pl. 37:15.17; 55:27.28 ("Calendar?") (PAM Nos. 36.1566; 36.1567). Diese Objekte, die immer wieder auch als Kalender bezeichnet werden, könnten auch Spiele gewesen sein; auch hier widerspricht die eine Funktion nicht zwingend der anderen!

15 O. TUFNELL, Lachish III (1953), 224. 381f, Pl. $37: 3$ = 56:23 ("Calendar?"); vgl. auch den unstratigrafierten Fund Pl. 57:28.

16 G. LouD, Megiddo II (OIP 62; Chicago/IL 1948), 166, Pl. 268:6.

17 F.W.M. PETRIE, Beth-Pelet I (London 1930), 13, Pl. 40:481 ("calendar tablet").

18 Ob das knöcherne Täfelchen des 7.Jh.s v.Chr. aus Aroër ( $\underline{\text { Hirbet }} \boldsymbol{c}_{\text {Ara }} \boldsymbol{c}_{\text {ir }}$ / Negev) mit $3 \times 10+12(=42)$ Löchern ein Spiel ist (Abb. 27), ist zweifelhaft, vgl. A. BIRAN, "And David Sent Spoils ... to the Elders in Aroer" (1 Samuel 30:26-28), BAR 9,2 (1983), 37 ("Calendar?"); ders. - R. CoHEN, Aroer, 1980, IEJ 31 (1981), 131, Pl. 24:D ("a gaming board or a calendar").

19 J.-W. MEYER, Lebermodell oder Spielbrett, in: R. HACHMANN (ed.), Bericht über die Ergebnisse der Ausgrabungen in Kāmid el-Lōz in den Jahren 1971 bis 1974 (SBA 32; Bonn 1982), 53-79, Abb. 7f. 11; ders., in: R. HACHMANN (ed.), Ergebnisse der Ausgrabungen in Kāmid el-Lōz in den Jahren 1977 bis 1981 (1986), 123-143; ders., in: R. HACHMANN (ed.), Frühe Phöniker im Libanon (1983), 101-104. 126-128, Kat.-Nrn. 24f. Zum Fundkomplex auch R. HACHMANN, Das Grab eines Stadtkönigs von Kumidi, in: Anatolia and the Near East. Studies in Honor of T. ÖzGÜÇ, ed. K. EMRE et al. (Ankara 1989), 159-181, fig. 6.

20 M. Dunand, Fouilles de Byblos II (Paris 1954), 310. 505. 531. 533. 571. 573, Nos. 9734. 12202. 12526. 13079, fig. 340. 559. 610. 661 (Levels VI; XI; XII und XIV).

21 E. FugmanN, Hama II 1 (1958), 76, PI. 103:3 A435 (Niveau J 1); P.J. RIIS - M.-L. BuHL, Hama II 2 (1990), 20-243, fig. 114:958. 963 (Bâtiment IV und V, Niveau E: der genaue Spieltyp ist nicht mehr zu ermitteln), vgl. 316 (AramGraf 50); B. HROUDA, Tell 
aus Tell el-Fārc $a$ Süd Grab 201 (Abb. 26), Lachisch Gräber 120 und 521 und Hamā G IX $79^{25}$ sind als kleine knöcherne Steckspiele gestaltet. Ob die knöchernen Objekte aus Geser ${ }^{26}$, Lachisch ${ }^{27}$, Nessana ${ }^{28}$, Tell Ğemme ${ }^{29}$, Tell enNasbe (Abb. 33) ${ }^{30}$ oder Tell Bêt Mirsim (Stratum A) ${ }^{31}$ ein Spielzeug darstellen, ist fraglich. Die Belege stammen aus Wohnbereichen (z.B. Arad, Geser, Hazor, Megiddo, Hamā, Byblos), aus Palästen (z.B. Kāmid el-Lōz) ${ }^{32}$, aus Gräbern (z.B. Lachisch, Tell el-Fār $\mathcal{C}_{a}$ Süd) und aus Tempeln (z.B. Megiddo) und waren aus Stein, Knochen (oder Elfenbein) gefertigt. Die Spielsteine waren zumeist konisch und / oder pyramidal; soweit das Spiel als Löcher-Spiel gestaltet war wie in Lachisch oder Tell el-Fār $c a$ Süd, konnten die Spielsteine

Halaf IV: Die Kleinfunde aus historischer Zeit (Berlin 1962), 52, Taf. 41i; 43a. Vgl. auch das Fundmaterial aus $H a b \bar{u}$ ba Kabĩra, wo es offenbar eine Werkstatt für (30-Felder-?)Brettspiele gab, E. STROMMENGER, Habuba Kabira. Eine Stadt vor 5000 Jahren (12.Sendschrift der DOG; Mainz 1980), 56, Abb. 46.

22 J. SCHAwE, Brettspiel, RlA 2 (1938), 62; C. Preusser, Die Wohnhäuser in Assur (WVDOG 64; Berlin 1954), 21, Taf. 14:b; B. MEISSNER, Die babylonischen Kleinplastiken (Texte und Materialien der Frau Professor Hilprecht Collection of Babylonian Antiquities im Eigentum der Universität Jena 4; Leipzig 1934), 22, Taf. 10 (Inv.-No. A 70).

23 J. DE Morgan - R. DE MECQuenem, Mémoires de la Délégation en Perse 7 (Paris 1905), fig. 349; R. DE MECQUENEM et al., Memoires de la Mission Archéologique en Iran 29 (1943), 44f, fig. 39:1-3.

24 Vgl. z.B. H.-G. BuchHolz, Bronzezeitliche Brettspiele aus Zypern, ActaPrHistA 13-14 (1982), 67-74; S. SwINY, The Kent State University Expedition to Episkopi Phaneromeni, Part 2 (SIMA 74,2; Nikosia - Göteborg 1986), 32-65, fig. 33-37. 40f. 42. 55f; ders., Prehistoric Cyprus: A Current Perspective, BA 52 (1989), 186.

25 P.J. RIIS, Hama II 3 (1948), 178, fig. 228 (période IV).

26 R.A.S. MACALISTER, Gezer II-III (1912), 452f, Pl. $226: 37.59$ ("Amulets"). Vgl. auch E.E. PlatT, Bone Pendants, BA 41 (1978), $25 f$ ( 3 x 7 Löcher).

27 O. TUFNELL, Lachish III (1953), Pl. 63:12.15; 41:10.13 (PAM Nos. 38.727; 39.823)

28 H.D. Colt, Excavations at Nessana (Auja Hafir, Palestine), Vol. 1 (London 1962), 51f, Pl. 21:23 (PAM No. 36.1344).

29 F.W.M. PETRIE, Gerar (1928), 17, Pl. 34:4 ("purpose unknown").

30 CH.CH. McCown, Tell en-Nasbeh I (Berkeley - New Haven 1947), 248. 302, Pl. 90:23 ("magical object", "tool of magic").

31 W.F. Albright, The Excavation of Tell Beit Mirsim, Vol. III: The Iron Age (AASOR 21-22; New Haven 1943), 83. 211, Pl. 29:15-15a = 60:12.

32 In Tamassos auf Zypern stammen alle Spielbretter und Spielsteine der archaischklassischen Zeit aus den Tempelbereichen der Astarte-Aphrodite und der Kybele, vgl. H.-G. BuCHHOLZ, ActaPrHistA 13-14 (1982), 67-74. Vgl. auch I. MicHAELIDOU-NICOLAOU, Table à jeu de Dhekelia (Chypre), BCH 89 (1965), 112-127; ders., Une nouvelle table à jeu de Chypre, BCH 94 (1970), $549 f$. 
auch die Form von Stäbchen bzw. Stiften haben, die man in die Löcher stecken konnte.

In Ägypten weisen einige der quadratischen Felder der Senet-Bretter häufig Inschriften auf, die zeigen, daß die Spiele auch im (Toten-)Kult eine gewisse Bedeutung hatten ${ }^{33}$; außerhalb Ägyptens fehlen - von den ägyptischen Exporten abgesehen - diese und ähnliche Inschriften völlig. Im Vergleich zu Ägypten scheint eine geringere kultische Verwendung bzw. eine geringere religiöse Konnotation der Spiele zu beobachten zu sein: Der homo ludens palaestiniensis dürfte, worauf auch das Fehlen der Verbindung von Spielen und Festen in den schriftlichen Quellen Palästinas hindeutet, zumindest beim Spielen weniger homo religiosus gewesen sein als der Ägypter (jedenfalls so wie ihn die Ägyptologen gerne darstellen ${ }^{34}$ ).

Neben dem 30-Felderspiel gab es eine Reihe von Spiel-Varianten mit mehr (Abb. 28) oder weniger Feldern, deren Zahl sich aber häufig nicht sicher bestimmen läßt, weil ein nicht unerheblicher Teil der Belege nur fragmentarisch überliefert ist. Diese Felderspiele ${ }^{35}$ stammen z.B. aus dem neolithischen $\mathrm{el}$ $B \bar{e} d a^{36}$, aus dem Bereich des mittelbronzezeitlichen Tempels von Hazor (Stratum XVI) ${ }^{37}$, des spätbronzezeitlichen Heiligtums vom Tell Dēr $c_{A l l a}$

33 Vgl. z.B. E.B. Pusch, Das Senetspiel im Alten Ägypten (1979), 385-400: Der 'Große Brettspieltext', der den Spielverlauf dazu benutzt, "den Durchgang des Toten durch die Unterwelt und seine Seligwerdung zu schildern".

34 Vgl. auch W. ZIMMERLI, Die Weltlichkeit des Alten Testaments (Göttingen 1971), passim. W.M. REFAT, Le jeu de trente cases dans l'Égypte Ancienne, Vol. I: Texte (Diss. phil. Université libre; Brüssel 1972), 6ff bezweifelt - m.E. zu Recht - die sonst von Ägyptologen häufig zu stark betonte Beziehung des Senet-Spiels zum (Jenseits-) Glauben; den Senet-Spielbretter Palästinas, soweit sie nicht aus Ägypten importiert waren, fehlen darüberhinaus die religiösen Texte.

35 Vgl. z.B. F. Thureau-Dangin - M. Dunand, Til-Barsib (BAH 23; Paris 1936), 159f, Pl. 14:3 (sekundäres Graffito); G. PLOUG, Hama IV 3. Fouilles et Recherches de la Fondation Carlsberg 1931-1938. Les petits objects médiévaux sauf les verres et poteries (Kopenhagen 1969), 106, fig. 40:3 (?); F.W.M. PETRIE, Objects of Daily Use (1927), 55, Pl. 48:178; R. DE MECQuenEM et al., Memoires de la Mission Archéologique en Iran 29 (1943), 44f, fig. 39:1-3. Zu weiteren, in Palästina allerdings nicht belegten Brettspielen vgl. z.B. A. Evans, The Palace of Minos, Vol. I: The Neolithic and Early and Middle Minoan Ages (London 1921), 472-483, fig. 338-340. 344. 346, Pl. 5; R.S. BRUMBACH, The Knossos Game Board, AJA 79 (1975), 135-137; W.N. BROWN, The Indian Games of Pachisi, Chaupar, and Chausar, Exped. 6 (1964), 32-35.

36 D. KIRKBRIDE, Five Seasons at the Pre-Pottery Neolithic Village of Beidha in Jordan, PEQ 98 (1966), 34, fig. 8.

37 Y. YADIN, Hazor III-IV. Plates (1961), Pl. 260:28 = 335:5; ders., Hazor III-IV. Text (1989), 223 (Area H, Stratum 3). 
$(?)^{38}$, aus dem eisenzeitlichen ${ }^{39}$ sowie dem hellenistischen Geser ${ }^{40}$, Marescha (Tell Sandahanne $)^{41}$ und Aseka (Tell Zakarîye) ${ }^{42}$ und werden heute noch gespielt ${ }^{43}$.

Auf zweiseitig bespielbaren Spielbrettern wie z.B. dem von Hazor (Abb. 25) oder denen aus Kämid el-Lōz befindet sich zuweilen dem 30-Felderspiel gegenüber ein anderes Felderspiel, das in der Regel $4+4+12$, also insgesamt 20 Felder aufweist und ebenfalls von zwei Spielern gespielt wurde. Dieses Brettspiel ist in Palästina seit der Mittelbronzezeit belegt (Tell Bēt Mirsim ${ }^{44}$, Tell el- ${ }^{c} A \breve{g} \breve{g} \bar{u}^{45}$ ) und wurde besonders in der Spätbronzezeit (z.B. Bet-Schemesch $^{46}$, Megiddo Stratum VIIA ${ }^{47}$, Geser $\left.{ }^{48}, K a \overline{a m i d} ~ e l-L \bar{o} z^{49}\right)$ und in der Eisenzeit II gespielt, wie Fundmaterial aus Hazor Stratum VIII (Abb. 25) ${ }^{50}$, Tell el-Fār $c_{a}$ Süd, Grab 220 (Abb. 29) $)^{51}$ oder Geser ${ }^{52}$, aber auch aus $\operatorname{Ham}^{53}$ und

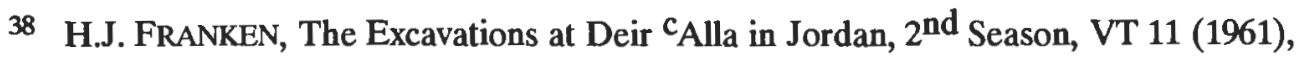
365.

39 R.A.S. MACALISTER, Gezer II-III (1912), 299-301, Pl. $201: 9$.

40 R.A.S. MACALISTER, Gezer II-III (1912), 299-302, fig. 442, Pl. 201:12.

41 F.J. BLISS - R.A.S. MACALISTER, Excavations in Palestine during the Years 18981900 (London 1902), 57, Pl. 19:16.

42 F.J. BLISS - R.A.S. MACALISTER, Excavations in Palestine (1902), 144f, fig. 56:1-3.

43 Vgl. z.B. L. SAADA, Kharbga, EI 4 (1978), 1071f; N. SCHMIDT, Sinai und Rotes Meer (1988), 46f.

44 W.F. Albright, The Excavations of Tell Beit Mirsim, Vol. II: The Bronze Age (AASOR 17; New Haven 1938), 48f, Pl. 37 (= PAM 33.1856); ders., Mizraim 1 (1939), 130-133, Pl. 14; ANEP ${ }^{2}$ No. 214.

45 F.W.M. PETRIE, Ancient Gaza III (London 1933), Pl. 28:25; möglicherweise handelt es sich aber auch um ein 30-Felderspiel.

46 E. GRANT, Rumeileh being Ain Shems Excavations (Palestine), Part III (Biblical and Kindred Studies 5; Haverford 1934), fig. 4:5-140.

47 G. Loud, The Megiddo Ivories (OIP 52; Chicago/IL 1938), 19, Pl. 47 (No. $220=$ PAM 38.826). 50 (No. 224 = OIM A 22295A). 51 (No. 225 = OIM A 22272).

48 R.A.S. MACALISTER, Gezer II-III (1912), 299f, Pl. 201:2.4.

49 J.-W. MEYER, in: R. HACHMANN (ed.), Bericht über die Ergebnisse der Ausgrabungen in Kāmid el-Lōz in den Jahren 1971 bis 1974 (1982), 53-79; ders., in: R. HACHMANN (ed.), Bericht über die Ergebnisse der Ausgrabungen in Kāmid el-Lōz in den Jahren 1977-1981 (1986), 123-143.

50 Y. YADIN, Hazor II (Jerusalem 1960), 34, Pl. 78:6 = 164:13: Variante mit $5+5+$ 12 (?) Feldern.

51 F.W.M. PETRE, Beth-Pelet I (1930), 10. 12, Pl. 34:188.

52 R.A.S. MACALISTER, Gezer II-III (1912), 299f, Pl. 201:3.11. 
Tell Halāf (Guzāna $)^{54}$ zeigen. Außerhalb Palästinas ist es schon früher, aber auch vor allem in der (Spät-)Bronzezeit in Mesopotamien ${ }^{55}$, Syrien ${ }^{56}$, Ägyp$\operatorname{ten}^{57}$ und Zypern ${ }^{58}$ gut belegt und wurde dort ebenfalls bis in das 8./7.Jh.v.Chr. gespielt ${ }^{59}$. Insgesamt stammen die Belege aus so unterschiedlichen Fundorten wie aus Palästen (z.B. Megiddo, Kämid el-Lōz, Mari), Wohnbereichen (z.B. Bet-Schemesch, Hazor, Tell Bēt Mirsim, Hamā), Gräbern (z.B. Tell el-Fārc $c_{a}$ Süd, Grab 220; Tell el-c $A$ ğğül, Grab 363; Hamā G IX 201; Ur) und Tempeln (z.B. Kämid el-Lōz; Assur). Die Spielbretter bestanden aus

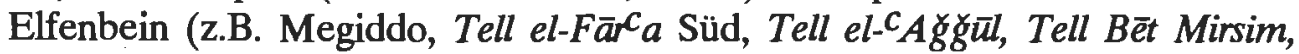
Kāmid el-Lōz) und / oder Holz (z.B. Tell Bēt Mirsim, Kāmid el-Lōz, Hamāa) oder (Kalk-)Stein (z.B. Bet-Schemesch, Hazor, Tell Haläf). Die Anordnung der Felder war zumeist rechtwinklig zueinander, die Spielbretter etwa 15-30 $\mathrm{cm}$ lang und 5-10 cm breit. Daneben konnte das Spielbrett auch die Form ei-

53 P.J. RIIS, Hama II 3 (1948), 174-176, fig. 218f; E. FugmanN, Hama II 1 (1958), 177. 179, fig. 216 (bâtiment III, période E).

54 E.D. VAN BurEN, A Gaming-Board from Tall Halaf, Iraq 4 (1937), 11-15; vgl. B. HroudA, Tell Halaf IV (1962), 8, Taf. 7:43a-b.

55 Vgl. z.B. C.L. WoolleY, Ur Excavations Vol. II: The Royal Cemetery. A Report on the Predynastic and Sargonid Graves excavated between 1926 and 1931 (Oxford 1934), 274-279, Pl. $95-99$ (U 9000. 9776. 10478. 10557. 11162); E. HEINRICH, Fara. Ergebnisse der Ausgrabungen der Deutschen Orient-Gesellschaft in Fara und Abu Hatab, ed. W. ANDRAE (Berlin 1931), 146, Taf. 76g; W. ANDRAE, Der Anu-Adad-Tempel in Assur (WVDOG 10; Leipzig 1909), 86, Abb. 79. 81; A. HARRAK, Another Specimen of an Assyrian Game, AfO 34 (1987), 56 (Assur); E.J. BANKs, Bismya or The Lost City of Adab (1912), 355f.

56 Vgl. z.B. A. Parrot, Mission Archéologique de Mari II. Le Palais (BAH 68; Paris 1958), 12f. 47. 182f. 247. 275, fig. 7. 183. 211. 291. 333.

57 Vgl. z.B. B.E.J. PETERSON, LÄ 1 (1975), 853f; E.B. PUSCH, Eine unbeachtete Brettspielart, SAK 5 (1977), 199-212; A. EGGEBRECHT (ed.), Ägyptens Aufstieg zur Weltmacht (1987), Nr. 90f; A. WIEDEMANN, Das Spiel im alten Ägypten (1912), 184.

58 Vgl. z.B. A.S. MURRAY - A.H. SMTTH - H.B. WALTERS, Excavations in Cyprus (London 1900), 12f. 31, fig. 19, Pl. 1 (aus Grab 58); E.B. PUSCH, Das Senetspiel im Alten Ägypten (1979), 307f, Nr. 58; W. ORTHMANN, Der Alte Orient (1975), Abb. 472; P. DIKAIOS, Enkomi. Excavations 1948-1958, Vol. 1: The Architectural Remains. The Tombs (Mainz 1969), 255; ders., Enkomi Vol. 2 (Mainz 1969), Pl. 128:65f; 156:49f; V. Karageorghis - C. EliotT, Palaepaphos-Skales. An Iron Age Cemetery in Cyprus (Ausgrabungen in Alt-Paphos auf Cypern 3) (Konstanz 1983), 183. 427f, fig. 116. 134.

59 Weitere Belege aus Syrien z.B. N. EGAMI - Sh. WAHITA - K. ISHIDA, Excavations at Tell Mastuma, Syria, 1988, BAOM 10 (1988-1989), 62-66, fig. 8, Pl. 5:h (Steinbrett 24 x 9 $\times 3,3 \mathrm{~cm}$, Level I-2). 
nes Lebermodells haben ${ }^{60}$ oder zumindest daran erinnern; dabei war ein Teil der Spielfelder asymmetrisch angeordnet. Belege für diese Form des $4+4+$

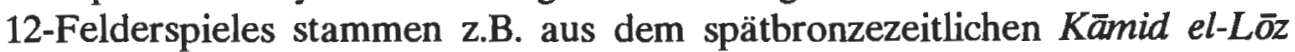
und Bet-Schemesch (Abb. 30) ${ }^{61}$. Die Form des Lebermodells weist darauf hin, da $B$ das Spiel auch in kultischen (und juridischen) Zusammenhängen als Orakel verwendet werden konnte. Daneben ist das Spiel - außerhalb Palästinas - in einer weiteren Variante belegt, bei der das Spielfeld aus einer Anordnung von in der Regel $4+4+8+2+2$ Feldern besteht (Abb. 31) ${ }^{62}$.

So wie auf doppelseitig verwendeten Spielbrettern das 30-Felder- und das 20-Felder-Spiel gleichzeitig belegt sind, so gab es auch Spielbretter, die neben dem 20-Felder-Spiel eine andere Form von Brettspiel aufweisen konnten, nämlich ein Löcher- oder Steck-Spiel mit rund 60 Löcher. In (spät-) bronzezeitlichen Ortslagen Palästinas [z.B. Megiddo (Abb. 32) ${ }^{63}$, BetSchean $^{64}$, Tell Dêr $\left.{ }^{c_{A l l a}}(?)^{65}\right]$, Ägyptens ${ }^{66}$, Anatoliens ${ }^{67}$, Mesopotamiens ${ }^{68}$

60 Vgl. z.B. ANEP2 fig. 594f; R.D. BIGGS - J.-W. MEYER, Lebermodelle, RIA 6 (19801983), 518-527; O. LORETZ, Leberschau, Sündenbock, Asasel in Ugarit und Israel. Leberschau und Jahwestatue in Psalm 27. Leberschau in Psalm 74 (UBL 3; Altenberge 1985), passim; J.-W. MEYER, Untersuchungen zu den Tonlebermodellen aus dem Alten Orient (AOAT 39; Kevelaer - Neunkirchen-Vluyn 1987), 24-32 u.ö.; ders., in: M. DiETRICH - O. LORETZ, Mantik in Ugarit (ALASP 3; Münster 1990), 241-280; Zu den Lebermodellen aus Palästina vgl. G. LOUD, Megiddo Il (1948), 147. 159, Pl. 255:1f (Stratum VII); B. LANDSBERGER - H. TADMOR, Fragments of Clay Liver Models from Hazor, IEJ 14 (1964), 201-218; Y. YADIN, Hazor III-IV. Plates (1961) P1. 315; ders., Hazor III-IV. Text (1989), 229; ANEP2 fig. 844 (Stratum XV).

61 E. GraNT, Rumeileh being Ain Shems Excavations, Part III (1934), fig. 4:5-80; Pl. 20:2.

62 E.J. BANKS, Bismya or The Lost City of Adab (1912), 355 (unbekannte Herkunft und Datierung); E.B. PUSCH, SAK 5 (1977), 199-212; A. DE KAINLIS, Un jeu assyrien du Musée du Louvre, RA 39 (1942-1944), 19-34; C.L. WoolleY, Ur Excavations Vol. II: The Royal Cemetery (1934), 276, Pl. 95; vgl. ANEP2 No. 212.

63 G. Loun, The Megiddo Ivories (1938), 19, Pl. 47-50.

64 E.D. OREN, The Northern Cemetery of Beth Shan (1973), 93. 120f, fig. 41:37 = 76:1; 45:23 = 76:1 (Tombs 7 und 90).

65 H.J. FRANKEN, VT 11 (1961), 365.

66 F.W.M. PETrie - G. Brunton, Sedment I (London 1924), 7f, Pl. 22:13; E. PuSCH, Ein zweiter Beleg für das Spielbrett Kairo JdE 68.127, GM 22 (1976), 53-57.

67 N. ÖZGüÇ, Excavations at Acemhöyük, Anadolu 10 (1966), 46f, fig. 3, PI. 26:1; T. ÖzGÜÇ, Kültepe-Kaniş II: New Researches at the Trading Center of the Ancient Near East (TTKY V.Dizi, Sa. 41; Ankara 1986), 81-83, Pl. 132:7-9. 
und Irans ${ }^{69}$ wurden Spielbretter gefunden, die häufig eine deutliche Ähnlichkeit mit mykenischen Schildformen aufweisen ${ }^{70}$. Sie weisen in der Regel statt der sonst üblichen quadratischen Felder Löcher auf, in die die stäbchenförmigen Spielsteine bzw. -stifte gesteckt werden konnten. Die Spielregeln zu diesen Löcher- oder Steckspielen sind weitgehend unbekannt ${ }^{71}$. Ein Teil der Spielbretter bestand aus Elfenbein (z.B. Bet-Schean, Megiddo). Sie müssen für die Oberschicht, in deren Besitz sie sich befanden, beträchtliche Wertgegenstände dargestellt haben ${ }^{72}$; die Besitzer verwendeten sie nicht nur als Spielzeug, sondern auch als Kapitalanlagen und Handelsware, und horteten sie entsprechend wie z.B. in dem kellerartigen Anbau des Palastes 2041 von Megiddo (Stratum VIIA). Spiele dieser Form sind nur während der Spätbronzezeit in Palästina belegt.

Die Löcher- bzw. Steckspiele, deren Formen auch eher an Ovale u.ä. erinnern, konnten aus Stein oder Ton bestehen und stammen zumeist aus Wohnbereichen (z.B. Geser, Tell Ğemme, Ur) bzw. Palästen (Megiddo), aber auch aus Gräbern (z.B. Bet-Schean, Tepe Sialk). Belegt sind sie vor allem in Ägyp$\operatorname{ten}^{73}$, Mesopotamien ${ }^{74}$ (Assur ${ }^{75} ;$ Hafāăğ $\bar{\imath}^{76} ;$ Nimrū $^{77}$; Ninive ${ }^{78}$; Nippur ${ }^{79}$;

68 F. WETzEL - E. SCHMIDT - A. MALlwitZ, Das Babylon der Spätzeit (1957), 36, Nr. 2, Taf. 42d = L. JAKOB-RosT u.a., Das Vorderasiatische Museum (Mainz 1992), Nr. 71 (Babylon).

69 Vgl. z.B. P. AMIET, Les Antiquités du Luristan (Paris 1976), 97f, fig. 240 (Paris, Louvre, AO 25342).

70 H. BORCHARDT, Frühe griechische Schildformen, in: H.-J. BUCHHOLZ - J. WIESNER (ed.), Kriegswesen 1: Schutzwaffen und Wehrbauten (ArchHom I E 1; Göttingen 1977), 1-56 (Typ I: Schild mit seitlicher Einziehung).

71 Vgl. z.B. R.C. BELL, Board and Table Games, Vol. I (21979), 20ff; F.V. GRUNFELD, Spiele der Welt (1979), 118-123.

72 Vgl. auch J. BotTERo, Jeu graphique ou talisman? Note additionelle, Syria 33 (1956), 17-25: mi-lul-ti NUN.MEŠ, das mit "la joie des princes" übersetzt wird.

73 Vgl. z.B. F.W.M. PETrIE, Objects of Daily Use (1927), 51-57, Pl. 47; 48:176. 178; ders. - G. BRUNTON, Sedment I (1924), 7f. 12, Pl. 21:14; 22:8f (aus Grab 2122, 9.10.Dyn.); 22:10-25; H. CARNAVON - H. CARTER, Five Years' Explorations at Thebes. A Record of Work 1907-1911 (London u.a. 1912), 56-59, fig. 14, Pl. 50 (aus Pit Tomb No. 25).

74 C.J. GadD, An Egyptian Game in Assyria, Iraq 1 (1934), 45-50; R.S. Ellis - B. BuchanaN, An Old Babylonian Gameboard with Sculptured Decoration, JNES 25 (1966), 192-201, vgl. F. BLOCHER, Untersuchungen zum Motiv der nackten Frau in der altbabylonischen Zeit (1987), 93f. 216; F. WETZEL - E. SCHMIDT - A. MALLWITZ, Das Babylon der Spätzeit (WVDOG 62; Berlin 1957), 36, Taf. 42d (?).

75 E. KLENGEL-BrandT, AoF 7 (1980), 119-126 (Ass 14918 - VA 7319; Ass 16476 VA 4988; VA Ass 4261). 
Nuzi80; Sippar ${ }^{81}$; Ur ${ }^{82}$ ), Elam ${ }^{83}$, Iran ${ }^{84}$, Anatolien $^{85}$, Syrien [Tell Ailūn (?) ${ }^{86}$; Rās el- CAin $\left.^{87}\right]$ und Palästina (Geser ${ }^{88}$, Tell Ğemme ${ }^{89}$ ), wo sie insbesondere während der Spätbronze- und Eisenzeit II benutzt wurden. Ein Teil der Spiele stammt aus königlichem Besitz ${ }^{90}$.

76 H.D. Hill - T. JACOBSEN - P. Delougaz, Old Babylonian Public Buildings in the Diyala Region (OIP 98; Chicago/IL 1990), 227. 234, Pl. 66:e.

77 C.J. GADD, Iraq 1 (1934), 47, No. 4, Pl. $7 \mathrm{~b}$ (BM 123333).

78 C.J. GADD, Iraq 1 (1934), 48, Nos. 6-8 [BM 91930 + 12104; 81-7-27,183 (80-7$19,329 ; 80-7-19,327+?) ; 81-2-4,19(+83-1-18,645 ; 81-2-4,18$ ?]; E. NASSOUHI, Un curieux monument néo-assyrien en mabre rouge veine, RA 22 (1925), 17-22.

79 D.E. MCCOWN - R.C. HAINES, Nippur 1 (1967), 104, PI. 147; 153.

80 R.F.S. STARR, Nuzi. Report on the Excavations at Yorgan Tepe near Kirkuk, Iraq conducted by Harvard University in Conjunction with the ASOR and The University Museum of Philadelphia 1927-1931, Vol. II: Plates and Plans (Cambridge/MA 1937), 33, Pl. 117:L; 123:B; ders., Vol. I: Text (1939), 469.

81 C.J. GADD, Iraq 1 (1934), 49, No. 9, Pl. 8a (BM 118768).

82 L. Woolley, Ur Excavations Vol. IX: The Neo-Babylonian and Persian Periods (London 1962), 128, PI. 29:U18117; C.J. GADD, Iraq 1 (1934), 47, Nos. 2-3, Pl. 8 b (BM 123331 und University Museum Pennsylvania).

83 R. DE MeCQuenEm et al., Memoires de la Mission Archéologique en Iran 29 (1943), 44f, fig. 39.

84 R. GHIRShMAN, Fouilles de Sialk près de Kashan 1933, 1934, 1937, Vol. II (Musée du Louvre - Département des Antiquités Orientales, Série Archéologique Tome V; Paris 1939), 42-44. 217, fig. 4a, Pl. 22:8; P. AMIET, Les antiquités du Luristan (Paris 1976), 97f, fig. 240.

85 T. ÖZGÜç, Excavations at Kültepe 1954 (TTKY 19; Ankara 1955), 67, fig. 16; K. BrTTEL, Bogazköy. Die Kleinfunde der Grabungen 1906-1912. 1. Funde hethitischer Zeit (WVDOG 60; Leipzig 1937 = Osnabrück 1967), 22f, Taf. 14:13.

86 U. MOORTGAT-CORRENS, Ein Spielbrett vom Tell Ailun (?), in: FS für J. FriEDRICH zum 65.Geb., ed. R. VON KIENLE et al. (Heidelberg 1959), 339-345.

87 J. Nougayrol, Jeux profanes, jeux sacrés, RA 41 (1947), 46-49, fig. 8.

88 R.A.S. MACALISTER, Gezer II (1912), 416, fig. 501 ("Degenerated Asthoreth Plaque"); $\mathrm{AOB}^{2}$ Nr. 562 ("Primitive Figur und Amulett"); H.TH. BOSSERT, Altsyrien (Tübingen 1951), Abb. 1074 ("Brettidol"); S.A. CoOK, The Religion of Ancient Palestine in the Light of Archaeology (SchL 1925; London 1925), Pl. $28: 2$ ("Conventional Astarte-Plaque"); A. Millard, Archaeology and the World of the Bible, BAIAS 6 (1986-1987), 46f, Pl. 1 ("game-board").

89 F.W.M. PETRIE, Gerar (1928), 18, Pl. 39:22 = 60:88c (JF 179): 18.Dyn.

90 R. BorgER, HKL III (1975), 127, § 114; ders., Die Inschriften Asarhaddons, Königs von Ägypten (AfO.B 9; Graz 1956 = Osnabrück 1967), 69, §31. 
Das Mühle-Spiel scheint in Palästina erst in römisch-byzantinischer Zeit aufgekommen zu sein ${ }^{91}$, wie die verschiedenen Grafitti auf Stein in Nessana (Abb. 34) ${ }^{92}$, Elousa (Abb. 35) ${ }^{93}$, Jerusalem (Abb. 36) ${ }^{94}$ oder Kapernaum ${ }^{95}$ zeigen und blieb über die Kreuzfahrerzeit ${ }^{96}$ bis zum heutigen Tag beliebt ${ }^{97}$.

91 Von latein. merelli "Setzsteine", [griech. triodion (?)], engl. Nine Men's Morris, franz. Morelles; arab. es-sĭğa, drĭs. Mögliche literarische Belege sind z.B. Ovid, ars amat. 3,365f; ders., tristia 2,481f; Pseudo-Ovid, de vetula 1,636-648. Vgl. auch H. LAMER, RE 13,2 (1927), 1987f u.ö. Vgl. G.E. KIRK, Nine Men's Morris - Morelles - Mühlespiel in Palestine, JPOS 18 (1938), 229-232; auch H. LAMER, Lusoria tabula, RE 13,2 (1927), 1900-2029; L. BECQ DE FOUQUIERES, Les jeux des anciens (21873), 384ff; H.J.R. MURRAY, A History of Board-Games (1952), 37-50; M. RIEMSCHNEIDER, Glasberg und Mühlebrett, Symbolon 6 (1968), 137-149; J. COUPRY, Un joueur de marelle au marché de Philippes, BCH 70 (1946), 102-105, fig. 1f; M.-J. Chavane, Salamine de Chypre VI: Les petits objects (1975), 193-197, PI. 53:572-574; 73:572. Undatierte Belege aus Palästina z.B. F.W.M. PETRIE, Gerar (1928), 19, P1. $42: 7$ (Tell Ğemme); S.J. SALLER, Excavations at Bethany (1949-1953) (SBF.CMa 12; Jerusalem $1957=1982), 127$, Pl. 84:9.16; auch H. SCHMIDT - P. KAHLE (ed.), Volkserzählungen aus Palästina II (1930), 22f.

92 G.E. KIRK, JPOS 18 (1938), 229-232 (undatierter Oberflächenfund).

93 G.E. KIRK, JPOS 18 (1938), 229-232 (undatierter Oberflächenfund), fig. 2 ist kein Mühlespiel.

94 M. ALINE DE Sion, La Forteresse Antonia à Jérusalem (1956), 129f, Pl. 45. 47f; R.A.S. MACALISTER - J.G. DUNCAN, Excavations on the Hill of Ophel, Jerusalem 19231925 (PEFA 4; Jerusalem 1926), 131. 169, fig. 174, Pl. XIII:4 [römisch (?) und byzant.].

95 V. CoRBo, La sinagoga di Cafarnao dopo gli scavi del 1969 (SBF.CMi 9; Jerusalem 1970), Tav. I.

96 Vgl. z.B. C.N. JohNS, Excavations at Pilgrims' Castle, 'Atlit (1932-3): Stables at the South-West of the Suburb, QDAP 5 (1936), 32f, Pl. 25:1f; auch J.-P. THALMANN, Tell cArqa (Liban Nord). Campagnes I-III (1972-1974). Rapport préliminaire, Syria 55 (1978), 15, fig. 3.

97 Vgl. z.B. C. NIEBUHR, Reisebeschreibung nach Arabien, Bd. $1(1774=1968), 170 f$, Taf. 25:L-M; G.E. KIRK, JPOS 18 (1938), 229-232; P.G. BREWSTER, EW 11 (1960), 17f; E. LASKER, Brettspiele der Völker (Berlin 1931), 232-235; F.M. BöHME, Deutsches Kinderlied und Kinderspiel $(1897=1967)$, 644f, Nr. 557; R.C. BELL, Board and Table Games, Vol. I (21979), 91-95; K. TRAPP, Bantu-Spiele (Diss. phil.; 1960), 114f; F. KLEPZIG, Kinderspiele der Bantu (1972), 181f; E. GlonNEGGER, Das Spiele-Buch (Ravensburg 1988), 162ff; TH. MÜLLER-ALFELD, Brettspiele (Frankfurt a.M. - Berlin 1963), 21ff; F.V. GRUNFELD, Spiele der Welt (1979), 59-61.

Das Schlangen-Spiel (ägypt. $m h n$ ), dessen Spielregeln nicht bekannt sind, hatte in Palästina keine Bedeutung; es wurde auf einem runden Spielbrett gespielt, das die Form einer eingeroltten Schlange hatte und deren Körper in Spielfelder eingeteilt war; vgl. dazu z.B. W. DECKER, Spiel, LÄ 5 (1984), 1150; H. RANKE, Das altägyptische Schlangenspiel (SHAW.PH 4; Heidelberg 1920), 1-30; E. GLONNEGGER, Das Spiele-Buch 
Das Sandstein-Exemplar vom Tell Ğemme ist nur schwer zu datieren ${ }^{98}$. In ayyubidisch-mamelukischer Zeit sind in Jerusalem Schalen belegt, auf deren Basis sich ein Mühle-Grafitto befand: Stülpte man sie um, diente die Schale als Spielbrett (Abb. 37) ${ }^{99}$. Die Spielregeln waren schon im Altertum wohl die gleichen wie heute: Das Spiel wurde und wird (ohne Würfel) auf einem quadratischem Spielbrett von zwei Spielern gespielt, von denen jeder abwechselnd 9 weiße bzw. schwarze Steine auf die Schnitt- oder Endpunkte der Linien des Spielfeldes setzt. Dabei versucht jeder Spieler, eine "Mühle", d.h. drei Steine in einer Linie zu erhalten. Wer eine "Mühle" gelegt hat, darf dem Gegenspieler einen freien Stein wegnehmen. Besonders vorteilhaft ist eine Zwick- oder Doppelmühle, bei der das Öffnen der einen Mühle das Schließen der anderen bedeutet: Jeder eigene Zug bringt einen Stein des Gegenspielers ein. Verlierer ist, wer nur noch zwei Spielsteine besitzt oder aber bewegungsunfähig ist.

(1988), 38ff; P. MONTET, Le jeu du Serpent, CEg 30,60 (1955), 189-197; T. KENDALL, Schlangenspiel, LÄ 5 (1984), 653-655; B.E.J. PETERSON, Brettspiel, LÄ 1 (1975), 853; A.F. SHORE, A "Serpent" Board from Egypt, BMO 26 (1963), 88-91; J. VANDIER, Manuel d'archéologie égyptienne IV (1964), 486-493; A. WIEDEMANN, Das Spiel im alten Ägypten (1912), 183; S. SWINY, Bronze Age Gaming Stones from Cyprus, RDAC 1980, 66-74, fig. 1-5, Pl. 11f; ders., A Spiral Game (Mehen) from Lemba Area II?, Levant 14 (1982), 53f; ders., The Kent State University Expedition to Episkopi Phaneromeni, Part 2 (1986), fig. 38-42. 58-60; ders., BA 52 (1989), 186; auch R. DAVIES, Some Arab Games and Puzzles, Sudan Notes and Records 8 (1925), 137-152; R. HolLER, Murmeln, Schusser, Klicker (21987), 13f. 94f.

98 F.W.M. PETRIE, Gerar (1928), 19, Pl. 42:7.

99 A.D. Tushingham, Excavations in Jerusalem, Vol. I (1985), 143. 334, fig. 39:21; als Dekoration vgl. auch D. PrINGLE, Medieval Pottery from Caesarea: The Crusader Period, Levant 17 (1985), 190, fig. 12:58; A.H.S. MEGAw, Supplementary Excavations on a Castle Site at Paphos, Cyprus, 1970-1971, DOP 26 (1972), 323ff, Pl. 28. 
Das Dame-Spiel ${ }^{100}$ [arab. (luc ${ }^{c}$ bet ed-)dāmā; neuhebr. damāh; italien. dama, französ. damier; Spielsteine $=$ ferses $\left.{ }^{101}\right]$ dürfte mit dem römischen ludus latrunculorum weitgehend identisch $\operatorname{sein}^{102}$. Es wurde und wird von zwei Spielern an einem quadratischen Spielbrett mit zumeist $8 \times 8^{103}$ oder $10 \times 10^{104}$ quadratischen und abwechselnd weißen und schwarzen Spielfeldern mit meist 12 bzw. 20 runden Spielsteinen pro Spieler - ohne Würfel - gespielt, die für jede Partei schwarz bzw. weiß gehalten sind. Ziel ist es, mit möglichst vielen Steinen die hinterste gegnerische Reihe zu erreichen und damit Steine in 'Damen' zu verwandeln. Sieger ist, wer dem Gegner alle Steine weggenommen oder ihn so eingeschlossen hat, daß er nicht mehr ziehen kann. Einen sicheren Beleg für das Spiel aus dem antiken Palästina gibt es m.W. nicht.

Manqala ${ }^{105}$ wird heute noch in Vorderasien, Ägypten und anderswo gespielt ${ }^{106}$. Ob die Graffiti in Petra ${ }^{107}$ und auf Umm el-Biyāra (Abb. 38) ${ }^{108} \mathrm{zu}$

100 C. NIEBUHR, Reisebeschreibung nach Arabien, Bd. $1(1774=1968), 171$; W. THESIGER, Die Brunnen der Wüste (21991), 260; F. RoSENTHAL, Gambling in Islam (1975), 46; F.I. KHURI, Tents and Pyramids. Games and Ideology in Arab Culture from Backgammon to Autocratic Rule (London 1990), 18f. 136f; M. BUBER, Die Erzählungen der Chassidim (1949), 518; E. LASKER, Brettspiele der Völker (1931), 204-225; F.M. BöHME, Deutsches Kinderlied und Kinderspiel $(1897=1967)$, 645f, Nr. 558; C.D. GRUPP, Dame. Brettspiel mit allen Varianten (Niedernhausen/Ts. 1979), 102ff; E. GlonNEGGER, Das Spiele-Buch (1988), 144ff; F.V. GRunFELD, Spiele der Welt (1979), 85-87; R.F. MüllER, Dame. Duell mit flachen Steinen (Düsseldorf 1988), 109ff; K.W. KRUIJSWIJK, Algemene historie en bibliografie van het damspel (Den Haag 1966), 14ff. $181 \mathrm{ff}$.

101 Vgl. auch arab. firzān (Dame beim Schachspiel).

102 L. BECQ DE FOUQuiERES, Les jeux des anciens (21873), 422-456; H. LAMER, RE 13,2 (1927), 1976-1979; A. SCHMITT, in: Jahresberichte des Beethoven-Gymnasiums Bonn (1977-1978), 28-31; R.G. AUSIIN, Roman Board Games, GaR 4 (1934-1935) 24 30; K. SCHNEIDER, Latrunculorum ludus, RE 23 (1924), 980-984; A. MAU, diagrammismos, RE 9 (1903), 311f. Wichtigste literarische Quelle ist der Panegyricus Laus Pisonis 190-208 eines unbekannten Verfassers auf den antineronischen Verschwörer des Jahres 65 n.Chr., Piso; vgl. auch Seneca, de tranq. animi 14,7; Ovid, ars amat. 3,357ff und Hist.Aug., quadr.tyr. 13,1ff [Proculus soll, nachdem er zehn Partien dieses Spiels hintereinander gewonnen hatte, von einem Spaßmacher (scurra) zum Augustus ausgerufen worden sein (ave, Auguste)].

$103 \mathrm{Zu}$ quadratischen Spielbrettern (mit unterschiedlich vielen Spielfeldern) vgl. z.B. M.A. MurRaY - J.C. Ellis, A Street in Petra (London 1940), 25, Pl. 7:4 (9 x 9 Spielfelder).

104 Engl. dame, draughts, amerikan. checkers.

105 Arab. manqala von naqala "vom Platz bewegen, fortbewegen"; auch Mbao, Wari u.a. genannt. Vgl. allgemein F. RoSENTHAL, Gambling in Islam (1975), 43f; F.I. KHURI, Tents and Pyramids (1990), 18f. 138f; R.C. BELL, Board and Table Games ( $\left.{ }^{1979}\right)$, Vol. 
Varianten dieses Spiels gehören, ist ebenso unsicher wie ihre Datierung (nabatäisch oder postnabatäisch?). Das Spielbrett besteht in der Regel aus sechs oder mehr Spielmulden auf jeder Langseite und je einer Gewinnmulde an den Schmalseiten. Zu Anfang des Spiels befinden sich in jeder der 12 Spielmulden vier Steine (Bohnen, Nüsse o.ä.). Ziel ist es, möglicht viele gegnerische Steine zu erobern; das Spiel endet, wenn alle Mulden eines Spielers leer sind und sein Gegner keine Möglichkeit mehr hat, ihm wieder Steine hinüberzuspielen.

Das Zwölf-Linien- bzw. Zwölf-Punkte-Spiel (latein. ludus duodecim scripta und tabula), das am besten mit dem im italien. tavola > türk. tavla > arab. (lucbet et-)țāwila, nard, engl. backgammon; franz. tric-trac; deutsch Puff genannten Spiel vergleichbar ist ${ }^{109}$, wurde und wird auf einem symmetrisch an-

I, 113-124, Vol. II, 71-77; E. GlonNEGGER, Das Spiele-Buch (1988), 208ff; F.V. GRUNFELD, Spiele der Welt (1979), 20-24; H.J.R. MURRAY, A History of Board-Games (1952), 158-225; H. SBRZESNY, Die Spiele der !Ko-Buschleute (1976), 156-163; S. CulIN, Mancala, the National Game of Africa, in: E.A. AVEDON - B. SUTTON-SMITH (ed.), The Study of Games (New York u.a. 1971), 94-102.

106 F.W.M. PETRIE, Objects of Daily Use (1927), 55, Pl. 47:175 (Memphis); C. NIEBUHR, Reisebeschreibung nach Arabien, Bd. 1 (1774 = 1968), 171, Taf. 25:H; J.D. WhITING, Petra. Ancient Caravan Stronghold, The National Geographic Mag. 67 (1935), 139; ders., Bedouin Life in Bible Lands. The Nomads of the "Houses of Hair" offer unstinted Hospitality to an American, a.a.O. 71 (1937), 77; E.W. LANE, Sitten und Gebräuche der heutigen Egypter II (1856), 176-179, Taf. 46:A; F. VON LUSCHAN, Zusammenhänge und Konvergenz, MAGW 48 (1919), 51-55, Abb. 45-48; S. SWINY, The Kent State University Expedition to Episkopi Phaneromeni, Part II (1986), fig. 56:h (Aleppo); M. CoHEN, JA 18 (1911) 491ff, PI. B; M. GRIAULE, Jeux Dogons (TMIE 32; Paris 1938), 166ff; K. TrAPP, Bantu-Spiele (Diss. phil.; 1960), 115-125.

107 G. Dalman, Petra und seine Felsheiligtümer (1908), 97f; Nr. 1a; 4f.m; 10b; 11; 86; 108; 121d, Abb. 25. 106. 121.

108 M.A. MURRAY - J.C. Ellis, A Street in Petra (1940), 35, fig. 10; W.H. MORTON, Umm el-Biyara, BA 19 (1956), 24, fig. 6.

109 L. BECQ DE FOUQUIERES, Les jeux des anciens ( $\left.{ }^{2} 1873\right)$, 357-383; Joh. Malalas, Chron. 5, § 22; A. ScHMITT, in: Jahresberichte des Beethoven-Gymnasiums Bonn (1977-1978), 23-28; A. MAU, Duodecim scripta, RE 5 (1905), 1794-1796; H. LAMER, RE 13,2 (1927), 1979ff; ders., Zwei Zeugnisse über römische Brettspiele, Hermes 60 (1925), 107-110; R.G. AusTiN, GaR 4 (1934-1935), 30-34; M.-J. ChAVANE, Salamine de Chypre VI: Les petits objects (1975), 197-205, PI. 53:571.575f; 72:571.575; R.G. AUSTIN, Zeno's Game of table, JHS 54 (1934), 202-205 (zu Anth. Graeca 9,482); K. HIMLY, Einige Worte über das persische Brettspiel Nerd, ZDMG 33 (1879), 679-681; C. NIEBUHR, Reisebeschreibung nach Arabien $(1774=1968), 171 ;$ F. ROSENTHAL, Gambling in Islam (1975), 40-43; E. LASKER, Brettspiele der Völker (1931), 236-245; F.I. KHURI, Tents and Pyramids (1990), 18f. 134f; H.J.R. MURRAY, The Mediaeval Game of Tables, MAe 10 (1941), 57-69; ders., A History of Board-Games (1952), 113ff; R.C. BELL, 
gelegten Spielbrett mit 12 Linien gespielt, die in der Mitte durch eine Querlinie oder eine Unterbrechung geteilt waren, sodaß sich $2 \times 12$ Linien bzw. längliche Dreiecke gegenüberliegen. Zum Spiel gehörten meist 15 weiße bzw. schwarze Spielsteine und zwei Würfel pro Spieler. Die Spielregeln dürften den heute noch üblichen weitgehend entsprochen haben, wenn man von den neueren Weiterentwicklungen und Varianten absieht. Sieger ist, wer seine Steine als erster über die 24 Linien gebracht hat. Das Spiel ist wahrscheinlich erst in der römischen oder byzantinischen Zeit in Palästina aufgekommen und wird noch heute gerne gespielt.

$\mathrm{Zu}$ den verschiedenen Brettspielen gehörten Spiel- oder Setzsteine ${ }^{110}$, die eine pyramidale, anthropo- und theriomorphe ${ }^{111}$, turm-112, scheiben-, kegel-

Board and Table Games (21979), Vol. I, 30ff, Vol. II, 14-23; E. FALKENER, Games Ancient and Oriental and How to play them (New York $1892=21961$ ), 252ff; E. GLONNEGGER, Das Spiele-Buch (1988), 26-28. 31ff; A. KLUGE-PINSKER, Schachspiel und Trictrac (Sigmaringen 1991), 55ff; F.V. GRUNFELD, Spiele der Welt (1979), 143-145. 150-155; TH. MÜLlER-AlFELD, Brettspiele (1963), 11ff; T. HollaND, Backgammon (München 1982), 7ff; O. JACOBY - J.R. CRAWFORD, Das Backgammon-Buch (München 1974), 7-63; G.W. FiNK - G. FUCHS, Backgammon für Anfänger und Könner (Niedernhausen/Ts. 1990), passim; E. HEYKEN - M.B. FISCHER, Das BackgammonHandbuch (Niedernhausen/Ts. 1985), passim. Vgl. auch W.K. PRrTCHETT, "Five Lines" and IG $\mathrm{I}^{2}, 324$, CalifStClAnt 1 (1968), 187-215, Pl. 1-8.

110 Griech. pessos, vgl. syr. pess $\bar{a}$, pest $\bar{a}$; hebr. / aramä. ps [HAL ${ }^{3}$ 3, 892; G. DALMAN, Aramäisch-Neuhebräisches Handwörterbuch $\left.\left(3_{1938}=1987\right), 339\right], p(y) s t^{\prime} / h$ [G. DALMAN, a.a.O., 341; M. JASTROW, A Dictionary of the Targumim $(1903=1989)$, 1168], akkad. passu (AHw 839); latein. tesserae, calculi u.a.; griech. auch chondroi > aramä. 'sqwndry [S. KRAUSS, Griechische und lateinische Lehnwörter im Talmud, Midrasch und Targum II (1899 = 1964), 96]. Vgl. auch allgemein A. MAU, Calculi, RE 3 (1899), 1345; K. REGLING, RE II 9 (1934), 851-854; H. LAMER, RE 13,2 (1927), 2015-2020; S. LASER, Sport und Spiel (1987), 123-126.

111 Vgl. z.B. M. SAlEH - H. SourouZIAN (ed.), Die Hauptwerke im Ägyptischen Museum Kairo (1986), Nr. 12; P. MONTET, Tombeaux de la I $^{\mathrm{re}}$ et la IV $\mathrm{IV}^{\mathrm{e}}$ dynasties à AbouRoach. Deuxième partie: Inventaire des objects, Kêmi 8 (1946), 186-192; F.J. DöLGER, Spielmarken in Fischform aus einem heidnischen Römergrab bei St. Matthias in Trier in: ders., Ichthys 5 (Münster i.W. 1943), 19-35. Ägyptische Spielsteine konnten auch die Gestalt eines (kriegs-)gefangenen Ausländers, z.B. eines Asiaten, haben, vgl. z.B. W.J. TATT, Game-Boxes and Accessories from the Tomb of Tut ${ }^{c}$ ankamūn (1982), 36f, Pl. 13; dazu passen mental lateinische Inschriften auf Spielbrettern bzw. -türmen wie z.B. "Parthi occisi / Britto victus / ludite Romani" (ILS Nr. 8626a).

112 Vgl. z.B. P. GILBERT, Irrigation, jeux de damier et sens rectangle dans l'art égyptien, CEg 40 (1965), 72-78. 
${ }^{113}$, halbkugel- oder zylinderförmige o.ä. Gestalt hatten, aus Materialien wie Stein $^{114}$, Terrakotta ${ }^{115}$, Fayence ${ }^{116}$, Glas ${ }^{117}$, Knochen ${ }^{118}$, Elfenbein ${ }^{119}$ oder Kamel-Dung ${ }^{120}$ bestehen konnten und in Gräbern, Wohnvierteln, Palästen, Tempel und anderen Bauten gefunden wurden. Meist wurden sie ohne eindeutigen Zusammenhang mit den Spielbrettern gefunden, so daß nicht klar ist, welche Spielsteine zu welchen Brettspielen gehören. Die scheibenförmigen ${ }^{121}$ Setzsteine dürften z.B. zu Mühle- und BackgammonSpielen, die kegel- und zylinderförmigen meist zu Felderspielen wie dem

113 Vgl. A. GARDINER, Egyptian Grammar ( $\left.{ }^{3} 1982\right)$, 547, Y 6.

114 Vgl. z.B. R.A.S. MACALISTER, Gezer II-III (1912), 301f, Pl. 201; M. DuNAND, Byblos II (1954), 486. 679. 923, fig. 522. 809. 1035 u.ö.

115 Vgl. auch G. LOUD, Megiddo II (1948), Pl. 288:9; Ch.Ch. MCCown, Tell enNaşbeh I (1947), 245, Pl. 90:15-21; R.A.S. MACALISTER, Gezer II-III (1912), 301ff, fig. 443, P1. 201; E.C.L. DURING CASPERS, AION 47 (1987), 67-74, fig. 18-20.

116 Vgl. z.B. O. TUFNELL, Lachish III (1953), Pl. 56:2; G. LoUD, Megiddo II (1948), P1. 191:10-13; G. VAN DER KOOIJ - M.M. IBRAHIM, Picking up the Threads... (1989), 100, No. 94; J.-W. MEYER, in: R. HACHMANN (ed.), Frühe Phöniker im Libanon (1983), Kat.-Nr. 26-28.

117 Vgl. z.B. Ovid, ars amat. 2,208; Martial, epigr. 7,72,8; 14,18; Laus Pisonis 193.

118 Vgl. z.B. G. Loud, Megiddo II (1948), Pl. 191:9.14f; R.A.S. MACALISTER, Gezer II-III (1912), 301ff, fig. 443; P.J. RIIS - M.-L. BUHL, Hama II 2 (1990), 212f, fig. 98:782.

119 Vgl. z.B. R.A.S. MACALISTER, Gezer II-III (1912), 302ff, fig. 443; F.W.M. PETRIE,

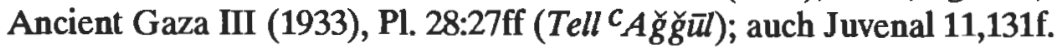

120 J.J. HESS, Von den Beduinen des Innern Arabiens (1938), 140; J. RAABE et al., The Cild and Play (1980), fig. 13; W. THESIGER, Die Brunnen der Wüste ( $\left.{ }^{2} 1991\right), 260$.

121 Vgl. z.B. Ch.Ch. MCCown, Tell en-Nașbeh I (1947), 245, Pl. 90:15-21; R.A.S. MACALISTER, Gezer II-III (1912), 301ff, fig. 443; P.J. RIIS - M.-L. BUHL, Hama II 2 (1990), 212f, fig. 98:782; J.-W. MEYER, in: R. HACHMANN (ed.), Frühe Phöniker im Libanon (1983), Kat.-Nr. 26-28. 
Senet-Spiel gehört haben ${ }^{122}$. Die Löcher- bzw. Steckspiele dagegen hatten kleine Stäbchen als Spielsteine ${ }^{123}$.

Heiden ${ }^{124}$, Juden ${ }^{125}$, Christen ${ }^{126}$ und Moslems ${ }^{127}$ belegten Würfel- und Brettspiele mit Verboten, zumindest soweit dabei um Geld oder Geldwerte

122 Vgl. z.B. D.T. ARIEL, Excavations at the City of David 1978-1985, Vol. II (1990), 122-124, fig. 9A.B:BI 21 (Jerusalem, Stratum 17); O. TUFNELL, Lachish III (1953), PI. 56:2; dies. et al., Lachish IV. The Bronze Age (Oxford u.a. 1958), 234, Pl. 54:6; R.A.S. MACALISTER, Gezer II-III (1912), 301ff, Pl. 201; G. LoUD, Megiddo II (1948), Pl. 288:9; Ch. Clamer, Qad. 14 (1981), 33; F.W.M. PETRIE, Ancient Gaza III (1933), Pl. 28:27f $\left(\right.$ Tell $c_{A}$ ğğull); Z. MESHEL, Horvat Ritma - An Iron Age Fortress in the Negev Highlands, TA 4 (1977), 125, fig. 8:10, Pl. 11,3 ("stone weight or gaming piece"); J.-W. MEYER, in: R. HACHMANN (ed.), Frühe Phöniker im Libanon (1983), Kat.-Nr. 26-28; M. DUNAND, Byblos II (1954), 486ff. 679. 923, fig. 522. 809. 1035; E. FEUCHT, Vom Nil zum Neckar (1986), Nr. 349; auch A. GARDINER, Egyptian Grammar ( $\left.{ }^{3} 1982\right)$, 547, Y 6. 123 Auch diese Objekte, die zumeist aus Knochen hergestellt wurden, aber von recht unterschiedlicher Größe sein konnten, hatten mehrere Funktionen: Sie konnten als Spielsteine, Los-Stäbchen und Amulette / Schmuck dienen, vgl. z.B. E.E. PLATT, BA 41 (1978), 23-28; zum Stab-Orakel vgl. W. GuNDEL, Rhabdomanteia, RE 2,1 (1914), 13-18, wozu bekanntlich auch Pfeile als Orakel-Stäbe dienen konten, vgl. z.B. G.J. BOTTERWECK - H.A. HOFFNER, hes, ThWAT 3 (1977-1982), 133f; A. FISCHER, Pfeile aus Nab'Holz, ZDMG 58 (1904), 877-887; J. WellHAUSEN, Reste arabischen Heidentums (Berlin - Leipzig 1927), 132f; J. SCHEFTELOWTZ, Alt-palästinensischer Bauernglaube $(1925=1975)$, § 60; F. RosENTHAL, Gambling in Islam (1975), 32ff. Zu arab. maisir, einem Losspiel mit Pfeilen, vgl. B. CARRA DE VAUX, Maisir, EI 3 (1936), 168 (z.B. Koran, Sure 2,219; 5,90-92).

124 Vgl. z.B. Plautus, mil. glor. 164; Horaz, carm. 3,24,58 (vetita alea); Cicero, Phil. 2,56; Ovid, tristia 2,471f (non leve crimen); Martial, epigr. 5,84; 14,1.3; Isidor von Sevilla, etym. 18,68 (de interdictione aleae); im Corpus Iuris Civilis z.B. Dig. 11,5,1ff, auch C. SCHOENHARDT, Alea. Über die Bestrafung des Glückspiels im älteren römischen Recht. Eine strafrechtsgeschichtliche Studie (Stuttgart 1885), passim; E. WEISS, Lex publica, RE 24 (1925), 2404.

125 Vgl. z.B. bSan. 24b.25b; allgemein S. KRAUSS, Talmudische Archäologie III (1912), 110. 113; H.H. COHN, Gambling, EJ 7 (1971), 299-303.

126 Vgl. z.B. Eusebios, hist. eccl. 5,18,11; Klem. Alex., Paid. 3,11,75; Hieronymus, de viris ill. $\mathbf{4 0}$ (mit der rhetorischen Frage "tabula ludit et tesseris propheta?"); Lex alearia; Canones Apost. 42f; 79.Kanon des Konzils von Elvira (Anfang 4.Jh.n.Chr.); 50.Kanon des Trullanums II (Konstantinopel, 692 n.Chr.); Cod. Iust. 3,43,1 u.ö.; zumeist liefen die Verbote im Christentum auf eine vorübergehende Exkommunikation der Laien und eine Absetzung bzw. 'Degradierung' der Kleriker hinaus. Vgl. auch das deutsche Sprichwort: "Der Spieler ist von Gott verachtet, weil er nach fremdem Gelde trachtet". 
gespielt wurde, und vor allem um Auswüchse zu bekämpfen. Gelegentlich verteufelten sie diese Spiele aber im wahrsten Sinn des Wortes, indem sie sie zusammen mit idolatria, moechia, furtum, rapina, fraus etc. als temptationes diaboli in einen Topf warfen: So heißt es z.B. in dem unter dem Namen Cyprians überlieferten Traktat de aleatoribus 128 nicht nur: "alea ne luseris" oder "aleam noli respicere", sondern auch: "Esto potius non aleator, sed Christianus", oder "aleae tabula, quod est diaboli venabulum" bzw. "ubi diabolus praesto est". Kyrill, Bischof von Jerusalem (ca. 348-386 n.Chr.), schrieb in seinen Katechesen unter anderem: "pompē de diabolou esti theatromaniai kai hippodromiai..." (Kat.myst. 1,6). Hier werden das Spielen mit Würfeln an sich und nicht etwa nur seine Auswüchse ebenso verurteilt wie der Besuch des Theaters oder der Wagenrennen. Die Verbote und Verteufelungen verhinderten jedoch weder, daß in den Vorhöfen von Synagogen ${ }^{129}$ sowie Kirchen und Klöstern ${ }^{130}$ Palästinas Brettspiele in die Plattenböden geritzt wurden $^{131}$, damit man sich vor, nach und eventuell auch während der Gottesdienste die Zeit besser vertreiben konnte, noch daß den Toten Würfel oder Brettspiele ins Grab gelegt wurden ${ }^{132}$ oder daß die Repräsentanten von Gesetz und Religion wie Kaiser, Priester ${ }^{133}$ und Äbte entgegen den Gesetzen unbekümmert Würfel- und Brettspiele spielten.

127 Vgl. z.B. F. RosENTHAL, Kimār, EI 5 (1986), 108-110. Besonders sinnig ist die Formulierung "auch jedes erlaubte Spiel ist gestattet" eines islamischen Reformers aus dem Jahr 1218 / 1803, in: Religionsgeschichtliches Lesebuch H. 16 (ed. A. BERTHOLET) (Tübingen 21931), 164.

128 CSEL 54,3 (1871), 92-104; A. HARNACK, Der pseudocyprianische Tractat de aleatoribus (1888), 11ff.

129 V. Corbo, La sinagoga di Cafarnao dopo gli scavi del 1969 (1970), Tav. I. Vgl. aber auch H.H. CoHN, Gambling, EJ 7 (1971), 301.

130 Vgl. z.B. V. TZAFERIS, The Excavations of Kursi - Gergesa ('CAtiqot ES 16; Jerusalem 1983), 20, Pl. 7:4. Gregor von Tours, hist. 10,16,5-26 berichtet von der Äbtissin des Ragunde-Klosters in Poitiers, Leubowera, der von ihren Gegnerinnen - teilweise zu Recht - vorgeworfen wurde, sie habe mit Würfeln (ein Brettspiel) gespielt (ad tabulam ipsa luserit, 10,16,6); die Äbtissin wies in ihrer Verteidigung daraufhin, daß dies weder durch die Hlg. Schrift noch durch kanonisches Recht verboten sei (tamen nec in regula per scripturam prohibere nec in canonibus retulit, 10,16,25f).

131 Vgl. schon die auf den Dächern (u.ä.) altägyptischer Tempel eingeritzten Brettspiele, z.B. im Chons-Tempel von Karnak, im Totentempel des Userkaf in Saqqara oder im Sonnenheiligtum des Niuserre in Abusir, E.B. PUSCH, Das Senetspiel im Alten Ägypten (1979), 169-171. 356-360. 363f, Nrn. 6-8. 72-74. 76, Taf. 39b. 40a-b. $91 f$.

132 R.A.S. MACAlisTER, The Excavation of Gezer, Vol. I (1912), 317 = ders., Vol. IIIII (1912), 304, Pl. 78:26 (frühchristliches Grab 40). Vgl. z.B. auch Pindar, frg. 107.

133 Vgl. z.B. Plutarch, quaest. Rom. 35 (im Herakles-Tempel). 
Aus dem römischen Jerusalem ${ }^{134}$ und Aschkelon ${ }^{135}$ sind scheibenförmige Steine aus Knochen bekannt, die beidseitig beschriftet bzw. verziert waren (Abb. 39). Derartige Scheiben waren in verschiedenen Serien bzw. Formen im gesamten römischen Reich verbreitet. Auf dem Avers der einen Scheibe aus Jerusalem ist eine äygptische Pylonenanlage (griech. ptera ?!) im erhabenen Relief abgebildet und auf dem Revers das lateinische Zahlzeichen XIIII und die griechischen Inschrift PTERA ID eingeritzt ${ }^{136}$. Auf dem Avers der anderen Scheibe aus Jerusalem ist eine Hand mit ausgestrecktem Zeigefinger und ausgestrecktem kleinen Finger in erhabenem Relief abgebildet und auf dem Revers das lateinische Zahlzeichen XIIII eingeritzt ${ }^{137}$. Die Scheiben sind alexandrinischer Herkunft. Sie wurden und werden u.a. ${ }^{138}$ als Eintrittsbillets für das Theater bzw. Circus interpretiert ${ }^{139}$, doch könnte es sich bei ihnen auch um Spielsteine bzw. Spielmarken handeln; bei welchem Spiel sie dann aber eingesetzt worden sein sollen, ist unbekannt ${ }^{140}$.

134 N. AVIGAD, Discovering Jerusalem (1983), 193f, fig. 239 (ca. 2.Hälfte des 1.Jh.s v.Chr. bzw. der 1.Hälfte des 1.Jh.s n.Chr.).

135 L.E. STAGER, Ashkelon Discovered. From the Canaanites to Romans and Moslems (Washington/DC 1991), 42 mit der Beschriftung PHAMOLHS VII $H$ auf dem Revers und zwei Gebäuden auf dem Avers; vgl. dazu E. AlFÖLDI-ROSENBAUM, Alexandriaca. Studies on Roman Game Counters III, Chiron 6 (1976), 221f. 234f, Taf. 26, Nos. 64-69. Zur Aufschrift vgl. A. RUSCH, Paamyles, RE 18,2 (1942), 2053; J.G. GRIFFTTHS, Pamylien, LÄ 4 (1982), 659f

136 E. AlFöldi-RoSEnBAUM, Chiron 6 (1976), 222f, 235: XVI, Taf. 27, Nos. 70-73. 83.

137 E. Alföldi-Rosenbaum, The Finger Calculus in Antiquity and in the Middle Ages. Studies on Roman Game Counters I, FMSt 5 (1971), 1-9.

138 R. GöBL, Antike Numismatik I-II (München 1978), 31f, Taf. 8.

139 Vgl. z.B. auch A. HAMBURGER, Surface-Finds from Caesarea Maritima - Tesserae, in: L.I. LEVINE - E. Netzer (ed.), Excavations at Caesarea Maritima 1975, 1976, 1979 Final Report (Qedem 21; Jerusalem 1986), 187f.

140 Vgl. vor allem H. LAMER, RE 13,2 (1927), 2013-2015 u.ö.; H. LECLERQ, DACL 7,2 (1927), 2511-2513; J.H. VAN DER WERFF, Notes on a Grafitto from the Basilica Aemilia, BABesch 48 (1973), 83-90; K. REGLING, RE II 9 (1934), 851-854; M. RosTOVTZEFF, Interpretation des tessères avec figures, chiffres et légendes en os, RAr IV.Série (1905), 110-124; A. AlFÖLDI, Heiden und Christen am Spieltisch, JAC 18 (1975), 19-21 und E. Alföldi-RosenBAUM, The Muses on Roman Game Counters. Studies on Roman Game Counters II, Muse 9 (1975), 13-20; dies., Ruler Portraits on Roman Game Counters from Alexandria. Studies on Roman Game Counters IV, in: Eikones. Studien zum griechischen und römischen Bildnis. FS für H. JUCKER zum 60.Geb. (AK Bh. 12), Bern 1980, 29-39; M. JENTOFT-NILSEN, Some Objects relating to the Theatre, GettyMusJ 10 (1982), 159-162, fig. 4f; auch T.V. BUTTREY, The Spintriae as a Historical Source, NumC 13 (1983), 52-63, Pl. 3f. 


\section{KREISEL}

Kinder verschiedenster Kulturen und Nationen spielen auch heute noch mit Kreiseln. Aus literarischen, epigraphischen und ikonographischen Quellen ist nicht unmittelbar zu belegen, daß palästinische ${ }^{1}$ Kinder in der Antike wie z.B. Ägypter ${ }^{2}$, Griechen ${ }^{3}$, Römern ${ }^{4}$ u.a. ${ }^{5}$ mit den verschiedenen Arten von Krei-

1 Arab. nahla, hudrüf, auch furrēra; neuhebr. $s^{e}$ bîbôn; H. SCHMIDT - P. KAHLE (ed.), Volkserzählungen aus Palästina I (1918), 76f: "Das Kreiselspiel wird in Bir-Zet so gemacht: die Kinder schneiden aus einem Stück Granatapfelschale ein rundes Stück heraus, stecken einen Stab hinein und wirbeln den Kreisel".

2 F.W.M. PETRIE, Objects of Daily Use (1927), 58, Pl. 50:352. 359 f (Peitschen-Kreisel aus Holz).

3 Griech. strobilos, strombos, bembix, kōnos, rhombos. Vgl. z.B. Homer, Il. 14,413; Platon, politeia 436d-e; Aristophanes, aves 1461ff; ders., pax 864; ders., vesp. 1517. 1530; Anth. Graeca 6,309; 7,89,10; Orph. frag. Nr. 34 (KERN); Suida 1,467 (ADLER). Auch S. LASER, Sport und Spiel (1987), 98f, Abb. 38; L. DEUBNER, Antike 6 (1930), 166f, Abb. 4, Taf. 15a; A.S.F. Gow, 'Iygr, rhombos, rhombus, turbo, JHS 54 (1934), 1-19; L. GRASBERGER, Erziehung und Unterricht im klassischen Alterthum I 1 (1864), 77-81. 159; A. HUG, Rhombos, RE II 1 (1914), 1069f; ders., Turbo, RE II 7,14 (1948), 1374-1376; R. SCHMIDT, Die Darstellung von Kinderspielzeug und Kinderspiel (1977), 39-44; S. MENDNER, RAC 10 (1978), 855. 866. 888; K. SCHAUENBURG, AW 7,3 (1976), 43 ; I. WEHGARTNER, Attisch weißgrundige Keramik. Maltechniken, Werkstätten, Formen, Verwendung (Keramikforschungen 5; Mainz 1983), 66. 96, Kat.-Nr. 62, Taf. 31.

4 Latein. turbo, strobilus. Vgl. z.B. Plinius d.Ä., nat. hist. 2,47; Cicero, de fat. 42; Kallimachos, epigr. 1,9ff = Diog. Laert. 1,80; Persius, sat. 3,4ff; A.S.F. Gow, JHS 54 (1934), 1-19; L. BECQ DE FOUQUIERES, Les jeux des anciens (21873), 170-175; A. HUG, RE II 7,14 (1948), 1374-1376; A. BLANCHET, Enfant joueur de "sabot", RAr. VI.Série, IV (1934), 195f; G. CAPUTO, Dell'antico giuoco del paleo, Hist(M) 7 (1933), 185-198; J. VÄTERLEIN, Roma ludens (1976), 45f, Abb. 14; G. LAFAYE, Turben, turbo, DarS 5 (1919), 541f.

5 Ethnologische Belege z.B. bei L. BAUER, Volksleben im Lande der Bibel ( $\left.{ }^{2} 1903\right), 74$; R. ANDREE, Das Kreiselspielen und seine Verbreitung, Globus 69 (1896), 371-373; H. DAMM, Kreiselspiele bei den Indonesiern und Südseevölkern, in: In memoriam K. WEULE (Leipzig 1929), 299-334; G. CHANAN - H. FranCIS, Toys and Games of Children of the World (1984), passim; F.V. GRUNFELD, Spiele der Welt (1979), 174-176; F.K. MATHYS, Im Freien gespielt (1975), 12f; V. HARMS, Der Terminus "Spiel" in der Ethnologie (1969), 172f. 213-215; K. TrAPP, Bantu-Spiele (Diss. phil.; 1960), 88-91; F. KLEPZIG, Kinderspiele der Bantu (1972), 60f. 93f. 229. 247f. 275f. 337. 351. 467; J. HILLS, Das Kinderspielbild von Pieter Bruegel d.Ä. (1957), 41-44, Nr. 56; A. LUKACSY, Spiele der Welt (1972), 98f; S. PAUL, Notizen zu einigen afrikanischen Geschicklichkeitsspielen (Lic. phil. masch. Uppsala 1962), 97ff; dies., Afrikanische Kreiseltypen und 
seln gespielt haben. Indirekt ist der Beweis allerdings leicht zu führen: Allein schon die Ähnlichkeit der Spindel mit einem Kreisel ${ }^{6}$ legt es nahe, aus einem Spinnwirtel oder einer runden, zentriert durchbohrten Scherbe und einem Holzstäbchen einen Stab-, Drill- bzw. Finger-Kreisel zu machen (Abb. 40) ${ }^{7}$, der mit Hilfe des Daumens und Mittelfingers in Drehung versetzt wurde (Tibull 1,5,4) - ähnlich wie man es auch mit Münzen machen konnte (Abb. 43) ${ }^{8}$. Zudem wurde das griech. Wort für Kreisel strobilos ins Aramäische als 's/ștrwbyl übernommen'. Am Hanukka-Fest spielen jüdische Kinder mit kubusförmigen Würfel-Kreiseln bzw. Drehwürfeln (Tetotum, jidd. Trendl, Trejdl u.ä.) (Abb. 42), dessen vier Außenseiten mit den Anfangsbuchstaben $n-g$ - $h$ $-\zeta / p$ (ns gdwl hyh $5 \mathrm{~m} / p h=$ "Ein großes Wunder ist dort / hier geschehen" bzw. nichts - ganz / gib! - halb - stell ein!) markiert sind; gespielt wird um Nüsse oder ähnliches, und man gewinnt oder verliert je nach den Buchstaben, der nach oben liegend zum Stillstand gekommen ist ${ }^{10}$; ähnliches war und ist auch am christlichen Lichterfest, Weihnachten, üblich ${ }^{11}$. Vergleichbare Drehwürfel waren schon lange zuvor in Ägypten bekannt ${ }^{12}$. Aller Wahrscheinlichkeit haben die Kinder des antiken Palästina auch mit Kletter-Kreiseln ("Jo-jo") ge-

Kreiselspiele, Veröffentlichungen aus dem Übersee-Museum in Bremen B II,4 (1971), 237-272; S. PETRIGNANI, Il Catalogo dei Giacattoli (Rom 1988), 46f; H. SBRZESNY, Die Spiele der !Ko-Buschleute (1976), 107-110; M. GRIAULE, Jeux et divertissements abyssins (1935), 13-15, Pl. I:1-3; XIX:1.

6 Vgl. z.B. Catull, carm. 64,314ff; auch R. HoLlER, Kreisel (homo ludens; München 1989), 88.

7 O. REUTHER, Die Innenstadt von Babylon (1926 = 1968), Taf. 84:195h; R. HoLlER, Kreisel (1989), 18-36.

8 Zum chalkismos s. oben Kap. 1.

9 S. KRAUSS, Griechische und lateinische Lehnwörter im Talmud, Midrasch und Targum II $(1899=1964), 121$.

10 M. Zobel, Das Jahr des Juden in Brauch und Liturgie (Bücherei des SchockenVerlages 55-56; Berlin 1936), 138; M. GRUNWALD, Chanukka, in: Fr. THIEBERGER (ed.), Jüdische Feste, jüdischer Brauch. Ein Sammelwerk (Berlin 21967 = 1976), 344; F.V. GRUNFELD, Spiele der Welt (1979), 142.

11 F.M. BöHME, Deutsches Kinderlied und Kinderspiel $(1897=1967), 643 f$, Nr. 554 mit den vier lateinischen Buchstaben $A$ (= Alles), $H$ (= Halbgewonnen), $O$ (= Null, Nichts) und $S$ (Setzen, d.h. der Spieler muß noch hinzulegen); auch R.C. BELL, Board and Table Games (21979), Vol. I, 148, Vol. II, 7-10; R. NoLL, Seltsame Spielwürfel, BJB 174 (1974), 567-569: $N D$ = Nimm deins!, $N H=$ Nimm halb!, $N G$ = Nimm ganz!, $S Z=$ Setze zu!, $L S=$ Lasse stehen!, $T A=$ Trink aus!.

12 Vgl. z.B. R. DRENKHAHN, Elfenbein im Alten Ägypten. Leihgaben aus dem PetrieMuseum London (Katalog des Deutschen Elfenbeinmuseums Erbach; Erbach 1986), 52. 56, Nr. 74 (Grabfund aus der 19.Dyn.). 
spielt ${ }^{13}$. Auch das "capita-aut-navia"-Spiel ist eine Art Kreiselspiel (Kap. 1, Abb. 43).

Auch wenn außerhalb Palästinas verschiedentlich Kreisel aus dauerhaften Materialien wie Terrakotta oder Stein gefunden wurden, so dürfte der Großteil aller Kreisel doch aus vergänglichem Holz hergestellt gewesen sein. Mit Kreiseln spielten Götter (z.B. Hermes) ebenso wie Kinder (und selten auch Erwachsene), und dies bei nichtkultischen wie auch bei kultischen Anlässen ${ }^{14}$. Griechische $^{15}$ und andere Originalfunde ${ }^{16}$, literarische (z.B. Anth. Graeca

13 Ein Geschicklichkeitsspiel mit einer Schnur, die sich an einer Doppelscheibe ("Fadenrädchen") auf- und abwickelt (engl. yo-yo); erhalten sind fast nur tönerne Nachbildungen, die - vor allem als ex-votos und Grabbeigaben - die hölzernen Originale imitieren. M. JANSEN (ed.), Vergessene Städte am Indus. Frühe Kulturen in Pakistan vom 8. bis 2.Jahrtausend (Mainz 1987), 273, Kat.-Nr. C 82; S. PAUL, Notizen zu einigen afrikanischen Geschicklichkeitsspielen (Lic. phil. masch.; Uppsala 1962), 116; G.N. VAN BEEK, BASOR 275 (1989), 53-58; P.G. BREWSTER, ZE 80 (1955), 89f; G. CHANAN - H. FRANCIS, Toys and Games of Children of the World (1984), 69. 80, Abb. 119. 157; F.V. GRUNFELD, Spiele der Welt (1979), 262; R. Holler, Kreisel (1989), 75-79; L. DEUBNER, Antike 6 (1930), 166-168, Abb. 6-9; H. GosSEN, 'Iygx, RE 10,2 (1919), 1384-1386; A.S.F. GOW, JHS 54 (1934), 1-19; I. WEHGARTNER, Attisch weißgrundige Keramik (1983), 154-160. 220-222, Kat.-Nrn. 1-6, Taf. 52f; H. RüHFEL, Das Kind in der griechischen Kunst (1984), 232-235 (Anm. 187), Abb. 98f; R. SCHMIDT, Die Darstellung von Kinderspielzeug und Kinderspiel (1977), 81-85; J. VÄTERLEIN, Roma ludens (1976), Abb. 16; G. Schumacher, Tell el-Mutesillim I. Fundbericht (Leipzig 1908), Taf. 34:a ("Wirtel); F.W.M. PETRIE, Objects of Daily Use (1927), 53, Pl. 48:35.38.42 ("Reels"); R. ANTHES, Mit Rahineh 1956 (1965), 131f, Pl. 48:295. $297-300$ ("Spools, Earstuds?"); H. GolDMAN, Excavations at Gözlü Kule, Tarsus, Vol. II (1956), 338f, Pl. 455:22 (?). Vgl. auch die Kinderverse bei E. BorNEMANN, Studien zur Befreiung des Kindes I (1973), Nr. 153 und 839: "Irgendwo / Auf dem Klo / sitzt ein Mann / und spielt Jojo"; "Hier auf dem Klo / spielt man nicht Jojo!".

Im Alten Orient offenbar noch nicht bekannt war jenes Geschicklichkeitsspiel, das man heute Diabolo nennt und bei dem man einen sanduhrförmigen Körper mit einer Schnur in Rotation versetzt, in die Höhe schnellen läßt und wieder aufzufangen versucht, vgl. z.B. M. GRIAUle, Jeux et divertissements abyssins (1935), 26-28, Pl. I:5; S. PAUL, BaA 18 (1970), 219-221; V.F. GRUNFELD, Spiele der Welt (1979), 260f.

14 Vgl. z.B. A.D. TRENDALl - G. SCHNEIDER-HERRMANN, BABesch 50 (1975), 267270; auch A. JEREMIAS, Handbuch der altorientalischen Geisteskultur (Berlin - Leipzig 21929), 140; A.E. JENSEN, Mythos und Kult bei Naturvölkern ( $\left.{ }^{2} 1960=1991\right), 102 f$.

15 P. Wolters - G. BRUNS, Das Kabirenheiligtum bei Theben I (Berlin 1940), $123 \mathrm{f}$ u.ö., Taf. 18:4ff u.ö.; K. BRAUN - TH.E. HAEVERNICK, Bemalte Keramik und Glas aus dem Kabirenheiligtum bei Theben (1981), 114, Taf. 34:32.34 (Kreisel aus Speckstein); B. SCHMALTZ, Terrakotten aus dem Kabirenheiligtum bei Theben (1974), 141 (Kreisel aus Terrakotta). 
6,309) und epigraphische Belege ${ }^{17}$ zeigen, daß Kreisel als ex-votos in Heiligtümern und Tempeln hinterlegt werden konnten; außerdem wurden Kreisel in Wohnquartieren und Gräbern gefunden. Das Orthostaten-Relief des 8.Jh.s v.Chr. aus Karkemisch (Abb. 18) zeigt Königssöhne beim Spielen mit kegelförmigen Schnur- bzw. Peitschen-Kreiseln (Abb. 41) ${ }^{18}$, wobei sie sie mit Hilfe von Peitschen bzw. Geißeln ${ }^{19}$ in Rotation versetzen.

"Wie zuweilen ein Kreisel sich dreht unterm Wirbel der Peitsche, den in großem Bogen die Knaben rings in der freien Halle treiben, versessen aufs Spiel;

der fliegt unterm Hieb des Riemens in kreisendem Rund, unwissend bestaunen, von oben schauend, die Knaben verwundert das wirbelnde Buchsbaumgebilde;

Schläge geben ihm Kraft" (Vergil, Aeneis 7,378-384) ${ }^{20}$.

16 M. DUNAND, Byblos II (1954), 345f, fig. 10199 könnte ein Kreisel (aus Terrakotta) sein.

17 IG 7 (1892), Nr. 2420:22.

18 Vgl. z.B. Persius, sat. 3,51; Kallimachos, epigr. 1,9f = Diog. Laert. 1,80. Allgemein R. HOLLER, Kreisel (1989), 37-61.

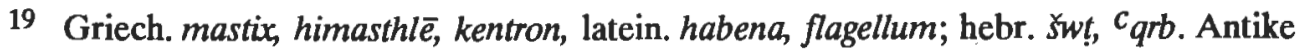
Darstellungen z.B. bei A.D. TRENDALL - G. SCHNEIDER-HERRMANN, BABesch 50 (1975), 267-270; Originalfunde z.B. R. HAMPE, Neuerwerbungen 1957-1970. Katalog der Sammlung Antiker Kleinkunst des Archäologischen Instituts der Universität Heidelberg, Bd. 2 (1971), 11f, Taf. 12:22 (Kreisel aus Terrakotta). Zusammenfassend z.B. A. HUG, RE III (1929), 1768. 1776f; G. FOUGERES, Flagellum, DarS 2, 1154; Vgl. auch R. HollER, Kreisel (1989), 53-61. Nach dem Leben und Taten Alex.s von Makedonien (ed. H. VAN THIEL), 1,36,1ff; 1,38,7; 2,7,1.

20 Übersetzung von J. GöTTE. Vgl. auch G. HIRST, Note on Vergil Aeneid VII 376384, CQ 31 (1937), 65f. Die Papyrus-Funde von Masada und Nessana belegen, daß Vergils Aenëis im römischen Palästina bekannt war, vgl. P.Mas. II, No. 721 und P.Ness. II, Texts 1f. 


\section{IUNX}

Vor kurzem - aber keineswegs als erster - hat G.N. VAN BEEK erneut darauf aufmerksam gemacht, daß die in Wohnbereichen und Gräbern Palästinas häufig gefundenen (Ton-)Scheiben, die zweifach durchbohrt sind, wahrscheinlich als (Kinder-)Spielzeug verwendet worden sind (Abb. 44) ${ }^{1}$. Derartige Scheiben mit einem Durchmesser von ca. 3-5 cm sind in Palästina ${ }^{2}$, Phönizien $^{3}$, Syrien $^{4}$ und anderswo ${ }^{5}$ vor allem während der Bronze- und Eisenzeit,

1 G.N. VAN BEEK, The Buzz: A Simple Toy from Antiquity, BASOR 275 (1989), 53-58. Vgl. z.B. auch N. MEYER, Un "Diable" découvert dans les fouilles urbaines de SaintDenis, Archaeologia musicalis 1 (1987), 8.

2 Y. AHARON, Beer-Sheba I (1973), Pl. $73: 9$ ("button", aus Haus 25, Stratum II); W.F. ALBRIGHT - J.L. KELSO, The Excavations of Bethel (1934-1960) (1968), 18f. 58 ("It may be a bull-roarer"). 68. 231. 279, Pl. 33:12; 115:16; B. BAGATTI, I Monumenti di Emmaus el-Qubeibeh (SBF.CMa 4; Jerusalem 1947), Tav. 32, Fot. 69:13; R.G. BolING, Excavations at Tananir, 1968, in: G.M. LANDES (ed.), Report on Archaeological Work at Șuwwānet eth-Thantya, Tananir, and Khirbet Minha (Munhata) (BASOR.S 21; Missoula/MT 1975), 56, fig. 30:a ("button"); A. CHAMBON, Tell el-Far'ah 1. L'âge de fer (Mémoire no. 31; Paris 1984), Pl. 77:1f (niveau VII); W.G. DEVER (ed.), Gezer IV (Jerusalem 1986), 86. 115, Pl. 57:20 ("spindle whorl" bzw. "button", Eisenzeit I); Pl. 60:6 ("button", Eisenzeit I); Pl. 61:9 ("button"); W.J. BENNETT - J.A. BLAKELEY (ed.), Tell el-Hesi. The Persian Period (Stratum V) (1989), 302-304, fig. $225: 3$ ("button" aus Stein); R.A.S. MACALISTER, The Excavation of Gezer, Vol. II-III (1912), 90. 93, Pl. 24:33; 132:37-39; R.S. LAMON - G.M. SHIPTON, Megiddo I (1939), Pl. 102:14-18 (Strata II-IV) ("button"); F.W.M. PETRIE - (E.J.H. MACKAY) - (M.A. MURRAY), City of Shepherd Kings, (Ancient Gaza V; London 1952), 18f, Pl. 24:39f (Mittelbronzezeit II); ders., Gerar (1928), 18, Pl. 39:24f (Eisenzeit II) ("Children now spin such discs as toys by means of two stretched strings passing through the holes"); E. MACDONALD, in: F.W.M. PETRIE, Beth-Pelet II (London 1932), 14, Pl. 23:37 (chalkolith.); Y. YADIN, Hazor I (1958), Pl. 89:16 = 159:27 ("Button", Spätbronzezeit II); ders., Hazor II (1960), Pl. 127:7 ("Button", Spätbronzezeit II); F.J. BLISS - R.A.S. MACALISTER, Excavations in Palestine during the Years 1898-1900 (1902), 143. 148, Pl. 73: 12S; 78; zu Bet-Schean vgl. G.N. VAN BEEK, BASOR 275 (1989), 53-58 (Spätbronzezeit II).

3 M. DUNAND, Fouilles de Byblos II (1954), 373. 485. 497, fig. 408:10580; 519:11967; 544:12126; auch P.M. BIKAI, The Pottery of Tyre (Warminster 1978), 13, PI. 14:24 (Stratum III).

4 Vgl. z.B. B. HroudA, Tell Halaf IV (1962), 52. 55, Taf. 41:264-269.

5 R. ANTHES, Mit Rahineh 1956 (1965), 134, no. 320, Pl. 50a (ptolemä.?); J.-L. HUOT et al., Larsa. Preliminary Report of the Seventh Campaign at Larsa and the First Campaign at Tell el-'Oueili (1976), Sumer 36 (1980), 123, fig. 23:h ("weight"); E. KARUTZ, Über Kinderspielzeug, ZE 43 (1911), 237-239, Abb. 3; M. GRIAULE, Jeux et divertisse- 
aber auch später gut belegt. G.N. VAN BEEK führt seinen Indizienbeweis über eigene Kindheitserinnerungen und über moderne Beispiele aus den USA und Australien, übersieht aber dabei, daß das Spielen mit doppelt durchbohrten Scheiben schon im griechischen und römischen Kulturraum als 'iygx, iunx bzw. iynx bekannt war ${ }^{6}$ und es aus der arabischen Halbinsel näherliegende ethnologische Parallelen gibt ${ }^{7}$. Zum Spielen wurde eine Schnur durch die beiden Löcher der Scheibe gezogen; durch das Spannen (bzw. Aufwickeln) und Entspannen der Schnur geriet der Scheiben-'Kreisel' ins Schwingen bzw. Hüpfen, wobei häufig ein schwirrender bzw. summender Ton entstehen konnte (Abb. 45) $)^{8}$. Ob man in Palästina beim Spielen mit dem 'Liebesrädchen' bzw. Zauber-Kreisel auch, wie es bei Griechen und Römern häufig der Fall war, Zauber- und Liebessprüche sprach (vgl. z.B. Anth. Graeca 5,205), ist unbekannt. Die weitverbreiteten Interpretationen dieser Scheiben als Knöpfe oder Spinnwirtel sind jedenfalls kaum haltbar.

"Iygx, ziehe du mir zu meinem Hause den Jüngling!" (Theokrit 2,17ff) ${ }^{9}$

ments abyssins (1935), Pl. I:6; ders., Jeux Dogons (1938), 94f; F. KLEPZIG, Kinderspiele der Bantu (1972), 51; H. SBRZESNY, Die Spiele der !Ko-Buschleute (1976), 107, Abb. 29.

6 H. GossEN, Iygx, RE 10,2 (1919), 1384-1386; E. BRANDT, Ein spätklassischer Silberring in München, AK 12 (1969), 61-67; J.B. BURY, Iygx in Greek Magic, JHS 7 (1886), 157-160; A.S.F. GOW, JHS 54 (1934), 1-19; J. DE LA GENIERE, Une roue à oiseaux du Cabinet des Médailles, REA 60 (1958), 27-35; W. RICHTER, Wendehals, KP 5 (1975), 1366f; L. DEUBNER, Antike 6 (1930), 166-168, Abb. 6-9; G. VAN HOORN, Choes and Anthesteria (1951), 46, fig. 402; G.W. NELSON, A Greek Votive Iynx-Wheel in Boston, AJA 44 (1940), 443-456, fig. 1; H. RÜHFEL, Das Kind in der griechischen Kunst (1984), 232-235, Abb. 98f; K. Schauenburg, AW 7,4 (1976), 32; G.R. DAVIDSON, The Minor Objects. Corinth 12 (1952), 304, P1. 125:2631f.

7 Ch.M. Doughty, Travels in Arabia Deserta I (London 1936), 480; G. JACOB, Altarabisches Beduinenleben $(21897=1967), 113.254$; vgl. G. CHANAN - H. FRANCIS, Toys and Games of Children of the World (1984), 69. 80, Abb. 119. 157; R. HoLlER, Kreisel (1989), $112 f$.

8 Abb. 45 nach einer Wandmalerei in der 'Casa dell'Amore Punito' (VII 2,23) in Pompeii (Neapel, National-Museum, Inv. 9257), vgl. z.B. I. BRAGANTINI et al., Pitture e pavimenti di Pompei III. Regioni VII, VIII, IX (Rom 1986), 77f; K. SCHEFOLD, Pompeijanische Malerei. Sinn und Ideengeschichte (Basel 1952), Taf. 21.

9 Vgl. im Deutschen z.B. "Spindel, Spindel, geh du aus / Bring den Freier in mein Haus!". 


\section{PUPPEN}

Anthropomorphe ${ }^{1}$ und vor allem theriomorphe Terrakotta-Figurinen dürften palästinische Kinder in der Antike - auch - als Spielzeug benutzt haben. Indizien dafür sind nicht nur ethnologische Belege und solche aus vergleichbaren Kulturen, sondern z.B. auch die in eisenzeitlichen Kinder-Gräbern von Deve Hüyük bei Karkemisch beobachtbare geschlechtsspezifische Verteilung von Pferden und Reitern auf Knaben- und von gynaikomorphen Figurinen auf Mädchen-Gräber" ${ }^{2}$ "Dolls ... for a girl, for a boy horses or horsemen"3. Daß vor allem die in der Eisenzeit (und auch sonst) fast gänzlich überwiegenden weiblichen Terrakotta-Figurinen an sich weibliche Gottheiten darstellen (Abb. 46), widerspricht ihrer zeitweisen Verwendung als Puppen durch Kinder nicht. Wie in Gesellschaften, die keine Überfluß-Gesellschaften sind, fast alle materiellen Gegenstände mehrere Funktionen haben konnten, so konnten auch Götterbilder, die als Massenware produziert wurden und denen von der Armhaltung und Nacktheit abgesehen - eindeutige Göttersymbole bzw. -attribute weitgehend fehlen, als Kinderspielzeug verwendet werden,

1 Vgl. z.B. T.A. Holland, A Study of Palestinian Iron Age Baked Clay Figurines, with special Reference to Jerusalem: Cave 1, Levant 9 (1977), 121-155; U. HÜBNER, Das Fragment einer Tonfigurine vom Tell el-Milh. Überlegungen zur Funktion der sog. Pfeilerfigurinen in der israelitischen Volksreligion, ZDPV 105 (1989), 47-55 (die Anm. 57 ziehe ich, soweit sie den Aspekt des Spielzeugs angeht, zurück); ders., Figurinen aus Terrakotta, in: V. FrITZ (ed.), Kinneret (1990), 119-121, Taf. 42 C-D. 102; zum Fundmaterial in Transjordanien vgl. A.J. ${ }^{\mathrm{C}} \mathrm{AMR}$, A Study of the Clay Figurines and Zoomorphic Vessels of Tans-Jordan (Ph.D. Thesis, unpubl.; University of London 1980), Nos. 1ff.

2 Vgl. L. Woolley, Hittite Burials Customs, LAAA 6 (1914), 87-98; ders., A North Syrian Cemetery of the Persian Period, LAAA 7 (1914-1916), 115-129; E. KLENGELBRANDT, Kleinfunde aus Deve Hüyük bei Karkamisch im Vorderasiatischen Museum Berlin, in: Resurrecting the Past. A Joint Tribute to A. BoUNNI (UNHAII 67; Leiden 1990), (133-151), 144.

3 So etwas vereinfachend L. WOOLLEY, LAAA 6 (1914), 95f; vgl. auch P.R.S. MOOREY, Cemeteries of the First Millenium B.C. at Deve Hüyük (BAR.IS 87; Oxford 1980), 100-104. Die Meinung von R. WENNING, Wer war der Paredros der Aschera? Notizen zu Terrakottastatuetten in eisenzeitlichen Gräbern, BN 59 (1991), 91, wonach "keine der Götter- und Tierstatuetten aus diesen Gräbern ... sich m.E. als Spielfigur interpretieren" läßt, überzeugt mich allerdings auch nicht. 
ohne daß dies eine nennenswerte Zweckentfremdung dargestellt hätte $e^{4}$; es liegt nicht nur in der Natur der ambi- bzw. polyvalenten Gegenstände, sondern auch im Wesen spielender Kinder, "daß eine klare Unterscheidung zwischen Spiel- und Kultobjekt kaum möglich ist, sondern ihre Funktionsbereiche sich eng berühren bzw. überschneiden"5. Mancher Handwerker (kerameus), der Götterbilder herstellte, hielt nicht von ungefähr das Leben für ein Kinderspiel (Sap.Sal. 15,12: LXX paignion, Vulg. ludus).

Puppen, die als solche hergestellt wurden, gab es im alten Israel natürlich auch: Aus 1.Sam. 19,8-176 läßt sich mit an Sicherheit grenzender Wahrscheinlichkeit nicht nur rekonstruieren, daß im alten Israel mit Puppen gespielt wurde, sondern auch, aus welchen Materialien sie gefertigt waren: Um ihren Ehemann David vor ihrem eigenen Vater zu retten, täuscht ${ }^{7}$ Michal die Häscher Sauls, indem sie das häusliche Götterbild (ha-t ${ }^{2}$ rapîm $)^{8}$ nimmt, es aufs bzw. ins Bett legt, um den Kopf herum mit einem Geflecht aus Ziegenhaaren ( $k^{e}$ bir ha- $c_{i z z i m}$ ) versieht und ihm ein Kleidungsstück (baegaed) anzieht ${ }^{9}$; Michal wiederholt damit als erwachsene Frau, was sie als Mädchen oft gespielt hat, wenn sie ihre Puppe(n) schlafen legte. Eine so schöne, täuschend echte Puppe dürfte, natürlich im Format etwas kleiner, dürfte der Traum eines jeden palästinischen Mädchens gewesen sein.

4 Vgl. D.C. KURTZ - J. BOARDMAN, Thanatos. Tod und Jenseits bei den Griechen (Mainz 1985), 241. 247f. 254f u.ö. Zur Verwendung von Puppen als 'Sandsäcke' beim Boxtraining vgl. Platon, nomoi 830b.

5 S. PAUl, Afrikanische Puppen (BaA 6; Berlin 1970), 141.

6 Zum möglichen Verständnis vgl. z.B. H. RouILLARD - J. TROPPER, TRPYM, rituels de guérison et culte des ancêtres d'après 1 Samuel XIX 11-17 et les textes parallèles d'Assur et de Nuzi, VT 37 (1987), 340-361; S. SCHROER, In Israel gab es Bilder. Nachrichten von darstellender Kunst im Alten Testament (OBO 74; Fribourg - Göttingen 1987), 137-139; K. BUDDE, Die Bücher Samuel (KHC AT 8; Tübingen - Leipzig 1902), 136-139; H.W. HERTZBERG, Die Samuelbücher (ATD 10; Göttingen 41968), 132-135; H.J. STOEBE, Das erste Buch Samuelis (KAT 8,1; Gütersloh 1973), 355-365; F. STOLZ, Das erste und zweite Buch Samuel (ZB AT 9; Zürich 1981), 127-131.

7 Vgl. z.B. Pausanias 9,3,1f.

8 Vgl. z.B. K. SEYBOLD, $t^{2}$ ājim, Idol(e), THAT 2 (21979), 1057-1060; H.J. STOEBE, Das erste Buch Samuelis (1973), 363-365; H. ROUILLARD - J. TROPPER, VT 37 (1987),

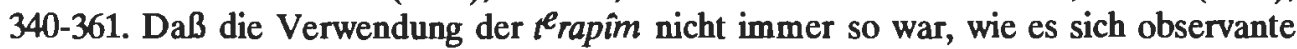
Kreise vorstellen mochten, zeigt im übrigen das Beispiel der Rachel (Gen. 31,30ff), vgl. z.B. S. SCHROER, In Israel gab es Bilder (1987), 139-141.

9 Vogelscheuchen dürften von ähnlicher Machart gewesen sein, vgl. Jer. 10,3-5; Bar. 6,70 . 
Im antiken Israel ${ }^{10}$ und seiner Umwelt ist eine Fülle von mehr oder weniger sorgfältig hergestellten (Glieder)-Puppen aus verschiedenen Materialien erhalten ${ }^{11}$ oder aber über literarische oder ikonographische Belege bezeugt ${ }^{12}$.

10 J.L. KELSO, The Excavation of Bethel (1934-1960) (AASOR 39; Cambridge/MA 1968), 89, Pl. 115:1 (No. 2229).

11 Vgl. allgemein z.B. C. Fox, The Doll (New York 1973), passim; G. WHITE, European and American Dolls (London 1976), passim; auch H.H. JOSEPH, A Book of Marionettes (London 21931), passim.

12 Beispiele aus Ägypten: A.R. DAviD, Toys and Games from Kahun in the Manchester Museum Collection, in: Studies in Honour of H.W. FaIRMAN (1979), 12, Pl. 2; E. DoETSCH-AMBERGER, Ägyptische Sammlung (Köln 1987), Nr. 244; K.M. ElDERKIN, Jointed Dolls in Antiquity, AJA 34 (1930), 455-479; E. FEUCHT, Puppe, LÄ 4 (1982), 1201f; dies., Vom Nil zum Neckar (1986), Nr. 549; E. BRUNNER-TRAUT, Spielzeug, LÄ 5 (1984), 1152; F.W.M. PETRIE, Objects of Daily Use (1927), 59f, Pl. 51-53; M. SALEH H. SOURouZIAN (ed.), Die Hauptwerke im Ägyptischen Museum Kairo (1986), Nr. 81; L. BORCHARDT - H. RICKE, Die Wohnhäuser in Tell el-Amarna (WVDOG 91; Berlin 1980), 32. 34. 37. 55 u.ö.; A. WIEDEMANN, Das Spiel im alten Ägypten (1912), 163-170.

Orientalische Beispiele: arab. $l u c b a$, lu $c_{a b i j j e}$; neuhebr. bubāh; akkad.passu(m) (AHw 839); B. LANDSBERGER, WZKM 56 (1960), 117-126; R.D. BARNETT, From Arad to Carthage: Harvest Rites and Corn-Dollies, ErIs 20 (1989), 1*-11*; H. STIERLIN, Städte in der Wüste. Petra, Palmyra und Hatra - Handelszentren am Karawanenweg (Antike Kunst im Vorderen Orient; Fribourg - Stuttgart - Zürich 1987), 173, Abb. 154 (parthische Gliederpuppe aus Knochen aus Seleukia am Tigris aus Kindergrab, 16,5 cm h.; Bagdad, Iraq Mus.); auch O. REUTHER, Die Innenstadt von Babylon (1926 = 1968), 257 (Kindergrab).

Griechische, römische und frühchristliche Beispiele (neurospasta; korai; nymphai, glēnai; plaggones; pupa, pupula; sigillaria u.a.): L. BECQ DE FOUQUIERES, Les jeux des anciens (21873), 27-31; L. DEUBNER, Antike 6 (1930), 166, Abb. 5 (Gliederpuppe aus Ton); F. DöLGER, Ichthys 5 (Münster i.W. 1943), 5f, Anm. 13; ders., Antike und Christentum 5 (Münster i.W. 1936), 77f. 125f. 296; J. DöRIG, Von griechischen Puppen, AntK 1 (1958), 41-52, Taf. 22-26; K.M. ElderKIN, AJA 34 (1930), 455-479; G. HERZOG-HAUSER, Neurospasta, RE 17,1 (1936), 161-163; D.C. KURTZ - J. BOARDMAN, Thanatos. Tod und Jenseits bei den Griechen (1985), 240 f. 247 u.ö.; S. LASER, Sport und Spiel (1987), 96-98, Abb. 37, Taf. III; M. KAMPERMAN-MuldER, Terracotta Doll in Utrecht, BABesch 48 (1973), 115-118; G.R. DAVIDSON - D.B. THOMPSON, Small Objects from the Pnyx I (Hesperia Suppl. 7; Baltimore/MD 1943), 114-118, Nos. 5-13 ("Figures with jointed Limbs"); A. HUG, RE III A2 (1929), 1764. 1774; H. LECLERQ, Marionettes, DACL 10,2 (1932), 2163-2167; ders., Jeux et Jouets IV, DACL 7,2 (1927), 2516-2519, fig. 6248-6251; M. RIEMSCHNEIDER, Spielbrett und Spielbeutel in Antike und Mittelalter, AEth 8 (1959), 309-326; E. SCHMIDT, Spiele und Spielzeug der Kinder (1971), 38-51; R. SCHMIDT, Die Darstellung von Kinderspielzeug und Kinderspiel (1977), 114-128; J. VÄTERLEIN, Roma ludens (1976), 28-32, Abb. 8-10; F. VANDENABEELE, A propos de quelques terres cuites grecques à membres mobiles, BMAH 43-44 (1971-1972), 23-52. Vgl. auch J. HILls, Das Kinderspielbild von Pieter Bruegel d.Ä. 
Unzweifelhaft dienten sie Kindern zum Spielen, konnten aber ebenso gut als ex-votos dienen. Griechische Epigramme u.a. belegen den Brauch, daß junge Mädchen kurz vor der Heirat ihre Puppen und deren Kleider der Artemis oder anderen Gottheiten weihten ${ }^{13}$. Puppen als ex-votos finden auch heute noch an zahlreichen Wallfahrtsorten Verwendung ${ }^{14}$, und zahllose Marienund Jesus-Figuren in Kirchen der Neuzeit sind nichts anderes als entsprechend verwendete und drappierte Spielzeug-Puppen aus Plastik oder anderen Werkstoffen, die ihrer ursprünglichen Bestimmung ohne weiteres wieder zugeführt werden könnten. Götterbilder ent-puppen sich zuweilen als Kinderspielzeug15 - und umgekehrt. Lukian, der als Kind gerne aus Wachs Menschen und Tiere als Spielzeug nachbildete, sollte ob dieser Begabung auf Wunsch seiner Eltern das Handwerk eines Bildhauers und Produzenten von Götterbildern erlernen; der Tatsache, daß er sich diesem Wunsch trotz der Prügel von verschiedener Seite erfolgreich widersetzte und seinen Unterhalt anderweitig verdiente, verdanken wir seine zu Recht berühmten Schriften (Lukian, somn. 2).

Die Herstellung von Puppen und Götterbildern ${ }^{16}$ hat sich im Prinzip kaum unterschieden; darauf weisen auch die polemischen Bemerkungen späterer Zeiten hin wie z.B. die von Lactanz, inst. div. 2,4,12ff (um 300 n.Chr.), nach der Götterbilder die Puppen der Erwachsenen sind ${ }^{17}$ - eine Bemerkung, die keineswegs nur polemisch ist, sondern zugleich eine reale Möglichkeit des

(1957), 7f, Nr. 2. In den römischen Katakomben konnten Puppen in den frischen Kalkmörtel der Grabverschlüsse als eine Art Grabbeigabe gedrückt werden, vgl. J. FINK, Die römischen Katakomben (1978), 26, Abb. 16.

13 Vgl. z.B. Anth. Graeca 6,280; Schol. Horaz sat. 1,5,66; Persius, sat. 2,69f. Von Heraklit B 70 ist der Spruch überliefert: "Kinder werfen ihr Spielzeug weg, wenn sie Männer werden" - was bekanntlich auch nur bedingt stimmt: "Der Mann, auf dem Markte strenggesinnt / Ist im Haus' ein spielend Kind", vgl. 1001 altarabische Sprichwörter, deutsch von F. RÜCKERT, ed. H. BOBZIN (Wiesbaden 1988), 74. Knaben weihten Hermes oder anderen Gottheiten Klappern, Bälle, Astragale, Kreisel und ähnliches Spielzeug (z.B. Anth. Graeca 6,309). Vgl. auch E. LEMKE, Spiel-, Zauber- und andere Puppen, ZVVK 25 (1915), 126-136.

14 Vgl. z.B. J.B. ConNelly, Standing before one's God. Votive Sculpture and the Cypriot Religious Tradition, BA 52 (1989), 216.

15 Vgl. z.B. R. HAUSSHERR, Jesuskind, LCI $2(1970=1990)$, 402: "sakrales Spielzeug für Nonnen, eine Art von Puppen".

16 Vgl. demnächst A. BerLeJung, Zur Theologie der Bilder. Aspekte des altorientalischen und alttestamentlichen Verständnisses der Götterbilder (Diss. theol. masch.; Heidelberg) (in Vorbereitung).

17 ...nihil aliud esse quam grandes pupas non a virginibus..., sed a barbartis hominibus consecratas [Institutions Divines II (SC 337; Paris 1987), ]. 
Umgangs mit kleinformatigen Götterbildern beschreibt. Neben den eisenzeitlichen gynaikomorphen Terrakotten sind Puppen ${ }^{18}$ vor allem aus römischer, byzantinischer und islamischer Zeit in Palästina belegt, z.B. in Jerusalem $^{19}$, Hirbet Dēr Dusāwi und Tell er-Rusūm ${ }^{20}$, Hirbet el-Mefŏir (Abb. 49) ${ }^{21}$ und $\underline{\text { Hirbet el-Minye }}{ }^{22}$ (Abb. 48); sie ähneln sehr den gedrechselten Püppchen (sog. Docken) Mitteleuropas ${ }^{23}$. Die schönste und besterhaltenste Puppe aus dem spätantiken Palästina stammt aus Nessana (Hafïr el- $c_{A u}$ ğa $\left.\bar{a}\right)^{24}$; sie stellt offensichtlich ein Wickelkind dar (Abb. 47). Daß Säuglinge bzw. Kleinkinder im antiken Palästina in dieser bis heute weitverbreitenen Art gewickelt wurden, hatte für diese Phase der Kindheit einen nicht unerheblichen Einfluß auf ihr Spielverhalten: Im gewickelten Zustand konnten sie so gut wie nicht spielen, waren aber deshalb gleichzeitig durch Schlangen, Skorpione u.ä. nicht so gefährdet (Jes. 11,8).

(Mechanische) Puppen und Marionetten [griech. neurospasta; latein. nervis alienis mobile lignum (Horaz, sat. 2,7,82) u.a.; neuhebr. mrywnth) konnten auch von berufsmäßigen Puppen-Spielern verwendet werden (z.B. Xenophon, Symp. 4,55); auf Jahrmärkten und bei ähnlichen Gelegenheiten ließen sie gegen entsprechendes Entgeld die Puppen tanzen ${ }^{25}$. Auch dies ist für das helle-

18 Vgl. auch R.S. LAMON - G.M. SHIPTON, Megiddo I (1939), 157, Pl. 101:12 "amulett or doll(?)"; R.H. SMITH, Pella of the Decapolis I (The College of Wooster 1973), 191. 226f, Pl. 67:236; 84:236 (Tomb 7, Chamber).

19 L.Y. RAHMANI, Roman Tombs in Shmuel ha-Navi Street, IEJ 10 (1960), 146f, Pl. 21:c (Grab I, 3.Jh. n.Chr.); J.W. CROWFOOT - G.M. FITZGERALD, Excavations in the Tyropoeon Valley, Jerusalem 1927 (PEFA 5; London 1927), 100, Pl. 21:34 (Room 33, spätröm.-byz.); vgl. auch R.W. HAMILTON - S.A.S. HUSSEINI, Shaft Tombs on the Nablus Road, Jerusalem, QDAP 4 (1935), 172, Pl. 82:3 (Tomb 6: "A Bone Handle carved to represent a Female Figure").

20 L.R. RAHMANI, IEJ 31 (1981), 72-74, Pl. 14:A-C.

21 L.R. RAHMANI, IEJ 31 (1981), 77, Pl. 14:D.

22 L.R. RAHMANI, IEJ 31 (1981), 80, Pl. 15:B.

23 V. KUTSCHERA, Spielzeug. Spiegelbild der Kulturgeschichte (Salzburg 1975), 133f, Abb. 7a-j; 8a-d.

24 Jerusalem, Palestine-Museum: L. BEllinger, Textiles, in: H.D. Colt (ed.), Excavations at Nessana (Auja Hafir, Palestine) (London 1962), 50, Pl. 29:5: "doll with ivory head", vgl. Pl. 21:6 (7.-8.Jh.n.Chr.).

25 H. BLÜMNER, Fahrendes Volk im Altertum (1981), 23f; A. SCHÜRMANN, Griechische Mechanik und antike Gesellschaft. Studien zur staatlichen Förderung einer technischen Wissenschaft (Boethius 27; Stuttgart 1991), 190ff; J.G.T. GRÄSSE, Die Geschichte des Puppenspiels und der Automaten (Puppenspielkundliche Quellen und Forschungen 1; Leipzig 1856 = Bochum 1977), 625ff; A. RAAB, Theaterpuppen in Vergangenheit und Gegenwart (Kaufbeuren 1979), 6ff. 
nistisch-römisch-byzantinische Palästina ebenso vorauszusetzen wie die in islamischer Zeit aufgekommenen Schattenspiele ${ }^{26}$.

Erinnert sei hier auch an die an Puppen erinnernden Vogelscheuchen auf den Feldern [Jer. 10,527; Ep.Jer. 69 (probaskanion) bzw. Bar. 6,69 (formido)] $]^{28}$, die Haman-Puppen (Est. 3,1ff), die vor allem im orientalischen Judentum für das Purim-Fest hergestellt und dann verbrannt werden ${ }^{29}$, an die ägyptischen Verwünschungstexte, die auf anthropomorphen Terrakotten notiert waren und die man dann in einem Sympathiezauber zerbrach ${ }^{30}$, und an die sog. 'Rachepuppen' aus dem griechischen Kulturraum ${ }^{31}$. Daß Kinder von Erwachsenen manchmal wie Puppen (paignia) behandelt wurden, belegt Plutarch, cons. ad uxor. 6.

Ein Teil der Miniatur-Möbel und -Gefäße aus Terrakotta ${ }^{32}$ dürfte von Kindern beim Spielen mit ihren Puppen verwendet worden sein (Abb. 50-51).

\footnotetext{
"Wenn man Kindern eine ihrer Spielsachen wegnimmt, werfen sie alle hin und schreien und weinen"

(Plutarch, de tranq. animi 8)
}

26 P. KAHLE, Islamische Schattenspielfiguren aus Egypten I-II, Islam 1 (1910), 264 299; 2 (1911), 143-195; H.-L. BoBBER et al., Türkisches Schattentheater Karagöz: Eine Handreichung für lustvolles Lernen (Frankfurt a.M. 1983), 15ff; Ch.-P.N. BORATAV, Karagöz, EI 4 (21978), 601-603; W. HOENERBACH, Das nordafrikanische Schattentheater (BOS NS 6; Mainz 1959), passim; H. RITTER (ed.), Karagös. Türkische Schattenspiele, 1.-3.Folge (Hannover - Leipzig - Wiesbaden 1924. 1941. 1953), passim; U. SPULER, Schattentheater, Lex. der Islam. Welt 2 (1974), $90 \mathrm{f}$.

27 Vgl. aber auch $\mathrm{HAL}^{3}$ 4, 1617f; arab. nuttär, neuhebr. dahli.

28 G. Dalman, Arbeit und Sitte in Palästina 2 (1932), 57. $62 f$.

29 M. ZoBel, Das Jahr des Juden (Berlin 1936), 154; M. GRUNwALD, Chanukka, in: Fr. THIEBERGER (ed.), Jüdische Feste, jüdischer Brauch ( $21967=1976), 364368$.

30 ANET $^{3}$ 328f; ANEP ${ }^{2}$ No. 593. Vgl. auch E. LEMKE, ZVVK 25 (1915), 126ff. Vgl. später $a J-M a s^{C} \bar{u} d \bar{l}$, Bis zu den Grenzen der Erde (Murü̆g ad-dahab), 182.

31 D.C. KuRTZ - J. BoARDMAN, Thanatos. Tod und Jenseits bei den Griechen (1985), 260, Abb. 79.

32 Zu Belegen aus Palästina unten Kap. 12. Zu einem Terrakotta-Puppenstuhl aus dem Heiligtum des Juppiter Anxurus bei Terracina vgl. H. KäHLER, Götterspielzeug, Die Kunst und das schöne Heim 53 (1955), 86f. 
Überhaupt dürfte ein nicht geringer Teil des antiken Spielzeugs aus gebranntem Ton bestanden haben; neben den anthropomorphen und theriomorphen Terrakotten kann man wahrscheinlich auch einen Teil der kleinen tönernen Wägelchen u.ä. mehr dazu rechnen, die in Palästina ${ }^{1}$ und seinen angrenzenden Gebieten ${ }^{2}$ häufig und im übrigen auch in Kinder-Gräbern ${ }^{3}$ belegt

1 Vgl. z.B. H. WeIPPERT, Wagen, BRL 21977, 356; M.A. LITTAUER - J.H. CrouWEL, Wheeled Vehicles and Ridden Animals in the Ancient Near East (HO 7.Abt. 1,2,B 1; Leiden - Köln 1979), passim. Die zahlreichen (Terrakotta-)Räder belegen die Existenz von Wägelchen und Nachziehspielzeug in fast allen Perioden der palästinischen Geschichte, z.B. E. SELLIN - C. WATZINGER, Jericho (WVDOG 22; Leipzig 1913 = Osnabrück 1973), 151, Abb. 184:12 ("Rad... von einem Terrakottawägelchen?"); F.V. WiNNETT - W.L. REED, The Excavations at Dibon (Dhïbân) in Moab (AASOR 36-37; New Haven/CT 1964), 59. 70. 77, Pl. 59:11 = 77:13 ["(Perhaps clay) wheel from toy cart or chariot"]; Y. YADIN et al., Hazor II (1960), 155, Pl. 146:29 ("may have belonged to models of cult chariots"; V. FRTZ, Kinneret (1990), 131, Taf. 34 C.D = 66:16 ("Rad für ein Spielzeug"); W.G. DEVER, Gezer IV (1986), 19, P1. 49:8; 54:7; 115B ("chariot wheel"); F.J. BLISS - R.A.S. MACALISTER, Excavations in Palestine during the Years 1898-1900

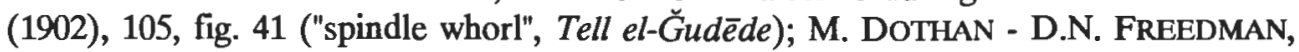
Ashdod I (1967), fig. 26:9 ("wheel"); M. DuNAND, Fouilles de Byblos II (1954), 241. 258. 892f, fig. 265; 1006:17116 u.ö. ("disque"); W.M.F. PETrIE et al., Ancient Gaza V (1952), 18, Pl. 24:16f ("Wheels of toy chariots").

2 M. LitTAUER - J.H. Crouwel, A Terracotta Wagon Model from Syria in Oxford, Levant 22 (1990), 160-162; H. LIEBOWTI, Terra-Cotta Figurines and Model Vehicles. The Oriental Institute Excavations at Selenkahiye, Syria (Bibl. Mes. 22; Malibu 1988), 19-21, Pl. 31-34; E. STROMMENGER, Planwagen aus dem mittleren Euphrattal, in: Resurrecting the Past. A Joint Tribute to A. BoUNNI (UNHAII 67; Leiden 1990), 297-306; E. ÖZGEN, A Group of Terrakotta Wagon Models from Southeastern Anatolia, AnSt 36 (1986), 165-171; ANEP ${ }^{2}$ fig. 169 (Tepe Gawra); E. BRUNNER-TRAUT, Spielzeug, LÄ 5 (1984), 1153; A. HUG, RE III A 2 (1929), 1775; N. CHOLIDIS, MDOG 121 (1989), 197-222 lehnt ein Verständnis als Spielzeug ab und plädiert stattdessen für eine kultische Interpretation.

$\mathrm{Zu}$ Griechen und Römern (griech. hamaxis; latein. plostellum) vgl. z.B. Philostrat, Heroik. 19,2 (KAYSER); J.D. BEAZLEY, Aryballos, ABSA 29 (1927-1928), 187-215; J.H. CROUwEL, Chariots and Other Means of Land Transport in Bronze Age Greece (Allard Pierson Series 3; Amsterdam 1981), passim; L. DEUBNER, Antike 6 (1930), 174, Abb. 1-3, Taf. 14a.b (aus Ton, an Stab bzw. Schnur gezogen oder geschoben); E. SCHUPPE, Plostellum, RE 41 (1951), 463; H. RÜHFEL, Kinderleben im klassischen Athen (1984), 138-141, Abb. 76-79; dies., Das Kind in der griechischen Kunst (1984), 116-118. 122-124, Abb. 47. 50. 74f; E. SCHMIDT, Spiele und Spielzeug der Kinder (1971), 
sind ${ }^{4}$. Direkt beweisbar ist ein Verständnis als Spielzeug nicht; immerhin sprechen die geringe Größe, die Räder ${ }^{5}$, die den Gegenständen ein Stück 'Leben' verleihen (und aufgrund ihrer Form in den meisten Fällen eindeutig von Spinnwirtel unterschieden werden können), das billige Herstellungsmaterial, die Belege in privaten Wohnbereichen wie in Kindergräbern, die ikonographischen Belege des griechisch-römischen Bereichs sowie ethnologische Parallelen dafür. Die andere Interpretation, die diese Objekte als Kultgegenstände verstehen will, hat die (angebliche) Zerbrechlichkeit des Materials und entsprechende Fundkontexte für sich, kann aber z.B. bei Terrakotta-Tieren auf Rädern keine plausible Erklärung dafür anbieten, warum man eigens bewegliche Räder montiert hat statt sie gleich wegzulassen oder aber nur als unbewegliche Appliken anzudeuten; im übrigen ist Nachziehspielzeug ethnologisch weltweit nachweisbar. Generell führt auch hier eine eindimensionale Alternativ-Diskussion (entweder Spielzeug oder ex-votos) nicht sehr weit; besser ist es, mit einer Zwei- oder Mehrfachfunktion zu rechnen, die Kindern einen Umgang mit den Objekten als Spielzeug und Erwachsenen einen Umgang als Kultobjekten ermöglichte. In jedem Fall stand den Kindern des antiken Palästinas offensichtlich auch mechanisches Spielzeug 6 wie Gliederpuppen bzw. Marionetten zur Verfügung. Die Wägelchen sind im (bronzeund eisenzeitlichen) Palästina interessanterweise deutlich weniger belegt als im mesopotamischen und aramäischen Raum, was mit dem höheren Stand der Technologie und der militärischen Aufrüstung in diesen Gebieten zusammengehangen haben dürfte.

31-33; R. SchmidT, Die Darstellung von Kinderspielzeug und Kinderspiel (1977), 103114; F.A.G. BECK, Album of Greek Education (1975), 47, Nos. 277-281; K. SCHAUENBURG, AW 7,3 (1976), 42f; Ch. VORSTER, Griechische Kinderstatuen (1983), 23-26. Vgl. auch G. CHANAN - H. FRANCIS, Toys and Games of Children of the World (1984), passim; M. GrIAUle, Jeux Dogons (1938), 53-56; F. KLEPZIG, Kinderspiele der Bantu (1972), 64-66, 227f. 338 u.ö.

3 Vgl. z.B. L. NABO, Der extramurale Friedhof, in: E. STROMMENGER et al., Ausgrabungen in Tall Bica 1985, MDOG 119 (1987), 46-49, Abb. 28.

4 Aristophanes, nub. 878ff (Roß und Wagen als Spielzeug aus Leder); Plutarch, Dion 9 (Wägelchen aus Holz als Knaben-Spielzeug).

5 Vgl. z.B. Y. ChIYonoBU, Disc-Wheels of Ancient Mesopotamia, BAOM 10 (19881989), 153-183 (japan., mit English Summary).

$6 \mathrm{Zu}$ der mechanischen Spieldose bzw. Spielautomaten mit Tanzzwergen aus Lišt (12.Dyn.), die durch Zug eines im Innern der Spieldose angebrachten Fadens zum Drehen gebracht werden konnten, vgl. M. SALEH - H. SOUROUZIAN (ed.), Die Hauptwerke im Ägyptischen Museum Kairo (1986), Nr. 90. Zu Marionetten vgl. z.B. auch C. NIEBUHR, Reisebeschreibung nach Arabien, Bd. 1 (1774 = 1968), 187. Zu Terrakotta-Tieren auf vier Rädern vgl. oben Kap. 4. 
Zum Kinder-Spielzeug kann man wohl auch einen Teil der Miniaturgefäße $\mathrm{e}^{7}$, -betten ${ }^{8}$ u.ä. aus Terrakotta und anderen Materialien zählen, die in Palästina häufig gefunden wurden (Abb. 50-51); wahrscheinlich haben sie Kindern beim Spiel mit ihren Puppen gedient, waren also Teile von 'Puppenstuben'?.

Nicht alle palästinischen Knaben wuchsen zu Helden wie David heran, der mit seiner Schleuder ${ }^{10}$ Goliath tötete (1.Sam. 17,40). Daß Schleudern, deren Erfindung immerhin den "Syrophönikern" zugeschrieben wurde (Plinius d.Ä., nat. hist. 7,201), nicht nur als Kriegs- und Jagdwaffen und als Schutz gegen wilde Tiere dienten, ist bekannt. Ethnologisches Vergleichsmaterial zeigt ${ }^{11}$,

7 Vgl. z.B. M. Dothan - D.N. FreEdman, Ashdod I ('cAtiqot ES 7; Jerusalem 1967), fig. 25:2; 42:16; 43:7-9; 46:6f; G. LoUD, Megiddo II (1948), 148, Pl. 256:13; O. TUFNELL, Lachish III (1953), 234; O. REUTHER, Die Innenstadt von Babylon (1926 = 1968), 163; D.C. KURTZ - J. BOARDMAN, Thanatos. Tod und Jenseits bei den Griechen (1985), 247. 253f; H. KÄHLER, Die Kunst und das schöne Heim 53 (1955), 88f; K. GRÖBER - J. METzGER, Kinderspielzeug aus alter Zeit ( $\left.{ }^{2} 1965\right), 109$.

8 Vgl. z.B. F. CRÜSEMANN, Die Kleinfunde, in: V. FrITZ - A. KEMPINSKI (ed.), Ergebnisse der Ausgrabungen auf der Hirbet el-Mšăš (1983), 132, Taf. 109:8 = 172:13; L. BORCHARDT - H. RICKE, Die Wohnhäuser in Tell el-Amarna (1980), 152 ("Puppenbett"). 206 u.ö.; E. BrunNER-TrauT, Spielzeug, LÄ 5 (1984), $1153 \mathrm{f}$.

9 Vgl. z.B. auch F. DölgER, Kinderküchen der Antike mit dem Fisch auf der Auftragsschüssel und auf dem Roste, in: ders., Ichthys 5 (1943), 1-7, Taf. 47 (u.a. Terracina, Juppiter-Anxurus-Tempel); F. KLEPZIG, Kinderspiele der Bantu (1972), 455: L. DAIKEN, Children's Toys throughout the Ages (London 1953), $102 \mathrm{ff.}$

$10 \mathrm{Mrgmh}$ und ylqwt, schleudern = ql',twl; z.B. Ri. 20,16; Sach. 9,15. Vgl. z.B. L. BAUER, Volksleben im Lande der Bibel (21903), 74; M. KRANZ, Probleme der Leiblichkeit (Diss. phil. masch.; Köln 1965), 109-112; W. DECKER, Schleuder, LÄ 5 (1984), 656; (K. GALLING) - H. WEIPPERT, Schleuder, BRL ${ }^{2}$ (1977), 282; E.J. BANKS, Bismya or The Lost City of Adab (1912), 411; G. CHANAN - H. FRANCIS, Toys and Games of Children of the World (1984), 117, fig. 270; E. FEUCHT, Vom Nil zum Neckar (1986), Nr. 550; A.R. DAVID, Toys and Games from Kahun in the Manchester Museum Collection, in: Studies in Honour of H.W. FAIRMAN (1979), 13, Pl. 4 (12.Dyn., Schleuder und Schleudersteine).

11 A. MUSIL, Arabia Petraea III (1908 = 1989), 284; ders., Arabia Deserta (New York 1927), 17; ders., The Manners and Customs of the Rwala Bedouins (ASG 6; New York 1928), 256; C.R. RASWAN, Im Land der schwarzen Zelte. Mein Leben unter den Beduinen (Berlin 1934), 13f. 30; L. BAUER, Volksleben im Lande der Bibel (21903), 5; J.J. HeSs, Von den Beduinen des Innern Arabiens (1938), 105; auch K.G. LiNDBLOM, Die Schleuder in Afrika und anderwärts (Stockholm 1927), 14; ders., The Sling, especially in Africa. Additional Notes to a Previous Paper (Stockholm 1940), 6ff. Anders, aber keineswegs überzeugend G. DALMAN, Arbeit und Sitte in Palästina 6 (Gütersloh 1939), 
daß sie in den Händen von Kindern auch als - meist selbst hergestelltes Kriegs-, Jagd- und 'bloßes' Spielzeug dienten und dienen ${ }^{12}$. Ähnliches ist auch für Speer ${ }^{13}$ sowie Pfeil und Bogen anzunehmen'14; ein mittelsyrisches Rollsiegel aus dem spätbronzezeitlichen Bet-Schean ${ }^{15}$ zeigt - den erwachsenen - Pharao Ramses II. beim Schießen auf eine Zielscheibe (Abb. $52)^{16}$. Auch das in islamischer Zeit in Syrien und Palästina gut belegte

241: "Aber nach dem Obigen ist klar, daß die Hirtenschleuder der Israeliten kein Spielzeug gewesen ist".

12 Vgl. z.B. Diog. Laert. 6,30; L. GRASBERGER, Erziehung und Unterricht im klassischen Alterthum III (1881), 157-168; E. SCHMIDT, Spiele und Spielzeug der Kinder (1971), 28-33; M. GRIAULE, Jeux et divertissements abyssins (1935), 8f; ders., Jeux Dogons (1938), 50f; F. KLEPZIG, Kinderspiele der Bantu (1972), 54ff. 225f. 334f. 446f; S. PAUL, Notizen zu einigen afrikanischen Geschicklichkeitsspielen (Lic. phil. masch.; Uppsala 1962), 122ff. 150ff; dies., Spiel in Afrika, Evangelische Kinderpflege 22 (1971), 326-339; F.M. BöHME, Deutsches Kinderlied und Kinderspiel $(1897=1967), 622 f$, Nr. 498; I. WEBER-KellerMANN - R. FALKENBERG (ed.), Was wir gespielt haben (1992), 218ff.

13 M. Griaule, Jeux et divertissements abyssins (1935), 92-94; ders., Jeux Dogons (1938), 46ff.

14 Vgl. z.B. Herodot 1,136; H. WEIPPERT, Bogen, BRL ${ }^{2}$ (1977), 49f; G.J. BOTTERWECK - H.A. HOFFNER, ThWAT 3 (1977-1982), 128-134; U. HÜBNER, Pfeil, NBL, (im Druck); O. KeEL, Der Bogen als Herrschaftssymbol, (1977), in: ders. et al. (ed.), Studien zu den Stempelsiegeln aus Palästina / Israel, Bd. III (OBO 100; Fribourg - Göttingen 1990), 29-65. 263-279; M. KRANZ, Probleme der Leiblichkeit (Diss. phil. masch.; Köln 1965), 104-108; TH. BAUER, Das Inschriftenwerk Assurbanipals II (AB 2; Leipzig 1933) 89; B. LANDSBERGER, WZKM 56 (1960), 129; AHw 906f (qaštu); W. DECKER, Annotierte Bibliographie zum Sport im alten Ägypten (1978), Nrn. 179-236; L. GRASBERGER, Erziehung und Unterricht im klassischen Alterthum III (1881), 150-157; S. LAMER, Sport und Spiel (1987), 62-68, Abb. 22-24; Plutarch, de lib. educ. 11; H. RIEDEL, Leibesübungen und körperliche Erziehung (1942), 14-26; W. KNAUTH - S. NADJMABADI, Das altiranische Fürstenideal von Xenophon bis Ferdousi (1975), 104ff; M. GRIAULE, Jeux Dogons (1938), 48-50.

15 A. Rowe, Catalogue of Egyptian Scarabs, Scaraboids, Seals and Amulets in the Palestine Archaeological Museum (Kairo 1936), 252f, PI. 28:S.61; D. Collon, First Impressions (1987), 154f, No. 684; J. NougAYrol, Cylindres-sceaux et empreintes de cylindres trouvés en Palestine (BAH 33; Paris 1939), 63-65, P1. 7:129; ANEP2 fig. 338. Zum Bogenschießen bzw. Jagd Amenophis' II. in Qadesch (Tell Nebi Mend) vgl. E. EDEL, Die Stelen Amenophis' II. aus Karnak und Memphis mit dem Bericht über die asiatischen Feldzüge des Königs, ZDPV 69 (1953), 130. $173 f$.

16 Auf die kultischen, magischen und pädagogischen Bedeutungen des Bogenschießens wird hier nicht eingegangen, vgl. dazu z.B. V. HAAS, Kompositbogen und BogenschieBen als Wettkampf im Alten Orient, Nikephoros 2 (1989), 27-42. 305f; L. DÜRR, Zum altorientalischen Gedankenkreis: "Der König als Meister im Bogenschießen, von der Gottheit unterrichtet", OLZ 34 (1931), 697; H. SCHÄFER, König Amenophis II. als Mei- 
Stockfechten (arab. nabbūt; muḥ̄ăgafa) ${ }^{17}$ dürfte dort schon in vorislamischer Zeit nicht unbekannt gewesen sein, wie die Verwendung der xyla (latein. fustes, ligna) in Matth. 26,47 par. Mark. 14,43; Luk. 22,52 andeutet.

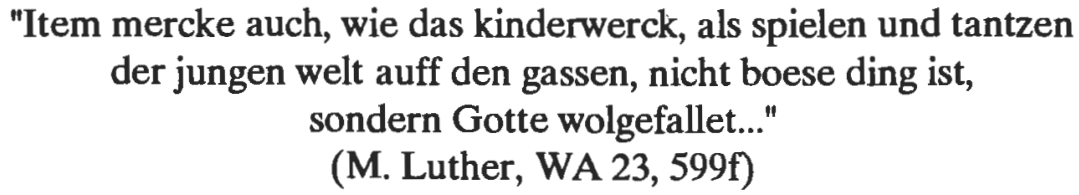

sterschütze, OLZ 32 (1929), 233-244; ders., Weiteres zum Bogenschießen im alten Ägypten, OLZ 34 (1931), 89-96; ders., Die kupferne Zielscheibe in der Sphinxinschrift Thutmosis des IV., ZÄS 67 (1931), 92-95; W. DECKER, Schießscheibe, LÄ 5 (1984), 601; ders., Sport und Spiel im Alten Ägypten (1987), 42-54; ders., Quellentexte zu Sport und Körperkultur im alten Ägypten (1975), 44f. 48f. 52ff u.ö.; ders., Zur Bogenprobe des Odysseus, KBSW 6 (1977), 149-153; ders. - J. KLAUCK, Königliche Bogenschießleistungen der 18. ägyptischen Dynastie. Historische Dokumente und Aspekte für eine experimentelle Überprüfung, KBSW 3 (1974), 23-55; E. EDEL, Bemerkungen zu den Schießsporttexten der Könige der 18.Dynastie, SAK 7 (1979), 23-39; A.D. TouNY - S. WENIG, Sport in Ancient Egypt (1969), 33-38; W. BURKERT, Von Amenophis II. zur Bogenprobe des Odysseus, Grazer Beiträge 1 (1973), 69-78; auch W. KNAUTH, Stadion 2 (1976), 53-61. Zu Herodes d.Gr. vgl. Joseph., BJ 1,21,13 (§ 430); zu Jahwe Hi. 16,12; Threni 3,12: hebr. mtrh = Zielscheibe (auch 1.Sam. 20,20).

17 Vgl. z.B. J. VANDIER d'ABBADIE, Deux nouveaux ostraca figurés, ASAE 40 (1940), 467-488, fig. 50-58, Pl. 43f; C. NIEBUHR, Reisebeschreibungen nach Arabien, Bd. 1 $(1774$ = 1968), 169, Taf. 25:B; C. DIEM, Nabbut (Stockfechten), Olympische Rundschau 3,3 (1938), 12-17; W. DECKER, Annotierte Bibliographie zum Sport im Alten Ägypten (1978), Nrn. 250-253; J.G. WETZSTEIN, Der Nebbût der Araber, Monatsschrift für das Turnwesen 2,1 (1883), 6-12; E.W. LANE, Sitten und Gebräuche der heutigen Egypter II (Leipzig 1856), 184; auch H. DAMM, Die gymnastischen Spiele der Indonesier und Südseevölker, 1.Teil (Leipzig 1922), 29-31; F. KLEPZIG, Kinderspiele der Bantu (1972), 508-514. 


\section{POSSENREISSER, GAUKLER UND ROLLEN-SPIELE}

$\mathrm{Da} ß$ es in den antiken und nachantiken Kulturen Palästinas wie in denen Mesopotamiens und anderswo Possenreißer, Spaßmacher und Hofnarren $\mathrm{gab}^{1}$, die als mehr oder weniger professionelle Alleinunterhalter größere Gruppen von Menschen vergnügten ${ }^{2}$, zeigen m.E. - allerdings unfreiwillig Simson laut Ri. 16,25-27 [sh pq pi. und (V.27) qal inf. cs.; LXX paizein, empaizein; Vulg. ludere] und Eleasar (4.Makk. 6,17). Der von den Philistern gefangene und geblendete Simson wurde im Vorhof des Dagon-Tempels zu Gaza gezwungen, vor seinen Peinigern den Spaßmacher zu spielen - und er spielte ihnen gehörig auf, wie jeder weiß. Der von Antiochos IV. Epiphanes gefolterte Eleazar sagte laut 4.Makk. 6,17: "Nein, so elend sollten wir Kinder Abrahams nicht gesinnt sein, daß wir mit verweichlichter Seele ein uns beschämendes Possenspiel aufführen" (aprepes hēmin drama hypokrinastai). Jesus wurde von seinen Gegnern planos (latein. seductor) genannt (Matth. 27,63); der meistens üblichen Übersetzung als "Verführer" steht nicht entgegen, daß planos auch die Bezeichnung für fahrende Possenreißer, Gaukler

1 Hebr. bdwh'; akkad. aluzinnu (AHw2 39f); sum. a-tar-di/du 11 "verhöhnen" [B. HüBNER - A. REIZAMmER, Inim Kiengi I (Marktredwitz 1985), 35]. W.H.PH. RÖMER, Der Spaßmacher im alten Zweistromland. Zum "Sitz im Leben" altmesopotamischer Texte, Persica 7 (1977), 43-68; B. MEISSNER, Studien zur assyrischen Lexikographie (MAOG 13,2; Leipzig 1940), 4-6; S. KRAUSS, Talmudische Archäologie III (1912), 104. 106f; C. SCHICK, in: A. STRoBel, Conrad Schick. Ein Leben für Jerusalem (Fürth/Bay. 1988), 92. 96; vgl. aramä. $b d w h$ ', G. DALMAN, Aramäisch-Neuhebräisches Handwörterbuch $\left({ }_{1}^{1} 1938=1987\right), 48 ;$ M. JASTROW, A Dictionary of the Targumim $(1903=1989), 139$. Griech. gelōtopoios u.a., latein. planus regius u.a., vgl. auch Hist. Aug., quadr.tyr. 13,2; Plinius d.Ä., nat. hist. 35,89; Xenophon, Symp. 4,50; H. BLÜMNER, Fahrendes Volk im Altertum (1918), 3ff; arab. mazzāh, māzih, mush $a$; Ibn Iyâs, Alltagsnotizen eines ägypti-

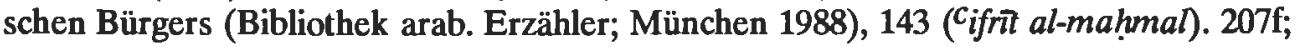
Ibn ㅂallikân, Die Söhne der Zeit (Bibliothek arab. Erzähler; München 1984), 65ff; $A b \bar{u}$ l-Farağ, Und der Kalif beschenkte ihn reichlich (Bibliothek arab. Erzähler; München 1982), 128-152 (Abü Duläma, gest. 778 n.Chr.); Arabische Märchen aus dem Morgenland, ed. U. ASSAF-NOWACK (Frankfurt a.M. 1987), 79. $120 \mathrm{f}$ ( $A b \bar{u}$ Nuwās, gest. ca. 810 n.Chr.).

2 Vgl. z.B. C. NieBuHR, Reisebeschreibung nach Arabien, Bd. 1 (1774 = 1968), 188f; K. MAY, Von Bagdad nach Stambul (KARL MAYs Werke. Hist.-Krit. Ausgabe für die KARL-MAY-Gedächtnis-Stiftung; Freiburg 1907 = Zürich 1990), 323f (in Damaskus). 
und Taschenspieler ist ${ }^{3}$, wie sie neben Bauchrednern ${ }^{4}$, Seiltänzern ${ }^{5}$ u.a. häufig auf Festen und Jahrmärkten ihr Spiel mit ihrer Kundschaft trieben.

Auf einem Orthostaten-Relief des 14.Jh.s v.Chr. aus Alaça-Höyük ist ein Gauklerszene mit einem Schwertschlucker ${ }^{6}$ und zwei Akrobaten dargestellt (Abb. 53)7. Auf dem Relief eines Eckorthostaten des 8.Jh.s v.Chr. aus Sendschirli sieht man zwei Tamburin-Spieler bzw. Akrobaten, von denen der klei-

3 H. BLÜMNER, Fahrendes Volk im Altertum (1918), 3ff; vgl. auch A. MAU, Circulator, RE 3 (1899), 2570; A. HUG, Psēphopaiktēs, RE 23 (1959), 1357 und ders., Praestigiator, RE 44 (1954), 1567f: der praestigiator in Hist. Aug., L. Verus 8,11 stammt aus Syrien.

4 Griech. eggastrimythoi, latein. ventriloquus. Vgl. z.B. Tertullian, adv. Marc. 4,25,4; ders., adv. Prax. 19; Hieronymus, Comm. in Esaiam Libri 3,8,20; auch H. BLÜMNER, Fahrendes Volk im Altertum (1918), 24f. Zu den divinatorischen Möglichkeiten des Bauchredens vgl. T. FAHD, La divination arabe (1966), 171-174.

5 Latein. funambulus; z.B. Seneca de ira 2,12,4; Hist. Aug., Marc.Aurel. 12,12; Terenz, Hecyra, Prolog; Anth. Lat. 281; auch Constitutiones Apost. 6,9,2-4 (und 8,32,9-11). Vgl. G. HeRzoG-HAUSER, Neurobatēs, RE 17 (1936), 158; W. KROLL, Skandalistēs, RE II 5 (1927), 438; H.C. Montgomery - W. KROLL - E. MEHL, Petauron, RE 19 (1937), 1124f; H. BLÜMNER, Fahrendes Volk im Altertum (1918), 13-15; H. SCHMIDT - P. KAHLE (ed.), Volkserzählungen aus Palästina I (1918), 90f; auch W. KROLL, Kontopaiktes, RE 11 (1922), 1343; W. DERBOLAV, Der Kopf- und Handstand als Gauklerkunststück und Kinderspiel, Leibesübungen und körperliche Erziehung 56 (1937), 534538.

6 Vgl. z.B. Plutarch, Lykurg. 19,4; Apuleius, meta. 1,4,2-5; H. BLÜMNER, Fahrendes Volk im Altertum (1918), 20f.

7 K. BITTEL, Die Hethiter (1976), 201. 334, Abb. 218 (Ankara, Arch. Museum); E. AKURGal, Die Kunst der Hethiter $\left({ }^{2} 1976\right)$, Abb. 93 oben. Zu Gauklern und Akrobaten vgl. z.B. Anth. Graeca 9,533; (16,387b); Martial, epigr. 9,38; Expositio totius mundi et gentium E 32 (calopectae in Castabala, einem nicht identifizierbaren Ort an der phönizisch-syrischen Küste - falls damit nicht das kilikische Hierapolis gemeint ist!); auch W. DEONNA, Le symbolisme de l'acrobatie antique (1953), passim; S. LASER, Sport und Spiel (1987), 72-74, Abb. 27f; E. BRUNNER-TRAUT, Akrobaten, LÄ 1 (1975), 117; W. DECKER, Sport und Spiel im Alten Ägypten (1987), 144-154; ders., Annotierte Bibliographie zum Sport im alten Ägypten (1978), Nrn. 375-383; A. HUG, Praestigiator, RE 44 (1954), 1567f; C. ZINTZEN, Gaukler, KP 2 (1975), 703; W.F. VoLBACH, Elfenbeinarbeiten der Spätantike und des frühen Mittelalters (Mainz ${ }^{3} 1976$ ), 36f, Taf. 9:19; M.E. ROGERS, Domestic Life in Palestine (1862 = 1989), 213; H. RIEDEL, Leibesübungen und körperliche Erziehung (1942), 41-43; A.D. TOUNY - S. WENIG, Sport in Ancient Egypt (1969), 78ff; J. JÜTHNER, Kybistētēr, RE 22 (1922), 2299f; W. KROLL, Thaumatopoioi, RE Suppl. 6 (1935), 1278-1282; A. MAU, Cernulus, RE 3 (1899), 1983; F.A.G. BECK, Album of Greek Education (1975), 52, Nos. 323-331; D. LEVI, Antioch Mosaic Pavements I-II (1947), 273-277, Pl. 63e (Bath E, Vestibule 3). Zu Leiter-Akrobaten vgl. auch H. BLÜMNER, Fahrendes Volk im Altertum (1918), 12f. 
nere und jüngere (bartlose) dem größeren und älteren (bärtigen) auf den Schultern steht (Abb. 54) ${ }^{8}$. Ähnliches darf man auch für das antike Palästina voraussetzen: Hieronymus (apol. contra Rufin. 3,31) behauptet von Sim $\mathrm{C}_{\text {on }}$ Bar Kosiba, daß er des öfteren einen angezündeten Strohhalm in den Mund gehalten und dann ausgeatmet habe, um den Eindruck zu erwecken, als ob er Flammen speie: Der Sternen-Sohn [br / $\left.b n k w k b^{\prime}\right]$ und Feuerschlucker, der so als als Lügen-Sohn $\left[b r / b n k w z(y) b^{\prime} / h\right]$ dargestellt wird', soll danach einen Trick benutzt haben, der von Anführern Aufständischer gerne zur Ermutigung ihrer Mitkämpfer angewendet wurde; auch Eunus, ein Syrer aus Apameia, der an der Spitze des 1.sizilanischen Sklaven-Aufstandes (136/135132 v.Chr.) stand, bediente sich seiner ${ }^{10}$. Bar Kosiba und Eunus praktizierten aus politischen Motivationsgründen, was normalerweise Gaukler ihrem staunenden Publikum zur Unterhaltung darboten.

An anderer Stelle beklagt Hieronymus die Anwesenheit der zahlreichen Huren (scorta), Schauspieler (mimi) ${ }^{11}$ und Possenreißer (scurrae) ${ }^{12}$ in der

8 F. VON LUSCHAN, Ausgrabungen in Sendschirli IV (Berlin 1911), 354, Abb. 259b; W. ORTHMANN, Untersuchungen zur späthethitischen Kunst (1971), 63. 393f. 546f, Plan 10, Taf. 63:f (Zincirli F/8a); L. JAKOB-ROST, Altertum 11 (1965), 6-8.

9 "Atque ut ille Barchochebas, auctor seditionis iudaicae, stipulam in ore succensam anhelitu ventilabat ut flammas evomere putaretur", vgl. Feuerschlucker auch bei Athenaios 4,129d; H. BLÜMNER, Fahrendes Volk im Altertum (1918), 19. Zum Personalnamen bzw. den Beinamen vgl. P. SCHÄFER, Der Bar-Kokhba-Aufstand. Studien zum zweiten jüdischen Krieg gegen Rom (Texte und Studien zum Antiken Judentum 1; Tübingen 1981), 51-55. 62.

10 Diodor Sic., bibl. 34/35,2,6f; Florus, epitome 2,7(19): "idque ut divinitas fieri proba$r e t$, in ore abdita nuce quam sulphure et igni stipaverat, leniter inspirans flammam inter verba fundebat".

11 Zu den (Panto)-Mimen vgl. z.B. Expositio totius mundi et gentium E 32 (pantomimi in Caesarea Maritima) und den schauspielernden Nero (Tacitus, Ann. 14,15; 15,50; Sueton, Nero 20,1; Plinius d.J., Panegyr. 46,4) und allgemein L. ROBERT, Pantomimen im griechischen Orient (1930), in: ders., Opera Minora Selecta (Amsterdam 1969), 654 670; K. VRETSKA, Mimus, KP 3 (1975), 1309-1314: ders., Pantomimos, KP 4 (1975), 478-481. Daß es dabei häufig pädagogisch nicht stubenrein zuging, belegt z.B. Plinius d.J., ep. 7,24,4: "Seine Großmutter hielt sich Pantomimen... Quadratus bekam sie nie zu sehen, weder im Theater noch zu Hause... Aus ihrem eigenen Mund hörte ich..., daß sie sich die vielen Mußestunden ihres Geschlechts mit dem Brettspiel (lusu calculonum) zu vertreiben oder sich von ihren Pantomimen etwas vorzuspielen lassen pflegte, aber wenn sie das eine odere andere wollte, stets ihren Enkel hinaus an seine Bücher schickte". Vgl. auch H. LEPPIN, Histrionen. Untersuchungen zur sozialen Stellung von Bühnenkünstlern im Westen des Römischen Reiches zur Zeit der Republik und des Principats (Antiquitas 1,41; Bonn 1991), passim; B. WARNECKE, Histrio, RE 8 (1913), 2116-2128. 
Heiligen Stadt Jerusalem, die die Moral der Pilger gefährdeten (ep. 58,4) ${ }^{\mathbf{1 3}}$. Theodora, die spätere Kaiserin und Gemahlin Justinians, die Tochter eines Tierwärters (therriokomos bzw. arkotrophos) der grünen Zirkuspartei in Konstantinopel, gehörte zu den gelōtopoioi bzw. bōmolochiai und tingelte als solche und als Prostituierte ("Hetäre zu Fuß") "durch den ganzen Osten", also von Alexandria, über Palästina (?!) und Tyros bis nach Konstantinopel; das jedenfalls behauptet Prokop, Anekdota 9. Der Talmud belegt, daß jüdischen Kreisen der Spätantike Zauberkünstler ${ }^{14}$, Possenreißer, Artisten ${ }^{15}$, Bauchredner, Schlangenbeschwörer (Kap. 4) und Puppenspieler nicht unbekannt waren (z.B. bAZ 18b; bSan. 67b). "Man erzählt von Rabbi Šimcon b. Gamaliel ${ }^{16}, \mathrm{da} \beta$ er, wenn er sich an der Feier der Wasserprozession beteiligte, mit acht Fackeln jonglierte, die eine warf, die andere auffing, ohne daß sie einander berührten... Levi jonglierte vor Rabbi mit acht Messern, Šemuël vor dem [sasanidischen] König Šapur mit acht Gläsern Wein, Abbajje vor Raba mit acht Eiern, und wie manche sagen, mit vier Eiern" (bSukka 53a) ${ }^{17}$.

Auch mit dem verhafteten Jesus trieb man seine Spiele. Auch wenn sich die Täter und die neutestamentlichen Verfasser dessen nicht bewußt gewesen sein sollten, so handelte es sich bei dieser Form von politisch motivierten Erwachsenen-Ritualen ursprünglich um 'unschuldige' Kinderspiele ${ }^{18}$. Im Falle von Jesus wurden sie von Erwachsenen pervertiert: Im Hintergrund der grausamen Behandlung Jesu vor dem Hohenpriester Kaiphas (Matth. 26,67 par. Mark. 14,65 par. Luk. 22,63f) steht wohl das Kinderspiel "Wer rupft, wer

12 A. HUG, Scurra, RE II 3 (1921), 911f; auch P. MAAS, Gelōtopoioi, RE 7,1 (1910), 1019-1021; E.W. LANE, Sitten und Gebräuche der heutigen Egypter II (1856), 225-228; vgl. z.B. Philo Alex., in Flacc. 72; Hist. Aug., quadr.tyr. 13,1f.

13 Vgl. die zahlreichen Gaukler in der Heiligen Stadt Mekka, die in den verschiedensten Reiseberichten häufig belegt sind, vgl. z.B. nur J.L. BURCKHARDT, Reisen in Arabien $(1830=1963), 145$.

14 Fr. STUTZ, Zaubern (Niedernhausen/Ts. 1984), 9ff; A. ADRION, Die Kunst zu Zaubern (Köln 1978), passim; E.W. LANE, Sitten und Gebräuche der heutigen Egypter II (1856), 223f.

$15 \mathrm{Zu}$ den Stier-Springern, wie sie jetzt auch auf einer minoischen Wandmalerei aus Auaris / Nil-Delta belegt sind, vgl. oben Kap. 4.

16 I. BuRgansKy, Simon b. Gamaliel, EJ 14 (1971), 1555.

17 Vgl. Joh. Chrysostomos, ad pop. Antiochenum hom. 19,4 [PG 49 (1862), 196]: hoi de machairas enallax eis ton aera akontizontes, kai pasas apo tēs lathēs dexomenoi pali... (in Antiocheia, 4.Jh. n.Chr.); allgemein R. BAIER - TH. ERATH - P. HOFMANN - S. PÖLL MANN, Jonglieren (homo ludens; München 1989), passim.

18 Zu Kinderspielen, die mit gegenseitigem Necken, Hänseln oder Schikanieren zu tun haben, vgl. z.B. M. GRIAULE, Jeux et divertissements abyssins (1935), 143-157; ders., Jeux Dogons (1938), 228ff. 240ff. 
zupft, wer hat's getan?", also das aus griechischen u.a. Quellen bekannte Kinderspiel kollabismos (Pollux 9,129) ${ }^{19}$, in dem Jesus den Prügelknaben spielen mußte. Als Jesus später im Prätorium zu Jerusalem von römischen Soldaten als "König der Juden" verspottet wurde (Matth. 27,27-30 par. Mark. 15,16-20 par. Joh. 19,2f $)^{20}$ und dabei gute Miene zum bösen Spiel machen mußte, dann steht dahinter das unter den Kindern der damaligen Zeit beliebte Königsspiel basilinda ${ }^{21}$, ein Spiel, das Jesus schon als siebenjähriger Knabe - allerdings unter erfreulicheren Bedingungen - mit seinen gleichaltrigen Spielkameraden gespielt hatte und das sich angesichts der zahllosen Herrschaftswechsel in der Geschichte Palästinas stets großer Beliebtheit und Aktualität erfreut haben dürfte (Arab. Kindheitsev. 42,2); Nero hatte seinen noch unmündigen Stiefsohn Rufrius Crispinus ertränken lassen, weil dieser ständig Feldherren- und

19 L. BECQ DE FOUQuiERES, Les jeux des anciens (21873), 88f; L. GRASBERGER, Erziehung und Unterricht im klassischen Alterthum I (1864), 114f; J. VÄTERLEIN, Roma ludens (1976), 23; E. Frh. vON KÜNSSBERG, Rechtsbrauch und Kinderspiel (SHAW.PH 7; Heidelberg 1920), §§ 17ff u.ö.

20 Anders P. WENDLAND, Jesus als Saturnalien-König, Hermes 33 (1898), 175-179; H. REICH, Der König der Dornenkrone, NJPP 1894, 705-733; H. VollMER, "Der König der Dornenkrone", ZNW 6 (1905), 184-198; TH. BIRT, Zum Königsmimus, Ph. 77 (1921), 427f; R. DELBRUECK, Antiquarisches zu den Verspottungen Jesu, ZNW 41 (1942), 127 ("äußerliche Anregung durch den Mimus, die Saturnalien, das Sakäenfest"), vgl. auch J. GEFFCHEN, Die Verhöhnung Christi durch die Kriegsknechte, Hermes 41 (1906), 220-229; M. ALINE DE SION, La Forteresse Antonia à Jérusalem (1956), 139142; F. CumonT, Les actes de S. Dasius, AnBoll 16 (1897), 5-16.

21 Vgl. z.B. Herodot 1,114f; Sueton, Nero 35; Horaz, ep. 1,1,59f (at pueri ludentes 'rex eris' aiunt, 'sic recte facies'); Heraklit, frag. B 52; Pomp. Trogus 1,5; Seneca, const. sap. 12,2; Hist. Aug., Sev. 1,4 und P.Lic.Gall. 4,3 (auch quadr.tyr. 13,1f); Pollux 9,110; Tacitus, Ann. 13,15 (regnum lusu sortientim evenerat); mittellatein. Hist. von Alexander d.Gr. 32; J. Taillardat (ed.), Suétone, Peri paidiōn (1967), Nr. 18; Epiktet, diatr. 3,15,12 "Treibe es nicht wie die Kinder: Heute Philosoph, morgen Steuereintreiber, dann Redner, dann Prokurator des Kaisers!". M. BUBER, Die Erzählungen der Chassidim (1949), 287; A. HUG, RE III A 2 (1929), 1765; H. SCHMIDT - P. KAHLE (ed.), Volkserzählungen aus Palästina II (1930), 92f; A. MAU, Basilinda, RE 3 (1899), 99; L. GRASBERGER, Erziehung und Unterricht im klassischen Alterthum I 1 (1864), 53-55; L. BECQ DE FOUQUIERES, Les jeux des anciens (21873), 63ff; F.F. SCHWARZ, Candragupta Sandrakottos, Altertum 18 (1972), 94; E. Frh. VON KüNSSBERG, Rechtsbrauch und Kinderspiel (1920), §§ 61-63. Nach G. BINDER, Die Aussetzung des Königskindes Kyros und Romulus (BKP 10; Meisenheim 1964), 18f. 23f. 27-29. $198 f$ und anderen Autoren soll es sich bei dem Basilinda-Spiel ursprünglich um ein achämenidisches Königsritual handeln; vgl. (aber) auch die Ersatzrituale hethitischer und mesopotamischer Könige [H.M. KÜMMEL, Ersatzrituale für den hethitischen König (StBt 3; Wiesbaden 1967), 1 ff. 169ff] und die Rolle, die der babylonische König im Ritual des Neujahrsfestes spielen mußte (TUAT 2,222f). 
Kaiserrollen beim Spielen übernommen hatte (Sueton, Nero 35). Während der Demonstrationen in Alexandria gegen den Besuch Agrippas 1. (Philo Alex., In Flacc. 36-39) nahmen die Menschen einen schwachsinnigen Mann namens Karabas "mit ins Gymnasion und stellten ihn auf einen erhöhten Platz, wo er allen sichtbar war; sie stülpten ihm ein Blütenbüschel von Papyrus als Krone auf den Kopf und umhüllten seinen Körper mit einer Matte als Mantel; anstatt eines Szepters gab ihm einer ein kurzes Stück einheimischen Papyrus... Als er nun wie bei Bühnenpossen die Zeichen der Herrschaft trug und zum König geschmückt war, stellten sich junge Leute mit Stöcken auf den Schultern wie Lanzenträger rechts und links als Leibwache auf. Dann traten andere vor ihn, teils als wollten sie ihm huldigen, teils wie um einen Prozeß zu führen, teils als suchten sie in öffentlichen Angelegenheiten seinen Rat. Dann brach die ringsum stehende Menge in ein unsinniges Geschrei aus: 'Marin' riefen sie - so wird angeblich bei den Syrern der Herrscher genannt". Unter Kindern beliebt waren auch Nachahmungen von Verhaftungen und Gerichtsverhandlungen (z.B. Plutarch, Cato min. 2) ${ }^{22}$; die Vater-Mutter-(Kind-) Rollenspiele dürften zu ihren häufigsten Spielen überhaupt gehört haben ${ }^{23}$.

Auch die öffentlichen Bestrafungen und Hinrichtungen hatten oft den Charakter von Schauspielen (Luk. 23,35: kai eistēkei ho laos theōrōn; 1.Kor. 4,9: theatron egenēthēmen). Männer, Frauen und Kinder strömten zu den Hinrichtungs- und Verurteilungsstätten, um dem Spektakel mit angenehmen Grausen beizuwohnen, z.B. bei den Spielen, die Agrippa I. in Berytos veranstalte und dazu Kriminelle zum Spiel auf Leben und Tod in die Arena schickte [Joseph., Ant. 19,7,5 (\$336f)] ${ }^{24}$.

Die Kleider des Gekreuzigten wurden laut dem Neuen Testament durch Lose aufgeteilt (Matth. 27,35 parr.) ${ }^{25}$. Frühchristliche Darstellungen ${ }^{26}$ dieser

22 Erinnert sei hier auch daran, daß der ägyptische Pharao bei bestimmten kultischen Anlässen "einen Gott spielen" konnte, vgl. E. HoRNUNG, ErJb 51 (1982), 513f; ders., Geschichte als Fest (Darmstadt 1966), 9-29. Zu den Rollenspielen arabischer BeduinenKinder vgl. CH.M. DouGHTY, Travels in Arabia Deserta I (1936), 480.

23 Vgl. z.B. S. PAUL, Sozialisierung afrikanischer Kinder durch Rollenspiele, in: FS für S. WOLF zum 65.Geb. (Abh. und Berichte des Staatlichen Museums für Völkerkunde Dresden 34; Ost-Berlin 1975), 228-260; I. WeBER-KellermanN - R. FALKENBERG (ed.), Was wir gespielt haben (1992), 162ff u.ö.

24 Vgl. auch Tertullian, de spect. 21; A. HENNECKE - W. SCHNEEMELCHER (ed.), Neutestamentliche Apokryphen II ( $\left.{ }^{4} 1971\right), 247-249$ (Paulus-Akten); vgl. auch K. MAY, Von Bagdad nach Stambul $(1907=1990)$, 481f.

25 Matth. 27,35 (ballontes klēron - sortem mittentes) par. Mark. 15,24 (dito) par. Luk. 23,35 (ebalon klērous - miserunt sortes). 
Szene wie z.B. palästinische Pilger-Ampullen ${ }^{27}$, Buch-Illustrationen (Abb. $55)^{28}$ oder Ikonen (Abb. 56) ${ }^{29}$ zeigen, wie die Henker die Kleider Jesu unter sich aufteilten, indem sie miteinander das Mor(r)a-Spiel [(digitis) micare "mit den Fingern schnellen"] ${ }^{30}$, eine Art Knobeln ${ }^{31}$, spielten: Dabei strecken die beiden Spieler gleichzeitig eine beliebige Anzahl von Fingern je ihrer rechten Hand aus und rufen dazu so schnell wie möglich die Summe aller ausgestreckten Finger; wer die richtige Zahl getroffen hat, hat gewonnen. Die literarische Interpretation des Loswerfen bei Joh. 19,23f (alla lachōmen... hina he

26 E. LuCCheSI PALli, Morraspiel, LCI $3(1971=1990)$, 281f; A. DE WAAL, Das Moraspiel auf Darstellungen der Verlosung des Kleides Christi, RQ 8 (1894), 145f.

27 A. Grabar, Ampoulles de Terre Sainte (Paris 1958), Monza Ampoules Nos. 2. 515, Bobbio Ampoules Nos. 6. 18, Pl. 5. 11-16. 18. 22. 24. 26. 28. 37-39. 47. 49. 54f; J. ENGEMANN, Palästinische Pilgerampullen im F.J. Dölger-Institut in Bonn, JAC 16 (1973), 26, auch M. ENGLISH Frazer, in: K. WeITZMANN (ed.), Age of Spirituality (New York 1979), 565f. 585f, fig. 79, No. 524; K. WEITZMANN, Loca Sancta and the Representational Arts of Palestine, DOP 28 (1974), 40f, fig. 17f.

28 The Rabbula Gospels. Facsimile Edition of the Miniature of the Syriac Manuscript Plut. I,56 in the Medicean-Laurentian Library, ed. C. Cecchelli et al. (Olten Lausanne 1959), 69-71, fol. 13a (586 n.Chr., aus Bêt Sagba in Nord-Mesopotamien). Vgl. dazu J. LEROY, Les manuscripts syriaques à peintures conservés dans les Bibliothèques d'Europe et d'Orient (BAH 72; Paris 1964, 159. 177ff u.ö., Pl. 32; D.H. WriGHT, The Date and Arrangement of the Illustrations in the Rabbula Gospels, DOP 27 (1973), 197-208; K. WEITZMANN, DOP 28 (1974), 40f, fig. 21.

29 K. Weitzmann et al., Frühe Ikonen (München - Wien 1965), Taf. 6 (Sinai, Katharinen-Kloster, 8.Jh.); ders, DOP 28 (1974), 40f, fig. 19.

30 Griech. lachmos, iachinos. Vgl. z.B. Petronius, sat. 44,7; Nonnos, Dion. 33,77f (methepōn heterotropa daktyla cheirōn); Augustin, trin. 8,5,8; CIL 6,1770 (Verbot); auch Cicero, div. 2,41,85; ders., de fin. 2,52; ders., de off. 3,(19),77; Sueton, Aug. 13,2; Calpurnius, eclog. 2,26f. Vgl. z.B. H. HEYDEMANN, Das Morraspiel, AZ 29 (1872), 151-154, Taf. 56; L. BECQ DE FOUQUIERES, Les jeux des anciens (21873), 290-294; A. HUG, RE III A 2 (1929), 1772; K. ANDREE, Die Verbreitung des Morraspiels, Globus 28 (1875), 159; K. SCHNEIDER, Micare, 'Morra spielen', RE 15,2 (1932), 1516f; R. SCHMIDT, Die Darstellung von Kinderspielzeug und Kinderspiel (1977), 138-141; J. VÄTERLEIN, Roma ludens (1976), 60f; E. FALKENER, Games Ancient and Oriental (1892 = 21961), 103111; S. MENDNER, RAC 10 (1978), 867. 888; O.W. REINMUTH, Micare, KP 3 (1975), 1286f; auch K. SCHAUENBURG, AW 7,3 (1976), 40f; S. LA SORSA, Come giuocono i fanciulli d'Italia (Neapel 1937), 137; F.M. BöHME, Deutsches Kinderlied und Kinderspiel $(1897=1967), 633 f$, Nr. 522-626. Vgl. oben auch par impar.

31 Theophrast, char. 5,5; U. RÜDIGER, Schlauch und Hammeraxt - ein antikes Kinderspiel, MDAI(R) 73-74 (1966-1967), 248-250; S. PAUL, Notizen zu einigen afrikanischen Geschicklichkeitsspielen (Lic. phil. masch. Uppsala 1962), 173ff; dies., Das Fingerknobeln und ähnliche Spiele in Afrika, Anthr. 66 (1971), 145-172. 
graphē plērōtē... kai epi ton himatismon mou ebalon klēron) ${ }^{32}$ als Morraspiel findet sich z.B. bei Nonnos, Metaphrasis S.Evangelii Ioannei 19,125 (daktyla cheiros aphentes).

"Laß, Vater, genug sein das grausame Spiel!" (Fr. SCHILLER, Der Taucher)

32 Den alttestamentlichen Hintergrund bildet Ps. 22,19. 


\section{HELLENISTISCH-RÖMISCH-BYZANTINISCHE}

\section{MASSENBELUSTIGUNGEN}

In der hellenistisch-römischen Zeit mit ihren neuen ökonomischen und kulturellen Möglichkeiten und Bedingungen ${ }^{1}$ änderten sich die privaten Spielgewohnheiten der palästinischen Bevölkerung kaum, soweit es die traditionellen Spiele angeht. Doch kamen nun neue, bis dahin völlig unübliche Vergnügungen (delectabiles ${ }^{2}$ ) hinzu, an denen die Bevölkerung zum Teil aber mehr als passive Zuschauer ${ }^{3}$ denn als aktive Mitspieler in Erscheinung trat: Es begann mit den athletischen und musikalischen Agone griechischer Tradition, die in Tyros schon für das Jahr 331 v.Chr. nachweisbar sind (Plutarch, Alex. 29). Wahrscheinlich im Jahr 174 v.Chr. hatte der Hohepriester Jason (ca. 175-172 v.Chr.) Festgesandte als Repräsentanten des hellenistischen Jerusalem zu den Herakles-Agonen in Tyros geschickt (2.Makk. 4,18-20) ${ }^{4}$, und 166 v.Chr. hatte Antiochos IV. Epiphanes Jerusalems Vertreter nach Daphne geladen, damit sie dort an den von ihm veranstalteten Feierlichkeiten und Agonen teilnehmen konnten [1.Makk. 1,44-54; (2.Makk. 4,9); OGI Nr. 253] .

Jahrzehnte später kamen die ludi römischer Tradition hinzu, also Pferdeund Wagenrennen, Tierhatzen (venationes) und Gladiatorenkämpfe (munera), die von den Herrschenden ebenfalls zur propagandistischen Darstellung ihres politischen Selbstverständnisses und zwecks Belustigung ihrer Untertanen inszeniert wurden ("panem et circenses": Juvenal, sat. 10,81) ${ }^{6}$. Diese neuartigen Volksbelustigungen fanden weithin Anklang, aber natürlich

1 Vgl. auch C. DIEM, Alexander der Große als Sportsmann (Frankfurt a.M. 1957), passim.

2 So die Expositio totius mundi et gentium E 32 in Bezug auf syrisch-palästinische Orte wie Caesarea Maritima, Gaza und Aschkelon.

3 Vgl. z.B. A. GuTTMAN, Sports Spectators from Antiquity to the Renaissance, JSH 8 (1981), 7-12; H. KINDERMANN, Das Theaterpublikum der Antike (Salzburg 1979), 18ff; H. JÜRGENS, Pompa diaboli (1972), 191-198.

4 P. SCHÄFER, Geschichte der Juden in der Antike (1983), $52 \mathrm{ff}$.

5 J.G. BungE, Die Feiern Antiochos' IV. Epiphanes in Daphne im Herbst 166 v.Chr., Chiron 6 (1976), 53-71; ders., Münzen als Mittel politischer Propaganda: Antiochos IV. Epiphanes von Syrien, SCO 16 (1974), 43-52.

6 Vgl. z.B. C.M. Weber, Panem et circenses. Massenunterhaltung als Politik im antiken Rom (Düsseldorf 1983), passim; P. VEYNE, Brot und Spiele. Gesellschaftliche Macht und politische Herrschaft in der Antike [(franz. 1976) Frankfurt 1990], passim; I. WEILER, Der Sport bei den Völkern der Alten Welt (Darmstadt ${ }^{2} 1988$ ), passim. 
auch Gegner; letztere stammten aus den Reihen jener, die sich mit einem massiven Alleinvertretungsanspruch für das wahre Israel hielten ${ }^{7}$. Sie versuchten, die neue öffentliche Spielkultur, wie sie spätestens ab der Zeit Antiochus IV. Epiphanes (175-164 v.Chr.) in Jerusalem von Einheimischen (!) ${ }^{8}$ nicht von Fremden - eingeführt worden war, aber auch traditionelle Spiele (Bar. 3,17), durch Verurteilung der Spiele, ihrer Betreiber und ihrer Zuschauer zu bekämpfen: Laut 1.Makk. 1,14; 2.Makk. 4,9-18; 4.Makk. 4,20; bAZ 18b u.a. lehnten sie die Einrichtungen des Gymnasions ${ }^{9}$, des Ephebeions bzw. der Palästra ${ }^{10}$ und die damit verbunden Übungen $a b^{11}$, an denen sich aber auch - unter anderen - Priester des Jerusalemer Tempels versuchten [vgl. Jo-

7 R.R. Chambers, Greek Athletics and the Jews 165 A.C. - A.D. 70 (Ph.D. unpubl.; Miami University 1980), 5ff.

8 M. LÄMmER, Jason's Gymnasium in Jerusalem, in: Proceedings of the Pre-Olympic Seminar on the History of Physical Education and Sport in Asia, Wingate Institute 1972 (Netanya 1972), 51-70; ders., Griechische Wettkämpfe in Jerusalem und ihre politische Hintergründe, KBSW 2 (1973), 182-227.

9 Vgl. z.B. M. HENGEL, Judentum und Hellenismus (WUNT 10; Tübingen ${ }^{3} 1988$ ), 121-143. 506f u.ö.; A. KOCH, Die Leibesübungen im Urteil der antiken und frühchristlichen Anthropologie. Ein Beitrag zur Geschichte des Sportes (Schorndorf 1965), 11ff; H.A. HARRIS, Greek Athletics and the Jews (Trivium 3; Cardiff 1976), 28ff; A. KASHER, The Jewish Attitude to the Alexandrian Gymnasium in the First Century A.D., AmJAncHist 2 (1976), 148-161; R.R. CHAMBERS, Greek Athletics and the Jews 165 A.C. - A.D. 70 (Ph.D. unpubl.; Miami University 1980), 76-129; auch J. DELORME, Gymnasion. Étude sur les monuments consacrés à l'éducation en Grèce (BEFAR 296; Paris 1960), passim; W. ZIETZSCHMANN, Wettkampf- und Übungsstätten in Griechenland II: Palästra - Gymnasion (Schorndorf 1961), passim; W. ElligER, Gymnasium, NBL 1 (1991), 364f.

10 Vgl. z.B. W. ZIETZSCHMANN, Wettkampf- und Übungsstätten in Griechenland II (1961), passim; M. WUNNERLICH, Griechische Wettkampf- und Palästradarstellungen (Diss. phil. masch.; Freiburg i.Br. 1986), passim; W. ORTH, Zum Gymnasium im römerzeitlichen Ägypten, in: Althistorische Studien. FS für H. BENGTSON (Hist. ES 40; Wiesbaden 1983), 223-232.

11 Der in 2.Makk. 4,14 genannte Diskos meint wahrscheinlich nicht die bekannte Wurfscheibe, sondern ein (optisches und / oder akustisches) Signalgerät, das den Beginn der Übungen anzeigte, vgl. A. WILHELM, Neue Beiträge zur griechischen Inschriftenkunde V (SAWW.PH 214,4; Wien - Leipzig 1932), 44-47.

Zum Diskos als Sportgerät vgl. z.B. J. JÜTHNER, Die athletischen Leibesübungen der Griechen II (SÖAW.PH 249,2; Wien 1968), 123-303; F.A.G. BECK, Album of Greek Education (1975), 34, Nos. 184-188; S. LASER, Sport und Spiel (1987), 58-62, Abb. 21; M. LAVRENCIC - G. Doblhofer - P. MAURTISCH, Diskos. Sporthistorischer Kommentar (Quellen-Dokumentation zur Gymnastik und Agonistik im Altertum 1; Köln u.a. 1991), passim; W. DECKER, Zum Ursprung des Diskuswerfens, Stadion 2 (1976), 212: "außergriechische, wahrscheinlich semitische Provenienz des Diskus"! 
seph., Ant. 12,5,1 ( $\S 241)]^{12}$. Zur Begründung führten die Gegner an, daß es sich dabei um "heidnische Lebensweisen" [1.Makk. 1,14; 2.Makk. 4,13 ta nomina tōn ethnōn; prosbasis allophylismou, vgl. Joseph., Ant. 15,8,1 (§ 267)] bzw. "griechische Lebensart" (2.Makk. 4,10.13 ho hellēnikos charaktēr; vgl. auch akmē hellēnismou) handele und diese 'dem Gesetz' widersprächen (2.Makk. 4,11.14); mit dieser Bewertung wurde gleichzeitig behauptet, daß nichtjüdische bzw. nichtchristliche Lebensformem und die mit den neuen Gepflogenheiten verbundenen griechischen Tugenden wie die $\operatorname{arete}^{-13}$ oder kalokagathia oder Musen wie Melpomene ${ }^{14}$ per se verderbt seien und daß die

12 Vgl. dazu R. BAllou, The Role of the Jewish Priesthood in the Expansion of Greek Games in Jerusalem, CJHSPhE 1 (1970), 70-81. In der antiken Mittelmeerwelt sind im übrigen häufig Epheben-Vereinigungen, Gymnasiarchen u.ä. belegt, deren Mitglieder bzw. Amtsinhaber ganz oder teilweise aus Juden bestanden, vgl. z.B. G. LÜDERIT, Corpus jüdischer Zeugnisse aus der Cyrenaika (BTAVO.B 53; Wiesbaden 1983), 11-21 (Kyrene); CPJ No. 153:72ff; 157:I:7f; Philo Alex., spec. 2,229f (Alexandria); CIJ II No. 755 (Hypaipa, Lydien) und allgemein R.R. CHAMBERS, Greek Athletics and the Jews 165 A.C. - A.D. 70 (Ph.D. unpubl.; Miami University 1980), 129ff. Die Synagoge in Sardis ist integraler Teil des Bad-Gymnasium-Komplexes, A.R. SEAGER - A.TH. KRAABEL, The Synagogue and the Jewish Community, in: G.M.A. HANFMAN (ed.), Sardis from the Prehistoric to Roman Times. Results of the Archaeological Exploration of Sardis 1958-1975 (Cambridge/MA - London 1983), 168-190, fig. 207. 211, P1. IV; F.K. YEGÜL, The Bath-Gymnasium Complex at Sardis. Archaeological Exploration of Sardis 3 (Cambridge/MA - London 1985), passim. In eine Wand des Gymnasiums von Priene ist eine Menora eingraviert, vgl. H.A. HARRIS, Greek Athletics and the Jews (1976), 93f, Pl. I. In Milet ist folgende Sitzplatzinschrift im dortigen Theater erhalten: "topos Eioudeōn tōn kai Theosebion", CIJ II, Nr. 748; A. DEISSMANN, Licht vom Osten (Tübingen ${ }^{4}$ 1923), 391f, Abb. 82.

13 Vgl. z.B. S.G. MILlER, Arete. Ancient Writers, Papyri, and Inscriptions on the History and Ideals of Greek Athletics and Games (Chicago/IL 1979), Nos. $7 \mathrm{ff}$.

14 Der Königsweg (1987), Nr. 212 (Petra, Arch. Mus. Inv.-No. J.P. 516); vgl. die tragischen und komischen Masken z.B. auf einer römerzeitlichen Grabtür in Jafo [J. PIN-

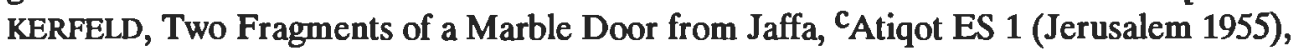
89-94, fig. 2, Pl. 7:1], auf einem Sarkophag vom Tell Mubārak (Tel Mevōrak) [J. OLAMI J. RINGEL, in: E. STERN, Excavations at Tel Mevorakh (1973-1976), Part I (Qedem 9; Jerusalem 1978), 10f, Pl. 5], auf tesserae [A. HAMBURGER, Surface-Finds from Caesarea Maritima - Tesserae, in: L.I. LEVINE - E. NETZER (ed.), Excavations at Caesarea Maritima (1986), 198, Nos. 42ff, Pl. II], auf Öllampen [R. ROSENTHAL-HEGINBOTTOM, Römische Bildlampen aus östlichen Werkstätten (GOF 2,5; Wiesbaden 1981), 68] und auf Münzen [z.B. A. SpLJKERMAN, The Coins of the Decapolis and Provincia Arabia (SBF.CMa. 25; Jerusalem 1978), 194f, Nr. 22, Pl. 42:22] etc. [J.W. CROWFOOT, Sculptural Work, in: ders. et al., The Objects from Samaria (1957), 84]; zur prähellenistischen Geschichte der Masken vgl. z.B. D. RTTTIG, Maske, RlA 7 (1987-1990), 448f; S. SCHROER, In Israel gab es Bilder (1987), 146-154. Zu Statuen von Musen vgl. z.B. R. 
Heilige Schrift nur eine einzige Interpretation zulasse. Die Anhänger der Massenunterhaltungen dagegen wiesen immer wieder - durchaus zu Recht, wenn auch mit Hilfe eines ebenso durchsichtigen Biblizismus - darauf hin, daß das Gesetz bzw. die Heilige Schrift kein explizites Verbot dieser Massenbelustigungen überliefere ${ }^{15}$ : Als Agrippa I. von dem Jerusalemer Pharisäer Simon ob seines Lebenswandels öffentlich kritisiert wurde, ließ der König ihn ins Theater (nicht ins Amphitheater!) von Caesarea Maritima kommen und fragte ihn: "Sage mir: Was von dem, was hier geschieht, ist gegen das Gesetz?" Simon "aber wußte nichts mehr vorzubringen" [Joseph., Ant. 19,7,4 (§ 332-334) $]^{16}$. Einige, wie z.B. der Verfasser des Aristeas-Briefes $(\$ 284)^{17}$, billigten bestimmten Theater-Aufführungen eine pädagogische Funktion zu. Der kultische Charakter einiger Spiele ${ }^{18}$ und vor allem die Exzesse bei den munera und venationes gab ihren Gegnern und Kritikern - nicht nur aus ihrer jeweiligen Sicht - größtenteils Recht; der damit verbundene undifferenzierte Rigorismus aber, der die Gegner - gleichgültig, ob es sich um Heiden, Juden oder Christen handelte - von der Mentalität und Alltagswelt ihrer angeblich so vergnügungssüchtigen Glaubensgenossen trennte, sorgte für die in solchen Fällen häufig zu beobachtende Unglaubwürdigkeit und wirkte sich stattdessen eher kontraproduktiv aus. Das, was sie für so gottlos hielten, breitete sich rasch und vielerorten aus und wurde zu einem selbstverständlichen Bestandteil der damaligen palästinischen Kultur.

Vor allem Herodes d.Gr. trat hier als Förderer, Bauherr und Mäzen auf: Er stiftete Siegerpreise [Joseph., BJ 1,21,11 ( $\$ 423)$ ], ließ Gymnasien in Pto-

WENNING, Hellenistische Skulpturen in Israel, Boreas 9 (1983), 111f; J.W. CROWFOOT, in: ders. et al., The Objects from Samaria (1957), 72, P1. 7:31.

15 So z.B. Tertullian, de spect. 1. 3. 18f u.ö. Vgl. auch Novatian, de spect. (CCSL 4, 153ff) und den unter dem Namen Cyprian überlieferten Traktat de spect. [CSEL 54,3 (1871), 3-13].

16 M. LÄMMER, Griechische Agone und römische Spiele unter der Regierung des jüdischen Königs Agrippa I., KBSW 10-11 (1981-82), 206-209.

17 "Es ist für die (rechte) Lebensführung nützlich und geziemend, sich anzusehen, was mit Anstand gespielt wird, und sich schickliche und anständige Szenen aus dem Leben vor Augen zu führen. Denn darin liegt eine gewisse Belehrung" (vgl. auch §§ 314-316). Vgl. auch W. WEISMANN, Kirche und Schauspiele. Die Schauspiele im Urteil der lateinischen Kirchenväter unter besonderer Berücksichtigung von Augustin (Cass. 27; Würzburg 1972), 110ff. 180ff.

$18 \mathrm{DaB}$ die gleichen Spiele - ohne die kultischen Beitaten paganer Tradition - in byzantinischer Zeit von Christen weiter durchgeführt wurden, zeigt, daß der kultischer Charakter der Spiele in der römischen Zeit in den Augen ihrer Zuschauer kaum mehr als eine mehr oder weniger lästige religöse Pflichterfüllung war, die den Beginn der eigentlichen Spiele nur verzögerte. 
lemaïs, Damaskus und Tripolis [Joseph., BJ 1,21,11 (\$ 422)], Theater in Jerusalem, Caesarea Maritima, Damaskus und Sidon [Joseph., BJ 1,21,8 (\$ 415); 1,21,11 ( $\$ 422)$; ders., Ant. 15,8,1 ( $\$ 268$ )] und Amphitheater in Jerusalem und Caesarea Maritima erbauen [Joseph., Ant. 15,8,1 ( $\S 268)$ ], begründete dort im Jahr der 192.Olympiade und zu Ehren des römischen Kaisers die im 5-Jahres-Zyklus abgehaltenen Agone [Joseph., BJ 1,21,8 (§ 415); ders., Ant. $16,5,1(\$ 137)]^{19}$ und richtete Gymnasiarchien für alljährlich durchgeführte Wettkämpfe ein [Joseph., BJ 1,21,11 ( $\$ 423)$ ]. Zugleich unterstützte er die Olympischen Spiele, wo er auch das Amt eines Agonothetes übernahm [Joseph., BJ 1,21,12 (§ 427); ders., Ant. 16,5,3 (§ 149)] ler bzw. Athleten nahmen demnach mit an Sicherheit grenzender Wahrscheinlichkeit an den Olympischen Spielen teil, konnten sich aber nur selten als Sieger verewigen ${ }^{21}$. Der Enkel Herodes' d.Gr., Agrippa I. (41-44 n.Chr.), der sich auf seinen Münzprägungen auf einer quadriga abbilden ${ }^{22}$ und eine Abwendung von den Agonen griechischer Tradition hin zu den Spielen römischer Tradition erkennen ließ, ließ in Berytos (Beirüt) ein Theater und ein Amphitheater errichten [Joseph., Ant. 19,7,5 (\$ 338)] und in Caesarea Maritima Schauspiele (theōriai) veranstalten, wo er von Teilen des Publikums

19 M. LÄMmER, Die Kaiserspiele von Caesarea im Dienste der Politik des Königs Herodes, KBSW 3 (1974), 95-164.

20 Joseph., BJ 1,21,12 (§ 426-428); ders., Ant. 16,5,3 (§ 149). Vgl. M. LÄMMER, Eine Propaganda-Aktion des Königs Herodes in Olympia, KBSW 1 (1972), 160-173; ders., King Herod's Endowment to the Olympic Games, in: Proceedings of the Pre-Olympic Seminar on the History of Physical Education and Sport in Asia, Wingate Institute 1972 (Netanya 1972), 31-50; J. YEKUTIELI, Herod, King of Jerusalem, prevents the Decline of the Ancient Olympic Games (A Historic Episode in the Games of the 193rd Olympiade), in: Report of the Sixth Summer Session of the International Olympic Academy 1966 (Athen 1967), 156-158. Zur finanziellen Unterstützung des Gymnasiums auf Kos vgl. Joseph., BJ 1,21,11 (\$ 423). Zu Olympia vgl. zuletzt K.-W. WEEBER, Die unheiligen Spiele. Das antike Olympia zwischen Legende und Wirklichkeit (Zürich - München 1991), passim.

21 Vgl. den Olympiasieger (200.Olympiade, 21 n.Chr.), der aus - dem transjordanischen (?) - Petra stammte, Eusebios, Chron. 101,23 (PG 19,237). L. MORETTI, Olympionikäi, i vincitori negli antichi agoni olympici (AANL.M 356; Rom 1959), 55ff; nachweisbar sind immerhin Sieger aus Sidon, Seleucia Pieria und Antiocheia (und Laodicea ad mare?); zu Antiocheia vgl. auch G. DowNEY, The Olympic Games of Antioch in the Fourth Century A.D., (1939), in: G. FATOUROS - T. KRISCHER (ed.), Libanios (WdF 621; Darmstadt 1983), 173-184; C. MILLON - B. SCHOULER, Les Jeux Olympiques d'Antioche, Pallas 34 (1988), 61-76.

22 J. MEYSHAN, The Coinage of Agrippa the First, IEJ 4 (1954), 188. 196, No. 4, Pl. 17:2-3. Vgl. dazu auch W. WEBER, Das Ehrenrecht des Wagenfahrens in römischen 
als (falscher) Gott verehrt und dafür von dem einen und wahren Gott mit dem Tod bestraft worden sein soll [Apg. 12,21-23; Joseph., Ant. 19,8,2 (§ 345)] $]^{23}$. Agrippa II. ließ in Berytos das Theater und Amphitheater weiter ausbauen [Joseph., Ant. 20,9,4 (\$211f)] und Titus ließ 70 n.Chr. in Caesarea Philippi Gladiatorenspiele durchführen [Joseph., BJ 7,2,1 (§23f)] ${ }^{24}$.

In der Folge dieser Kulturpolitik wurde das Aramäische bzw. Hebräische um eine Vielzahl neuer Wörter aus dem Griechischen bereichert: aus griech. sphaira (Ball) wurde spyr'/ $h$, aus griech. psēphos (Brettspiel, Spielstein) psyps, aus griech. chondroi (latein. tesserae) 'sqwndry, aus griech. astragalos 'strqlyl', aus griech kybos (Würfel) qwby', aus griech. strobilos (Kreisel) 's/ștrwbyl, aus griech. hippodromos (Pferderennbahn) 'ypwdrwmyn, aus griech. theatron (Theater) $t$ 'trwn, aus griech. stadion 'stdyn oder aus latein. circus qrqs' $/(w) n$ etc. ${ }^{25}$. Vor allem aber gab es nun während der römischen ${ }^{26}$ und byzantinischen $^{27}$ Zeit in nahezu jeder größeren polis ${ }^{28}$ Palästinas ein Theater (Abb.

Städten, in: Spätantike und frühes Christentum (Liebieghaus) (Frankfurt a.M. 1983), 308-311.

23 M. LÄMMER, KBSW 10-11 (1981-82), 209-220; D.R. SCHWARTZ, Agrippa I. The Last King of Judaea (Texte und Studien zum Antiken Judentum 23; Tübingen 1990), $145 \mathrm{ff}$.

24 Diese Gladiatorenspiele setzen mit großer Wahrscheinlichkeit ein schon vor Titus erbautes Amphitheater voraus, vgl. R. RosenTHAL, Caesarea Philippi, in: Archäologisches Lexikon zur Bibel, ed. A. NEGEV - J. REHORK (München u.a. 1972), 198.

25 Später wurde z.B. arab. (țāwlet) zahr ins Italien. (gioco della zara, vgl. z.B. Dante, Div. com., purg. 6,1-3), Franz. und Deutsche hasard übernommen.

26 Vgl. M. LÄMMER, KBSW 3 (1974), 95-164; ders., KBSW 2 (1973), 182-227; ders., Griechische Wettkämpfe in Galiläa unter der Herrschaft des Herodes Antipas, KBSW 5 (1976), 37-67; ders., KBSW 10-11 (1981-1982), 199-237; ders., The Introduction of Greek Contests into Jerusalem through Herod the Great and its Political Significance, in: Physical Education and Sports in the Jewish History and Culture. Proceedings of an International Seminar at Wingate Institute July 1973, ed. U. SIMRI (Netanya 1973), 1838; H.A. HARRIS, Greek Athletics and the Jews of Palestine, in: a.a.O., 91-7; ders., Greek Athletics and the Jews in the Diaspora in the Early Roman Empire, in: a.a.O., 490-49 (v.a. zu Philo Alex.); ders., Greek Athletics and the Jews (Cardiff 1976), passim.

27 J. Alouf, Physical Culture in the Period of the Talmud, in: Physical Education and Sports in the Jewish History and Culture. Proceedings of an International Seminar at Wingate Institute July 1973, ed. U. SIMRI (Netanya 1973), 5-11 (hebr.; English Summary 39*); M. LAMMER, Ideologiacl Tendencies in the Historiography of Sport in the Jewish Culture (with Particular Consideration of Biblical and the Hellenic-Talmudic Eras), a.a.O., 54-72.

28 Eine weitgehende Ausnahme bilden die mehr oder weniger geschlossenen jüdischen Siedlungsgebiete in Zentraljudäa und Galiläa (vgl. aber Tiberias und Tarichaiai, wo Organisatoren, Zuschauer und ein Teil der Aktiven Juden waren!). 
57) ${ }^{29}$, dazu häufig ein Amphitheater (Abb. 60) ${ }^{30}$, ein Stadion ${ }^{31}$, einen Circus bzw. ein Hippodrom (Abb. 59) $)^{32}$, ein Odeon (Abb. 58) (33 $^{33}$ / oder ein Gym-

29 Das Kulturphänomen Theater wurde im antiken Orient u.a. bis nach Palmyra und Babylon exportiert. In Cisjordanien literarisch belegt und / oder archäologisch nachgewiesen vor allem in Aschkelon (P.Ryl. IV, No. 627:213ff), Jerusalem [vgl. Joseph., Ant. 15,8,1 (§ 268)], Caesarea Maritima [schon Joseph., BJ 1,21,8 (§ 415); Ant. 15,9,6 (§ 341)], Diocaesarea (Sepphoris), Dor, Elusa, Jericho (Tell es-Samrät) [Joseph., Ant. 17,6,3 (§ 161)], Hirbet eš-Š̄une ( $K^{e}$ far Š̆üñ), Neapolis (Näblus), Sebaste-Samaria, Skythopolis und Tiberias. In Transjordanien vor allem belegt in Abila, Gadara (zwei Theater), Gerasa (drei Theater), el-Hamme, Hippos (?), Philadelphia (laut Muqaddasi 175 und Yāqūt III 760 soll Salomo der Erbauer dieses Theaters gewesen sein), Petra und es-Sabra. In Syrien und Phönizien vor allem in Edreï / Adraa ( $\left.\operatorname{Cer}^{\mathcal{C}} \vec{a}\right)$, Damaskus, Sidon [Joseph., BJ 1,21,11 (\$ 422)], Bostra, Byblos, Philippopolis, Soada (Suwēda), Sakkaia (Šaqqa), Kanatha (vgl. CIG Nr. 4614), Saḥr in der Le ̌̆ğă, Apameia, Gabala und Palmyra. Vgl. auch Apg. 19,29-41 (Ephesos).

Die frühesten Theaterbauten in Palästina (Caesarea Maritima, Jerusalem, Jericho, eventuell Sepphoris u.a.) sind wahrscheinlich unter Herodes d.Gr. entstanden. Vgl. zusammenfassend z.B. H.-P. KUHNEN, Palästina in griechisch-römischer Zeit (HdArch, Vorderasien 2,2; München 1990), 193ff; A. SEGAL, Die Theaterbauten im alten Palästina in römisch-byzantinischer Zeit, AW 18,1 (1987), 2-21; ders., Theatres in Ancient Palestine during the Roman-Byzantine Period, SCI 8-9 (1985-1988), 145-165; E. FREzOULS, Les édifices des spectacles en Syrie, in: Archéologie et Histoire de la Syrie II. La Syrie de l'époque achémenide à l'avènement de l'Islam (Schriften zur Vorderasiatischen Archäologie 1; Saarbrücken 1989), 385-406; auch M.T. BOATWRIGHT, Theaters in the Roman Empire, BA 53 (1990), 184-192; H.-D. BLUME, Einführung in das antike Theaterwesen (Darmstadt 31991), 107ff; G. LA PIANA, The Byzantine Theater, Spec. 11 (1936), 171-211; A. VoGT, Études sur le théâtre Byzantin, Byz. 6 (1931), 37-74. 623-640; A. MÜlleR, Das Bühnenwesen in der Zeit von Constantin d.Gr. bis Justinian, NJKA 23 (1909), 36-55; PH. DerchaIN, Kultspiele, LÄ 3 (1980), 856-859; E. DrIOTON, Le théâtre dans l'Ancienne Égypte, Rev. d'Histoire du Théâtre 6 (1954), 7-45; H. SCHLÖGL, Schauspieler, LÄ 5 (1984), 545f; ders., Theater, LÄ 6 (1986), 463f; B.H. STRICKER, The Origin of the Greek Theatre, JEA 41 (1955), $34-47$ (nicht überzeugend).

30 Amphitheater, Stadien und Hippodrome sind keineswegs immer klar zu unterscheiden. Häufig meinen die literarischen Belege Mehrzweckbauten (vor allem in Caesarea Maritima, Jericho u.a.), z.T. wurden Stadien später in Hippodrome verwandelt; die folgenden Beleglisten dürfen daher nicht zu eng verstanden werden. Literarisch, epigraphisch und / oder archäologisch sind 'Amphitheater' belegt bzw. nachgewiesen z.B. in Jerusalem [vgl. Joseph., Ant. 15,8,1 ( $\$ 268)$ ], Caesarea Maritima [schon Joseph., BJ 1,21,8 (§ 415); Ant. 15, 9,6 (§ 341)], Caesarea Philippi (s.o.), Eleutheropolis, Jericho [Joseph., BJ 1,33,8 (\$ 666)], Legio, Neapolis, Pella (?), Skythopolis und Bostra (?). Vgl. zusammenfassend z.B. H.-P. KUHNEN, Palästina in griechisch-römischer Zeit (1990), 193ff; A. HÖNLE - A. HENZE, Römische Amphitheater und Stadien. Gladiatorenkämpfe und Circusspiele (Feldmeilen 1981), 74ff. 133ff; E. POLLACK, Arena, RE 2 (1896), 638640. 
nasion (Palästra) ${ }^{34}$. Für Jerusalem ${ }^{35}$ und Gerasa ist das Gymnasion, das bis Babylon am Euphrat ${ }^{36}$ und $A i ̈ \underline{H}$ anum am Oxus ${ }^{37}$ exportiert worden war, lite-

31 Aramä. Lehnwort 's(s)țyn (bAZ 18b). Literarisch, epigraphisch und / oder archäologisch belegt bzw. nachgewiesen z.B. in Gaza, Jerusalem, Jericho, Caesarea Maritima, Samaria-Sebaste, Skythopolis und Tiberias [Joseph., BJ 2,21,6 (§ 618); 3,10,10 (§ 539); ders., vita 92. 331; jErubin 22b]; die Graffiti aus dem Stadion von Samaria-Sebaste könnten Szenen innerhalb desselben widerspiegeln, J.W. CROWFOOT - K.M. KENYON E.L. SUKENIK, The Buildings at Samaria (London $1942=1966$ ), 42-46,. fig. 14f. Vgl. zusammenfassend z.B. W. ZIETZSCHMANN, Wettkampf- und Übungsstätten in Griechenland I: Das Stadion (1960), passim; A. HöNLE - A. HENZE, Römische Amphitheater und Stadien (1981), passim. Die Beiträge von L. BouTros, The Phoenician Stadium of Amrit, Olympic Review 112 (1977), 114-120; ders., Phoenician Sport. Its Influence on the Origin of the Olympic Games (Amsterdam 1981), passim, werden hier nur wegen ihres Unterhaltungswertes angeführt: Das Stadion von $c_{\text {Amrit } / \text { Marathos wird ins }}$ 15.Jh.v.Chr. zurückdatiert!

32 Hippodrome sind literarisch, epigraphisch und / oder archäologisch vor allem belegt bzw. nachgewiesen in Caesarea Maritima [archäolog. und epigraph., vgl. B. LIFSHITZ, Une Inscription Byzantine de Cesarée en Israël (Caesarea Maritima), REG 70 (1957), 118-132; L. ROBERT, Bulletin épigraphique, REG 71 (1958), 344], Elusa (?), Gadara, Gaza, Gerasa [archäolog. und epigraph., vgl. C.H. KRAELING, Gerasa, City of the Decapolis (New Haven/CT 1938), 85ff. 445, Insc. No. 194], Herodion, Jericho (Tell es-Samrät) [Joseph. BJ 1,33,6 (§ 659); ders., Ant. 17,6,5; 8,2; 9,5 (§ 175. 178. 193. 233); Euseb., hist. eccl. 1,8,12: "sog. Hippodrom"], Jerusalem [Joseph., BJ 2,3,1 (§ 44); ders., Ant. 17,10,2 (§ 255)], Neapolis (Malalas, Chronogr. 18, § 446), Sebaste-Samaria, Tarichaiai [Joseph., BJ 2,21,3 (\$ 599); ders., vita 132. 138], [Hebron nur in einer - textkritisch unsicheren - Stelle in TestXII Patr. Joseph 20,3]; auch Bostra, Philippopolis, Tyros u.a. Ein Hippodrom ist wohl auch auf einem der omayyadischen Mosaike der Großen Moschee in Damaskus [Joseph., Ant. 13,15,1 (§ 389)] abgebildet, vgl. R. ETTiNGHAUSEN (ed.), Arabische Malerei (Genf 1962), 24. 26. Vgl. zusammenfassend z.B. O.W. REINMUTH, Hippodromos, KP 2 (1975), 1162f; H.-P. KUHNEN, Palästina in griechischrömischer Zeit (1990), 193ff.

33 Literarisch, epigraphisch und / oder archäologisch belegt bzw. nachgewiesen z.B. in Antipatris, Skythopolis, Pella, Philadelphia, Abila, Caesarea Maritima (Malalas, Chronogr. 10, § 261; angeblich von Vespasian erbaut), Aschkelon (P.Ryl. IV, No. 627:213ff), Kanatha (vgl. CIG Nr. 4614) und Dura-Europos (?) u.a.

34 Literarisch, epigraphisch und / oder archäologisch belegt bzw. nachgewiesen z.B. in Jerusalem [schon 2.Makk. 4,9.12 (175 v.Chr.)], Ptolemaïs (Akko), Petra (?) [J. DELORME, Gymnasion (1960), 218f], Damaskus und Tripolis [Joseph., BJ 1,21,11 (§ 422); 2,20,2 (\$560)].

35 Joseph., BJ 2,16,3 (§ 344); 4,9,12 (§ 581); 5,4,2 (§ 144); 6,3,2 (§ 191); 6,6,2 (§ 325); $6,8,2$ (§ 377); ders., Ant. 12,5,1 (\$ 241); 20,7,11 (\$ 189).

36 (F. WETZEL - E. SCHMIDT) - A. MALLWTTZ, Das Babylon der Spätzeit (1957), 16ff, Taf. 2-11; vgl. auch (aber nicht überzeugend) G.E. KIRK, Gymnasion or Khan? A Hellenistic Building at Babylon, Iraq 2 (1935), 223-231. 
rarisch bzw. epigraphisch auch als xystos belegt ${ }^{38}$, der in Jerusalem über eine Brücke mit dem Tempelbezirk verbunden war $^{39}$ und dem in Gerasa ein xystarchēs vorstand, der dieser Amt lebenslang (dia biou) innehatte ${ }^{40}$. Auf diesen 'Spielplätzen' wurden zu den verschiedensten Anlässen oder auch in regelmäßigen Abständen ${ }^{41}$ entsprechende agonistische ${ }^{42}$ bzw. gymnastische ${ }^{43}$ und musikalische Veranstaltungen griechischer und römischer Tradition durchgeführt, die unter der Leitung von agōnothetai standen ${ }^{44}$. Palästinische

37 O. Guillaume, Fouilles d'Aï Khanoum II (Mémoires de la Délegation Archéologiques française en Afghanistan 26; Paris 1983), Pl. IA-B.

38 Vgl. z.B. W. LÄMMER, KBSW 2 (1973), 192-194; Vitruv, de arch. 5,11,4; F. POLAND, Geschichte des griechischen Vereinswesens (Leipzig 1909 = 1967), 147-150; A. vON GLADISS, Xystos, KP 5 (1975), $1441 f$.

39 Zur vermutlichen Lage B. MAZAR, Der Berg des Herrn (1979), 65. 193f, Abb. 121.

40 K. BURESCH, Schumacher's Inschriften aus Dscherasch, ZDPV 18 (1985), 145-147, Nr. 8; C.B. WELLES, in: C.H. KraELING (ed.), Gerasa (1938), 434f, No. 170 bzw. IGR III, Nr. 1371; auch C.A. FORBES, Ancient Athletic Guilds, CP 50 (1955), 238-252. Der prōtothronos in einer griechischen Inschrift des 6.Jh.s n.Chr. aus Gaza könnte auch ein Amt bei agonistischen Spielen meinen, F.W.M. PETRIE, Gerar (1928), 26, Pl. 71 = C.A.M. GLUCKER, The City of Gaza in the Roman and Byzantine Periods (BAR.IS 325; Oxford 1987), Nr. 14, 128-131.

$41 \mathrm{Vgl}$. z.B. in Jerusalem [agon pentaetērikos athlēmatōn bzw. panēgyros tēes pentaetêridos, vgl. Joseph., Ant. 15,8,1 (§ 267); vgl. ders., BJ 1,21,11 (\$§ 423f. 426)], in Caesarea Maritima [z.B. Joseph., Ant. 16,5,1 ( $\$ 138) ; 19,8,2$ ( $\$ 343)$; ders., BJ 1,21,8 (§ 415); CIG II, I 220, § 4472] und in Gerasa [C.B. WelLES, in: C.H. KRAELING (ed.), Gerasa (1938), 442-445, Nos. 192-194].

42 Die griechische Inschrift des Aurelios Septimios Eirēnaios aus Laodicea ad mare belegt, daß er - unter anderen - an Wettkämpfen (agōn) in Aschkelon, Skythopolis, Caesarea Maritima und Caesarea Philippi (?) teilgenommen hat, IGLS 4 (1955), Nr. 1265 = CIG III, Nr. 4472 = IGR III, Nr. 1012 = L. MORETTI, Iscrizioni agonistiche Greche (Rom 1953), Nr. 85. Eine Inschrift aus Didyma (3.Jh.n.Chr.) erwähnt einen Sieger im (Kinder-)Boxkampf, der wahrscheinlich aus Caesarea Philippi / Banyās stammte, vgl. A. REHM (ed.), Didyma II: Die Inschriften (1958), Nr. 179 bzw. L. RoBERT, Hellenica 11-12 (Paris 1960), 441-446; L. ROBERT, Gn. 31 (1959), 664; B. LIFSHITZ, Études sur l'histoire de la province romaine de Syrie, ANRW II 8 (1977), 3ff. Eine griechische Inschrift aus Rhodos erwähnt einen Athleten bzw. Sieger eines Agon, der wahrscheinlich ebenfalls aus Caesarea Philippi / Banyāss stammte, vgl. L. ROBERT, Hellenica 11-12 (1960), 443f; B. LIFSHITZ, ANRW II 8 (1977), 3ff.

43 Vgl. auch die Malereien an der Westwand der Audienzhalle des omayyadischen

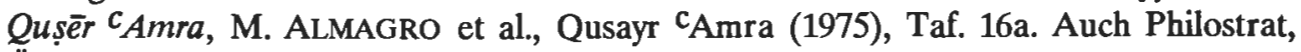
Über Gymnastik, ed. J. JüTHNER (Leipzig 1909 = Amsterdam 1969), passim.

44 C.B. WELlES, The Inscriptions, in: C.H. KRAELING (ed.), Gerasa (1938), No. 144:6; 192:2.7.14 (agōnothesia) u.ö.; in No. 192:17 ist vom gymnasiarchōn die Rede. Vgl. Herodes d.Gr. als Agonothetes in Olympia sowie die von ihm eingerichteten Gymnasiar- 
Athleten verschiedenster Disziplinen tingelten auch außerhalb Palästinas von Wettkampf zu Wettkampf ${ }^{45}$, von außerhalb reisten andere nach Palästina ${ }^{46}$, um sich ihren Anteil an den dortigen Preisgelder zu erkämpfen ${ }^{47}$. Athleten und Theaterkünstler organisierten sich in Städten wie Gerasa ${ }^{48}$ und Gadara $(?)^{49}$, in denen es immerhin zwei Theater und ein Hippodrom bzw. Stadion

chien, Joseph., BJ 1,21,11f ( $\$ 423.427)$; ders., Ant. 16,5,3 (\$ 149); schon Ant. 12,3,1 ( 120); Gymnasiarchen sind auch in Philadelphia ( ${ }^{c}$ Ammān), Arados und Balanaia (Leukas - Bānyās) u.a. belegt [IGLS 21,2 (1986), Nr. 29; 4, Nr. 1302; 7, Nr. 4001; 1, Nr. 166; G. DE JERPHANION - L. JALABERT, MUSJ 5 (1911), 316-318, Nr. 10]. Zum Amt des Agonotheten vgl. O.W. REINMUTH, Agonothetes, KP 1 (1975), 140f; M. WÖRRLE, Stadt und Fest im kaiserzeitlichen Kleinasien. Studien zu einer agonistischen Stiftung aus Oinoanda (München 1988), 183-209.

45 Vgl. Eusebios, Chron. 101,23 (PG 19,237). Zu phönizischen Athleten auf Wettkämpfen innerhalb und außerhalb der phönizischen Städte vgl. z.B. J. EBERT, Griechische Epigramme auf Sieger an gymnischen und hippischen Agonen (ASAW.PH 63,2; Leipzig 1972), 188-193.

46 C.B. Welles, The Inscriptions, in: C.H. KraELING (ed.), Gerasa (1938), No. 194; in der Inschrift No. 170 (s.o.) nennt sich der Antiochener (aus Daphne) M.Aurelios A1ketas paradoxos, also siegreicher Athlet, vgl. K. SCHNEIDER, Paradoxos, RE 18,3 (1949), 1166f. Eine griechische Inschrift aus dem karischen Aphrodisias belegt, daß der Pankratiast M.Ailios Aurelios Menandros an Wettkämpfen in Neapolis (Näblus), Caesarea Maritima, Skythopolis, Gaza, Caesarea Philippi, Philadelphia ( ${ }^{A}$ Ammān), Tyros, Damaskus, Bostra u.a. teilgenommen hatte, L. MORETTI, Iscrizioni agonistiche Greche (1953), Nr. 72. Vgl. auch Joseph., Ant. 15,8,1 (\$ 269).

47 Vgl. z.B. eine griechische Inschrift des 6.Jh.s n.Chr. aus Gaza bei F.W.M. PETRIE, Gerar (1928), 26, P1. 71 = C.A.M. GluCKER, The City of Gaza (1987), Nr. 14, 128-131; zu Herodes d.Gr. als Stifter von Siegerpreisen für Kos vgl. Joseph., BJ 1,21,11 (\$ 423). Zur Höhe der Preisgelder vgl. vor allem J. EBERT, Zu griechischen agonistischen Inschriften, WZ(H).GS 15 (1966), 375-387. Die unterschiedliche Höhe der Preisgelder zeigt deutlich die zunehmende Bevorzugung der schwerathletischen vor den leichtathletischen Disziplinen. Zu der neugefundenen Mosaik-Darstellung mit Siegespreisen und Preisverleihung aus Baṭn ez-Zamür östl. Capsa (Tunesien) vgl. M. KHANOUSSI, Ein römisches Mosaik aus Tunesien mit der Darstellung eines agonistischen Wettkampfes, AW 22 (1991), 146-153.

48 C.B. Welles, The Inscriptions, in: C.H. KraELING (ed.), Gerasa (1938), No. 192:35: Psēphisma tês hieras synodou tōn [apo t] $\bar{e}[s$ oiko]umen [ēs peri ton Dionyson kai kyrion hēmōn autokratora]... techneitōn hieroneikōn stephaneitōn kai tōn toutōn synagōnistōn; I.E. STEPHANES, Dionysiakoi Technitai. Symbolēs stēn prosōpographia tou theatrou kai tēs mousikēs tōn archaiōn Hellēnōn (Heraklion 1988), u.a. Nos. 1239. 3013. Vgl. auch F. Poland, synodos 2, RE II 4 (1932), 1420-1434; H.W. PleKET, Some Aspects of the History of the Athletic Guilds, ZPE 10 (1973), 197-227.

$49 \mathrm{Zu}$ der griechischen Inschrift aus Gadara, in der die Bedeutung des Terminus technitēs (vgl. z.B. IGLS 4,1532. 1545. 1850. 1990; 5,2098. 2138. 2143. 2617. 2644; 7,4042) nicht ganz klar ist, vgl. S. MrTTMANN, Beiträge zur Siedlungs- und Territorialgeschichte 
gab, in den dem Gott Dionysos geweihten technitai-Vereinigungen ${ }^{50}$. Manche der Herakles-(Melqart-)Darstellungen bzw. -Erwähnungen, die in Palästina gefunden wurden ${ }^{51}$, könnten an seine Funktion als Schutzpatron des römerzeitlichen Weltverbandes der reisenden Schwerathleten erinnern ${ }^{52}$. In Städten wie Samaria-Sebaste und Skythopolis wurden Athleten-Statuen aufgestellt $^{53}$. Naturschauspiele wie Wasserfälle und ähnliches wurden in den Wasserspielen $^{54}$ der Nymphäen nachgeahmt, z.B. in Gadara (?), Gerasa, HipposSusita, Philadelphia, Skythopolis, Petra und Bostra ${ }^{55}$.

Die Baulichkeiten für die ludi publici bzw. munera und spectacula boten bedeutend mehr Zuschauern Platz als Tempel, Synagogen oder Kirchen ${ }^{56}$. Vor allem Wagen-57 bzw. Pferderennen ${ }^{58}$ im Circus ${ }^{59}$, aber auch Ring- ${ }^{60}$, Faust-61

des nördlichen Ostjordanlandes (ADPV 2; Wiesbaden 1970), 176f, Nr. 12, Abb. 28; F. ZAYADINE, A Dated Greek Inscription from Gadara - Um Qeis, ADAJ 18 (1973), 78, Pl. 49; B. MERSHEN - E.A. KNAUf, From Gadar to Umm Qais, ZDPV 104 (1988), 131.

50 Vgl. allgemein F. PoLAND, Geschichte des griechischen Vereinswesens (1909 = 1967), 129-152; ders., Technitai, RE 2,5 (1934), 2473-2558; M. SAN NiCOLO, Ägyptisches Vereinswesen zur Zeit der Ptolemäer und Römer I (MBPF 2,1; München 21972), 46-65; W.H. GROSs, Technitai, KP 5 (1975), 553f; I.E. STEPHANES, Dionysiakoi Technitai (1988), passim.

51 Vgl. z.B. IGLS 21,2 (1986), Nr. 29 ( ${ }^{c_{A m m}} \bar{a} n$ ). 127 (Madeba); A. SPLuKERMAN, The Coins of the Decapolis and Provincia Arabia (1978), 313 u.ö.; 2.Makk. 4,18-20; J.W. CROWFOOT, in: ders. et al., The Objects from Samaria (1957), 71, Pl. 6.

52 R. MERKELBACH, Herakles und der Pankratiast, ZPE 6 (1970), 47-49; vgl. auch die griechischen Inschriften mit der Nennung des Hermes und Herakles aus dem Gymnasium in $A i$ Hanum, L. RoberT, in: P. BERNARD et al., Fouilles d'Aï Khanoum I (Mémoires de la Délegation Archéologique en Afghanistan 21; Paris 1973), 207ff, Pl. 109.

53 J.W. CROWFOoT, in: ders. et al., The Objects from Samaria (1957), 72. 75, P1. 7:1f; G. FUKS, Scythopolis - A Greek City in Eretz-Israel (Jerusalem 1983), 133 (hebr.).

54 Vgl. Heron von Alexandria, Opera I: Pneumatica et automata, ed. W. SCHMIDT (Leipzig 1899), 1ff. 336ff; A. SCHÜRMANN, Griechische Mechanik und antike Gesellschaft (1991), passim.

55 Vgl. z.B. A. SEgal, Town Planning and Architecture in Provincia Arabia (BAR.IS 419; Oxford 1988), 8f. 23. 55. 106, fig. 25-28. 31. 52-55. 129; A. VON GLADISS, Wasserspiele, KP 5 (1975), $1350 f$.

56 Zum Zustrom zu den Spielen (und dem Verhalten der Zuschauer) vgl. z.B. Martial, epigr. (lib. spect.) 1,3; allgemein H. KINDERMANN, Das Theaterpublikm der Antike (1979), 18ff; A. GUTTMAN, JSH 8 (1981), 7-12.

57 Zu den Wagenfahrten König Schulgi's von Ur vgl. SAHG Nr. 24 bzw. TUAT 2,673681 oder ANET $^{3}$ 584-586. 
58 Vgl. z.B. C.B. Welles, The Inscriptions, in: C.H. KRAELING (ed.), Gerasa (1938), No. 194 (hippotrophos); Joseph., Ant. 15,8,1 (\$ 271); Hieronymus, vita Hilar. 20 (Gaza); Malalas, Chronogr. 15, § 382; 18, § 446; Prokop, bell. Pers. 2,11,32 (Apameia). Vgl. auch M. HENIG - M. Whiting, Engraved Gems from Gadara in Jordan (1987), Nos. 281288; R. ROSENTHAL-HEGINBOTTOM, Römische Bildlampen aus östlichen Werkstätten (1981), 76. 111, Taf. 18 unten (Gerasa); S. KRAuss, Circus, JE 4, 103f; A. HÖNLE - A. HENZE, Römische Amphitheater und Stadien (1981), 96ff u.ö.; A. CAMERON, Porphyrius, the Charioteer (Oxford 1973), 1ff; J.H. HUMPHREY, Roman Circuses. Arenas for Chariot Racing (London 1986), 438-539; CH. LANDES (ed.), Le cirque et les courses de chars, Rome - Byzance (Lattes 1990), passim; S. LASER, Sport und Spiel (1987), 26-32, Abb. 3f. 33; R. PopPLOW, Totenkult und Wagenrennen in Alt-Mykene, LE 7 (1958), 210-215. 248-252; auch W. DECKER, Sport und Spiel im Alten Ägypten (1986), 54-62: ders., Ein ägyptisches Wort für "Hippodrom"?, SAK 2 (1975), 49-54 ( $h w j$ gw); ders., Annotierte Bibliographie zum Sport im alten Ägypten (1978), Nrn. 108-116; P.W. HAIDER, Trainingsanlagen im alten Ägypten?, Nikephoros 1 (1988), 1-27. 301; E. REISCH, Apobatess, RE 2 (1894), 2814-2817; V. OLrvoVA, History of Physical Education and Sport 2 (1974), 50-52; dies., Chariot Racing in the Ancient World, Nikephoros 2 (1989), 65-89. 307f; D. AYAlON, Notes on the Furüsiyya Exercises and Games in the Mamlūk Sultanate, (1961), in: ders., The Mamlūk Military Society (London 1979), 31-62.

Die Wagenrennen in einem Hippodrom (hebr. 'ypwdrwmyn) in Jerusalem zur Zeit Salomos, wie sie in einem Midrasch u.a. behauptet werden, sind legendär, vgl. dazu z.B. A. JELLINEK (ed.), Bet ha-Midrasch 5 (Jerusalem ${ }^{3}$ 1967), $37-39$ (hebr.); J.T. MILIK, "SaintThomas de Phordêsa" et Gen. 14,17, Bib. 42 (1961), 77-84; J. PERLES, Thron und Circus des Königs Salomo, MGWJ 21 (1872), 122-139; S. MUNTNER, Das Wettrennen des Königs Salomo oder jüdischer Sport im 4. bis 6.Jahrhundert n.Chr., Der Schild 5,3 (1926), 22; F. PINCZOwER, Sport bei den Juden im Altertum I. Die Rennbahn des Königs Salomo (1930 = Tel Aviv 1968), passim; A. WüNSCHE, Salomos Thron und Hippodrom. Abbilder des babylonischen Himmelsbildes (Ex Oriente Lux 2,3; Leipzig 1906), 36-42; E. Ville-Patlagean, Une image de Salomon en Basileus Byzantin, RÉJ 121 (1962), 9-33.

59 Vgl. hebr. / aramä. qrqs('), qrqs(w)n, vgl. G. DALMAN, Aramäisch-Neuhebräisches Handwörterbuch $\left({ }^{3} 1938=1987\right), 392$.

60 C.B. Welles, The Inscriptions, in: C.H. KraELING (ed.), Gerasa (1938), No. 194 (palaistēs); Expositio totius mundi et gentium E 32 (athletae luctatores in Aschkelon); vgl. auch Joseph., Ant. 15,8,1 (\$270) (hai gymnikai askēseis).

61 Griech. pykteyein; pygmachē, pyx; s. unten Kap. 16. Zu der Inschrift aus Didyma, die einen Kinder-Boxkampf-Sieger erwähnt, der wahrscheinlich aus Caesarea Philippi / Banyās stammte (s.o.). Vgl. weiter 1.Kor. 9,26; Test.Hiob 4,10; R. ROSENTHAL - R. SIVAN, Ancient Lamps in the Schloessinger Collection (1978), Nos. 67. 127; L. JAKOBRosT, Altertum 11 (1965), 3-7; F.A.G. BECK, Album of Greek Education (1975), 35f, Nos. 198-205; S. LASER, Sport und Spiel (1987), 37-49, Abb. 10-13, Taf. Ic; S. MARINATOS, Kreta, Thera und das mykenische Hellas $\left({ }^{3} 1976\right), 144 f .155$, Abb. 106f, Taf. 38 u.ö.; J. CoulOMB, Les boxeurs minoens, BCH 105 (1981), 27-40; A.D. TOUNY - S. WENIG, Sport in Ancient Egypt (1969), 22f; W. DECKER, Boxen, LÄ 1 (1975), 847f; ders., 
und andere Athleten-Wettkämpfe ${ }^{62}$ im Gymnasium bzw. Palästra ${ }^{63}$ und im Stadion, musische Aufführungen im Theater ${ }^{64}$ sowie die am meisten beliebten $^{65}$ Gladiatorenkämpfe ${ }^{66}$, Tierhatzen ${ }^{67}$ und Naumachien ${ }^{68}$ im Amphitheater

Sport und Spiel im Alten Ägypten (1987), 96; ders., Annotierte Bibliographie zum Sport im alten Ägypten (1978), Nrn. 254-256; D. WILDUNG (ed.), Kleopatra. Ägypten um die Zeitenwende (Mainz 1989), Nr. 129 und M. MOGENSEN, Ein altägyptischer Boxkampf, ZÄS 57 (1922), $87 f$.

62 Vgl. C.B. Welles, The Inscriptions, in: C.H. KraELING (ed.), Gerasa (1938), No. $193 \mathrm{f}$ (pankratiastēs); No. 194 (pentathlos); Expositio totius mundi et gentium E 32 (pammacharii in Gaza); auch 1.Kor. 9,24; Phil. 2,16; 3,14; Gal. 2,2; 5,7; Hebr. 12,1. Zu der griechischen Inschrift aus Rhodos, in der ein Athlet bzw. Sieger eines Agon erwähnt wird, der wahrscheinlich aus Caesarea Philippi / Banyās stammte, s.o. Der Fund zweier bronzener strigiles in Grab L 24 in ${ }^{c}$ Atlit (4.Jh.v.Chr.) kann ebenfalls auf sportliche Betätigung hindeuten [wie auch Funde griechischer Aryballoi in Palästina und auch die

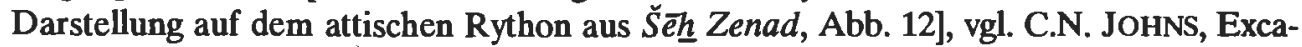
vations at cAtlit (1930-1). The South-Eastern Cemetery, QDAP 2 (1933), 97f, fig. 81, Pl. 34:914f; auch Philo Alex., spec. 2,229f; mŠabb 22,6; 2.Makk. 4,14 (chorēgia), dazu E. REISCH, chorēgos, RE 3 (1899), 2422f und A. WilhELM, Neue Beiträge V (1932), 44-46; M. DAYAGI-MENDELS, Perfumes and Cosmetics in the Ancient World (Israel Museum Catalogue No. 305; Jerusalem 1989), 22 (Jabne); M. HENIG - M. WHITING, Engraved Gems from Gadara in Jordan (1987), No. 301f; C. DAVARAS, Stadion 5 (1979), 196-198. 213-217, Abb. 3 (Grab 3 und 8); CH. UlF, Die Einreibung der griechischen Athleten mit Öl. Zweck und Ursprung, Stadion 5 (1979), 220-238; Y. AlOUF - U. SIMRI - J.H. SILVER et al., Sports, EJ 15 (1971), 291-318; J. KLATZKIN, Leibesübungen, EJ 10 (1934), 740-754: F.H. VIZETELLY, Athletes, Athletics, and Fieldsports, JE 2 (1902), 269-273.

63 Laut Philo Alex., spec. 2,229f gab es in Alexandria dazu für jüdische Kinder einen eigenen Unterricht (gymnastike kai aleiptikēe).

64 Die Expositio totius mundi et gentium E 32 erwähnt insbesondere die Pantomimen von Caesarea Maritima. Der Tyrer Apollonius zeigt sich in komischen und tragischen Rollen ausgebildet, Hist. Apollonii regis Tyri 16; allgemein E. WÜST, Mimos, RE 15,2 (1932), 1727-1764.

$\mathrm{Zu}$ möglichen altorientalischen Vorläufern vgl. S.N. KRAMER (ed.), Enmerkar and the Lord of Aratta, a Sumerian Epic Tale of Iraq and Iran (Museum Monographs; Philadelphia/PN 1952), passim; M. LAMBERT, Le jeu d'Enmerkar, Syria 32 (1955), 213-221; auch K. SETHE (ed.), Dramatische Texte zu altägyptischen Mysterienspielen (UGAÄ 19; Leipzig 1928 = Hildesheim 1964), passim.

65 Vgl. z.B. Tertullian, de spect. 12; Augustin, conf. 1,10,16; 3,2,2; Cassius Dio 68,15,1; Origines, exhort. ad mart. 18; Libanios, ep. 40-42 (im Antiochia des 4.Jh.s n.Chr.). Vgl. W. WeISMANN, Kirche und Schauspiel (1972), 133ff. Zum Ansehen der Gladiatoren, das durch das untrennbare Gewebe der drei Grundgefühle Furcht, Abscheu und Bewunderung (dominus, medicus, decus, suspirium etc. puparum bzw. puellarum u.ä. mehr in pompeianischen Graffiti CIL 4, 4289. 4345. 4353. 4358. 4397. 8916) geprägt war, vgl. H. AIGNER, Zur gesellschaftlichen Stellung von Henkern, Gladiatoren und Berufsath- 
(Abb. 60) gehörten jetzt zu den Massenbelustigungen, bei denen einheimische und ausländische Akteure ihre heidnischen, jüdischen, samaritanischen

leten, in: I. WEILER (ed.), Soziale Randgruppen und Außenseiter im Altertum (Graz 1988), 205-209.

66 Vgl. z.B. Joseph., BJ 7,2,1 (§ 23) (Caesarea Philippi); ders., Ant. 15,8,1 (§ 273); 19,7,5 (\$ 338); bGitt. 47a; S. ATLAS, Simon ben Lakisch, JL IV 4 (1930), 424f; vgl. auch die Grafitti in einem römerzeitlichen Grab bei Tell ${ }^{c} E t \overline{t u} n$ : V. TZAFERIS, A Monumental Roman Tomb on Tel ${ }^{{ }^{C} \text { Eitun, }}{ }^{\mathrm{C}}$ Atiqot HS 8 (Jerusalem 1982), 22-30, fig. 2 (hebr.) oder Öllampen u.a. mit Gladiatoren-Darstellungen z.B. aus $B \bar{e} t \breve{S}^{\mathcal{C}} \bar{a}$ rìm, Bēt Nettîf oder

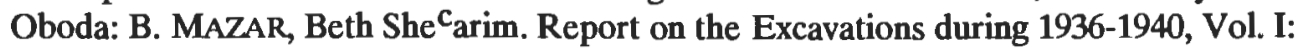
Catacombs 1-4 (Jerusalem 1973), 114. 213, fig. 22:4; D.C. BARAMKI, Two Roman Cisterns at Beit Nattif, QDAP 5 (1936), 5, Pl. 3:2; 6:1; A. HAMBURGER, in: L.I. LEVINE E. NETZER (ed.), Excavations at Caesarea Maritima (1986), 198, Nos. 31-33, Pl. I; A. NEGEV, The Nabatean Potter's Workshop at Oboda (Bonn 1974), 26f, P1. 15:65-72; ders., The Late Hellenistic and Early Roman Pottery of Nabatean Oboda (Qedem 22; Jerusalem 1986), No. 1108; R. ROSENTHAL-HEGINBOTTOM, Römische Bildlampen aus östlichen Werkstätten (1981), 110f u.ö., Abb. 14:2f; 17:4, Taf. 20f; dies. - R. SIVAN, Ancient Lamps in the Schloessinger Collection (1978), Nos. 60-64. 68f. 95f. 136. 193. 197. 218f. 228; allgemein A. HöNLE - A. HENZE, Römische Amphitheater und Stadien (1981), 13ff; A. Piganiol, Recherches sur les jeux romains. Notes d'archéologie et d'histoire religieuse (Strasbourg - Paris 1923), 126ff; L. ROBERT, Les Gladiateurs dans l'Orient Grec (Paris 1940), passim, mit Nachträgen in: ders., Monuments de Gladiateurs dans l'Orient Grec, in: ders., Hellenica 3 (Paris 1946), 112-150; 5 (Paris 1948), 7799; 7 (Paris 1949), 126-151; 8 (Paris 1950), 39-72; W. WEISMANN, Gladiator, RAC 11 (1981), 23-45. Gladiatorenkämpfe und Tierhatzen wurden in Palästina vor allem in Caesarea Maritima und Samaria-Sebaste durchgeführt. Der Einsiedler Hilarion glaubte im Traum - vom Teufel versucht -, Zuschauer bei einem Gladiatorenkampf zu sein (Hieronymus, vita Hilar. 7).

67 Vgl. z.B. Joseph., BJ 7,2,1 (§ 23); ders., Ant. 15,8,1 (§ 273); 16,5,1 (§ 137); D.C. BARAMKI, QDAP 5 (1936), 5, Pl. 3:1; M. DOTHAN - D.N. FREEDMAN, Ashdod I (1967), fig. 11:17; R. ROSENTHAL - R. SIVAN, Ancient Lamps in the Schloessinger Collection (1978), Nos. 76. 227; M. HENIG - M. WHITING, Engraved Gems from Gadara in Jordan (1987), Nos. 288. 406 (?); auch z.B. A. HöNLE - A. HENZE, Römische Amphitheater und Stadien (1981), 104ff; J.C. GolviN, L'amphithêâtre romain. Essai sur la théorisation de sa forme et de ses fonctions I-II (Paris 1988), passim; G. JENNISON, Animals for Show and Pleasure in Ancient Rome (1937), 42ff.

68 Für Gadara (aber nicht in einem eigenen Amphitheater oder im Yarmük, sondern wahrscheinlich in der Südostecke des Sees Gennesaret) - numismatisch - belegt: Y. MESHORER, Coins of the City of Gadara struck in Commemoration of a Local Naumachia, Sefunim 1 (1966), 28-31; ders., City-Coins of Eretz-Israel (1978), 82; A. SPLJKERMAN, The Coins of the Decapolis and Provincia Arabia (1978), 144ff, No. 66. 66a. 69f. 75. 84f. 87-89. 93f. 96. Allerdings konnten Naumachien wohl auch anderswo, so z.B. vielleicht auch im Amphitheater von Beth-Schean, durchgeführt werden; das Theater von Caesarea Maritima weist jedenfalls entsprechende Erweiterungen bzw. Umbauten auf, vgl. A. FrovA (ed.), Scavi di Caesarea Maritima (Rom 1966), 146ff. 
und christlichen Zuschauer unterhielten: "Circus plenus, clamor populi, gaudia civium"69. Die hippodromiai waren "ein Schauspiel, dem die Römer leidenschaftlich ergeben waren", schrieb Joseph., Ant. 19,1,4 (\$ 24); und Ammianus Marc., hist. 28,4,29 notierte: "eisque templum et habitaculum et contio et cupitorum spes omnis Circus est Maximus". So verwundert es nicht, daß miteinander konkurrierende Besitzer von Rennpferden (circenses equi) ${ }^{70}$ sich gegenseitig mit Schadenzauber belegten, um den Gegner am Siegen zu hindern: Ein Duumvir aus Gaza, ein Verehrer des Marnas ${ }^{71}$, hatte mit Hilfe eines Zauberers bzw. magischen Mitteln ${ }^{72}$ die Pferde seines christlichen Konkurrenten Italicus aus Majoumas Gazes zu beeinflussen versucht; Italicus wandte sich in seiner Not an den Einsiedler Hilarion, der ihm - nicht ohne zu zögern angesichts soviel überflüssigen Zeitvertreibs - durch Segenswasser erfolgreich Hilfe gewährte ${ }^{73}$ : Beim Wagenrennen ${ }^{74}$ fingen die Räder des Viergespanns ${ }^{75}$ des heidnischen Beamten an vor Hitze zu glühen. Ein anderes Mal heilte Hilarion einen heidnischen Wagenlenker (auriga) ${ }^{76}$ aus Gaza unter der Bedingung der Übernahme des christlichen Glaubens und der Absage von seinem

69 ILS Nr. 8626e; M. IHM, in: Bonner Studien. R. KEKULE gewidmet (1890), 236, Nr. 39 (Inschrift aus Monteleone / Sabinerland).

70 E. Pollack, Equi circenses, RE 6 (1909), 267-271.

71 G. Mussies, Marnas God of Gaza, ANRW II 18,4 (1990), 2412-2457.

$72 \mathrm{Zu}$ Mitteln und Gegenmitteln derartiger Rennzauber vgl. Ammianus Marc., hist. 28,4,30f; R. WüNSCH (ed.), Antike Fluchtafeln (Bonn 21912), Nr. 3f bzw. A. AudOLLENT (ed.), Defixionum tabellae (Paris 1904 = Frankfurt a.M. 1967), Nrn. 241f. 265 u.ö.; F. DöLGER, Segenswasser als religiöse Sicherung der Rennpferde gegen den Schadenzauber beim Zirkusrennen, in: ders., Antike und Christentum 1 (Münster i.W. 1929), 221-228. Das sog. "Kugelspiel" aus Konstantinopel (5.Jh.n.Chr.) in der Frühchristlich-Byzantinischen Sammlung des Bode-Museums zu Berlin (Inv.-Nr. 1895) ist kein Spiel, sondern ein Los-Gerät, vgl. J. GoTTWALD, Das byzantinische Kugelspiel im Kaiser-Friedrich-Museum zu Berlin, AA 1931, 152-172; A. EFFENBERGER, Frühchristlich-Byzantinische Sammlung, in: Pergamon- und Bodemuseum (Mainz 1990), 122, Abb. 10.

73 Hieronymus, vita Hilar. 20. F. DöLGER, Ein christlicher Rennstallbesitzer aus Maiuma beim heiligen Hilarion, in: ders., Antike und Christentum 1 (1929), 215-220.

74 Vgl. auch Prokop von Gaza, ep. 99.

75 Die vergleichsweise kleinen palästinischen Rennbahnen boten kaum mehr Platz als für Bigen und Quadrigen. Vgl. z.B. auch E. PoLlACK, Bigae, RE 3 (1899), 465-467; K. SCHNEIDER, Quadriga, RE 47 (1963), 681-686; K.M.D. DUNBABIN, The Victorious Charioteer on Mosaics and Related Monuments, AJA 86 (1982), 65-89.

E. POLLACK, auriga, RE 2 (1896), 2549. 
(orchēstēs), die einer der Circus-Parteien angehörten, konnten zu Opfern von Zaubereien (der Gegenpartei?) werden, wie eine griechische Fluchtafel aus Aphek (Fiq, Ğōlān $)$ belegt ${ }^{78}$.

$\mathrm{Da} ß$ der Besuch der Spiele nicht immer nur diesen selbst galt, sondern auch der Möglichkeit, sich an geliebte Personen heranmachen zu können, ist z.B. bei Ovid mehrfach belegt:

"Dicht neben deiner Dame sollst du ungehindert sitzen.

Schmiege deine Seite immerzu, so eng du kannst, an die ihre ...

$\mathrm{Da}$ du mir nur recht eifrig fragst, wessen Pferde jetzt kommen:

Dann ergreife unverzüglich die Partei dessen, dem ihre Gunst gilt, wer es auch sein mag" (ars amat. 1,135ff) ${ }^{79}$.

78 A. MARICQ, Tablettes de défixion de Fĩq (Audollent 15 = IGR III 1543; Aud. 16), Byz. 22 (1952), 360-368.

79 Vgl. auch amor. 3,2! 


\section{GEWICHT-HEBEN}

Zu den sportlichen Spielen, die in Palästina weit verbreitet waren, aber erst seit der hellenistischen Zeit belegt sind, gehörte auch das Heben großer Gewichte als spielerische, schwerathletische Betätigung starker Männer ${ }^{1}$, die ihre körperlichen Kräfte messen wollten; schon damals wurden sie gerne "Herculesse" genannt: "'Rusticellus, welcher Hercules genannt wurde, konnte seinen Maulesel in die Höhe heben, Fufius Salvius trug zwei Zentner schwere Gewichte an den Füßen, ebensoviele an den Händen und vier Zentner auf den Schultern eine Leiter hinauf'. Auch wir haben einen Mann, der den verheißungsvollen Namen Athanatos führte, mit einem 500 Pfund schweren Brustpanzer aus Blei und mit ebenso schweren Kothurnen angetan auf der Theaterbühne umhergehen sehen. Den Athleten Milon brachte niemand, wenn er einmal fest stand, von der Stelle, und niemand bog ihm, wenn er einen Apfel hielt, auch nur einen Finger gerade" (Plinius d.Ä., nat. hist. 7,83). In einem Epigramm des Martial $(5,12)$ heißt es: "Daß der Masklion mit der langen Stange stolz die schwankenden Gewichte auf der Stirn trägt, daß der riesige Ninus sieben Knaben oder acht mit den beiden Armen aufhebt, will mir durchaus nicht so schwierig erscheinen; trägt mein Stella ja doch an einem Finger, mag es dieser, mag's jener sein, zehn Mädchen".

In Sach. $12,3 \mathrm{a}^{2}$ ist in metaphorischer Weise von einem 'aebaen ma ${ }^{c a_{m a ̄ s a ̄ h}}$ die Rede, der wohl zurecht meist als "Hebestein" im genannten Sinn verstan-

1 Vgl. z.B. Seneca, de ira 2,12,4; Martial, epigr. 5,12; auch H. BlÜMNER, Fahrendes Volk im Altertum (1918), 5ff.

2 Die literarkritische bzw. redaktionsgeschichtliche Einordnung des Halbverses ist wie seine Datierung umstritten, doch dürfte eine Ansetzung in die hellenistische Zeit das wahrscheinlichste sein, vgl. z.B. O. PLÖGER, Theokratie und Eschatologie (WMANT 2; Neukirchen 1959), 97ff; M. SAEBø, Sacharja 9-14. Untersuchungen von Text und Form (WMANT 34; Neukirchen-Vluyn 1969), 92f. 254-269; K. ElLIGER, Das Buch der Zwölf Kleinen Propheten II (ATD 25; Göttingen 71975), 166. 169; F. HORST, Die Zwölf Kleinen Propheten (HAT I 14; Tübingen 3 1964), 254f; W. RUDOLPH, Haggai - Sacharja 1-8 - Sacharja 9-14 - Maleachi (KAT XIII 4; Gütersloh 1976), 216f. 221.

3 Der masoretische Text weist keine Varianten auf, vgl. LXX lithos katapatoumenos und Vulg. lapis oneris! Vgl. auch den lithos dokimasias (< 'bn mś') bei Sir. 6,21. Targum zu Sach. 12,3 übersetzt interpretierend 'bn tgl' "Stein des Anstoßes". Vgl. auch G.R. DRIVER, Old Problems re-examined, ZAW 80 (1968), 178-181. Zum Gewichtheben vgl. z.B. auch M. KRANZ, Probleme der Leiblichkeit (Diss. phil. masch.; Köln 1965), 126128; A.D. TOuNY - S. WenIG, Sport in Ancient Egypt (1969), 33; F. RosentHAL, Gambling in Islam (1975), 56. 
den wird. Laut Hieronymus, in Zach. 12,3 war es noch in byzantinischer Zeit "in den Städten Palästinas Sitte und ein bis heute in ganz Juda bewahrter alter Brauch, daß in den Dörfern, Städten und Kastellen runde Steine von schwerstem Gewicht hingelegt werden, an denen sich die jungen Leute zu üben und die sie nach der Maßgabe ihrer Kräfte zu heben pflegen, die einen bis zu den Knien, andere bis zum Nabel, andere bis zu den Schultern und zum Kopf; einige heben zum Beweis ihrer großen Stärke das Gewicht mit aufgereckten beiden Händen über den Scheitel ${ }^{4}$. Hieronymus nennt in seiner vita Hilar. 17 einen Marsitas, der aus der Gegend von Jerusalem stammte und sich rühmte, "15 Scheffel Getreide längere Zeit hindurch und eine ziemliche Strecke weit fortzutragen zu können, ja selbst die Esel an Stärke zu übertreffen".

4 "Mos est in urbibus Palaestinae, et usque hodie per omnem Iudaeam vetus consuetudo servatur, ut in vinculis, oppidis et castellis rotundi ponantur lapides gravissimi pondens, ad quos invenes exercere se soleant; et eos pro varietate virum sublevare, alii usque ad genua, alii usque ad umbiculum, alii ad humeros et caput, nonnulli super verticum, rectis iunctisque manibus, magnitudinem virium demonstrantes, pondus extollant". 


\section{AGONISTISCHE METAPHORIK IM NEUEN TESTAMENT}

Bei Paulus ${ }^{1}$ und im übrigen Neuen Testament fällt auf, daß er und andere Verfasser die agonistischen Veranstaltungen und Übungen der römischen Zeit zwar ablehnten, sie aber gleichzeitig sehr gerne im metaphorischen Sinne zu paränetischen Zwecken verwendeten ${ }^{2}$ : Die wahrhaft Gläubigen sollen sich weniger um leibliche Übungen (sōmatikē gymnasia) bemühen als sich vielmehr in eusebeia üben (gymnaze de seauton pros eusebeian) (1.Tim. 4,7f) ${ }^{3}$ und sich im Ringen um den wahren Glauben doch wie Athleten ${ }^{4}$ [1.Kor. 9,25 (agōnizomai); 2.Tim. 2,5], Faustkämpfer (1.Kor. 9,26: pykteyein) oder Läufer (1.Kor. 9,24; Gal. 2,2; 5,7; Phil. 2,16; 3,14; Hebr. 12,1) verhalten. Wer weiß, wie antike Box-Handschuhe bzw. -Riemen insbesondere der römischen Zeit aussahen, ahnt rasch, wie unpassend zumindest dieser Vergleich ist: Sie sollten den Gegner nicht schützen, sondern mehr oder weniger schwer verletzen oder gar töten helfen ${ }^{5}$ : "Der arme Teufel scheint die Hälfte seiner Zähne mit

1 Vgl. O. BroneEr, The Apostle Paul and the Isthmian Games, BA 25 (1962), 2-31; V.C. PFTTZNER, Paul and the Agon Motif. Traditional Athletic Imagery in the Pauline Literature (NT.S 16; Leiden 1967), passim; R.R. CHAMBERS, Greek Athletics and the Jews 165 A.C. - A.D. 70 (Ph.D. unpubl.; Miami University 1980), 57-75; vgl. K.-A. BENKENDORF, Untersuchungen zu den platonischen Gleichnissen, Vergleichen und Metaphern aus dem Bereich der Gymnastik und Agonistik (Diss. phil. masch.; Tübingen 1966), 26ff.

2 Zum Problem vgl. auch R. MERKELBACH, Der griechische Wortschatz und die Christen, ZPE 18 (1975), 101-148; auch J.A. SAWHILL, The Use of Athletic Metaphors in the Biblical Homilies of St.John Chrysostom (Ph.D. Diss.; Princeton 1928), passim; W. WEISMANN, Kirche und Schauspiele (1972), 111ff. 180ff.

3 V.8 ist, wie V.9 zeigt, ein Zitat, wohl stoischer Herkunft. Vgl. dazu C. SPICQ, Gymnastique et morale, d'après I Tim., IV,7-8, RB 54 (1947), 229-242; J. RoLOFF, Der erste Brief an Timotheus (EKK 15; Neukirchen-Vluyn - Zürich 1988), 243-246.

4 Bei Joseph., Ant. 8,12,3 (§ 302) wird schon Bascha, ein König von Israel (um 900 v.Chr.), als Athlet in Sachen Sünden bezeichnet.

5 Falls Paulus nicht Trainingshandschuh gemeint haben sollte, was unwahrscheinlich ist. Boxhandschuh bzw. -riemen griech. meilichē, himas, oxys, mymēex, latein. caestus. Vgl. J. JÜTHNER, Über antike Turngeräthe (AAES 12; Wien 1896), 65-95; ders., Caestus, RE 5 (1897), 1319-1321; ders., Körykomachia, RE 11 (1922), 1450f; ders. - E. MEHL, Pygme (pugilatus), RE Suppl. 9 (1962), 1306-1352; S. LASER, Sport und Spiel (1987), 43; S. MENDNER, Boxhandschuhe im Altertum, Gym. 60 (1953), 20-26; K.T. FROST, Greek Boxing, JHS 25 (1905), 213-225; O.W. REINMUTH, Boxen; Caestus, KP 1 (1975), 938. 1009f; ders., Pygmé, KP 4 (1975), 1246-1248; L. ROBERT, pykteuein, (1929), in: ders., Opera Minora Selecta (Amsterdam 1969), 691-708; W. RUDOLPH, Olympi- 
all dem Blut und Sand, wovon er den ganzen Mund voll hat, auszuspeien" (Lukian, Anacharsis 3) oder "Sieh dir nur Olympikos an, mein Kaiser! Einst hatte er alles, Nase, Brauen und Kinn, Ohren ${ }^{6}$ und Lider wie wir. Seit er sich aber als Boxer hat eintragen lassen, fehlt alles; selbst sein väterliches Gut ging ihm verloren dabei. Denn sein Bruder zeigte sein Bild dem Richter, und dieser, der keine Ähnlichkeit fand, hat ihn als Fremden erklärt" (Anth. Graeca 11,75) ${ }^{7}$. In Test.Hiob 27,3-5 wird Hiob als Pankrator im Kampf gegen Satan geschildert: "Du warst wie ein Athlet, der mit einem anderen Athleten kämpfte. Und sie brachten sich gegenseitig zu Fall. Und der, der oben zu liegen kam, brachte den unter ihm Liegenden zum Schweigen, indem er ihm seinen Mund mit Sand verstopfte, und brach ihm jedes Glied. Während der es aber mit Standhaftigkeit ertrug und nicht aufgab, schrie der Obenliegende doch noch laut auf. So auch du, Hiob: Du hast unten gelegen und wurdest gepeinigt, hast aber schließlich doch den Sieg davongetragen".

Beliebt war die agonistische Metaphorik auch bei der Beschreibung von Märtyrerszenen (z.B. 3.Makk. 11,20f; 13,15; 17,11; 4.Makk. 6,10; 17,12-16; 1.Clem. 5,1f; 6,2; 2.Clem. 7,1ff; Ignatios von Antiochia, ad Polykarp 1,2; 2,3; $3,1)$.

In der frühchristlich-byzantinischen Zeit wurden Wertungen, wie sie in observanten jüdischen Kreisen seit der hellenistischen Zeit gepflegt wurden ${ }^{8}$, von Christen übernommen und verstärkt, nicht zuletzt dadurch, daß auch Christen bei den in spätrömischer Zeit zunehmenden Exzessen der ludes pu-

scher Kampfsport in der Antike (SSA 47; Ost-Berlin 1965), 8ff; TH.F. SCANLON, Greek Boxing Gloves. Terminology and Evolution, Stadion 8-9 (1982-1983), 31-45; ders., Boxing Gloves and the Games of Gallienus, AJP 107 (1986), 110-114; W. WACHE, Stadion 3 (1977), 24ff; M. WUNNERLICH, Griechische Wettkampf- und Palästradarstellungen (Diss. phil. masch.; Freiburg i.Br. 1986), 11-153; auch C.A. FORBES, Accidents and Fatalities in Greek Athletics, in: Classical Studies in Honor of W.A. OLDFATHER (Urbana/IL 1943), 50-59; R. BROPHY, Deaths in the Pan-Hellenic Games: Arrachion and Creugas, AJP 99 (1978), 363-390; ders. - M. BROPHY, Deaths in the Pan-Hellenic Games II: All Combative Sports, AJP 106 (1985), 171-198; S. DIXIN, Deaths in the Panhellenic Games II: All Combative Sports, AJP 106 (1985), 171-198; M.B. POLIAKOFF, Deaths in the Pan-Hellenic Games: Addenda et Corrigenda, AJP 107 (1986), 400-402; ders., Kampfsport der Antike (1989), 97-122; Philostrat, imag. 2,6; Pausanias 8,40.

6 Vgl. dazu auch R. MerkelbaCH, Die ruhmvollen Blumenkohl-Ohren des Pionios von Smyrna, ZPE 76 (1989), 17f; z.B. Martial, epigr. 7,32,5.

7 Vgl. z.B. auch Anth. Graeca 11,76-78. 81. 258; Theokrit 22,60-134; Vergil, Aen. 5,422ff; Philostrat, imag. 2,6.

8 S. KRAUSS, Talmudische Archäologie III (1912), 113-121; H.L. STRACK - P. BILLERBECK, Kommentar zum Neuen Testament aus Talmud und Midrasch IV $1\left(5_{1969}\right)$, 401405 . 
blici gelegentlich selbst als Belustigungsmaterial in die Arenen geführt wurden'. Es nimmt nicht Wunder, daß die ludes publici in ihren Augen nichts anderes als ludes diabolici bzw. pompa diaboli waren ${ }^{10}$; die Täter, die die ludi organisierten, genossen sie auch als solche, die Opfer dagegen erlitten sie als teufliches Menschenwerk (vgl. Simson und Jesus, Kap. 13).

Unter den Berufsgladiatoren war aber auch der ein oder andere Tora-Gelehrte zu finden, eine Tätigkeit, die ihren akademischen Karrieren nur hilfreich war ${ }^{11}$. Hin und wieder geschah es auch, daß ein Schauspieler im Zuge seines Berufsrisikos zum Märtyrer wurde, wie z.B. Gelasinos von Heliopolis ( $\mathrm{Ba}^{c}$ albek): Er hatte die Rolle des Täuflings in einem satirischen Taufmimus 12 übernommen und dabei auf der Bühne seine Bekehrung erlebt. Das heidnische Publikum brach die Vorstellung aufgebracht ab und steinigte Gelasinus zu Tode ${ }^{13}$; immerhin starb er wohl als Christ - sofern man eine derartige Bühnen-Taufe für gültig halten kann (so z.B. Augustin, de bapt. 7,101f).

Nicht nur die Theater-Aufführungen ${ }^{14}$, sondern auch die venationes und selbst die munera blieben noch Jahrzehnte nach der sog. konstantinischen Wende en vogue und wurden weiterhin von erheblichen Teilen der christli-

9 Vor allem in Caesarea Maritima unter Decius, Diocletian und Maximin Daja. Vgl. z.B. Eusebios, mart., passim; ders., hist. eccl. 5, praef. u.ö.

10 H. JÜrgens, Pompa diaboli (1972), 173ff; W. WEISMANN, Kirche und Schauspiele (1972), 72ff; D.R. FRENCH, Christian Emperors and Pagan Spectacles: The Secularization of the 'Ludi' A.D. 382-525 (Ph.D. Diss. unpubl.; University of California, Berkeley/CA 1985), 30ff; auch C. GöllmaNn, Zur Beurteilung der öffentlichen Spiele Roms bei Tacitus, Plinius d.J., Martial und Juvenal (Diss. phil. masch.; Münster i.W. 1942), 1ff. 101-103; S. SCHMIDT, Mark Aurel und Spectacula, Stadion 10 (1984), 21-43.

11 S. ATLAS, Simon ben Lakisch, JL 4,2 (1930), 424f.

12 Zur christlichen (und heidnischen) Kritik in der Antike an Mimus und Pantomimus vgl. z.B. W. WEISMANN, Kirche und Schauspiele (1972), 72ff u.ö.; auch T. FRANK, The Status of Actors at Rome, CP 26 (1931), 11-20.

13 Malalas, Chronogr. 12, § 314; Chron. Paschale 275c-276a (PG 92,684c-685b); W. WEISMANN, Gelasinos von Heliopolis, ein Schauspieler-Märtyrer, AnBoll 93 (1975), 3966. Vgl. auch Act.SS.Nov. II (1894), 227-232; Act.SS.Sept. V (1755), 37; Act.SS.Apr. II (1675), 213; J. LINK, Die Geschichte der Schauspieler nach einem syrischen Manuscript der königlichen Bibliothek in Berlin (Diss. phil. Bern 1903; Berlin 1904), 10ff; CH. VAN DE VORST, Une passion inédite de S. Porphyre le mime, AnBoll 29 (1910), 258-275.

14 G.J. THEOCHARIDIS, Beiträge zur Geschichte des byzantinischen Profantheaters im IV. und V. Jahrhundert auf Grund der Predigten des Iohannes Chrysostomos, Patriarchen von Konstantinopel (Diss. phil.; München; Thesssaloniki 1940), 20ff. 67ff u.ö.; A. VoGT, Études sur le théâtre Byzantin, Byz. 6 (1931), 37-74. 623-640; V. COTTAS, Le théâtre à Byzance (Paris 1931), passim. 
chen ${ }^{15}$, jüdischen ${ }^{16}$ und samaritanischen ${ }^{17}$ Bevölkerung als willkommene Vergnügungen besucht. Auch unter den christlichen Klerikern ${ }^{18}$ gab es immer wieder Anhänger der Circus-Parteien ${ }^{19}$, was sich nicht nur in Inschriften über Kirchen-Portalen niederschlagen konnte, sondern auch zu Parteiungen in Siedlungen führte, die über keine Hippodrome oder ähnliche Bauten verfügten wie z.B. Umm el-Ğimāl. Vor allem die beliebten Wagenrennen führten auch in Palästina zuweilen zu bürgerkriegsähnlichen Unruhen nicht nur zwischen den Circus-Parteien, sondern auch zwischen Christen einerseits und Samaritanern und Juden andererseits ${ }^{20}$. Die Mehrheit der christlichen und jüdischen ${ }^{21}$ Theologen wie z.B. Tertullian ${ }^{22}$, Kyrill von Jerusalem (Kat. myst.

15 G. VILLE, Les jeux de gladiateurs dans l'empire chrétien, MAH 72 (1960), 273-335.

16 Vgl. z.B. Malalas, Chronogr. 18, § 446. Vgl. auch H.L. STRACK - P. BILLERBECK, Kommentar zum Neuen Testament IV (51969), 401-405.

17 Vgl. z.B. Malalas, Chronogr. 15, § 382; 18, § 446.

18 Vgl. neben Prokop von Gaza, ep. 99,8-10 auch die entsprechenden Inschriften von Caesarea Maritima und Umm el-Ğimāl (s.u.).

19 Vgl. die Inschriften der Circus-Parteien der byzantinischen Zeit vor allem in Caesarea Maritima [C.B. GERRA, Le iscrizioni, in: A. FROVA (ed.), Scavi di Caesarea Maritima (Rom 1966), 224f; B. LIFSHITZ, REG 70 (1957), 118-132; L. ROBERT, REG 71 (1958), 344], Jerusalem [W.H. WADDINGTON, Inscriptions Grecques et Latines de la Syrie (Paris 1870), No. 1900; P. THомSON, Die lateinischen und griechischen Inschriften der Stadt Jerusalem, ZDPV 44 (1921), 6, Nr. 10; ders., Die lateinischen und griechischen Inschriften der Stadt Jerusalem, 1.Nachtrag, ZDPV 64 (1941), 208, Nr. 10], Gerasa [C.B. WELlES, in: C.H. KRAELING, Gerasa (1938), No. 194], Fiq (Ğölān) [A. MARICQ, Byz. 22 (1952), 360ff; IGR 3,1543], Umm el-Ǧimäl [E. LITTMANN et al. (ed.), Greek and Latin Inscriptions in Syria. PPUAES III A 3 (Leiden 1913), 148-150. 154, Nos. 256. 266], Bostra [IGLS 13,1 (1982), 365, No. 9442], Taff / Le ğğ $\bar{a}$ [E. LITTMANN et al. (ed.), Greek and Latin Inscriptions in Syria. PPUAES III A 7 (1921), No. 804], c Ormān [R. DUSSAUD, Voyage archéologique au Safâ (1921), 164, no. 33] und Bac albek / Heliopolis [IGLS 6 (1967), No. 2836]. Vgl. zusammenfassend z.B. Y. DAN, Circus Factions (Blues and Greens) in Byzantine Palestine, Jerusalem Cathedra 1 (1981), 105119; A. CAMERon, Circus Factions: Blues and Greens at Rome and Byzantium (Oxford 1976), bes. 314ff; M. JunKelmanN, Die Reiter Roms I (1990), 130-136; A. MARICQ, Factions du cirque et parties populaires, BAB.L 36 (1950), 396-421; B. SCHRODT, Sports of the Byzantine Empire, JSH 8 (1981), 40-59; auch J. PERLES, MGWJ 21 (1872), 122ff; B.H. VANDENBERGHE, Saint Jean Chrysostome et les spectacles, ZRGG 7 (1955), 34-46.

Die angebliche Existenz der Circus-Parteien und Durchführung von Wagenrennen in salomonischer Zeit, wie sie ein Midrasch behauptet, ist natürlich Retrojektion aus der römisch-byzantinischen Zeit (s.o.).

20 Malalas, Chronogr. 15, § 382; 18, § 446.

21 Vgl. z.B. bAZ 18 b. 
1,6), Novatian (de spect. CCSL 4, 153ff), $J a^{c} q \bar{o} b$ von $\operatorname{Sarüg}^{23}$ und andere ${ }^{24}$ schmähten dagegen die verschiedenen Massenbelustigungen - teils zu Recht, teils zu Unrecht - als Unzucht, Götzendienerei u.ä.; Chorikios von Gaza schrieb immerhin eine "apologia mimorum". Ganz im rigiden und repressiven Geiste derer, die Spiele, Vergnügungen und Volksbelustigungen grundsätzlich als gotteslästerlich betrachten, schreckten sie nicht davor zurück, ihren Gemeindemitgliedern nicht nur die hellenistisch-römischen Massenbelustigungen wie den Besuch des Theaters (z.B. Const. Apost. 2,62,2), sondern auch die traditionellen, eher privaten Spiele pauschal madig zu machen. So benutzte z.B. der Verfasser des Eph.-Briefes 4,14 das Würfelspiel (kybeia) als Bild infantilen Verhaltens und der Verführung zur Gottlosigkeit ${ }^{25}$.

22 De spect. Vgl. dazu J. KöHNE, Die Schrift Tertullians "Über die Schauspiele" in kultur- und religionsgeschichtlicher Bedeutung (Diss. phil.; Breslau 1928; Berlin 1929), passim; S. MENDNER, RAC 10 (1978), 873-882.

23 Jacob of Serugh's Homilies on the Spectacles of the Theatre, ed. C. Moss, Muséon 48 (1935), 87-112.

24 Vgl. z.B. A. Miodonski, Anonymus adversus aleatores und die Briefe an Cyprian, Lucian, Celerinus und an den karthageniensischen Klerus (Cypr., epist. VIII, XXIXXIV) (Leipzig 1889), passim; Min. Felix, Oct. 37,11; Cod. Iust. 11,44,1 = Cod. Theod. $15,5,5 ; 15,12,1$.

25 H.L. STRACK - P. BiLlerBeCK, Kommentar zum Neuen Testament aus Talmud und Midrasch III (21954), 599. 


\section{NACHSPIEL: SPIELEN UND LEBEN}

$\mathrm{Da} ß$ alle - insbesondere junge - Tiere spielen ${ }^{1}$, gilt allgemein als anerkannt ${ }^{2}$; von daher ist klar, daß auch Menschen seit den Anfängen ihrer Geschichte spielten. Dies bedeutet nicht, daß sie deswegen gleich auch Spielzeug im engeren Sinn herstellten. Spielzeug, daß sich aus heutiger Sicht als solches erkennen läßt, scheint in Palästina erst seit dem Neolithikum nachweisbar zu sein, obwohl man auch lange zuvor schon gespielt hatte. Hier wie auch sonst überall war Spielen eine zentrale menschliche Lebensäußerung, ein "Totalphänomen"3: "Der Mensch spielt nur, wo er in voller Bedeutung des Wortes Mensch ist, und er ist nur da ganz Mensch, wo er spielt", schrieb F.

1 Vgl. z.B. I. EIBL-EIBESFELDT, Über die Jugendentwicklung des Verhaltens eines männlichen Dachses (Meles meles L.) unter besonderer Berücksichtigung des Spieles, Zt. für Tierpsychologie 7 (1950), 327-355; E. GWINNER, Über einige Bewegungsspiele des Kolkraben (Corvus corax L.), Zt. für Tierpsychologie 23 (1966), 28-36; M. MEYERHolzAPFEL, Das Spiel bei Säugetieren, in: Handbuch der Zoologie 8,10,5 (2.Lief.) (Berlin 1956), 1-36; C.K. TAYLOR - G.S. SAAYMAN, in: J.S. BRUNER et al. (ed.), Play Its Role in Development and Evolution (1976), 239-243.

2 Vgl. z.B. C. Alleman, Über das Spiel. Die Spieltheorien, Menschen- und Tierspiel (Diss. phil.; Zürich 1956), passim; G. BALLY, Vom Spielraum der Freiheit. Die Bedeutung des Spiels bei Tier und Mensch (Basel - Stuttgart 21966 ), passim; F.J.W. BUYTENDuK, Wesen und Sinn des Spiels. Das Spiel des Menschen und der Tiere als Erscheinungsformen der Lebenstriebe (Berlin 1933), passim; K. GROOS, Die Spiele der Tiere (Jena ${ }^{3} 1930$ ), passim; G. VON KUJAWA, Ursprung und Sinn des Spiels (1949), 33-41; B. HASSENSTEIN, Instinkt - Lernen - Spielen - Einsicht. Einführung in die Verhaltensbiologie (München 1980), 112ff; ders., Spielen in verhaltensbiologischer Sicht, in: H. RöHRS (ed.), Das Spiel - ein Urphänomen des Lebens (Erziehungswiss. Reihe 23; Wiesbaden 1981), 159-167; P. PorTMANN, Das Spiel als gestaltete Zeit. Betrachtungen eines Biologen, in: G.-K. KalTENBRUNNER (ed.), Im Anfang war das Spiel (München 1987), 51-68; O. KoEHLER, Vom Spiel der Tiere, in: W. MARX (ed.), Das Spiel. Wirklichkeit und Methode (Freiburger Dies Universitatis 13; Freiburg i.Br. 1967), 79-105; S. MILlaR, Psychologie des Spiels (1973), 58-100.

3 R. CAILloIs, Die Spiele und die Menschen (Stuttgart 1960), 202, der die Spiele mittels 6 verschiedener Punkte zu definieren versucht: 1 . Freiwilligkeit, 2. eigene Grenzen von Zeit und Raum, 3. Ungewißheit über Verlauf und Ausgang, 4. Unproduktivität im materiellen Sinn, 5. Regeln und 6. Fiktivität ("zweite Wirklichkeit"). Zum Spiel als Totalphänomen vgl. auch H. SCHEUERL, Spiel - ein menschliches Grundverhalten?, in: ders. (ed.), Theorien des Spiels $\left({ }^{10} 1975\right), 189-208$; H. Hesses Roman 'Das Glasperlenspiel', (1943) [Ges. Werke 9 (und 11, 90-98); Frankfurt a.M. 1970], passim. 
SCHILLER später ${ }^{4}$. Spielen war ein Teil des Lebens wie Essen und Trinken, Beten und Arbeiten: Ein Aspekt des fest- und alltäglichen Lebens von Menschen jeden Alters, aller sozialen Schichten und beiderlei Geschlechts. Deshalb konnte man im Spiel stets ein Abbild des eigenen menschlichen Lebensspiels sehen: "Wohl, dies alles ist Spiel, und doch, in dem sinnlosen Zufall dieses rollenden Wurfs waltet die Laune des Glücks. Schillernd entfaltet sich dir das Bild des menschlichen Lebens, wenn es bald hoch dich erhebt, bald in die Tiefe dich stürzt. Wir aber loben den Mann, der immer, im Leben und Spiele, seiner Freude und Qual Grenzen zu setzen versteht" (Anth. Graeca 9,768). In der Neuzeit hat es L. PIRANDELLO in seinen Autobiographischen Notizen (1924) anders formuliert: "Ich finde, das Leben ist ein recht trauriges Possenspiel. Ohne zu wissen, wieso, weshalb und woher, sind wir ständig gezwungen, uns aus eigenem Antrieb mit der Erfindung der Wirklichkeit zu betrügen ..., die sich von Zeit zu Zeit als eitel und illusorisch erweist. Wer das Spiel verstanden hat, vermag sich nicht mehr zu betrügen; wer sich jedoch nicht mehr zu betrügen vermag, der kann weder Geschmack noch Freude am Leben mehr finden".

Menschliches Leben bzw. Kulturen ohne Spiele sind undenkbar; wenn laut der mittellateinischen Hist. von Alexander d.Gr. 99 Dindimus, der König der indischen Brahmanen, an den makedonischen Herrscher schreibt: "Spiele lieben wir nicht", dann ist das nicht viel mehr als eine Stilisierung eines AskeseMotivs.

Ebenso haben auch die meisten antiken Herleitungen der Spiele kaum einen historischen Anhaltspunkt, gleichgültig ob sie nun Palamedes zum Erfinder des Würfels ${ }^{5}$ oder Salomo zu dem des Schachspiels machten: Wenn z.B. Herodot 1,94 den Lydern unter ihrem König Atys die Erfindung des Würfel-, Astragal-, Ball-Spiels (vgl. Plinius d.Ä., nat. hist. 7,205) und aller anderen Spiele mit Ausnahme der Brettspiele zuschrieb, dann liegt damit kein Beleg für die Herkunft dieser Spiele vor; die Erzählung versucht vielmehr eine plausible Erklärung für die nützliche Funktion von Spielen zu

4 Über die ästhetische Erziehung des Menschen, 15.Brief (Sämmtliche Werke XII; Stuttgart - Tübingen 1847), 61. Vgl. auch W. SDUN, Zum Begriff des Spiels bei Kant und Schiller, KantSt 57 (1966), 500-518; G.M. MARTIN, "Wir wollen hier auf Erden schon...". Das Recht auf Glück (1970), 49ff.

5 S. KARUSU, AM 88 (1973), 55-65, Taf. 53-55; E. WÜsT, Palamedes, RE 36,1 (1942), 2506f. Eine eigenartige Überlieferung von der Erfindung des Würfelspiels im pseudocyprian. Traktat de aleatoribus, CSEL 54,3 (1871), 92ff; A. HARNACK, Der pseudocyprianische Tractat de aleatoribus (1888), 11ffvor: Der namentlich nicht genannte Erfinder des Würfelspiels ließ von sich - unter Inspiration des Teufels - eine Statue anfertigen 
"herrschte in ganz Lydien eine große Hungersnot. Anfangs ertrugen die Lyder sie geduldig, als sie aber immer fortdauerte, suchten sie Abhilfe, und jeder erdachte etwas anderes. Damals wurden Würfel- und Astragalspiel, das Ballspiel und alle anderen Spiele erfunden, nur nicht das Brettspiel... Durch diese Spiele vertrieben sie den Hunger in der Weise, daß sie einen ganzen Tag lang spielten, um die EBlust nicht aufkommen zu lassen, und den nächsten Tag aßen und spielten sie nicht. So lebten sie 18 Jahre lang...".

Auch wenn ich hier nur über einen ausgewählten Teil der tatsächlich gespielten Spiele eingegangen und eine Reihe von Spielen gar nicht behandelt habe [z.B. Fadenspiele ${ }^{6}$, auf Stelzen Gehen ${ }^{7}$, Witze ${ }^{8}$ und Wetten ${ }^{9}$, Wort- und Sprachspiele wie Reime ${ }^{10}$ (Kinderreim Matth. 11,17 par. Luk. 7,32*) ${ }^{11}$ oder

und kam so zu göttlichen Ehren. Zu islamischen Erfinder-Traditionen vgl. z.B. J. SoMOGYI, IslQ 3 (1956-1957), 238-240.

6 K. TRAPP, Bantu-Spiele (Diss. phil.; 1960), 96-103; F. KLEPZIG, Kinderspiele der Bantu (1972), 94-97. 248f. 352-355. 467-469; H. SBRZESNY, Die Spiele der !KoBuschleute (1976), 95-102.

7 Neuhebr. $k^{e}$ lōnās. Vgl. z.B. Pollux 4,104; Artemidor 3,15; auch F. BROMMER, Antike Stelzentänze: Gypones und Hypogones, AK 11 (1968), 50-52; L. BECQ DE FOUQUIERES, Les jeux des anciens (21873), 107f; W. KROLL, Kalobatês, RE 10 (1919), 1756; F.V. GRUNFELD, Spiele der Welt (1979), 242f; L. GRASBERGER, Erziehung und Unterricht im klassischen Alterthum I 1 (1864), 128-131; H. BLÜMNER, Fahrendes Volk im Altertum (1918), 15; K.G. LINDBLOM, The Use of Stilts, especially in Africa and America (Stockholm 1927), 5ff; F.K. MATHYS, Im Freien gespielt (1975), 19-21; V. HARMS, Der Terminus "Spiel" in der Ethnologie (1969), 173f; F. KLEPZIG, Kinderspiele der Bantu (1972), 128f. 485 u.ö.; A.E. JENSEN, Mythos und Kult bei Naturvölkern $(21960=1991)$, $101 f$.

8 F. CRÜSEMANN, Zwei alttestamentliche Witze. I Sam 21,11-15 und II Sam 6,16.20-23 als Beispiel einer biblischen Gattung, ZAW 92 (1980), 215-227; E.D. KollmaNN, A Soldier's Joke or an Epitaph?, IEJ 22 (1972), 145f (Wādi et-Tuwēbe); L. Löw, Die Lebensalter in der jüdischen Literatur (1875), 346ff, neuhebr. $b^{e}$ dihăh; halaṣāh; mahatālāh; hidūd.

9 Hi. 1,6ff; 2,1ff; 2.Kön. 18,23 par. Jes. 36,8; bS̆abb 31. Hebr. $c_{r b}$ I hitp., HAL 3, 829f. Vgl. z.B. auch Cicero, de off. 3,19 (77); Quintilian, inst. orat. 1,3,11; H. SCHMIDT - P. KAHLE (ed.), Volkserzählungen aus Palästina I (1918), 54f; F. ROSENTHAL, Gambling in Islam (1975), 26-31.

10 Neuhebr. hāüüz. Vgl. z.B. K. SETHE, Ein altägyptischer Fingerzählreim, ZÄS 54 (1918), 16-39; J. VÄTERLEIN, Roma ludens (1976), 24f; auch D. HAGEDORN, Zwei Spielverse, ZPE 2 (1968), 65-68; W. GUGLIELMI, Wortspiel, LÄ 6 (1986), 1287-1291; H.M. ENZENSBERGER (ed.), Allerleihrauh. Viele schöne Kinderreime (Frankfurt a.M. 1961), passim; L. RÖHRICH, Kinderreim und Kinderspiel - gestern und heute, in: Kinderkultur, ed. H. KösTLIN (Bremen 1987), 199-218; U. BAADER, Kinderspiele und 
Rätsel bzw. Ratespiele (Ri. 14,12ff; 1.Kön. 10,2ff12; 2.Chr. 9,1; Joseph., Ant. $8,5,3, \S 143) ; 8,6,5, \S 165 f f)^{13}$, Drachen-Fliegen-Lassen (syr. Ahị̂qar) ${ }^{14}$, Hand-

derkultur, ed. H. KöSTLIN (Bremen 1987), 199-218; U. BAADER, Kinderspiele und Spiellieder II (Tübingen 1979), 285ff; P. RÜHMKORF, agar agar-zaurzaurim. Zur Naturgeschichte des Reims und der menschlichen Anklangsnerven (Reinbek bei Hamburg 1981), passim; G. SCHLÄGER, Einige Grundfragen der Kinderspielforschung 2: Kind und Sprachspiel, ZVVK 28 (1918), 15-25; überaus lesenswert auch E. BORNEMANN, Studien zur Befreiung des Kindes I-III (1973-1976), passim.

11 Eulēsamen hymin kai ouk ōrchēsasthe / ethrēnēsamen kai ouk ekopsasthe (eklausate); auch bSanh. 103a. Vgl. dazu W. GRUNDMANN, Das Evangelium nach Lukas (ThHk 3; Berlin Ost 91981), 167: gehört "möglicherweise Kinderspielen zu"; O. LINTON, The Parable of the Children's Game: Baptist and Son of Man, NTS 22 (1978), 159-179; D. ZELLER, Die Bildlogik des Gleichnisses Mt 11,16f. / Luk 7,31f., ZNW 68 (1977), 252-257; zuletzt F. BovON, Das Evangelium nach Lukas, 1.Teilband (EKK 3,1; Neunkirchen-Vluyn 1989), 380f; U. LuZ, Das Evangelium nach Matthäus. 2.Teilband: Mt 817 (EKK 1,2; Zürich - Braunschweig - Neukirchen-Vlyun 1990), 182-190.

12 Die Rätsel, die sicherlich nicht von der unhistorischen Figur der Königin von Saba stammen, sind im alttestamentlichen Text nur als solche genannt, aber nicht eigens ausgeführt; letzteres geschieht dann in den späteren Legendenausweitungen, vgl. R. BEYER, Die Königin von Saba (Bergisch-Gladbach 1991), 135ff. 151ff.

13 Vgl. z.B. auch Prov. 30,15ff; Sir. 25,1ff. Hebr. hydh, HAL ${ }^{3}$ 1, 296; C. WESTERMANN - B. REICKE, Rätsel, BHH 3 (1966), 1552f; H.-P. MÜlLER, Der Begriff "Rätsel" im Alten Testament, VT 20 (1970), 465-489; L. BAUER, Volksleben im Lande der Bibel (21903), 257ff; F. RoseNTHAL, Gambling in Islam (1975), 31f; L. Löw, Die Lebensalter in der jüdischen Literatur (1875), 346ff; zu den Rätseln (Kattowes) am Hanukka-Fest vgl. z.B. M. ZoBEL, Das Jahr des Juden (1936), 344f; K. OHLERT, Rätsel und Rätselspiele der alten Griechen (Berlin $21912=$ Hildesheim 19679), 83ff; W. SCHULTZ, Rätsel, RE I A 1 (1914), 62-125, spez. 122-124; J. HuIZINGA, Homo Ludens (1956 = 1987), 122ff; Gellius, Noct. Att. 12,6,1-3; Quintilian, inst. orat. 1,3,11; J. TAILlarDat (ed.), Suétone. Peri paidiōn (1967), Nr. 3; F.M. BöHME, Deutsches Kinderlied und Kinderspiel $(1897$ = 1967), 681-701; E. BORNEMANN, Unsere Kinder im Spiegel ihrer Lieder, Reime, Verse und Rätsel. Studien zur Befreiung des Kindes I (1973), 200f; K. TRAPP, Bantu-Spiele (Diss. phil.; 1960), 105-109.

14 Das 'Luftschloß', das Ahiqar für den ägyptischen Pharao bauen sollte, war nichts anderes als eine Art Drachen, vgl. F.C. CONYBEARE - J.R. HARRIS - A. SMITH LEWIS (ed.), The Story of Ahikar from the Aramaic, Syriac, Arabic, Armenian, Ethiopic, Old Turkish, Greek und Slavonic Versions (Cambridge 21913), 114ff (syr.) u.ö. Vgl. auch Gellius, Noct. Att. 10,12,9f; arab. țaijāra(t ez-zrār); neuhebr. ${ }^{c}$ apīpōn; tayāāäh; H. HEYDEMANN, Drachenspiel, AZ 25 (1867), 125f; A. JEREMIAS, Handbuch der altorientalischen Geisteskultur (21929), 140; K. WEULE, Ethnologie des Sports, G.A.E. BoGENG (ed.), Geschichte des Sports aller Völker und aller Zeiten Bd. I (1926), 56, fig. 31; F.M. FELDHAUS, Geschichte des Maschinensports, in: a.a.O., Bd. II (1926), 758, fig. 770; R. SCHMIDT, Die Darstellung von Kinderspielzeug und Kinderspiel (1977), 64f; F.K. MATHYS, Im Freien gespielt (1975), 24-26; F. KLEPZIG, Kinderspiele der Bantu (1972), 
und Kopfstand ${ }^{15}$ - auch weil sie in Palästina z.T. erst relativ spät belegt sind [wie z.B. Karten-16 und Pfänder-Spiele ${ }^{17}$, Polo (Abb. 59) ${ }^{18}$ und andere Reiter-

(Niedernhausen/Ts. 1987), 6-13; M. BACHER, Spiel mit Wind und Papier. Ein Hobbybuch vom Drachenbauen und Papierfalten (Würzburg 1978), passim; D. CARPENIIER J. BACHELET, Alles über Drachenbau (Freiburg i.Br. 1980), 5ff; F.V. GRUNFELD, Spiele der Welt (1979), 219-225; S. TYRelL, Drachen selber bauen. Phantasievolle Modelle aus aller Welt (München 1980), 34ff; R. MoulTON, Das Drachenbuch. Geschichte Flugtechnik - Selbstbau von Drachen (Ravensburg 1982), 9 ff.

15 Vgl. Herodot 6,129; A.D. TounY - S. WENIG, Sport in Ancient Egypt (1969), 48f; W. DERBOLAV, Leibesübungen und körperliche Erziehung 56 (1937), 534-538; auch die deutschen Kinderreime "Was wollen wir machen? / Auf dem Kopf stehen und lachen", "Was sollen wir spielen? / Auf dem Kopf stehen und schielen", "Was sollen wir tun? / Auf dem Kopf stehen und ruhn", vgl. P. RÜHMKORF, Über das Volksvermögen. Exkurse in den literarischen Untergrund (Reinbek bei Hamburg 1969), 67.

16 Im Judentum spätestens seit dem Mittelalter verboten (neuhebr. $q^{\mathcal{C}} l \bar{a} p$ ), vgl. z.B. G. ABRAHAMS, Cards and Cardplaying, EJ 5 (1971), 168; M. BUBER, Die Erzählungen der Chassidim (1949), 272; K. HIMLY, Morgenländisch oder abendländisch? Forschungen zu gewissen Spielausdrücken, ZDMG 43 (1889), 417-463. 555ff; K. HOLTER, Ein mamlukisches Kartenspiel, WZKM 67 (1975), 165-168; L. Löw, Die Lebensalter in der jüdischen Literatur (1875), 329ff; L.A. MAYER, Mamluk Playing Cards, BIFAO 38 (1939), 113-118; ders., Mamluk Playing Cards (Leiden 1971), passim; J.L. BURCHHARDT, Reisen in Arabien $(1830=1963), 306$; C. NIEBUHR, Reisebeschreibung nach Arabien, Bd. $1(1774=1968), 173 ;$ F. ROSENTHAL, Gambling in Islam (1975), 62ff. Allgemein vgl. z.B. F.V. GRUNFELD, Spiele der Welt (1979), 113-117; D. HofFMANN, Gemalte Spielkarten. Eine kleine Geschichte der Spielkarten (Frankfurt a.M. 1985), passim; E.S. TAYLOR, The History of Playing Cards (London 1865 = Rutland/VT 1973), passim; G. vON KUJAWA, Ursprung und Sinn des Spiels (1949), 83-110; H. REICHELT, Kartenspiele von Baccara bis Whist (Wiesbaden 1987), passim; K. LICHTwITZ, Neues Buch der siebzehn und vier Kartenspiele (Niedernhausen/Ts. 1988), passim; P. HORN, Jb. Deutsch als Fremdsprache 8 (1982), 178-188; auch A.S. PusCHKIN, Pique-Dame (1834).

17 Vgl. z.B. Calpurnius 2,23; Carmina Einsidlensia, 1,5ff [ed. D. KoRZENIEWSKI, Hirtengedichte aus neronischer Zeit (Darmstadt ${ }^{21987)}$, 76f].

18 Zum angeblichen oder tatsächlichen Polo-Feld in Gerasa vgl. C.H. KRAELING, Gerasa (1938), 86. 97. 101; I. BROWING, Jerash and the Decapolis (London 1982), 107-111; anders A.A. OSTRASZ, The Hippodrome of Gerasa: A Report on Excavations and Research 1982-1987, in: Jerash Archaeological Project 1984-1988, Vol. II (Paris 1989), 73f, Anm. 25. Vgl. auch Ibn Iyâs, Alltagsnotizen eines ägyptischen Bürgers (1988), 58; M. COHEN, JA 18 (1911), 482-484; J. ZICK-NÜSSEN, in: Museum für Islamische Kunst. Staatliche Museen Preußischer Kulturbesitz. Katalog (Berlin ${ }^{2} 1979$ ), 137, Nr. 515, Abb. 10. 72 (Damaskus, 13.Jh.n.Chr.); D. AYALON, Notes on the Furüsiyya Exercises and Games, in: ders., The Mamlūk Military Society (1979), 53-55; M. JUNKELMANN, Die Reiter Roms II (1991), 162, Abb. 91. 
spiele $^{19}$, Zahlenspiele ${ }^{20}$, Zusammensetz-Spiele (Puzzle) ${ }^{21}$, Schach ${ }^{22}$ oder das Anlege-Spiel Domino (arab. und neuhebr. dōmin̄ō) ${ }^{23}$, dessen Bezeichnung

19 H. Le BonNIEC, Trojaspiel, dtv-Lexikon der Antike. Kulturgeschichte 2 (1971), 168; F. RosenTHAL, Gambling in Islam (1975), 55f; K. SCHNEIDER, Lusus Troiae, RE 26 (1927), 2059-2067; E. MEHL, Troiaspiel, RE Suppl. 8 (1956), 888-905; K.-W. WEEBER, Troiae lusus. Alter und Entstehung eines Reiterspiels, AncSoc 5 (1974), 171-196; C. DIEM, Das Trojanische Reiterspiel (Berlin 1942), passim; ders., Asiatische Reiterspiele. Ein Beitrag zur Kulturgeschichte der Völker (Documenta Hippologica; Berlin $21942=$ Hildesheim u.a. 1982), 104-272; L. MERCIER, La Chasse et les Sports chez les Arabes (1927), 181-239; M. Frh. VON OPPENHEIM, Der Djerî̀d und das Djerîd-Spiel, Isl. 2 (1926), 590-617; V.J. PARRY, Djerïd, EI 2 (21965), 532f; M. JUNKELMANN, Die Reiter Roms II (1991), 142ff. 203f.

20 Vgl. E. LASKER, Brettspiele der Völker (1931), 170-203; A. BORST, Das mittelalterliche Zahlenkampfspiel (SHAW.PH Suppl. 5, 1986; Heidelberg 1986), 31 ff.

21 Griech. ostomachion, stomachion; latein. loculus Archimedius: Ausonius, cento nupt. 17, ed. H.G.E. WHITE (London - Cambrigde/MA 1919 = 1961), 395-397; Archimedes, Opera omnia II, ed. I.L. HEIBERG (Leipzig 21913), 416-424; J. VÄTERLEIN, Roma ludens (1976), 15-17; Fr. Hultsch, Archimedes 3, RE 3 (1895), 539; R.C. BELL, Board and Table Games, Vol. II (21979), 66-70; E. GLONNEGGER, Das Spiele-Buch (1988), 92ff; F.V. GRUNFELD, Spiele der Welt (1979), $274 f$.

22 Pers.-arab. eš-šăh māt "Der König ist gestorben", arab. šatran̋̆. Zu Salomo als dem Erfinder des Schachspiels vgl. z.B. M.J. BIN GuRION, Der Born Judas. Märchen und Geschichten (Berlin 1934), 76-79. Vgl. allgemein z.B. S. PowELS, Zur Geschichte des Schachspiels bei Indern und Arabern, in: Studia Semitica nec non Iranica. FS für K. MACUCH (Wiesbaden 1989), 201-212; B. CARRA de VAUX, Shatrandj, EI(D) 4 (1934), 363f; R. FINKENZELLER - W. ZIEHR - E.M. BÜHRER, Schach. 2000 Jahre Spiel-Geschichte (Aarau - Stuttgart 1989), 11ff; A. KLUGE-PINSKER, Schachspiel und Trictrac (1991), 9ff; A. KoHOUT, Ist das Schachspiel im Talmud genannt und unter welchem Namen?, ZDMG 46 (1892), 130-135 (mit Überlegungen zu 'sqwndry u.ä.); E. LASKER, Brettspiele der Völker (1931), 14-88; W. LAUTERBACH, Das unsterbliche Spiel. Einführung in die Schachkunst (Berlin - New York ${ }^{51987)}$ ), passim; L. Löw, Die Lebensalter in der jüdischen Literatur (1875), 327f; M. STEINSCHNEIDER, Schach bei den Juden, in: A. VAN DER LINDE, Geschichte und Litteratur des Schachspiels I (1874), 155-202 (auch als Monographie 1873); J. PETzOLD, Das Königliche Spiel. Die Kulturgeschichte des Schach (Stuttgart u.a. 1987), passim; C. NIEBUHR, Reisebeschreibung nach Arabien, Bd. 1 (1774 = 1968), 171; M.E. RoGERs, Domestic Life in Palestine (London $1862=$ 1989), 357; M. BUBER, Die Erzählungen der Chassidim (1949), 732f; F. ROSENTHAL, Gambling in Islam (1975), 37-40; R. WIEBER, Das Schachspiel in der arabischen Literatur von den Anfängen bis zur zweiten Hälfte des 16.Jahrhunderts (Beiträge zur Sprach- und Kulturgeschichte des Orients 22; Walldorf/Hessen 1972), passim; W. WIEGAND, Das königliche Spiel (Berlin 1959), passim; F.V. GRUNFELD, Spiele der Welt (1979), 62-69.

23 Daneben gibt es natürlich auch andere Herleitungen des Namens, um deren Historizität es allerdings auch nicht viel besser bestellt ist, vgl. R.C. BELL, Board and Table 
nach legendarischer Überlieferung auf Ps. 109,1 (Vulg.: "Dixit dominus domino meo sede a dextris meis") zurückgehen soll] - , so möchte ich an diesem Punkt mit einigen zusammenfassenden Beobachtungen abschließen.

In Palästina war Spielen seit den Anfängen seiner Besiedlung allgemein verbreitet; Spielzeug im engeren Sinn ist spätestens seit dem Neolithikum nachweisbar. Die literarischen, epigraphischen, archäologischen und ikonographischen Lücken sind immens. Spielregeln sind in Palästina nicht erhalten, doch lassen sie sich z.T. aus griechischen, römischen und mittelalterlichen Quellen rekonstruieren und für die vorhellenistischen Epochen voraussetzen. Zusammenhängende theologische ${ }^{24}$, philosophische ${ }^{25}$, anthropologische bzw.

Games ( ${ }^{2}$ 1979), Vol. I, 149-172, Vol. II, 101-113; E. GLONNEGGER, Das Spiele-Buch (1988), 78ff; TH. MÜlLER-AlFELD, Brettspiele (1963), 16ff; F.V. GRUNFELD, Spiele der Welt (1979), 104-107; F.M. BöHME, Deutsches Kinderlied und Kinderspiel (1897 = 1967), 646, Nr. 560; B. THOLE - T. WERNECK, Spiel und Spaß mit Domino (Ravensburg 1982), 19ff. Ein Domino-Stein (6/5) aus Knochen wurde in Grannus / Grand (Lothringen) gefunden und ist im dortigen Museum ausgestellt; ob er allerdings tatsächlich aus römischer Zeit stammt, ist mir keineswegs sicher!

24 H.-J. HERMISsON, Gottes Freiheit - Spielraum des Menschen. Alttestamentliche Aspekte eines biblisch-theologischen Themas, ZThK 82 (1985), 129-152; G.M. MARTIN, Spiel in der Bibel - Kreuz im Spiel. Zwei Grundfragen zur Diskussion um die "Theologie des Spiels", EvErz 27 (1975), 21-30; D.L. MILLER, Gods and Games. Toward a Theology of Play (New York u.a. 21973), passim; ders., The Kingdom of Play: Some Old Theological Light from Recent Literature, USQR 25 (1970), 343-360; ders., Theology and Play Studies: An Overview, JAAR 39 (1971), 349-354; J. MolTMANN, Die ersten Freigelassenen der Schöpfung. Versuche über die Freude an der Freiheit und das Wohlgefallen am Spiel (München 1971), 9ff; W. PANNENBERG, Anthropologie in theologischer Perspektive,(Göttingen 1983), 312-328; H. SCHEUERL (ed.), Theorien des Spiels $\left({ }^{10} 1975\right)$, passim; N. SPIEGLER, Das Leben spielen. Phänomene jugendlichen Verhaltens (Gütersloh 1978), 125-169. 252f.

25 Vgl. z.B. G. von KuJAWA, Ursprung und Sinn des Spiels (Nördlingen 1949), 43-55; H. KUTZNER, Erfahrung und Begriff des Spiels. Versuch, den Menschen als spielendes Wesen zu denken (Diss. phil. masch.; Freie Universität Berlin 1973), passim; A. GEHLEN, Der Mensch. Seine Natur und seine Stellung in der Welt (Frankfurt a.M. ${ }^{9} 1971$ ), 205-212; M. GISI, Der Begriff Spiel im Denken J.-P. Sartres (MPF 1976; Meisenheim 1979), passim; D. GöBEL, Über das Spielen (Diss. phil. masch.; Heidelberg 1955), 3ff; S. LEM, Sade und die Spieltheorie (Frankfurt a.M 1986), 79-118; H. PLESSNER, Der Mensch im Spiel, (1967), in: ders., Ges. Schriften 8 (Frankfurt a.M. 1983), 307-313; H. ZDARZIL, Zur Theorie des menschlichen Spiels, in: Rationalität - Phänomenalität - Individualität. FS für H. und M. GLOCKNER (Bonn 1966), 247-270; I. HEIDEMANN, Philosophische Theorien des Spiels, KantSt 50 (1958-1959), 316-322; dies., Freiheit und Bindung im Spiel, in: Das Spiel, ed. Ausschuß Deutscher Leibeserzieher (Frankfurt 1959), 81-86; dies., Der Begriff des Spiels und das ästhetische Weltbild in der Philosophie der Gegenwart (Berlin 1968), passim. 
ethologische ${ }^{26}$, sozialwissenschaftliche ${ }^{27}$, psychologische ${ }^{28}$, wirtschaftstheoretische ${ }^{29}$, mathematisch-stochastische ${ }^{30}$ Spieltheorien ${ }^{31}$ fehlen. Dennoch lassen sich eine Reihe von Tendenzen aufzeigen:

26 Vgl. z.B. W. HildebrandT, Homo ludens. Die Spiele des Menschen in der Sicht der Anthropologie, in: G.-K. KALTENBRUNNER (ed,), Im Anfang war das Spiel (1987), 90-107; H. SCHEUERL, Die pädagogisch-anthropologische Dimension des Spiels, in: K.J. KREUZER (ed.), Handbuch der Spielpädagogik 1 (1983), 31-42; K. LORENZ, Vergleichende Verhaltensforschung. Grundlagen der Ethologie (Wien - New York 1978), 261265.

27 Vgl. z.B. J. PIEPER, Grundformen sozialer Spielregeln (Frankfurt ${ }^{3} 1955$ ), passim; G. RUNKEL, Soziologie des Spiels (Frankfurt a.M. 1986), 7ff; M. SHUBIK (ed.), Spieltheorie und Sozialwissenschaft (Hamburg 1965), passim; F.I. KHUR, Tents and Pyramids (1990), $27 \mathrm{ff}$.

28 G. BITTNER, Psychoanalytische Aspekte des Spiels, in: O. GRUPE - H. GABLER - U. GÖHNER (ed.), Spiel - Spiele - Spielen (Schorndorf 1983), 122-130; K. HARTMANN, Über psychoanalytische "Funktionstheorien" des Spiels, (1962), in: H. RöHRS (ed.), Das Spiel - ein Urphänomen des Lebens (Erziehungswiss. Reihe 23; Wiesbaden 1981), 119128; R. VAN DER KOOU, Die psychologischen Theorien des Spiels, in: K.J. KREUZER (ed.), Handbuch der Spielpädagogik 1 (1983), 297-336; A. RüSSEL, Das Kinderspiel. Grundlinien einer psychologischen Theorie (München 21965 = Darmstadt 1977), passim; S. Millar, Psychologie des Spiels (Ravensburg 1973), 23-57.

29 Vgl. z.B. H. ARNASZUS, Spieltheorie und Nutzenbegriff aus marxistischer Sicht (Frankfurt a.M. 1974), 7ff; O. MORGENSTERN, Spieltheorie und Wirtschaftswissenschaft (Wien - München 1963), $9 f f$.

30 Vgl. z.B. R. Vogelsang, Die mathematische Theorie der Spiele (Bonn u.a. 1963), 30ff; G. KLAUS, Spieltheorie in philosophischer Sicht (Berlin 1968), 85ff; R. INEICHEN (oben Kap. 6, Anm. 18).

31 Zu Spieltheorien vgl. z.B. C. Alleman, Über das Spiel. Die Spieltheorien, Menschenspiel und Tierspiel (Diss. phil.; Zürich 1951), passim; A. FLITNER, Spielen lernen. Praxis und Bedeutung des Kinderspiels (München ${ }^{8} 1986$ ), 13ff; O. GRUPE, Bewegung, Spiel und Leistung im Sport (Schorndorf 1982), 108-157; H. HECKMANN, Entwurf einer Psychologie des Spielens, PsF 27 (1963-1964), 225-243; J. RAABE, Different Approaches to Play, in: dies. et al. (ed.), The Child and Play (1980), 5-23; H. SCHEUERL, Alte und neue Spieltheorien. Wandlungen ihrer pädagogischen Interessen und Perspektiven, EvErz 27 (1975), 2-21; ders., Zur Begriffsbestimmung von "Spiel" und "spielen", (1975), in: H. RÖHRS (ed.), Das Spiel - ein Urphänomen des Lebens (Erziehungswiss. Reihe 23; Wiesbaden 1981), 41-49; ders., Spieltheorien im Wandel, in: O. GRUPE - H. GABLER - U. GÖHNER (ed.), Spiel - Spiele - Spielen (1983), 76-88; B. SUTTON-SMTTH, Spiel: Das Vermitteln von Neuem, in: Sport in unserer Welt - Chancen und Probleme, ed. O. GRUPE (Berlin u.a. 1973), 607-613; ders., Die Dialektik des Spiels. Eine Theorie des Spielens, der Spiele und des Sports (Schorndorf 1978), passim. 
1) (Proto-) Sach. 8,4f malte ein idyllisches und ideales Stadt-Bild in einem seiner (echten) ${ }^{32}$ Verheißungsworte. Das ungestörte Spielen der Kinder, das friedvolle Zusammenleben der (Großeltern- und Enkel-) Generationen beschreibt Realität und Utopie zugleich: "Und es sollen wieder alte Männer und alte Frauen auf den Plätzen Jerusalems sitzen, jeder mit seinem Stock in seiner Hand vor hohem Alter, und die Plätze der Stadt sollen voll sein von kleinen Jungen und von kleinen Mädchen, die auf ihnen spielen". Die Kinder des antiken Palästina spielten wohl sehr viel weniger in der drangvollen Enge der Wohnhäuser (z.B. Sir. 32,11f; bBB 91b; Plutarch, Cato min. 2; ders., Dion 9) als vielmehr und vor allem auf den Gassen und Plätzen der Siedlungen [vgl. Jer. 6,11; 9,20; 1.Makk. 2,9; Matth. 11,16f par. Luk. 7,32 (agora) ] ${ }^{33}$ oder auf den Dächern der Wohnhäuser ${ }^{34}$; die Regenzeit dürfte das Spielen im Freien deutlich reduziert haben ${ }^{35}$. Wie wichtig die 'Spielplätze' der Erwachsenenwelt waren, zeigt auch ein Ausschnitt aus einem sumerisch und akkadisch überlieferten Lied auf den Unterweltsgott Nergal: "Herr, auf den Spielplatz (akkad. ašar milulti) stelle dich nicht / (zum Spielplatz tritt nicht hin); vom Spielplatz vertreibe die Kleinen nicht!"36. Als Spielplätze konnten nicht nur Häuser,

32 Yldym w-yldwt $m^{e}$ sahaqīm b-rhbty-h (LXX paidariōn kai korasiōn paizontōn en tais plateiais; Vulg. infantibus et puellis ludentibus in plateis). Vgl. z.B. K. ELLIGER, Das Buch der Zwölf Kleinen Propheten II ( ${ }^{1975)}$, 138f; F. HORST, Die Zwölf Kleinen Propheten $\left({ }^{3} 1964\right)$, 242; W. RUDOLPH, Haggai - Sacharja 1-8 (1976), 41. 147f.

33 Cicero, Phil. 2,56; Plutarch, Alkibiades 2,15; Vergil, Aen. 7,379; Martial, epigr. 14,169; Anth. Graeca 7,89,9; Kallimachos, epigr. 1,9 = Diog. Laert. 1,80; Augustin, conf. 2,4,9; vgl. O. CullmanN, in: W. SCHNEEMELCHER (ed.), Neutestamentliche Apokryphen I ( $\left.{ }^{5} 1987\right), 366$. Vgl. z.B. auch E.W. ANDRAE - R.M. BOEHMER, Bilder eines Ausgräbers. Walter Andrae im Orient 1898-1919 (Berlin 1989), Nr. 43, Taf. 30 (BabylonKuwēriš); E. WEGNER, Das Ballspiel der Römer (1938), 7ff; allgemein G. AICK, Die Befreiung des Kindes. Kleine Kulturgeschichte des Spiels und des Kinderspielplatzes (Hamburg 1963), passim; H. HetzER - L. BENNER - L. PEE, Kinderspiel im Freien (München - Basel 1966), 17ff; A. BENGTSSON, Ein Platz für Kinder. Plädoyer für eine kindgemäße Umwelt (Wiesbaden - Berlin 1971), passim; Kinderspielplätze. Beiträge zur kindorientierten Gestaltung der Wohnumwelt, ed. G. SCHOTTMAYER - R. CHRISTMANN, Bd. 1-2 (Stuttgart u.a. 1976), passim; N. KLUGE (ed.), Spielpädagogik (Bad Heilbrunn/Obb. 1979), 120ff; B. KRAUS, Spielecken - Spielplätze (Basel 1979), passim.

34 O. CullmanN, in: W. SchnEEMElcher (ed.), Neutestamentliche Apokryphen I $\left(5_{1987)}, 356\right.$.

35 Vgl. z.B. R. DiRX, Kinderspiele von Januar bis Dezember (Düsseldorf 1984), passim; P. ThIEsEN, Schönwetterspiele. Praxis des Spiels im Freien mit 3- bis 7jährigen (Freiburg i.B. 1986), passim.

36 H. ZimmerN, Das Nergallied Berl. VAT 603 = Philad. CBM 11344 = Lond.Sm. 526, ZA 31 (1917-1918), 111-121 (Z. 20f); SAHG Nr. 15. 
Höfe und Paläste, sondern auch Tempel, Kirchen und Synagogen oder Theater und Arenen benutzt werden.

2) So wie in dem Bauen und Niederreißen des Propheten Ezechiel in einem 'Sandkasten' in Jerusalem (Ez. 4f) der spielerische Kon- und Destruktionstrieb von Kindern gut zum Ausdruck kommt, so der Nachahmungtrieb von Kindern in Matth. 11,16f par. Luk. 7,32; sie ahmen Erwachsene spielerisch nach ${ }^{37}$, diese aber wollen nicht immer mitspielen: "Sie sind den Kindern gleich, die auf dem Markt sitzen und rufen einander zu: 'Wir haben euch aufgespielt, und ihr habt nicht getanzt; wir haben Klagelieder gesungen, und ihr habt nicht geweint". Auch die Mädchen, die mit Puppen spielten, spielten die Rolle der Mutter, und nahmen damit ihre (wahrscheinliche) Zukunft vorweg $^{38}$; gleichzeitig konnten sie mit der Puppe, einem Liebesobjekt von großer emotionaler Bedeutung, eigenen Ängsten wirksam begegnen. Wenn das Jesus-Kind Spatzen aus Ton herstellte und dann fliegen ließ, dann steht - wenn man von der Wundertheologie absieht - dahinter entwicklungs ${ }^{39}$ und spiel-

37 Vgl. z.B. Seneca, de const. sap. 12,2; Platon, nomoi 643b-c. Zum Imitationsverhalten von Kindern vgl. z.B. J. PIAGET, Nachahmung, Spiel und Traum. Die Entwicklung der Symbolfunktion beim Kinde (Ges. Werke 5, Studienausgabe; Stuttgart 1975), $21 \mathrm{ff}$; S. Millar, Psychologie des Spiels (1973), 155ff; S. PAUL, in: FS für S. WOLF zum 65.Geb. (1975), 227ff.

38 Zu Mutter-Kind-Spielen vgl. z.B. H. SBRZESNY, Die Spiele der !Ko-Buschleute (1976), 123-127, auch G. HARTMANN, Die Puppe als Erziehungsregulativ bei den Karaja, Brasilien, Tribus 33 (1984), 97-103.

39 A. Flitner, Spielen - Lernen. Praxis und Deutung des Kinderspiels (München Zürich ${ }^{8} 1986$ ), passim; ders. (ed.), Das Kinderspiel - Texte (München ${ }^{4} 1978$ ), passim; F. und TH. CaPlan, The Power of Play (Garden City/NY 1973), 1ff; J. ChâTEAU, Das Spiel des Kindes (21976), passim; M. ENDERLIN, Das Spielzeug in seiner Bedeutung für die Entwicklung des Kindes (Langensalza 1907), passim; E.H. ERIKSON, Kinderspiel und politische Phantasie. Stufen in der Ritualisierung der Realität (Frankfurt a.M. 1978), passim; L. SAATMANN, Laßt Kinder spielen (München - Basel 1965 = 1970), passim; H. NITSCH-BERG, Kindliches Spiel zwischen Triebdynamik und Enkulturation. Der Beitrag der Psychoanalyse und der Entwicklungstheorie Piagets (Stuttgart 1978), 11ff; M.W. PIERS (ed.), Play and Development (New York 1972), passim; L.S. WYGOTSKI, Das Spiel und seine Rolle für die psychische Entwicklung des Kindes, (1973), in: H. RöHRS (ed.), Das Spiel - ein Urphänomen des Lebens (Erziehungswiss. Reihe 23; Wiesbaden 1981), 129-146; J.F. CHRISTIE - E.P. JOHNSON, Die Rolle des Spiels in der sozial-intellektuellen Entwicklung, in: W. EINSIEDLER (ed.), Aspekte des Kinderspiels (Weinheim - Basel 1985), 67ff; A. RüSSEL, Spiel und Arbeit in der menschlichen Entwicklung, in: Handbuch der Psychologie 3, ed. H. THOMAE (Göttingen 21959), 502-534; H. und M. PAPOUSEK, Das Spiel in der Frühentwicklung des Kindes, Suppl. pädiat. prax. 18 (1977), 17-32; L. SCHENK-DANZINGER, Entwicklungspsychologie (Wien ${ }^{9} 1975$ ), 89ff; dies., Studien zur Entwicklungspsychologie (1963), 86-92; dies., Zur entwicklungs- 
psychologisch betrachtet ein typisches Fiktionsspiel von (Klein-)Kindern, nämlich die Verlebendigung von Leblosem.

3) Die pädagogische $e^{40}$, soziale ${ }^{41}$, kognitive ${ }^{42}$ und therapeutische ${ }^{43}$ Dimensionen des Spielens waren den Erwachsenen in Palästina durchaus bekannt, auch wenn sie keine expliziten pädagogischen Theorien entwickelten. So schrieb z.B. Hieronymus in einem seiner Briefe (ep. 107,4): "Besorge ihr Buchstaben aus Buchs oder Elfenbein und lasse sie deren Namen lernen! Sie soll damit spielen, und sie wird aus dem Spiel Belehrung schöpfen'44.

psychologischen Bedeutung des Spiels, in: K.J. KREUZER (ed.), Handbuch der Spielpädagogik 1 (1983), 369-383; S. SCHMIDTCHEN - A. ERB, Analyse des Kinderspiels. Ein Überblick über neuere psychologische Untersuchungen (1976), 8ff; B. und SH. SUTTONSMrTH, Hoppe, hoppe, Reiter. Die Bedeutung von Kinder-Eltern-Spielen (1986), $15 \mathrm{ff}$.

40 Vgl. z.B. Quintilian, inst. orat. 1,3,11; auch U. BAER, Wörterbuch der Spielpädagogik (Basel 1981), passim; G. BITTNER, Zur pädagogischen Theorie des Spielzeugs (1968), in: H. RöHRS (ed.), Das Spiel - ein Urphänomen des Lebens (Erziehungswiss. Reihe 23; Wiesbaden 1981), 51-61; P. MOOR, Die Bedeutung des Spiels in der Erziehung. Betrachtungen zur Grundlegung einer Spielpädagogik (Bern - Stuttgart 1962), passim; H. RETTER, Spielzeug. Handbuch zur Geschichte und Pädagogik der Spielmittel (Weinheim - Basel 1979), 36ff. 302ff; H. SCHEUERL, Das Spiel ( $\left.{ }^{9} 1979\right)$, 11ff; ders., EvErz 27 (1975), 2-21; G.E. SCHÄFER, Das Selbst im Spiel, ZP 26 (1980), 13-27; Y.S. TOUREH, Use of Play Activities for Educational Purposes, in: J. RAABE et al. (ed.), The Child and Play (1980), 64-66.

41 S. PaUl, in: FS für S. Wolf zum 65.Geb. (1975), 227ff; H. SBRZESNY, Die Spiele der !Ko-Buschleute (1976), 225ff; St. SCHMIDTCHEN - A. ERB, Analyse des Kinderspiels (1976), 52ff.

42 Vgl, z.B. Quintilian, inst. orat. 1,3,10ff; auch M. GRUNWALD, Chanukka, in: FR. THIEBERGER (ed.), Jüdisches Fest, jüdischer Brauch (21967 = 1976), 344 (Kwittlech); M. KAUKE, Spielintelligenz. Spielend lernen - Spielen lernen? (Heidelberg - Berlin New York 1991, passim.

43 Vgl. z.B. Plinius d.J., ep. 3,1,8; Celsus, de med. 1,2.6; auch H. BENESCH, Spiel als therapeutische Alternative (Tübingen 21980), passim; C. FAUST, Spielverhalten aus ärztlicher Sicht, in: W. MARX (ed.), Das Spiel. Wirklichkeit und Methode (Freiburg i.B. 1967), 67-77; L. SAATMANN, Kinder spielen sich gesund (Stuttgart 1952), passim; H. ZULLIGER, Heilende Kräfte im kindlichen Spiel (Stuttgart 61979$)$, passim; E. WEGNER, Das Ballspiel der Römer (1938), 40-45; S. MillaR, Psychologie des Spiels (1973), 218234; H. GOETZE - W. JAEDE, Die nicht-direktive Spieltherapie (Frankfurt a.M. 1979), passim; G.E. SCHÄFER, Heilendes Spiel, Kindheit 1 (1979), 239-250; St. SCHMIDTCHEN - A. ERB, Analyse des Kinderspiels (1976), 99ff; V.M. AXIINE, Kinder-Spieltherapie im nicht-direktiven Verfahren (München - Basel 61984), 14ff.

44 Drei Zitate aus Fr. FröBEL, Die Menschenerziehung (1826), in: ders., Ausgewählte Schriften II, ed. E. HoFFMANN (Godesberg 1951), 36: "Spielen, Spiel ist die höchste Stufe der Kindesentwicklung". "Die Spiele dieses Alters sind die Herzblätter des ganzen 
4) Der Wert, der dem Spielen aufgrund seiner dialektischen Verbindung von Realität und Illusion (< * in-ludere), Ernst und Spaß, Sieg und Niederlage, Glück und Pech, Regel und Zufall, Spannung und Entspannung, Konzentration und Muße (hebr. šäbbat, griech. schole, latein. otium) schon in der Antike zugesprochen wurde, kommt in einer Überlieferung Herodots $(2,173)^{45}$ gut zum Ausdruck: Der ägyptische Pharao belehrte seine Kritiker, indem er sagte: "Nur wenn man den Bogen braucht, spannt man ihn. Hielte man ihn dauernd gespannt, so würde er zerbrechen und, wenn man ihn brauchte, hätte man keinen Bogen mehr. Nicht anders ist es mit dem Menschen. Ist er immer nur ernst und fleißig und läßt dem Scherz und der Torheit keinen Raum, so wird er unvermerkt ganz toll oder ganz schlaff und müde. Darum gebe ich diesem so gut seine Zeit wie jenem". Plutarch, reg. et imp. apophtheg. 181 überliefert, daß Alexander d.Gr. einige seiner Freunde bestraft haben soll, weil sie nicht bloß zum Vergnügen und Scherz Würfel gespielt hatten. Ein altarabisches Sprichwort sagt: "Ein Spiel / Ist ernster Geschäfte Ziel"46, und eine lateinische Grabinschrift aus Rom lautet (CIL VI, Nr. 16169): "...ioceris, ludas! Hortor: hfc (sic) summa est severitas" ["... 'Scherze, spiele!' Ich ermahne (dich): Das ist höchster Lebensernst!'"]. Der homo ludens ist eben zumeist auch ein homo sapiens.

5) Die Spielzeug-Herstellung lag in der Regel in der Hand der privaten Konsumenten, seien es die Kinder selbst ${ }^{47}$ oder Erwachsene ${ }^{48}$ : Es wurde für den Eigenbedarf produziert. Die begrenzten materiellen Möglichkeiten der weitaus größten Bevölkerungsteile haben nicht dazu geführt, daß sie deshalb weniger spielten ${ }^{49}$. Die Oberschicht ließ sich gelegentlich Spiele aus wertvollen Materialien wie Elfenbein o.ä. eigens von erfahrenen Handwerkern anfertigen. Der Handel mit Spielzeug war gering, der Import ausländischen Spielzeugs minimal.

6) Gespielt wurde in allen Bevölkerungsschichten, von beiden Geschlechtern, von Kindern wie Erwachsenen, von Lebenden und von Toten. Geschlechtsspezifische Unterschiede beim Spielen bzw. Spielzeug sind nur gelegentlich

künftigen Lebens". "Das Spiel... ist... nicht Spielerei; es hat hohen Ernst und tiefe Bedeutung; pflege, nähre es, Mutter, schütze, behüte es, Vater!".

45 Das Motiv ist in der Antike öfters belegt, vgl. z.B. Phaedrus, Liber fab. 3,14.

461001 alt-arabische Sprichwörter, deutsch von FR. RÜCKERT (1988), 74.

47 F.W.M. PETrie, Objects of Daily Use (1927), Pl. 53; allgemein P. CALMETTES, Les joujoux (Paris 1924), 251ff.

48 Von Eltern hergestellt, z.B. J.J. Hess, Von den Beduinen des Innern Arabiens (1938), 139.

49 Vgl. H. Hetzer, Kindheit und Armut. Psychologische Methoden in Armutsforschung und Armutsbekämpfung (Leipzig 2 1937), 64ff. 
und mit einem gewissen Unsicherheitsgrad nachweisbar: Mädchen dürften z.B. eher mit Puppen Rollenspiele und Knaben z.B. eher mit Waffen Jagdund Kriegsspiele gespielt haben. Der Großteil der Spiele wurde sowohl von Mädchen als auch von Knaben gespielt, viele davon auch von beiden gemeinsam wie z.B. die Fang- und Versteckspiele. Erst in römischer Zeit sind literarische Belege erhalten, in denen die Trennung von Mädchen und Jungen beim Spielen verlangt wird: "Sexus femineus suo vingatur sexui; nesciat, immo timeat cum pueris ludere" (Hieronymus, ep. 128,4) ${ }^{50}$.

Insgesamt dürften Knaben und Männer ${ }^{51}$ mehr gespielt haben als Mädchen und Frauen: In den patriarchalen Gesellschaften des antiken Palästina waren die Arbeitsgebiete der Mädchen und Frauen umfassender und zeitintensiver $^{52}$, ihre Freizeit knapper bemessen als sie der Knaben und Männer.

Auch die Unterschiede zwischen den Spielen Erwachsener und denen von Kindern sind nur schwer belegbar ${ }^{53}$ : Der natürliche Nachahmungstrieb der Kinder, die Spiele der Erwachsenen zu spielen, wurde durch das enge Beieinanderwohnen der Menschen und durch die kaum vorhandene Trennung von Kinder- und Erwachsenenwelt ${ }^{54}$ verstärkt. Die Adoleszenz wurde schneller erreicht; die Kindheit war, was ihre Dauer betrifft, kürzer und durch Kinderarbeit $^{55}$ stärker geprägt als dies heute der Fall ist.

50 Vgl. Hieronymus, ep. 107,4.

51 Vgl. für die Gegenwart z.B. L. SchmITZ, Spiel und Sammlung - Macht und Sinn. Glücksspiel im türkischen Männer-Cafés in Köln, in: Männerbande - Männerbünde II (Ethnolog. NF 15,2; Köln 1990), 157-16.

52 Vgl. z.B. B. MERSHEN, Töpferin, Flechterin, Weberin und Gerberin. Zum Haushaltshandwerk im Ostjordanland, in: Pracht und Geheimnis, ed. G. VöLGER et al. (1987), 100-105.

53 Zur Korrelation Spieltyp - Lebensalter vgl. neben der schon aufgeführten Literatur von L. SCHENK-DANZinger, J. PIAGET, B. und S. SutTon-Smith u.a. auch H. HeTZER, Spiel und Spielzeug für jedes Alter (München 161977), passim.

54 Vgl. z.B. P. ARIES, Geschichte der Kindheit (L'enfant et la vie familiale sous l'ancien régime, 1960) (dtv 4320; München 1988), passim und demnächst U. HÜBNER, Kindheit und Jugend in Israel und Juda, (in Vorbereitung).

55 Vgl. z.B. F. NuSCHELER - H.-M. GROSSE-OETRINGHAus (ed.), Kinderhände. Kinderarbeit in der Dritten Welt (Baden-Baden 1988), 21ff. Zur Freizeit in Antike und Gegenwart sowie zum Freizeit-Verhalten (Quintilian, inst. orat. 1,3,11) vgl. G. EICHLER, Spiel und Arbeit. Zur Theorie der Freizeit (problemata 73; Stuttgart - Bad Cannstatt 1979), passim; ders., Spiel und Freizeit, in: O. GRUPE - H. GABLER - U. GöHNER (ed.), Spiel - Spiele - Spielen (1983), 232-242; W. NAHRSTEDT, Die Entstehung der Freizeit. Dargestellt am Beispiel Hamburgs (Göttingen 1972), 17ff; E. OLSHAUSEN et al. (ed.), Mensch und Arbeit (Humanistische Bildung 14; Stuttgart 1990), passim; H. SCHILLING 
Kleinkinder haben vor allem mit Rasseln, Klappern und Amuletten, ältere Kinder Sandkasten- und Versteck-Spiele oder mit Bällen ${ }^{56}$ und Schleuder, Puppen und Spieltieren, Miniaturgeschirr und Wägelchen, Iunx und Kreisel u.ä. gespielt. Von Kindern und Erwachsenen gleichermaßen gespielt wurden vor allem Astragal-, Würfel- und Brettspiele. Die Spiele der städtischen und der ländlichen Bevölkerung dürften sich nur unwesentlich voneinander unterschieden haben; in der hellenistisch-römischen Zeit waren die großen Gebäude-Komplexe wie Theater und Hippodrome Magneten für nicht unerhebliche Teile auch der umliegenden ländlichen Bevölkerung.

Spielen gelernt und Spiele kennengelernt haben Kinder zumeist von ihren Altersgenossen und weniger von ihren Eltern oder anderen Erwachsenen. Insofern waren sie die wesentlichen Träger und Tradenten ihrer eigenen Spielkultur; die Phantasie der Kinder, für die Nahrung, Kleidung und Spielzeug alles andere als Selbstverständlichkeiten waren, wog die - materiell kärgliche Spielzeugkultur im zumeist provinziellen Palästina spielend auf.

7) Spiele, die ihrem Wesen nach per se konservativ sind, haben sich in einer meist jahrhunderte-, z.T. jahrtausendelangen kulturellen Kontinuität mehr oder weniger unverändert über die verschiedenen Epochen der palästinischen Geschichte erhalten. Wie die zahlreichen Belege aus anderen zeitgleichen Kulturen und die ebenso zahlreichen ethnologischen Befunde zeigen, ist die Mehrzahl dieser traditionellen Spiele in den vorindustriellen Gesellschaften des Mittelmeerraums und Vorderasiens in der Tendenz multikulturell und omnipräsent. Ein erheblicher Teil von ihnen wird noch heute von Kindern und / oder Erwachsenen selbst moderner Industriegesellschaften gespielt.

Innovationen kamen nur gelegentlich auf wie z.B. der kubische Würfel, das Mühle-Spiel, die hellenistisch-römischen Massenbelustigungen, Schach, Polo (?) und das Spielen mit Karten. Verschiedene Spiele verschwanden nach einer gewissen Zeitspanne wieder wie z.B. manche der Steck- bzw. Löcherspiele und der größte Teil der hellenistisch-römischen Massenbelustigungen.

Fremde Einflüsse bzw. Importe sind gelegentlich zu beobachten wie z.B. das Mühle-Spiel (?) oder hellenistisch-römische Massenbelustigungen. Manche Spiele, die außerhalb Palästinas eine gewisse Verbreitung hatten wie das Kot-

(ed.), Aspekte der Freizeit (Gießen 1978), passim; H.-G. VeSTER, Zeitalter der Freizeit. Eine soziologische Bestandsaufnahme (Darmstadt 1988), 8ff. Die ludi publici der römischen Zeit galten - auch in Palästina - als feriae.

56 Vgl. auch Fr. FröBEL, Der Ball, das erste Spielwerk der Kindheit; Erste Gabe: Der Ball als erstes Spielzeug des Kindes, (1838), in: ders., Ausgewählte Schriften III, ed. H. HEILAND (Düsseldorf - München 1974), 13-33. 35-52. 
tabos-Spiel ${ }^{57}$, wurden dagegen in Palästina wohl nicht gespielt; immerhin zeigt die im achämenidischen Palästina gefundene attische Importware eine auffällige Vorliebe für Gefäßtypen, die für den Gebrauch bei Symposien geeignet waren ${ }^{58}$; deshalb ist nicht auszuschließen, daß die ein oder andere Scherbe von einem beim Kottabos-Spiel zu Bruch gegangenen Gefäß herrührt.

8) War schon das Interesse der alt- und neutestamentlichen Verfasser an Spielen und Spielzeug aus verschiedenen Gründen ziemlich gering, so kann man doch feststellen, daß weder das Alte noch das Neue Testament diesbezügliche Spielverbote überliefern. Negative Wertungen und Verbote kamen erst - offenbar im Zusammenghang mit den Exzessen der Massenbelustigungen - in der hellenistisch-römischen Zeit auf, blieben aber stets Minderheitenmeinungen. Der Großteil der Bevölkerung im antiken Palästina hielt nichts von derartigen Beschränkungen und sah keinen Grund, der eigenen Spiellust nicht zu frönen oder auf die Besuche im Theater oder ähnlichen Vergnügungsorten zu verzichten: Sie glaubten, ohne dabei einem Hedonismus zu verfallen, an einen Gott, der auch ein Gott der Liebe, der Freude, des Glücks und des Spiels war - und ist.

"Das Spiel ist aus" - "Rien ne va plus"

(Redensart)

57 Vgl. z.B. Nonnos, Dion. 33,65ff; Diog. Laert. 6,46; Anth. Graeca 5,296; Pollux 9,94; Suida 3,164 (ed. A. ADler); J. TAIllardat (ed.), Suétone. Peri paidiōn (1967), Nr. 4; L. BECQ DE FOUQUIERES, Les jeux des anciens (21873), 212-240; K. SCHNEIDER, Kottabos, RE 22 (1922), 1528-1541; W. DEONNA, Un divertissement de table "à clochepied" (1959), 18-23; K. SARTORI, Das Kottabos-Spiel der alten Griechen (Diss. phil.; München 1893), 9ff; P. MINGAZZIN, Sulla pretesa funzione oraculare del kottabos, AA 1950-1091, 35-47; B.A. SPARKES, Kottabos: An Athenian After-Dinner Game, Arch. 13 (1960), 202-207.

58 R. Wenning, Nachrichten über Griechen in Palästina in der Eisenzeit, in: Proceedings of the First International Congress on The Hellenic Diaspora from Antiquity to Modern Times, Vol. I, ed. J.M. FossEY (Amsterdam 1991), 207f. 


\section{LITERATURVERZEICHNIS}

ABRahams G., Cards and Cardplaying, EJ 5 (1971), 168

$A B \bar{u} L-F A R A \breve{g} A L-I S S_{F A H} \bar{a} N \bar{l}$, Und er Kalif beschenkte ihn reichlich, ed. G. RoTTER. Auszüge aus dem "Buch der Lieder" (Kitāb al-A $\dot{g} \bar{a} n \bar{l}$ ) (Bibliothek Arab. Erzähler), Stuttgart 1982

ADLER A., Erotische Kinderspiele, Anthropophyteia 8 (1911), 256-258

AdRION A., Die Kunst des Zauberns, Köln 1978

AELIAN, Works, ed. A.R. BRENNER - F.H. FoBEs (The Loeb Classical Library), London 1949

AGDE G. et al., Sicherheit auf Kinderspielplätzen, Wiesbaden 1981

AHARAONI Y. (ed.), Beer-Sheba I, Tel Aviv 1973

- (ed.), Lachish V, Tel Aviv 1975

- (ed.), Arad Inscriptions, Jerusalem 1981

AHIKAR. The Story from the Aramaic, Syriac, Arabic, Armenian, Ethiopic, Old Turkish, Greek and Slavonic Versions, ed. F.C. CONYBEARE - J.R. HARRIS - A. SMITH LEwIS, Cambridge 21913

AICK G., Die Befreiung des Kindes. Kleine Kulturgeschichte des Spiels und Kinderspielplatzes, Hamburg 1963

AIGNER H., Zur gesellschaftlichen Stellung von Henkern, Gladiatoren und Berufsathleten, in: I.

WEILER (ed.), Soziale Randgruppen und Außenseiter im Altertum, Graz 1988, 201-220

AITKEN B., The Game of Knucklebones - "Jugar a las tabas", Folkl. 62 (1951), 329

AKURGaL E., Die Kunst der Hethiter, München 21976

Albrighr W.F., The Excavations of Tell Beit Mirsim I-III (AASOR 12. 17. 21-22), New Haven 1932. 1938. 1943

- , A Set of Egyptian Playing Pieces and Dice from Palestine, Mizraim 1 (1933), 130-134

- / Kelso J.L., The Excavation of Bethel (1934-1960) (AASOR 39), Cambridge/MA 1968

ALFÖLDI A., Heiden und Christen am Spieltisch, JAC 18 (1975), 19-21

Alföldi-Rosenbaum E., The Finger Calculus in Antiquity and in Middle Ages. Studies on Roman Game Counters I, FMSt 5 (1971), 1-9

- , The Muses on Roman Game Counters. Studies on Roman Game Counters II, Muse 9 (1975), 13-20

-, Alexandriaca. Studies on Roman Game Counters III, Chiron 6 (1976), 205-239

-, Ruler Portraits on Roman Game Counters from Alexandria. Studies on Roman Game Counters IV, in: Eikones. Studien zum griechischen und römischen Bildnis. FS für H. JUCKER zum 60.Geb. (AK Bh. 12), Bern 1980, 29-39

Alleman C., Über das Spiel. Die Spieltheorien, Menschenspiel und Tierspiel, Diss. phil. Zürich 1951

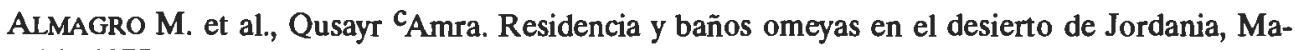
drid 1975

Alouf J., Physical Culture in the Period of the Talmud, in: Physical Education and Sports in the Jewish History and Culture. Proceedings of an International Seminar at Wingate Institute July 1973, ed. U. SIMRI, Netanya 1973, 5-11 (hebr.; English Summary 39*)

- / SimRI U. / Silver J.M. et al., Sports, EJ 15 (1971), 291-318

AlTHEIM F., Ludus talarius, RE 2,4 (1932), 2061-2063

ALTENMÜLLER H., Jagd; Jagddarstellungen, LÄ 3 (1980), 221-224. 224-230

AMANDRY P., Os et coquilles, in: L'Antre Corycien II (BCH.S 9), Athen - Paris 1984, 347-380

Ambrosius, Opera, Pars Altera, ed. K. SCHENKL (CCSL 22,2), Prag u.a. 1897

AMIET P., Les antiquités du Luristan, Paris 1976

AMIRAN R. et al., Early Arad, Jerusalem 1978

AMMIANUS MARCELLINUS, historiae,. Lateinisch und deutsch, ed. W. SEYFARTH (SQAW 21,1-4), Berlin Ost ${ }^{2} 1978-{ }^{5} 1986$ 
CAMr A.-J., A Study of the Clay Figurines and Zoomorphic Vessels of Trans-Jordan during the Iron Age, with Special Reference to their Symbolism and Function, Unpubl. Ph.D. Thesis, University of London 1980

ANAKREON, ed. B. GENTILI, Rom 1958

ANDERSEN F.G., Shiloh II. The Remains from the Hellenistic to the Mamlūk Periods (Publications of the National Museum. Archeological-Historical Series Vol. 23), Kopenhagen 1985

ANDRAE W., Der Anu-Adad-Tempel in Assur (WVDOG 10), Leipzig 1909

- , Die jüngeren Ischtar-Tempel in Assur (WVDOG 58), Leipzig 1935 = Osnabrück 1967

- / BOEHMER R.M., Bilder eines Ausgräbers, Berlin 1989

ANDREE R., Die Verbreitung des Morraspiels, Globus 28 (1875), 159

- , Das Kreiselspielen und seine Verbreitung, Globus 69 (1896), 371-373

ANDREws W.S., Magic Squares and Cubes, London 1917 = New York 1960

ANTHES R., Mit Rahineh 1956 (University Museum Monograph), Philadelphia/PN 1965

ANTHOLOGIA GRAECA. Griechisch und deutsch, Bd. I-IV, ed. H. BECKBY, München 1957-1958

ANTHOlogia Latina, Pars Prior 1-2, ed. A. Riese, Leipzig 1894-1906

Apokryphe Evangelien des Neuen Testaments, ed. H. DANIEL-RoPS - F. AMIOT, Zürich ${ }^{2} 1958$

Apollonios Rhodios, Argonautica, Tome I-III, ed. F. VlaN - É. DELAGE, Paris 1974-1981

Die APOSTOLISCHEN VĀTER, ed. J.A. FISCHER (SUC 1), Darmstadt ${ }^{8} 1981$

APUlEIUS, Metamorphosen (Der Goldene Esel). Lateinisch und deutsch, ed. E. BRANDT et al. (Tusculum), München - Zürich ${ }^{4} 1989$

- , Opuscules philosophiques (Du Dieu de Socrate; Platon et sa doctrine; Du Monde) et Fragments, ed. J. BEAUJEU, Paris 1973

ARABISCHE MÄRCHEN AUS DEM MORGENLAND, ed. U. AsSAF-NowaCK (Fischer-TB 680), Frankfurt a.M. 1987

ARCHĀOLOGIE ZUR BiBEL. Kunstschätze aus den biblischen Ländern (Liebighaus Frankfurt a.M.), Mainz 1981

ARCHIMEDES, Opera omnia I-IV, ed. I.L. HEIBERG et al., Leipzig - Stuttgart ${ }^{2} 1910-1975$

ARDLEY G., The Role of Play in the Philosophy of Plato, Ph. 42 (1967), 226-244

ARIEL D.T., Excavations at the City of David 1978-1985 (Qedem 30), Jerusalem 1990

ARIEl Sh. / SEver I., Play in the Desert and Play in the Town: On Play Activities of Bedouin Arab Children, in: H.B. SchWARTZMAN (ed.), Play and Culture. 1978 Proceedings of the Association for the Anthropological Study of Play, West Point/NY 1977, 164-175

ARIES PH., Geschichte der Kindheit (dtv wiss. 4320), München ${ }^{8} 1988$ (L'enfant et la vie familiale sous l'ancien régime, Paris 1960)

- / DuBY G. (ed.), Geschichte des privaten Lebens I, Frankfurt a.M. 1989

ARISTEAs-Brief (Lettre d'Aristée à Philocrate), ed. A. Pelletier (SC 89), Paris 1962

ARIsTOPHANES, Works, Vol. I-III, ed. B.B. Rogers (The Loeb Classical Library), London Cambridge/MA 1924

ARISTOTELES, The "Art" of Rhetorics, ed. J.H. FREESE (The Loeb Classical Library), London Cambridge/MA $1926=1967$

- , On Sophistical Refutations. On Coming-to-be and Passing-away. On the Cosmos, ed. E.S.

FORSTER - D.J. FURLEY, London - Cambridge/MA 1955 = 1965

ARMBRUSTER F., Lirum, larum, Löffelstiel. Gedanken übers Kinderspiel, in: G.-K. KaltENBRUNNER (ed.), Im Anfang war das Spiel. Schöpfertum und Glück zwischen Arbeit und Freizeit, München 1987, 32-50

ARNASZUS H., Spieltheorie und Nutzenbegriff aus marxistischer Sicht, Frankfurt a.M. 1974

ARNDT M. (ed.), Didaktische Spiele, Stuttgart ${ }^{9} 1980$

ARTEMIDOR, The Interpretation of Dreams. Oneirocritica, ed. R.J. WHTTE, Park Ridge/NJ 1975

AthenAios, The Deipnosophists, Vol. I-VI, ed. Ch.B. Gulick (The Loeb Classical Library),

London - Cambridge/MA 1927-1937

ATLAS S., Simon ben Lakisch, JL 4,2 (1930), 424f

AUdollent A. (ed.), Defixionum tabellae, Paris 1904 = Frankfurt a.M. 1967 
Augustinus, Confessiones, ed. L. VERHEIJEN (CCSL 27), Turnholt 1981

- , De trinitate libri XV, ed. W.J. MouNTAIN / F. GLORIE (CCSL 50-50a), Turnholt 1968

- , De civitate dei libri I-XXII (CCSL 47-48), Turnholt 1955

-, De baptismo libri VII, ed. M. Petschenig (CSEL 51), Wien - Leipzig 1908 = New York London 1963, 143-376

AusonIUS, Works, Vol. I-II, ed. H.G.E. WHTTE (The Loeb Classical Library), London - Cambridge/MA 1919-1921 = 1961

AustiN R.G., Zeno's game of tablēe (A.P. IX.482), JHS 54 (1934), 202-205

- , Roman Bord Games I-II, GaR 4 (1934-1935), 24-34. 76-82

- , Greek Board-Games, Antiquity 14 (1940), 257-271

A VEDON E.M. / SutTon-SMrTH B. (ed.), The Study of Games, New York u.a. 1971

Avigad N., Discovering Jerusalem, Nashville - Camden - New York 1983

Avi-YoNAH M., Nacaran, EAEHL 3 (1977), 891-894

- , Mosaic Pavements in Palestine, QDAP 2 (1933), 136-181; 3 (1934), 26-73

AXLıNE V.M., Kinder-Spieltherapie im nicht-direktiven Verfahren, München - Basel ${ }^{6} 1984$

AYAlon D., Notes on the Furüsiyya Exercises and Games in the Mamlūk Sultanate, (1961), in: ders., The Mamlūk Military Society. Collected Studies, London 1979, 31-62

AYMARD J., Quelques remarques sur les jeux avec les taureau à l'époque romaine, $\mathrm{EtCl} 23$ (1955), 259-266

BAADER U., Kinderspiele und Spiellieder I-II, Tübingen 1979

BABRIOS, Mythiamboi, in: Fabeln der Antike. Griechisch und deutsch, ed. H.C. SCHNUR - E. KELLER (Tusculum), München - Zürich 21985 , 244ff

BACHER M., Spiel mit Wind und Papier. Ein Hobbybuch vom Drachenbauen und Papierfalten, Würzburg 1978

BAER U., Wörterbuch der Spielpädagogik, Basel 1981

BagatTi B. / Milik J.T., Gli Scavi Del "Dominus Flevit" (Monte Oliveto - Gerusalemme), Parte I: La Necropoli del Periodo Romano (SBF.CMa 13), Jerusalem $1958=1981$

Baier R. / Erath Th. / Hofmann P. / S. PöllmanN, Jonglieren (homo ludens), München 1989

Baldacci T., Musik, Tanz und Spiel, in: A.M. Donadoni-Roveri (ed.), Das Alte Ägypten. Das Alltagsleben. Ägyptisches Museum Turin, Mailand 1987, 250-267

Baldus H.R., Eine antike Elefanten-Dressur. Zu einem Münzbild König Jubas II., Chiron 20 (1990), 217-220

BALlou R., The Role of the Jewish Priesthood in the Expansion of Greek Games in Jerusalem, CJHSPhE 1 (1970), 70-81

Bally G., Vom Spielraum der Freiheit. Die Bedeutung des Spiels bei Tier und Mensch, Basel Stuttgart 21966

BANKs E.J., Bismya or The Lost City of Adab. A Story of Adventure, of Exploration, and of Excavation among the Ruins of the Oldest of the Buried Cities of Babylonia, New York - London 1912

BARAMKI D.C., Two Roman Cisterns at Beit Nattif, QDAP 5 (1936), 3-10

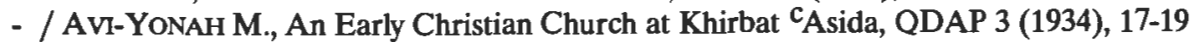

BARAN M., Kinderspiele, in: The Proceedings of the 10th International Congress of Classical Archaeology, Vol. I, Ankara - Izmir 1973, Ankara 1978, 433-435

BARDTKE H., Spiel, Spielen, Spielleute, Calwer Bibellex. ${ }^{5} 1985,1269$

BARNETT R.D., Ancient Ivories (Qedem 14), Jerusalem 1982

- , From Arad to Cathage: Harvest Rites and Corn-Dollies, ErIs 20 (1989), 1*-11*

BARRELET M.-TH., Les déesses armées et ailées, Syria 32 (1955), 222-260

BARTH CH., Die Errettung vom Tode in den individuellen Klage- und Dankliedern des Alten Testaments, ed. B. JANOwSKI, Zürich 21987

BARTHEL TH.S., Spiele der Osterinsulaner, in: Beitrăge zur Völkerforschung. FS für H. DAMM zum 65.Geb., Berlin Ost 1961, 27-42

BAR-YoseF O., Pre-Pottery Neolithic Sites in Southern Sinai, BA 45 (1982), 9-12 
BASILIOS Von SELEUKIA, de vita Theclae, PG 85 (1864), 477-618

BAsS G.F., Cape Gelidonya. A Bronze Age Shipwreck (TAPhS NS 57,8), Philadelphia/PA 1967

BATTEN L.W., Helkath Hazzurim, 2 Samuel 2,12-16, ZAW 26 (1906), 90-94

BAUER L., Volksleben im Lande der Bibel, Leipzig 21903

BAUER Th., Das Inschriftenwerk Assurbanipals II (AB NF 2), Leipzig 1933

BAumgarTEN H., Spiele, dtv-Lexikon der Antike. Kulturgeschichte 2, München 1971, 131-133

- , Spiele, Lexikon der Alten Welt $3(1965=1990)$, $2860 \mathrm{f}$

BAUMgarTnER W. / STAMM J.J. (ed.), Hebräisches und Aramäisches Lexikon zum Alten Testament I-IV, Leiden 1967-1990

BAYER L., Das Spielzeugmuseum der Stadt Nürnberg, Nürnberg ${ }^{2} 1979$

BEAUduIN G., Jeux d'enfants grecs, Diss. phil, Louvain 1934- 1935 (mir nicht zugänglich)

BEAZLEY J.D., Aryballos, ABSA 29 (1927-1928), 187-215

BECHER W., Oxybaphon, RE 36 (1942), 2021f

BECK F.A.G., Album of Greek Education. The Greeks at School and at Play, Sydney 1975

BecK H. et al., Polyklet. Der Bildhauer der griechischen Kunst (Liebieghaus Frankfurt a.M.), Mainz 1990

BECKER-DONNER E. et al. (ed.), Spiel und Spielzeug aus aller Welt. Sonderausstellung 1971/72, Museum für Völkerkunde Wien, Wien 1971

BECQ DE FOUQUIERES L., Les jeux des anciens. Leur description, leur origine, leurs rapports avec la religion, l'histoire, les arts et les moeurs, Paris ${ }^{2} 1873$

BEEK G.N. vaN, The Buzz: A Simple Toy from Antiquity, BASOR 275 (1989), 53-58

BeHRENS P., Sinuhe B 134ff oder die Psychologie des Zweikampfes, GM 44 (1981), 7-11

- , Stierkampf, LÄ 6 (1986), $16 f$

BELL R.C., Board and Table Games from many Civilizations, Vol. I-II, New York ${ }^{2} 1979$

BELLIN P., L'enfant saharien à travers ses jeux, JSAf 33 (1963), 47-104

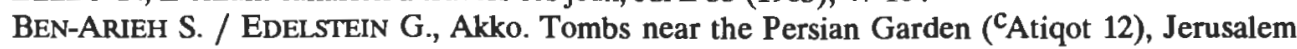
1977

BEN-Dov M., In the Shadow of the Temple. The Discovery of Ancient Jerusalem, Cambridge u.a. 1985

BENESCH H., Spiel als therapeutische Alternative. Neue Trends zum Spielverhalten der Erwachsenen, Tübingen 21980

Bengtsson A., Ein Platz für Kinder. Plädoyer für eine kindgemäße Umwelt, Wiesbaden - Berlin 1971

BENKENDORF K.-A., Untersuchungen zu den platonischen Gleichnissen, Vergleichen und Metaphern aus dem Bereich der Gymnastik und Agonistik, Diss. phil. masch. Tübingen 1966

Bennett W.J. / Blakeley J.A., Tell el-Hesi. The Persian Period (Stratum V). The Joint Archaeological Expedition to Tell el-Hesi Vol. 3 (ASOR Excavation Reports), Winona Lake/IN 1989

Ben-Tor A. / Portugali Y. (ed.), Tell Qiri. A Village in the Jezreel Valley (Qedem 24), Jerusalem 1987

BERLINER A., Tumerisches in der heiligen Schrift, Jüdische Turnzeitung 3,4 (1902), 57-63

Bernard P. et al., Fouilles d'Aï Khanoum I (Campagnes 1965, 1966, 1967, 1968) (Mémoires de la Délegation Archéologique française en Afghanistan 21), Paris 1973

BERnE E., Spiele der Erwachsenen. Psychologie der menschlichen Beziehungen, Reinbek bei Hamburg 1970

BERNERT E. / KROLl W., Omilla, RE 35,1 (1939), 379

BERTRAM G., paizō; empaizo, ThWNT 5 (1954), 625-629. 629-635

BETT H., The Games of Children, their Origin and History, London 1929

BEYER R., Die Königin von Saba, Bergisch Gladbach 1991

Biblia Hebraica Stuttgartensia, ed. K. Elliger - W. Rudolph, Stuttgart ${ }^{3} 1987$

BIERS W.R., Gaming Heroes: Ajax and Achilles on a Lekythos in Missouri, Muse 23 (1989-1990), 48-57 
BIESANTZ H., Die thessalischen Grabreliefs. Studien zur nordgriechischen Kunst (DAI Athen), Mainz 1965

BIGGS R.D. / MEYER J.-W., Lebermodelle, R1A 6 (1980-1983), 528-527

BikAI P.M., The Pottery of Tyre, Warminster 1978

BINDER G., Die Aussetzung des Königskindes Kyros und Romulus (BKP 10), Meisenheim a.G. 1964

BIRAN A., "And David sent Spoils ... to the Elders in Aroer" (1 Samuel 30:26-28), BAR 9,2 (1983), 28-37

- , The Dancer from Dan, the Empty Tomb and the Altar Room, IEJ 36 (1986), 168-187

- / COHEN R., Aroer, 1980, IEJ 31 (1981), 131f

BIRCH S., Le roi Rhampsinite et le jeu de dames, RAr NS 12 (1865), 56-65

-, Rhampsinitus and the Game of Draughts, Transactions of the Royal Society of Literature of the United Kingdom 9 (1870), 256-270

BIRT Th., Zum Königsmimus, Ph. 77 (1921), $427 f$

BrtTel K., Boğazköy. Die Kleinfunde der Grabungen 1906-1912. I. Funde hethitischer Zeit (WVDOG 60), Leipzig 1937 = Osnabrück 1967

-, Die Hethiter. Die Kunst Anatoliens vom Ende des 3. bis zum Anfang des 1.Jahrtausends vor Christus (Universum der Kunst), München 1976

- / GÜTERBOCK H.-G., Vorläufiger Bericht über die dritte Grabung in Boğazköy, MDOG 72 (1933), 1-53

BITTNER G., Zur pädagogischen Theorie des Spielzeugs, (1968), in: H. RöHRs (ed.), Das Spiel ein Urphänomen des Lebens (Erziehungswiss. Reihe 23), Wiesbaden 1981, 51-61

- , Psychoanalytische Aspekte des Spiels, in: O. GRUPE - H. Gobler - U. GôHNER (ed.), Spiel Spiele - Spielen (Schriftenreihe des Bundesinstituts für Sportwissenschaft 49), Schorndorf 1983, 122-130

BlanCHET A., Enfant joueur de "Sabot", RAr VI.Sér. 4 (1934), $195 f$

BLAU L., Das altjüdische Zauberwesen, Budapest 1898 = Graz 1974

BLISS F.J., Excavations at Jerusalem 1894-1897, London 1898

- / MACALISTER R.A.S., Excavations in Palestine during the Years 1898-1900, London 1902

BLOCHER F., Untersuchungen zum Motiv der nackten Frau in der altbabylonischen Zeit (MVS 4), München 1987

BLÜMNER H., Fahrendes Volk im Altertum (SBAW.PPH 1918, 6), München 1918

BLUM W., Kleists Marionettentheater und das Drahtpuppengleichnis bei Platon, ZRGG 23 (1971), 40-49

BLUME H.-D., Einführung in das antike Theaterwesen, Darmstadt ${ }^{3} 1991$

Blumenthal E., Zu Sinuhes Zweikampf mit dem Starken von Retjenu, in: Fontes atque Pontes.

FS für H. BRUNNER, ed. M. Görg (ÄAT 5), Wiesbaden 1983, 42-46

BOARDMAN J., Exekias, AJA 82 (1978), 11-25

BOATWRIGHT M.T., Theaters in the Roman Empire, BA 53 (1990), 184-192

BOBBER H.-L. et al., Türkisches Schattentheater Karagöz. Eine Handreichung zum lustvollen Leben, Frankfurt a.M. 1983

BöHM F., Antike Kinderspiele, ZVVK 26 (1916), $423 \mathrm{f}$

BöHME F.M., Deutsches Kinderlied und Kinderspiel. Volksüberlieferungen aus allen Landen deutscher Zunge, Leipzig 1897 = Nendeln 1967

BOEHMER R.M., Die Kleinfunde aus Boğazköy aus den Grabungskampagnen 1931-1939 und 1952-1969 (Boğazköy-트attuša 7; WVDOG 87), Berlin 1972

- , Die Kleinfunde aus der Unterstadt von Boğazköy. Grabungskampagnen 1970-1978

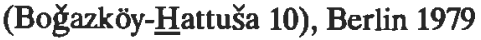

- / WREDE N., Astragalspiele in und um Warka, BaghM 16 (1985), 399-404

BöHR E., Der Schaukelmaler (Forschungen zur antiken Keramik II. Reihe, Kerameus 4), Mainz 1982 
BÖKÖNYI S., Tierknochenfunde aus dem Bereich der Werkstatt von Kāmid el-Lōz, in: B. FRIsCH et al. (ed.), Kāmid el-Lōz 6. Die Werkstätten der spätbronzezeitlichen Paläste (SBA 33), Bonn $1985,199-205$

Bös M., Spielsteine als Rennpferde, BJB 155-156 (1955-1956), 178-183

- , Nochmals 'Spielsteine als Rennpferde', BJB 155-156 (1955-1956), 317

BOESE J., Altmesopotamische Weihplatten. Eine sumerische Denkmalsgattung des 3.Jahrtausends v.Chr. (UAVA 6), Berlin - New York 1971

- , Ringkampfdarstellungen in Frühdynastischer Zeit, AfO 22 (1968-1969), 30-38

BoEsSNECK J., Die Tierknochenfunde aus dem Kabirenheiligtum bei Theben (Böotien), München 1973

Boling R.G., Excavations at Tananir, 1968, in: G.M. LANDES (ed.), Report on Archaeological Work at Șuwwănet eth-Thanìya, Tananir, and Khirbet Minḥa (Munḥata) (BASOR.S 21), Missoula/MT 1975, 25-85

Bolte J., Zur Geschichte der Losbücher, in: G. WICKRAM, Werke IV, ed. J. Bolte, Tübingen 1903 = Hildesheim - New York 1974, 276-348

- , Die Legende von Augustin und den Knäblein am Meere, ZVVK 16 (1906), $90-95$

LE BoNNIEC H., Ludi; Trojaspiel, dtv-Lexikon der Antike. Kulturgeschichte 2, München 1971, 22 25. 168

Boratav P.N., Classification générale des jeux, in: VI Congrès Internationale des Sciences Anthropologiques et Ethnologiques II,2, Paris 1964, 141-148

- , Karagöz, EI 4 (21978) 601-603

BORCHARDT H., Frühe griechische Schildformen, in: H.-G. BuchHOLZ - J. WIESNER (ed.), Kriegswesen 1: Schutzwaffen und Wehrbauten (ArchHom I E 1), Göttingen 1977, 1-56

BORCHARDT L. / RICKE H., Die Wohnhäuser in Tell el-Amarna, ed. V. FRITZ - R. STADELMANN (WVDOG 91), Berlin 1980

BORDREUIL P. / GUBEL E., Bulletin d'antiquités archéologiques du Levant inédites ou méconnues VI (BAALIM), Syria 67 (1990), 483-520

BORGER R., Handbuch der Keilschriftliteratur I-III, Berlin - New York 1967-1975

- , Die Inschriften Asarhaddons, Königs von Assyrien (AfO.B 9), Graz 1956 = Osnabrück 1967

BORGHOUTS J.F., The Evil of Apopis, JEA 59 (1973), 114-150

BORNEMANN E., Studien zur Befreiung des Kindes I-III: I. Unsere Kinder im Spiegel ihrer Lieder, Reime, Verse und Rätsel; II: Die Umwelt des Kindes im Spiegel seiner "verbotenen" Lieder, Reime, Verse und Rätsel; III: Die Welt der Erwachsenen in den "verbotenen" Reimen deutschsprachiger Stadtkinder, Olten - Freiburg i.Br. 1973. 1974. 1976

BORST A., Das mittelalterliche Zahlenkampfspiel (SHAW.PH 5, Suppl.), Heidelberg 1986

BosSERT H. TH., Ein hethitisches Königssiegel. Neue Beiträge zur Geschichte und Entzifferung der hethitischen Hierglyphenschrift (IF 17), Berlin 1944

- , Altsyrien, Tübingen 1951

BOTTERo J., Jeu graphique ou talisman? Note additionelle, Syria 33 (1956), 17-35

BOTTER WECK G.J. / HOFFNER H.A., hes, ThWAT 3 (1977-1982), 128-134

Boutros L., The Phoenician Stadium of Amrit, Olympic Review 112 (1977), 114-120

-, Phoenician Sport. Its Influence on the Origin of the Olympic Games, Amsterdam 1981

Bovon F., Das Evangelium nach Lukas, 1.Teilband (EKK 3,1), Neukirchen-Vluyn 1989

BRAKHOFF J. (ed.), Glück - Spiel - Sucht. Beratung und Behandlung von Glückspielern, Freiburg i.Br. 1989

BRANDT E., Ein spätklassischer Silberring in München, AK 12 (1969), 61-67

Braude W.G., The Midrash on Psalms (Midrash Tehillim) I-II (YIS 13), New Haven/CT 1959

Braudel F. / Duby G. / AYMard M., Die Welt des Mittelmeeres. Zur Geschichte und Geographie kultureller Lebensformen, Frankfurt a.M. 1990

Braun K. / Haevernick Th.E., Bemalte Keramik und Glas aus dem Kabirenheiligtum bei Theben (Das Kabirenheiligtum bei Theben IV), Berlin 1981 
BrEDNICH R.W., Vogel am Faden. Geschichte und Ikonographie eines vergessenen Kinderspiels, in: Studien zu Kultur, Sprache und Landesgeschichte. FS für M. ZENDER zum 65.Geb., ed. E. ENNEN - G. WIEGELMANN, Bd. I, Bonn 1972, 573-597

BREWSTER P.G., A Collection of Games from India, with some Notes on Similar Games in other Parts of the World, ZE 80 (1955), 88-102

- , The Earliest Known List of Games: Some Comments, AcOr 23 (1959), 33-42

- , The Egyptian Game Khazza Lawizza and its Burmese Counterparts, ZE 85 (1960), 211-213

-, A Sampling of Games from Turkey, EW 11 (1960), 15-20

BROMMER F., Antike Stelzentänze: Gypones und Hypogones, AK 11 (1968), 50-52

- , Huckepack, GettyMusJ 6-7 (1978-1979), 139-146

BroneER O., The South Stoa and its Roman Successors. Corinth 1,4, Princeton/NJ 1954

-, The Apostle Paul and the Isthmian Games, BA 25 (1962), 2-31 = BA-Reader 2 (1975), 393420

BROPHY R., Deaths in the Pan-Hellenic Games: Arrachion and Creugas, AJP 99 (1978), 363-390

- and M., Deaths in the Pan-Hellenic Games II: All Combative Sports, AJA 106 (1985), 171-198

BRown W.N., The Indian Games of Pachisi, Caupar, and Chausar, Exped. 6 (1964), 32-35

BROWNING I., Jerash and the Decapolis, London 1982

BRUECKNER A., Polyklets Knöchelwerfer (BWPr 77), Berlin 1920

BRÜCKNER W., Spiel, LCI $4(1972=1990)$, $190 \mathrm{f}$

BRUMBACH R.S., The Knossos Game Board, AJA 79 (1975), 135-137

BRUNEAU PH., Le Motif des coqs affrontés dans l'imagerie antique, BCH 89 (1965), 90-121

Bruner J.S. / Jolly A. / Sylva K. (ed.), Play: Its Role in Development and Evolution, Harmondsworth 1976

BRUNNER H., Altägyptische Erziehung, Wiesbaden 1957

BRUNNER-TRAUT E., Die altägyptischen Scherbenbilder (Bildostraka) der deutschen Museen und Sammlungen, Wiesbaden 1956

- , Akrobaten, LÄ 1 (1975), 117

- , Lieblingstier, LÄ 3 (1980), 1054-1056

- , Spielzeug, LÄ 5 (1984), 1152-1156

-, Die Alten Ägypter. Verborgenes Leben unter Pharaonen, Stuttgart u.a. ${ }^{3} 1981$

BUBER M., Die Erzählungen der Chassidim, Zürich 1949

BuCHENMATT J.D., Die 7.Seite des Würfels (homo ludens), München 1990

BuchHolz H.-G., Bronzezeitliche Brettspiele aus Zypern, ActaPrHistA 13-14 (1982), 67-74

- , Rasseln und Schellen, Reifen, Wippen und Schaukeln; Brettspielende Helden, in: S. LASER, Sport und Spiel (ArchHom T), Göttingen 1987, 100-116. 126-184

BUDDE K., Die Bücher Samuel (KHC 8), Tübingen - Leipzig 1902

BÜTTNER CH., Kriegsspielzeug oder die Organisierung der Feindseligkeit, Kindheit 1 (1979), 153168

- , Kriegsspiele - Anlaß, Dynamik und Interventionsmöglichkeiten, Kindheit 4 (1982), 163-181

BuNge J.G., Münzen als Mittel politischer Propaganda: Antiochos IV. von Syrien, SCO 16 (1974), 43-52

- , Die Feiern Antiochos' IV. in Daphne im Herbst 166 v.Chr. Zu einem umstrittenen Kapitel syrischer und ju däischer Geschichte, Chiron 6 (1976), 53-71

BURCKHARDT J.L., Reisen in Arabien, Weimar 1830 = Stuttgart 1963

BUREN E.D. VAN, A Gaming-Board from Tall $\underline{\text { Halaf, Iraq }} 4$ (1937), 11-15

BURESCH K., Schumacher's Inschriften aus Dscherasch, ZDPV 18 (1895), 141-148

BURGANSKY I., Simeon ben Gamliel, EJ 14 (1971), 1555

BURKERT W., Homo Necans. Interpretationen altgriechischer Opferriten und Mythen (RVV 32), Berlin - New York 1972

- , Von Amenophis II. zur Bogenprobe des Odysseus, Grazer Beiträge 1 (1973), 69-78

- , Götterspiele und Götterburleske im altorientalischen und griechischen Mythen, ErJb 51 (1982), 335-367

BURY J.B., Lynx in Greek Magic, JHS 7 (1886), 157-169 
Buschrhausen H. (ed.), Byzantinische Mosaiken aus Jordanien, Wien 1986

BUSCHOR E., Grab eines attischen Mädchens, München ${ }^{2} 1962$

BUTTERWECK A., Jakobs Ringkampf am Jabbok. Gen. 32,4ff in der jüdischen Tradition bis zum

Frühmittelalter (Judentum und Umwelt 3), Frankfurt a.M. - Bern 1981

BuTTREY T.V., The Spintriae as a Historical Source, NumC 13 (1973), 52-63

BuYTENDiJK F.J.W., Wesen und Sinn des Spiels. Das Spiel des Menschen und der Tiere als Erscheinungsformen der Lebenstriebe, Berlin 1933

CAGNAT R., Inscriptiones graecae ad res romanas pertinentes I-IV, Paris 1911-1927

Calllois R., Die Spiele und die Menschen. Maske und Rausch, Stuttgart 1960

CALmettes P., Les joujoux, Paris 1924

CALPURNIUS, Bucolica vel Eclogae. Lateinisch und deutsch, ed. D. KorzEnIEwsKI, Hirtengedichte aus neronischer Zeit (Texte zur Forschung 1), Darmstadt ${ }^{2} 1987$, 1-73

Cameron A., Porphyrius. The Charioteer, Oxford 1973

- , Circus Factions. Blues and Greens at Rome and Byzantium, Oxford 1976

CANGE DU CH., Glossarium mediae et infimae Latinitatis, Vol. I-IX, 1883-1887 = Graz 1954

Canones Apostolorum --> LAUCHERT

CAPLAN F. and TH., The Power of Play, Garden City/NY 1973

CAPUTO G., Dell'antico giuoco de paleo, Hist(M) 7 (1933), 184-198

CaRmina Einsidlensia. Lateinisch und deutsch, ed. D. KoRZENIEwSKI, Hirtengedichte aus neronischer Zeit (Texte zur Forschung 1), Darmstadt 2 1987, 75-85

Carnarvon H. / Carter H., Five Years' Explorations at Thebes. A Record of Work 1907-1911, London u.a. 1912

CARPENTIER D. / BACHELET J., Alles über Drachenbau, Freiburg i.Br. 1980

CARR H.A., The Survival Values of Play, London 1902

CARRA DE VAUX B., Shatrandj, EI(D) 4 (1934), $363 \mathrm{f}$

- , Maisir, EI(D) 3 (1936), 168

CARTER CH., Athletic Contests in Hittite Religion Festivals, JNES 47 (1988), 185-187

CARTER H., Tut-ench-Amun. Ein ägyptisches Königsgrab Bd. I-III, Leipzig 1924-1934

CARTIEDGE S.A., Games, NT, IDB 2 (1962), 353f

CAsson L. / Hetrich E.L. (ed.), Excavations at Nessana Vol. 2: Literary Papyri, Princeton/NJ 1950

CATULL, Gedichte. Lateinisch und deutsch, ed. W. EISENHUT, Darmstadt ${ }^{9} 1986$

CELsus, de medicina, Vol. I-III, ed. W.G. SPENCER (The Loeb Classical Library), London Cambridge/MA 1935-1938

Chambers R.R., Greek Athletics and the Jews 165 A.C. - A.D. 70, Ph.D.Diss. (unpubl.) Miami University 1980

Chambon A., Tell el-Far'ah 1. L'âge du fer, Paris 1984

Chamisso A. von, Werke I-IV, Berlin ${ }^{6} 1874$

Chanan G. / Francis H., Toys and Games of Children of the World, Paris - Barcelona 1984

ChanTraine H., Tessera, KP 5 (1975), $615 f$

Chateau J., Das Spiel des Kindes. Natur und Disziplin des Spielens nach dem dritten Lebensjahr, Paderborn ${ }^{2} 1976$

Chavane M.-J., Salamine de Chypre VI: Les petits objects, Paris 1975

CHEHAB M.H., Les terres cuites de Kharayeb [BMB 10 (1951-1952); 11 (1953-1954)], Paris 1952. 1954

ChiYonobu Y., Disc-Wheels of Ancient Mesopotamia, BAOM 10 (1988-1989), 153-183 (japan.; English Summary)

CHOLIDIS N., Tiere und tierförmige Gefäße auf Rädern. Gedanken zum Spielzeug im Alten Orient, MDOG 121 (1989), 197-220

Chorikios von GAZA, Opera, ed. R. FoERSTER - E. RICHTSTEIG, Leipzig - Berlin 1929 = Stuttgart 1972

CHRISTIAN A., Volkskundliche Aufzeichnungen aus Haleb / Syrien, Anthr. 12-13 (1917-1918), 1014-1025 
Chronicon Paschale, PG 92, 69-1146

CICERO, Über das Fatum. Lateinisch und deutsch, ed. K. BAYER (Tusculum), Zürich - München $3_{1980}$

-, De officiis. Lateinisch und deutsch, ed. H. GUNERMAnN (Reclam 1889), Stuttgart ${ }^{2} 1984$

- , Gespräche in Tusculum. Lateinisch und deutsch, ed. O. GIGON (Tusculum), Zürich - München ${ }^{5} 1984$

5, Staatsreden, Teil 3: Die Philippischen Reden. Lateinisch und deutsch, ed. H. KaSTEN, Berlin 5,1988

- , De divinatione. Lateinisch und deutsch, ed. Chr. SCHÄUBLIN (Tusculum), Darmstadt 1991

-, De finibus bonorum et malorum. Lateinisch und deutsch, ed. O. Gigon - L. STRAMME (Tusculum), Zürich - München 1988

Clamer CH., A Late Bronze Age Burial Cave near Shechem, Qad. 14 (1981), 30-34 (hebr.)

Clason A.T., Animals, in: Picking up the Threads... A Continuing Review of Excavations at Deir

Alla, Jordan, ed. G. VAN DER KOOJ - M.M. IBRAHIM, Leiden 1989, 39-42

Codex Iustinianus > Corpus Iuris Civilis Bd. II, ed. P. KrÜGER, Berlin ${ }^{14} 1967$

CodeX Theodosianus I-II, ed. Th. MommSEN, Berlin ${ }^{3} 1962$

COHEN M., Jeux Abyssins, JA 18 (1911), 463-497

COHEN S.J.D., Masada: Literay Tradition, Archaeological Remains and the Credibility of Josephus, JSS 33 (1982), 385-405

CoHN C.C., Gambling, EJ 7 (1971), 299-303

CoHN M., Spiel und Wette, JL 4,2 (1930), $548 \mathrm{f}$

Collodi C. (LoRenZini C.), Le avventure di Pinocchio, Florenz 1880 = Turin 1968

Collon D., First Impressions. Cylinder Seals in the Ancient Near East, London 1987

ColT H.D., Excavation at Nessana (Auja Hafir, Palestine), London 1962

Columella, De re rustica, Bd. I-III. Lateinisch und deutsch, ed. W. RichTER, München 19811983

COMSTOCK M. / Vermeule C., Greek and Roman Bronzes in the Museum of Fine Arts, Boston, Boston/MA 1971

CONNELly J.B., Votive Sculpture of Hellenistic Cyprus, Nikosia 1988

Constitutiones Apostolorum, ed. M. METZger (SC 320. 329. 336), Paris 1985-1987

CooK S.A., The Religion of Ancient Palestine in the Light of Archaeology (SchL), London 1925

CORBo V., La sinagoga di Cafarnao dopo gli scavi del 1969 (SBF.CMi 9), Jerusalem 1970

Cornwall I.W., Appendix K, in: K.M. KENYON (ed.), Excavations at Jericho II, London 1965, 697-703

CORPus IURIS Civilis Tom. I-III, ed. P. KRÜGER - TH. MOMMSEN - R. SCHOLL, Berlin ${ }^{16} 1954$. ${ }^{14} 1967.10_{1972}$

CotTon H.M. / Geiger J. (ed.), Masada II: The Latin and Greek Documents, Jerusalem 1989

CotTas V., Le théâtre à Byzance, Paris 1931

COULOMB J., Les boxeurs minoens, BCH 105 (1984), 27-40

COUPRY J., Un joueur de marelle au marché de Philippes, BCH 70 (1946), 102-105

CRATTY B.C., Aktive Spiele und soziales Lernen, Ravensburg 1977

CROFT D.J. / HEss R.D., Kleine Kinder lernen spielend, München 1974

Crouwel J.H., Chariots and Other Means of Land Transport in Bronze Age Greece (Allard Pierson Series 3), Amsterdam 1981

CROWFOOT J.W. / KenYon K.M. / SuKenIK E.L., The Buildings at Samaria (Samaria-Sebaste 1), London $1942=1966$

- / - / CRowfoot G.M., The Objects from Samaria (Samaria-Sebaste 3), London 1957

- / FitzGerald G.M., Excavations in the Tyropoeon Valley, Jerusalem 1927 (PEFA 5), London 1927

CRUSEMANN F., Zwei alttestamentliche Witze. I Sam 21,11-15 und II Sam 6,16.20-23 als Beispiele einer biblischen Gattung, ZAW 92 (1980), 215-227

CurfF R., The World of Toys, Feltham 1969 
Culin S., Mancala, the National Game of Africa, in: E.A. AvEdon - B. SuTton-SMTTH (ed.), The Study of Games, New York u.a. 1971, 94-102

Cumont F., Les Actes de S.Dasius, AnBoll 16 (1897), 5-16

Cyprianus, Opera omnia III. Appendix scriptorum quae Caecili Cypriani nomen ferunt, ed. W. HARTEL (CSEL 54,3), Bonn 1871

DAIKEN L., Children's Games: A Bibliography, Folkl. 61 (1950), 218-22

-, Children's Toys throughout the Ages, London 1953

DALES G.F., Of Dice and Men, JAOS 88 (1968), 14-23

Dalman G., Palästinischer Diwan, Leipzig 1901

- , Petra und seine Felsheiligtümer, Leipzig 1908

- , Arbeit und Sitte in Palästina I-VII, Gütersloh 1928-1942

- , Aramäisch-Neuhebräisches Handwörterbuch zu Targum, Talmud und Midrasch, Göttingen 1938 = Hildesheim - Zürich - New York 1987

DAмм H., Die gymnastischen Spiele der Indonesier und Südseevölker, 1.Teil: Die Zweikampfspiele, Leipzig 1922

- , Kreiselspiele bei den Indonesiern und Südseevölkern, in: In memoriam K. WEULE, Leipzig 1929, 299-334

DAN Y., Circus Factions (Blues and Greens) in Byzantine Palestine, Jerusalem Cathedra 1 (1981), 105-119

DANTE ALIGHIERI, La Divina Commedia. Italienisch und deutsch, ed. H. GMELIN, München 1991

Daremberg Ch. / SAGlio E. (ed.), Dictionnaire des Antiquités Grecques et Romains I-V, Paris 1877-1919

DATTENBERG H., Stierspringer am Nil, Bild der Wissenschaft 12 (1991), 139

DAuPhIn C. / Edelstein G., L'église byzantine de Nahariya (Israël). Étude Archéologique (Byz. Mnēmeia 5), Thessaloniki 1984

Davaros C., Das Grab eines kretischen Wettkampfsiegers? Vorläufiger Grabungsbericht, Stadion 5 (1979), 193-219

DAvid A.R., Toys and Games from Kahun in the Manchester Museum Collection, in: Glimpses of Ancient Egypt. Studies in Honour of H.W. FaIRMAN, ed. J. RufFLE - G.A. Gaballa - K.A. KrTCHEN (Orbis Aegyptiorum Speculum), Warminster 1979, 12-15

Davidson G.R., The Minor Objects. Corinth 12, Princeton/NJ 1952

- / Thompson D.B., Small Objects from the Pnyx I (Hesperia Suppl. 7), Baltimore/MD 1943

Davies R., Some Arab Games and Puzzles, Sudan Notes and Records 8 (1925), 137-152

DAvies R.W., The Daily Life of the Roman Soldier under the Principate, ANRW II 1 (1974), 299-338

Dayagi-Mendels M., Perfumes and Cosmetics in the Ancient World (Israel Museum Catalogue No. 305), Jerusalem 1989

DECKER W., Ball; Ballspiel; Boxen; Dressur, LÄ 1 (1975), 608. 609f. 847f. 1145

- , Ein ägyptisches Wort für "Hippodrom"?, SAK 2 (1975), 49-54

- , Neue Dokumente zum Ringkampf im alten Ägypten, KBSW 5 (1976), 7-24

- , Zum Ursprung des Diskuswerfens, Stadion 2 (1976), 196-212

- , Zur Bogenprobe des Odysseus, KBSW 6 (1977), 149-153

- , Sport und Königtum im alten Ägypten, in: F.K. MATHYS - M. TRIET (ed.), Spiel und Sport im alten Ägypten, Basel 1978, 11-21

- (ed.), Quellentexte zu Sport und Körperkultur, St.Augustin 1975

- , Annotierte Bibliographie zum Sport im alten Ägypten, St.Augustin 1978

-, Bibliographie zum Sport im alten Ägypten, Stadion 5 (1979), 161-192; 7 (1981), 153-172; 8-9 (1982-1983), 183-214; Nikephoros 1 (1988), 245-268; 2 (1989), 185-216

- , Das sog. Agonale und der altägyptische Sport, in: FS für E. EDEL (ÄAT 1), Bamberg 1979, 90-104

- , Ringen; Schießscheiben; Schleuder; Schwimmen; Spiel, LÄ 5 (1984), 265f. 601. 656. 765f. $1150-1152$

- , Wettkampf, LÄ 6 (1986), 1238-1240 
- , Sport und Spiel im Alten Ägypten (Beck's Archäologische Bibliothek), München 1987

- , Sport im Alten Ägypten, SAK.B 4 (1991), 35-45

- / HERMANN W. / ReIS M., Jahresbibliographie zum Sport im Altertum 1989, Nikephoros 2 (1989), 217-240

- / KLAUCK J., Königliche BogenschieBleistungen der 18. ägyptischen Dynastie. Historische Dokumente und Aspekte für eine experimentelle Überprüfung, KBSW 3 (1974), 23-55

- / LÄMMER M., Kritische Bemerkungen zu einer Geschichte der Leibesübungen, Sportwissenschaft 2 (1972), 312-322

DEGEN R., New Inscriptions from Hatra (Nos. 231-80), JEOL 20-23 (1968-1974), 402-422

DeISSMANN A., Licht vom Osten. Das Neue Testament und die neuentdeckten Texte der hellenistisch-römischen Welt, Tübingen ${ }^{4} 1923$

Delaporte L., Catalogue des Cylindres Orientaux et des Cachets de la Bibliothèque Nationale. Album des Planches, Paris 1920

DELORME J., Gymnasion. Étude sur les monuments consactés à l'éducation en Grèce (BEFAR 296), Paris 1960

Deonna W., Le symbolisme de l'acrobatie antique (Collection Latomus 9), Brüssel 1953

- , Les dodécaèdres Gallo-Romaines ajourés et bouletés. A propos du dodécaèdre d'Avenches, Bulletin d'Association pro Aventico 16 (1954), 19-89

- , Un divertissement de table "à cloche-pied" (Collection Latomus 49), Bruxelles 1959

DERBolav W., Der Kopf- und Handstand als Gauklerkunststück und Kinderspiel, Leibesübungen und körperliche Erziehung 56 (1937), 534-538

DERCHAIN PH., Kultspiele, LÄ 3 (1980), 856-859

DESSAU H. (ed.), Inscriptiones Latinae selectae I-II, Berlin 1892-1916 = 1962

DEUBNER L., Zum Astragalspiel, AA 44 (1929), 272-281 = in: ders., Kleine Schriften zur klassischen Altertumskunde (BKP 140), Königstein/Ts. 1982, 342-347

- , Spiele und Spielzeug der Griechen, (1930), in: ders., Kleine Schriften zur klassischen Altertumskunde (BKP 140), Königstein/Ts. 1982, 360-375

DEVER W.G. et al., Gezer I-II. IV, Jerusalem 1970. 1974. 1986

Deveria Th., Les jeux de dames en Égypte, in: ders., Memoirs et fragments II (Bibliothèque Égyptologique 5), Paris 1897, 83-96

DEvrIEs C.E., A Ritual Ball Game?, in: Studies in Honor of J.A. WILson (SAOC 35), Chicago/IL 1969, 25-35

DIDYMOS DER Blinde, Kommentar zu Hiob (Tura-Papyrus) I-IV,1 (PTA 1-3. 33,1), A. HENRICHS - U. HAGEDORN et al., Bonn 1968-1985

DiEBnER B.J., "Glatzkopf, komm herauf...! (2Kön. 2,23f), DBAT 20 (1984), 169-179

DIEM C., Nabbût (Stockfechten), Olympische Rundschau 3,3 (1938), 12-17

- , Das Trojanische Reiterspiel, Berlin 1942

-, Asiatische Reiterspiele. Ein Beitrag zur Kulturgeschichte der Völker (Documenta Hippologica), Berlin ${ }^{2} 1942$ = Hildesheim - Zürich - New York 1982

-, Alexander der Große als Sportsmann, Frankfurt a.M. 1957

- , Weltgeschichte des Sports und der Leibeserziehung, Stuttgart 1960

DIEM W., Falknerei, Lex. der Islam. Welt 1 (1974), 170

DIERICHS A., Erotik in der Kunst Griechenlands (AW Sondernr.), Mainz 1988

DiETRICH B.C., A Rite of Swinging during the Anthesteria, Hermes 89 (1961), 36-50

DiETRICH M. / LORETZ O., Ringen und Laufen als Sport in Ugarit (KTU 1.6 VI 16b-22a), UF 19 (1987), 19-22

- / - / MEYER J.-W. et al., Mantik in Ugarit. Keilalphabetische Texte der Opferschau - Omensammlungen - Nekromatie (ALASP 3), Münster 1990

DikAIOS P., Enkomi. Excavations 1948-1958, Vol. II. IIIa, Mainz 1969. 1971

DioDoRus of SICILY, Works, Vol. I-XII (The Loeb Classical Library), London - Cambridge/MA 1933-1967

Diogenes Laertius, Lives of Eminent Philosphers, Vol. I-II, ed. R.D. Hicks (The Loeb Classical Library), London - Cambridge/MA 1925 = 1965-1966 
Dion Chrysostomos, Discourses, Vol. I-V, ed. J.W. Cohoen et al. (The Loeb Classical Library), London - Cambridge/MA 1932-1951

DiRX R., Gaukler, Kinder, kluge Köpfe. Das Spiel einst und jetzt, Hannover 1968

- , Das Buch vom Spiel, Gelnhausen 21981

- , Kinderspiel von Januar bis Dezember, Düsseldorf 1984

DITTENBERGER W. (ed.), Orientis Graeci Inscriptiones Selectae I-II, Leipzig 1903-1905

DöLGER F., Ichtys Bd. 5, Münster i.W. 1943

- , Antike und Christentum 1-5, Münster i.W. 1919-1936

DöRIG J., Von griechischen Puppen, AntK 1 (1958), 41-52

- , Tarentinische Knöchelspielerinnen, MusHelv 16 (1959), 29-58

DörInG A., Historische Kinderspiele, in: Kinderkultur (Hefte des Focke-Museums 73), Bremen $1987,261-270$

DOETSCH-AMBERGER E., Ägyptische Sammlung, Köln 1987

Dolch M., Vom Ursprung des luftgefüllten Lederballs, Stadion 7 (1981), 53-92

- , Paolo Corteses Bemerkungen über das Ballspiel der geistlichen Würdenträger (1510), Stadion 8-9 (1982-1983), 85-97

DOMMERSHAUSEN W., Spiel, BL 21968, $1623 \mathrm{f}$

- , gōrāl, ThWAT 1 (1970-1973), 991-9998

- , hošaen, ThWAT 3 (1977-1982), 277-279

DONNER H., Israel unter den Völkern. Die Stellung der klassischen Propheten des 8.Jahrhunderts v.Chr. zur Außenpolitik der Könige von Israel und Juda (VT.S 11), Leiden 1964

DoRnemann R.H., The Archaeology of the Transjordan in the Bronze and Iron Ages, Milwaukee/WI 1983

DostojeWSKI F.M., Der Spieler. Aus den Erinnerungen eines jungen Mannes, (russ. 1867) (Werke deutsch 13), Lepizig 1921

DOTHAN M. et al., Ashdod I-IV (CAtiqot ES 7. 9-10. 15), Jerusalem 1967-1982

Dothan T., Excavations at the Cemetery of Deir el-Balah (Qedem 10), Jerusalem 1979

DoughtY CH.M., Travels in Arabia Deserta I-II, London 1936

DowNEY G., The Olympic Games of Antioch in the Fourth Century A.D., (1939), in: G. FATOUROS - T. KRISCHER (ed.), Libanios (WdF 621), Darmstadt 1983, 173-184

DRAKE F.M., A Sixth Century Greek Mosaic at Um Jerar, PEQ 1918, 122-124

DrENKHAHN R., Elfenbein im Alten Ägypten. Leihgaben aus dem Petrie-Museum London (Katalog des Deutschen Elfenbeinmuseums Erbach 101), Erbach 1986

DRIESCH A. VON DEN / BOESSNECK J., Reste von Haus- und Jagdtieren aus der Unterstadt von Boğazköy-ㅌattuša, Grabungen 1958-1973 (Boğazköy-프attuša 11), Berlin 1981

DRIOTON E., Un ancien jeu copte, BSAC 6 (1940), 177-206

- , Le théâtre dans l'Ancienne Egypte, Revue d'histoire du théâtre 6 (1954), 7-45

Driver G.R., Old Problems re-examined, ZAW 80 (1968), 174-183

Ducos P., Le jeu d'osselets de la tombe 6 de Politico, RDAC 1965, $28 \mathrm{f}$

DÜRR L., Zum altorientalischen Gedankenkreis: "Der König als Meister im Bogenschießen, von der Gottheit unterrichtet", OLZ 34 (1931), 697

DUNAND M., Sondages archéologiques effectués à Bostan-ech-Cheikh près Saïda, Syria 7 (1926), 1-8

- , Fouilles de Byblos, Tome II. Texte. Atlas, Paris 1950. 1954

-, Nouvelles inscriptions phéniciennes du temple d'Echmoun à Bostan ech-Cheikh, près Sidon, BMB 18 (1965), 105-109

- , La statuaire de la favissa du temple d'Echmoun à Sidon, in: Archäologie und Altes Testament. FS für K. GALLING zum 8.Januar 1970, ed. A. KuSCHKE - E. KuTSCH, Tübingen 1970, 6167

DunBaBIN K.M.D., The Victorious Charioteer on Mosaics and Related Monuments, AJA 86 (1982), 65-89

DUNKEL P.F., Schattenfiguren - Schattenspiele. Geschichte - Herstellung - Spiel, Köln 1984

During CASPERs E.C.L., Of linga Stones and Gaming Boards, AION 47 (1987), 67-74 
DUSSAUd R., Bibliographie, Syria 16 (1935), $222 \mathrm{f}$

EATON E.S., An Egyptian High Jump, BMFA 35 (1937), 54 f

EBELING E. (ed.), Literarische Keilschrfttexte aus Assur, Berlin 1953

EBERT J., Zu griechischen agonistischen Inschriften, WZ(H).GS 15 (1966), 375-387

- , Griechische Epigramme auf Sieger an gymnischen und hippischen Agonen (ASAW.PH 63,2), Berlin 1972

EDEL E., Die Stelen Amenophis' II. aus Karnak und Memphis mit dem Bericht über die asiatischen Feldzüge des Königs, ZDPV 69 (1953), 97-176

- , Bemerkungen zu den SchieBsporttexten der Könige der 18.Dynastie, SAK 7 (1979), 23-39

Egami N. / Wahrta SH. / Ishida K., Excavations at Tell Mastuma, Syria, 1988, BAOM 10 (1988-1989), 47-76

EGGEBRECHT A. (ed.), Ägyptens Aufstieg zur Weltmacht, Mainz 1987

EGGER R., Eine Darstellung des lusus iuvenalis, JÖAI 18 (1915), 115-129

EHELOFF H., Wettkampf und scenisches Spiel im hethitischen Ritual (SPAW.PH 21), Berlin 1925

EHLERS W., Oscilla, RE 18,1 (1942), 1567-1578

EHRENBERG V., Losung, RE 13 (1927), 1451-1504

EIBL-EIBESFELDT I., Über die Jugendentwicklung des Verhaltens eines männlichen Dachses

(Meles meles L.) unter besonderer Berücksichtigung des Spiels, Zt. für Tierpsychologie 7

(1950), 327-355

EICHBERg H., Die Kulturrelativität des Spiels, Jb. Deutsch als Fremdsprache 8 (1982), 159-177

EICHLER G., Spiel und Arbeit. Zur Theorie der Freizeit (problemata 73), Stuttgart - Bad Cannstatt 1979

- , Spiel und Freizeit, in: O. GruPE - H. Gobler - U. GöhNER (ed.), Spiel - Spiele - Spielen

(Schriftenreihe des Bundesinstituts für Sportwissenschaft 49), Schorndorf 1983, 232-242

EIGEN M. / WINKLER R., Das Spiel. Naturgesetze steuern den Zufall, München 21976

EINSIEDLER W. (ed.), Aspekte des Kinderspiels. Pädagogisch-psychologische Spielforschung, Weinheim - Basel 1985

EISENHUT W., Ver, RE 8 A 1 (1955), 905-911

EISSFELDT O., Ein gescheiterter Versuch der Wiedervereinigung Israels (2.Sam. 2,12-3,1), (1951), in: ders., Kleine Schriften III, Tübingen 1966, 132-146

- , Noch einmal: Ein gescheiterter Versuch der Wiedervereinigung Israels, (1952), in: ders., Kleine Schriften III, Tübingen 1966, 147-150

ELDERKIN K.M., Jointed Dolls in Antiquity, AJA 34 (1930), 455-479

Elgavish J., Archaeological Excavations at Shiqmona: Field Report I. The Levels of the Persian

Period, Seasons 1963-1965, Haifa 1968 (hebr.)

ELLIGER K., Das Buch der zwölf Kleinen Propheten (ATD 25), Göttingen ${ }^{7} 1975$

ELLIGER W., Gymnasion, NBL 1 (1991), $364 f$

Ellis R.S. / Buchanan B., An Old Babylonian Gameboard with Sculptered Decoration, JNES 25 (1966), 192-201

ElsChENBROICH D., Spielen und Spielzeug, (1973), in: H. RöHRS (ed.), Das Spiel - ein Urphänomen des Lebens (Erziehungswiss. Reihe 23), Wiesbaden 1981, 63-82

- , Kinder werden nicht geboren. Studien zur Entstehung der Kindheit, Frankfurt a.M. 1977

EMERY W.B., The Royal Tombs of Ballana and Qustul I-II (Mission Archéologique de Nubie 1929-1934), Kairo 1938

ENDERLIN M., Das Spielzeug in seiner Bedeutung für die Entwicklung des Kindes, Langensalza 1907

ENFANT EN-JEU. Les pratiques des enfants durant leur temps libre en fonction des types d'environnemet et des idéologies, ed. M.-J. Chombart de LAUVE - Ph. Bonnen et al., Paris 1980

ENZENSBERGER H.M., Allerleirauh. Viele schöne Kinderreime, Frankfurt a.M. 1961

EPIKTET, The Discourses, Vol. I-II, ed. W.A. OldFATHER (The Loeb Classical Library), London

- Cambridge/MA 1925. $1928=1956.1959$

EPIPHANIOS, Ancoratus. Panarion 1-33. 34-64 (GCS 25. 31), ed. K. Holl, Leipzig 1915. 1922 
ErIKson E.H., Kinderspiel und politische Phantasie. Stufen in der Ritualisierung der Realität, Frankfurt a.M. 1978

ETtinghausen R. (ed.), Arabische Malerei, Genf 1962

EURIPIDES, Tragödien, Teile 1-6. Griechisch und deutsch, ed. D. EBENER, Berlin 21990

EUSEBIOS, Liber de martyribus Palaestinae, PG 20 (1857), 1547-1520

- , Chronikon, PG 19 (1857), 99-598

-, Historia ecclesiae, ed. E. SchWARTZ, Kleine Ausgabe, Leipzig ${ }^{3} 1922$

EUSTATHIOS vON THESSALONIKI, Commentarii ad Homeri Iliadem et Odysseam, Vol. I-IV, Leipzig 1827-1829 = Hildesheim 1966

Evans A., The Palace of Minos, Vol. I-IV, London - New York 1921-1964

Evans J.D., Excavations in the Neolithic Settlement at Knossos, 1957-60, Part I, ABSA 59 (1964), $132-240$

Exposttio Totius Mundi Et Gentium, ed. J. Rouge (SC 124), Paris 1966 [vgl. zuletzt H.J. DREXHAGE, Die 'Expositio totius mundi et gentium'. Eine Handelsgeographie aus dem 4.Jahrh. n.Chr., eingeleitet, übersetzt und mit einführender Literatur versehen, Münstersche Beiträge zur Antiken Handelsgeschichte 2,1 (1983), 3-41]

FAHD T., La divination arabe. Études religieuses, sociologiques et folkloristiques sur le milieu natif de l'Islam, Straßburg 1966

- , Kur $\varepsilon_{a}$, EI 5 (21986), $398 f$

EL-FAKHARANI F., Das Theater von Amman in Jordanien AA 1975, 377-403

FAlKENSTEIN A. / von SODEN W. (ed.), Sumerische und akkadische Hymnen, Zürich - Stuttgart 1953

FALKener E., Games Ancient and Oriental and How to Play them, London $1892=$ New York 21961

FAUST C., Spielverhalten aus ärztlicher Sicht, in: W. MARX (ed.), Das Spiel. Wirklichkeit und Methode (Freiburger Dies Universitatis 13), Freiburg i.Br. 1967, 67-77

FAUTH W., Anthesteria, KP 1 (1975), 372-374

FEITELSON D. / Ross G.S., The Neglected Factor - Play, Human Development 16 (1973), 202223

Feldhaus F.M., Geschichte des Maschinensports, in: G.A.E. BogENG (ed.), Geschichte des Sports aller Völker und Zeiten Bd. II, Leipzig 1926, 725-768

Feldman L.H., Masada: A Critique of Recent Scholarship, in: J. NeUSNER (ed.), Christianity, Judaism and other Greco-Roman Cults, Part 3 (StJLA 12,3), Leiden 1975, 218-248

FENSHAM F.C., The Battle between the Men of Joab and Abner as a possible Ordeal by Battle?, VT 20 (1970), $356 f$

FERNEA R.A. / GERSTER G., Nubians in Egypt, Austin 1973

FERrUA A., Tavole lusorie scritte, Epig. 8 (1946), 53-73; 10 (1949) 21-58

- , Nuove tabulae lusoriae iscritte, Epig. 26 (1964), 3-44

FETZ F. und E. (ed.), Gymnastik bei Philostratos und Galen (Studientexte zur Leibeserziehung 4), Frankfurt a.M. 1969

FEUCHT E., Puppe, LÄ 4 (1982), $1201 \mathrm{f}$

- (ed.), Vom Nil zum Neckar. Kunstschätze Ägyptens aus pharaonischer und koptischer Zeit an der Universität Heidelberg, Berlin u.a. 1986

FinK E., Oase des Glücks. Gedanken zu einer Ontologie des Spiels, Freiburg - München 1957

- , Spiel als Weltsymbol, Stuttgart 1960

- , Das kindliche Spiel, in: Das Spiel, hg. Ausschuß Deutscher Leibeserzieher, Frankfurt a.M. 1959, 109-119

FINK G.W. / Fuchs G., Backgammon für Anfänger und Könner, Niedernhausen/TS. 1990

FINK J., Die römischen Katakomben (AW Sondernr.), Mainz 1978

FinkenZeller R. / ZieHER W. / BÜHRER E.M., Schach. 2000 Jahre Spiel-Geschichte, Aarau Stuttgart 1989

FisCHART J., Geschichtklitterung (Gargantua). Glossar. Text der Ausgabe letzter Hand von 1590, ed. U. NYSSEN, Düsseldorf 1963-1964 
FISCHER A., Pfeile aus Nab'-Holz, ZDMG 58 (1904), 877-887

FISCHER H., Spiele der Wotut (Ost-Neuguinea), in: Beiträge zur Völkerforschung. FS für H. DAMM zum 65.Geb., Berlin Ost 1961, 141-152

FISCHER H.G., Hunde, LÄ 3 (1980), 77-82

Firzgerald G.M., A Sixth Century Monastery at Beth-Shan (Scythopolis), Philadelphia/PN 1939

FLEMMING W., Weihnachtsspiele, RGG $6\left({ }^{3} 1962\right), 1569-1571$

FLITNER A., Untersuchungen zur Förderung des Kinderspiels, ZP 21 (1975), 441-448

- , Spielen - Lernen. Praxis und Deutung des Kinderspiels, München - Zürich ${ }^{8} 1986$

- (ed.), Das Kinderspiel - Texte, München ${ }^{4} 1978$

FLORUS, Epitome of Roman History, ed. E.S. FORSTER (The Loeb Classical Library), London Cambridge/MA 1984

FOLEY D.J., Toys through the Ages, Philadelphia 1962

FORBES C.A., Ostrakinda, RE 36 (1942), 1673

- , Accidents and Fatalities in Greek Athletics, in: Classical Studies in Honor of WA. OLDFATHER, Urbana/IL 1943, 50-59

- , Ancient Athletic Guilds, CP 50 (1955), 238-252

ForTuNA M.T., Campagne di scavo ad Akko 1961-1962 (Memorie dell'Isituto Lombardo - Accademia di Scienze e Lettere, Classe di Lettere - Scienze Morali e Storiche 29,4), Milano 1966, 439-578

Fox C., The Doll, New York 1973

Frank T., The Status of Actors at Rome, CP 26 (1931), 11-20

Franke P.R. / HiRMER M., Die griechische Münze, München 21972

FRANKEN H.J., Excavations at Deir cAlla in Jordan, $2^{\text {nd }}$ Season, VT 11 (1961), 361-372

- / STEINER M.L., Excavations in Jerusalem 1961-1967, Vol. II: The Iron Age Extramural Quarter on the South-East Hill, Oxford u.a. 1990

FrANKForT H., More Sculptures from the Diyala Region (OIP 60), Chicago/IL 1943 - et al., The Gimilin Temple and the Palace of the Rulers at Tell Asmar (OIP 43), Chicago/IL 1940

FRASER A., Spielzeug. De Geschichte des Spielzeugs in aller Welt (A History of the Toys, London 1966), Oldenburg - Hamburg 1968

FREEMAN K., Copper Fly, GaR 6 (1936), 18-30

FrENCH D.R., Christian Emperors and Pagan Spectacles: The Secularization of the 'Ludi' A.D. 382-525, Ph.D. Diss. (unpubl.) University of California, Berkeley/CA 1985

FREUDENREICH D. / GrÄSSER H. / KöBERLING J., Rollenspiel: Rollenspiellernen für Kinder und Erwachsene, Hannover ${ }^{5} 1981$

FreY J.-B. (ed.), Corpus Inscriptionum Judaicarum I-II (SSAC 1. 3), Città del Vaticano 1936. 1952 = New York 1975

Frezouls E., Les édifices des spectacles en Syrie, in: Archéologie et Histoire de la Syrie II. La Syrie de l'époque achéménide à l'avènement de l'Islam (Schriften zur vorderasiatischen Archäologie 1), Saarbrücken 1989, 385-406

FriTZ V. (ed.), Kinneret. Ergebnisse der Ausgrabungen auf dem Tell el- ${ }^{c}$ Orēme am See Gennesaret (ADPV 15), Wiesbaden 1990

- / KEMPINSK A. (ed.), Ergebnisse der Ausgrabungen auf der Hirbet el-Mšăš (ADPV), Wiesbaden 1983

FRITZSCH K.E. / BaCHMANN M., Deutsches Spielzeug, Hamburg 1965

FröBel Fr., Ausgewählte Schriften I-III, ed. E. HoFFMANN - H. HEILAND, Godesberg - Düsseldorf - München 1951-1974

FRÖHLING U. (ed.), Droge Glücksspiel, München 1984

Frommberger H. / Freyhoff U. / SPIES W. (ed.), Lernendes Spielen - Spielendes Lernen, Hannover u.a. 1976

FROST K.T., Greek Boxing, JHS 26 (1906), 213-225

Frova A. (ed.), Scavi di Caesarea Maritima, Rom 1966 
Fugman E., Hama II 1. Fouilles et Recherches de la Fondation Carlsberg 1931-1938. L'architecture des périodes pré-hellénistiques (Nationalmuseets Skrifter, Større Beretninger 4), Kopenhagen 1958

FuKs G., Scythopolis - A Greek City in Eretz-Israel, Jerusalem 1983 (hebr.)

GADD C.J., An Egyptian Game in Assyria, Iraq 1 (1934), 45-50

- , Babylonian Chess?, Iraq 8 (1946), 66-72

Galenos, De parvae pilae exercitu, ed. F. und L. FETZ, Gymnastik bei Philostrat und Galen (Studientexte zur Leibeserziehung 4), Frankfurt a.M. 1969, 101-106

Gallien in der Spätantike. Katalog, Mainz 1980

GALLING K., Spielgerät, BRL ${ }^{1}$ (1927), 494f

- , Amulett; Jagd, BRL ${ }^{2}$ (1977), 10f. 150-152

- (ed.), Textbuch zur Geschichte Israels, Tübingen ${ }^{3} 1979$

GAMER-WALlERT I., Der verzierte Löffel. Seine Formgeschichte und Verwendung im alten Ägypten (ÄA 16), Wiesbaden 1967

GANZMANN-MEYER L., "Temple-Boys" - Weihestatuen klassischer Zeit in Griechenland, auf Zypern und im Vorderen Orient, Liz. phil. masch. Universität Basel 1979

- / MEIdEN H. AN DER / STUCKY R.A., Das Eschmunheiligtum von Sidon. Die Funde der türkischen Ausgrabungen von 1901 bis 1903 im Archäologischen Museum in Istanbul, IM 37 (1987), 81-130

GARDINER A., Egyptian Grammar, Oxford ${ }^{3} 1982$

GARDINER E.N., Wrestling, JHS 25 (1905), 14-31. 263-293

- , Athletics of the Ancient World, Chicago $1978=1987$

GEERTZ C., Deep Play: Notes on the Balinese Cockfight, Daed. 101 (1972), 1-37

GEFFCHEN J., Die Verhöhnung Christi durch die Kriegsknechte, Hermes 41 (1906), 220-229

GeHLEn A., Der Mensch. Seine Natur und seine Stellung in der Welt, Frankfurt a.M. ${ }^{9} 1971$

GEIST H. (ed.), Pompeianische Wandinschriften, München 1936

GELB I.J., Homo ludens in Early Mesopotamia, StOr 46 (1976), 43-76

Gellius, Noctes Atticae, Bd. I-II, ed. F. WeISs, Leipzig 1875 = Darmstadt 1987

GENIERE J. DE LA, Une roue à oiseaux du Cabinet des Médailles, REA 60 (1958), 27-35

GERLACH P. / PAUL J., Goldenes Kalb, LCI 2 (1970 = 1990), 478-482

GERLEMAN G., $\xi^{k e} \bar{o} l$, THAT $2\left({ }^{2} 1979\right), 837-841$

GERSDORF D. VON, Kinderbildnisse aus vier Jahrtausenden, Berlin 21989

Ghirshman R., Fouilles de Sialk près de Kashan 1933, 1934, 1937, Vol. II (Musée du Louvre Départment des Antiquités Orientales, Série Archéologique Tome V), Paris 1939

GiBSON J.C.L. (ed.), Textbook of Syrian Semitic Inscriptions I-III, Oxford 1971-1982

GILBERT P., Irrigation, jeux de damier et sens du rectangle dans l'art égyptien, CEg 40 (1965), 72 78

Gilgamesch-Epos, ed. A. SCHOTT - W. von SOdEN, Stuttgart 1978

GINSBERG H.L., Some Emendations in Isaiah, JBL 69 (1950), 51-60

GisI M., Der Begriff Spiel im Denken J.-P. Sartres (MPF 176), Meisenheim 1979

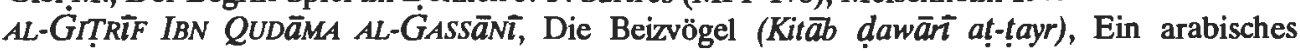

Falknereibuch des 8.Jahrhunderts, ed. D. MÖLLER - F. VIRE, Hildesheim 1987

GLADISS A. voN, Wasserspiele; Xystos, KP 5 (1975), 1350f. 1441f

GlonNeGGer E., Das Spiele-Buch. Brett- und Legespiele aus aller Welt. Herkunft, Regeln und Geschichte, Ravensburg 1988

GluCKER C.A.M., The City of Gaza in the Roman and Byzantine Periods (BAR.IS 325), Oxford 1987

GöBEL D., Über das Spielen, Diss. phil. masch. Heidelberg 1955

GöBL R., Antike Numismatik I-II, München 1978

GoEPEL K., Beiträge zur Geschichte des Ballspiels, in: 31.Jahresbericht des Wilhelms-Gymnasium in Eberswalde, Schuljahr 1908/1909, Eberswalde 1909, 3-24

Göllmann C., Zur Beurteilung der öffentlichen Spiele Roms bei Tacitus, Plinius d.J., Martial und Juvenal, Diss. phil. masch. Münster i.W. 1942 
GöRgENS A., Alte und neue Würfelspiele, Düsseldorf 1987

GOETHE J.W. VON, Aus meinem Leben. Dichtung und Wahrheit (Werke in sechs Bänden, Bd. 5), Wiesbaden ${ }^{3} 1952$

Götze A. / Karo G. / Roeder G. / Thomsen P. / Unger E., Spiel und Spielzeug, RLV 12 (1928), 342-347

Goldman H., Excavations at Gözlü Kule, Tarsus, Vol. II: From the Neolithic through the Bronze Age, Princeton/NJ 1956

Golvin J.-C., L'amphithéâtre Romain. Essai sur la théorisation de sa forme et de ses fonctions III, Paris 1988

GORDON C.H., Belt-Wrestling in the Bible World, HUCA 23 (1950-1951), 131-136

GossEN H., 'Iygx; Käfer, RE 10 (1919), 1384-1386. 1478-1489

- / STEIER A., Schildkröte, RE 2,3 (1921), 427-433

GoTTWALD J., Das byzantinische Kugelspiel im Kaiser-Friedrich-Museum zu Berlin, AA 1931, 152-172

Grabar A., Ampoulles de Terre Sainte (Monza - Bobbio), Paris 1958

GrÄsse J.G.T., Die Geschichte des Puppenspiels und der Automaten (Puppenspielkundliche Quellen und Forschungen 1), Leipzig 1856 = Bochum 1977

Grant E., Rumeileh being Ain Shems Excavations (Palestine), Part III (Biblical and Kindred Studies 5), Haverford/PN 1934

- / Wright G.E., Ain Shems Excavations (Palestine) Part IV-V (Biblical and Kindred Studies 8), Haverford/PN 1938-1939

GRASBERGER L., Erziehung und Unterricht im klassischen Alterthum, mit besonderer Rücksicht auf die Bedürfnisse der Gegenwart, nach den Quellen dargestellt I-III, Würzburg 1864-1881

GREENSTONE J.H., Gambling, JE 5, 563

GREGOR d.Gr., Moralia in Job, PL 75, 509-1162

GREGOR VON TOURS, Historiarum libri decem, ed. R. BUCHNER, Bd. 1-2 (Ausgewählte Quellen zur deutschen Geschichte des Mittelalters 1. 3), Darmstadt 1955-1956

GRESSMANN H., Die Anfänge Israels (Von 2.Mose bis Richter und Ruth) (SAT I 2), Göttingen 21922

-, Altorientalische Bilder zum Alten Testament, Berlin - Leipzig $21927=1970$

GrIAUle M., Jeux et divertissements abyssins (BEHE.R 49), Paris 1935

- , Jeux Dogons (TMIE 32), Paris 1938

GrIFFTTHS J.G., Pamylien, LÄ 4 (1982), $659 \mathrm{f}$

GrIMAL P., Les jardins romains à la fin de la république aux deux premiers siècles de l'empire.

Essai sur le naturalisme romain (BEFAR 155), Paris 1943

Gröber K. / MeTZGER J., Kinderspielzeug aus alter Zeit, Hamburg ${ }^{2} 1965$

Groos K., Die Spiele der Menschen (Documenta Semiotica 3), Jena 1899 = Hildesheim - New York 1973

- , Die Spiele der Tiere, Jena ${ }^{3} 1930$

Gross W.H., Abacus; Alveus; Automaten, KP 1 (1975), 1f. 284. $781 \mathrm{f}$

-, Loculi, KP 3 (1975), 702

- , Spiele; tabula lusoria: Technitai, KP 5 (1975), 310-313. 481. $553 \mathrm{f}$

GRUNDEL W., Griechische Ballspiele, AA 1935, 80-95

GrundmanN W., Das Evangelium nach Lukas (ThHK 3), Berlin Ost ${ }^{9} 1981$

GRUNFELD F.V., Spiele der Welt, Zürich 1979

Grunwald M., Games and Sports, JE 5 (1904), $564 f$

- , Chanukka, in: Fr. ThIEBERgER (ed.), Jüdisches Fest, jüdischer Brauch. Ein Sammelwerk, Berlin $21967=1976,343-346$

GRUPE O., Bewegung, Spiel und Leistung im Sport. Grundthemen der Sportanthropologie, Schorndorf 1982

GRUPP C.D., Dame. Brettspiel in allen Varianten, Niedernhausen/Ts. 1979

GuARDIN R., Vom Geist der Liturgie (Ecclesia Orans 1), Freiburg i.Br. 1922 
GüNTHER H., Um Ball und Tor. Streifzug durch die Geschichte der Ball-, Wurf- und Laufspiele, Leipzig 1955

GUGLIELMI W., Wortspiel, LÄ 6 (1986), 1287-1291

GuIllard R., Étude sur l'hippodrome de Byzance I-II. A propos du chapitre 69 du livre I du Livre des Cérémonies des courses à Byzance, BySl 23 (1962), 203-230; 25 (1964), 234-253

GuIllaume O., Fouilles d'Aï Khanoum II (Mémoires de la Délegation Archéologique Française en Afghanistan 26), Paris 1983

GUNDEL W., Rhabdomanteia, RE II 1 (1914), 13-18

GUNDERT H., Wahrheit und Spiel bei den Griechen. Homer - Tragödie - Platon, in: W. MARX (ed.), Das Spiel. Wirklichkeit und Methode (Freiburger Dies Universitatis 13), Freiburg i.Br. 1967, 13-34

- , Zum Spiel bei Platon, in: Beispiele. FS für E. FinK zum 60.Geb., ed. L. LANDGREBE, Den Haag 1965, 188-221

GunN B., "Finger-Numbering" in the Pyramid Texts, ZÄS 57 (1922), $71 f$

GURION M.J. BIN, Der Born Judas. Märchen und Geschichten, Berlin 1934

GuRney O.R. / Finkelstein J.J. / Hulin P. (ed.), The Sultantepe Tablets I-II (Occasional

Publ. of the British Institute of Archaeology at Ankara 3.7), London 1957. 1964

GuTtMan A., Sport Spectators from Antiquity to the Renaissance, JSH 8 (1981), 5-27

GUY P.L.O., Megiddo Tombs (OIP 33), Chicago/IL 1938

GWINNER E., Über einige Bewegungsspiele des Kolkraben (Corvus corax L.), Zt. für Tierpsychologie 23 (1966), 28-36

HAAS V., Kompositbogen und Bogenschießen als Wettkampf im Alten Orient, Nikephoros 2 (1989), 27-42. 305f, Abb. 1-2

HABEL E., Ludi publici, RE Suppl. 5 (1931), 608-630

HaCHIILI R., On the Mosaicists of the "School of Gaza", ErIs 19 (1987), $46-59$ (hebr.; English Summary $74^{*}$ )

Hachmann R., Das Grab eines Stadtkönigs von Kumidi, in: Anatolia and the Near East. Studies in Honor of T. ÖzGüÇ, ed. K. EMRE et al., Ankara 1989, 159-181

HADZisteliou-Price TH., The Type of the Crouching Child and the 'Temple Boys', ABSA 64 (1969), 95-111

HAEFELI L., Spruchweisheit und Volksleben in Palaestina, Luzern 1939

HÄHNLE A., Gnōrismata, Diss. phil. Tübingen 1929

HAGEDORN D., Zwei Spielverse, ZPE 2 (1968), 65-68

HAGSTROEM K.-H., Les préludes antiques de la théorie des probabilités, Stockholm 1932

HAHN H., Vom Ernst des Spielens, Stuttgart ${ }^{2} 1974$

HAIDER P.W., Trainingsanlagen im alten Ägypten?, Nikephoros 1 (1988), 1-27. 301

HAIDING K., Das Spielbild Pieter Bruegels, in: Bausteine zur Geschichte, Völkerkunde und Mythenkunde 1.Hb.bd., Wien 1937, 58-74

HALlE E., Die Leibesübung bei den Juden, LE 1962, 273-280

Hallo W.W., The First Purim, BA 46 (1983), 19-29

HAMBURGER A., Gems from Caesarea Maritima ('Atiqot ES 8), Jerusalem 1968

- , Surface-finds from Caesarea Maritima - Tesserae, in: LEVINE L.I. / NETZER E. (ed.), Excavations at Caesarea Maritima 1975, 1976, 1979 - Final Report (Qedem 21), Jerusalem 1986, 187204

HAMILTON R.W., Excavations at Tell Abu Hawām, QDAP 4 (1934), 1-69

- / HussEIN S.A.S., Shaft Tombs on the Nablus Road, Jerusalem, QDAP 4 (1935), 170-174

HAMPE R., Die Stele aus Pharsalos im Louvre (BWPr 107), Berlin 1951 [teilweise = ders., Antikes und modernes Griechenland, ed. E. SIMON (KAW 22), Mainz 1984, 191-197]

- , Neuerwerbungen 1957-1970. Katalog der Sammlung Antiker Kleinkunst des Archäologischen Instituts der Universität Heidelberg, Mainz 1971

HANFMANN E., Über das Bauen der Kinder, Zt. für Kinderforschung 36 (1930), 255-334

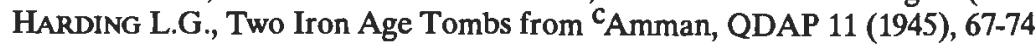


HARMS V., Der Terminus "Spiel" in der Ethnologie. Eine begriffskritische Untersuchung, dargestellt anhand von Berichten über die Kultur der Samoaner (Diss. phil. Hamburg; Arbeiten aus dem Institut für Völkerkunde der Universität zu Göttingen 4), Hamburg 1969

HARNACK A., Der pseudocyprianische Tractat de aleatoribus. Die älteste lateinische christliche Schrift. Ein Werk des römischen Bischofs Victor I. (Saec. II) (TU 5,1), Leipzig 1888

HARRAK A., Another Specimen of an Assyrian Game, AfO 34 (1987), $56 \mathrm{f}$

HARRIS H.A., Greek Athletics and the Jews of Palestine, in: Physical Education and Sports in the Jewish History and Culture. Proceedings of an International Seminar at Wingate Institute July 1973, ed. U. SIMRI, Netanya 1973, 9-17

-, Greek Athletics and the Jews in the Diaspora in the Early Roman Empire, in: Physical Education and Sports in the Jewish History and Culture. Proceedings of an International Seminar at Wingate Institute July 1973, ed. U. SIMRI, Netanya 1973, 40-49

- , Greek Athletics and the Jews (Trivium 3), Cardiff 1976

HARTMANN F., Alea, RE 1 (1894), 1358f

Hartmann G., Die Puppe als Erziehungsregulativ bei den Karaja, Brasilien, Tribus 33 (1984), 97-103

HARTMANN K., Über psychoanalytische "Funktionstheorien" des Spiels, (1962), in: H. RöHRS (ed.), Das Spiel - ein Urphänomen des Lebens (Erziehungswiss. Reihe 23), Wiesbaden 1981, 119-128

HASSENSTEIN B., Instinkt, Lernen, Spielen, Einsicht. Einführung in die Verhaltensbiologie, München 1980

- , Spielen in verhaltensbiologischer Sicht, in: H. RöHRS (ed.), Das Spiel - ein Urphänomen des Lebens (Erziehungswiss. Reihe 23), Wiesbaden 1981, 159-167

HAUSSHERR R., Jesuskind, LCI $2(1970=1990)$, 400-406

HaWkINS J.D., Some Historical Problems of the Hieroglyphic Luwian Inscriptions, AnSt 29 (1979), 153-167

- , Karkamiš, R1A 5 (1976-1980), 426-446

HeATon E.W., Biblischer Alltag. Zeit des Alten Testaments, München 1960

HEBERDEY R., Zu den kleinasiatischen Astragalenorakeln, WSt 50 (1932), 82-95

- (ed.), Tituli Asia Minoris III 1: Tituli Pisidiae, Wien 1949

HeCKHAusen H., Entwurf einer Psychologie des Spielens, PsF 27 (1963-1964), 225-243

Heidemann I., Philosophische Theorien des Spiels, KantSt 50 (1958-1959), 316-322

-, Freiheit und Bindung im Spiel, in: Das Spiel, hg. Ausschuß Deutscher Leibeserzieher, Frankfurt a.M. 1959, 81-86

- , Der Begriff des Spiels und das ästhetische Weltbild in der Philosophie der Gegenwart, Berlin 1968

Heimpel W. / TRÜMPELMANN L., Jagd, RIA 5 (1976-1980), 234-238

HEINE H., Sämtliche Gedichte, Leipzig 1925

HEINEVETTER F., Würfel- und Buchstabenorakel in Griechenland und Kleinasien, Breslau 1912

HeINRICH E., Fara. Ergebnisse der Ausgrabungen der Deutschen Orient-Gesellschaft in Fara und Abu Hatab 1902-03, ed. W. ANDRAE, Berlin 1931

HEINZ-MOHR G., Spiel mit dem Spiel, Hamburg 1959

-, Das Globusspiel des Nikolaus von Kues - Erwägungen zu einer Theologie des Spiels (Kleine

Schriften der Cusanus-Ges., H. 8), Trier 1965

HELCK W., Jagd und Wild im alten Vorderasien, Hamburg 1968

HellwiNG S., Human Exploitation of Animal Resources in the Early Iron Age Strata at Tel Beer-Sheba, in: Z. Herzog (ed.), Beer-Sheba II: The Early Iron Age Settlements, Tel Aviv 1984, 105-115

- , Faunal Remains from the Early Bronze and Late Bronze Ages at Tel Kinrot, TA 15-16 (19881989), 212-220

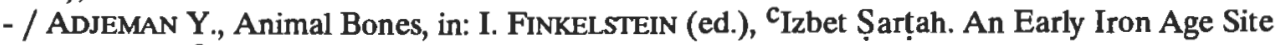
near Rosh Hacayin, Israel (BAR.IS 299), Oxford 1986, 141-152 
- / Feig N., Animal Bones, in: Z. Herzog - G. RAPP - O. NEgBI (ed.), Excavations at Tel Michal, Israel, Minneapolis/MN - Tel Aviv 1989, 236-247

HENDERSON R.W., Ball, Bat and Bishop: The Origin of Ball Games, New York 1947

HENGEL M., Judentum und Hellenismus (WUNT 10), Tübingen ${ }^{3} 1988$

HENIG M. - WhITING M., Engraved Gems from Gadara in Jordan. The Sa'd Collection of Intaglios and Cameos, Oxford 1987

HERAKLIT, Fragmente. Griechisch und deutsch, ed. B. SNELL, Darmstadt ${ }^{10}{ }_{1989}$

HERMANN A., Ertrinken, RAC 6 (1966), 370-409

Hermary A., Catalogue des Antiquités de Chypre: Sculptures. Musée du Louvre. Département des Antiquités Orientales, Paris 1989

HERMISSON H.-J., Gottes Freiheit - Spielraum des Menschen. Alttestamentliche Aspekte eines biblisch-theologischen Themas, ZThK 82 (1985), 129-152

HERODOT, Historiae, Vol. I-II, ed. C. HuDE, Oxford ${ }^{3} 1927=1960$

Heron von ALEXANDRIa, Opera I-V. Griechisch und deutsch, ed. W. SCHMidT et al., Leipzig 1899-1914

Herter H., Das Leben ein Kinderspiel, (1961), in: ders., Kleine Schriften, ed. E. VogT, München 1975, 584-597

HeRTZBERG H.W., Die Bücher Josua, Richter, Ruth (ATD 9), Göttingen ${ }^{4} 1969$

HERzoG R., Das Kind mit der Fuchsgans, JÖAI 6 (1903), 215-236

Herzog Z. (ed.), Beer-Sheba II: The Early Iron Age Settlements, Tel Aviv 1984

- / RAPP G. / NEGBI O. (ed.), Excavations at Tel Michal, Israel, Minneapolis/MN - Tel Aviv 1989

HERZOG-HAuser G., Neurobatēs; Neurospasta, RE 17 (1936), 158. 161-163

Hess J.J., Von den Beduinen des Innern Arabiens. Erzählungen, Lieder, Sitten und Gebräuche, Zürich - Leipzig 1938

Hesse H., Das Glasperlenspiel, in: ders., Ges. Werke Bd. 9, 1ff (vgl. Bd. 11, 90ff), Frankfurt a.M. 1970

Hessel E., Das Spiel Phaininda-Harpastum, Gym. 67 (1960), 226

HESTRIN R. / DAYAGi-MENDELs M. (ed.), Inscribed Seals, Jerusalem 1979

HETT W.S., The Games of the Greek Boy, GaR 1 (1931-1932), 24-29

HETZER H., Kind und Schaffen. Experimente über konstruktive Betätigungen im Kleinkindalter (Quellen und Texte zur Jugendkunde 7), Jena 1931

-, Kindheit und Armut. Psychologische Methoden in Armutsforschung und Armutsbekämpfung, Leipzig 21937

- , Spiele und Spielzeug für jedes Alter, München ${ }^{16} 6_{1977}$

- / Benner L. / Pee L., Kinderspiel im Freien (Erziehung und Psychologie 46), München - Basel 1966

HEYDEMANN H., Drachenspiel, AZ 25 (1867), $125 \mathrm{f}$

- , Das Morraspiel, AZ 29 (1871), 151-154

-, Die Knöchelspielerin im Palazzo Colonna zu Rom (HallWPr 2), Halle 1877

- , Dionysios' Geburt und Kindheit (HallWPr 10), Halle 1885

HEYKEN E. / FisCHER M.B., Das Backgammon-Handbuch, Niedernhausen/Ts. 1985

HiCKMANN E., Rassel, L

Hieronymus, Epistulae, Pars I-III ed. J. Hilberg (CSEL 54-56), Leipzig - Bonn 1910. 1912. 1918

- , Commentariorum in Esaiam Libri (CCSL 73-73a), Turnholt 1963

- , Commentarii in prophetas minores, ed. M. ADRIEN (CCSL 76a), Turnholt 1970

- , De viribus inlustribus, ed. C.A. BERNoulli (SQS 11), Freiburg i.Br. - Leipzig 1896 = Frankfurt a.M. 1968

- , Vita S. Hilarionis, PL 23 (1883), 29-54

-, Apologia contra Rufinum, ed. P. LARDET (SC 303), Paris 1983

HildebrandT P., Das Spielzeug im Leben des Kindes, Berlin 1904 
Hildebrandt W., Homo ludens. Die Spiele des Menschen in der Sicht der Anthropologie, in: G.-K. KALTENBRUNNER (ed.), Im Anfang war das Spiel. Schöpfertum und Glück zwischen Arbeit und Freizeit, München 1987, 90-107

Hill H.D. / Jacabsen T. / Delougaz P., Old Babylonian Public Buildings in the Diyala Region (OIP 98), Chicago/IL 1990

HILls J., Das Kinderspielbild von Pieter Bruegel d.Ä., (1560) (Veröffentlichungen des Österreichischen Museums für Volkskunde 10), Wien 1957

HIMLY K, Einige Worte über das persische Brettspiel Nerd, ZDMG 33 (1879), 679-681

- , Morgenländisch oder abendländisch? Forschungen nach gewissen Spielausdrücken, ZDMG 43 (1889), 415-463. 555-578

HimMELHEBER G., Spiele. Gesellschaftsspiele aus einem Jahrtausend (Katalog des Bayer. Nationalmuseums 14), München 1972

HIRST G., Note on Vergil Aeneid VII 376-384, CQ 31 (1937), $65 \mathrm{f}$

HistorIA APOLLONII REgIS TYRI. Lateinisch und deutsch, ed. F.P. WAIBLINGER, München 1978

Historia Augusta, ed. D. MAgIE (The Loeb Classical Library), Cambridge/MA - London 1921 $=1968$

HISTORIE VON ALEXANDER DEM GROSSEN, aus dem Mittellateinischen übersetzt von W. KIRSCH, Leipzig 21978

HönLE A. / HENZE A., Römische Amphitheater und Stadien. Gladiatorenkämpfe und Circusspiele, Feldmeilen 1981

HÖHLER G., Glück und Spiel, in: G.-K. KalTEnBRunNer (ed.), Im Anfang war das Spiel. Schöpfertum und Glück zwischen Arbeit und Freizeit, München 1987, 108-129

HOENERBACH W., Das nordafrikanische Schattentheater (BOS NS 6), Mainz 1959

HoERTH A.J. jr., Game Boards in the Ancient Near East (M.A. Thesis unpubl.), University of Chicago 1961 (mir nicht zugänglich)

Hoffmann D., Gemalte Spielkarten. Eine kleine Geschichte der Spielkarten, Frankfurt a.M. 1985

HOGARTH D.G., Carchemish I, London $1914=1969$

HoLL O., Sardanapal, LCI $4(1972=1990), 44 f$

HollaND T., Backgammon, München 1982

Holland T.A., A Study of Palestinian Iron Age Baked Clay Figurines, with Special Reference to Jerusalem: Cave 1, Levant 9 (1977), 121-155

Holler R., Murmeln, Schusser, Klicker, München ${ }^{3} 1990$

- , Kreisel (homo ludens), München 1989

HOLTER K., Ein mamlukisches Kartenspiel, WZKM 67 (1975), 165-168

HOMER, Ilias. Griechisch und deutsch, ed. H. RUPE (Tusculum), Zürich - München ${ }^{9} 1989$

- , Odyssee, Griechisch und deutsch, ed. A. WEIHER (Tusculum), Zürich - München ${ }^{9} 1990$

HOMERISCHE HYMNEN. Griechisch und deutsch, ed. A. WEIHER, Darmstadt ${ }^{5} 1986$

HoMmel. H., Tanzen und Spielen, (1949), in: ders., Symbola I, Hildesheim u.a. 1976, 18-22

HOORN G. vaN, Choes and Anthisteria, Leiden 1951

HOPFNER Th., Astragalomanteia, RE Suppl. 4 (1924), 51-56

HORAZ, Sämtliche Werke. Lateinisch und deutsch, ed. H. FÄRBER, München - Zürich ${ }^{10} 1985$

HORN H.G., Si per me misit, nil nisi vota feret. Ein römischer Spielturm aus Froitzheim, BJB 189 (1989), 139-160

HORN P., Spiele auf Leben und Tod. Kartenspiele bei Günter Grass und James Matthews, Jb.

Deutsch als Fremdsprache 8 (1982), 178-188

HORNUNG E., Geschichte als Fest, Darmstadt 1966

- , Pharao ludens, ErJb 51 (1982), 479-516

- (ed.), Das Totenbuch der Ägypter, Zürich - München 1979

Hrouda B., Tell Halaf IV: Die Kleinfunde aus historischer Zeit, Berlin 1962

HÜBNER B. / ReIZAMmer A., Inim Kiengi I-II. Sumerisch-deutsches Glossar, Marktredwitz 1985-1986

HÜBNeR F. / Koch U., Boule, Pétanque, Boccia (homo ludens), München 1988 
HÜBNER U., Bett; Pfeil, NBL 1 (1991), $288 f$ (bzw. im Druck)

- , Das Fragment einer Tonfigurine vom Tell el-Milh. Überlegungen zur Funktion der sog. Pfeilerfigurinen in der israelitischen Volksreligion, ZDPV 105 (1989), 47-55

-, Schweine, Schweineknochen und ein Speiseverbot im alten Israel, VT 39 (1989), 225-236

-, Die Keramik. Figurinen aus Terrakotta, in: V. Frrz (ed.), Kinneret. Ergebnisse der Ausgrabungen auf dem Tell el-'c Orēme am See Gennesaret 1982-1985 (ADPV 15), Wiesbaden 1990, 9198. 119-121

- , Die Ammoniter. Untersuchungen zur Geschichte, Kultur und Religion eines transjordanischen Volkes im 1.Jahrtausend v.Chr. (ADPV), Wiesbaden 1992

- , Kindheit und Jugend im eisenzeitlichen Israel und Juda (in Vorbereitung)

Hug A., Praestigiator, RE 44 (1954), 1567f

- , Rhombos; Rota, RE II 1 (1914), 1069f. 1148-1152

-, Schoinophylinda; Scurra, RE II 3 (1921), 618; $911 \mathrm{f}$

-, Skaperda, RE III A 1 (1927), 439

-, Spiele; Spielzeug, RE III A 2 (1929), 1762-1774. 1774-1778

- , Psēphopaiktēs, RE 23 (1959), 1357

HuIzINGA J., Homo ludens. Vorm Ursprung der Kultur im Spiel, Hamburg $1956=1987$

HulTsCH Fr., Abacus, RE 1 (1893), 5-10

- , Archimedes 3, RE 3 (1895), 507-539

HumBert J.-B. / ZaYAdine F. / NAJJAR M., Citadelle d'Amman, Jebel Qala ${ }^{c_{h}}$ 1988-1989, LA 39 (1989), 248-253

HUMPHREY J.H., Prolegomena to the Study of the Hippodrome at Caesarea Maritima, BASOR 213 (1974), $2-45$

- , Roman Circuses. Arenas for Chariot Racing, London 1986

Huot J.-L. et al., Larsa. Preliminary Report of the Seventh Campaign at Larsa and the First Campaign at Tell el-Queili (1976), Sumer 36 (1980), 99-132

IBN $\underline{\text { H}} A L L I K \bar{a} N$, Die Söhne der Zeit, ed. H. FäHNDRICH. Auszüge aus dem biographischen Lexikon "Die Großen, die dahingegangen" (Wafayāt al- $a^{c} y \bar{a} n$ ) (Bibliothek Arab. Erzähler), Stuttgart 1984

IBN IYās, Alltagsnotizen eines ägyptischen Bürgers. Auszüge aus Bd. IV, ed. A. SCHIMMEL

(Muntazam bad' ad-dunyā wa-ta'nh̆h al-umām) (Bibliothek Arab. Erzähler), Stuttgart 1985

IBN SIRIN, Das Traumbuch, ed. H. KLOPFER, München 1989

IHM M., Römische Spieltafeln, in: Bonner Studien. Aufsätze aus der Altertumswissenschaft R. KeKulE zur Erinnerung an seine Lehrtätigkeit in Bonn gewidmet von seinen Schülern, Berlin 1890, 223-239

ILIFFE J.H., Pre-Hellenistic Greek Pottery in Palestine, QDAP 2 (1933), 16-26

- , Imperial Art in Trans-Jordan. Figurines and Lampes from a Potter's Store at Jerash, QDAP 11 (1945), 1-26

IMHOOF-BLUMER F., Beiträge zur Erklärung griechischer Münztypen, Nomisma 5 (1910), 25-42

- , Beiträge zur Erklärung griechischer Münztypen IV: Knöchelspiel vor Kultbildern, Nomisma 6 (1911), 4-7

IMMERWAHR H.R., An Inscribed Terracotta Ball in Boston, GRBS 8,4 (1967), 255-266

INEICHEN R., "Die Wahrscheinlichkeit ist nämlich ein Grad der Gewißheit..." Rückblicke auf die Vorgeschichte der Wahrscheinlichkeitsrechnung, Bull. Soc. Fribourg Sc. Nat. 75 (1986), 59-93

-, Schwierigkeiten mit dem Wahrscheinlichkeitsbegriff - ein Blick in die Geschichte, Zentralblatt für Didaktik der Mathematik 19 (1987) 103-107

- , Didaktik und Elementarmathematik. Das Problem der drei Würfel in der Vorgeschichte der Stochastik, Elemente der Mathematik 42 (1987), 69-75

- , Dante-Kommentare und die Vorgeschichte der Stochastik, Historia Mathematica 15 (1988), 264-269

- , Modellbildung von Zufallsphänomenen im Laufe der Geschichte. Einige Illustrationen zur Didaktik der Stochastik, Der Mathematikunterricht 6 (1990), 41-49 
IsIDOR von SEVILLA, Etymologiarum Libri, PL 82 (1850), 9-728

JACOB G., Altarabisches Beduinenleben, nach den Quellen geschildert, Berlin $21897=$ Hildesheim 1967

JACOBY O. / CROWFORD J.R., Das Backgammon-Buch, München 1974

JACQUENIM A., Petits objects divers, in: L'Antre Corycien II (BCH.S 9), Athen - Paris 1984, 166175

JAKOB-Rost L., Sport im Alten Orient?, Altertum 11 (1965), 3-8

- et al., Das Vorderasiatische Museum (Staatliche Musen zu Berlin), Mainz 1992

JALABERT L. et al. (ed.), IGLS 1: Commagène e Cyrrhestique NoS. 1-256, Paris 1926

- , IGLS 4: Laodicée. Apamène, Nos. 1243-1997 (BAH 61), Paris 1955

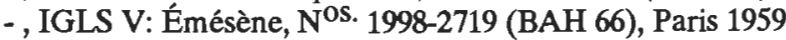

JANATA A., Vorderasien, in: E. BECKER-DonNER et al. (ed.), Spiel und Spielzeug aus aller Welt. Sonderausstellung 1971/72, Museum für Völkerkunde Wien, Wien 1971, 32-34

JANSEN M. (ed.), Vergessene Städte am Indus. Frühe Kulturen in Pakistan vom 8. bis 2.Jahrtausend, Mainz 1987

$J_{A} C_{Q \bar{o} B}$ VON $S_{A R \bar{u} G}$, Homilies on the Spectacles of the Theatre, ed. C. Moss, Muséon 48 (1935), $87-112$

JAROS K., Sichem. Eine archäologische und religionsgeschichtliche Studie mit besonderer Berücksichtigung von Jos 24 (OBO 11), Göttingen - Fribourg 1976

JASTROW M., Dictionary of the Targumim, Talmud Babli, Yerushalmi and Midrashic Literature, New York $1903=1989$

JEAN CH.-F. / HoFTuZER J., Dictionnaire des Inscriptions sémitiques de l'Ouest, Leiden 1965

JELlineK A. (ed.), Bet ha-Midrasch. Sammlung kleiner Midraschim und vermischter Abhandlungen aus der ältern jüdischen Literatur, Teil I-VI, Jerusalem ${ }^{3} 1967$

JENNI E., Das hebräische Piel. Syntaktisch-semasiologische Untersuchung einer Verbalform im Alten Testament, Zürich 1968

JENNINGS-BRAMLEY W.E., Sport among the Bedawîn, PEQ 1900, 369-376

Jennison G., Animals for Show and Pleasure in Ancient Rome, Manchester 1937

JENSEN A.E., Spiel und Ergriffenheit, Paid. 2 (1942), 124-139

-, Mythos und Kult bei Naturvölkern, Wiesbaden 21960 = München 1991

JENSEN R.C., The Kourion Ballplayer, RDAC 1984, 281-284

JENTOFT-NILSEN M., Some Objects relating to the Theatre, GettyMusJ 10 (1982), 159-164

JEREMIAS A, Handbuch der altorientalischen Geisteskultur, Berlin - Leipzig 21929

Jerphanion G. DE / JALABert L., Taurus et Cappadocie. Inscriptions de Séleukie de Piérie, MUSJ 5 (1911), 283-332

JESUS SIRACH, Ecclesiastico. Testo ebraico con apparato critico e versioni greca, latina e siriaca, ed. F. VATTIONI, Neapel 1969

JohANNES CHRYsostomos, Ad populum Antiochenum homilia, PG 49 (1862), 15-222

- , In Mattheum homilia, PG 57 (1862), 13-472

- , Fragmenta in beatum Job, PG 64 (1862), 505-660

JoHNs C.N., Excavations at ${ }^{{ }^{A} \text { At It }}$ (130-1). The South-Eastern Cemetery, QDAP 2 (1933), 41-104

- , Excavations at Pilgrims' Castle, 'Atlit (1932-3). Stables at the Southwest of the Suburb, QDAP 5 (1936), 31-60

JOSEPH H.H., A Book of Marionettes, London ${ }^{2} 1931$

Josephus Flavius, De Bello Judaico. Griechisch und deutsch, Bd. 1-3, ed. O. Michel - O. BAUERNFEIND, Darmstadt ${ }^{3} 1982.19631969$

- , Vol I. IV-IX: The Life. Against Appion. Jewish Antiquities, ed. H.S.J. THACKERY (The Loeb Classical Library), London - Cambridge/MA 1926-1965

JÜNGER G.F., Die Spiele. Ein Schlüssel zu ihrer Bedeutung, Frankfurt 1953

JÜRgens H., Pompa Diaboli. Die lateinischen Kirchenväter und das antike Theater (TBAW 46), Stuttgart u.a. 1972

JÜTHNER J., Caestus, RE 5 (1897), 1319-1321

- , Über antike Turngeräthe (AAES 12), Wien 1896 
- , Die Namen der Astragalwürfe, JÖAI.Bh. 23 (1926), 105-116

- , Körykomachia, RE 11 (1922), $1450 \mathrm{f}$

-, Kybistētēr, RE 22 (1922), $2299 \mathrm{f}$

-, Die athletischen Leibesübungen der Griechen I: Geschichte der Leibesübungen; II: Einzelne

Sportarten: Lauf, Sprung- und Wurfbewerbe (SÖAW.PH 249,1-2), Wien 1965. 1968

- / MEHL E., Pygme (pugilatus), RE Suppl. 9 (1962), 1306-1352

Junkelmann M., Die Reiter Roms I-II (KAW 45. 49), Mainz 1990-1991

Juvenal, Satirs, ed. G.G. Ramsay (The Loeb Classical Library), London - Cambridge/MA

$21940=1969$

KÄHLER H., Götterspielzeug, Die Kunst und Das schöne Heim 53 (1955), 84-87

KAHLE P., Islamische Schattenspielfiguren aus Egypten I-II, Islam 1 (1910), 264-299; 2 (1911), 143-195

KAIBEL G., Ein Würfelorakel, Hermes 10 (1876), 193-202

KAINLIS A. DE, Un jeu assyrien du Musée du Louvre, RA 39 (1942-1944), 19-34

KAISER O., Das Buch des Propheten Jesaja Kapitel 1-12 (ATD 17), Göttingen ${ }^{5} 1981$

- , Der Prophet Jesaja Kapitel 13-39 (ATD 18), Göttingen ${ }^{3} 1983$

- (ed.), Texte aus der Umwelt des Alten Testaments I 1ff, Gütersloh 1982ff

KALT E., Spiel, in: Biblisches Reallexikon 2 (21939), $732 \mathrm{f}$

KALTENBRUNNER G.-K. (ed.), Im Anfang war das Spiel. Schöpfertum und Glück zwischen Arbeit und Freizeit, München 1987

KAMPERMAN-Mulder M., Terracotta Doll in Utrecht, BABesch 48 (1973), 115-118

KanafanI Gh., Palästinensische Erzählungen I-II, Basel 1983-1984

KARAgeorghis V., A Late Cypriote Tomb at Tamassos, RDAC 1965, 11-27

- , Chronique des fouilles et découvertes archéologiques à Chypre en 1964, BCH 89 (1965), 231300

- , Excavations in the Necropolis of Salamis II, London 1970

- , Palaepaphos-Skales. An Iron Age Cemetery in Cyprus (Ausgrabungen in Alt-Paphos auf Cypern 3), Konstanz 1983

KARUSU S., Der Erfinder des Würfels. Das älteste griechische mythische Portrait, AM 88 (1973), $55-65$

KARUTZ E., Über Kinderspielzeug, ZE 43 (1911), 237-239

KASHER A., The Jewish Attitude to the Alexandrian Gymnasium in the First Century A.D., AmJAncHist 2 (1976), 148-161

KAUKE M., Spielintelligenz. Spielend lernen - Spielen lernen?, Heidelberg - Berlin - New York 1991

KAYSER W., Kunst und Spiel. Fünf Goethe-Studien, Göttingen 1961

KEEL O., Die Weisheit spielt vor Gott. Ein ikonographischer Beitrag zur Deutung des $\mathrm{m}^{\mathrm{e}}$ sahäquät (sic) in Sprüche 8,30f, Fribourg - Göttingen 1974

- , Wirkmächtige Siegeszeichen im Alten Testament (OBO 5), Göttingen - Fribourg 1974

- , Vögel als Boten (OBO 14), Fribourg - Göttingen 1977

-, Jahwes Entgegnung an Ijob. Eine Deutung von Ijob 38-41 vor dem Hintergrund der zeitgenössischen Bildkunst (FRLANT 121), Göttingen 1978

- , Deine Blicke sind Tauben. Zur Metaphorik des Hohen Liedes (SBS 114-115), Stuttgart 1984

-, Das Hohelied (ZB AT 18), Zürich 1986

- , Der Bogen als Herrschaftssymbol. Einige unveröffentlichte Skarabäen aus Ägypten und Israel zum Thema "Jagd und Krieg", (1977), in: ders. et al. (ed.), Studien zu den Stempelsiegeln aus Palästina / Israel, Bd. III (OBO 100), Fribourg - Göttingen 1990, 27-65. 261-279

- (ed.), Altorientalische Miniaturkunst, Mainz 1990

KEIMER L., Quelques remarques sur la huppe (uppa epops) dans l'Égypte ancienne, BIFAO 30 (1931), 305-331

Kendall Th., Passing through the Netherworld. The Meaning and Play of Senet, an Ancient Egyptian Funerary Game, Belmont/MA 1978

- , Schlangenspiel, LÄ 5 (1984), 653-655 
KENYON K. / Holland T.A., Excavations at Jericho I-V, London 1960-1983

KERKHOF V.I., Catalogue of the Shechem Collection in the Rijksmuseum van Oudheden in Leiden, OMRO 50 (1969), 28-109

KESSLER K., Untersuchungen zur historischen Topographie Nordmesopotamiens nach keilschriftlichen Quellen des 1.Jahrtausends v.Chr. (BTAVO.B 26), Wiesbaden 1980

KHANoussi M., Ein römisches Mosaik aus Tunesien mit Darstellung eines agonistischen Wettkampfes, AW 22 (1991), 146-153

KINDERMANN H., Das Theaterpublikum der Antike, Salzburg 1979

KINDERSPIELPLĀTZE. Beiträge zur kindorientierten Gestaltung der Wohnumwelt I-II, ed. G. SCHOTTMAYER - R. CHRISTMANN (Schriftenreihe des Bundesministers für Jugend, Familie und Gesundheit 44,1-2), Stuttgart u.a. 1976

KIRK G.E., Gymnasion or Khan? A Hellenistic Building at Babylon, Iraq 2 (1935), 223-231 - , Nine Men's Morris - Morelles - Mühlespiel, JPOS 18 (1938), 229-232

KIRKBRIDE D., Five Seasons at the Pre-Pottery Neolithic Village of Beidha in Jordan, PEQ 98 (1966), 8-72

KLATZKIN J., Leibesübungen, EJ 10 (1934), 740-754

KLAUS G., Spieltheorie in philosophischer Sicht, Berlin Ost 1968

KLEIN A.E., Some Greek Playthings, TPAPA 62 (1931), XXVIIf

KLEIN A. und R., Das Spielzeug des Dionysos (Sokratische Hefte 23), Manuheim 1982

KLEMENS AlEXANDRINUS, Stromata, ed. O. STÄHLIN - L. FrǘchTEL (GCS 52), Berlin ${ }^{3} 1960$

- , Paidagogos, ed. H.-I. MARROU et al. (SC 70. 108. 158), Paris 1960-1970

KiENGEL-BrandT E., Spielbretter und Würfel aus Assur, AoF 7 (1980), 119-126

- , Kleinfunde aus Deve Hüyük bei Karkamisch im Vorderasiatischen Museum Berlin, in: Resurrecting the Past. A Joint Tribute to A. BoUNNI (UNHAII 67), Leiden 1990, 133-151

KLUGE N. (ed.), Spielpädagogik. Neuere Beiträge zur Spielforschung und Spielerziehung, Bad Heilbrunn/Obb. 1980

- , Sexuelle Grunderfahrungen im Spiel, in: K.J. KREUZER (ed.), Handbuch der Spielpädagogik 2, Düsseldorf 1983, 145-156

KLUGE-PINSKER A., Schachspiel und Trictrac, Sigmaringen 1991

KNAuf E.A., Zum "Einzelkämpfer" Sinuhe B 110, GM 33 (1979), 33

- , Qaus, UF 16 (1984), 93-95

KNAUTH W., Die sportlichen Qualifikationen der altiranischen Fürsten, Stadion 2 (1976), 1-89 - / NADJMABAdi S., Das altiranische Fürstenideal von Xenophon bis Ferdousi. Nach den antiken und einheimischen Quellen dargestellt, Wiesbaden 1975

KNOBLOCH J., Griech. kindynos m. 'Gefahr' und das Würfelspiel, Glotta 53 (1975), 78-81

KoCH A., Die Leibesübungen im Urteil der antiken und frühchristlichen Anthropologie. Ein Beitrag zur Geschichte des Sportes, Schorndorf 1965

KoCH-HARNACK G., Knabenliebe und Tiergeschenke. Ihre Bedeutung im päderastischen Erziehungssystem Athens, Berlin 1983

KoEHLER O., Vom Spiel bei Tieren, in: W. Marx (ed.), Das Spiel. Wirklichkeit und Methode (Freiburger Dies Universitatis 13), Freiburg i.Br. 1967, 79-105

KöHNE J., Die Schrift Tertullians "Über die Schauspiele" in kultur- und religionsgeschichtlicher Bedeutung (Diss. phil. Münster i.W. 1928), Berlin 1929

DER KÖNIGSWEG. 9000 Jahre Kunst und Kultur in Jordanien und Palästina, Mainz 1987

KöTZSCHE-BREITENBRUCH L., Die neue Katakombe an der Via Latina in Rom. Untersuchungen zur Ikonographie der alttestamentlichen Wandmalereien (JAC Erg.bd. 4), Münster i.W. 1976

KoHUT A., Ist das Schachspiel im Talmud genannt und unter welchem Namen?, ZDMG 46 (1892), 130-135

KollesCH J., Aristoteles, De motu anim. 701b 2-9, Ph. 104 (1960), $143 \mathrm{f}$

KollmanN E.D., A Soldier's Joke or an Epitaph?, IEJ 22 (1972), 145f

KOOIJ R. VAN DER, Empirische Spielforschung. Überblick und neuere Ergebnisse, in: K.J. KREUZER (ed.), Handbuch der Spielpädagogik 1, Düsseldorf 1983, 89-158 
- , Die psychologischen Theorien des Spiels, in: K.J. KREUZER (ed.), Handbuch der Spielpädagogik 1, Düsseldorf 1983, 297-336

KORAN. Übersetzung, Kommentar und Konkordanz von R. PARET, Stuttgart u.a. ${ }^{4} 1985$

KrAELING C.H. (ed.), Gerasa, City of the Decapolis, New Haven/CT 1938

Kramer S.N., Enmerkar and the Lord of Aratta, a Sumerian Epic Tale of Iraq and Iran (Museum Monographs), Philadelphia/PN 1952

KRAMPE W., Die Gymnastik in der Bibel, Deutsche Turn-Zeitung 27 (1881), 269-272; 29 (1881), 289-292; 31 (1881), 313-316; 33 (1881), 337-339

KranZ M., Probleme der Leiblichkeit im biblichen (sic) Judentum, Diss. phil. masch. Köln 1965

KraUs B., Spielecken - Spielplätze, Basel 1979

Kraus K., Das Buch der Glücksspiele, Bonn 1952

Kraus Th. / L. von MatT, Lebendiges Pompeji. Pompeji und Herculaneum. Antlitz und Schicksal zweier antiker Städte, Köln 1973

KRAUSS S., Circus, JE 5, $103 \mathrm{f}$

- , Talmudische Archäologie I-III, Leipzig 1910-1912

- , Griechische und lateinische Lehnwörter im Talmud, Midrasch und Targum I-II, Berlin 18981899 = Hildesheim 1964

KREISER K., Schach, Lex. der Islam. Welt 2 (1974), 88

KRENKEL W., Wachs, KP 5 (1975), 1343f

KREUZER H., Würfelspiele, Wiesbaden 1987

KREUZER K.J., Zur Geschichte der pädagogischen Betrachtung des Spiels und der Spile, in: ders. (ed.), Handbuch der Spielpädagogik 1, Düsseldorf 1983, 229-280

KROLL W., Kalobatēs, RE 10 (1919), 1756

- , Konopaiktes, RE 11 (1922), 1343

- , Skandalistès, RE II 5 (1927), 438

-, Thaumatopoioi, RE Suppl. 6 (1935), 1278-1282

KRUuswiJK K.W., Algemene historie en bibliografie van het damspel, Den Haag 1966

KuBITSCHEK W., Ein Bronzegewicht aus Gela, JÖAI 10 (1907), 127f

KÜMMEL H.M., Ersatzrituale für den hethitischen König (StBT 3), Wiesbaden 1967

KÜNSSBERG E. VON, Rechtsbrauch und Kinderspiel. Untersuchungen zur deutschen Rechtsgeschichte und Volkskunde (SHAW.PH 7, 1920), Heidelberg 1920

KuHNEN H.-P., Palästina in griechisch-römischer Zeit (HdArch Vorderasien II 2), München 1990

KuJAwa G. voN, Ursprung und Sinn des Spiels (Kleine Bücherei zur Geistesgeschichte 4), Leipzig 1949

KURTZ D.C. / BOARDMAN J., Thanatos. Tod und Jenseits bei den Griechen (KAW 23), Mainz. 1985

KUTSCHERA V., Spielzeug. Spiegelbid der Kulturgeschichte, Salzburg 1975

KUTZNER H., Erfahrung und Begriff des Spiels. Versuch den Menschen als spielendes Wsen zu denken, Diss. phil. masch. Freie Universität Berlin 1973

KYLE D.G., Athletics in Ancient Athens (Mnemosyne Suppl. 95), Leiden 1987

Kyrill von JeruSAleM, Catéchèses mystagogiques, ed. A. Piédagnel - P. PARIs (SC 126), Paris 1966

LACEY W.L., Die Familie im alten Griechenland (KAW 14), Mainz 1983

LACTANZ, Institutions divines I-II, ed. P. Monat (SC 326. 337), Paris 1986. 1987

LÄMmer M., Eine Propaganda-Aktion des Königs Herodes in Olympia, KBSW 1 (1972), 160-173 - , King Herod's Endowment to the Olympic Games, in: Proceedings of the Pre-Olympic Seminar on the History of Physical Education and Sport in Asia, Netanya Wingate Institute 1972, 5170

-, Jason's Gymnasium in Jerusalem, in: Proceedings of the Pre-Olympic Seminar on the History of Physical Education and Sport in Asia, Netanya Wingate Institute 1972, 31-50

- , The Introduction of Greek Contests into Jerusalem through Herod the Great and its Political Significance, in: Physical Education and Sports in the Jewish History and Culture. Proceedings of an International Seminar at Wingate Institute July 1973, ed. U. SIMRI, Netanya 1973, 18-38 
- , Ideological Tendencies in the Historiography of Sport in the Jewish Culture (with Particular Consideration of the Biblical and the Hellenic-Talmudic Eras), in: Physical Education and Sports in the Jewish History and Culture. Proceedings of an International Seminar at Wingate Institute July 1973, ed. U. SIMRI, Netanya 1973, 54-72

- , Griechische Wettkämpfe in Jerusalem und ihre politischen Hintergründe, KBSW 2 (1973), 182-227

- , Die Kaiserspiele von Caesarea im Dienste der Politik des Königs Herodes, KBSW 3 (1974), 95-164

- , Griechische Wettkämpfe in Galiläa unter der Herrschaft des Herodes Antipas, KBSW 5 (1976), 37-67

- , Griechische Agone und römische Spiele unter der Regierung des jüdischen Königs Agrippa

I., KBSW 10-11 (1981-1982), 199-237

LAFAYE G., Latrunculi; ludi; lusoria tabula, DarS III 2, 992-995. 1356-1362. 1403-1405

- , Pila; pilarius; pupa, DarS IV 1, 475-478. 478f. 768f

- , Talus; tesserae; trochus; tropa; turben (turbo), DarS V 1, 28-31. 125-136. 492f. 496f. $541 \mathrm{f}$

LAMBERT M., Le jeu d'Enmerkar, Syria 32 (1955), 213-221

LAMBert W.E. / PARKer S.B., Enūma Eliš. The Babylonian Epic of Creation. The Cuneiform

Text, Birmingham - Oxford $1966=1974$

LAMER H., Zwei Zeugnisse über römische Brettspiele, Hermes 60 (1925), 104-110

- , Lusoria tabula, RE 13,2 (1927), 1900-2029

- , Das Fünfsteinspiel, Philologische Wochenschrift 48 (1928), 571-576

LAMON R.S. / SHIPTON G.F., Megiddo I (OIP 42), Chicago/IL 1939

Lancy D.F. / Tindall B.A. (ed.), The Study of Play: Problems and Prospects, West Point/NY 1977

LANCZKOWSKI G. / SCHEUERL H., Spiel, RGG 3 6 (1962), 243-245

LANDES CH. (ed.), Le cirque et les courses de chars, Rome - Byzance, Lattes 1990

LANDSBERGER B., Einige unerkannt gebliebene oder verkannte Nomina des Akkadischen, WZKM 56 (1960), 109-129

- / TADMOR H., Fragments of Clay Liver Models from Hazor, IEJ 14 (1964), 201-219

LANE E.W., Sitten und Gebräuche der heutigen Egypter I-III, Leipzig 1856

LANG M. / Crosby M., Weights, Measures and Tokens. The Athenian Agora Vol. X, Princeton/NJ 1964

La PIANA G., The Byzantine Theater, Spec. 11 (1936), 171-211

LAPP P.W., The 1963 Excavations at Tacannek, BASOR 173 (1964), 4-44

- , Taanach by the Waters of Megiddo, BA 30 (1967), 2-27

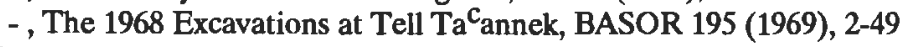

LASER S., Sport und Spiel (ArchHom T), Göttingen 1987

LASKER E., Brettspiele der Völker, Berlin 1931

LA SORSA S., Come giuocano i fanciulli d'Italia, Neapel 1937

LATTE K., Askōliasmos, (1957), in: ders., Kleine Schriften zu Religion, Recht, Literatur und Sprache der Griechen und Römer, München 1968, 700-707

LAUCHERT F. (ed.), Die Kanones der wichtigsten altkirchlichen Concilien nebst den apostolischen Kanones, Freiburg - Leipzig 1896

LAUS PISONIS, ed. A. SEEL, Diss. phil. masch. Erlangen - Nürnberg 1969

LAUTERBaCH W., Das unsterbliche Spiel. Einführung in die Schachkunst, Berlin - New York $5_{1987}$

LaVrencic M. / Doblhofer G. / MaurtiSCh P., Diskos. Sporthistorischer Kommentar (Quellen-Dokumentation zur Gymnastik und Agonistik im Altertum 1), Köln u.a. 1991

LEBEN UND TATEN ALEXANDERS VON MAKEDONIEN. Der griechische Alexanderroman nach der Handschrift L. Griechisch und deutsch, ed. H. vaN THIEL (Texte zur Forschung 13), Darmstadt 21983

LECLERCQ H., Jeu, tables de; Jeux et jouets, DACL 7,2 (1927), 2469-2481. 2504-2527

LEE J.R., Early Bronze Age Game Stones from Bab edh-Dhra, Jordan, Levant 14 (1982), 171-174 
LEFEVRE E., Theatrum Mundi: Götter, Gott und Spielleiter im antiken Drama, in: Theatrum Mundi. Götter, Gott und Spielleiter im Drama von der Antike bis zur Gegenwart. FS für H. KuNISCH zum 80.Geb., ed. F. LINK - G. NIGGL (LWJ Sonderbd.), Berlin 1981, $50-91$

LEGRand PH.-E., saltus, DarS IV 2, 1054-1056

LEHMANN-FilHES M., Vielseitige Verwendung der Schafknochen in Island, ZVVK 19 (1909), 433-435

LEITH M.J.W., Greek and Persian Images in Pre-Alexandrine Samaria: The Wâdi ed-Dâliyeh Seal Impressions, Ph.D. Diss. unpubl. Harvard University 1990

LEM S., Sade und die Spieltheorie, Frankfurt a.M. 1981

LEMKE E., Das Fangsteinchenspiel, ZVVK 16 (1906), 46-66

- , Spiel-, Zauber- und andere Puppen, ZVVK 25 (1915), 126-136

LEPPIN H., Histrionen. Untersuchungen zur sozialen Stellung von Bühnenkünstlern im Westen des Römischen Reiches zur Zeit der Republik und des Principtas (Antiquitas 1,41), Bonn 1991

LERNAU H., Animal Remains, in: Y. AHARON (ed.), Lachish V, Tel Aviv 1975, 86-103

- , Mammalian Remains, in: B. RothenBERg (ed.), The Egyptian Mining Temple at Timna. Researches in the Arabah 1959-1984, Vol. I, London 1988, 246-253

LEROY J., Les manuscripts syriaques à peintures conservés dans les Bibliothèques d'Europe et d'Orient (BAH 72), Paris 1964

LESKY A., Ein ritueller Scheinkampf bei den Hethitern, (1926), in: ders., Gesammelte Schriften, Bern - München 1966, 310-317

LEVI D., Antioch Mosaic Pavements, Vol. I-II, Princeton/NJ - London - The Hague 1947

LEVINE L.I., Roman Caesarea. An Archaeological-Topographical Study (Qedem 2), Jerusalem 1975

- / NETZER E., Excavations at Caesarea Maritima 1975, 1976, 1979 - Final Report (Qedem 21), Jerusalem 1986

LEVY S. / Avi-YonaH M. et al., The Ancient Synagogue of $\mathrm{Ma}^{\mathrm{c}}$ on (Nirim), Rabinowitz-Bulletin $3(1960), 6-40$

LEWINSKI Y.-T., Games, EJ 7 (1971), 303-308

Libanios, Briefe. Griechisch und deutsch, ed. G. FAtouros - T. Krischer (Tusculum), München 1980

LICHTENSTEIN M. / RABINOWTTZ L.I., Lots, EJ 11 (1971), 510-513

LichrwITZ K., Neues Buch der siebzehn und vier Kartenspiele, Niedernhausen/Ts. 1988

LiEbowrTz H., Terra-Cotta Figurines and Model Vehicles. The Oriental Institute Excavations at Selenkahiye, Syria 1965 and 1967. Final Report 1 (Bibl. Mes. 22), Malibu 1988

LIFsHrTZ B., Une Inscription Byzantine de Cesarée en Israël (Caesarea Maritima), REG 70 (1957), 118-132

-, Inscriptions de Césarée, RB 74 (1967), 50-59

- , Études sur l'histoire de la Province Romaine de Syrie, ANRW II 8 (1977), 3-30

LiNDBLOM K.G., Die Schleuder in Afrika und anderwärts (Riksmuseets Etnografiska Avdeining Smärre Meddelanden 2), Stockholm 1927

- , The Use of Stilts, especially in Africa and America (Riksmuseets Etnografiska Avdelning Smärre Meddelanden 3), Stockholm 1927

- , The Sling, especially in Africa. Additional Notes to a Previous Paper (Riksmuseets Etnografiska Avdelning Smärre Meddelanden 17), Stockholm 1940

LINDE A. VAN DER, Geschichte und Litteratur des Schachspiels I-II, Berlin 1874

LINK F., Götter, Gott und Spielleiter, in: Theatrum Mundi. Götter, Gott und Spielleiter im Drama von der Antike bis zur Gegenwart. FS für H. KuNISCH zum 80.Geb., ed. ders. - G. NiGGL (LWJ Sonderbd.), Berlin 1981, 1-47

LINK J., Die Geschichte der Schauspieler nach einem syrischen Manuscript der königlichen Bibliothek in Berlin (Diss. phil. Bern 1903), Berlin 1904

Linton O., The Parable of the Children's Game: Baptist and Son of Man (Matt. XI 16-19 = Luke VII 31-5): A Synoptic Text-Critical, Structural and Exegetical Investigation, NTS 22 (1976), 159-179 
LIPINSKI E., 'Urîm and Tummìm, VT 20 (1970), 495f

- , liwjātāan, ThWAT 4 (1982-1984), 522-527

LiTTAUER M.A. / Crouwel J.H., A Terracotta Wagon Model from Syria in Oxford, Levant 22 (1990), 160-162

LITTMANN E. et al. (ed.), Greek and Latin Inscriptions in Syria, PPUAES Div. III A 1-7, Leiden 1907-1921

LLOYD A.B., Herodotus Book II. Introduction and Commentary 1-98.99-182 (EPRO 43,1-3), Leiden 1975. 1976. 1988

LloYd S., Beycesultan Vol. III 1: Late Bronze Age Architecture (Occasional Publications of the British Institute of Archaeology at Ankara 11), London 1972

LÖNNQUIST B., Zwei Spieltraditionen, in: Kinderkultur, ed. K. KösTLIN (Hefte des Focke-Museums 73), Bremen 1987, 255-260

LöSCHENKOHL E., Leistung, Lernprozeß und Motivation im Kinderspiel. Untersuchungen zum Spielerfolg von Kindern im technischen und verbalen Bereich, Wien 1981

Löw L., Beiträge zur jüdischen Alterthumskunde II: Die Lebensalter in der jüdischen Literatur von physiologischem, rechts-, sitten- und religionsgeschichtlichem Standpunkte betrachtet, Szegedin 1875

LOFFREDA S., The Late Chronology of the Synagogue of Capernaum, in: L.I. LEVINE (ed.), Ancient Synagogues Revealed, Jerusalem 1981, 52-56

LoGSTRUP K.E., Spielleidenschaft, RGG $^{3} 6$ (1962), 245-248

LOMBARD CH., An Introduction to the Ethnological Study of Children's Games, in: J. RAABE et al. (ed.), The Child and Play. Theoretical Approaches and Teaching Applications (UNESCO Educational Studies and Documents 34), Paris 1980, 48-63

LORENZ K., Vergleichende Verhaltensforschung. Grundlagen der Ethologie, Wien - New York 1978

LORETZ O., Leberschau, Sündenbock, Asasel in Ugarit und Israel. Leberschau und Jahwestatue in Psalm 27. Leberschau in Psalm 74 (UBL 3), Altenberge 1985

- , Ugarit und die Bibel, Darmstadt 1990

Loud G., The Megiddo Ivories (OIP 52), Chicago/IL 1938

- , Megiddo II (OIP 62), Chicago/IL 1948

LOVE B. (ed.), Play the Game, London 1978

LOVETT E., The Ancient and Modern Game of Astragals, Folkl. 12 (1901), 280-289

LUCAN, De bello civili. Lateinisch und deutsch, ed. G. LUCK (SQAW 34), Berlin Ost 1989

LUCCHESI PALLI E., Morraspiel, LCI 3 (1971 = 1990), 281f

LÜDERIZZ G., Corpus jüdischer Zeugnisse aus der Cyrenaika (BTAVO.B 53), Wiesbaden 1983

LÜDERS H., Das Würfelspiel im alten Indien, (1907), in: ders., Philologica Indica. Ausgewăhlte kleine Schriften, Göttingen 1940, 106-175

LUDUS DE ANTICHRISTO. Lateinisch und deutsch, ed. R. ENGELSING (reclam 8561), Stuttgart 1985

LUKACSY A., Spiele aus aller Welt, Budapest 1972

LUKIAN, Works, Vol. I-VIII, ed. A.H. HARMON (The Loeb Classical Library), Cambridge/MA London 1968-1979

Luschan F. von, Ausgrabungen in Sendschirli IV, Berlin 1911

- , Zusammenhänge und Konvergenz, MAGW 48 (1919), 1-146

- / ANDRAE W., Die Kleinfunde von Sendschirli (Sendschirli V), Berlin 1943

LUSCHEY H., Iran und der Westen von Kyros bis Khosrow, AMI NF 1 (1968), 15-37

Lux U., Eine altchristliche Kirche in Mādeba, ZDPV 83 (1967), 165-182

- , Die Apostel-Kirche in Mādeba, ZDPV 84 (1968), 106-129

LuZ U., Das Evangelium nach Matthäus. 2.Teilband: Mt 8-17 (EKK 1,2), Zürich - Braunschweig - Neukirchen-Vluyn 1990

MAAs P., Gelōtopoioi, RE 7,1 (1910), 1019-1021

MACALISTER RA.S., The Excavation of Gezer 1902-1905 and 1907-1909, London 1912 
- / Duncan J.G., Excavations on the Hill of Ophel, Jerusalem 1923-1925 (PEFA 4), Jerusalem 1926

MacDonald B., The Wadi el Hasā Archaeological Survey 1979-1983, West Central Jordan, Waterloo/Ontario 1988

MACRIDY TH., Sépulture enfantine de Harah, RB 13 (1904), $560 f$

MACrobius, Saturnalia, Tome 1-2, ed. H. BorneCQUE et al., Paris 1937

MĀHL E., Gymnastik und Athletik im Denken der Römer (Heuremata 2), Amsterdam 1974

MAGEN U., Assyrische Königsdarstellungen - Aspekte der Herrschaft (BagF 9), Mainz 1986

Magnanini P., Le iscrizioni fenicie dell'Oriente, Rom 1973

MAINZER M., Über Jagd, Fischfang und Bienenzucht bei den Juden der tannäischen Zeit, Frankfurt a.M. 1910

Malalas Joh., Chronographia, ed. L. Dindorf, Bonn 1831 (vgl. PG 97, 65-718)

MANN U., Der Ernst des heiligen Spiels, ErJb 51 (1982), 9-58

MARC AurEL, Wege zu sich selbst. Griechisch und deutsch, ed. R. NiCKEL (Tusculum), Zürich München 1990

MARICQ A., Factions du cirque et parties populaires, BAB.L 36 (1950), 396-421

- , Tablettes de défixion de Fiq (Audollent 15 = IGR III 1543; Aud. 16), Byz. 22 (1952), 360-368

Marinatos S. - Hirmer M., Kreta, Thera und das mykenische Hellas, München ${ }^{3} 1976$

MARTIAL, Epigrams, ed. W.C.A. KeR (The Loeb Classical Library), London - Cambridge/MA $1919-1920=1961$

MARTIN G.M., "Wir wollen hier auf Erden schon...". Das Recht auf Glück, Stuttgart u.a. 1970

- , Spiel in der Bibel - Kreuz im Spiel. Zwei Grundfragen zur Diskussion um die "Theologie des Spiels", EvErz 27 (1975), 21-30

MARTIN-ACHARD R., L'oracle contre Shebnâ et le pouvoir des clefs, Es. 22,15-25, ThZ 24 (1968), 241-254

$A L-M A S C \bar{u} D \tilde{l}$, Bis zu den Grenzen der Erde. Auszüge aus dem "Buch der Goldwäschen" (Murü̆ğ ad-dahab), ed. G. RoTTER, (Bibliothek Arab. Erzähler), Stuttgart 1982

MATHYS F.K., Der Kulturwert alter Kinderspiele, in: Das Spiel, ed. AusschuB Deutscher Leibeserzieher, Frankfurt a.M. 1959, 91-104

- , Im Freien gespielt. Kleine Historie des Kinderspiels, Basel 1975

-, Ist die Schwarze Köchin da? Alte Kinderspiele, Frauenfeld 1983

- , 4500 Jahre FuBball, Basler Magazin (Basler Zeitung) 22 (1990), 1-5

- / Triet M. (ed.), Spiel und Sport im alten Ägypten, Basel 1978

MATZ D., Greek and Roman Sport. A Dictionary of Athletes and Events from the Eighth Century B.C. to the Third Century A.D., Jefferson/NC - London 1991

MAU A., Alveus; Apodidraskinda; Artiazein; Astragalos; Ballspiel, RE 2 (1896), 1704f. 1793-1795. 2819. 2832-2834

- , Basilinda; Capita aut navia, RE 3 (1899), 99. 1513

- , Calculi; Cernulus; Chalkē myia; Chalkismos; Chelichelōnē; Chytrinda; Circulator, RE 3 (1899), 1345. 1983. 2067. 2092. 2226f. 2528f. 2570

- , Crepitaculum, RE 4 (1901), $1705 \mathrm{f}$

- , Diagrammismos; Dielkystinda, RE 9 (1903), 311f. 475

- , Duodecim Scripta, RE 5 (1905), 1794-1796

- , Epostrakismos, RE 6,1 (1907), 251

- , Episkyros, RE 11 (1907), 1999f

- , Fritillus; Gelōtopoio, RE 13 (1910), 108-110. 1019-1021

MAXIMOS ConfEsSOR, Peri diaphorōn aporiōn (Ambiguonum liber), PG 91 (1865), 1031-1418

MAY K., Von Bagdad nach Stambul. Reiseerzählung (KARL MAYs Werke. Historisch-kritische Ausgabe für die KARL-MAY-Gedächtnis-Stiftung IV 3), Freiburg 1907 = Zürich 1990

MA YER L.A., Mamluk Playing Cards, BIFAO 38 (1939), 113-118

- , Mamluk Playing Cards, ed. R. ETtinghausen - O. Kurz (The L.A. MAYER Memorial Studies in Islamic Art and Archaeology 1), Leiden 1971 
MAYER-OPIFICIUS R., Götterpaare in Kleinasien und Mesopotamien, in: Studien zu Religion und Kultur Kleinasiens. FS für Fr.K. DÖRNER zum 65.Geb., Vol. II (EPRO 66), Leiden 1978, 595601

MAZAR B., Beth She ${ }^{c_{a r i m}}$ Report on the Excavations during 1936-1940, Vol. I: Catacombs 1-4, Jerusalem 1973

- , Der Berg des Herrn. Neue Ausgrabungen in Jerusalem, Bergisch-Gladbach 1979

MCCown CH.CH., Tell en-Nașbeh I, Berkeley - New Haven 1947

McCown D.E. / Haines R.C. / HANSEN D.P., Nippur I. Temple of Enlil, Scribal Quarter and Soundings (OIP 78), Chicago/IL 1967

MCGOVERN P.E., The Late Bronze and Early Iron Ages of Central Transjordan: The Baq ${ }^{c} a h$ Valley Project, 1977-1981 (University Museum Monograph 65), Philadelphia/PN 1986

Mecquenem M. DE et al., Mémoires de la Mission Archéologique en Iran 29. Mission de Susiane, Paris 1943

MEGAw A.H.S., Supplementary Excavations on a Castle Site at Paphos, Cyprus, 1970-1971, DOP 26 (1972), 323-343

MEHL E., Antike Schwimmkunst, München 1927

- , Schwimmen, RE Suppl. 5 (1931), 847-864

- , Troiaspiel, RE Suppl. 8 (1956), 888-905

- , Stammen die modernen Ballspiele von einem altägyptischen Fruchtbarkeitsritus ab?, LE 6 (1963), 8-12 [Rez. von R.W. HENDERson, Ball, Bat and Bishop, 1947]

MEINECKE G., Selbstgefährdungstendenzen im Spiel eines Säuglings, PsB 2 (1956), 299-307

MEISSENBURG E., Altägyptische, -griechische und -römische Brettspiele. Eine Bibliographie, Börsenblatt für den Deutschen Buchhandel, Frankfurter Ausgabe 23.Jg., H. 72 (1967), 2055-2060

- , Altägyptische, -griechische und -römische Brettspiele, Ziva antika 22 (1972), 171-182

MEISSNER D., Die babylonischen Kleinplastiken (Texte und Materialien der Frau Professor Hilprecht Collection of Babylonian Antiquities im Eigentum der Universität Jena 4), Leipzig 1934

- , Studien zur assyrischen Lexikographie (MAOG 13,2), Leipzig 1940

MENDNER S., Boxhandschuhe im Altertum, Gym. 60 (1953), 20-26

- , Das Ballspiel im Leben der Völker, Münster i.W. 1956

- , Das Spiel Phaininda-Harpastum, Gym. 66 (1959), 517-524

- , Gesellschaftsspiele, RAC 10 (1978), 847-895

Mensch und Arbeit, ed. E. OLSHAUSEN et al. (Humanistische Bildung 14), Stuttgart 1990

MENTS VAN M., Rollenspiel: effektiv, München 1985

Mercier L., La Chasse et les Sports chez les Arabes, Paris 1927

MERGEn A., Spielsucht, in: FS für W. SARSTEDT zum 70.Geb., ed. R. HAMM, Berlin - New York 1981, 189-196

Meriggi P., Manuale di Eteo Geroglifico, Parte II: Testi - $1^{\mathrm{a}}$ Serie. I Testi neo-etei più o meno complete (Incunabula Graeca 13), Rom 1967

MERKELBACH R., Herakles und der Pankratiast, ZPE 6 (1970), 47-49

- , Der griechische Wortschatz und die Christen, ZPE 18 (1975), 101-148

- , Die ruhmvollen Blumenkohl-Ohren des Pionios von Smyrna, ZPE 76 (1989), 17f

MERSHEN B., Töpferin, Flechterin, Weberin und Gerberin. Zum Haushaltshandwerk im Ostjordanland, in: Pracht und Geheimnis. Kleidung und Schmuck aus Palästina und Jordanien, ed. G. VöLGER et al., Köln 1987, 100-105

- , Amulette als Komponenten des Volksschmuckes im Jordanland, in: a.a.O., 106-109

-, Amulets and Jewelry from Jordan - A Study on the Function and Meaning of Recent Dead Necklaces, Tribus 38 (1989), 43-58

- / KNAUF E.A., From Gadar to Umm Qais, ZDPV 104 (1988), 128-145

MESHEl Z., Horvat Ritma - An Iron Age Fortress in the Negev Highlands, TA 4 (1977), 110-135

MESHORER Y., Coins of the City of Gadara struck in Commemoration of a Local Naumachia, Sefunim 1 (1966), 28-32 (hebr.)

- , City-Coins of Eretz-Israel and the Decapolis in the Roman Period, Jerusalem 1984

- / QEDAR Sh., The Coinage of Samaria in the Fourth Century BCE, Jerusalem 1991 
MEUSZYNSKI J., Die Rekonstruktion der Reliefdarstellungen und ihrer Anordnung im Nordwestpalast von Kalhu (Nimrūd) (BagF 2), Mainz 1981

MEYER J.-W., Lebermodell oder Spielbrett, in: R. HACHMANN (ed.), Bericht über die Ergebnisse der Ausgrabungen Kāmid el-Lōz in den Jahren 1971 bis 1974 (SBA 32), Bonn 1982, 53-79

- , Die Spielbretter KL 78:534 und KL 78:536 bis, in: R. HACHMANN (ed.), Bericht über die Ergebnisse der Ausgrabungen Kāmid el-Lōz in den Jahren 1977 bis 1981 (SBA 36), Bonn 1986, 123-143

- , Spielbretter aus Kāmid el-Lōz, in: R. HACHMANN (ed.), Frühe Phöniker im Libanon. 20 Jahre deutsche Ausgrabungen in Kāmid el-Lōz, Mainz 1983, 101-104

- , Untersuchungen zu den Tonlebermodellen aus dem Alten Orient (AOAT 39), Kevelaer Neukirchen-Vlyun 1987

MEYER N., Un "Diable" découvert dans les fouilles urbaines de Saint-Denis, Archaeologia musicalis $1(1987) 8$

MEYERE V. DE, De Kinderspelen von Pieter Bruegel den Oude verklaart, Amsterdam 1941

MeYer-HolzaPfel M., Das Spiel bei Säugetieren, in: Handbuch der Zoologie 8,10,5 (2.Lief.), Berlin 1956, 1-36

MEYSHAN J., The Coinage of Agrippa the First, IEJ 4 (1954), 186-200

Michaelidou-Nicolaou I., Table à jeu de Dhekelia (Chypre), BCH 89 (1965), 122-127

- , Une nouvelle table à jeu de Chypre, BCH 94 (1970), 549f

MiCHEL E., Die Assur-Texte Salmanassars III. (858-824), 3.Fortsetzung, WO 1,4 (1949), 255-271

Michon E., La Collection archéologique de l'Université Saint Joseph acquise par la Musée de Beyrouth, Syria 3 (1922), 171-175

MiELSCH H., Zur Deutung und Datierung der Knöchelspielerinnen des Alexandros, MDAI.R 86 (1979), 233-248

MillaR S., Psychologie des Spiels, Ravensburg 1973

Millard A., Archaeology and the World of the Bible, BAIAS 6 (1986-1987), 46-48

MILLER D.L., The Kingdom of Play: Some Old Theological Light from Recent Literature, USQR $25(1970), 343-360$

- , Theology and Play Studies: An Overview, JAAR 39 (1971), 349-354

-, Gods and Games. Toward a Theology of Play, New York u.a. 21973

Miller S.G., Arete. Ancient Writers, Papyri, and Inscriptions on the History and Ideals of Greek Athletes and Games, Chicago/IL 1979

Millon Cl. / Schouler B., Les Jeux Olympiques d'Antioche, Pallas 34 (1988), 61-76

MiNGAZZINI P., Sulla pretesa funzione oraculare del Kottabos, AA 1950-1951, 35-57

MiNUCIUS FElix, Octavius. Lateinisch und deutsch, ed. B. KYTZLER (Reclam 9860), Stuttgart 1977

Miodonski A., Anonymus adversus aleatores und die Briefe an Cyprian, Lucian, Celerinus und an den karthageniensischen Klerus (Cypr., epist. VIII, XXI-XXIV), Leipzig 1889

Miron R., Kāmid el-Lōz 10: Das 'Schatzhaus' im Palastbereich. Die Funde (SBA 46), Bonn 1990

MisCHNA, Vol. I-VI, ed. H. ALBECK - H. YALON, Jerusalem 1952-1958

Mitchell B., Ancient Ball Games, CJ 34 (1938-1939), 103

MITTMANN S., Beiträge zur Siedlungs- und Territorialgeschichte des nördlichen Ostjordanlandes (ADPV 2), Wiesbaden 1970

- , "Reigentänze" in Ex 32,18, BN 13 (1980), 41-45

MrTTWOCH E., Abessinische Kinderspiele. Amharische Texte übersetzt und erklärt, MSOS 13 (1910), 107-140

MOGENSEN M., Ein altägyptischer Boxkampf, ZÄS 57 (1922), 87f

MOHR W., Murmelspiel. Ein Experiment, in: FS für J. TRIER zum 70.Geb., ed. W. FOERSTE - K.H. BoRCK, Köln - Graz 1964, 47-68

Moltmann J., Die ersten Freigelassenen der Schöpfung. Versuche über die Freude an der Freiheit und das Wohlgefallen am Spiel, München 1971

MOMMSEN H., Achill and Aias pflichtvergessen?, in: Tainia. FS für R. HAMPE zum 70.Geb., ed. H.A. CAHN - E. Simon, Mainz 1980, 139-152 
Montgomery H.C. / Kroll W. / Mehl E., Petauron, RE 19 (1937), 1124f

MoNTET P., Tombeaux de la $\mathrm{I}^{\mathrm{re}}$ et de la IV ${ }^{\mathrm{e}}$ dynastie à Abou-Roash, Kêmi 8 (1946), 11-69. 156223

- , Le jeu du Serpent, CEg 30,60 (1955) 189-197

Moor P., Die Bedeutung des Spiels in der Erziehung. Betrachtungen zur Grundlegung einer Spielpädagogik, Bern - Stuttgart 1962

MOOREY P.R.S., Cemeteries of the First Millenium B.C. at Deve Hüyük (BAR.IS 87), Oxford 1980

MoOrTgat-Correns U., Ein Spielbrett vom Tell Ailun (?), in: FS für J. Friedrich zum 65.Geb., ed. R. vON KIENLE et al., Heidelberg 1959, 339-345

MOREL CH., Basilinda, DarS I (1877), 681

MORETTI L., Iscrizioni agonistiche greche (Studi pubblicati dall' Istituto Italiano per la Storia Antica 12), Rom 1953

- , Olympionikai, i vincitori negli antichi agoni olimpici (AANL.M 356), Rom 1959, 55-198

MORGENSTERN O., Spieltheorie und Wirtschaftswissenschaft, Wien - München 1963

MORTON B., Kuscheltiere - kunterbunt und selbstgemacht, Stuttgart 1977

MORTON W.H., Umm el-Biyara, BA 19 (1966), 26-36

MosCATI S., L'epigrafia ebraica antica 1935-1950, Rom 1951

- (ed.), The Phoenicians, Milano 1988

Mosso A., Ceramica neolitica di Phaestos e vasi dell'epoca minoica primitiva, MAnt 19 (1908), 141-218

Moulton R., Das Drachenbuch. Geschichte - Flugtechnik - Selbstbau von Drachen, Ravensburg 1982

Mozart W.A., Musikalisches Würfelspiel. Eine Anleitung "Walzer oder Schleifer mit zwei Würfeln zu componieren ohne Musikalisch zu seyn, noch von der Composition etwas zu verstehen" (1793 / 1796), ed. K.H. TAUBERT, Mainz - London - New York 1956

MülleR A., Das Bühnenwesen in der Zeit vom Constantin d.Gr. bis Justinian, NJKA 23 (1909), $36-55$

MÜLLER J., Das Fangsteinspiel in den Rheinlanden, ZVVK 28 (1918), 26-41

MÜLlER R.F., Dame. Duell mit flachen Steinen, Düsseldorf 1988

MÜLLER W.W., The Meaning of Sabaic KRWM, in: Arabian Studies in Honour of M. GHUL, ed.

M.M. IBRAHIM, Wiesbaden 1989, 89-96

MÜlleR-AlfELD TH., Brettspiele, Frankfurt a.M. 1963

MUNTNER S., Leibesübungen bei den Juden, Menorah 4,6-7 (1926), 378-393

- , Das Wettrennen des Königs Salomo oder jüdischer Sport im 4. bis 6.Jahrhundert n.Chr., Der Schild 5,3 (1926), 22

- / Theilhaber F.A., Sport und Körperkultur bei den Juden, JL 4,2 (5) (1930), 560-567

MuRRAY A.S. / SMrTh A.H. / WALTERS H.B., Excavations in Cyprus, London 1900

MurRAY M.A. / Ellis J.C., A Street in Petra, London 1940

MURRAY H.J.R., The mediaeval game of tables, MAe 10 (1941), 57-69

- , A History of Board-Games other than Chess, Oxford 1952

MusCarella O.W., The Iron Age at Dinkha Tepe, Iran, MMJ 9 (1974), 35-90

Museum für Islamische Kunst Berlin. Staatliche Museen Preußischer Kulturbesitz. Katalog, ed.

K. BRISCH et al., Berlin ${ }^{2} 1979$

MusIL A., Arabia Petraea I-III, Wien 1907-1908 = Hildesheim u.a. 1989

- , Arabia Deserta. A Topographical Itinerary, New York 1927

-, The Manners and Customs of the Rwala Bedouins (American Geographical Society, Oriental Explorations und Studies 6), New York 1928

Mussies G., Marnas God of Gaza, ANRW II 18,4 (1990), 2412-2457

NACIRI M., Die Einstellung des Islam zum Sport, in: Sport in unserer Welt - Chancen und Probleme, ed. O. GRuPE et al., Berlin - Heidelberg - New York 1973, 652-654

NAEGELE I.M. / HAARMANN D. (ed.), Darf ich mitspielen? Kinder verständigen sich in vielen Sprachen - Anregungen zur interkulturellen Kommunikationsförderung, Weinheim - Basel 1986 
NAHRSTEDT W., Die Entstehung der Freizeit. Dargestellt am Beispiel Hamburgs, Göttingen 1972

NASH W.L., Ancient Egyptian Draughts-Boards and Draughts-Men, PSBA 24 (1902), 341-348

NASSOUHI E., Un curieux monument néo-assyrien en marbre rouge veine, RA 22 (1925), 17-22

NEEDLER W., A Thirty-Square Draught-Board in the Royal Ontario, JEA 39 (1955,) 60-75

Negev A., The Nabatean Potter's Workshop at Oboda, Bonn 1974

- , The Late Hellenistic and Early Roman Pottery of Nabatean Oboda (Qedem 22), Jerusalem 1986

NELSON G.W., A Greek Votive Iynx-Wheel in Boston, AJA 44 (1940), 443-456

NETZER E., The Winter Palaces of the Judean Kings at Jericho at the End of the Second Temple

Period, BASOR 228 (1977), 1-13

- , Greater Herodium (Qedem 13), Jerusalem 1981

NEUBECKER A.J., Altgriechische Musik. Eine Einführung, Darmstadt 1977

NeuTsCH B., Spiel mit dem Astragal, in: Ganymed. Heidelberger Beiträge zur antiken Kunstgeschichte, ed. R. HERBIG, Heidelberg 1949, 18-28

- , Archäologische Ausgrabungen und Funde im Bereich der unteritalischen Soprintendezen von Tarent, Reggio di Calabria und Salerno (1949-1955), AA 1956, 193-450

NEWBERRY P.E., Beni Hasan II, London 1894

Newson J. / NEwson E., Toys and Playthings, Harmondsworth 1979

NIEBUHR C., Reisebeschreibung nach Arabien und den umliegenden Ländern, Bd. I-III, Kopenhagen 1774-1778 = Hamburg $1837=$ Graz 1968

NIKOLAUS VON KUES, Philosophisch-theologische Schriften. Studien- und Jubiläumsausgabe Bd.

III. Lateinisch und deutsch, ed. L. GABRIEL - D. DUPRE - W. DUPRE, Wien 1967

NiLsSON M.P., Griechische Feste von religöser Bedeutung mit Ausschluß der attischen, 1906 = Darmstadt 1957

NITSCH-BERG H., Kindliches Spiel zwischen Triebdynamik und Enkulturation. Der Beitrag der Psychoanalyse und der Entwicklungstheorie Piagets, Stuttgart 1978

NoLl R., Seltsame Spielwürfel, BJB 174 (1974), 567-569

Nolle J., Südkleinasiatische Losorakel in der römischen Kaiserzeit, AW 18,3 (1987), 41-49

Nonnos, Dionysiaka, Vol. I-II, ed. W.H.D. RousE (The Loeb Clasical Library), Cambridge/MA

- London 1940 = 1962-1963

- , Metaphrasis S.Evangelii Ioannei, ed. F. PAssovius, Leipzig 1834

NOTH M., Das 2.Buch Mose. Exodus (ATD 5), Göttingen ${ }^{1973}$

Nougayrol J., Cylindres-sceaux et empreintes de cylindres trouvés en Palestine (BAH 33), Paris 1939

- , Jeux profanes, jeux sacrés, RA 41 (1947), 46-53

NovatIAN, Opera, ed. G.F. DiERCKS (CCSL 4), Turnholt 1972

Novum TESTAMENTUM Graece ${ }^{26}$ et Latine, ed. K. und B. Aland, Stuttgart 1983

NuSCHELER F. / Grosse-OETRINGHAUS H.-M. (ed.), Kinderhände. Kinderarbeit in der Dritten Welt, Baden-Baden 1988

Nux, ed. R.M. PulBrooK, Maynooth 1985 [vgl. ed. H. RuPPRECHT (Pseudoovidiana 3), Mitterfels 1982]

ÖZGEN E., A Group of Terracotta Wagon Models from Southeastern Anatolia, AnSt 36 (1986), 165-171

ÖzGǓç N., Acemhöyük Kazilari / Excavations at Acemhöyük, Anadolu / Anatolia 10 (1966), 128. 29-52

ÖzGÜÇ T., Kültepe Kazisi Raporu 1948. Ausgrabungen in Kültepe (TTKY 5,10), Ankara 1950

- , Excavations at Kültepe 1954 (TTKY 19), Ankara 1955

- , Kültepe-Kaniş II: New Researches at the Trading Center of the Ancient Near East (TTKY

V.Dizi, Sa. 41), Ankara 1986

OFFNER G., Jeux corporels en Sumer. Documents relatifs à la compétition athlétique, RA 56 (1962), 31-38

OHLERT K., Rätsel und Rätselspiele der alten Griechen, Berlin ${ }^{2} 1912=$ Hildesheim 1979 
Olivova V., Games and Sport Elements in Ancient Mesopotamia, History of Physical Education and Sport 2 (1974), 47-70

- , Chariot Racing in the Ancient World, Nikephoros 2 (1989), 65-89. 307f, Abb. 4-11

OLsson K.A., The God Game, Cleveland 1968

OOMS I., Spiel und Ernst bei Platon, Diss. phil. masch. Bonn 1957

OPPENHEIM M. Frh. voN, Der Djerĭd und das Djeríd-Spiel, Isl. 2 (1926), 590-617

OPPERMANN S., Schwimmen, KP 5 (1975), 47

OREN E.D., The 'Herodian Doves' in the Light of Recent Archaeological Discoveries, PEQ 101 (1968), 56-61

- , The Northern Cemetery of Beth Shan (University Museum Monograph), Leiden 1973

ORIGines, Werke I-II, ed. P. KoETSCHAU (GCS 2-3), Leipzig 1899

ORPHCORUM Fragmenta, ed. O. KERN, Berlin 21963

ORTH W., Zum Gymnasium im römerzeitlichen Ägypten, in: Althistorische Studien. FS für H.

BENGSTON zum 70.Geb. (Hist. ES 40), Wiesbaden 1983, 223-232

ORTHMANN W., Untersuchungen zur späthethitischen Kunst (SBA 8), Bonn 1971

- (ed.), Der Alte Orient (PKG 14), Berlin 1975

OsTASZ A.A., The Hippodrome of Gerasa: A Report on Excavations and Research 1982-1987, in: Jerash Archaeological Project 1984-1988, Vol. II, Paris 1989, 51-77

OSTEN H.H. von der, The Alishar Hüyük Seasons of 1930-1932 Part II. III (OIP 29. 30; Researches in Anatolia 8. 9), Chicago/IL 1937

OTTO E., Ball, Schlagen des, LÄ 1 (1975), 608f

OTZEN B., ' $b d$, ThWAT 1 (1970-1973), 20-24

OVADIAH A., Gaza, EAEHL 2 (1976), 408-417

- and R., Hellenistic, Roman and Early Byzantine Mosaic Pavements in Israel (Bibliotheca Archaeologica 6), Rom 1987

Ovid, Tristia. Epistulae ex Ponto. Lateinisch und deutsch, ed. W. WiLlige, Darmstadt 1990

- , Ars amandi. Lateinisch und deutsch, ed. N. HolzBERG (Tusculum), Zürich - München ${ }^{2} 1988$

-, Amores. Liebesgedichte. Lateinisch und deutsch, ed. W. MARG - R. HARDER, München - Zürich $6_{1984}$

- 12 Metamorphosen. Lateinisch und deutsch, ed. E. RösCH (Tusculum), Zürich - München

PALITZSCH F., Brettspiele in vorgeschichtlicher Zeit, Deutsche Schachzeitung 86 (1931), 98-100

PANNENBERG W., Anthropologie in theologischer Perspektive, Göttingen 1983

PAPAOIKONOMOU Y., L'enfant aux astragales. A propos d'une stèle funéraire crétoise, BCH 105 (1981), 255-263

PAPOUSEK H. und M., Das Spiel in der Frühentwicklung des Kindes, Suppl. pädiat. prax. 18 (1977), 17-32

PARLASCA I., Terrakottenfunde aus Petra, in: M. LINDNER - J.P. ZertLer (ed.), Petra - Königin der Weihrauchstraße, Fürth 1991, 111-127

PARLASCA K., Einige singuläre Kleinfunde aus Petra, in: a.a.O., 129-134

PARrot A., Mission Archéologique de Mari II. Le Palais (BAH 68), Paris 1958

- et al., Die Phönizier (Universum der Kunst), München 1977

PARRY V.J., Dieñd, EI 2 (21965), 532f

Patlagean E., Byzanz im 10. und 11.Jahrhundert, in: PH. ARIEs - G. Duby (ed.), Geschichte des privaten Lebens I, Frankfurt a.M. 1989, 515-599

PAUL S., Notizen zu einigen afrikanischen Geschicklichkeitsspielen. Lic. phil. masch. Uppsala 1962

- , Afrikanische Ballspiele, BaA NF 18 (1970), 155-251

-, Afrikanische Puppen (BaA.B 6), Berlin 1970

- , Afrikanische Konzentrationsspiele, in: Afrikanische Sprachen und Kulturen im Querschnitt.

FS für J. LUKAS (Hamburger Beiträge zur Afrikakunde 14), Hamburg 1971, 358-367

- , Das Fingerknobeln und ähnliche Spiele in Afrika, Anthr. 66 (1971), 145-172

-, Spiel in Afrika, Evangelische Kinderpflege 22 (1971) 326-339 
- , Afrikanische Fangsteinchenspiele, ZE 96 (1971), 32-70

- , Afrikanische Kreiseltypen und Kreiselspiele, Veröffentlichungen aus dem Übersee-Museum in Bremen B II,4 (1971), 237-272

- , Sozialisierung afrikanischer Kinder durch Rollenspiele, in: FS für S. WoLF zum 65.Geb. (Abh. und Berichte des Staatlichen Museums für Völkerkunde Dresden 34), Berlin (Ost) 1975, 227-260

-, Zur Sozialisationsfunktion von Spielen in afrikanischen Kulturen, in: Bericht über die 5.Tagung Entwicklungspsychologie. Universität Augsburg 1981, Bd. I: Grundlagenorientierte Forschung, ed. R. OERTER, Ausgburg 1981, 18-23

- , The Wrestling Tradition and its Social Functions, in: Sport in Africa. Essays in Social History, ed. W.J. BAKER - J A. MONGAN, New York - London 1987, 23-46

Paulinus von Nola, Poemata, PL 61, 437-744

Pausantas, Description of Greece, Vol. I-IV, ed. W.H.S. Jones (The Loeb Classical Library), Cambridge/MA - London 21966

PAXson E.W., War Gaming, in: E.M. AVEDon - B. SUTTON-Smrth (ed.), The Study of Games, New York u.a. 1971, 278-301

PEET T.E. / LOAT W.L.S., The Cemeteries of Abydos III, London 1913

PENNICK N., Games of the Gods. The Origin of Board Games in Magic and Divination, London 1988

PERDRIzet P., Le jeu alexandrin de l'icosaèdre, BIFAO 30 (1931), 1-16

PERgaMon- UND BodemUSEUM. Antike Welt auf der Berliner Museumsinsel, Mainz 1990

PERLES J., Thron und Circus des Königs Salomo, MGWJ 21 (1872), 122-139

PERsius, Liber satirarum, ed. O. JAHN, Leipzig 1843 = Hildesheim 1967

PETERSON B.E.J., Brettspiel, LÄ 1 (1975), 853-855

PETRIE F.W.M., Objects of Daily Use, London 1927

- , The Royal Tombs of the First Dynasty I, London 1900

-, Gerar, London 1928

- , Beth Pelet I-II, London 1930-1932

- et al., Ancient Gaza I-V, London 1931-1952

- / BRUNTON G., Sedment I, London 1924

- / ElLIS J.C., Anthedon, Sinai, London 1937

Petrignani S., Il Catalogo dei Giacattoli, Rom 1988

PETRONIUs, Satyrica - Schelmengeschichten. Lateinisch und deutsch, ed. K. MÜrLER - W. EHLERS, Zürich - München ${ }^{3} 1983$

PETzOLD J., Das Königliche Spiel. Die Kulturgeschichte des Schach, Stuttgart u.a. 1987

PEZARD M., Qadesh. Mission archéologique à Tell Nebi Mend 1921-1922 (BAH 15), Paris 1931

PfITZNER V.C., Paul and the Agon Motif. Traditional Athletic Imagery in the Pauline Literature (NT.S 16), Leiden 1967

PhAEDRUs, Liber fabularum. Lateinisch und deutsch, ed. O. SCHÖNBERGER (reclam 1144), Stuttgart ${ }^{4} 1987$

PHLo, Works, Vol. I-X / Suppl. I-II, ed. F.H. Colson et al. (The Loeb Classical Library), London - Cambridge/MA 1967-1971

PHLLOSTRAT, Über Gymnastik. Griechisch und deutsch, ed. J. JÜTHNER, Leipzig - Berlin $1909=$ Amsterdam 1969

PHILOSTRAT, Eikones. Die Bilder. Griechisch und deutsch, ed. O. SCHÖNBERGER, München 1968

- , Hērōikos, in: ders., Opera Vol. II, ed. C.L. KAYSER, Leipzig 1871, 128-219

PIAGET J., Das moralische Urteil beim Kinde, Zürich 1954

- , Nachahmung, Spiel und Traum. Die Entwicklung der Symbolfunktion beim Kinde (Gesammelte Werke 5, Studienausgabe), Stuttgart 1975

- , Die Entstehung des Spiels, (1975), in: H. RÖHRS (ed.), Das Spiel - ein Urphänomen des Lebens (Erziehungswiss. Reihe 23), Wiesbaden 1981, 23-39

PICARD $\mathrm{CH}_{\text {., }}$ Les Antécédents des "Astragaloizontes" Polyclétéens et la consultation par les dés, Rev.Et.Gr. 42 (1929), 121-136 
PICCIRILlo M., Chiese e mosaici della Giordania Settentrionale (SBF.CMi 30), Jerusalem 1981 - , Chiese e mosaici di Madaba (SBF.CMa 34), Jerusalem 1989

PIEPER J., Grundformen sozialer Spielregeln, Frankfurt a.M. ${ }^{3} 1955$

PIEPER M., Ein Text über das ägyptische Brettspiel, ZÄS 66 (1931), 16-33

- , Das Brettspiel der alten Ägypter und seine Bedeutung für den ägyptischen Totenkult (Wissenschaftliche Beiträge zum Jahresbericht des Königstädtischen Realgymnasiums zu Berlin, Ostern 1909), Berlin 1909

Pters M.W. (ed.), Play and Development. A Symposium, New York 1972

Piganiol A., Recherches sur les jeux romains. Notes d'archéologie et d'histoire religieuse, Strasbourg - Paris 1923

Pilch H., Sprache als Spiel und Methode, in: W. MARX (ed.), Das Spiel. Wirklichkeit und Methode (Freiburger Dies Universitatis 13), Freiburg i.Br. 1967, 51-65

PINCZOWER F., Der jüdische Läufer, Berlin 1937

- , Sport bei den Juden im Altertum I. Die Rennbahn des Königs Salomo. Nach einem handschriftlichen Midrasch der Staatsbibliothek München - cod. 222 fol. 50a-56b - in deutscher Übersetzung hg., 1930 = Tel Aviv 1968

PINDAR, Siegesgesänge und Fragmente. Griechisch und deutsch, ed. O. WERNER (Tusculum), München ${ }^{3} 1968$

PINKERFELD J., Two Fragment of a Marble Door from Jaffa, ${ }^{\text {CAtiqot ES }} 1$ (1955), 89-94

PINNEY G.F., Money-Bags?, AJA 90 (1986), 218

PINON R., Probleme einer europäischen Kinderspielforschung, HBVK 58 (1967), 9-45

PrTRE G., Giuochi fanciulleschi siciliani raccolti e descritti, Palermo 1883

PITSCH H., Zoologischer Garten, LÄ 6 (1986), 1420-1423

Platon, Sämtliche Werke I-X. Griechisch und deutsch, ed. K. HülsER, Frankfurt a.M. 1991

Platt E.E., Bone Pendants, BA 41 (1978), 23-28

Plautus, Works, Vol. I-V, ed. P. Nixon (The Loeb Classical Library), London - Cambridge/MA 1016-1932

PlekeT H.W., Some Aspects of the History of the Athletic Guilds, ZPE 10 (1973), 197-227

Plessner H., Der Mensch im Spiel, (1967), in: ders., Ges. Schriften 8, Frankfurt a.M. 1983, 307313

PliniUs d.Ä., Naturalis historia, Vol. I-X, ed. H. RackHAM et al. (The Loeb Classical Library), London - Cambridge/MA ${ }^{2} 1949-1963$

PLinIUs d.J., Briefe. Lateinisch und deutsch, ed. H. KASTEN (Tusculum), Zürich - München ${ }^{6} 1990$ - , Panegyricus Traiano imperatori dictus. Lateinisch und deutsch, ed. W. KüHN (Texte zur Forschung 51), Darmstadt 1985

PlöGer O., Theokratie und Eschatologie (WMANT 2), Neukirchen-Vluyn 1959

Ploug G., Hama IV 3: Fouilles et Recherches de la Fondation Carlsberg 1931-1938. Les petits objects médievaux sauf les verres et poteries (Nationalmuseets Skrifter, Større Beretninger 7), Kopenhagen 1969

PluTARCH, Lives, Vol. I-XI, ed. B. Perrin (The Loeb Classical Library), Cambridge/MA - London 1959-1962

- , Moralia, ed. F.C. BABBrTt et al. (The Loeb Classical Library), Cambridge/MA - London $1960-1976$

Poland F., Geschichte des griechischen Vereinswesens, Leipzig $1909=1967$

- , synodos 2, RE II 4 (1932), 1420-1434

- , Technitai, RE II 5 (1934), 2473-2258

PoliakofF M.B., Jacob, Job, and other Wrestlers: Reception of Greek Athletics by Jews and Christians in Antiquity, JHS 11,2 (1984), 48-65

-, Deaths in the Pan-Hellenic Games: Addenda et Corrigenda, AJP 107 (1986), 400-402

- , Studies in the Terminology of the Greek Combat Sports (BKP 146), Königsstein/Ts. 1982

- , Kampfsport der Antike. Das Spiel um Leben und Tod, Zürich - München 1989

Pollack E., Arena; auriga, RE 2 (1896), 638-640. 2549

- , Bigae, RE 3 (1899) 465-467 
- , Equi circenses, RE 6 (1909), 267-271

PollarD J., Birds in Greek Life and Myth (Aspects of Greek and Roman Life), Plymouth 1977

Pollux, Onomastica (Lexicographi Graeci 9,1-3), ed. E. BETHE, Stuttgart 1900-1937 = 1966

Polybios, The Histories, Vol. I-VI, ed. W.R. Paton (The Loeb Classical Library), London Cambridge/MA 1960

PoPLIN F., Contribution ostéo-archéologique à la connaissance des astragales de l'Antre Corycien, in: L'Antre Corycien II (BCH.S 9), Athen - Paris 1984, 381-393

PoPPA R., Kāmid el-Lōz 2. Der eisenzeitliche Friedhof. Befunde und Funde (SBA 18), Bonn 1978

PopPLow R., Totenkult und Wagenrennen in Alt-Mykene, LE 7 (1958), 248-252. 210-215

PoRTMANN A., Das Spiel als gestaltete Zeit. Betrachtungen eines Biologen, (1975), in: G.-K. Kaltenbrunner (ed.), Im Anfang war das Spiel. Schöpfertum und Glück zwischen Arbeit und Freizeit, München 1987, 51-68

Portmann P., Pieter Bruegel d.Ä., Kinderspiele (Orbis pictus 36), Bern - Stuttgart 1961

PoTTIER E. et al., La nécropole de Cheikh Zenad, Syria 7 (1926), 193-208

- , Note complémentaire sur le rhyton de Cheikh Zenad, Syria 8 (1927), 174

Preusser C., Die Wohnhäuser in Assur (WVDOG 64), Berlin 1954

Pringle D., Medieval Pottery from Caesarea: The Crusader Period, Levant 17 (1985), 171-202

PRITCHARD J.B., Ancient Near Eastern Pictures, Princeton/NJ 21974

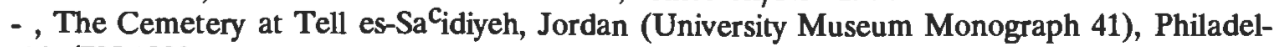
phia/PN 1980

PRTTCHETT W.K., "Five Lines" and IG I², 324, CalifStClAnt 1 (1968), 187-215, Pl. 1-8

ProkoP, Werke I und III: Anekdota. Perserkriege. Griechisch und deutsch, ed. O. VEH (Tusculum), München ${ }^{3} 1981.1971$

- , Epistolae et declamationes, ed. A. GARZYA - R.-J. LoENERTZ (SPB 9), Ettal 1963

Properz, Gedichte. Lateinisch und deutsch, ed. R. HELM (SQAW 18), Berlin (Ost) ${ }^{4} 1986$

PruSs F., Würfelspiele für jung und alt, Niedernhausen/Ts. 1990

PseUdO-Ovid, De Vetula. Untersuchungen und Text, ed. P. KLOPSCH (Mittellatein. Studien und Texte 2), Leiden - Köln 1967

PusCH E.B., Das Senetspiel im Alten Ägypten, Teil 1,1-2 (MÄS 38), Berlin 1979

- , Ein zweiter Beleg für das Spielbrett Kairo JdE 68.127, GM 22 (1976), 53-57

- , Eine unbeachtete Brettspielart, SAK 5 (1977), 199-212

- , Senet, LÄ 5 (1984), 851-855

- , Tjau-Spiel, LÄ 6 (1986), 607f

PusCHKIN A.S., Pique-Dame, (1834), in: ders., Erzählungen, München $81991,383-416$

PUTZKE G., Geschichte des Schwimmsports, in: G.A.E. BoGENG (ed.), Geschichte des Sports aller Völker und aller Zeiten Bd. II, Leipzig 1926, 420-443

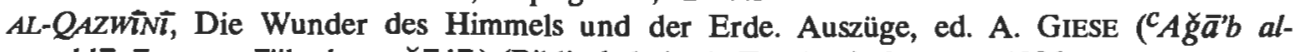
mahliūqāt wa-garä'ib al-mauğ $\bar{u} d \bar{a} t$ ) (Bibliothek Arab. Erzähler), Stuttgart 1986

QUINTILIAN, Institutiones oratoriae libri XII. Lateinisch und deutsch, ed. (Texte zur Forschung 23), Darmstadt 21988

RAAB A., Theaterpuppen in Vergangenheit und Gegenwart. Abriß der Geschichte des Schattenspiels, des Puppenspiels und des übrigen Figurentheaters nebst Sonderthemen, Kaufbeuren 1979

RAABE J., Different Approaches to Play, in: dies. et al. (ed.), The Child and Play. Theoretical Approaches and Teaching Applications (UNESCO Educational Studies and Documents 34), Paris 1980, 5-23

The Rabbula Gospels. Facsimile Edition of the Miniatures of the Syriac Manuscript Plut. 1,56 in the Medicean-Laurentian Library, ed. C. Cecchelli - G. FURLANI - M. SAlMi, Olten Lausanne 1959

RabiNowitZ N.L., Probability and Statistical Inference in Ancient und Medieval Jewish Literature, Toronto 1973

RADKE G., Trigon, RE II $13(1939,139$ 
RAHMAN L.Y., Roman Tombs in Shmuel ha-Navi Street, IEJ 10 (1960) 140-148.

- , Finds from a Sixth to Seventh Centuries Site near Gaza I: The Toys, IEJ 31 (1981), 72-80

- et al., The Tomb of Jason ( ${ }^{C}$ Atiqot HS 4), Jerusalem 1964 (hebr.)

- et al., Jason's Tomb, IEJ 17 (1967), 61-113

RAHNER H., Der spielende Mensch, Einsiedeln ${ }^{4} 1957$

RANKE H., Das altägyptische Schlangenspiel (SHAW.PH 4), Heidelberg 1920

RANKE K., Meister Altswerts Spielregister, SAVK 48 (1952), 137-197

RANKIN H.D., Toys and Education in Plato's Laws, Hermathena 92 (1958), 62-65

RAPPAPORT S., Spiele, JL 4,2 (5) (1930), 549-553

RAswan C.R., Im Land der schwarzen Zelte. Mein Leben unter den Beduinen, Berlin 1934

RAU R., Sandkastenspiele und andere, in: G.-K. KALTENBRUNNER (ed.), Im Anfang war das Spiel. Schöpfertum und Glück zwischen Arbeit und Freizeit, München 1987, 15-29

RAUSCHEN H., Die Spiele der Jugend aus Fischarts Gargantua cap. XXV, Jb. für Geschichte, Sprache und Literatur Elsaß-Lothringens 24 (1908), 53-145

REESE D.S., The Kition Astragali, in: V. KARAGEORGHIS (ed.), Excavations at Kition V, Part II. The Pre-Phoenician Levels, Nikosia 1985, 382-391

REFAT W.M., Le jeu de trente cases dans l'Égypte Anciennne, Vol. 1: Texte; Vol. 2: Figures et Planches, Diss. phil. Université libre, Brüssel 1972

REGLING K., Tessera, RE II 9 (1934), 851-854

REGNER J., Ludi circenses, RE Suppl. 7 (1940), 1626-1664

REHM A. (ed.), Didyma II: Die Inschriften, Berlin 1958

REICHEL A., Die Stierspiele in der kretisch-mykenischen Kultur, AM 34 (1909), 85-99

REICHEL R. (ed.). Spielpädagogik. Grundlagen und Berichte, Münster 1987

REICHELT H., Kartenspiele von Baccara bis Whist, Wiesbaden 1987

REICKE B. / EsKING E., Spiel, BHH 3 (1966), 1832-1835

REIFENBERG A., Ein neues hebräisches Gewicht, JPOS 16 (1936), 39-43

REINMUTH O.W., Ostrakismos, RE 18 (1942), 1674-1685

- , Agonothetes; Astragalos; Ballspiel; Boxen; Brettspiele; Caestus; Duodecim scripta, KP 1 (1975), 140f; 659f. 817f. 938. 943. 1009f

- , Duodecim scripta; Ephedrismos; Hahnenkämpfe; Harpaston, Hippodromos, KP 2 (1975), 176. 292. 917f. 943. 1162f

- , Latrunculorum ludus; Micare, KP 3 (1975), 516f. 1286f

-, Ostrakismos, KP 4 (1975), 376f

- , Pankration; Pentathlon; Pygme; Ringkampf, KP 4 (1975), 460. 617. 1246-1248. $1436 f$

REINACH S., Ephedrismos, DarS II 1, 636-638

REISCH E., Akrocheinismos; Apobatēs, RE 1 (1894), 1197f. 2814-2817

- , Askōliasmos, RE 2 (1896), 1698-1700

- , Chorēgos, RE 3 (1899), $2422 \mathrm{f}$

REISNER G.A. / Fisher C.L. / LYON D.G., Harvard Excavations at Samaria 1908-1910, Vol. I-II, Cambridge 1924

REITER K., Falknerei im Alten Orient? Ein Beitrag zur Geschichte der Falknerei, MDOG 120 (1988), 189-206

-, Falknerei im Alten Orient? II. Die Quellen, MDOG 121 (1989), 169-196

- , Falknerei in Ugarit, UF 22 (1990), 271-278

RETTER H., Spielzeug. Handbuch zur Geschichte und Pädagogik der Spielmittel, Weinheim - Basel 1979

REUTHER O., Die Innenstadt von Babylon (Merkes) (WVDOG 47), Leipzig 1926 = Osnabrück 1968

REY-COQUAIS J.-P. (ed.), IGLS 6: Baalbek et Beqac ${ }^{c}$, Nos. 2711-3017 (BAH 78), Paris 1967

- , IGLS 7: Arados et Régions Voisines. NOs. 4001-4061 (BAH 89), Paris 1970

RicCA C., Locri epizephyrii, NSDc 1913, Suppl. 11, Rom 1914, 3-54

Richard S. / BoraAs R.S., Preliminary Report of the 1981-82 Seasons of the Expedition to Khirbet Iskander and its Vicinity, BASOR 254 (1984), 63-87 
RICHMOND E.T., Basilica of the Nativity. Discovery of the Remains of an Earlier Church, QDAP 5 (1936), 75-81

RICHTER W., Reiher, KP 4 (1975), 1370

-, Schildkröte, KP 5 (1975), 9 f

Ridgeway W., The Game of Polis and Plato's Rep. 422E, JHS 16 (1896), 288-290

RIECHE A., So spielten die Alten Römer. Römische Spiele im Archăologischen Park Xanten, Köln ${ }^{2} 1984$

- , Römische Kinder- und Gesellschaftsspiele (Schriften des Limesmuseums Aalen 34), Aalen 1984

RIEDEL H., Leibesübungen und körperliche Erziehung in der osmanischen und kamâlistischen Türkei (Körperliche Erziehung und Sport 14), Würzburg 1942

RIEMSCHNEIDER M., "Sei gegrüBt", Altertum 1 (1955), 131-136

- , Spielbrett und Spielbeutel in Antike und Mittelalter, AEth 8 (1959), 309-326

- , Glasberg und Mühlespiel, Symbolon 6 (1968), 137-149

- , Das hethitische Spielbrett, in: M. LURKER (ed.), In memoriam E. UNGER. Beiträge zur Geschichte, Kultur und Religion des Alten Orients, Baden-Baden 1971, 103-110

RiIs P.J., Hama II 3. Fouilles et Recherches de la Fondation Carlsberg 1931-1938. Les cimitières à crémation (Nationalmuseets Skrifter, Større Beretninger 1), Kopenhagen 1948

- / BUHL M.-L., Hama II 2. Fouilles et Recherches de la Fondation Carlsberg 1931-1938. Les objects de la période dite syro-hittite (âge du fer) (Nationalmuseets Skrifter, Større Beretninger 12), Kopenhagen 1990

RingGren H. / ILlMAN K.-J. / FABRY H.-J., müu, ThWAT 4 (1982-1984), 763-787

RITTER H. (ed.), Karagös. Türkische Schattenspiele, 1.-3.Folge, Leipzig - Hannover - Wiesbaden 1924. 1941. 1953

RITTIG D., Maske, RIA 7 (1987-1990), $448 f$

ROBERT C., Griechische Kinderspiele auf Vasen, AZ 37 (1879), 78-84

- , Die Knöchelspielerinnen des Alexandros (HWPr 21), Halle a.d.S. 1897

RoBert L., Les Gladiateurs dans l'Orient Grec, Paris 1940

- , Hellenica 1-13, Limoges - Paris 1940-1965

- , Pantomimen im griechischen Orient, (1930), in: ders., Opera Minora Selecta I, Amsterdam $1969,654-670$

- , pykteuein (1929), a.a.O., 691-708

-, Monuments de Gladiateurs dans l'Orient Grec, in: ders., Hellenica 5 (1948), 77-99; 7 (1949), 126-151; 8 (1950), 39-72

- , Rez. A REHM, Didyma II: Die Inschriften, 1858, Gn. 31 (1959), 657-674

-, Inscriptions de Didymes et de Milet I, in: ders., Hellenica 11-12 (1960), 440-489

RoberTs C.H. / TURNER E.G. (ed.), Catalogue of the Greek and Latin Papyri in the John Rylands Library, Manchester, Vol. IV: Documents of the Ptolemaic, Roman, and Byzantine Periods (Nos. 552-717), Manchester 1952

RobINSON D.M., Excavations at Olynthus Part X. Metal and Minor Miscellaneous Finds, Baltimore/MA - London 1941

Robinson Th.H. / HoRST F., Die Zwölf Kleinen Propheten (HAT I 14), Tübingen ${ }^{3} 1964$

ROEDER G., Rampsinitos, RE I A 1 (1914), 140-147

- , Spiel und Spielzeug, RLV 12 (1928), 343-345

-, Ein Brettspiel um die Glïckseligkeit im Jenseits, in: ders., Die ägyptische Religion in Text und Bild IV: Der Ausklang der äygptischen Religion in Reformation, Zauberei und Jenseitsglauben (Die Bibliothek der Alten Welt, Reihe Der Alte Orient), Zürich - Stuttgart 1961

RöHRICH L., Kinderreim und Kinderspiel - gestern und heute, in: Kinderkultur, ed. K. KösTLIN (Hefte des Focke-Museums 73), Bremen 1987, 199-218

RörRs H., Das Spiel - ein Urphänomen des Lebens, in: ders. (ed.), Das Spiel - ein Urphänomen des Lebens (Erziehungswiss. Reihe 23), Wiesbaden 1981, 3-22

Röllig W., Beiträge zur nordsemitischen Epigraphik 1-4, WO 5 (1969-1970), 108-126

- , Sardanapal, KP 4 (1975), 1550f 
ROMER W.H.PH., Der Spaßmacher im alten Zweistromland. Zum "Sitz im Leben" altmesopotamischer Texte, Persica 7 (1977), 43-68

DiE ROMER AN MOSEL UND SAAR. Katalog, ed. H. CÖPPERS et al., Mainz ${ }^{2} 1983$

Rösch H.-E., Sporthistorische Überlegungen zu einer christlichen Anthropologie der Leiblichkeit, in: Forschung - Lehren - Handeln. Sportwissenschaftliche Beiträge im Gedenken an $\mathbf{H}$. GROLI, ed. H. ANDRECS - S. REDL, Wien 1976, 103-115

ROGERS M.E., Domestic Life in Palestine, London $1862=1989$

ROHLFS G., Antikes Knöchelspiel im einstigen Großgriechenland. Eine vergleichende historischlinguistische Studie, Tübingen 1963

RolLer L.E., Funeral Games in Greek Literature, Art and Life, Ph.D.phil. University of Pennsylvania 1977, Ann Arbor/MI 1981

RolofF J., Der erste Brief an Timotheus (EKK 15), Neukirchen-Vluyn - Zürich 1988

ROSENTHAL F., Gambling in Islam, Leiden 1975

- (ed.), An Aramaic Handbook (PLO NS 10), Wiesbaden 1967

- , Kimär; La $c_{i b}$, EI 5 (1986), 108-110. 615f

ROSENTHAL R., Römische Bildlampen aus östlichen Werkstätten (GOF II 5), Wiesbaden 1981

- / Sivan R., Ancient Lamps in the Schloessinger Collection (Qedem 8), Jerusalem 1978

RosTovTzEFF M., Interpretation des tessères avec figures, chiffres et légends en os, RAr IV.Série (1905), 110-124

ROUILARD M. / TropPer J., trpym, rituels de guérison et culte des ancetres d'après 1 Samuel XIX 11-17 et les textes parallèles d'Assur et de Nuzi, VT 37 (1987), 340-361

Rowe A., Catalogue of Egyptian Scarabs, Scaraboids, Seals and Amulets in the Palestine Archaeological Museum, Kairo 1936

RUBIN K.H., Early Play Theories Revisited: Contributions to Contemporary Research and Theory, in: D.J. PePLER - K.H. RubIN (ed.), The Play of Children: Current Theory and Research (Contributions to Human Development 6), Basel u.a. 1982, 4-14

RUDOLPH Werner, Olympischer Kampfsport in der Antike. Faustkampf, Ringkampf und Pankration in den griechischen Nationalfestspielen (SSA 47), Berlin (Ost) 1965

-, Der Sport in der spätantiken Gesellschaft, FuF 40 (1966), 208-210

RUDOLPH Wilh., Haggai - Sacharja - Maleachi (KAT XIII 4), Gütersloh 1976

RÜDIGER U., Schlauch und Hammeraxt - ein antikes Kinderspiel, MDAI(R) 73-74 (1966-1967), 248-250

RÜHFEL H., Kinderleben im klassischen Athen. Bilder auf klassischen Vasen (KAW 19), Mainz 1984

- , Das Kind in der griechischen Kunst von der minoisch-mykenischen Zeit bis zum Hellenismus (KAW 18), Mainz 1984

RÜHMKORF P., Über das Volksvermögen. Exkurse in den literarischen Untergrund, Reinbek bei Hamburg 1969

- , agar agar-zaurzaurim. Zur Naturgeschichte des Reims und der menschlichen Anklangsnerven, Reinbek bei Hamburg 1981

RüsSEl A., Das Kinderspiel. Grundlinien einer psychologischen Theorie, München ${ }^{2} 1965=$ Darmstadt 1977

-, Spiel und Arbeit in der menschlichen Entwickung, in: Handbuch der Psychologie 3: Entwicklungspsychologie, ed. H. THOMAE, Göttingen ${ }^{2} 1959,502-534$

RUNKEL G., Soziologie des Spiels (Hochschulschriften Sozialwissenschaften 25), Frankfurt a.M. 1986

RuSCH A., Paamyles, RE 18,2 (1942), 2053

SAADA L., Kharbga, EI 4 (1978), $1071 \mathrm{f}$

SAAD Z., Khazza lawizza, ASAE 37 (1937), 212-218

SAATMANN L., Kinder spielen sich gesund, Stuttgart 1952

- , Laßt Kinder spielen, München - Basel $1965=1970$

SAEB $\varnothing$ M., Sacharja 9-14. Untersuchungen von Text und Form (WMANT 34), Neukirchen-Vluyn 1969 
SaguJo E., Askolia; bestiae mansuelae, circures, DarS I, 472f. 689-705

- , Chiramaxium, DarS I 2, 1103

- , Duodecim scripta, DarS II 1, $414 \mathrm{f}$

Saleh M. / Sourouzian H. (ed.), Die Hauptwerke im Ägyptischen Museum Kairo, Mainz 1986

SALLER S.J., Excavations at Bethany (1949-1953) (SBF.CMa 12), Jerusalem $1957=1982$

- , Iron Age Tombs at Nebo, Jordan, LA 16 (1965-1966), 165-298

- / Bagati B., The Town of Nebo (Khirbet el-Mekhayyat) and other Ancient Christian Monuments in Transjordan (SBF.CMa 7), Jerusalem $1949=1982$

SAN Nicolo M., Ägyptisches Vereinswesen zur Zeit der Ptolemäer und Römer I-II (MBPF 2,12), München 21972

SANSONE D., Greek Athletics and the Genesis of Sport, Berkeley 1988

SARTORI K., Das Kottabos-Spiel der alten Griechen, Diss. phil. München 1893

SARTRE M. (ed.), IGLS 13,1: Bostra, Nos. 9001-9472 (BAH 113), Paris 1982

SASSON J.M., Reflections on an unusal Practice reported in ARM X:4, Or. 43 (1974), 404-410

SAWHILL J.A., The Use of Athletic Metaphors in the Biblical Homilies of St.John Chrysostom, Ph.D.Diss. Princeton 1928

SBRZENSKY H., Die Spiele der !Ko-Buschleute unter besonderer Berücksichtigung ihrer sozialisierenden und gruppenbindenen Funktionen (Monographien zur Humanethologie 2), München - Zürich 1976,

SCANLON TH.F., Greek Boxing Gloves: Terminology and Evolution, Stadion 8-9 (1982-1983), 3145

- , Boxing Gloves and the Games of Gallienus, AJP 107 (1986), 110-114

SCHĀFER G.E., Das Selbst im Spiel, ZP 26 (1980), 13-27

-, Heilendes Spiel, Kindheit 1 (1979), 239-250

SCHÄFER H., König Amenophis II. als Meisterschütz, OLZ 32 (1929), 233-244

- , Weiteres zum Bogenschießen im alten Ägypten, OLZ 34 (1931), 89-96

-, Die kupferne Zielscheibe in der Sphinxinschrift Thutmosis des IV., ZÄS 67 (1931), 92-95

SCHÄFER P., Der Bar-Kokhba-Aufstand. Studien zum zweiten jüdischen Krieg gegen Rom (Texte und Studien zum Antiken Judentum 1), Tübingen 1981

- , Geschichte der Juden in der Antike, Stuttgart - Neukirchen-Vlyun 1983

SCHAEFFER C.A., Fouilles et découvertes des XVIII et XIXe campagnes, 1954-1955, in: Ugaritica IV (MRS 15; BAH 74), Paris 1962,

Schaub H., End-Spiel und Spiel-Ende, in: G.-K. Kaltenbrunner (ed.), Im Anfang war das Spiel. Schöpfertum und Glück zwischen Arbeit und Freizeit, München 1987, 130-133

SCHAUENBURG K., Ganymed und Hahnenkämpfe auf römischen Sarkophagen, AA 1972, 501-516

- , Erotenspiele, AW 7,3 (1976), 39-52; 7,4 (1976), 28-35

SCHAWE J., Brettspiel, RIA 2 (1938), 62

SCHEFOLD K., Anhang I: Die Brettspieler, JdI 52 (1937), 68-70

SCHEFTELOWITZ J., Alt-palästinensischer Bauernglaube in religionsvergleichender Beleuchtung, Hannover 1925 = Osnabrück 1975

SCHEIDEWEILER F., Erinnas Klage um Baukis, Ph. 100 (1956), 40-51

SCHENK-DANZINGER L., Studien zur Entwicklungspsychologie und zur Praxis der Schul- und Beratungspsychologie, München - Basel 1963

- , Entwicklungspsychologie, Wien ${ }^{9} 1975$

- , Zur entwicklungspsychologischen Bedeutung des Spiels, in: K.J. KREUZER (ed.), Handbuch der Spielpädagogik 1, Düsseldorf 1983, 369-383

SCHEUERL H., Das Spiel. Untersuchungen über sein Wesen, seine pädagogischen Möglichkeiten und Grenzen, Weinheim - Basel ${ }^{9} 1979$

- , Zur Phänomenologie des Spiels, in: Das Spiel, ed. Ausschuß deutscher Leibeserzieher, Frankfurt a.M. 1959. 29-42

- , Zur Begriffsbestimmung von "Spiel" und "spielen", (1975), in: H. RöHRs (ed.), Das Spiel - ein Urphänomen des Lebens (Erziehungswiss. Reihe 23), Wiesbaden 1981, 41-49

- (ed.), Theorien des Spiels, Weinheim - Basel ${ }^{10} 1975$ 
- , Spiel - ein menschliches Grundverhalten?, in: ders. (ed.), Theorien des Spiels, Weinheim Basel ${ }^{10} 1975,189-208$

- , Alte und neue Spieltheorien. Wandlungen ihrer pädagogischen Interessen und Perspektiven, EvErz 27 (1975), 2-21

- , Spieltheorien im Wandel, in: O. GRUPE - H. GABLER - U. GÖHNER (ed.), Spiel - Spiele Spielen (Schriftenreihe des Bundesinstituts für Sportwissenschaft 49), Schorndorf 1983, 76-88

- , Die pädagogisch-anthropologische Dimension des Spiels, in: K.J. KREUZER (ed.), Handbuch der Spielpädagogik 1, Düsseldorf 1983, 31-42

-, Zum Stand der Spielforschung, in: W. EINSIEDler (ed.), Aspekte des Kinderspiels, Weinheim und Basel 1985, 9-31

SCHILlER F. vON, Über die ästhetische Erziehung des Menschen, in: ders., Sämmtliche Werke 12, Stuttgart - Tübingen 1847, 1-127

Schilling H. (ed.), Aspekte der Freizeit, Gießen 1978

SCHIMMELPFENNIG W., Drachen bauen und steigen lassen, Niedernhausen/Ts. 1987

SCHLÄGER G., Einige Grundfragen der Kinderspielforschung, ZVKK 27 (1917), 106-121. 199-215; 28 (1918), 15-25; 33-34 (1924), 137-152

SCHIÖGL H., Schauspieler, LÄ 5 (1984), $545 f$

- , Theater, LÄ 6 (1986), 463f

ScHLoz R., Probleme und Ansätze in der protestantischen Theologie, in: Sport im Blickpunkt der Wissenschaften. Perspektiven, Aspekte, Ergebnisse, Berlin - Heidelberg - New York 1972, 64-83. 93-97

SCHMALTZ B., Terrakotten aus dem Kabirenheiligtum bei Theben (Das Kabirenheiligtum V), Berlin 1974

SCHMID H.H., gōrāl, THAT $1\left({ }^{3} 1978\right), 412-415$

ScHMID R., Raum, Zeit und Publikum des geistlichen Spiels. Aussage und Absicht eines mittelalterlichen Massenmediums, München 1975

SCHMIDT E., Spielzeug und Spiele der Kinder im klassischen Altertum. Mit Beispielen aus den Beständen des Deutschen Spielzeugmuseums Sonneberg (Südthüringische Forschungen 7), Meiningen 1971

-, Die Darstellung von Kinderspielzeug und Kinderspiel in der griechischen Kunst (Raabser Märchen-Reihe 3), Wien 1977

SCHMIDT H. / KaHLE P., Volkserzählungen aus Palästina I-II (FRLANT 17. 47), Göttingen 1918. 1930

SCHMIDT N., Sinai und Rotes Meer, Köln 1988

SCHMIDT S., Mark Aurel und spectacula, Stadion 10 (1984), 21-43

SCHMIDT W., Spiele, Feste, Festspiele, Paid. 4 (1950), 11-22

SCHMIDTCHEN S. / ERB A., Analyse des Kinderspiels. Ein Überblick über neuere psychologische Untersuchungen, Köln 1976

SCHMTT A., Spielen, wie die Römer spielten, in: Jahresbericht 1977/78 Beethoven-Gymnasium Bonn, Bonn 1978, 17-31

SCHMrTZ L., Spiel und Sammlung - Macht und Sinn. Glücksspiel in türkischen Männer-Cafés in Köln, in: Männerbünde - Männerbande II (Ethnol. NF 15), Köln 1990, 157-160

SCHNEEMELCHER W. (ed.), Neutestamentliche Apokryphen I. Evangelien, Tübingen ${ }_{1987}$

SCHNEIDER K., Hahnenkämpfe; Harpastum, RE 7 (1912), 2210-2215. 2405-2407

- , Kottabos, RE 22 (1922), 1528-1541

- , Latrunculorum ludus, RE 23 (1924), 980-984

- , Lusus Troiae, RE 26 (1927), 2059-2067

- , Micare, RE 15,2 (1932), 1516f

- , Ocellati, RE 34 (1937), 1765

- , Tropa; Trygodiphēsis, RE II 13 (1939), 660f. $712 \mathrm{f}$

- , Paradaxos, RE 18,3 (1949), 1166f

- , Pilarius; Platagōnion, RE 40 (1950), 1320-1322. $2254 \mathrm{f}$

- , Posinda, RE 43 (1953), $830 \mathrm{f}$ 
- , Quadriga, RE 47 (1963), 681-686

SCHNEIDER-HERRMANN G., Der Ball bei den Westgriechen, BABesch 46 (1971), 123-133

SCHNELL R.F., Games, OT, IDB 2 (1962), $352 \mathrm{f}$

SCHNUTENHAUS F., Wortspiel, BHH 3 (1966), 2187

SCHOENHARDT C., Alea. Uber die Bestrafung des Glücksspiels im älteren römischen Recht. Eine strafrechtsgeschichtliche Studie (Diss. iur. Tübingen 1884), Stuttgart 1885

SChOlia Platonica, ed. W.Ch. GREene, Haverfod 1938

SCHORLEMMER H., Hiob auf der Bühne. Die dramatischen und theatralen Elemente des alttestamentlichen Buches Hiob, Diss. phil. masch. München 1983

SCHRAMM P.E., Sphaira - Globus - Reichsapfel. Wanderung und Wandlung eines Herrschaftszeichens von Caesar bis Elisabeth II., Stuttgart 1958

SCHRODT B., Sports of the Byzantine Empire, JHS 8 (1981), 40-59

SCHROER S., In Israel gab es Bilder. Nachrichten von darstellender Kunst im Alten Testament (OBO 74), Fribourg - Göttingen 1987

SCHÜRMANN A., Griechische Mechanik und antike Gesellschaft. Studien zur staatlichen Förderung einer technischen Wissenschaft (Boethius 27), Stuttgart 1991

SCHULTZ W., Rätsel, RE I A 1 (1914), 62-125

SCHUMACHER G., Tell el-Mutesillim I. Fundbericht, Leipzig 1908

SCHUPPE E., Taenia, RE 2,4 (1932) 2002-2006

- , Plostellum, RE 41 (1951) 463

SCHUSTER M., Wachtel, RE Suppl. 8 (1956), 906-911

SCHWARz F.F., Candragupta - Saandrakottos. Eine historische Legende in Ost und West, Altertum 18 (1972), 85-102

SCHWEIGER H., Bären mit Humor, in: Fr.K. DöRNER (ed.), Vom Bosporus zum Ararat (KAW 7), Mainz ${ }^{3} 1991,96-98$

SCULLARD H.H., The Elephant in the Greek and Roman World, London 1974

SDUN W., Zum Begriff des Spiels bei Kant und Schiller, KantSt 57 (1966), 500-518

SEAgER A.R. / KraAbel A.Th., The Synagoge and the Jewish Community, in: G.M.A. HANFMAN (ed.), Sardis from Prehistoric to Roman Times. Results of Archaeological Exploration of Sardis 1958-1975, Cambridge/MA - London 1983

SEBBANE M., Early Bronze and Middle Bronze I Board Games in Canaan and the Origin of the Egyptian Senet Game, ErIs 21 (1990), 233-248 (hebr.; English Summary 109*)

SEGAL A., Die Theaterbauten im alten Palästina in römisch-byzantinischer Zeit, AW 18,1 (1987), 2-21

- , Theatres in Ancient Palestine during the Roman-Byzantine Period, SCI 8-9 (1985-1988), 145165

-, Town Planning and Architecture in Provincia Arabia. The Cities along the Via Traiana Nova in the 1st - 3rd Centuries C.E. (BAR.IS 419), Oxford 1988

SEGER J.D., Gezer V: The Field I Caves, Jerusalem 1988

SEIDEL H., Musik in Altisrael. Untersuchungen zur Musikgeschichte und Musikpraxis Altisraels anhand biblischer und außerbiblischer Texte (BEATAJ 12), Frankfurt a.M. - Bern - New York Paris 1989

SEIDL U., Die babylonischen Kudurru-Reliefs. Symbole mesopotamischer Gottheiten (OBO 87), Fribourg - Göttingen 1989

Sellin E. / WATZinger C., Jericho, Die Ergebnisse der Ausgrabungen (WVDOG 22), Leipzig 1913 = Osnabrück 1973

SENECA d.J., Philosophische Schriften. Lateinisch und deutsch, Bd. I-V, ed. M. RosenBauch, Darmstadt 1976. ${ }^{3} 1989 .{ }^{3} 1989 .{ }^{2} 1984.1989$

- , Apocolocyntosis sive Ludus de morte Claudii Neronis. Lateinisch und deutsch, ed. A. BAUER (reclam 7676), Stuttgart 1990

- , Naturales quaestiones, Vol. I-II, ed. TH.H. CorcoRAN (The Loeb Classical Library), London - Cambridge/MA 1971-1972

SETHE K., Ein altägyptischer Fingerzăhlreim, ZÄS 54 (1918), 16-39 
- (ed.), Dramatische Texte zu altägyptischen Mysterienspielen (UGAÄ 10), Leipzig 1928 = Hildesheim 1954

SEYBOLD K., $t^{e}$ räfim, Idol(e), THAT $2\left({ }^{2} 1979\right), 1057-1060$

SEYDEL O., Spiel und Ritual. Überlegungen zur Reform des Gottesdienstes, WPKG 60 (1971), $507-515$

SEYRIG H., Quelques cylindres orientaux, Syria 32 (1955), 29-48

- , Cylindre représentant une tauromachie, Syria 33 (1956), 169-174

SHEARS L.M. / BowER E.M. (ed.), Games in Education and Development, Springfield/IL 1974

SHORE A.F., A 'Serpent'-Board from Egypt, BMQ 26 (1963), 88-91

SHUBIK M. (ed.), Spieltheorie und Sozialwissenschaften, Hamburg 1965

SidONIUS APOLIINARIS, Epistulae, PL 58 (1862), 443-640

SIMON E., Der Sport in der Sicht des Judentums, in: Sport in unserer Welt - Chancen und Pro-

bleme, ed. O. GRUPE et al., Berlin - Heidelberg - New York 1973, 647-652

Sion M.A. DE, La Forteresse Antonia à Jérusalem et la Question du Prétoire, Paris 1956

SKUBIK M. (ed.), Spieltheorie und Sozialwissenschaft, Hamburg 1965

SMEND R., Essen und Trinken - ein Stück Weltlichkeit des Alten Testaments, (1977), in: ders.,

Die Mitte des Alten Testaments. Gesammelte Studien 1, München 1986, 200-211

SMTTH R.H. et al., Pella of the Decapolis I, The College of Wooster 1973

SODEN W. VON, Akkadisches Handwörterbuch I-III, Wiesbaden ${ }^{2} 1985.1972 .1981$

- , "Als die Götter (auch noch) Mensch waren". Einige Grundgedanken des altbabylonischen

Atramhasis-Mythos, (1969), in: ders., Aus Sprache, Geschichte und Religion Babyloniens. Ges.

Aufsätze, Neapel 1989, 147-164

- , Ist im Alten Testament schon vom Schwimmen die Rede?, ZAH 4 (1991), 165-170

Söll G., Sport in der katholischen Theologie des 20.Jahrhunderts, in: Sport im Blickpunkt der

Wissenschaften. Perspektiven, Aspekte, Ergebnisse, Berlin - Heidelberg - New York 1972, 4363. 89-93

Solalinde A.G. (ed.), Antología de Alfonso X el Sabio, Buenos Aires - México 1941

SOMOGYI J., Muslim Table Games, IsIQ 2 (1956-1957), 236-244

SOPHOKLES, The Plays and Fragments, ed. L. CAMPBELL, Vol. I-II, Oxford ${ }^{2} 1879=$ Hildesheim 1969

SPARKES B.A., Kottabos: An Athenian After-Dinner Game, Arch. 13 (1960), 202-207

SPEISER E.A., Excavations at Tepe Gawra, Vol. I: Levels I-VIII, Philadelphia/PN 1935

SPICQ C., Gymnastique et morale, d'après I Tim., IV,7-8, RB 54 (1947), 229-242

SPIEGLER N., Das Leben spielen. Phänomene jugendlichen Verhaltens, Gütersloh 1978

SPIES O., Türkisches Puppentheater. Versuch einer Geschichte des Puppentheaters im Morgenland (Die Schaubühne 50), Emsdetten 1959

SPULER CH.-U., Schattentheater, Lex. der Islam. Welt 2 (1974), $90 \mathrm{f}$

STÄHLI H.-P., Knabe - Jüngling - Knecht. Untersuchungen zum Begriff $n c_{r}$ im Alten Testament (BET 7), Frankfurt a.M. - Bern - Las Vegas 1978

STAGER L.E., Ashkelon Discovered. From Canaanites to Romans and Moslems, Washington/DC 1991

STARR R.F.S., Nuzi. Report on the Excavations at Yorgan Tepe near Kirkuk, Iraq, conducted by Harvard University in Conjunction with the ASOR and The University Museum of Philadelphia 1927-1931, Vol. I-II (Text), Cambridge/MA 1937. 1939

STEINER P., Römisches Brettspiel und Spielgerät aus Trier, SaalburgJb 9 (1939), 34-45

STEINSCHNEIDER M., Schach bei den Juden, in: A. VAN DER LINDE, Geschichte und Litteratur des Schachspiels I, Berlin 1874, 155-202 (auch als Monographie Berlin 1873)

STEPHANES I.E., Dionysiakoi Technitai. Symbolēs stēn prosōpographia tou theatrou kai tēs mousikēs tōn archaiōn Hellēnōn, Heraklion 1988

STEPHENS F.J. (ed.), Votive and Historical Texts from Babylonia and Assyria (YOS, Babylonian Texts 9), New Haven 1937

STERN E., Excavations at Tel Mevorakh (1973-1976). Part I-II (Qedem 9. 18), Jerusalem 1978. 1984 
- , Phoenician Discoveries at Tel Dor, Qad. 22 (1989), 103-110 (hebr.)

STERN H., Le calendrier de 354. Etude sur son texte et ses illustrations (BAH 55), Paris 1953

STIERLIN H., Städte in der Wüste. Petra, Palmyra und Hatra - Handelszentren am Karawanenweg

(Antike Kunst im Vorderen Orient), Fribourg - Stuttgart - Zürich 1987

STILlWELl R. (ed.), Antioch on-the-Orontes II. Excavations 1933-1936, Princeton/NJ - London Den Haag 1938

- , The Potter's Quarter: The Terracottas (Corinth 15,2), Princeton/NJ 1952

STOEBE H.J., Das erste Buch Samuelis (KAT VIII 1), Gütersloh 1973

STÖCKLIN-MEIER S., Der Schneider hat 'ne Maus erwischt. Lebendiges Kreisspiel, Zürich 1973

STÖRK L., Gans, LÄ 2 (1977), 373-375

- , Wiedehopf, LÄ 3 (1980), 1245f

STolz F., Das erste und zweite Buch Samuel (ZB AT 9), Zürich 1981

STRACK H.L. / BilleRBECK P., Kommentar zum Neuen Testament aus Talmud und Midrasch III. IV, München ${ }^{2} 1954 .{ }^{5} 1969$

STRICKER B.H., The Origin of the Greek Theatre, JEA 41 (1955), 34-47

STROBEL A., Conrad Schick. Ein Leben für Jerusalem, Fürth/Bay. 1988

STROMMENGER E. (ed.), Sumer, Assur, Babylon. 7000 Jahre Kunst und Kultur an Euphrat und Tigris, Mainz 1978

- , Habuba Kabira. Eine Stadt vor 5000 Jahren. Ausgrabungen der Deutschen Orient-Gesellschaft am Euphrat in Habuba Kabira, Syrien (12. Sendschrift der Deutschen Orient-Gesellschaft), Mainz 1980

- , Planwagen aus dem mittleren Euphrattal, in: Resurrecting the Past. A Joint Tribute to A. BoUNNI (UNHAII 67), Leiden 1990, 297-306

STUTZ Fr., Zaubern, Niedernhausen/Ts. 1984

SUETON, Works, Vol. I-II, ed. J.C. RoLFE (The Loeb Classical Library), Cambridge/MA - London 21951 - 1979

SƯHLING F., Die Taube als religiöses Symbol im christlichen Altertum (RQ.S 24), Freiburg i.Br. 1930

SUIDAE Lexicon I-V, ed. A. AdLER (Lexicographi Graeci 1), 1928-1938 = Stuttgart 1971

SUSSMAN V., Astragal Menorah on Lay Lamps, Qad. 13 (1980), 119-121 (hebr.)

- , Omamented Jewish Oil-Lamps, Warminster 1982

SuTton-SmTth B., Spiel: Das Vermitteln von Neuem, in: Sport in unserer Welt - Chancen und

Probleme, ed. O. GRuPE et al., Berlin - Heidelberg - New York 1973, 607-613

- , Forschung und Theoriebildung im Bereich von Spiel und Sport, ZP 21 (1975), 325-334

- , The Folkgames of Children, Austin - London 1972

- , Die Dialektik des Spiels. Eine Theorie des Spielens, der Spiele und des Sports, Schorndorf 1978

- und S., Hoppe, hoppe, Reiter. Die Bedeutung von Kinder-Eltern-Spielen [engl. "How to Play with your Children (and When Not to)", 1974], München - Zürich 1986

SwEET W.E., Sport and Recreation in Ancient Greece. A Sourcebook with Translations, Oxford 1987

SwINY S., Bronze Age Gaming Stones from Cyprus, RDAC 1980, 54-78

- , A Spiral Game (Mehen) from Lemba Area II?, Levant 14 (1982), $53 \mathrm{f}$

- , The Kent State University Expedition to Episkopi Phaneromeni, Part 2 (SIMA 74:2), Nikosia

- Göteborg 1986

- , Prehistoric Cyprus: A Current Perspective, BA 52 (1989), 178-189

TACITUS, Germania. Lateinisch und deutsch, ed. G. PERL (SQAW 37,2), Berlin 1990

- , Annalen. Lateinisch und deutsch, ed. E. Heller (Tusculum), München - Zürich 1982

Taillardat J., Suétone. Peri blasphēmiōn. Peroi paidiōn (Extraits byzantines) (Nouvelle Collection de Textes et Documents), Paris 1967

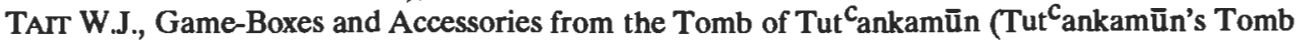
Series 7), Oxford 1982

TALlquist K.L. (ed.), Arabische Sprichwörter und Spiele, Helsingfors 1897 
TALMUD, Babylonischer, Bd. I-XII, ed. L. GolDSCHMDT, Königstein/Ts. ${ }^{3} 1981$

1001 alt-arabische Sprichwörter, deutsch von Fr. RUCKERT, ed. H. BOBZIN, Wiesbaden 1988

TAYLOR C.K. / SAAYMAN G.S., Play and Imitation in Dolphins, in: J.S. BRUNER et al. (ed.), Play

- Its Role in Development and Evolution, New York 1976, 239-243

TAYLOR E.B., The History of Games, in: E.M. AVEDon - B. SuTton-SMTTH (ed.), The Study of Games, New York u.a. 1971, 63-76

TAYLOR E.S., The History of Playing Cards, London 1865 = Rutland/VT 1973

TCHERIKower V.A. / Fuks A. (ed.), Corpus Papyrorum Judaicarum I-III, Cambridge 1957. 1960. 1964

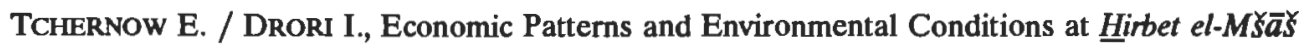
during the Early Iron Age, in: V. FRITZ - A. KEMPINSK (ed.), Ergebnisse der Ausgrabungen auf

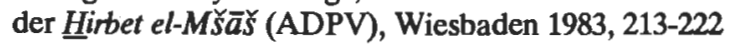

TEIXIDOR J., Bulletin d'épigraphie sémitique (1964-1980) (BAH 127), Paris 1986

TERTULlian, Opera Pars I-II (CCSL 1-2), Turnholt 1954

Testamenta XII PatriarchuM, ed. M. DE Jonge (PsVTGr 1,2), Leiden 1978

TESTAMENT Hiobs, ed. B. SCHALlER (JSHRZ 3,3), Gütersloh 1979

Thalmann J.P., Tell cArqa (Liban Nord). Campagnes I-II (1972-1974). Rapport préliminaire, Syria 55 (1978), 1-151

THIESEN P., Schönwetterspiele. Praxis des Spiels im Freien mit 3- bis 7jährigen, Freiburg i.Br. 1986

Theobald G., Hiobs Prozeß und Gottes Gericht. Die poetische Theodizee des Welttheaters, Diss. theol. masch. 1991

THEOCHARIDIS G.J., Beiträge zur Geschichte des byzantinischen Profantheaters im IV. und V. Jahrhundert, hauptsächlich auf Grund der Predigten des Iohannes Chrysostomos, Patriarchen von Konstantinopel (Diss. phil. München), Thessaloniki 1940

ThEOPHRASTOS, Charaktēres Ethikoi. Griechisch und deutsch, ed. D. KLOSE (Reclam 619/19a), Stuttgart 1974

THEsiger W., Die Brunnen der Wüste. Mit den Beduinen durch das unbekannte Arabien, München - Zürich 21991

ThIESEn P., Schönwetterspiele. Praxis des Spiels im Freien mit 3- bis 7jährigen, Freinurg i.Br. 1986

Thole B. / Werneck T., Spiel und Spaß mit Domino, Ravensburg 1982

THOMSEN P., Die lateinischen und griechischen Inschriften der Stadt Jerusalem, ZDPV 44 (1921), 1-61

- , Die lateinischen und griechischen Inschriften der Stadt Jerusalem, 1.Nachtrag, ZDPV 54 (1941), 203-256

- , Spiel und Spielzeug, RLV 12 (1928), 345f

Thureau-Dangin F. / Dunand M., Til-Barsib (BAH 23), Paris 1936

TIBULL, Gedichte. Lateinisch und deutsch, ed. R. HELM, Berlin $7_{1988}$

TiERBILDER aus vier Jahrtausenden. Antiken aus der Sammlung MiLDENBERG, ed. U. GeHRIG et al., Mainz 1983

TOBLER A.J., Excavations at Tepe Gawra, Vol. II: Levels IX-XX, Philadelphia/PN 1950

ToDD M.N., Teams of Ballplayers at Sparta, ABSA 10 (1903-1904), 63-77

Tом W., "Kaalkop, ga op!, Kom op! Of: Vaar op!"?, GThT 59 (1959), 149-151

TOSA M., Effetto Bambola. Storia, tecnica, collezionismo, Milano 1987

TOUCHEFEU-MEYNER O., Un nouveau "phormiskos" à figures noires, RAr 1972, 93-102

TounY A.D. / WeNiG S., Sport in Ancient Egypt, Leipzig 1969

TOUREH Y.S., Use of Play Activities for Educational Purposes, in: J. RAABE et al. (ed.), The Child and Play. Theoretical Approaches and Teaching Applications (UNESCO Educational Studies and Documents 34), Paris 1980, 64-66

TrAPP K., Bantu-Spiele. Ein Beitrag zur ethnologischen Spielforschung, Diss. phil. masch. Bonn 1960

Trendall A.D., The Shellal Mosaic, Canberra 1957 
- A.D. / SChneIder-HerRmann G., Eros with a Whipping-Top on an Apulian Pelike, BABesch 50 (1975), 267-270

TreU G., Die Bildwerke von Olympia in Stein und Thon (Olympia III), Berlin 1897

TUFFNEL O. et al., Lachish II-IV, London - New York - Toronto 1940-1958

TuRnBurl C., Vom Glück des Daseins. Wie die Bambuti-Pygmäen sich die Zeit vertreiben, in: G.-K. KALTENBRunNer (ed.), Im Anfang war das Spiel. Schöpfertum und Glück zwischen Arbeit und Freizeit, München 1987, 69-89

TushingHam A.D., Excavations in Jerusalem 1961-1967, Vol. 1, Toronto 1985

TYRELL S., Drachen selber bauen. Phantasievolle Modelle aus aller Welt, München 1980

Tzaferis V., A Monumental Roman Tomb at Tel 'Etun, 'A Atiqot HS 8 (1982), 22-30 (hebr.)

- , The Excavations of Kursi - Gergesa ('CAtiqot ES 16), Jerusalem 1983

UEBERHORST H., Leibesübungen in den Hochkulturen Mesopotamiens. Wertung des Leibes und der Leibesübungen in Altisrael. Leibesübungen im alten Ägypten, in: ders. (ed.), Geschichte der Leibesübungen Bd. 1, Berlin - München - Frankfurt a.M. 1972, 161-177. 178-189. 190-226

UeHLinger CH., "Zeichne eine Stadt ... und belagere sie!" Bild und Wort in einer Zeichenhandlung Ezechiels gegen Jerusalem (Ez 4f), in: Jerusalem. Texte - Bilder - Steine. FS für H. und O. KEEL zum 100. Geb. (NTOA 6), Fribourg - Göttingen 1987, 111-200

- , Leviathan und die Schiffe in Ps 104,25-26, Bib. 71 (1990), 499-526

Ulf CH., Die Einreibung der griechischen Athleten mit Öl. Zweck und Ursprung, Stadion 5 (1979), 220-238

Ulich M., "Eene, meene muh / raus bist du". Rituale und Freiräume im traditionellen Kinderspiel, ZP 31 (1985), 735-746

- / OBERhUEMER P. / Reidelhuber A. (ed.), Der Fuchs geht um...auch anderswo. Ein multikulturelles Spiel- und Arbeitsbuch, Weinheim - Basel 1987

UNGNAD A., Eponymen, RIA 2 (1939), 412-457

Usāma Ibn Munqid, Ein Leben im Kampf gegen Kreuzritterheere (Kitāb al-Kctibār), ed. G. ROTTER (Bibliothek Arab. Erzähler), München 1988

VÄTERLEIN J., Roma ludens. Kinder und Erwachsene beim Spiel im antiken Rom (Heuremata 5), Amsterdam 1976

VANDENABEELE F., A propos de quelques terres cuites grecques à membres mobiles, BMAH 4344 (1971-1972), 23-52

VANDenberg B., Play: A Concept in Need of a Definition?, in: D.J. PePLeR - K.H. Rubin (ed.), The Play of Children: Current Theory and Research (Contributions to Human Development 6), Basel u.a. 1982, 15-20

VANDENBERGHE B.H., Saint Jean Chrysostome et les spectacles, ZRGG 7 (1955), 34-46

VANDIER M., Manuel d'Archéologie égyptienne IV, Paris 1964

VANDIER D'ABBADIE J., Deux nouveaux ostraca figurés, ASAE 40 (1940), 467-488

VARRO, Saturarum Menippearum Fragmenta, ed. R. ASTBURY, Leipzig 1985

VATTIONI F., I sigilli ebraici I-III, Bib. 50 (1969), 357-388; Aug. 11 (1971), 447-454; AION 28 (1978), 227-254

- (ed.), Iscrizioni di Hatra, Neapel 1981

VAUX R. DE, Les combats singuliers dans l'Ancien Testament, RB 40 (1959), 495-508 = ders., Bible et Orient, Paris 1967, 217-230

VERGIL, Aeneis. Lateinisch und deutsch, ed. J. GÖTTE (Tusculum), Zürich - München ${ }^{7} 1988$

VESTER H.-G., Zeitalter der Freizeit. Eine soziologische Bestandsaufnahme, Darmstadt 1988

VEYNE P., Brot und Spiele. Gesellschaftliche Macht und politische Herrschaft in der Antike, Frankfurt a.M. 1990

VILLE G., Les jeux de gladiateurs dans l'empire chrétien, MAH 72 (1960), 273-335

Ville-PatzagEan E., Une image de Salomon en Basileus Byzantin, RÉJ 121 (1962), 9-33

VIRE F., Bayzara, EI $^{2} 1$ (1960), 1152-1155

VIROLLEAUD CH., Les travaux archéologiques en Syrie 1922-23, Syria 5 (1924), 44-52

VITRUV, De architectura. Lateinisch und deutsch, ed. C. FENSTERBUSCH, Darmstadt ${ }^{4} 1987$

VIZETELLY F.H., Athletes, Athletics, and Fieldsports, JE 2, 269-273 
Vogelsang R., Die mathematische Theorie der Spiele, Bonn u.a. 1963

VoGT A., Études sur le théâtre Byzantin, Byz. 6 (1931), 37-74. 623-640

VoIGT R.M., Die Laterale im Semitischen, WO 10 (1979), 93-114

VolbaCH W.F., Elfenbeinarbeiten der Spätantike und des frühen Mittelalters (RGZM, Kataloge Vor- und Frühgeschichtliches Altertum 7), Mainz ${ }^{3} 1976$

Volkmann H., Psephisma, KP 5 (1975), 1643

VolkMann H., Das Becherspiel. Darstellungen des Zauberers in der bildenden Kunst, Düsseldorf 1954

VOllmer H., "Der König der Domenkrone", ZNW 6 (1905), 194-198

VORST CH. VAN DE, Une passion inédite de S. Porphyre de mime, AnBoll 29 (1910), 258-275

VORSTER CH., Griechische Kinderstatuen, Diss. phil. Bonn 1982, Köln 1983

VRETSKA K., Mimus, KP 3 (1975), 1309-1314

- , Pantomimos, KP 4 (1975), 478-481

VRIES J. DE, Untersuchungen über das Hüpfspiel. Kinderspiel - Kulttanz (FF Communications 70,173), Helsinki 1957

VRIES DE K., Diving into the Mediterranean. Greek and Etruscan Paintings Reveal a Sport of Antiquity, Exped. 21,1 (1978), 4-8

Vulgata, ed. B. Fischer / R. Weber et al., Stuttgart ${ }^{3} 1983$

WAAL A. DE, Das Mora-Spiel auf den Darstellungen der Verlosungen des Kleides Christi, RQ 8 (1894), 145f

WACHE A., Unfälle bei Sport und Spiel nach römischem und geltendem Recht, Stadion 3 (1977), 4-43

WADDINGTON W.H. (ed.), Inscriptions grecques et latines de la Syrie, Paris 1870

WAGNER E., Hockeyspiel im Altertum, Ph. 103 (1959), 137-140

- , Kritische Bemerkungen zum Harpastum-Spiel, Gym. 70 (1963), 356-366

WALLE B. VAN DE, Schaukämpfe, LÄ 5 (1984), 543-545

WARD W.H., The Seal Cylinders of Western Asia, Washington/DC 1910

WARNECKE B., Histrio, RE 8 (1913), 2116-2128

WARning R., Ritus, Mythos und geistliches Spiel, in: M. FuHRMann (ed.), Terror und Spiel.

Probleme der Mythenrezeption (Poetik und Hermeneutik 4), München 1971, 211-239

WaszinK J.-H., Pompa diaboli, VigChr 1 (1947), 13-41

WATZINGer C., Denkmäler Palästinas I-II, Leipzig 1933-1935

WEBER C.M., Panem et circenses. Massenunterhaltung als Politik im antiken Rom, Düsseldorf 1983

WEBER W., Das Ehrenrecht des Wagenfahrens in römischen Städten, in: Spätantike und frühes Christentum (Liebieghaus), Frankfurt a.M. 1983, 308-311

Weber-Kellermann I. / FAlkenberg R. (ed.), Was wir gespielt haben. Erinnerungen an die Kinderzeit (Insel-TB 1371), Frankfurt a.M. 1992

WECKLEIN N., Der Fackelwettlauf, Hermes 7 (1873), 437-452

WEEBER K.-W., Troiae lusus. Alter und Entstehung eines Reiterspiels, AncSoc 5 (1974), 171-196 - , Die unheiligen Spiele. Das antike Olympia zwischen Legende und Wirklichkeit, Zürich München 1991

WEGNER E., Das Ballspiel der Römer (Diss. phil. Rostock), Würzburg 1938

WEHGARTNER I., Attisch weißgrundige Keramik. Maltechniken, Werkstätten, Formen, Verwendung (Keramikforschungen 5), Mainz 1983

WEHRHAHN K., Kinderlied und Kinderspiel (Handbücher zur Volkskunde 4), Leipzig 1909

WEIDNER E., "Nabû, der (Gott) des Schnellaufs", AfO 16 (1952-1953), 66

- , Ein Losbuch in Keilschrift aus der Seleukidenzeit, Syria 33 (1956), 175-182

-, Die assyrischen Eponymen, AfO 13 (1939-1941), 308-318

WEIL G., Die Königslose. J.G. Wetzsteins freie Nachdichtung eines arabischen Losbuches, MSOS 31, 2.Abt. (1928), 1-69

WEILER I., Der Agon im Mythos. Zur Einstellung der Griechen zum Wettkampf (Impulse der Forschung 16), Darmstadt 1974 
- / Ulf CH., Der Sport bei den Völkern der Alten Welt. Eine Einführung, Darmstadt 21988

Weimar P., Das Goldene Kalb. Redaktionskritische Erwägungen zu Ex. 32, BN 38-39 (1987), $117-160$

WEIPPERT H., Bogen; Schleuder; Spielgerät; Wagen, BRL ${ }^{2}$ (1977), 49f. 282. $310 \mathrm{f} .356$

- , Palästina in vorhellenistischer Zeit (HdArch Vorderasien II 1), München 1988

WEISMANN W., Kirche und Schauspiele. Die Schauspiele im Urteil der lateinischen Kirchenväter unter besonderer Berücksichtigung von Augustin (Cass. 27), Würzburg 1972

- , Gelasios von Heliopolis, ein Schauspieler-Märtyrer, AnBoll 93 (1975), 39-66

-, Gladiator, RAC 11 (1981), 23-45

WEIss E., Lex publica, RE 24 (1925), 2404

WEISSBACH F.M., Sardanapal, RE II 1,2 (1920), 2436-2475

WeITZMANN K. et al., Frühe Ikonen, München - Wien 1965

- , Loca Sancta and the Representational Arts of Palestine, DOP 28 (1974), 31-55

WellhausEn J., Mohammed in Medina. Das ist Vakidi's Kitab al-Maghazi, Berlin 1882

- , Reste arabischen Heidentums, Berlin - Leipzig 1927

WENDLAND P., Jesus als Saturnalien-König, Hermes 33 (1898), 175-179

WENGST K. (ed.), Didache (Apostellehre), Barnabasbrief, Zweiter Klemensbrief, Schrift an Diognet (SUC 2), Darmstadt 1984

WENNING R., Hellenistische Skulpturen in Israel, Boreas 6 (1983), 105-119

- , Nachrichten über Griechen in Palästina in der Eisenzeit, in: Proceedings of the First International Congress on The Hellenic Diaspora from Antiquity to Modern Times Vol. I, ed. J.M. FOSSEY, Amsterdam 1991, 207-219

- , Wer war der Paredros der Aschera? Notizen zu Terrakottastatuetten in eisenzeitlichen Gräbern, BN 59 (1991), 89-97

WENTZEL G., Aiōra (Alētis), RE 1 (1893), 1043f

WERFF J.H. VAN DER, Notes on a Grafitto from the Basilica Aemilia, BABesch 48 (1973), 83-90

WERNER R., Kleine Einführung ins Hieroglyphen-Luwische (OBO 106), Fribourg - Göttingen 1991

WESTERMANN C. / REICKE B., Rätsel, BHH 3 (1966), 1552

WeTzel Fr. / SchMidT E. / MALlWITZ A., Das Babylon der Spätzeit (WVDOG 62), Berlin 1957

WETzSTEIN J.G., Der Nebbût der Araber, Monatsschrift für das Turnwesen 2,1 (1883), 6-12

Weule K., Ethnologie des Sports, in: G.A.E. Bogeng (ed.), Geschichte des Sports aller Völker und aller Zeiten Bd. I, Leipzig 1926, 1-75

WILHELM A., Neue Beiträge zur griechischen Inschriftenkunde V (SAWW.PH 214,4), Wien Leipzig 1932

WHrTE G., Antique Toys and their Background, London 1971

Whrting J.D., Petra. Ancient Caravan Stronghold, The National Geographic Magazine 67 (1935), 129-165

- , Bedouin Life in Bible Lands. The Nomads of the "Houses of Hair" offer unstinted Hospitality to an American, The National Geographic Magazine 71 (1937), 59-83

WIDENGREN G., Der Feudalismus im alten Iran (WAAFLNW 40), Köln - Opladen 169

WIEBER R., Das Schachspiel in der arabischen Literatur von den Anfängen bis zur zweiten Hälfte des 16.Jahrhunderts (Beiträge zur Sprach- und Kulturgeschichte des Orients 22), Walldorf/Hessen 1972

WiEDEMANN A., Das Spiel im alten Ägypten, Elberfeld 1912 [ = Sonderdruck aus Zt. des Vereins für rheinische und westfälische Volkskunde 3 (1912), 161-187]

WiEDEMANn D., Der Sinn des Laufes im alten Ägypten, Diss. phil. masch. Wien 1975 (mit nicht zugänglich)

- , Lauf, LÄ 3 (1980), 939f

- , "...an diesem schönen Tage des Laufens (Pyr. 1555b), GM 83 (1984), 91-93

WIEGAND TH. / KNACKFUSS H., Didyma I, Berlin 1941

WiLDBERgER H., Jesaja 1-12. 13-27. 28-39 (BK X 1-3), Neunkirchen-Vlyun 21980. 1978. 1982

WiLDung D. / SCHOSKE S. (ed.), Kleopatra. Ägypten um die Zeitenwende, Mainz 1989 
WILSDORF H., Ringkampf im alten Ägypten (Körperliche Erziehung und Sport 3), Würzburg Aumühle 1939

WILSON JA., Ceremonial Games of the New Kingdom, JEA 17 (1931), 211-220

WinNETT F.V. / REED W.L., The Excavations at Dibon (Dhibân) in Moab (AASOR 36-37), New Haven/CT 1964

WISSMaNN H., Sport und nichtchristliche Religionen, in: Sport im Blickpunkt der Wissenschaften.

Perspektiven, Aspekte, Ergebnisse, Berlin - Heidelberg - New York 1972, 84-88. 97-100

WITTGENSTEIN L., Philosophische Untersuchungen, in: ders., Schriften 1, Frankfurt a.M. 1960, 279-544

WöRRLE W., Stadt und Fest im kaiserzeitlichen Kleinasien. Studien zu einer agonistischen Stiftung aus Oinoanda, München 1988

WOLL. J. / MERZENICH M. / GöTZ TH., Alte Kinderspiele, Stuttgart 1988

WOOLLEY L., Hittite Burial Customs, LAAA 6 (1914), 87-98

- , A North Syrian Cemetery of the Persian Period, LAAA 7 (1914-1916), 115-129

-, Ur Excavations Vol. II: The Royal Cemetery. A Report on the Predynastic and Sargonid Graves excavated between 1926 and 1931, Oxford 1934

- , Excavations at al Mina, Sueidia, I-II, JHS 58 (1938), 1-30. 133-170

- , The Iron-Age Graves of Carchemish, LAAA 26 (1939), 11-37

- , Ur Excavations Vol. IV: The Early Period, Philadelphia 1956

- , Ur Excavations Vol. IX: The Neo-Babylonian and Persian Periods, London 1962

- et al., Carchemish II-III, London $1921=1969.1952=1978$

Wright D.H., The Date and Arrangement of the Illustrations in the Rabbula Gospels, DOP 27 (1973), 197-208

WRIGHT G.E., Shechem. The Biography of a Biblical City, New York - Toronto 1965

WüNSCH R. (ed.), Antike Fluchtafeln, Bonn 21912

WÜNSCHE A., Salomos Thron und Hippodrom. Abbilder des babylonischen Himmels (Ex Oriente Lux 2,3), Leipzig 1906

WÜsT E., Mimos, RE 15,2 (1932), 1727-1764

-, Palamedes, RE 36,1 (1942), 2500-2512

WÜTHRICH L., Windrädchenlanze und Steckenpferd. Kinderturnier und Kampfspielzeug um 1500, ZSA 38 (1981), 279-289

WUNNERLICH M., Griechische Wettkampf- und Palästradarstellungen. Eine Untersuchung zu den Darstellungsprinzipien schwerathletisch-agonaler Darstellungen in der Zeit vom Ende des 8. bis zum Ende des 6.Jh.s v.Chr., Diss. phil. masch. Freiburg i.B. 1986

XENOPHON, Symposion. Griechisch und deutsch, ed. E. STÄRK (Reclam 2056), Stuttgart 1986

YADIN Y. et al., Hazor I-IV, Jerusalem 1958-1989

- , Masada. Der letzte Kampf um die Festung des Herodes, Hamburg ${ }^{3} 1967$

- et al. (ed.), Masada I, Jerusalem 1989

YEGUL F.K., The Bath-Gymnasium Complex at Sardis. Archaeological Exploration of Sardis 3, Cambridge/MA - London 1986

YEKUTIELI J., Herod, the King of Jerusalem, prevents the Decline of the Ancient Olympic Games (A Historic Episode in the Games of the 193rd Olympiad), Report of the Sixth Summer Session of the International Olympic Academy, Athen 1967, 156-158

ZAYADINE F., Une tombe du fer II à Samarie-Sebaste, RB 75 (1968), 562-585

- , A Dated Greek Inscription from Gadara - Um Qeis, ADAJ 18 (1973), 78

ZAZOFF P., Ephedrismos, ein altgriechisches Spiel, AntAbendl 11 (1962), 35-42

- , Antike Gemmen in deutschen Sammlungen IV, Wiesbaden 1975

ZDARZIL H., Zur Theorie des menschlichen Spiels, in: Rationalität - Phänomenalität - Individualität. FS für H. und M. GLOCKNER, ed. W. RITZEL, Bonn 1966, 247-270

ZELLER D., Die Bildlogik des Gleichnisses Mt 11,16f. / Luk. 7,31f., ZNW 68 (1977), 252-257

ZiAs J., A Roman Tomb at ${ }^{c_{A r}} \mathrm{c}_{\text {ara, }}{ }^{\mathrm{c}}$ Atiqot ES 14 (1981), 60-65 
ZiEgler R. / BoESSNECK J., Tierreste der Eisenzeit II, in: V. FrITZ (ed.), Kinneret. Ergebnisse der Ausgrabungen auf dem Tell el-c Orēme am See Gennesaret 1982-1985 (ADPV 15), Wiesbaden 1990, 133-158

ZIMMERN H., Das Nergallied Berl. VAT 603 = Philad. CBM 11344 = Lond. Sm 526, ZA 31 (1917-1918), 111-121

ZINGERLE J.V., Das deutsche Kinderspiel im Mittelalter, Innsbruck 1873

ZINTZEN C., Gaukler, KP 2 (1975), 703

ZoBEL M., Das Jahr des Juden in Brauch und Liturgie (Bücherei des Schocken-Verlages 55-56), Berlin 1936

ZoRI N., Nahalat Issachar, Jerusalem 1977 (hebr.)

ZsCHIETZMANN W., Wettkampf- und Ubungsstätten in Griechenland, Bd. I: Das Stadion; Bd. II: Palästra - Gymnasion, Schorndorf 1960-1961

Zulliger H., Das selbsterfundene Spiel als Ausdrucksmittel des Kindes, Pädagog. Rundschau 19 (1965), 250-252

-, Heilende Kräfte im kindlichen Spiel, Stuttgart ${ }^{6} 1979$ 


\section{REGISTER}

Die Seitenangaben beziehen sich unterschiedlos auf die Belege in Text und Anmerkungen; bei letzteren ist mit dem Ortsnamen häufig der Verweis auf den entsprechenden Buchtitel bzw. Grabungsbericht gemeint. Im Ortsregister sind nur die wichtigsten Belege erfaßt, Palästina, Israel, Juda, Griechenland u.ä. aber nicht eigens.

\section{Stellenregister}

\section{Altes Testament:}

$\begin{array}{lll}\text { Gen. } & 14,17 & 122 \\ & 17,17 & 15 \\ & 18,12 \mathrm{f} .15 & 15 \\ & 19,14 & 15 \\ & 21,6 & 15 \\ & 21,9 & 15 \\ & 25,22 & 19 \\ & 26,8 & 15 \\ & 31,30 \mathrm{ff} & 93 \\ & 32,23-33 & 18 \\ \text { Ex. } & 39,14.17 & 15 \\ & 10,2 & 15 \\ & 32,6 & 15 \\ \text { Num. } & 32,18 & 5 \\ \text { Ri. } & 22,29 & 15 \\ & 14,14 f & 137 \\ & 16,25 & 15 f .103 \\ & 16,27 & 16.103 \\ & 19,25 & 15 \\ 1 . \text { Sam. } & 20,16 & 100 \\ & 6,6 & 15 \\ & 17,40 & 100 \\ & 18,7 & 17 \\ & 19,8-17 & 93 \\ & 20,20 & 102 \\ & 21,11-15 & 136 \\ & 30,26-28 & 69 \\ & 31,4 & 15\end{array}$

2.Sam.

2,14

6,5

6,16

6,21

6,20-23

11-12

12,3

18,11

22,37

1.Kön. $\quad 10,2 \mathrm{ff}$

21

2.Kön. $\quad 2,23 \mathrm{f}$

18,23

1.Chr. 10,4

13,8

15,29

2.Chr. $\quad 9,1$

30,10

36,16

Est.

$3,1 \mathrm{ff}$

3,7

9,24

Dan.

5,24

Jes.

11,5

11,8

22,15-18

22,18

25,11

29,3

36,8

66,12

Jer.

5,27

6,11

8,17

9,20

$10,3-5$

10,5

15,17

30,19

31,4

38,19

Ez.

4-5

23,32

47,5

47,3

Jona $\quad 1,7$

Sach.

$8,4 \mathrm{f}$

9,15

11,16

12,3

Ps.

2,4

6,7

18,37
17 


\begin{tabular}{|c|c|c|c|c|c|}
\hline & 22,19 & 110 & & 15,24 & 108 \\
\hline & 37,13 & 16 & Luk. & 7,32 & 136. 142f \\
\hline & 52,8 & 16 & & 22,52 & 102 \\
\hline & $58,5 \mathrm{f}$ & 31 & & $22,63 \mathrm{f}$ & 106 \\
\hline & 59,9 & 16 & & 23,35 & 108 \\
\hline & $104,25 \mathrm{f}$ & 24 & Joh. & $19,2 \mathrm{f}$ & 107 \\
\hline & 104,26 & 24 & & $19,23 \mathrm{f}$ & $109 f$ \\
\hline & 109,1Vulg. & 140 & Apg. & $12,21-23$ & 116 \\
\hline Hi. & $1,6 \mathrm{ff}$ & 24.136 & & $19,29-41$ & 117 \\
\hline & $2,1 \mathrm{ff}$ & 24.136 & & $27,42 \mathrm{f}$ & 12 \\
\hline & 5,22 & 16 & 1.Kor. & 4,9 & 108 \\
\hline & 16,12 & 25. 102 & & 9,24 & 123.129 \\
\hline & 21,11 & 22 & & 9,25 & 129 \\
\hline & 29,24 & 16 & & 9,26 & 122 \\
\hline & 30,1 & 16 & & 10,7 & 15 \\
\hline & 38,3 & 18 & Gal. & 2,2 & 123.129 \\
\hline & $39,7.18 .22$ & 16 & & 5,7 & 123. 129 \\
\hline & 40,7 & 18 & Eph. & 4,14 & 133 \\
\hline & 40,15 & 36 & Phil. & 2,16 & 123.129 \\
\hline & 40,20 & 36 & & 3,14 & 129 \\
\hline & 40,24 & 31 & 1.Tim. & $4,7 f$ & 129 \\
\hline & 40,29 & $28 \mathrm{f}$ & 2.Tim. & 2,5 & 129 \\
\hline & 41,21 & 16 & Hebr. & 12,1 & 123 \\
\hline H1. & $1,1 \mathrm{ff}$ & 6 & & & \\
\hline Qoh. & 2,24 & 1 & & & \\
\hline & 3,4 & 16 & Apo & phen, Pseu & raphen u.ã.: \\
\hline & 3,13 & 1 & Ар0 & pilei, rseu & rapinen U.a.: \\
\hline & $5,17 \mathrm{f}$ & 1 & Aristeas & ef $\$ 284$ & 114 \\
\hline & 8,15 & 1 & & $\S 314-316$ & 114 \\
\hline & 9,7 & 1 & Bar. & $3,16 \mathrm{f}$ & 32 \\
\hline & 10,11 & 31 & & 3,17 & 112 \\
\hline Prov. & 1,26 & 16 & & 6,69 & 97 \\
\hline & $8,30 f$ & 17 & & 6,70 & 93 \\
\hline & 26,19 & 16. 57 & Ep.Jer. & 69 & 97 \\
\hline & 29,9 & 16 & Kindhe & arab. & $26,1 f \quad 36$ \\
\hline & $30,15 \mathrm{ff}$ & 137 & & & $40,1 \quad 22$ \\
\hline & 31,25 & 16 & & & $42,2 \quad 107$ \\
\hline Threni & 1,7 & 16 & Kindhei & armen. & 21,6 f 19 \\
\hline & 3,12 & 25.102 & Anome t & & $23,3 \quad 14$ \\
\hline & & & Kindhei & Thomas & $2,1-3,322$ \\
\hline & & & & & $9,127.31$ \\
\hline Neu & estament: & & 1.Makk & 1,14 & $112 \mathrm{f}$ \\
\hline & & & & $1,44-54$ & 111 \\
\hline Matth. & $11,16 f$ & $142 f$ & & 2,9 & 142 \\
\hline & 11,17 & 136 & & 6,32 & 8 \\
\hline & 26,47 & 102 & & 8,6 & 8 \\
\hline & 26,67 & 106 & & 9,48 & 12 \\
\hline & $27,27-30$ & 107 & 2.Makk & 4,9 & 111. 118 \\
\hline & 27,35 & 108 & & $4,9-18$ & 112 \\
\hline & 27,63 & 103 & & 4,10 & 113 \\
\hline Mark. & 14,43 & 102 & & 4,11 & 113 \\
\hline & 14,65 & 106 & & 4,12 & 118 \\
\hline & $15,16-20$ & 15. 107 & & 4,13 & 113 \\
\hline
\end{tabular}




\begin{tabular}{|c|c|c|c|c|c|}
\hline & 4,14 & 112f. 123 & bTaan. & $11 \mathrm{a}$ & 1 \\
\hline & $4,18-20$ & 111. 121 & jErubin & $22 \mathrm{~b}$ & 117 \\
\hline & 4,20 & 112 & jSan. & 10,1 & 39 \\
\hline & 11,21 & 8 & & $28 \mathrm{a}$ & 39 \\
\hline & 13,2 & 8 & jŠeq & $50 a$ & 12 \\
\hline 3.Makk. & 5,6 & 8 & $\mathrm{mSabb}$ & 22,6 & 123 \\
\hline & $11,20 f$ & 130 & tŠabb. & $10(11), 12 f$ & 39 \\
\hline & 13,15 & 130 & Targ. zu & ก. 21,9 & 15 \\
\hline & $17,11 f$ & 130 & Targ. zu & ch. 12,3 & 127 \\
\hline 4.Makk. & 4,20 & 112 & & & \\
\hline & 6,10 & 130 & & & \\
\hline & 6,17 & 103 & Nore & stsemitische Insch & riften: \\
\hline & $17,12-16$ & 130 & & & \\
\hline Sap.Sal. & 15,12 & 37.93 & Ahịqar & & 137 \\
\hline Sir. & 6,21 & 127 & Arad-O & ka Nrn. 50-57 & 60 \\
\hline & 11,30 & 29 & Bustāan-e & & $29 f$ \\
\hline & 12,13 & 31 & Hatra ( & TIONI) Nr. 23.125.23 & 16 \\
\hline & $13,6.11$ & 16 & KAI Nr. & 4 (Hatra Nr. 23) & 16 \\
\hline & $25,1 \mathrm{ff}$ & 137 & Masada & traka Nrn. 429-440 & 60 \\
\hline & 30,9 & 3 & VSE Nr & 9.252 & 34 \\
\hline & $32,11 \mathrm{f}$ & 20.142 & & & \\
\hline & 32,15f (Vulg.) & 20 & & & \\
\hline & 47,3 & 16f. 31 & & tamische ugritis & \\
\hline Pseudo-1 & & 24 & vies & tainiscie, ugarius & (c) bur \\
\hline Test.Hi. & 4,10 & 19. 122 & heth & che Quellen: & \\
\hline & 27,1 & 19 & & & \\
\hline & $27,3 \mathrm{ff}$ & 29.130 & ARM X & TUAT 2,84f) & 14 \\
\hline TestXII & Jos. & 20,3 & BM 333 & & 58 \\
\hline & & 118 & $\begin{array}{l}\text { Entuma } \\
\text { Gilgame }\end{array}$ & $\left(\mathrm{ANET}^{3} 78\right)$ & $\begin{array}{l}25 \\
18\end{array}$ \\
\hline & & & Hethit. & & 17. 21.59 \\
\hline & ch & idicche & & & 107 \\
\hline Ouel & cn- / aramaisc & Iascne & Hierogly & en-luw. Texte & 54 \\
\hline Quel & & & KTU 1.6 & [ $16 b-22 a$ & 18 \\
\hline & & & LKA Nr & & 49 \\
\hline bAZ & $3 b$ & 24 & Lugalba & I,346 (TUAT 2,34) & 18 \\
\hline & $18 b$ & 31.106. & SAHG I & & 142 \\
\hline & & 112.117. & SAHG 1 & 24 (TUAT $2,673 \mathrm{ff}$ ) & 121 \\
\hline & & 132 & STT I, I & & 49 \\
\hline bBB & $91 \mathrm{~b}$ & 142 & TUAT 2 & 2f (Akitu-Fest Babyl & on) 107 \\
\hline bGittin & $47 a$ & 124 & YOS 9, & 73 (Jahāllu) & 47. 53.62 \\
\hline bJoma & $78 b$ & 14 & & & \\
\hline bQidd. & $29 a$ & 12 & & & \\
\hline bSabb. & $\begin{array}{l}73 b \\
30 b\end{array}$ & $\begin{array}{l}14 \\
32\end{array}$ & Ägyr & che Quellen: & \\
\hline & 31 & 136 & & & \\
\hline & $94 a$ & 33 & 'Großer & ettspieltext' & 71 \\
\hline bSan. & $24 b$ & 32.83 & Sinuhe ] & $10 \mathrm{ff}\left(\mathrm{TGI}^{3} 5 \mathrm{f}\right)$ & 17 \\
\hline & 25a.b & 83 & Pyr. 155 & & 21 \\
\hline & $67 \mathrm{~b}$ & 106 & & & \\
\hline & $77 b$ & 39.41 & & & \\
\hline & $95 a$ & 33 & Aral & he Literatur: & \\
\hline & $103 a$ & 137 & & & \\
\hline bSukka & $53 a$ & 106 & $A b \bar{u} l-F_{c}$ & & 103 \\
\hline
\end{tabular}


al-Gițrif Ibn Qudāma al-Ġassānì 33

Ibn Hiallikān $\quad 103$

Ibn Iyās $\quad 103$

Ibn Sirin 57

Losbücher $52 \mathrm{f}$

Mahfüz N., Midaq-Gasse 23

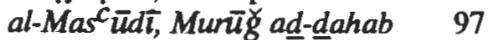

Muqadassī $175 \quad 117$

al-Qazwini

Qoran 2,219 83

3,49

$5,90-92$

Sprichwörter (Sammlung)

Usāma Ibn Munqid

Yāqūt III 760

36

83

28f. 33. 95. 145

7

117

\section{Sonstige griech. und latein. Quellen:}

Acta Ioan. 94-96

Acta Pauli

\section{5}

Acta SS., passim

Aelian, nat.hist. 2,6-8

- , var.hist. 12,15

Aischines 1,59

Ambrosius, de Tobia 11

Amm.Marc., hist. 28,4,21

- , hist. 28,4,29

- , hist. 28,4,30f

Anakreon82(54),2

111(34),1

Anth.Graeca 5,205

5,214

5,296

6,155

6,280

6,308

6,309

7,89

7,325

7,424

7,427

7,428

7,643

9,3

9,482

9,533

9,768

11,75

11,76-78

11,81
108

131

12

26. 37

47

58

57. 125

125

125

47

26. 56

91

26

148

35.59

59.95

48. 57.59

25. 49.86 .

89.95

86. 142

1

35

48. 56

43

6

12

47

104

135

130

130

130
11,258

12,44

12,46

12,47

12,212

14,8

14,62

14,116

14,138

16,27

$16,387 \mathrm{~b}$

Anth.Lat. 193

281

Apoll.Rhod., Arg. 3,117ff

Apuleius, de mundo 27

- , meta. 1,4,2-5

Aristoph., aves $1462 \mathrm{ff}$

- , nub. 763

- , nub. 877ff

- , pax 864

- , Plut.816

-, Plut. 1055ff

- , vesp.293ff

- , vesp. 1517

- , vesp. 1530

Aristot., rhet. 3,5

- , de mondo 389b

- , de mot.anim. 701b 2-9

Artemidor 1,55

3,1

3,5

3,15

Athenaios 4,129d

12,530

Audollent Nr.

$241 f$

265

Augustin, de bapt.

-, de civ.dei 2,20

-, conf. $\quad 1,9,14 f$

$1,10,16$

1,19

$1,19,30$

$2,4,9$

$3,2.2$

$8,6,14$

8,12

,- trin.

$8,5,8$

Ausonius, cento nupt.

- , Mosel. 225-239
24. 26. 38.

46. $56 \mathrm{f}$

26

104

86

7. 29.37

7.99

86

56

55

$56 \mathrm{f}$

86

86

$55 f$

26

55

13. 42

53. 57.60

35

136

105

1

$15 f$

126

125

125

$7,101 \mathrm{f}$

131

1

37

37. 123

28. 38.55

36. $55.57 \mathrm{f}$

14142

123

10

10

109

$17 \quad 139$

13 


\begin{tabular}{|c|c|c|c|c|}
\hline \multirow{2}{*}{$\begin{array}{l}\text { Babrios, myth. } 5 \\
\text { Basilios v.Seleukia, Thecla }\end{array}$} & 35 & \multicolumn{2}{|c|}{-, Dig. 47,11,11 } & 31 \\
\hline & 2,830 & \multicolumn{2}{|c|}{ CPJ No. 153:72ff } & 113 \\
\hline Calpurnius, eclog. 2,23 & 138 & \multicolumn{2}{|c|}{ CPJ No. 157:I:7f } & 113 \\
\hline - , eclog. $2,26 \mathrm{f}$ & 109 & \multicolumn{2}{|c|}{ "Cyprian", de spect. } & 114 \\
\hline Canon.Apost. $42 \mathrm{f}$ & 83 & \multicolumn{2}{|c|}{ "Cyprian", de aleator. } & 57.61 .84 . \\
\hline Carmin. Einsidl. 1,5ff & 138 & & & $135 f$ \\
\hline Cassius Dio 68,15,1 & 123 & \multicolumn{2}{|c|}{ Didymos d.Blinde, Hi.-Komm. } & 19 \\
\hline Catull, carm.2-3 & 28 & \multicolumn{2}{|c|}{ Diod.Sic., bibl. 5,22} & 59 \\
\hline,- carm. $61,132 \mathrm{ff}$ & 55 & \multicolumn{2}{|c|}{- , bibl. $34 / 35,2,6 \mathrm{f}$} & 105 \\
\hline carm. 64.314ff & 87 & \multicolumn{2}{|c|}{ Diog.Laert. 1,80} & 86.89 .142 \\
\hline Celsus, de med. 1,2.6 & 41. 144 & \multicolumn{2}{|c|}{6,30} & 101 \\
\hline Chorik. v.Gaza, apol.mim. & 133 & \multicolumn{2}{|c|}{6,46} & 148 \\
\hline Chron.Pasch. 275c-276a & 131 & \multicolumn{2}{|c|}{ Dion Chrys., orat. 4,135 } & 1 \\
\hline Cicero, div. $2,41,85$ & 109 & \multicolumn{2}{|c|}{ Elvira, Kanon 79} & 83 \\
\hline- , de fat. 42 & 86 & \multicolumn{2}{|c|}{ Epiktet, diatr. $3,15,12$} & 107 \\
\hline- de fin. 2,52 & 109 & \multicolumn{2}{|c|}{ Epiphanios, Pan. 30,7} & 12 \\
\hline- , de off. 3,77 & 109.136 & \multicolumn{2}{|c|}{ Euripides, Iph.Aulis 195ff } & 2 \\
\hline- , Phil. 2,56 & 58. 83.142 & \multicolumn{2}{|c|}{ Euseb, hist.eccl. 1,8,12 } & 118 \\
\hline- , Tusc. 5,35 & 1 & \multicolumn{2}{|c|}{-, hist.eccl. 5,18,11 } & 83. 131 \\
\hline CIG 3, Nr. 4472 (IGLS 1,166) & 119 & \multicolumn{2}{|c|}{-, Chron. 101,23 } & 115. 120 \\
\hline $4, \mathrm{Nr} .852$ & 59 & -, mart., $\mathrm{P}$ & sim & 131 \\
\hline $4, \mathrm{Nr} .4614$ & $117 \mathrm{f}$ & Eustathio & Il. 986,43 & 14 \\
\hline CIJ II, Nr. 748 & 113 & -, Il. 1289 & & 56 \\
\hline CIJ II, Nr. 755 & 113 & - Od. 139 & & 56 \\
\hline CIL II, Nr. 2262 & 1 & - Od. 140 & & 25 \\
\hline IV, Nr. $\quad 1595$ & 31 & Expos. to & Is mundi E 32 & 19. $104 \mathrm{f}$. \\
\hline 4289 & 123 & & & 111. $122 \mathrm{f}$ \\
\hline 4345 & 123 & Florus, e & ome $2,7(19)$ & 105 \\
\hline 4353 & 123 & Galenos, & parv.pilae & 9. 41 \\
\hline 4358 & 123 & Gellius & $10,12,9 f$ & 137 \\
\hline 4397 & 123 & & $12,6,1-3$ & 137 \\
\hline 8916 & 123 & & $14,1,23$ & 26 \\
\hline VI, Nr. & 1770 & Greg. d.C & Mor.in Job 1,3,4 & 19 \\
\hline & 109 & Greg. v.T & Irs, hist. $10,16,5-26$ & 84 \\
\hline VI, Nr. 1 & 6169 & Heraklit & B 52 & 107 \\
\hline & 145 & & B 70 & 95 \\
\hline VIII, Nr. & 7998 & Herodot & 1,94 & 135 \\
\hline & 61.63 & & $1,114 f$ & 107 \\
\hline VIII, Nr. & 17938 & & 1,136 & 101 \\
\hline & 1 & & 2,78 & 1 \\
\hline 1.Clem. 5,1f & 130 & & $2,122,1$ & 2. 25 \\
\hline 1.Clem. 6,2 & 130 & & 2,173 & 145 \\
\hline 2.Clem. 7,1ff & 130 & & 6,129 & 138 \\
\hline Cod.Iust.3,43,1 & 83 & Heron $\mathrm{A}$ & Pneum. & 121 \\
\hline Cod.Iust. $11,44,1$ & 133 & Hieronyn & ep. 58,4 & $105 f$ \\
\hline Cod.Theod. 15,5,5 & 133 & - , ep. 107 & & 144.146 \\
\hline Cod.Theod. 15,12,1 & 133 & -, ep. 128 & & 146 \\
\hline Columella $8,2,4 \mathrm{f}$ & 35 & -, apol.c. & af. 3,31 & 105 \\
\hline Const.Apost. 2,62,2 & 133 & - , in Es. & 3,20 & 104. 128 \\
\hline $6,9,2-4$ & 104 & - , in Zac & 12,3 & 128 \\
\hline $8,32,9-11$ & 104 & - , de vir.i & & 83 \\
\hline Corp.Iuris, Dig. 9,2,11 & 41 & -, c.Ioan. & ier. 30 & 19 \\
\hline,- Dig. $11,5,2$ & 83 & - , vita Hi & & 124 \\
\hline
\end{tabular}


- , vita Hilar. 16

-, vita Hilar. 17

- , vita Hilar. 20

Hist. von Alex.d.Gr. 99

Hist.Apoll.reg.Tyri 16

Hist_Aug., Heliog. 23

-, Sev. 1,4

-, P.Lic.Gall. 4,34,3

-, Marc.Aurel. 12,12

-, quadr.tyr.13,1ff

-, L.Verus 8,11

Homer, Il. 13,27-29

\section{4,413}

23,88

23,584

-, Od.6,100ff

Hom.Hymn. 24ff

\section{0-42}

151-154

152

242

Horaz, sat. $\quad 1,3,140 \mathrm{ff}$

$1,5,49$

$2,3,247 \mathrm{ff}$

$2,3,248$

$2,7,15$

$2,7,82$

- , carm. $\quad 3,24,57$

- , carm. 3,24,58

- , ep. $1,1,59 \mathrm{f}$

- , ep. 1,18,21f

- , de arte poet. $455 \mathrm{f}$

IG.EMiI, Nr. 324

II-III $^{2}$, Nr. 1533

IV,1, Nr. 121

VII, Nr. 2420

XIV, Nr.593

XIV, Nr. 2419,7f

IGLS 1, No. 166

4, No.

1265

1302

1532

1545

1850

1990

5, No. $\quad 2098$

2138

2143

2617

2644
125

128

121. 125

32107

135

1340

123

31

107

107

104

79. 103.

106

104

25

86

57

25

38

7. 26

32

7. 32

7

7

31

38

22

37. 56

47. 57

96

13

83

107

49

31

81

46

$58 \mathrm{f}$

89

59

59

120

119

120

120

120

120

120

120

120

120

120

120
6, No. $2836 \quad 132$

7, No. $4001 \quad 120$

7, No. $\quad 4042 \quad 120$

13,1, No. $9442 \quad 132$

21,1, No. $\quad 29 \quad 120$

21,1, No. $127 \quad 121$

Ignat.v.Ant., ad Pol. $1,2 \quad 130$

$2,3 \quad 130$

$3,1 \quad 130$

IGR 3, Nr. 1012 (CIG 3,4472) 119

3, Nr. 1371 (Gerasa 170) 119

3, Nr. 1543 (AUDOLlENT 15) 126. 132

ILS Nr. 8626a 81

$8626 \mathrm{e} \quad 125$

$8626 \mathrm{f}$

Isid.v.Sev., etym. 18,60ff $\quad 47.52$

$18,61 \quad 47$

$18,68 \quad 83$

$18,69 \quad 38$

Jakob von Sarūg, de spect. 133

Joh.Chrys., In Matth.hom. 23-34,6 19

-, In Matth.hom. 33,9 7

-, ep. 6

- , de stat. 1,11

- , ad popAnt.hom. 5,1 19

- , ad pop.Ant.hom 19,4 106

-, Frag. in Beat. Job 19

Joseph., Ant. $\quad 8,5,3(\$ 143) \quad 137$

$8,6,5(\S 165 f) \quad 137$

$8,12,3(\S 302) \quad 129$

$12,3,1(\S 120) \quad 119$

$12,5,1(\S 241) \quad 113$

$13,15,1(\S 389) \quad 118$

$15,3,3(\$ 53-56) \quad 12$

$15,8,1(\S 267) \quad 113.119$

$15,8,1(\S 268) \quad 115.117$.

120

$15,8,1(\S 269-273) \quad$ 121f. 124

$15,9,6(\$ 341) \quad 117$

$16,5,1(\S 137 f) \quad 115.119$.

124

$16,5,3(\S 149) \quad 115.119$

$17,6,3(\S 161) \quad 117$

$17,6,5(\S 175.178) \quad 118$

$17,8,2(\$ 193 f) \quad 118$

$17,9,5(\$ 233) \quad 118$

$17,10,2(\S 255) \quad 118$

$19,1,4(\$ 24) \quad 125$

$19,7,4(\$ 332-334) \quad 114$

$19,7,5(\S 335-338) \quad 108.114$.

124

$19,8,2(\S 343) \quad 119$

$19,8,2(\S 345) \quad 116$ 


\begin{tabular}{|c|c|c|c|c|}
\hline & $20,7,11(\S 189)$ & 118 & -, Anachar. 3 & 130 \\
\hline & $20,9,4(\S 2111)$ & 116 & $\therefore$, dial.deor. $4,3 \mathrm{f}$ & $26.56 f$ \\
\hline,$- \mathrm{BJ}$ & $1,21,8(\S 415)$ & 115.117. & - , dial.deor. 5,2 & $56 \mathrm{f}$ \\
\hline & & 119 & - , somn. 2 & 7.37.95 \\
\hline & $1,21,11(\S \S 422-426)$ & 119 & Macrobius, saturn. 1,7,22 & 14 \\
\hline & $1,21,11(\S 422)$ & $115.117 f$ & Malalas, chron. $\quad 5, \S 22$ & 80 \\
\hline & $1,21,11(\S 423)$ & 114f. 119f & $10, \S 261$ & 118 \\
\hline & $1,21,12(\$ \S 426-428)$ & 115 & $12, \S 314$ & 131 \\
\hline & $1,21,12(\S 427)$ & 115.119 & $15, \S 382$ & 57.122 . \\
\hline & $1,21,13(\S 429-431)$ & 34. 102 & & 132 \\
\hline & $1,22,2(\S 437)$ & 12 & $18, \S 446$ & 57. 118 . \\
\hline & $1,33,6(\S 659)$ & $117 \mathrm{f}$ & & 122. 132 \\
\hline & $1,33,8(\S 666)$ & 117 & Marc Aurel 1,6 & 35 \\
\hline & $2,3,1(\$ 44)$ & 118 & 7,3 & 26 \\
\hline & $2,16,3(\S 344)$ & 118 & Martial, epigr. 1,3 & 121 \\
\hline & $2,20,2(\S 560)$ & 118 & $4,14,8 \mathrm{f}$ & 47 \\
\hline & $2,21,3(\S 599)$ & 118 & $4,14,9$ & 55 \\
\hline & $2,21,6(\S 618)$ & 117 & 5,12 & 127 \\
\hline & $3,10,10(\S 539)$ & 117 & 5,84 & 55.83 \\
\hline & $4,9,12(\S 581)$ & 118 & $7,32,5$ & 130 \\
\hline & $5,4,2(\S 144)$ & 118 & $7,32,7 f$ & 38 \\
\hline & $6,3,2(\S 191)$ & 118 & $7,72,8$ & 82 \\
\hline & $6,6,2(\$ 325)$ & 118 & 9,38 & 104 \\
\hline & $6,8,1(\$ 377)$ & 118 & $11,6,2$ & 47 \\
\hline & $7,2,1(\$ 23 f)$ & 116. 124 & $13,1,7$ & 47 \\
\hline & $7,9,1(\S 397)$ & 60 & 14,1 & 55.83 \\
\hline- , vita & 92 & 117 & 14,3 & 83 \\
\hline & 132 & 118 & 14,14 & 46 \\
\hline & 138 & 118 & 14,16 & 47 \\
\hline & 331 & 117 & 14,18 & 82 \\
\hline Juvenal, sat & 10,81 & 111 & 14,19 & 55 \\
\hline - , sat. 11,13 & & 82 & 14,45 & 40 \\
\hline - , sat. 14,5 & & 47 & 14,47 & 40 \\
\hline Kallimacho & epigr. $1,9 f$ & 86. 89. 142 & 14,54 & 5 \\
\hline Klem.Alex., & strom. $1,159,1$ & 1 & 14,77 & 29 \\
\hline -, strom. 2 , & 18,6 & 1 & 14,168 & 13 \\
\hline -, Paid. 3,1 &, 75 & 58.83 & 14,169 & 13. 142 \\
\hline,- Paid. 3,4 & 51 & 38 & Max. Conf., peri diaph. (PG 91,1 & 416) 26 \\
\hline Kyrill Jerus & lem, kat.myst. 1,6 & 132 & Min. Felix, Oct. 3,5f & 12 \\
\hline Lactanz, ins & t.div. $2,4,12 \mathrm{ff}$ & 95 & Min. Felix, Oct. 37,11 & 133 \\
\hline Laus Piso. & 185-189 & 38 & MORETTI Nr. 72 & 120 \\
\hline & $190-208$ & 79 & MORETTI Nr. 85 (IGLS 4,1265) & 119 \\
\hline & 193 & 82 & Nik.v.Kues, ludus globi & 9f \\
\hline Leben $+\mathrm{T}$ & t.Alex. (THIEL) $1,1,5 \mathrm{f}$ & f 37 & Nonnos, Dion. $6,165 \mathrm{ff}$ & 26 \\
\hline & $1,3,9,3$ & 57 & -, Dion. 33,65ff & 148 \\
\hline & $1,5,1$ & 37 & -, Dion. 33,77f & 109 \\
\hline & $1,36,1 \mathrm{ff}$ & 39. 42.89 & -, Metaphr.S.Ev.Ion. 19,125 & 110 \\
\hline & $1,38,7$ & 39.42 .89 & Novatian, de spect. & 114. 133 \\
\hline & $2,7,1$ & 39.42 .89 & Nux & $56 \mathrm{f}$ \\
\hline & $2,9,4$ & 6 & $85 f$ & 55 \\
\hline Libanios, ep & $40-42$ & 123 & $125 f$ & 12 \\
\hline Lucan, de b & ello civ. 8,908 & 31 & 151f & 12 \\
\hline Lukian, An & char. 1 & 19 & OGI Nr. 253 & 111 \\
\hline
\end{tabular}


Origines, c. Celsum 2,55

-, de orat. 30,2

-, ex. ad mart. 18

Orph.Frag. (KERN)

34

Ovid, ars amat. $1,135 \mathrm{ff}$

2,208

3,353-380

3,383

- , amores 3,2

- , met. 10,260f

met. 10,262

- , ex Ponto 4,3,49

- , tristia

$2,471 \mathrm{ff}$
$2,481 \mathrm{f}$
2,485
2,486

Paulin. v.Nora, Poem.ult. 76

Pausanias $\quad 2,19,7$

$3,25,7$

$6,24,7$

$7,25,10$

8,40

$9,3,1 \mathrm{f}$

$10,30,2$

$10,31,1$

Persius, sat. $2,69 \mathrm{f}$

$3,4 \mathrm{ff}$

3,50

3,51

Petronius, satyr.

$$
\begin{aligned}
& 33,2 \\
& 44,7
\end{aligned}
$$

Phaedrus, Lib.fab. 3,14

Philo Alex., in Flacc. 36-39

-, in Flacc. 72

-, de fug. 46

-, leg.all. 3,190

-, spec. 2,229f

Philostrat, imag. 2,6

- , Heroik. 19,2 (KAYSER)

Photios, lex. p.606,8

Pindar, O1. 1,70ff

- , frag. 107 (WERNER)

Platon, Lysis 206e

-, nomoi 643b-c

$644 d-645 b$

$803 c-804 b$

$803 \mathrm{f}$

$830 \mathrm{~b}$

- , Phaidon 110b
82

38. 56.77.

79

13

126

28

38

27

8. 83

77

38

13

14

32

8. 12

$56 \mathrm{f}$

52.58

130

93

$56 \mathrm{f}$

2

95

86

55

89

2738

61

109

145

108

106

26

19

$18 f .113$.

123

6. 130

56.98

55

25

2

48. $56 \mathrm{f}$

37. 143

26

26

26

93

40.42
- , Phaidros 274d

25

- , politeia 436d-e

86

25

- politeia 604c

-, Theait. 181A

Plautus, capt. 22

- , capt. 1002

-, mel. 162

-, mil.glor. $163 f$

-, Trucul. 705

Plinius d.J., ep. 3,1,8

$4,2,3 \mathrm{f}$
$7,24,4$
$9,33,2$

-, Panegyr. 46,4

$9,24,4$

Plinius d.Ä., nat.hist. 2,47

7,83

7,201

7,205

9,24-33

10,120

25,11

$28,19.30$

34,55

35,89

Plutarch, Agesil. 25

-, Alex. 29

-, Alkibiad. 2,15

-, Anton. 29

-, Apophth.Lac. 70

-, Cato min. 2

-, de coh.ira9

-, de coh.ira14

-, cons. ad uxor. 6

-, Dion 9

-, de fort. 98

-, de Iside et Osir. 12

- , de lib. educ. 11

-, Lykurg. 19,4

-, Lys. 8,5

-, quaest. Rom. 35

, reg. et imp. 181

-, septem sap.conv. 20

-, de tranq.animi 5

-, de tranq.animi 8

P.Mas. II, No. 721

P.Ness. II, Nos. 1f

Pollux

4,104

7,105

7,203 ff

7,206

9,94

9,95f

9,99
11

26

28

28

51.83

38

40. 144

28

105

8. 12

105

86

127

100

19. 38.135

12

28

31

31

51

103

37

111

57. 142

56

37

108. 142

39. 57

57

97

7. 99.142

8

25

24. 101

104

57

25. 84

145

8

25

97

89

89

136

56

62

14. $54 \mathrm{f} .62$

148

54

56.62 


\begin{tabular}{|c|c|c|c|c|}
\hline 9,100 & 46. 62 & \multicolumn{2}{|c|}{-, Claud. 33} & 8f. 56.58 \\
\hline 9,101 & 56.62 & \multicolumn{2}{|c|}{, Nero 20,1} & 105 \\
\hline 9,102 & 55 & \multicolumn{2}{|c|}{- Nero 35} & $107 \mathrm{f}$ \\
\hline 9,103 & 55 & \multicolumn{2}{|l|}{ Tib. 14} & 46.52 .58 \\
\hline 9,104 & 38 & \multicolumn{2}{|l|}{ Tib. 72} & 28 \\
\hline 9,110 & 107 & \multirow[t]{10}{*}{-, Peri paic } & 1 & 52 \\
\hline 9,112 & 11 & & 2 & 38 \\
\hline 9,115 & 21 & & 3 & 137 \\
\hline 9,116 & 11 & & 4 & 148 \\
\hline 9,117 & 21.54 & & 7 & 11 \\
\hline 9,118 & 14 & & 9 & 12 \\
\hline 9,119 & 12 & & 12 & 40 \\
\hline 9,121 & 40 & & 16 & 14 \\
\hline 9,123 & 21 & & 17 & 21 \\
\hline 9,125 & 7 & & 18 & 107 \\
\hline 9,126 & 53 & \multirow[t]{4}{*}{ Suida } & 1,467 & 86 \\
\hline 9,127 & 5 & & 3,164 & 148 \\
\hline 9,129 & 107 & & 3,610 & 55 \\
\hline Polybios, hist. $\quad 1,84$ & 6 & & 4,581 & 8 \\
\hline $8,12,3$ & 1 & \multicolumn{2}{|c|}{ TAM III 1, Nr. 34f } & 53 \\
\hline 39,2 & 56 & \multicolumn{2}{|c|}{ Tacitus, Germ. 24} & 58 \\
\hline Pomp. Trogus 1,5 & 107 & \multicolumn{2}{|c|}{,- Germ. 32} & 6 \\
\hline PPUAES III A 3, Nr. 256. 266 & 132 & \multicolumn{2}{|c|}{-, Ann. 13,15 } & 107 \\
\hline PPUAES III A 7, Nr. 804 & 132 & \multicolumn{2}{|c|}{-, Ann. 14,15 } & 105 \\
\hline Prokop, bell.Pers. 2,11,32 & 122 & \multicolumn{2}{|c|}{-, Ann. 15,50 } & 105 \\
\hline - , ep. 99 & 125.132 & \multicolumn{2}{|c|}{ Terenz, Hecyra, Prolog } & 104 \\
\hline -, anekdota 9 & 106 & \multicolumn{2}{|c|}{ Tertullian, adv.Marc. 4,25,4 } & 104 \\
\hline Properz 2,24,13 & 46 & \multicolumn{2}{|c|}{-, adv.Iud. 9} & 5 \\
\hline P.Ryl. IV, No. 627 & $117 \mathrm{f}$ & \multicolumn{2}{|c|}{-, adv.Prax. 19} & 104 \\
\hline Ps.-Ovid, de vet. $1,246-261$ & 13 & \multicolumn{2}{|c|}{- de spect. 1.3} & 114 \\
\hline $1,262-357$ & 34 & \multicolumn{2}{|c|}{-, de spect. 12} & 123 \\
\hline $1,636-648$ & 77 & \multicolumn{2}{|c|}{- , de spect. $18 f$} & 114 \\
\hline Quintilian, inst.orat. $1,3,11 \mathrm{ff}$ & 136. 144 & \multicolumn{2}{|c|}{- , de spect. 21} & 108 \\
\hline Schol.Horaz sat. $1,5,66$ & 95 & Theokrit & $2,17 \mathrm{ff}$ & 91 \\
\hline Schol.Pind.Pyth. 4,337 & 58 & & $22,60-134$ & 130 \\
\hline Schol.Plat.Lys. 206e & $55 f$ & & $22,75 \mathrm{f}$ & 35 \\
\hline Seneca, apocol. 12,3 & 56.58 & Theoprast & char. 5,5 & 109 \\
\hline- , apocol. 14,3f & 56.58 & - , char. 5,9 & & 43 \\
\hline- apocol. $14,4-15,1$ & 47 & Tibull 1,5 & & 87 \\
\hline -, de const.sap. 12,2 & $\begin{array}{l}22.55 .107 . \\
143\end{array}$ & $\begin{array}{l}\text { Trullanun } \\
\text { Tura-Pap }\end{array}$ & $\begin{array}{l}\text { 50.Kanon } \\
>\text { Didymos }\end{array}$ & 83 \\
\hline -, de ira $2,12,4$ & 104.127 & Varro, sat & gatho $10 \mathrm{ff}$ & 31 \\
\hline -, de tranq.anim. 14,7 & 79 & Vergil, A & $5,422 \mathrm{ff}$ & 130 \\
\hline -, nat.quaest. 4 B 11,3 & 40 & -, Aen. 7, & $8-384$ & 89. 142 \\
\hline Sidon. Apoll., ep. 5,17,6 & 47 & Vitruv, de & rch. $5,11,4$ & 119 \\
\hline- , ep. $8,12,5$ & 47 & WADDINC & ON Nr. 1900 & 132 \\
\hline- , ep. 17 & 38.47 & Xenophor & Symp. 4,50 & 103 \\
\hline Sophokles, frg. 809 & 26.56 & -, Symp. & & 96 \\
\hline Sueton, Aug. 13,2 & 109 & & & \\
\hline 70,2 & 27 & & & \\
\hline 71 & 56 & Sonst & & \\
\hline 83 & 61 & & & \\
\hline -, Caes. 32 & 66 & Alphons c & eise, Buch de & $8 f$ \\
\hline
\end{tabular}


Bruegel d.Ä., Kinderspiele 9. 11. 21.28. $54 f$ f.

86.94 u.ö.

Caravaggio M., Il baro 57

Chamisso, Das Riesenspielzeug 26

Collodi, Pinocchio 31

26
9

Dante, Div.Com., Purg. 6,1-3 116

Dostojewski, Der Spieler $\quad 58$

Fischart, Geschichtklitterung 9

Goethe, Dichtung und Wahrheit 6f. 14

Heine, Die Heimkehr $38 \quad 35$

Herberger Sepp 40

Hesse, Glasperlenspiel $\quad 134$

Kleist, Marionettentheater $\quad 26$

Lessing, Minna von Barnhelm 63

Luther, Der Prophet Sacharja 102

Mozart (?), Musik. Würfelspiel 9

Nietzsche, Zarathustra

6. 24

Pirandello, Autobiogr.Notizen 135

Polyklet

Puschkin, Pique-Dame

Schiller, Der Taucher

- , Ästhet. Erziehung

Wittgenstein, Philo.Unter.

\section{Ortsregister}

Abila

$A b \bar{u} H a b b a>$ Sippar

Acemhüyük

Adab (Bismaya)

Adraa $\left(\operatorname{Der}^{\bar{a}} \bar{a}\right)>$ Edreï

Ägypten

Aphek > Antipatris

Afghanistan

Aï $\underline{\text { Hanum }}$

Akko / Ptolemaïs

Alaça Höyük

Alexandria

Alişar Hï̈yük

Aleppo

$c_{\text {Ammān / Philadelphia }}$

$c_{\text {Amrīt / Marathos }}$

Anatolien

138

110

$134 \mathrm{f}$

6

74 u.ö.

4. 12. $18 \mathrm{f}$.

25. 28.37.

40. 67. 71 .

73-75. 87.

94 u.ö.

48. 50 .

114f. 118

104

19. 53.106 .

108. 121.

123

45

22

45. 48. 50.

$117-121$

118

74. 76.98
Anchiale / Kilikien 1

Anthedon 65

Antiochia / Orontes 34. 47. 104.

106. 115 .

130

Antipatris (Aphek) 118

Apameia

105. 117.

122

Aphek (FTq, Ğōlän) 126. 132

Aphrodisias / Karien $\quad 52.120$

Arabien

4. 10.13.

22.39. 43.

53f. 67.77.

79. 82.91.

99f. $102 f$.

108. 138 .

145 u.ö.

Arad

Arados (Arwad)

$c_{A,} \mathcal{c}_{\text {ara }}$

Aroër (Negev)

Aschdod

60. 68. 70.

94

119

36

69

48. 50.61 .

98. 100 .

124

Aschkelon

14. 19.85 .

117-119.

122

Aseka 72

$\begin{array}{ll}\text { Assur } & \text { 62f. } 73.75\end{array}$

$74 \quad$ Athen

$c_{A t} \sqrt{l i t}$

28. 57. 59 .

94

64. 123

35. 106

41

Auxerre

$B a^{c}$ albek $>$ Heliopolis

$B \vec{a} b$ ed-Drä ${ }^{c}$

Babylon

68

36. 50.75 .

87. 94.100.

116. 118
$119 \mathrm{f}$

45

Balanaia (Leukas)

Balläna / Nubien

Banyās > Caesarea Philippi

el-Bēda

71

Berytos / Beinūt 108.115f

Bēt-Ğibrīn $\quad 64.117$

Bethanien 77

Bēt Sagba / Mesopotamien 109

Bethel

Bethlehem

$B \bar{e} t-N e t t \bar{t}$

$B \bar{e} t-\breve{S} e^{\mathcal{c}} \bar{a} r \bar{r}$
109

48. 90.94

34

124

124 


\begin{tabular}{|c|c|c|c|}
\hline \multirow[t]{4}{*}{ Bet-Schean } & 12. 33. 61 . & Enkomi & 73 \\
\hline & 63. $74 \mathrm{f} .90$ & Ephesos & 52 \\
\hline & $101.117-$ & Epidauros & 59 \\
\hline & 121. 124 & Episkopi Phaneromeni & 70. 78.80 \\
\hline Bet-Schemesch & $50.72-74$ & Euphrat & 6. 118 \\
\hline Beycesultan & 48 & Fiqq $(\bar{G} \bar{l} l \bar{a} n)>$ Aphek & \\
\hline$B \bar{i} r Z \bar{e} t$ & 86 & Froitzheim & 47 \\
\hline Bismaya > Adab & & Gabala & 117 \\
\hline Bobbio & 109 & Gadara & 12. 14. 26 . \\
\hline Bogazköy & $\begin{array}{l}44 f .47 .51 \\
54.59 .76\end{array}$ & & $\begin{array}{l}35.43 .56 . \\
117 f .120-\end{array}$ \\
\hline \multirow[t]{2}{*}{ Bostra } & $117 \mathrm{f} .120 \mathrm{f}$. & & 124 \\
\hline & 132 & Gallien & 1.60 \\
\hline Bostrenos (Nahr el-Auwali) & 29 & Gaza & 19. 29. 36 . \\
\hline Bustān eš-Šēh & $29 f$ & & 52.103. \\
\hline Buqqe $\bar{e}_{a}$ (Transjordanien) & 44. 50 & & $117-120$. \\
\hline Buraikos / Achaia & 52 & & $123-125$ \\
\hline \multirow[t]{2}{*}{ Byblos } & 69f. 82. & & 133 \\
\hline & 89f. 98. 117 & Gela / Sizilien & $58 \mathrm{f}$ \\
\hline \multirow{5}{*}{ Caesarea Maritima } & 11f. 14. 26. & Gennesaret-See & 124 \\
\hline & 57. 85. 105 . & Gerasa & 29.33. 117 \\
\hline & 113f. 115 . & & 123. 132 . \\
\hline & $117-120$. & & 138 \\
\hline & 123f. $131 \mathrm{f}$ & Geser & 44f. 48.50 . \\
\hline \multirow[t]{2}{*}{ Caesarea Philippi } & 116f. $119 f$. & & 61. 64. 69f. \\
\hline & $122-124$ & & 72. $75 f$. \\
\hline Cap Gelidonya & 51 & & 82f. 84.90. \\
\hline Castabala & 104 & & 98 \\
\hline Cordoba & 1 & $e l-\breve{G} i b$ & 34 \\
\hline Cyrenaika & 113 & Gibeon & 17 \\
\hline \multirow[t]{3}{*}{ Damaskus } & 103. 115 . & Grannus / Grand & 140 \\
\hline & 117. 120 . & Guzāna > T. Halāf & \\
\hline & 138 & Habüba Kabīa & 70 \\
\hline Dan & 61.64 & Ḣafăğ & 75 \\
\hline Daphne / Antiochia & 47. 111 . & Hafir el- ${ }^{c} A u \check{g} \bar{a}>$ Nessana & \\
\hline & 120 & Hagia Triada / Kreta & 10 \\
\hline \multicolumn{2}{|l|}{$\operatorname{Der}^{c} \bar{a}$ (Adraa) > Edreï } & Haleb > Aleppo & \\
\hline Dēr el-Balah & 12 & Ḣamā / Hamat & 44. 48.50 . \\
\hline Deve Hüyük & 92 & & $69-73.82$ \\
\hline Dekelia / Zypern & 70 & el-Hamme & 117 \\
\hline Dibon & 98 & Hatra & 16 \\
\hline \multirow[t]{2}{*}{ Didyma } & 59.119. & Hazor & $69-74.90$. \\
\hline & 122 & & 98 \\
\hline Diocaesarea > Sepphoris & & Hebron & 52.118 \\
\hline Dor & 14.30 .117 & Heliopolis / $B a^{c}$ albek & $131 \mathrm{f}$ \\
\hline Dura-Europos & 118 & Herodion & 12. 118 \\
\hline Edreï $(\operatorname{Der} \bar{c} \bar{a})$ & 117 & Hierapolis / Kilikien & 52.104 \\
\hline Elam & 76 & Hippo & 12 \\
\hline Eleusis & 57 & Hippos (Sūsittă & 117. 121 \\
\hline Eleutheropolis > Bēt Ğibrīn & & Hirbet $c_{A r} \bar{a}_{i r}>$ Aroër & \\
\hline Elusa (el-Halasa) & $77.117 \mathrm{f}$ & Firbet ${ }^{c}$ Asída & 29 \\
\hline Elvira / Spanien & 83 & Hirbet Dēr Dusāwi & 96 \\
\hline Emmaus (el-Qubēebe) & 90 & Finthet el-Fedēn & 33 \\
\hline
\end{tabular}




\begin{tabular}{|c|c|c|c|}
\hline Hirbet Iskander & 68 & Kos & 120 \\
\hline Hirbet el-Mefŏir & 96 & Kreta & 28.35 \\
\hline Hintet el-Minye & 96 & Kültepe-Kanis & 45.74 .76 \\
\hline Hirbet el-Mšăs & 36. 51.100 & Kumidi > Kämid el-Lōzz & \\
\hline Hirbet el-Muhaiyit & 34. 49 & el-Kurst & 84 \\
\hline 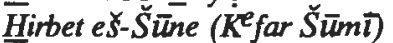 & 117 & Kyrene & 39f. 57 \\
\hline Hirbet et-Tenānir & 90 & Kyzikos & 57 \\
\hline Hirbet Zeraqūn & $68 f$ & Lachisch & 44. 49. 58 . \\
\hline Honvat Ritma & 83 & & 64. $69 \mathrm{f} .82$ \\
\hline Hypaipa (Lydien) & 52.113 & & 100 \\
\hline Idalion & 57 & Laodicea ad mare & 115.119 \\
\hline \multirow[t]{2}{*}{ Indien } & 53.63 .71 . & Larsa & 90 \\
\hline & 135 & Lato pros Kamara/Kreta & 48 \\
\hline Indus & 88 & Lĕ̆ğă & 117. 132 \\
\hline \multirow[t]{4}{*}{ Iran } & 34. 49. 59 . & Legio & 117 \\
\hline & 62. 64. 69f. & Lemba / Zypern & 78 \\
\hline & 75f. 101 & Lissos / Kreta & 49 \\
\hline & u.ö. & Liš / Ägypten & 99 \\
\hline Island & 52 & Locri & 48 \\
\hline${ }^{c}$ Izbet Șarța & 51 & Luristan & 76 \\
\hline Jabboq & 18 & Lydien & 113.135 \\
\hline Jafo & 51,113 & Madeba & $29.33 \mathrm{f}$ \\
\hline \multirow{2}{*}{ Jericho } & 12. 48.50 . & Mafraq & 33 \\
\hline & 52. $98.117 \mathrm{f}$ & Majoumas Gazēs & 125 \\
\hline \multirow[t]{10}{*}{ Jerusalem } & 14. 22.29 . & Mailand & 10 \\
\hline & 36. 49. 52 . & Makmiš (Tēl Mikkal) & 51 \\
\hline & $61.64 f$ & Malatya & 24 \\
\hline & $77 f .83 .85$. & $\mathrm{Ma}^{\mathrm{c}}$ on (Nirim) & 29 \\
\hline & 92. 96.103. & Maras & 28 \\
\hline & $106 f .111 f$. & Marescha & 72 \\
\hline & $115.117-$ & Mari & 73 \\
\hline & 119,122 & Marino & 63 \\
\hline & 128.132. & Masada & 60.64 .89 \\
\hline & $142 f$ & Megiddo & 44. $46.48 f$. \\
\hline Kahun & 94.100 & & $58.61 .69 \mathrm{f}$. \\
\hline Kalhu > Nimrüd & & & $72-75.82 f$. \\
\hline \multirow[t]{3}{*}{ Kāmid el-Lōz } & 44. $46.50 \mathrm{f}$. & & 88.90 .96$. \\
\hline & 56. $69 \mathrm{f}$ & & 100 \\
\hline & 72f. 74 & Mekka & 106 \\
\hline Kanatha & 117 & Mesopotamien & 69. $73-75$. \\
\hline Kapernaum & 77.84 & & 99.103 \\
\hline \multirow[t]{2}{*}{ Karkemisch } & 54. 57. 89. & Milet & 113 \\
\hline & 92 & al-Mina & 30 \\
\hline Karnak & 84 & Mit Rahine & 63.90 \\
\hline Kilikien & 1. & Monteleone/Sabinerland & 125 \\
\hline \multirow[t]{3}{*}{ Kinneret } & 36. $43 f$. & Monza & 109 \\
\hline & $50 f .58 .92$. & Mosel & 13.36 \\
\hline & 98 & $N a c_{a r a \bar{n}}$ & 29 \\
\hline Kition & 45.49 .57 & Nablus > Neapolis & \\
\hline Knossos & 10. 59.71 & Nahr el-Auwalt > Bostrenos & \\
\hline \multirow[t]{2}{*}{ Konstantinopel } & 83. 106 . & Nahariyya & 29 \\
\hline & 125 & Naukratis & 8 \\
\hline Korinth & $45-47.91$ & & \\
\hline
\end{tabular}




\begin{tabular}{|c|c|c|c|}
\hline Neapolis (Nälus) & $\begin{array}{l}52.57 . \\
117 f .120\end{array}$ & $\begin{array}{l}\text { Șafed } \\
\text { Sahr (Lĕğ̄a) }\end{array}$ & $\begin{array}{l}52 \\
117\end{array}$ \\
\hline Nebo & 33.43 & Saint-Denis & 90 \\
\hline \multirow[t]{2}{*}{ Nessana } & 70. 77.89. & Sakkaia (Šaqqa) & 117 \\
\hline & 96 & Salamis & 50 f. 77.80 \\
\hline Nevali Çori (SO-Anatolien) & 68 & Samaria & 64. 113f. \\
\hline Nimrüd (Kalhu) & 8. 75 & & $117 \mathrm{f} .121$. \\
\hline Ninive & 75 & & 124 \\
\hline Nippur & $64.75 f$ & Samos & 52 \\
\hline Nubien & 45.47 & Saqqara & 84 \\
\hline Numidien & 63 & Sardis & 113 \\
\hline Nuzi & 76 & Schilo & 65 \\
\hline Oboda & 124 & Sedment & $74 f$ \\
\hline Oinoanda / Lykien & 120 & Šēh Zenad & 40.123 \\
\hline Olympia & 59.115 & Šellāl & 29 \\
\hline Olynth & 45.49 & Selenkahiye & 98 \\
\hline${ }^{c}$ Ommān & 132 & Seleucia Pieria & 115 \\
\hline Ostia & 12 & Seleukia / Tigris & 94 \\
\hline Oxus & 118 & Selge / Pisidien & 57 \\
\hline Palmyra & $116 f$ & Sendschirli & $43-45.48 f$. \\
\hline Paphos & 57.73 .78 & & $104 f$ \\
\hline Patavium / Illyrien & 52 & Sepphoris & 117 \\
\hline Pella & $96.117 \mathrm{f}$ & Sichem & $44.61 .63 \mathrm{f}$ \\
\hline \multirow[t]{2}{*}{ Petra } & $28.47 .49 \mathrm{f}$ & Sidon & 29.40 .43 \\
\hline & $\begin{array}{l}113.117 f . \\
(120) .121\end{array}$ & Sinai & $\begin{array}{l}115.117 \\
68.72\end{array}$ \\
\hline Phaistos / Kreta & 59 & Sippar (Abū Habba) & 76 \\
\hline Pharsalos & 49 & Šiqmōnā (T. es-Samak) & 48 \\
\hline Philadelphia $>c_{A m m \bar{n}}$ & & Sizilien & 105 \\
\hline Philippi & 77 & Skythopolis > Bet-Schean & \\
\hline Philippopolis & $117 f$ & Soada (Suwēeda) & 117 \\
\hline \multirow[t]{3}{*}{ Phönizien } & 4. 57.f. 69 . & Susa & 59 \\
\hline & 90.117. & Sūsittā > Hippos & \\
\hline & 120 & Syrien & 4. 58.69 . \\
\hline Poitiers & 84 & & 73.76 .90$. \\
\hline Politiko $>$ Tamassos & & & 98. 102. \\
\hline Pompeii57. 91. 123 & & & 104f. 117 \\
\hline Priene & 113 & Taanach & 43.49 \\
\hline Ptolemaïs > Akko & & Taff $($ Le ğğ $\bar{a})$ & 132 \\
\hline Qadesch (T.Nebi Mend) & 44. 101 & Tamassos & 51.70 \\
\hline Qașr Hallābāt & 33 & Tarent & 47.56 \\
\hline el-Qubं̄̄be > Emmaus & & Tarichaiai & 116. 118 \\
\hline Qușer ${ }^{c}$ Amra & 8. 119 & Tarracina $>$ Terracina & \\
\hline el-Qustul / Nubien & 47 & Tarschisch & 51 \\
\hline R⿳亠幺幺s el- ${ }^{c}$ Ain / Syrien & 76 & Tarsus & $44 f .57 .88$ \\
\hline$R \bar{a} s$ es-Siāyga & 34 & Têl Miknal > Makmis & \\
\hline \multirow[t]{2}{*}{ Rhodos } & 57.119. & Tell $A \overline{b \bar{u}} H u w \bar{a} m$ & 50 \\
\hline & 123 & Tell Abū Siēme & 61.64 \\
\hline Rom & $\begin{array}{l}\text { 1. (4). } 61 . \\
95.145\end{array}$ & Tell el.c ${ }^{c}$ ğğul & $\begin{array}{l}44.61 .63 \mathrm{f} \\
72 \mathrm{f} .82 \mathrm{f}\end{array}$ \\
\hline Saar & 36 & T. Ahmar > Til Barsib & \\
\hline Saba & 137 & Tell el-Ailun & 76 \\
\hline es-Sabra & 117 & Tell el-Amama & 94. 100 \\
\hline
\end{tabular}




\begin{tabular}{|c|c|}
\hline Tell $c_{\text {Arq } \bar{a}}$ & 77 \\
\hline Tell Asmar (Ě̌nunna) & 24.50 .68 \\
\hline Tell Bēt Mirsim & $61.63 .72 f$ \\
\hline Tell $B i^{c_{a}}$ & 99 \\
\hline Tell Dér $c_{A l l \bar{a}}$ & 43. 71.74 \\
\hline Tell $c_{E t i \bar{n}}$ & 124 \\
\hline Tell el-Fāra Nord & 50.90 \\
\hline Tell el-Fārea Süd & 69f. $72 \mathrm{f}$ \\
\hline Tell el-Ğemme & $\begin{array}{l}68.70 .75- \\
78\end{array}$ \\
\hline Tell el-Ğudède & 98 \\
\hline Tell Halāä & 70.73 .90 \\
\hline Tell el-Hēesi & 44.90 \\
\hline Tell Mastūma & 73 \\
\hline Tell el-Milh & 36.92 \\
\hline Tell Mubärak (T. Mevōrak) & 113 \\
\hline Tell en-Nașbe & 34. 70.82 \\
\hline T. Nebi Mend > Qadesch & \\
\hline T. el ${ }^{c}$ Orēme > Kinneret & \\
\hline Tell er-Rusūm & 96 \\
\hline Tell es-Sacidiye & 12 \\
\hline T. es-Samrät > Jericho & \\
\hline T. Sandahanne > Marescha & \\
\hline Tell es-Seba ${ }^{c}$ & 34.43 .90 \\
\hline T. Zakarīye > Aseka & \\
\hline Tepe Gawra & 51.63 .98 \\
\hline Tepe Sialk & $75 f$ \\
\hline Terracina & 97.100 \\
\hline Thamugadi > Timgād & \\
\hline Theben / Böotien & $\begin{array}{l}45-47.49 . \\
88\end{array}$ \\
\hline Theben / Oberägypten & 47f. 75 \\
\hline Tiberias & 14. 116f \\
\hline Til Barsib (T. Ahmar) & 71 \\
\hline Timgād / Numidien & 1 \\
\hline Timna (H. Mune $\left.\bar{e}_{\text {iye }}\right)$ & 49 \\
\hline Trier & 81 \\
\hline Tripolis & 115. 118 \\
\hline Tunesien & 120 \\
\hline Tyros & 40. 90.106. \\
\hline & 111. 118. \\
\hline & 120.123 \\
\hline Ugarit & 18. 33. 43 . \\
\hline & 45. 54. 59. \\
\hline & 74 \\
\hline Umm el-Biyāna & 79 \\
\hline Umm el-Ğimāl & 132 \\
\hline Ur & 63. $73-76$. \\
\hline & 121 \\
\hline Wādi ed-Dāliye & 33.53 \\
\hline Wādi el-Hesa & 68 \\
\hline Wādi eț-Tuwēbe & 136 \\
\hline Yarmūk & 124 \\
\hline
\end{tabular}




\section{LISTE DER ABBILDUNGEN:}

1) Tönerne Rassel der Eisen-II-Zeit aus Kinneret

[V. FrITZ, Kinneret, Wiesbaden 1990, 97f, Taf. 76:22].

2) Minoische Schaukel-Terrakotta aus Hagia Triada / Kreta, 15.Jh.v.Chr. [nach S. LASER, Sport und Spiel, Göttingen 1987, Abb. 42a].

3) Vögel im Käfig: Mosaik aus Gerasa, Elia-Maria-Soreg-Kirche (7.Jh.n.Chr.) [nach M. PiCCIRlLlo, Chiese e Mosaici della Giordania Settentrionale, 1981, Tav. 32 / Foto 35].

4) Statue eines Knaben aus dem Eschmun-Tempels von Bustän ěs-Š $\bar{e} \underline{h}$ bei Sidon (4.Jh.v.Chr.) [nach S. MoscatI, The Phoenicians, Milano 1988, 285].

5) Bulle WD 2 aus dem Wadi ed-Daliye, 4.Jh.v.Chr. [nach M.J.W. LEITH, Greek and Persian Images in Pre-Alexandrine Samaria, 1990, $219 \mathrm{ff}, \mathrm{P1}$. 22:1].

6) Mosaik aus der Apostel-Kirche in Madeba, 6Jh.n.Chr. [nach U. Lux, ZDPV 84 (1968), Taf. 32].

7) Taube mit Halsband: Kirchen-Mosaik in Madeba (6.Jh.n.Chr.) [nach U. LuX, ZDPV 83 (1967), Taf. 35:C]

8) Byzantinisches Mosaik aus Bet-Schean [nach G.M. FitZGERALD, A Sixth Century Monastery at Beth-Shan, 1939, P1. 16].

9) Stempelsiegel des $y^{\prime} z n y h w{ }_{b} d h$-mlk (VSE Nr. 69) aus Tell en-Nașbe, 8.-7.Jh.v.Chr. [nach R. HESTRIN - M. DAYAGI-MENDELS, Inscribed Seals, Jerusalem 1979, No. 5].

10) Theriomorphe Terrakotten aus Tell el- ${ }^{c}$ Orēme, Ende 8.Jh.v.Chr. [nach V. Fritz, Kinneret, Wiesbaden 1990, Taf. 102:4-5].

11) Römerzeitlicher Terrakotta-Hahn auf zwei Achsen aus $\underline{H}$ irbet ${ }^{c} A r{ }^{\mathcal{E}}$ ana [nach R. Zias, CAtiqot ES 14 (1981), fig. 5].

12) Ballspielende Knaben: Vasenmalerei auf einem attischen Rhyton aus Š $\bar{e} \underline{h}$ Zenad / Syrien [E. PotTiER et al., Syria 7 (1926), 193ff, Pl. 40].

13) Unbearbeitete Astragale

14) Verzierter Astragal aus Sichem [nach V.I. KERKHOF, OMRO 50 (1969), fig. 25:28].

15) Münze aus Ephesos (3.Jh.n.Chr.), Revers: Zwei nackte Kinder sitzen einander gegenüber und würfeln mit Astragalen; dazwischen das erhöhte Kultbild der Artemis Ephesia (mit

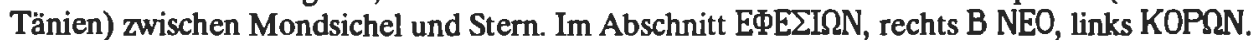
[nach F. IMHOOF-BlumER, Nomisma 6 (1911), 4, Taf. I:8]

16) Bulle WD 44 aus dem Wadi ed-Daliye, 4.Jh.v.Chr.

[nach M.J.W. LEITH, Greek and Persian Images in Pre-Alexandrine Samaria, 1990, 268ff, Pl. 27:1].

17) Bulle WD 40 aus dem Wadi ed-Daliye, 4.Jh.v.Chr. [nach M.J.W. LEITH, Greek and Persian Images in Pre-Alexandrine Samaria, 1990, 209ff, PI. 21:1].

18) Orthostaten-Relief aus Karkemisch, 8.Jh.v.Chr. [nach K. BrTtEL, Die Hethiter, München 1976, Abb. 295].

19) Würfelturm: Mosaik aus Daphne bei Antiochia [nach D. LeVI, Antioch Mosaic Pavements Vol. II, 1947, Pl. 79b-c].

20) Moderner katholischer Gebetswürfel

21) Würfel aus Sichem, 9.-8.Jh.v.Chr. [nach G.E. WrIGHT, Shechem, New York u.a. 1964, fig. 83].

22) Spätbronzezeitlicher Würfel aus Sichem [nach CH. ClamER, Qad. 14 (1981), 33] 
23) Eisen-II-zeitlicher Würfel aus Lachisch Strat. III

[Y. AHARONI, Lachish V, 1975, Pl. 15:7]

24) Würfel aus Dan (Eisenzeit IIC oder später)

[A. BIRAN, IEJ 36 (1986), 179ff, fig. 10, Pl. 21:C].

25) Doppel-Spielbrett aus Hazor mit 30- und 22 (?)-Felder-Brettspielen (9.Jh.v.Chr.)

[Y. YADIN, Hazor II, Jerusalem 1960, 34, P1. 78:6 = 164:13].

26) 30-Löcher-Steckspiel aus Tell el-Fār $c_{a}$ Süd, Grab 201, ca. 9.Jh.v.Chr.

[nach J.-W. MEYER, in: R. HACHMANN (ed.), Kāmid el-Lōz 1971-1974, 1982, 63, Abb. 8:4].

27) 42-Löcher-Steckspiel (?) aus $\underline{\text { Hirbet }}{ }^{c} A r \bar{a}^{c}$ ir (Negev), 7.Jh.v.Chr.

[nach A. BIRAN - R. COHEN, IEJ 31 (1981), 131, P1. 24:D].

28) 80-bzw. 84-Felder-Brettspiel (Grafitti) aus Elusa

[nach G.E. KIRK, JPOS 18 (1938), fig. 2].

29) 20-Felder-Brettspiel aus Tell el-Fār $\boldsymbol{c}_{a}$ Süd, Grab 220, 9.Jh.v.Chr. [nach J.-W. MEYER, in: R. HACHMANN (ed.), Kämid el-Lōz 1971-1974, 1982, 67, Abb. 9:5].

30) 20-Felder-Spielbrett in Form eines Lebermodells aus Bet-Schemesch, 13./12.Jh.v.Chr.

[nach J.-W. MEYER, in: R. HACHMAnN (ed.), Kāmid el-Lōz 1971-1974, 1982, 55, Abb. 5:2].

31) $4+4+8+2+2-B r e t t s p i e l$ aus $U r$

[nach J.-W. MEYER, in: R. HACHMANN (ed.), Kāmid el-Lōz, 1982, 67, Abb. 9:1].

32) Doppel-Spielbrett mit 20-Felder- und 58-Löcher-Brettspielen aus Megiddo Stratum VIIA [nach G. LOUD, The Megiddo Ivories, Chicago 1938, Pl. 47].

33) Spiel (?) vom Tell en-Nașbe, ca. 9.Jh.v.Chr.

[nach J.-W. MEYER, in: R. HACHMANN (ed.), Kämid el-Lōz 1971-1974, 1982, 63, Abb. 8:1].

34) Mühle-Brett (Graffito) aus Nessana

[nach G.E. KIRK, JPOS 18 (1938), fig. 1:2].

35) Mühle-Brett (Graffito) aus Elusa

[nach G.E. KIRK, JPOS 18 (1938), fig. 1:3].

36) Byzantinisches (?) Mühle-Brett aus Jerusalem (Grafitto)

[R.A.S. MACALISTER - J.D. DUNCAN, Excavations on the Hill of Ophel, London 1926, Pl. 13:4].

37) Ayyubidisch-mamelukische Schale aus Jerusalem mit Mühlespiel auf Basis

[nach A.D. TUSHINGHAM, Excavations in Jerusalem I, Toronto 1985, fig. 39:21].

38) Nabatäischer (?) Graffito eines Manqala (?)-Spiels aus Umm el-Biyāra [nach eigenen Aufnahmen].

39) Scheibenförmige Spiel (?)-Steine aus dem herodianischen Jerusalem [nach N. AvigaD, Discovering Jerusalem, Nashville u.a. 1983, fig. 239].

40) Finger-Kreisel: Rekonstruktion mit einem Spinnwirtel aus Hazor (Oberflächenfund)

41) Peitschen-Kreisel aus Theben / Böotien

[nach S. LASER, Sport und Spiel, Göttingen 1987, Abb. 38c]

42) Jüdischer Treidel

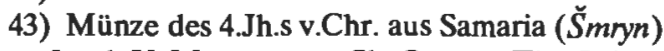

[nach Y. MESHORER - Sh. QEDAR, The Coinage of Samaria in the Fourth Century BCE, 1991, No. 16].

44) Iunx aus Hazor: unpublizierter Oberflächenfund. Die leicht gewölbte, gerundete Scherbe (Oberseite brown 7.5YR 5/2; Unterseite dark reddish gray 10R 3/1) dürfte von einem (scheibengedrehten) spätbronze- oder eisenzeitlichen Kochtopf stammen.

45) Römische Wandmalerei in der 'Casa dell'Amore Punito' (VII 2,23) in Pompeji [nach A.S.F. Gow, JHS 54 (1934), fig. 1].

46) Weibliche Götter-Terrakotta der Eisen-II-Zeit aus Bet-Schemesch, 7.Jh.v.Chr. [nach BRL 21977, Abb. 31:14].

47) Puppe aus Nessana (Palestine-Museum Jerusalem), 7.-8.Jh.n.Chr.

[nach H.D. ColT, Excavations at Nessana I, London 1962, P1. 29:5].

48) Islamische Puppe aus $\underline{\text { Hirbet el-Minye }}$

[nach L.Y. RAHMANI, IEJ 31 (1981), 80, Pl. 15:B]. 
49) Puppenkopf aus Hiibet el-Mefğir, 7.-8.Jh.n.Chr. [nach L.Y. RAHMANI, IEJ 31 (1981), 77, Pl. 14:D].

50) Miniatur-Bett (Terrakotta) aus Lachisch, Grab 1002, 8.Jh.v.Chr. [nach O. TUFNELL, Lachish III, London u.a. 1953, 374. 376, Pl. 29:21].

51) Miniatur-Gefäße aus Aschdod, 13. (max. $\varnothing 2 \mathrm{~cm})$ und 8.Jh.v.Chr. $(\max . \varnothing 5,8 \mathrm{~cm})$ [nach M. DOTHAN - D.N. FreEDMAN, Ashdod I, 1967, 82, fig 25:2; 42:16].

52) Rollsiegel aus Bet-Schean mit Darstellung Ramses' II., 13,Jh.v.Chr. [nach ANEP ${ }^{2}$ fig. 338].

53) Orthostaten-Relief aus Alaça Hüyük, 14.Jh.v.Chr. [nach K. BITTEL, Die Hethiter, München 1976, Abb. 218].

54) Orthostaten-Relief aus Sendschirli, 8.v.Chr. [nach F. VON LUSCHAN, Sendschirli IV, Berlin 1911, Abb. 259b].

55) Morra-Spiel nach dem syr. Cod. Plut. I,56, fol. 13a in der Bibl.Laurenz. Florenz (586 n.Chr.) [The Rabbula Gospels. Facsimile Ed., ed. C. CECCHELLI et al., 1959, 69-71, fol. 13a].

56) Morra-Spiel auf einer Kreuzigungsikone des 8 .Jh.s n.Chr. aus dem Katharinen-Kloster (Sinai)

[nach K. WertzmanN et al., Frühe Ikonen, 1965, Taf. 6].

57) Grundriß des römischen Theaters in Philadelphia ( $\left.{ }^{\mathcal{C}} A m m \bar{m} \bar{a} \mathbf{n}\right)$ [nach F. EL-FAKHARANI, AA 1975, 377ff, Abb. 2].

58) Grundriß des römischen Odeons von Philadelphia ( $\left.{ }^{c} A m m \bar{a} n\right)$ [nach A. HADIDI, in: D. HoMEs-FredERICQ et al. (ed.), Archaeology of Jordan II,1, 1989, 158].

59) Grundriß des römischen Hippodroms von Gerasa mit sekundär abgegrenztem Polo (?)-Feld [nach A.A. OsTrASZ, in: Jerash Archaeological Project 1987-1988, Vol. II, 1989, 57, fig. 3].

60) GrundriB des römischen Amphitheaters von Skythopolis [nach G. FoERSTER - Y. TSAFRIR et al., ESI 6 (1987-1988), fig. 14]. 

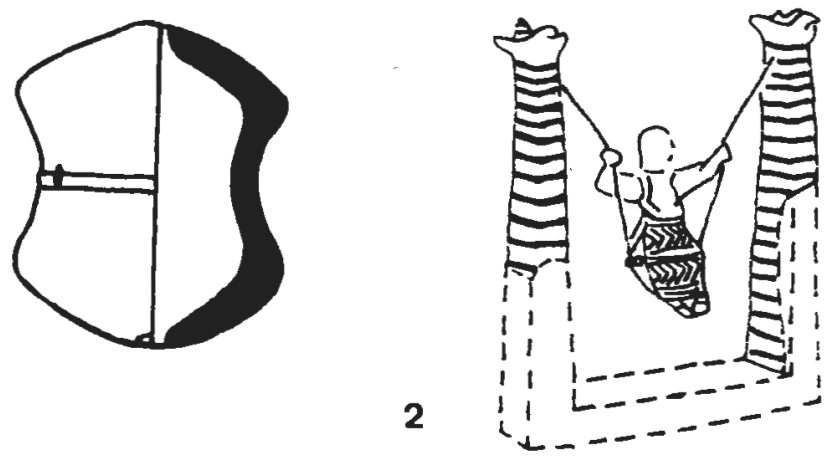

3

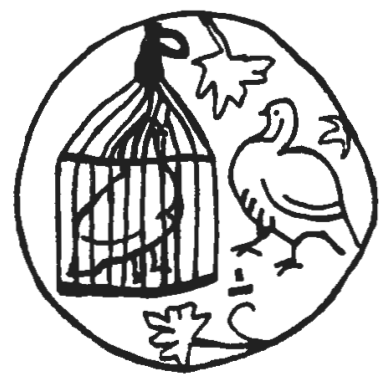

5
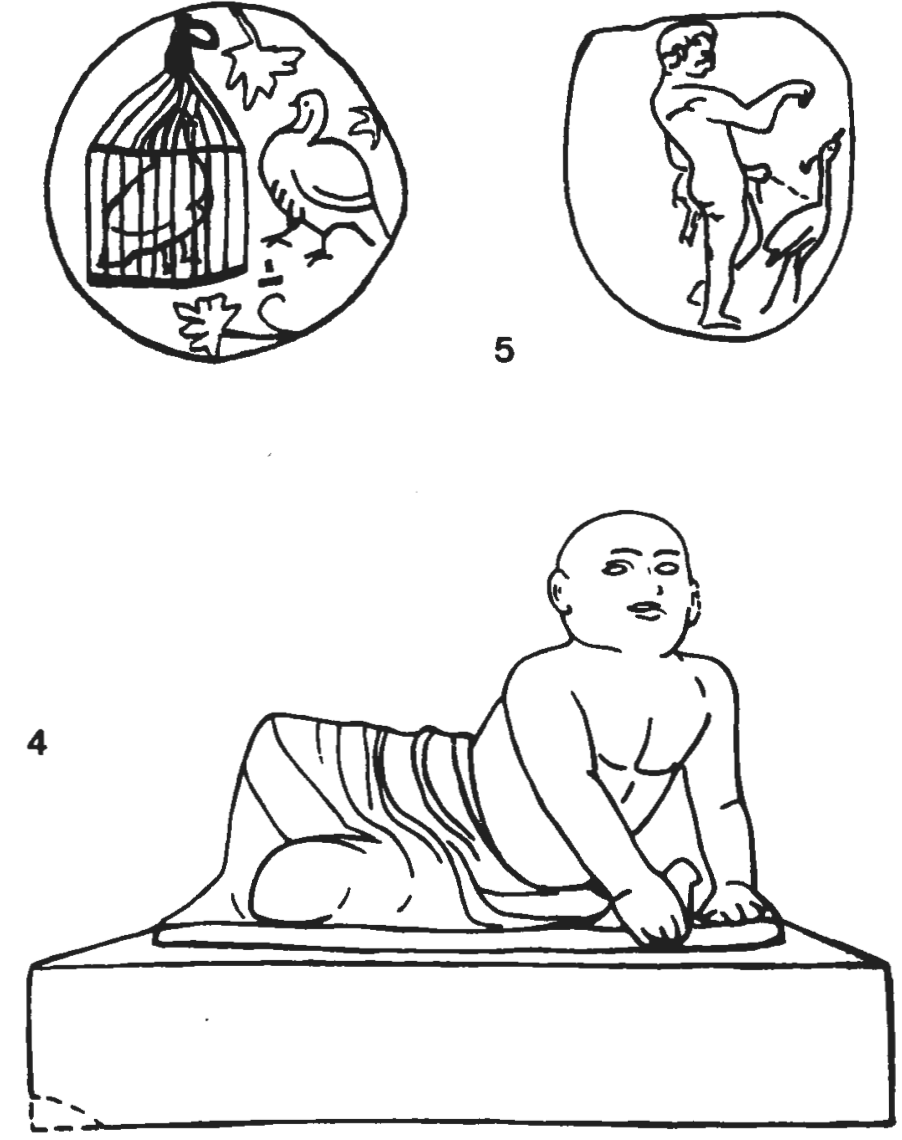
6
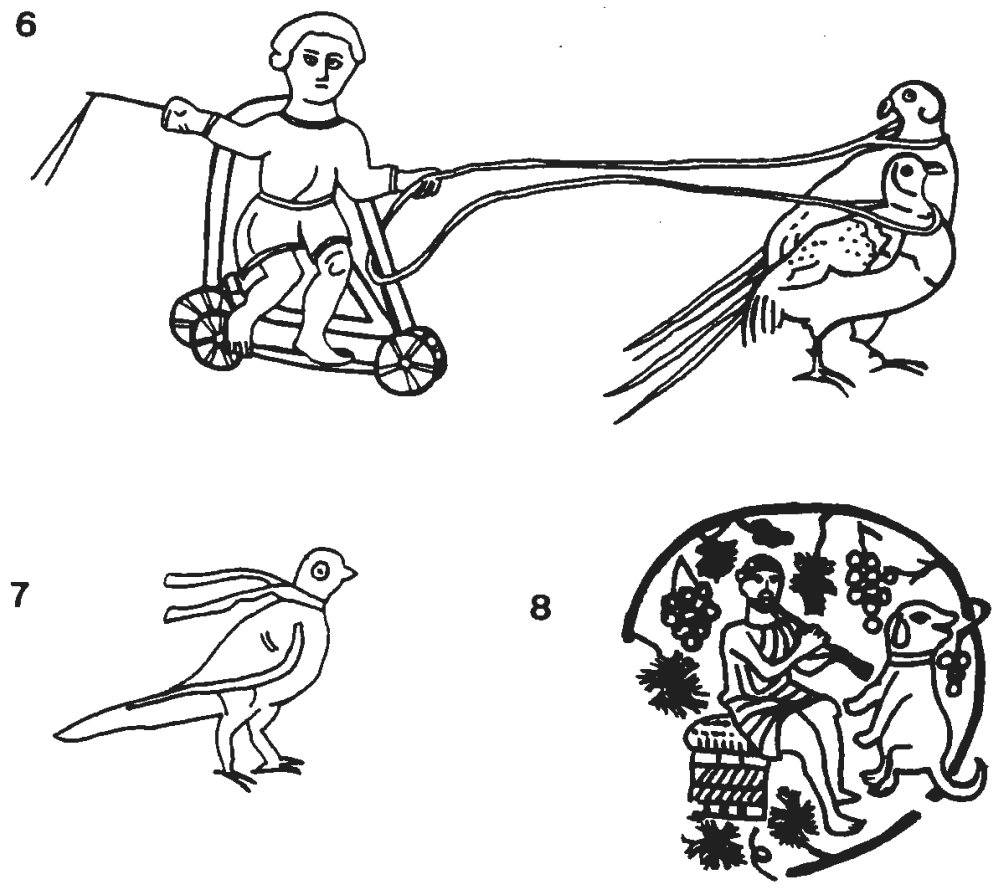

9
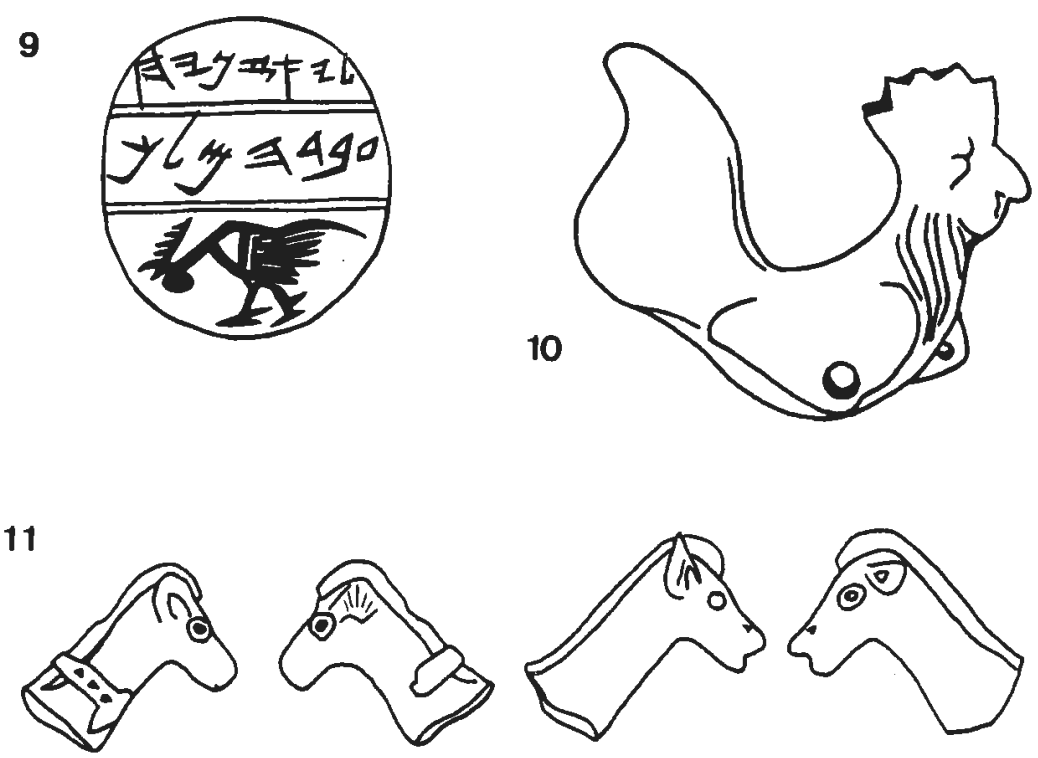

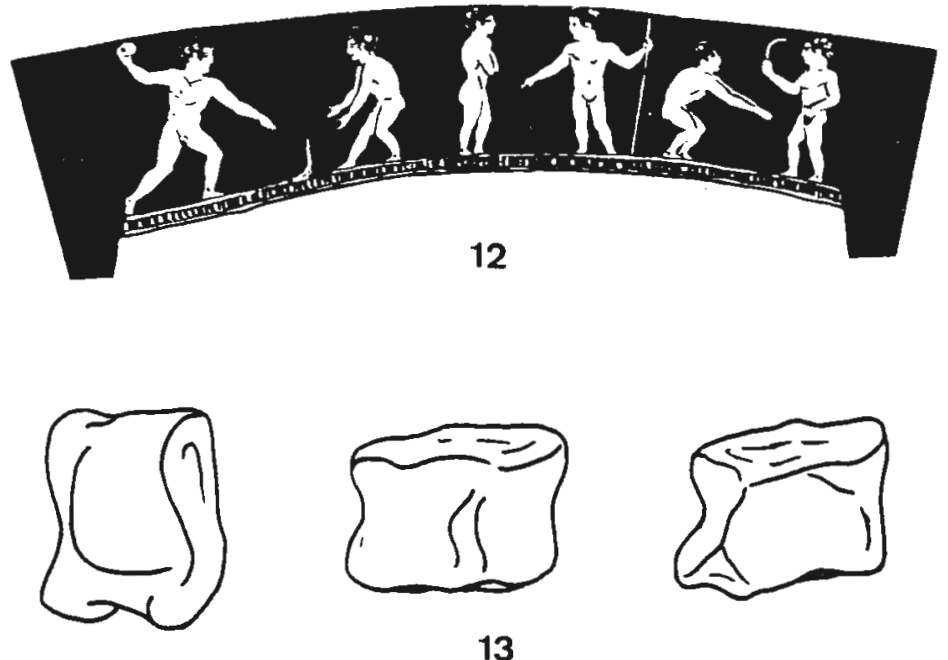

13
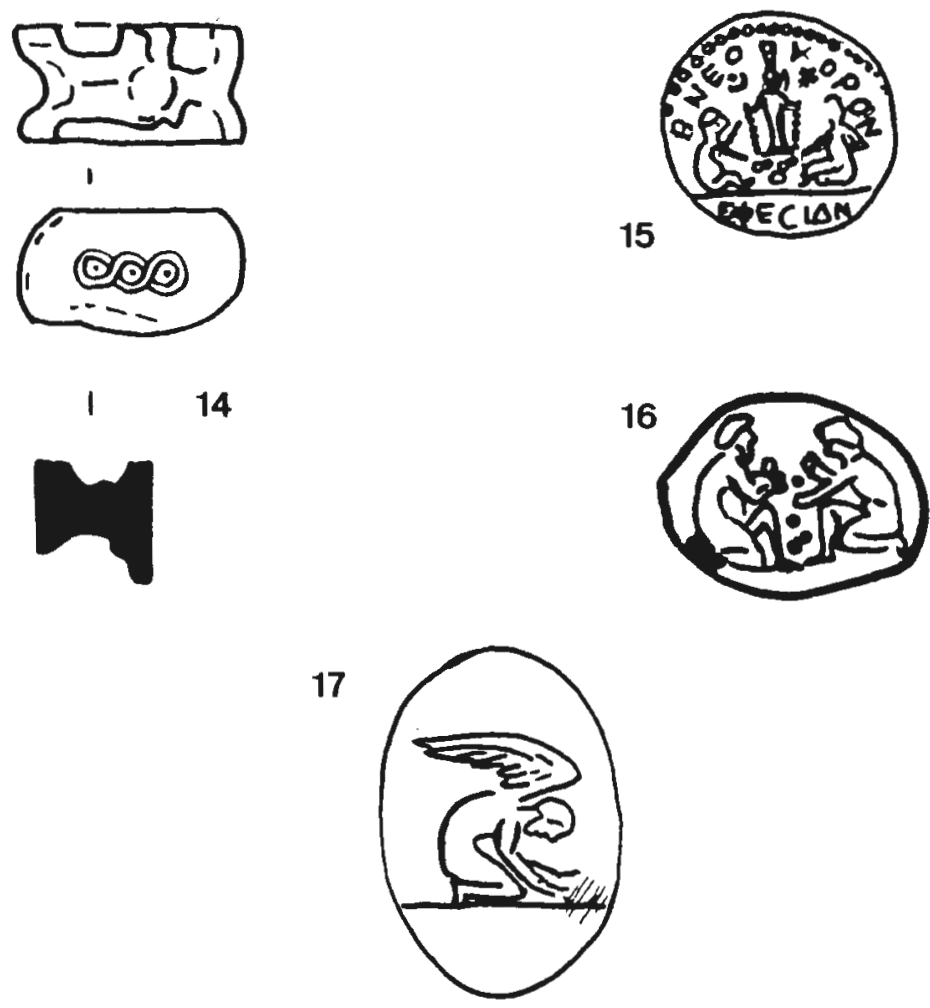

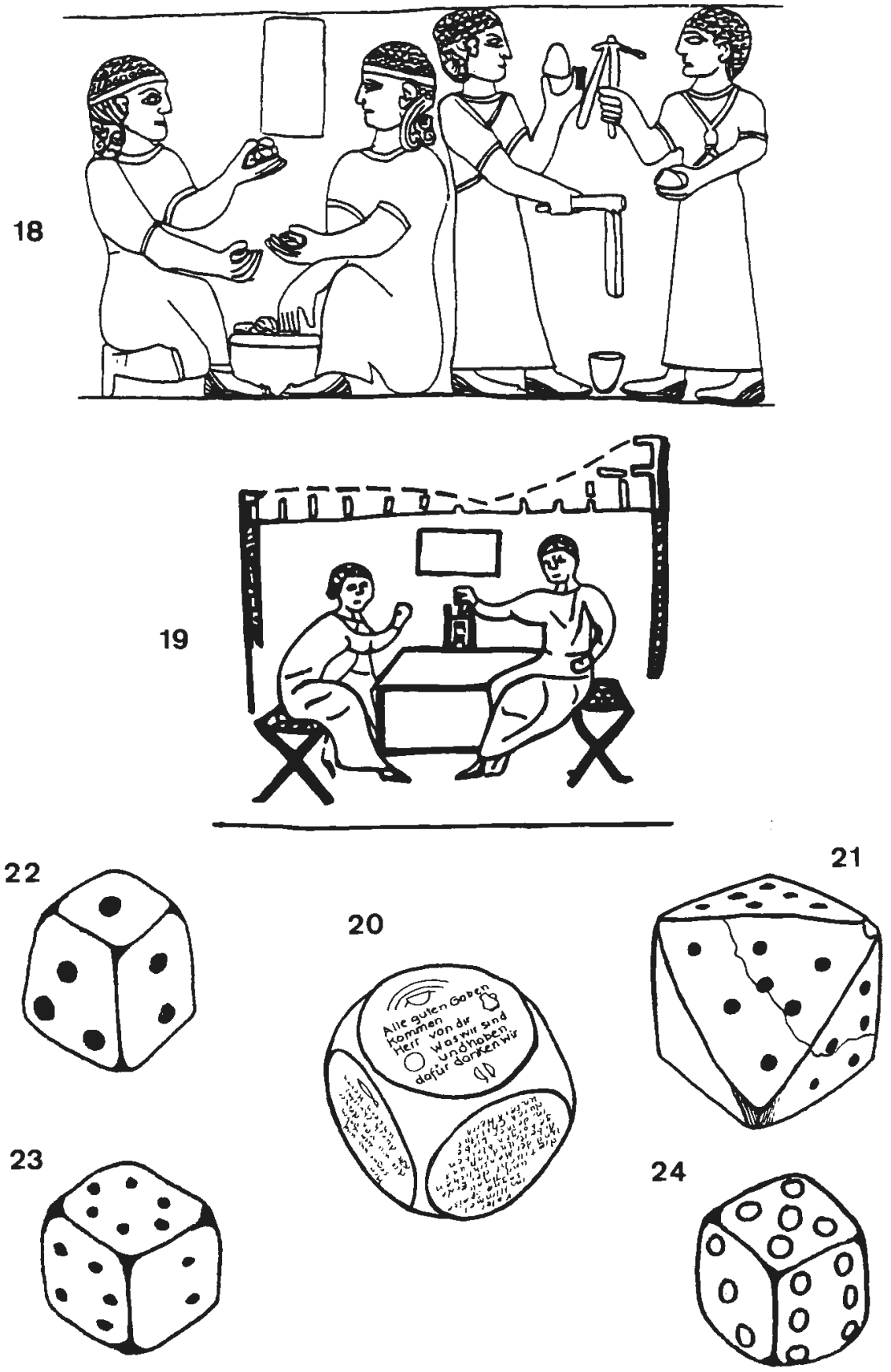

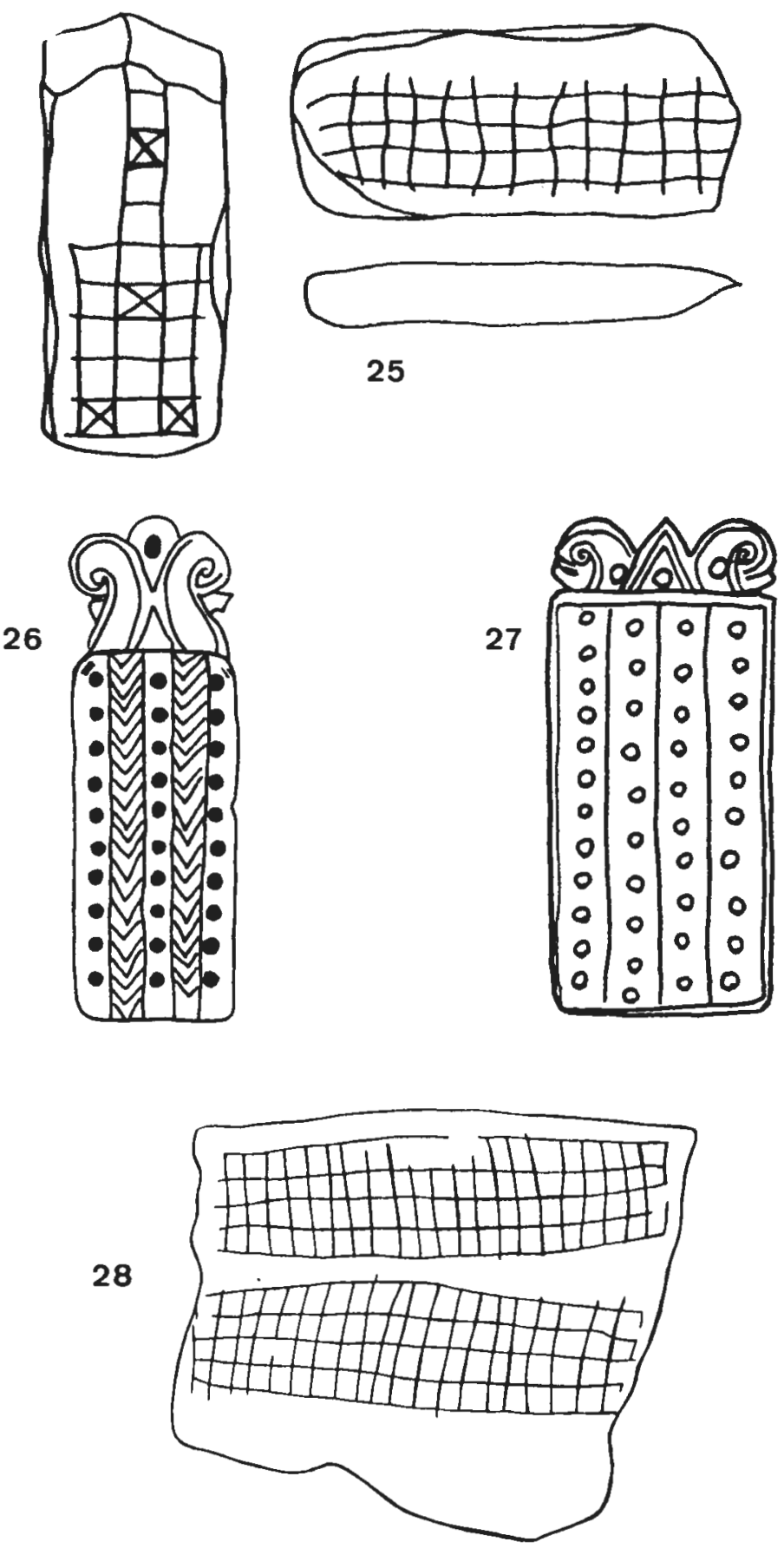


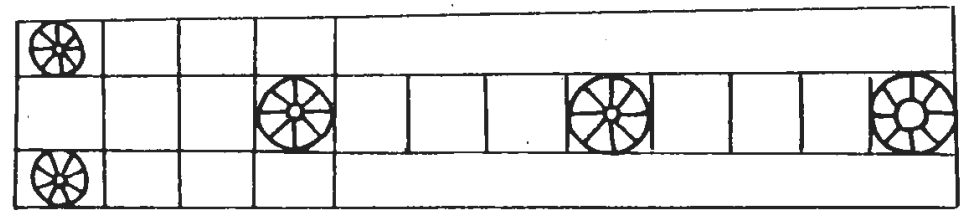

29

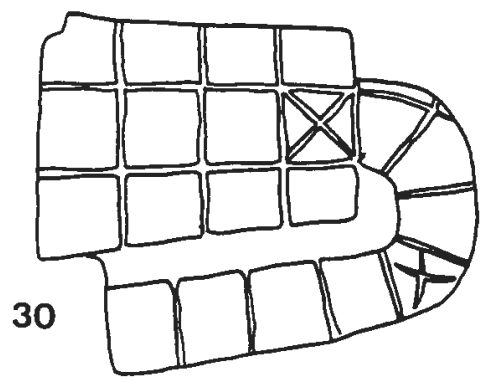

32
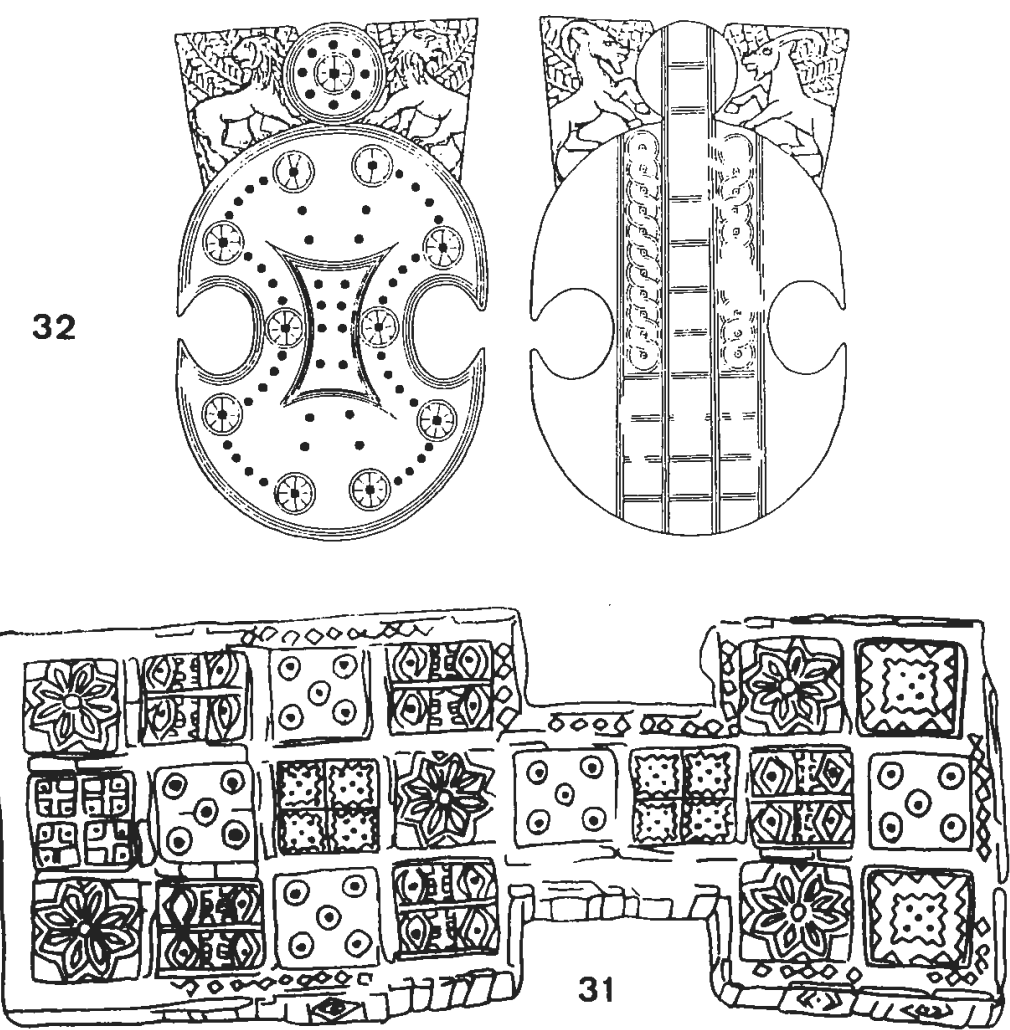

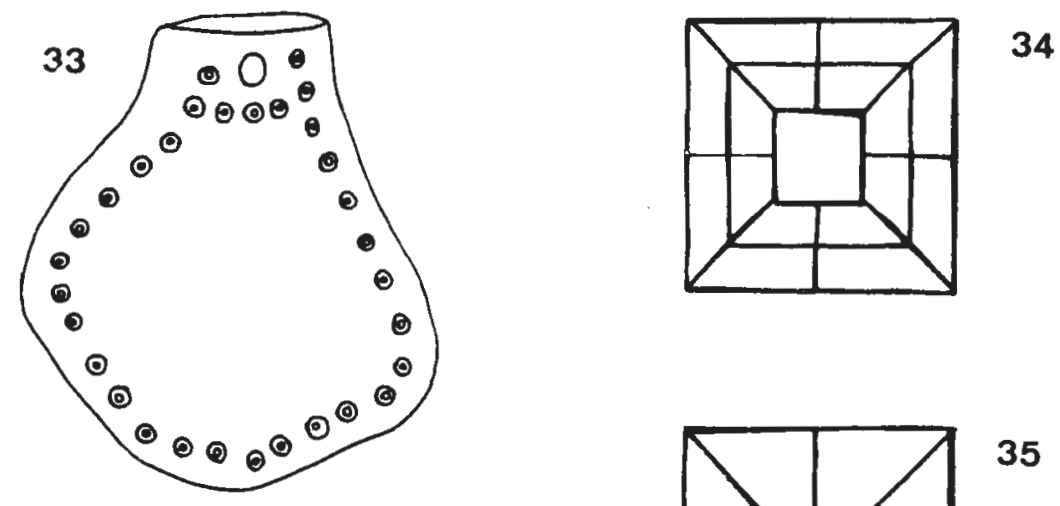

36
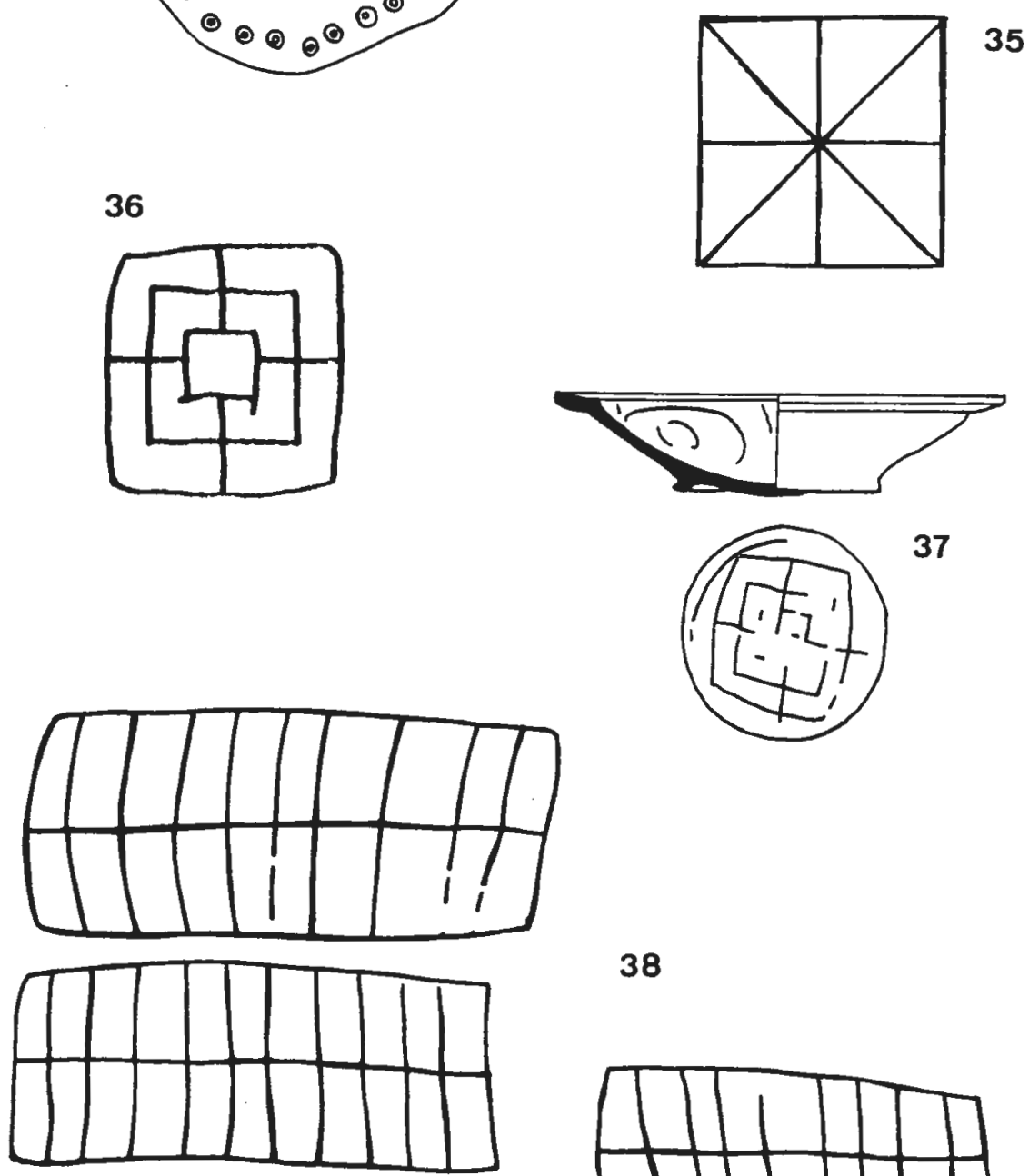

38

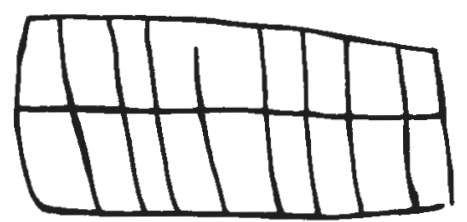


39
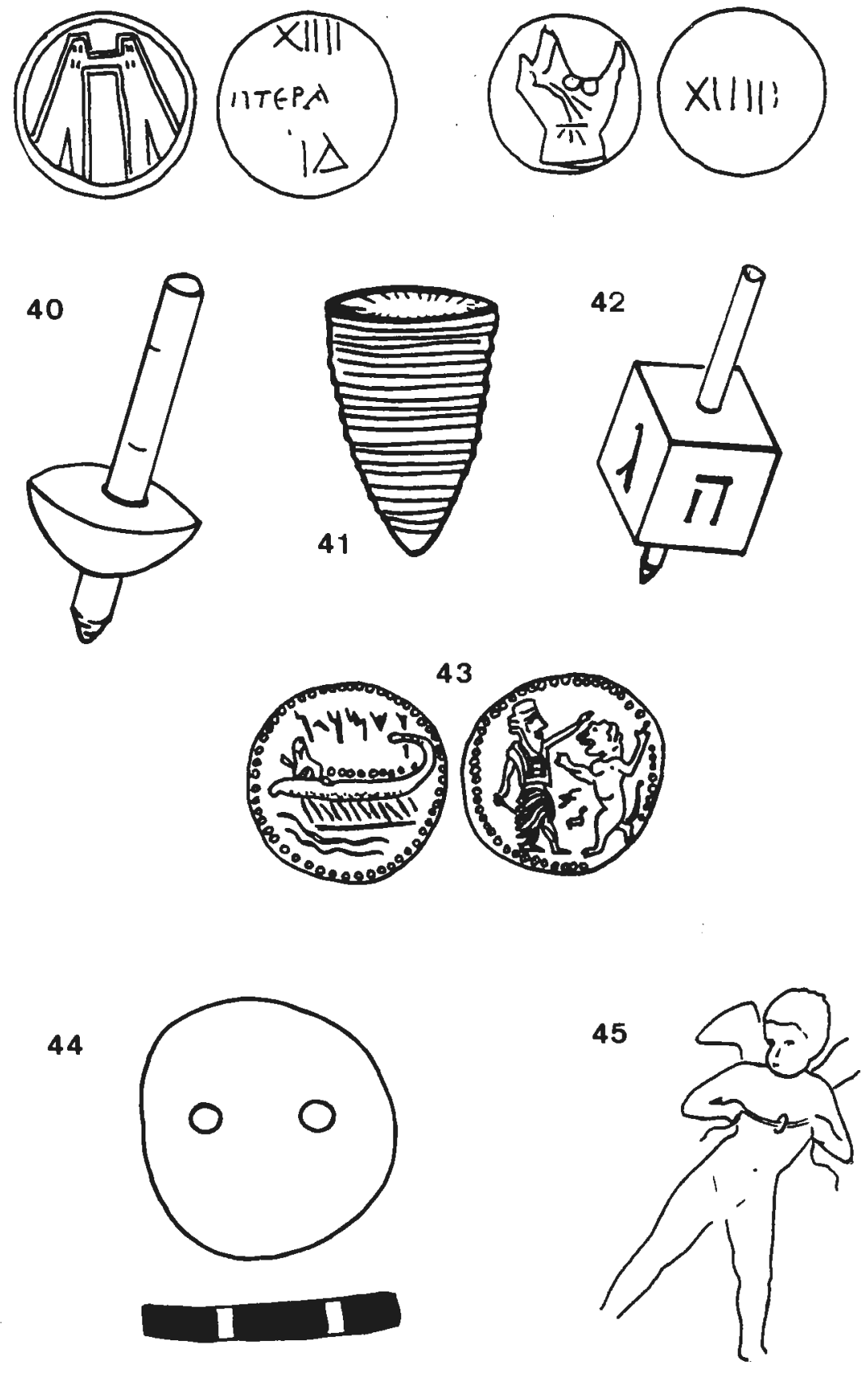

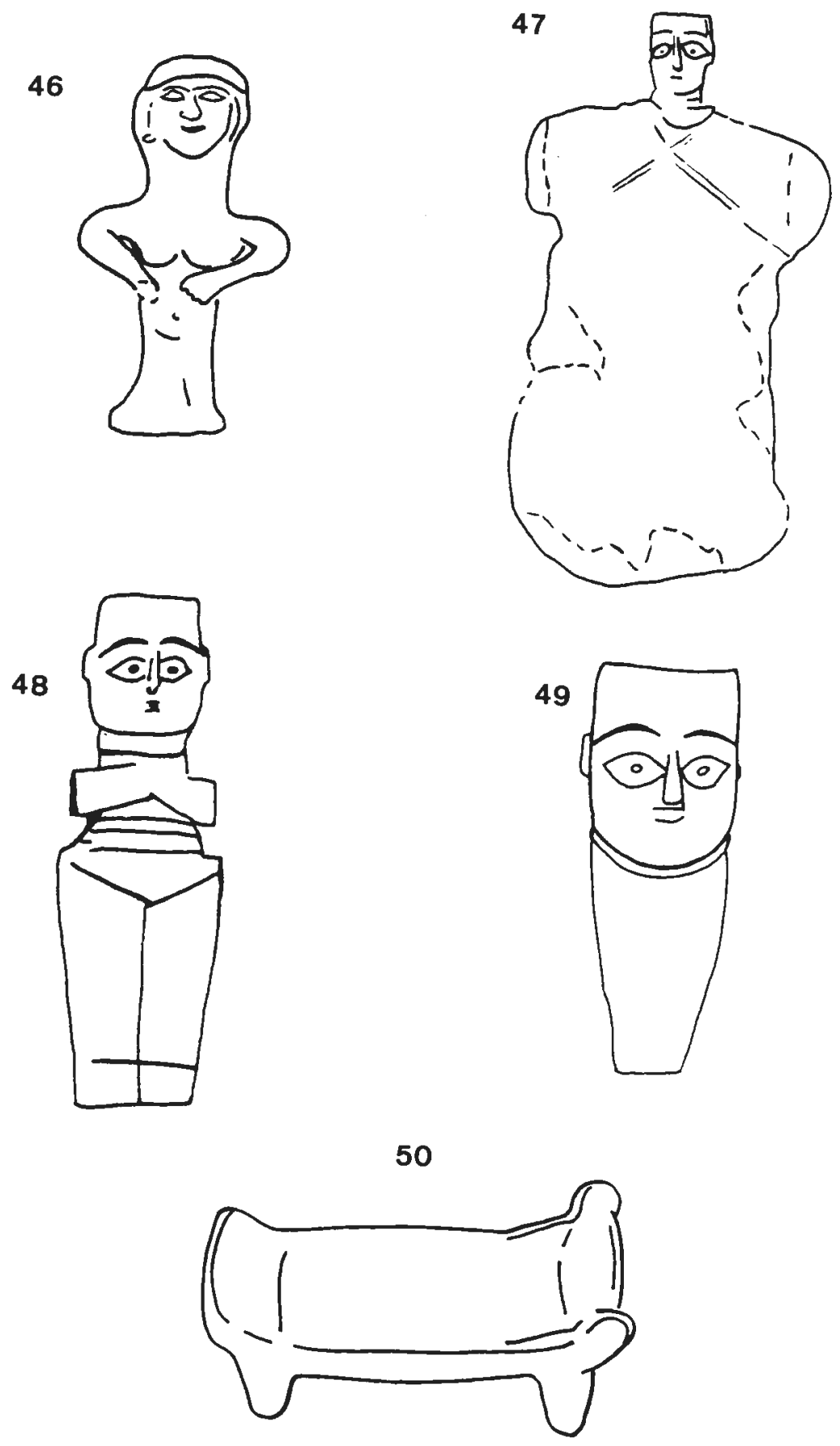
51
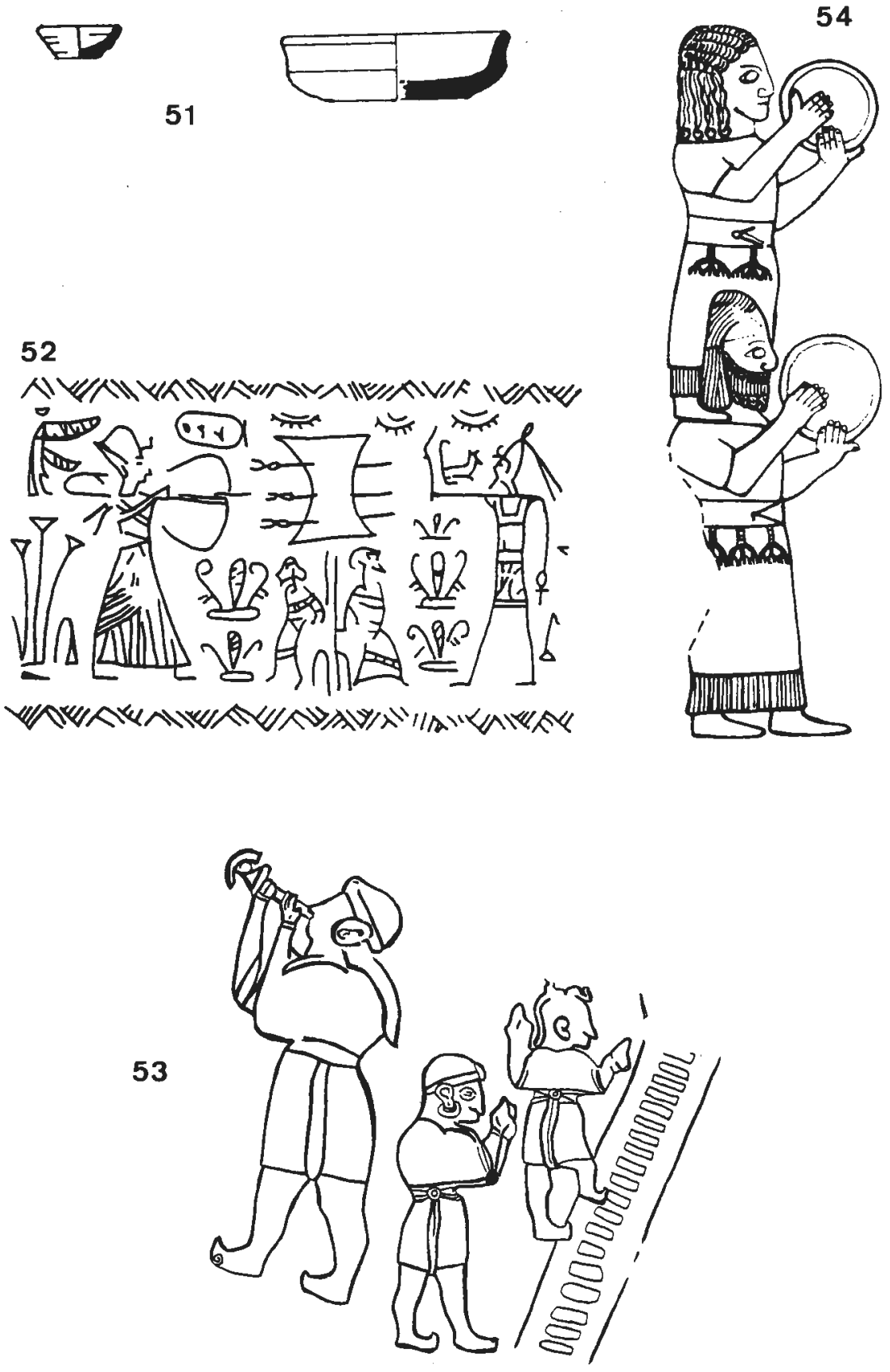

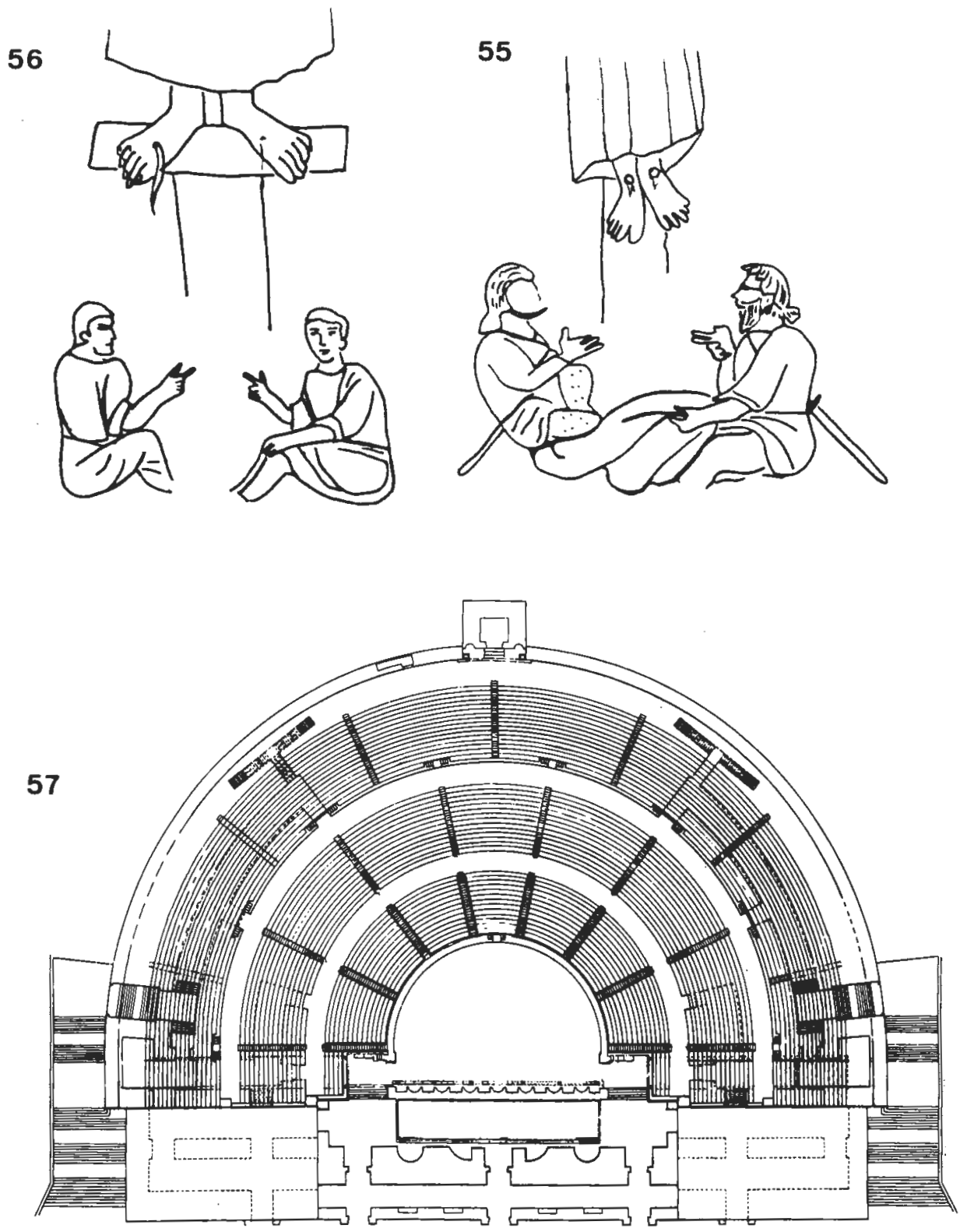

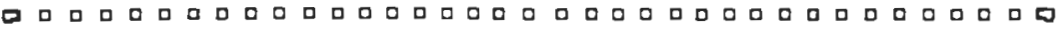




\section{9}
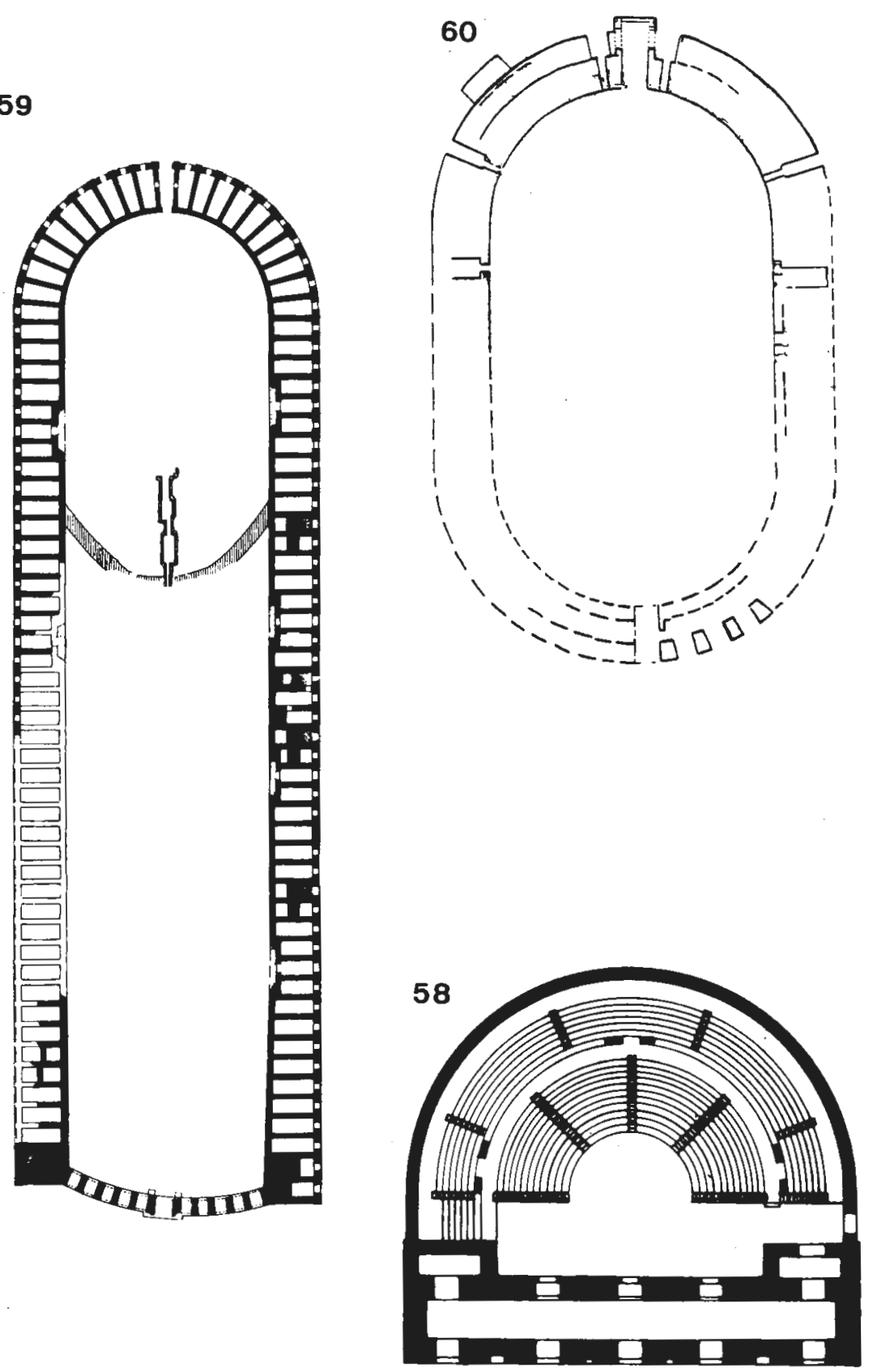


\section{ORBIS BIBLICUS ET ORIENTALIS}

Bd. 1 OTTO RICKENBACHER: Weisheitsperikopen bei Ben Sira. X-214-15* Seiten. 1973. Vergriffen.

Bd. 2 FRANZ.SCHNIDER: Jesus der Prophet. 298 Seiten. 1973. Vergriffen.

Bd. 3 PAUL ZINGG: Das Wachsen der Kirche. Beiträge zur Frage der lukanischen Redaktion und Theologie. 345 Seiten. 1974. Vergriffen.

Bd. 4 KARL JAROS: Die Stellung des Elobisten zur kanaanäischen Religion. 294 Seiten, 12 Abbildungen. 1982. 2. verbesserte und überarbeitete Auflage.

Bd. 5 OTHMAR KEEL: Wirkmächtige Siegeszeichen im Alten Testament. Ikonographische Studien zu Jos 8, 18-26; Ex 17, 8-13; 2 Kön 13, 14-19 und 1 Kön 22, 11. 232 Seiten, 78 Abbildungen. 1974. Vergriffen.

Bd. 6 VITUS HUONDER: Israel Soln Gottes. Zur Deutung eines alttestamentlichen Themas in der jüdischen Exegese des Mittelalters. 231 Seiten. 1975.

Bd. 7 RAINER SCHMITT: Exodus und Passa. Ibr Zusammenhang im Alten Testament. 124 Seiten. 1982. 2. neubearbeitere Auflage.

Bd. 8 ADRIAN SCHENKER: Hexaplarische Psalmenbruchstücke. Die hexaplarischen Psalmenfragmente der Handschriften Vaticanus graecus 752 und Canonicianus graecus 62 . Einleitung, Ausgabe, Erläuterung. XXVIII-446 Seiten. 1975.

Bd. 9 BEAT ZUBER: Vier Studien zu den Ursprüngen Israels. Die Sinaifrage und Probleme der Volks- und Traditionsbildung. 152 Seiten. 1976. Vergriffen.

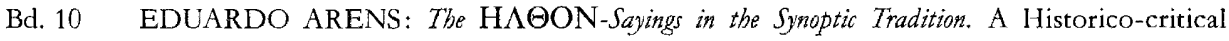
Investigation. 370 Seiten. 1976.

Bd. 11 KARL JAROS: Sichem. Eine archäologische und religionsgeschichtliche Studie, mit besonderer Berücksichtigung von Jos 24. 280 Seiten, 193 Abbildungen. 1976.

Bd. 11a KARL JAROS/BRIGITTE DECKERT: Studien zur Sichem-Area. 81 Seiten, 23 Abbildungen. 1977.

Bd, 12 WALTER BÜHLMANN: Vom recbten Reden und Schweigen. Studien zu Proverbien 10-31. 371 Seiten. 1976. Vergriffen.

Bd. 13 IVO MEYER: Jeremia und die falschen Propheten. 155 Seiten. 1977. Vergriffen.

Bd. 14 OTHMAR KEEL: Vögel als Boten. Studien zu Ps 68, 12-14, Gen 8, 6-12, Koh 10, 20 und dem Aussenden von Botenvögeln in Ägypten. - Mit einem Beitrag von Urs Winter zu Ps 56, 1 und zur Ikonographie der Göttin mit der Taube. 164 Seiten, 44 Abbildungen. 1977. Vergriffen.

Bd, 15 MARIE-LOUISE GUBLER: Die frühesten Deutungen des Todes Jesu. Eine motivgeschichtliche Darstellung aufgrund der neueren exegetischen Forschung. XVI-424 Seiten. 1977. Vergriffen.

Bd. 16 JEAN ZUMSTEIN: La condition du croyant dans l'Evangile selon Mattbieu. 467 pages. 1977. Epuisé.

Bd. 17 FRANZ SCHNIDER: Die verlorenen Söhne. Strukturanalytische und historisch-kritische Untersuchungen zu Lk 15. 105 Seiten. 1977.

Bd. 18 HEINRICH VALENTIN: Aaron. Eine Studie zur vor-priesterschriftlichen Aaron-Überlieferung. VIII-441 Seiten. 1978. 
Bd. 19 MASSÉO CALOZ: Etude sur la LXX origénienne du Psautier. Les relations entre les leçons des Psaumes du Manuscrit Coislin 44, les Fragments des Hexaples et le texte du Psautier Gallican. 480 pages. 1978.

Bd. 20 RAPHAEL GIVEON: The Impact of Egypt on Canaan. Iconographical and Related Studies. 156. Seiten, 73 Abbildungen. 1978.

Bd. 21 DOMINIQUE BARTHÉLEMY: Etudes d'histoire du texte de l'Ancien Testament. XXV-419 pages. 1978. Epuisé.

Bd. 22/1 CESLAS SPICQ: Notes de Lexicographie néo-testamentaire. Tome I: p. 1-524. 1978. Epuisé.

Bd. 22/2 CESLAS SPICQ: Notes de Lexicographie néo-testamentaire. Tome II: p. 525-980. 1978. Epuisé.

Bd. 22/3 CESLAS SPICQ: Notes de Lexicographie néo-testamentaire. Supplément. 698 pages. 1982.

Bd. 23 BRIAN M. NOLAN: The Royal Son of God. The Christology of Matthew 1-2 in the Setting of the Gospel. 282 Seiten. 1979. Out of print.

Bd. 24 KLAUS KIESOW: Exodustexte im Jesajabuch. Literarkritische und motivgeschichtliche Analysen. 221 Seiten. 1979. Vergriffen.

Bd. 25/1 MICHAEL LATTKE: Die Oden Salomos in ihrer Bedeutung für Neues Testament und Gnosis. Band I. Ausführliche Handschriftenbeschreibung. Edition mit deutscher Parallel-Übersetzung. Hermeneutischer Anhang zur gnostischen Interpretation der Oden Salomos in der Pistis Sophia. XI-237 Seiten. 1979.

Bd. 25/1a MICHAEL LATTKE: Die Oden Salomos in ibrer Bedeutung für Neues Testament und Gnosis. Band Ia. Der syrische Text der Edition in Estrangela Faksimile des griechischen Papyrus Bodmer XI. 68 Seiten. 1980.

Bd. 25/2 MICHAEL LATTKE: Die Oden Salomos in ibrer Bedeutung für Neues Testament und Gnosis. Band II. Vollständige Wortkonkordanz zur handschriftlichen, griechischen, koptischen, lateinischen und syrischen Überlieferung der Oden Salomos. Mit einem Faksimile des Kodex N. XVI-201 Seiten. 1979.

Bd. 25/3 MICHAEL LATTKE: Die Oden Salomos in ibrer Bedeutung für Neues Testament und Gnosis. Band III. XXXIV-478 Seiten. 1986.

Bd. 26 MAX KÜCHLER: Frübjüdische Weisheitstraditionen. Zum Fortgang weisheitlichen Denkens im Bereich des frühjüdischen Jahweglaubens. 703 Seiten. 1979. Vergriffen.

Bd. 27 JOSEF M. OESCH: Petucha und Setuma. Untersuchungen zu einer überlieferten Gliederung im hebräischen Text des Alten Testaments. XX-392-37* Seiten. 1979.

Bd. 28 ERIK HORNUNG/OTHMAR KEEL (Herausgeber): Studien zu altägyptischen Lebenslebren. 394 Seiten. 1979.

Bd. 29 HERMANN ALEXANDER SCHLÖGL: Der Gott Tatenen. Nach Texten und Bildern des Neuen Reiches. 216 Seiten, 14 Abbildungen. 1980.

Bd. 30 JOHANN JAKOB STAMM: Beiträge zur Hebräischen und Altorientalischen Namenkunde. XVI264 Seiten. 1980.

Bd. 31 HELMUT UTZSCHNEIDER: Hosea - Prophet vor dem Ende. Zum Verhältnis von Geschichte und Institution in der alttestamentlichen Prophetie. 260 Seiten. 1980.

Bd. 32 PETER WEIMAR: Die Berufung des Mose. Literaturwissenschaftliche Analyse von Exodus 2, 23-5, 5. 402 Seiten. 1980. 
Bd. 33 OTHMAR KEEL: Das Böcklein in der Milch seiner Mutter und Verwandtes. Im Lichte eines altorientalischen Bildmotivs. 163 Seiten, 141 Abbildungen. 1980.

Bd. 34 PIERRE AUFFRET: Hymnes d'Egypte et d'Israël. Etudes de structures littéraires. 316 pages, 1 illustration. 1981.

Bd. 35 ARIE VÁN DER KOOIJ: Die alten Textzeugen des Jesajabuches. Ein Beitrag zur Textgeschichte des Alten Testaments. 388 Seiten. 1981.

Bd. 36 CARMEL MCCARTHY: The Tiqqune Sopherim and Other Theological Corrections in the Masoretic Text of the Old Testament. 280 Seiten. 1981.

Bd. 37 BARBARA L. BEGELSBACHER-FISCHER: Untersucbungen zur Götterwelt des Alten Reiches im Spiegel der Privatgräber der IV. und V. Dynastie. 336 Seiten. 1981.

Bd. 38 MÉLANGES DOMINIQUE BARTHÉLEMY. Etudes bibliques offertes à l'occasion de son $60^{e}$ anniversaire. Edités par Pierre Casetti, Othmar Keel et Adrian Schenker.

724 pages, 31 illustrations. 1981.

Bd. 39 ANDRÉ LEMAIRE: Les écoles et la formation de la Bible dans l'ancien Israël. 142 pages, 14 illustrations. 1981.

Bd. 40 JOSEPH HENNINGER: Arabica Sacra. Aufsätze zur Religionsgeschichte Arabiens und seiner Randgebiete. Contributions à l'histoire religieuse de l'Arabie et de ses régions limitrophes. 347 Seiten. 1981.

Bd. 41 DANIEL VON ALLMEN: La famille de Dieu. La symbolique familiale dans le paulinisme. LXVII-330 pages, 27 planches. 1981.

Bd. 42 ADRIAN SCHENKER: Der Mäcbtige im Scbmelzofen des Mitleids. Eine Interpretation von 2 Sam 24. 92 Seiten. 1982.

Bd. 43 PAUL DESELAERS: Das Buch Tobit. Studien zu seiner Entstehung, Komposition und Theologie. 532 Seiten + Übersetzung 16 Seiten. 1982.

Bd. 44 PIERRE CASETTI: Gibt es ein Leben vor dem Tod? Eine Auslegung von Psalm 49. 315 Seiten. 1982.

Bd. 45 FRANK-LOTHAR HOSSFELD: Der Dekalog. Seine späten Fassungen, die originale Komposition und seine Vorstufen. 308 Seiten. 1982. Vergriffen.

Bd. 46 ERIK HORNUNG: Der ägytische Mytbos von der Himmelskub. Eine Ätiologie des Unvollkommenen. Unter Mitarbeit von Andreas Brodbeck, Hermann Schlögl und Elisabeth Staehelin und mit einem Beitrag von Gerhard Fecht. XII-129 Seiten, 10 Abbildungen. 1991. 2. ergänzte Auflage.

Bd. 47 PIERRE CHERIX: Le Concept de Notre Grande Puissance (CG VI, 4). Texte, remarques philologiques, traduction et notes. XIV-95 pages. 1982.

Bd. 48 JAN ASSMANN/WALTER BURKERT/FRITZ STOLZ: Funktionen und Leistungen des Mytbos. Drei altorientalische Beispiele. 118 Seiten, 17 Abbildungen. 1982. Vergriffen.

Bd. 49 PIERRE AUFFRET: La sagesse a bâti sa maison. Etudes de structures littéraires dans l'Ancien Testament et spécialement dans les psaumes. 580 pages. 1982.

Bd. 50/1 DOMINIQUE BARTHÉLEMY: Critique textuelle de l'Ancien Testament. 1. Josué, Juges, Ruth, Samuel, Rois, Chroniques, Esdras, Néhémie, Esther. Rapport final du Comité pour l'analyse textuelle de l'Ancien Testament hébreu institué par l'Alliance Biblique Universelle, établi en coopération avec Alexander R. Hulst $\dagger$, Norbert Lohfink, William D. McHardy, H. Peter Rüger, coéditeur, James A. Sanders, coéditeur. 812 pages. 1982. 
Bd. 50/2 DOMINIQUE BARTHÉLEMY: Critique textuelle de l'Ancien Testament. 2. Isaïe, Jérémie, Lamentations. Rapport final du Comité pour l'analyse textuelle de l'Ancien Testament hébreu institué par l'Alliance Biblique Universelle, établi en coopération avec Alexander R. Hulst †, Norbert Lohfink, William D. McHardy, H. Peter Rüger, coéditeur, James A. Sanders, coéditeur. 1112 pages. 1986.

Bd. 50/3 DOMINIQUE BARTHÉLEMY: Critique textuelle de l'Ancien Testament. Tome 3. Ézéchiel, Daniel et les 12 Prophètes. Rapport final du Comité pour l'analyse textuelle de l'Ancien Testament hébreu institué par l'Alliance Biblique Universelle, établi en coopération avec Alexander R. Hulst†, Norbert Lohfink, William D. McHardy, H. Peter Rüger, coéditeur†, James A. Sanders, coéditeur. 1424 pages. 1992.

Bd. 51 JAN ASSMANN: Re und Amun. Die Krise des polytheistischen Weltbilds im Ägypten der 18.-20. Dynastie. XII-309 Seiten. 1983.

Bd. 52 MIRIAM LICHTHEIM : Late Egyptian Wisdom Literature in the International Context. A Study of Demotic Instructions. X-240 Seiten. 1983.

Bd. 53 URS WINTER: Frau und Göttin. Exegetische und ikonographische Studien zum weiblichen Gottesbild im Alten Israel und in dessen Umwelt. XVIII-928 Seiten, 520 Abbildungen. 1987. 2. Auflage. Mit einem Nachwort zur 2. Auflage.

Bd. 54 PAUL MAIBERGER: Topographische und bistorische Untersuchungen zum Sinaiproblem. Worauf beruht die Identifizierung des Gabal Müsä mit dem Sinai? 189 Seiten, 13 Tafeln. 1984.

Bd. 55 PETER FREI/KLAUS KOCH: Reichsidee und Reichsorganisation im Perserreich. 119 Seiten, 17 Abbildungen. 1984. Vergriffen. Neuauflage in Vorbereitung

Bd. 56 HANS-PETER MÜLLER: Vergleich und Metapher im Hohenlied. 59 Seiten. 1984.

Bd. 57 STEPHEN PISANO: Additions or Omissions in the Books of Samuel. The Significant Pluses and Minuses in the Massoretic, LXX and Qumran Texts. XIV-295 Seiten. 1984.

Bd. 58 ODO CAMPONOVO: Königtum, Königsherrschaft und Reich Gottes in den Frübjüdischen Schriften. XVI-492 Seiten. 1984.

Bd. 59 JAMES KARL HOFFMEIER: Sacred in the Vocabulary of Ancient Egypt. The Term DSR, with Special Reference to Dynasties I-XX. XXIV-281 Seiten, 24 Figures. 1985.

Bd. 60 CHRISTIAN HERRMANN: Formen für ägyptische Fayencen. Katalog der Sammlung des Biblischen Instituts der Universität Freiburg Schweiz und einer Privatsammlung. XXVIII-199 Seiten. Mit zahlreichen Abbildungen im Text und 30 Tafeln. 1985.

Bd. 61 HELMUT ENGEL: Die Susanna-Erzäblung. Einleitung, Übersetzung und Kommentar zum Septuaginta-Text und zur Theodition-Bearbeitung. 205 Seiten + Anhang 11 Seiten. 1985.

Bd. 62 ERNST KUTSCH: Die chronologischen Daten des Ezechielbuches. 82 Seiten. 1985.

Bd. 63 MANFRED HUTTER: Altorientalische Vorstellungen von der Untervelt. Literar- und religionsgeschichtliche Ưberlegungen zu «Nergal und Ereškigal». VIII-187 Seiten. 1985.

Bd. 64 HELGA WEIPPERT/KLAUS SEYBOLD/MANFRED WEIPPERT: Beiträge zur prophetischen Bildsprache in Israel und Assyrien. IX-93 Seiten. 1985.

Bd. 65 ABDEL-AZIZ FAHMY SADEK: Contribution à l'étude de l'Amdouat. Les variantes tardives du Livre de l'Amdouat dans les papyrus du Musée du Caire. XVI-400 pages, 175 illustrations. 1985.

Bd. 66 HANS-PETER STÄHLI: Solare Elemente im Jabweglauben des Alten Testamentes. X-60 Seiten. 1985. 

Band I. 115 Seiten, 103 Abbildungen. 1985.

Bd. 68 WALTER BEYERLIN: Weisheitliche Vergewisserung mit Bezug auf den Zionskult. Studien zum 125. Psalm. 96 Seiten. 1985.

Bd. 69 RAPHAEL VENTURA: Living in a City of the Dead. A Selection of Topographical and Administrative Terms in the Documents of the Theban Necropolis. XII-232 Seiten. 1986.

Bd. 70 CLEMENS LOCHER: Die Ebre einer Frau in Israel. Exegetische und rechtsvergleichende Studien zu Dtn 22, 13-21. XVIII-464 Seiten. 1986.

Bd. 71 HANS-PETER MATHYS: Liebe deinen Nächsten wie dich selbst. Untersuchungen zum alttestamentlichen Gebot der Nächstenliebe (Lev 19,18). XII-204 Seiten. 1990. 2. verbesserte Auflage.

Bd. 72 FRIEDRICH ABITZ: Ramses III. in den Gräbern seiner Söbne. 156 Seiten, 31 Abbildungen. 1986.

Bd. 73 DOMINIQUE BARTHÉLEMY/DAVID W. GOODING/JOHAN LUST/EMANUEL TOV: The Story of David and Goliath. 160 Seiten. 1986.

Bd. 74 SILVIA SCHROER: In Israel gab es Bilder. Nachrichten von darstellender Kunst im Alten Testament. XVI-553 Seiten, 146 Abbildungen. 1987.

Bd. 75 ALAN R. SCHULMAN: Ceremonial Execution and Public Rewards. Some Historical Scenes on New Kingdom Private Stelae. 296 Seiten, 41 Abbildungen. 1987.

Bd. 76 JOŽE KRAŠOVEC: La justice $(S d q)$ de Dieu dans la Bible bébräque et linterprétation juive et chrétienne. 456 pages. 1988.

Bd. 77 HELMUT UTZSCHNEIDER: Das Heiligtum und das Gesetz. Studien zur Bedeutung der sinaitischen Heiligtumstexte (Ez 25-40; Lev 8-9). XIV-326 Seiten. 1988.

Bd. 78 BERNARD GOSSE: Isaie 13,1-14,23. Dans la tradition littéraire du livre d'Isaïe et dans la tradition des oracles contre les nations. 308 pages. 1988.

Bd. 79 INKE W. SCHUMACHER: Der Gott Sopdu - Der Herr der Fremdländer. XVI-364 Seiten, 6 Abbildungen. 1988.

Bd. 80 HELLMUT BRUNNER: Das börende Herz. Kleine Schriften zur Religions- und Geistesgeschichte Ägyptens. Herausgegeben von Wolfgang Röllig. 449 Seiten, 55 Abbildungen. 1988.

Bd. 81 WALTER BEYERLIN: Bleilot, Brecheisen oder was sonst? Revision einer Amos-Vision. 68 Seiten. 1988.

Bd. 82 MANFRED HUTTER: Behexung, Entsübnung und Heilung. Das Ritual der Tunnawiya für ein Königspaar aus mittelhethitischer Zeit (KBo XXI 1 - KUB IX 34 - KBo XXI 6). 186 Seiten. 1988.

Bd. 83 RAPHAEL GIVEON: Scarabs from Recent Excavations in Israel. 114 Seiten. Mit zahlreichen Abbildungen im Text und 9 Tafeln. 1988.

Bd. 84 MIRIAM LICHTHEIM: Ancient Egyptian Autobiographies chiefly of the Middle Kingdom. A Study and an Anthology. 200 Seiten, 10 Seiten Abbildungen. 1988.

Bd. 85 ECKART OTTO: Rechtsgescbicbte der Redaktionen im Kodex Ešnunna und im «Bundesbuch». Eine redaktionsgeschichtliche und rechtsvergleichende Studie zu altbabylonischen und altisraelitischen Rechtsüberlieferungen. 220 Seiten. 1989.

Bd. 86 ANDRZEJ NIWINSKI: Studies on the Illustrated Theban Funerary Papyri of the 11th and 10th Centuries B.C. 488 Seiten, 80 Seiten Tafeln. 1989.

Bd. 87 URSULA SEIDL: Die babylonischen Kudurru-Reliefs. Symbole mesopotamischer Gottheiten. 236 Seiten, 33 Tafeln und 2 Tabellen. 1989. 
Bd. 88 OTHMAR KEEL/HILDI KEEL-LEU/SILVIA SCHROER: Studien zu den Stempelsiegeln aus Palästina/Israel. Band II. 364 Seiten, 652 Abbildungen. 1989.

Bd. 89 FRIEDRICH ABITZ: Baugeschichte und Dekoration des Grabes Ramses' VI. 202 Seiten, 39 Abbildungen. 1989.

Bd. 90 JOSEPH HENNINGER SVD: Arabica varia. Aufsätze zur Kulturgeschichte Arabiens und seiner Randgebiete. Contributions à l'histoire culturelle de l'Arabie et de ses régions limitrophes. 504 Seiten. 1989.

Bd. 91 GEORG FISCHER: Jabwe unser Gott. Sprache, Aufbau und Erzähltechnik in der Berufung des Mose (Ex. 3-4). 276 Seiten. 1989.

Bd. 92 MARK A. O'BRIEN: The Deuteronomistic History Hypothesis: A Reassessment. 340 Seiten. 1989.

Bd. 93 WALTER BEYERLIN: Reflexe der Amosvisionen im Jeremiabuch. 120 Seiten. 1989.

Bd. 94 ENZO COR'TESE: Josua 13-21. Ein priesterschriftlicher Abschnitt im deuteronomistischen Geschichtswerk. 136 Seiten. 1990.

Bd. 95 ERIK HORNUNG (Herausgeber): Zum Bild Ägyptens im Mittelalter und in der Renaissance. Comment se représente-t-on l'Egypte au Moyen Age et à la Renaissance. 268 Seiten. 1990.

Bd. 96 ANDRÉ WIESE: Zum Bild des Königs auf ägyptischen Siegelamuletten. 264 Seiten. Mit zahlreichen Abbildungen im Text und 32 Tafeln. 1990.

Bd. 97 WOLFGANG ZWICKEL: Räucherkult und Räuchergeräte. Exegetische und archäologische Studien zum Räucheropfer im Alten Testament. 372 Seiten. Mit zahlreichen Abbildungen im Text. 1990.

Bd. 98 AARON SCHART: Mose und Israel im Konflikt. Eine redaktionsgeschichtliche Studie zu den Wüstenerzählungen. 296 Seiten. 1990.

Bd. 99 THOMAS RÖMER: Israels Väter. Untersuchungen zur Väterthematik im Deuteronomium und in der deuteronomistischen Tradition. 664 Seiten. 1990.

Bd. 100 OTHMAR KEEL/MENAKHEM SHUVAL/CHRISTOPH UEHLINGER: Studien $z u$ den Stempelsiegeln aus Palästina/Israel. Band III. Die Frühe Eisenzeit. Ein Workshop. XIV-456 Seiten. Mit zahlreichen Abbildungen im Text und 22 Tafeln. 1990.

Bd. 101 CHRISTOPH UEHLINGER: Weltreich und «eine Rede». Eine neue Deutung der sogenannten Turmbauerzählung (Gen 11,1-9). XVI-654 Seiten. 1990.

Bd. 102 BENJAMIN SASS: Studia Alphabetica. On the Origin and Early History of the Northwest Semitic, South Semitic and Greek Alphabets. X-120 Seiten. 16 Seiten Abbildungen. 2 Tabellen. 1991.

Bd. 103 ADRIAN SCHENKER: Text und Sinn im Alten Testament. Textgeschichtliche und bibeltheologische Studien. VIII-312 Seiten. 1991.

Bd. 104 DANIEL BODI: The Book of Ezekiel and the Poem of Erra. IV-332 Seiten. 1991.

Bd. 105 YUICHI OSUMI: Die Kompositionsgeschicbte des Bundesbuches Exodus 20,22b-23,33. XII-284 Seiten. 1991.

Bd. 106 RUDOLF WERNER: Kleine Einführung ins Hieroglyphen-Luwische. XII-112 Seiten. 1991.

Bd. 107 THOMAS STAUBLI: Das Image der Nomaden im Alten Israel und in der Ikonographie seiner sesshaften Nacbbarn. XII-408 Seiten. 145 Abb. und 3 Falttafeln. 1991.

Bd. 108 MOSHÉ ANBAR: Les tribus amurrites de Mari. VIII-256 Seiten. 1991.

Bd. 109 GÉRARD J. NORTON/STEPHEN PISANO (eds.): Tradition of the Text. Studies offered to Dominique Barthélemy in Celebration of his 70th Birthday. 336 Seiten. 1991.

Bd. 110 HILDI KEEL-LEU: Vorderasiatiscbe Stempelsiegel. Die Sammlung des Biblischen Instituts der Universität Freiburg Schweiz. 180 Seiten. 24 Tafeln. 1992.

Bd. 111 NORBERT LOHFINK: Die Väter Israels im Deuteronomium. Mit einer Stellungnahme von Thomas Römer. 152 Seiten. 1991. 
Bd. 112 EDMUND HERMSEN: Die zwei Wege des Jenseits. Das altägyptische Zweiwegebuch und seine Topographie. XII-282 Seiten, 1 mehrfarbige und 19 Schwarz-weiss-Abbildungen. 1992.

Bd. 113 CHARLES MAYSTRE: Les grands prêtres de Ptab de Memphis. XIV-474 pages, 2 planches. 1992.

Bd. 114 THOMAS SCHNEIDER: Asiatische Personennamen in ägyptischen Quellen des Neuen Reiches. 408 Seiten. 1992.

Bd. 115 ECKHARD VON NORDHEIM: Die Selbstbehauptung Israels in der Welt des Alten Orients. Religionsgeschichtlicher Vergleich anhand von Gen 15/22/28, dem Aufenthalt Israels in Ägypten, 2 Sam 7, 1 Kön 19 und Psalm 104. 240 Seiten. 1992.

Bd. 116 DONALD M. MATTHEWS: The Kassite Glyptic of Nippur. 208 Seiten. 210 Abbildungen. 1992.

Bd. 117 FIONA V. RICHARDS: Scarab Seals from a Middle to Late Bronze Age Tomb at Pella in Jordan. XII-152 Seiten, 16 Tafeln. 1992.

Bd. 118 YOHANAN GOLDMAN: Prophétie et royauté au retour de l'exil. Les origines littéraires de la forme massorétique du livre de Jérémie. XIV-270 pages. 1992.

Bd. 119 THOMAS M. KRAPF: Die Priesterschrift und die vorexilische Zeit. Yehezkel Kaufmanns vernachlässigter Beitrag zur Geschichte der biblischen Religion. XX-364 Seiten. 1992.

Bd. 120 MIRIAM LICHTHEIM: Maat in Egyptian Autobiographies and Related Studies. 236 Seiten, 21 Tafeln. 1992.

Bd. 121 ULRICH HÜBNER: Spiele und Spielzeug im antiken Palästina. 256 Seiten. 58 Abbildungen. 1992. 
Erstmals wird hier das Thema «Spielen und Spielzeug» für den Raum des antiken Palästina vom Neolithikum bis in die byzantinische Zeit monographisch abgehandelt. Dabei werden alle relevanten Quellen berücksichtigt, sowohl die literarischen und epigraphischen Texte als auch die archäologischen, ikonographischen und ethnologischen Funde und Belege. Damit wird ein Aspekt palästinischen Alltagslebens als eine zentrale menschliche Lebensäusserung neu entdeckt. 